\title{
Modelling Change in Supply Chain Structures and its Effect on Freight Transport Demand
}

Dipl.-Wi.-Ing. Ole Ottemöller geboren in Lübbecke

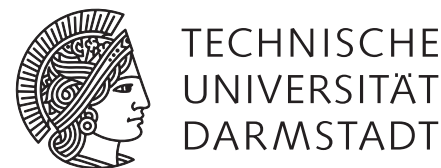

Fachgebiet

Verkehrsplanung und Verkehrstechnik

Chair of Transport Planning and Traffic

Engineering

Prof. Dr.-Ing.

Manfred Boltze

Zur Erlangung des akademischen Grades Doktor-Ingenieur (Dr.-Ing.) vom Fachbereich Bau- und Umweltingenieurwissenschaften der Technischen Universität Darmstadt genehmigte Dissertation.

Referent:

Korreferent:

Tag der Einreichung:

Tag mündlichen Prüfung:

Darmstadt 2017 - D17
Prof. Dr.-Ing. Manfred Boltze

Prof. Dr. Hanno Friedrich (Kühne Logistics University - KLU)

11. April 2017

4. Juli 2017 
Modelling Change in

Supply Chain Structures and its

Effect on Freight Transport Demand

Genehmigte Dissertation von Dipl.-Wi.-Ing. Ole Ottemöller aus Lübbecke

Herausgeber:

Technische Universität Darmstadt

Fachgebiet Verkehrsplanung und Verkehrstechnik

Otto-Berndt-Str. 2

64287 Darmstadt

www.tu-darmstadt.de/verkehr

fgvv@verkehr.tu-darmstadt.de

Schriftenreihe des Instituts für Verkehr

Fachgebiet Verkehrsplanung und Verkehrstechnik

Heft V 38

ISSN 1613-8317

Darmstadt 2017 


\section{Abstract}

Economic activity, especially in the manufacturing industries, is a major determinant of freight transport. Since the actual manufacturing processes are bound to specialised business establishments, which are only partially dispersed across space, commodity flows are required that connect locations of excess supply with locations that show unfulfilled demand for goods. In this context, economic reasoning of the involved actors leads to the formation of industry specific supply chain structures. Various authors emphasise the interrelation of these continuously evolving supply chain structures and freight transport demand. However, so far no disaggregate model exists that explicitly captures this interdependence.

The study at hand addresses this gap by developing a disaggregate model for simulating the impact of change in supply chain structures on the corresponding freight transport demand. The proposed model covers centralisation and vertical disintegration as examples of structural change. For this purpose, the model quantitatively describes spatially disaggregate supply chain structures, consisting of business establishments and commodity flows, on the level of entire sectors. The model development is accompanied by an interdisciplinary literature review that gives an overview of existing research on supply chain structures and freight transport demand.

The developed model consists of two phases. A first phase generates an artificial industry landscape of business establishments and commodity flows according to available aggregate statistics. The generation relies on elements of stochastic simulation and directed choice procedures. The model's second phase simulates change in the supply chain structures from the first phase. Using linear programming, a maximum solution range regarding the impact on freight transport is calculated. Increasing the degree of assumptions, the solution space can be narrowed. Here, the model applies a combination of stochastic simulation, linear programming, and fitting procedures.

The model is applied for analysing centralisation in the poultry industry and vertical disintegration in the automotive industry of Germany. For both cases, a broad range of data sources is used, e.g. common public statistics on establishment sizes and spatial distribution of employment but also sectoral data, e.g. from industry associations or case studies. The real-world consistency of spatial flow patterns is ensured by assigning commodity flows according to statistical macroscopic flows.

Overall, the simulation results show that an increase in freight transport performance is to be expected for the case of centralisation as well as vertical disintegration. However, the maximum solution ranges also indicate that assuming suitable location choice and flow assignment a reduction in freight transport performance is mathematically possible. The analysis also addresses the suitability of state measures for mitigating the impact of changes in the supply chain structure on freight transport demand.

In summary, the work describes a disaggregate model for simulating changes in the supply chain structure and their impact on freight transport demand. The model applications especially illustrate how the immanently required assumptions determine the impact of centralisation or vertical disintegration. 


\section{Zusammenfassung}

Wirtschaftliche Aktivität, insbesondere materialintensiver Wirtschaftszweige wie dem verarbeitenden Gewerbe, ist ein wesentlicher Treiber für die Entwicklung des Güterverkehrs. Eine entscheidende Rolle spielt hierbei die arbeitsteilige Herstellung von Gütern durch spezialisierte Betriebe, welche zumeist ungleichmäßig räumlich verteilt sind. Für den Ausgleich zwischen Angebot und Nachfrage der verschiedenen Waren sind somit Güterflüsse erforderlich, die Produktionsorte mit Verbrauchsorten verbinden. Die dazugehörige Güterverkehrsnachfrage hängt wesentlich von den Lieferkettenstrukturen auf der Ebene von Betrieben und Güterflüssen ab, die sich in der Folge durch das ökonomische Verhalten der involvierten Akteure herausbilden und kontinuierlich weiterentwickeln. Entsprechend betont eine Vielzahl von Veröffentlichungen aus dem Bereich der Güterverkehrsforschung die Bedeutung dieser Abhängigkeit. Es existieren jedoch bisher keine disaggregierten Güterverkehrsmodelle, die den Wirkungszusammenhang von Lieferkettenstrukturen und Güterverkehrsnachfrage explizit abbilden.

Die vorliegende Arbeit adressiert diese Lücke mit der Entwicklung eines disaggregierten Modells zur Simulation der Auswirkungen von Veränderungen in den Strukturen bestehender Lieferketten auf die Güterverkehrsnachfrage. Das entwickelte Modell ist insbesondere geeignet, um die Wirkungen von Zentralisierung sowie vertikaler Desintegration abzuschätzen. Zu diesem Zweck werden im Modell die Lieferketten ganzer Wirtschaftssektoren quantitativ und räumlich disaggregiert dargestellt. Betriebe und Güterflüsse zwischen ihnen dienen hierbei als zentrale Modellelemente. Die Modellentwicklung ist eingebettet in einen interdisziplinären Literaturüberblick, der bestehende Forschungen mit Bezug zur Struktur von Lieferketten und Güterverkehr zusammenfasst.

Das entwickelte Modell besteht aus zwei Phasen. In der ersten Modellphase wird eine synthetische Industrielandschaft, bestehend aus Betrieben und Güterflüssen, unter Berücksichtigung bestehender aggregierter Statistiken generiert. Die Erzeugung verwendet dabei vor allem Elemente stochastischer Simulation und gerichteter Auswahlprozesse. Die zweite Modellphase dient der Simulation von strukturellen Veränderungen in den Lieferketten der ersten Phase zur Abschätzung der Auswirkungen auf die dazugehörige Güterverkehrsnachfrage. Unter Verwendung linearer Programmierung wird die maximal mögliche Veränderung der Güterverkehrsleistung berechnet. Durch eine Konkretisierung von Annahmen hinsichtlich verschiedener Charakteristika der Strukturveränderung werden die Freiheitsgrade zur Lösungsfindung reduziert, wodurch der zulässige Lösungsbereich eingeschränkt wird. Für diesen Zweck verwendet das Modell eine Kombination aus stochastischer Simulation, linearer Programmierung und Matrixanpassungsverfahren.

In der vorliegenden Arbeit erfolgt eine Anwendung des entwickelten Modells zur Untersuchung einer Zentralisierung innerhalb des Geflügelsektors sowie von vertikaler Desintegration in der Automobilindustrie Deutschlands. Für beide Fälle wird eine Vielzahl unterschiedlicher Datenquellen genutzt. Dies sind zum einen für diese Zwecke übliche Statistiken, etwa zu Betriebsgrößen oder Beschäftigung nach Raumeinheiten, aber auch sektorspezifische Daten etwa von Industrieverbänden oder aus Fallstudien. Die Einhaltung gegebener makroskopischer Flüsse bei der Zuordnung von Güterflüssen zwischen Betrieben sichert ihre Realitätstreue hinsichtlich der räumlichen Dimension.

Die Simulationsergebnisse zeigen, dass sowohl für den Fall einer Zentralisierung als auch für den Fall einer vertikalen Desintegration unter den gegebenen Umständen mit einer Erhöhung der Güterverkehrsleistung zu rechnen ist. Allerdings deuten die berechneten maximalen Lösungsbereiche ebenfalls an, dass bei einer geeigneten Standortwahl und Zuordnung von Güterflüssen mathematisch sogar eine Reduzierung der Güterverkehrsleistung 
möglich ist. Die Modellanwendungen untersuchen daher auch exemplarisch ausgewählte staatliche Maßnahmen hinsichtlich ihrer Eignung, die güterverkehrlichen Auswirkungen von Veränderungen in den Lieferkettenstrukturen abzumildern.

Zusammengefasst entwickelt die vorliegende Arbeit also zunächst ein disaggregiertes Modell zur Simulation von strukturellen Veränderungen der Lieferketten ganzer Sektoren, um die daraus resultierende Auswirkung auf die Güterverkehrsnachfrage abzuschätzen. Die anschließenden, exemplarischen Anwendungen des Modells zeigen, wie die hinsichtlich der strukturellen Veränderungen erforderlichen Annahmen die möglichen Auswirkungen von Zentralisierung und vertikaler Desintegration festlegen. 


\section{Contents}

Abstract

Contents

1 Introduction 1

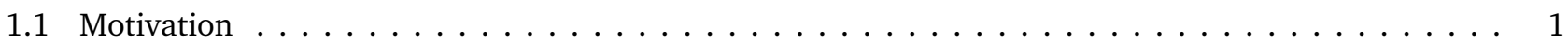

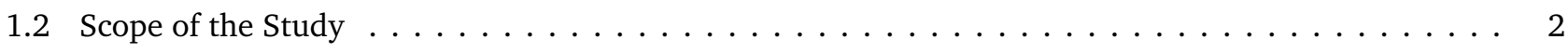

1.3 Research Questions and Structure of the Study . . . . . . . . . . . . . . . . 3

2 Change in Supply Chain Structures $\mathbf{5}$

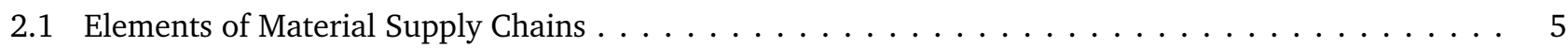

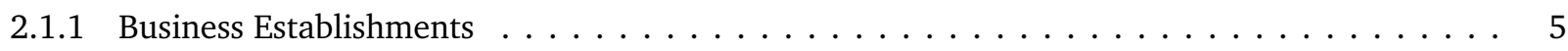

2.1 .2 Commodity Flows $\ldots \ldots \ldots \ldots \ldots$

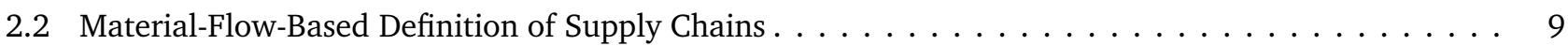

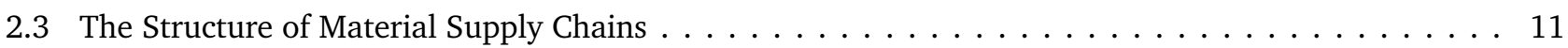

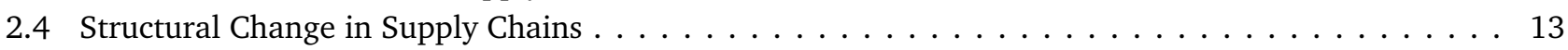

2.4.1 Categories and Examples of Structural Change within Supply Chains . . . . . . . . . . . . 13

2.4.2 Conclusions from the Examples of Change in the Structure of Supply Chains . . . . . . . . . 17

2.5 Economic Decisions Influencing Supply Chain Structures from a Perspective of Freight Transport

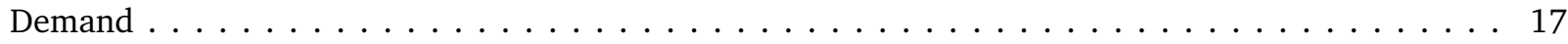

2.5 .1 Structure of the Literature Review . . . . . . . . . . . . . . . . . . . 17

2.5.2 The Interrelation of Supply Chain Management, Supply Chain Structures, and Freight Transport 18

2.5 .3 Decisions on Micro Level . . . . . . . . . . . . . . . . . . . . . . . . . 20

2.5.4 Approaches to Supply Chain Structures from a Meso and a Macro Perspective . . . . . . . . 26

2.5.5 Conclusions from the Literature Review Regarding the Analysis of Supply Chain Structures on Micro and Meso Level . . . . . . . . . . . . . . . . . . . . . . 41

3 Supply Chain Structures from the Macroscopic Perspective of Freight Transport 43

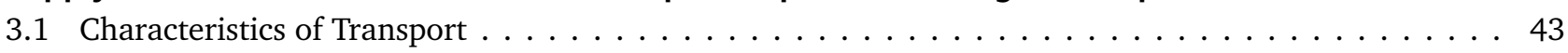

3.2 Characteristics of Freight Transport . . . . . . . . . . . . . . . . . . . . . 45

3.2.1 System Analysis of Freight Transport Demand . . . . . . . . . . . . . . . . . . . . . . . . . . . . . . . . . .

3.2 .2 Indicators for Freight Transport Demand . . . . . . . . . . . . . . . . . . . 48

3.2.3 Top-down Analysis of Freight Transport Demand . . . . . . . . . . . . . . . . . . . . 49

3.3 Existing Freight Transport Models . . . . . . . . . . . . . . . . . . . . . . . . . . . . . . . . . . . . . . . . . . . .

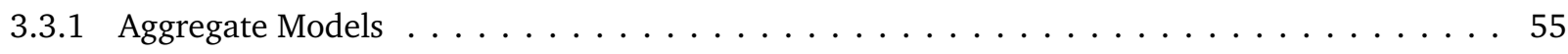

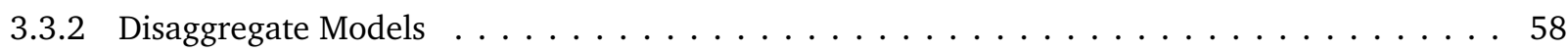

3.3.3 Land-Use Transport Interaction (LUTI) Models . . . . . . . . . . . . . . . . . . . . 61

3.4 Conclusions and Findings from the Area of Freight Transport . . . . . . . . . . . . . . . . . 62

4 Modelling Supply Chain Structures and Resulting Freight Transport Demand 65

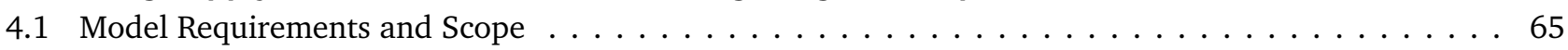

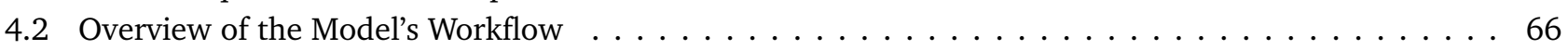

4.3 Focal Model Elements and Their Attributes . . . . . . . . . . . . . . . . . . 67 
4.4 Generating the Reference Population of Flows and Establishments (Phase 1) . . . . . . . . . . . 69

4.4.1 Overview of the Generation Procedure . . . . . . . . . . . . . . . . . . 69

4.4.2 Generating an Artificial Population of Establishments . . . . . . . . . . . . . . . . . 70

4.4 .3 Generating Commodity Flows between Establishments . . . . . . . . . . . . . . . . . 79

4.5 Simulation of Change in Supply Chain Structures (Phase 2) . . . . . . . . . . . . . . . . . . 89

4.5.1 Overview of Implemented Structure Effects and corresponding Model Procedures . . . . . . . 89

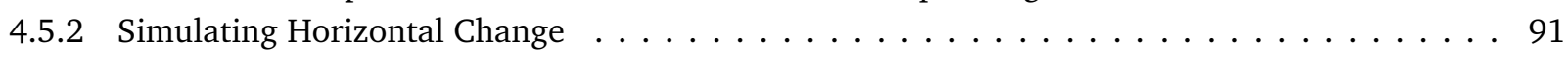

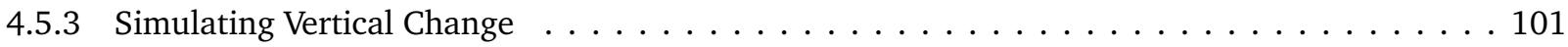

4.6 Technical Specifics of the Implemented Model . . . . . . . . . . . . . . . . . . . . . 105

4.6.1 Overall Architecture of the Implemented Model . . . . . . . . . . . . . . . . . . . 105

4.6.2 Software Pipeline Applied for Preparing and Solving Optimisation Problems . . . . . . . . . 106

4.6.3 Application of Simulation Batches for Assessing the Influences of Stochastic Elements . . . . 107

4.6 .4 Reporting and Visualisation Components . . . . . . . . . . . . . . . . . . . . 108

4.7 Model Validation and Verification . . . . . . . . . . . . . . . . . . . . . . 108

4.8 Conclusions Regarding Information Needs, Model Design, and Literature Findings . . . . . . . . . . 109

5 Model Application: Supply Chain Structure Effects in the German Poultry and Automotive Industry 113

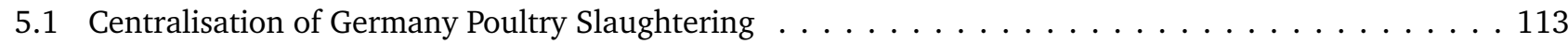

5.1 .1 Overview of the German Food Industry . . . . . . . . . . . . . . . . . . 113

5.1 .2 System Analysis of Poultry Supply Chains in Germany . . . . . . . . . . . . . . . . . . . . . . . . . . . . . . .

5.1.3 Overview of Data Sources Used for Modelling the Poultry Supply Chain . . . . . . . . . . . . . 121

5.1 .4 Overview of Application Scenario Poultry . . . . . . . . . . . . . . . . . . . . 121

5.1 .5 Simulation Results of Model Phase $1 \ldots \ldots \ldots \ldots \ldots \ldots \ldots \ldots$

5.1 .6 Simulation Results of Model Phase 2 . . . . . . . . . . . . . . . . . . . . 126

5.1.7 Partial Validation Based on Detailed Results from Model Phase 2 . . . . . . . . . . . . . 129

5.1.8 Potential Freight Transport Demand Related Measures in the Context of Supply Chain Restructurings . . . . . . . . . . . . . . . . . . . . . . . 140

5.1.9 Model Applications for Impact Analysis of Example State Measures . . . . . . . . . . . . . . . . 142

5.1.10 Conclusions From the Example Applications in the German Poultry Industry . . . . . . . . . . . . . . . . . . . . . . . .

5.2 Vertical Disintegration in the German Automotive Industry . . . . . . . . . . . . . . . . 153

5.2.1 Developments in the German Automotive Industry as a Motivation for Further Analysis . . . 153

5.2.2 System Description and Data Sources Used for Scenario Construction . . . . . . . . . . . . . . . . . . . . . . . . . . . . . . .

5.2 .3 Scope of Analysis and Required Assumptions . . . . . . . . . . . . . . . . . . . . . . . . . . . . . . . . . . . . .

5.2 .4 Partial Validation For the Output of Model Phase $1 \ldots \ldots$. . . . . . . . . . . . . . 157

5.2.5 Example Results from the Model's Second Phase in the Case of Vertical Disintegration . . . . . 160

5.2.6 Partial Validation of the Model's Second Phase for the Case of Vertical Disintegration . . . . . 162

5.2.7 Impact Assessment for Measures That Influence Appearing Establishments' Locations . . . . 163

5.2.8 Conclusions from the Example Applications in the German Automotive Industry . . . . . . 165

\section{Concluding Remarks}

6.1 Summary and Contributions to the Research Questions . . . . . . . . . . . . . . . . . . . . . . . . . . . . . . . .

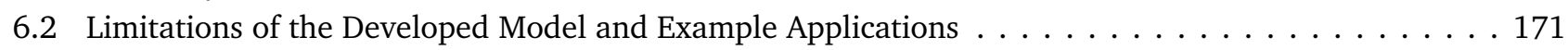

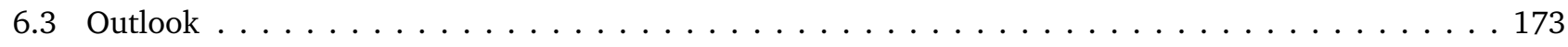

List of Symbols 


\section{List of Figures}

2.1 Business establishments and their attributes as entities for freight freight transport modelling . . . . 6

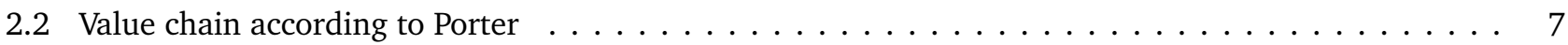

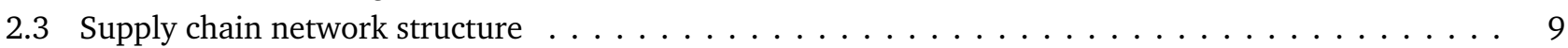

2.4 Categories of change in supply chain structures with examples $\ldots \ldots \ldots \ldots \ldots \ldots \ldots$

2.5 Example of changes in commodity flows in the case of centralisation $\ldots \ldots \ldots \ldots \ldots$

2.6 Example of changes in monetary flows and commodity flows in the case of vertical disintegration . . 15

2.7 Example of changes in monetary flows and commodity flows in the case of spatial changes . . . . 16

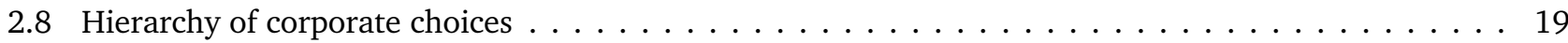

2.9 Framework for describing interdisciplinary interdependences of decisions $\ldots \ldots \ldots \ldots$

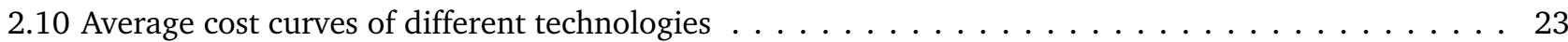

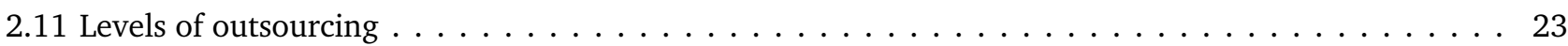

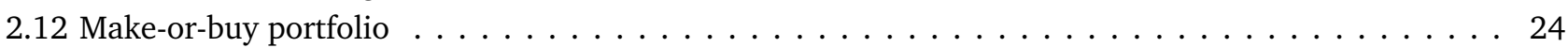

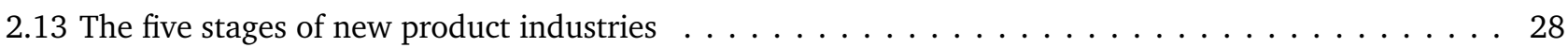

2.14 Average cost in an industry with multiple plants . . . . . . . . . . . . . . . . 29

2.15 Composition of location rent and resulting von Thünen's rings for the location of agricultural pro-

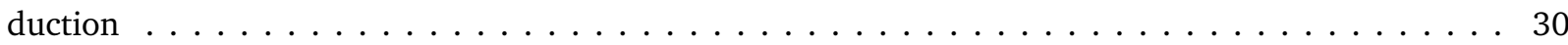

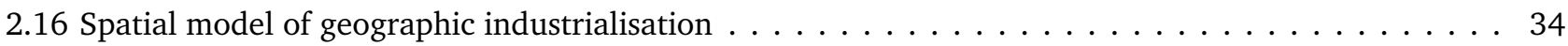

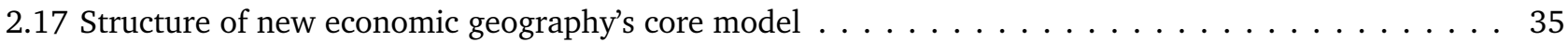

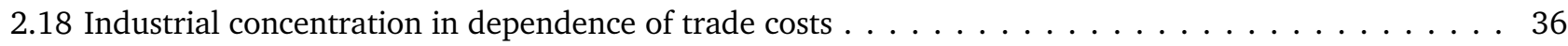

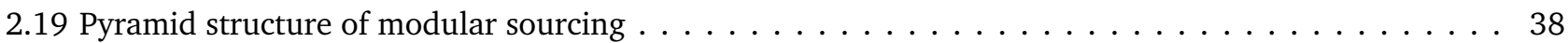

2.20 Logistics costs in dependence of the number of warehouses $\ldots \ldots \ldots \ldots$. . . . . . . . 40

3.1 Socio-economic environment of transport $\ldots \ldots \ldots \ldots \ldots \ldots \ldots \ldots \ldots \ldots \ldots \ldots$

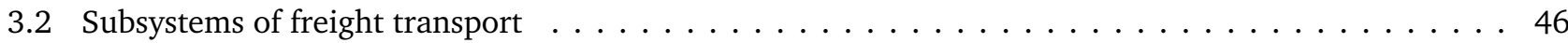

3.3 Example of trade flow and potential cargo flows for a multi-leg transport chain . . . . . . . . . 46

3.4 Development of gross domestic product and freight transport in Germany . . . . . . . . . . . . . . 49

3.5 Growth of transport volume, transport distance, and transport performance by mode for Germany . . 51

3.6 Transport volume by transported goods in Germany for the years 1999 and 2009 . . . . . . . . 51

3.7 Average transport distances by transported goods in Germany for the years 1999 and 2009 . . . . . 52

3.8 Comparison of the 4-step-approach and systems determining freight transport demand . . . . . . . 54

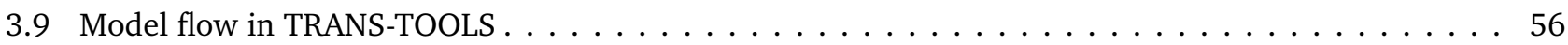

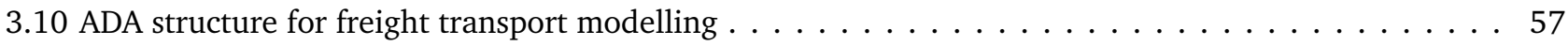

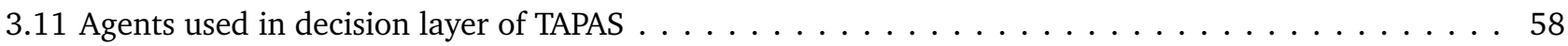

3.12 Simulation modules of INTERLOG . . . . . . . . . . . . . . . . . . . . . . . . . . . 59

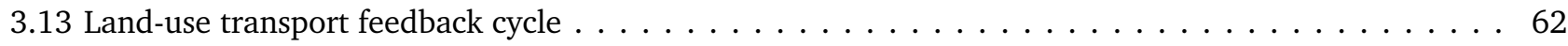

3.14 Freight modelling challenges and corresponding approaches $\ldots \ldots \ldots \ldots \ldots \ldots \ldots$

4.1 Schematic workflow applied for simulating changes in supply chain structures with according inputs,

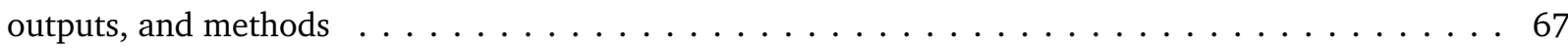

4.2 Business establishments with their fundamental attributes and commodity flows modelled as objects 68

4.3 Example of macro flows for a single commodity in a zonal space model . . . . . . . . . . . . . . 69

4.4 Process chart for establishment generation by Monte Carlo simulation . . . . . . . . . . . . 72

4.5 Process chart for the scoring of candidate sets of business establishments . . . . . . . . . . . . . 74 
4.6 Process chart for the generation of establishments using a discrete interval based distribution . . . . 76

4.7 Flowchart for the spatial assignment of establishments . . . . . . . . . . . . . . . . . 78

4.8 Schematic production-consumption matrix of macro flows . . . . . . . . . . . . . . . 80

4.9 Example of using the Lorenz curve function for discretisation . . . . . . . . . . . . . . . . 83

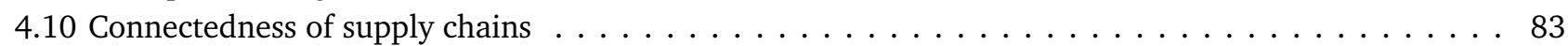

4.11 Flowchart for the assignment of suppliers to commodity flows . . . . . . . . . . . . . . 87

4.12 Flowchart for the relaxed constraint supplier selection . . . . . . . . . . . . . . . . 88

4.13 Range logic for dealing with different levels of constraints induced by assumptions . . . . . . . . 90

4.14 Comparing the application of sequential transport problems and a parallel location allocation prob-

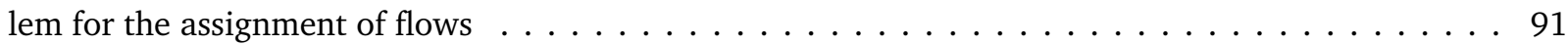

4.15 Example of the model procedure for simulating centralisation . . . . . . . . . . . . . . . . . . . . . . . . .

4.16 Selecting establishments considering selection probabilities by zone . . . . . . . . . . . . . . . . . . . . . . . . . . . .

4.17 Example of the model procedure for simulating vertical disintegration . . . . . . . . . . . . . . 102

4.18 Implemented control and data flow for solving optimisation problems . . . . . . . . . . . . . . 107

4.19 Validation as part of the model development and application . . . . . . . . . . . . . . 108

5.1 Sectoral supply-consumption chains for food products . . . . . . . . . . . . . . . . 114

5.2 Development of average establishment sizes in the German food industry and selected subcategories

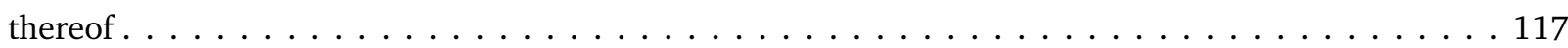

5.3 Development of the number of establishments in the German food industry and selected subcate-

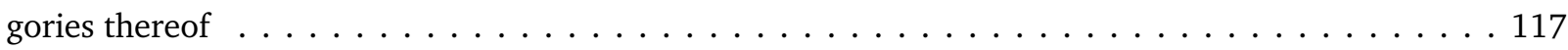

5.4 Poultry supply chain considered in model application . . . . . . . . . . . . . . . . . . . 118

5.5 Density maps of poultry farming and slaughtering for Germany . . . . . . . . . . . . . . . . . . 119

5.6 Map of employees in convenience food production and population density in Germany . . . . . . . . 120

5.7 Overview of poultry supply chain for application and required assumptions for centralisation . . . . . 122

5.8 Map showing the initial 128 focal establishments of poultry slaughtering with their flow relations . . 124

5.9 Boxplot aggregating the simulation results for a centralisation degree of $50 \%$. . . . . . . . . . . 129

5.10 Establishment output by size categories before and after a $50 \%$ centralisation of poultry slaughtering

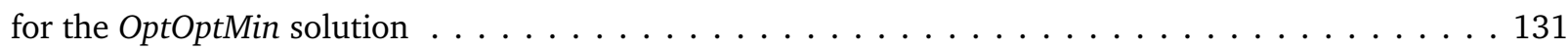

5.11 Establishment count by size categories before and after a $50 \%$ centralisation of poultry slaughtering

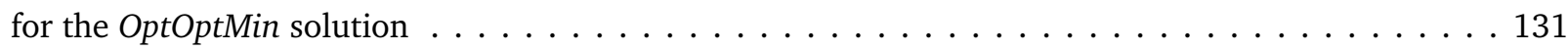

5.12 Spatial distribution of appearing establishments' sizes after a $50 \%$ centralisation of poultry slaugh-

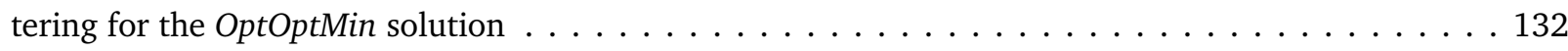

5.13 Map showing the 96 focal establishments (poultry slaughtering) that vanish during centralisation

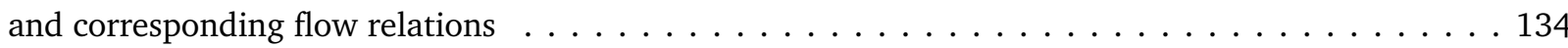

5.14 Map showing the up to 32 establishments that appear during centralisation of poultry slaughtering if optimal location choice, optimal assignment, and minimisation are assumed (OptOptMin) . . . . 135

5.15 Map showing the up to 32 establishments that appear during centralisation of poultry slaughtering if optimal location choice, optimal assignment, and maximisation are assumed (OptOptMax) . . . . 136

5.16 Map showing the 32 establishments that appear during centralisation of poultry slaughtering if stochastic location choice, optimal assignment, and minimisation are assumed (StochOptMin) . . . 137

5.17 Map showing the 32 establishments that appear during centralisation of poultry slaughtering if stochastic location choice, optimal assignment, and maximisation are assumed (StochOptMax) . . . 138

5.18 Map showing the 32 establishments that appear during centralisation of poultry slaughtering if stochastic location choice and macro flow assignment are assumed (StochMacro) . . . . . . . . . . 139

5.19 Poultry slaughtering's spatial layout and output for status quo and minimum transport performance

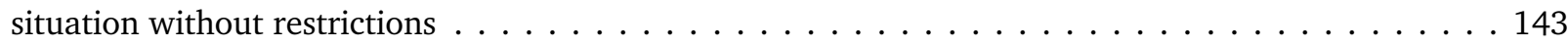

5.20 Barchart comparing the distribution of establishment outbut by size categories in status quo and optimal layout without further restrictions . . . . . . . . . . . . . . . . . . . . . 143

5.21 Poultry slaughtering's spatial layout and output for minimum transport performance using 128, 64,

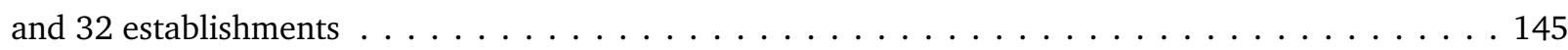


5.22 Map showing the transport minimal domestic freight flows resulting from complete offshoring of

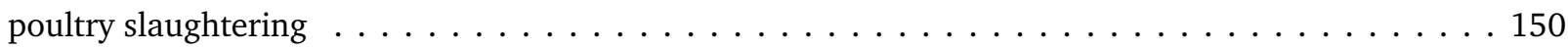

5.23 Ratio of value added in the German automotive industry . . . . . . . . . . . . . . . . . . 154

5.24 Automotive supply chain considered in model application for vertical disintegration . . . . . . . . . 155

5.25 Density maps of automotive suppliers and assembly for Germany . . . . . . . . . . . . . . . 156

5.26 Overview of change in automotive supply chain for application and required assumptions . . . . . 156

5.27 Map of tier-1 suppliers, car plants, and flow relations after model phase 1 . . . . . . . . . . . 158

5.28 Appearing establishments' spatial layout and output for different numbers of appearing establishments161

5.29 Boxplot aggregating the simulation results for an outsourcing degree of $50 \% \ldots$. . . . . . . . . . 162

5.30 Location probabilities by zone proportional to employment in manufacturing and its normalised

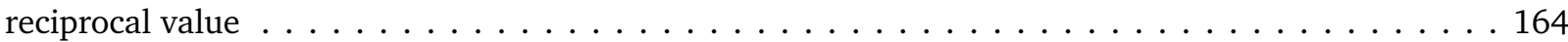




\section{List of Tables}

1.1 Chapters and corresponding research questions $\ldots \ldots \ldots \ldots \ldots \ldots \ldots \ldots \ldots$

2.1 Overview of supply-chain-structure-related decisions on establishment level (micro) and correspond-

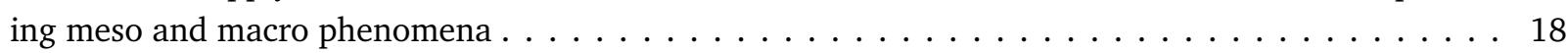

2.2 Structure of the input output table from national accouting $\ldots \ldots \ldots \ldots \ldots \ldots \ldots \ldots$

3.1 National accounting data on the German automotive industry for the years 2000 and $2010 \ldots \ldots 2$

3.2 Development of the number of business establishments in the German automotive industry from

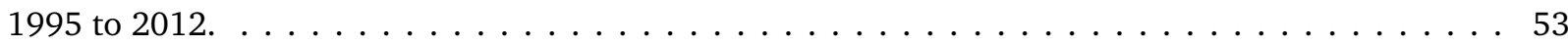

4.1 External inputs required for stochastically generating the initial population of establishments $\ldots . .70$

4.2 External inputs required for generating the initial population of commodity flows $\ldots \ldots \ldots 70$

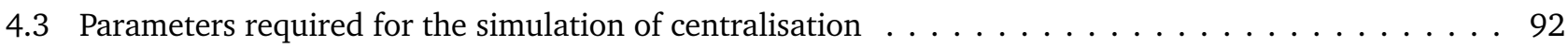

4.4 Parameters required for the simulation of outsourcing $\ldots \ldots \ldots \ldots \ldots \ldots \ldots \ldots \ldots \ldots$

5.1 Business establishments (count and number of employees) of the German food industry by produced

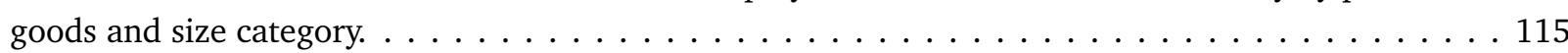

5.2 Krugman concentration indices for the poultry supply chain's industries $\ldots \ldots \ldots \ldots \ldots$

5.3 Overview of input data used for modelling the poultry supply chain $\ldots \ldots \ldots \ldots \ldots \ldots \ldots$

5.4 Average distances for macro flow and commodity flow populations after model phase $1 \ldots \ldots 125$

5.5 Number of commodity flows per sector relation after model phase $1 \ldots \ldots \ldots$. . . . . . . . 125

5.6 Incoming commodity flows per establishment by sector relation after model phase $1 \ldots \ldots$

5.7 Outgoing commodity flows per establishment by sector relation after model phase $1 \ldots \ldots$

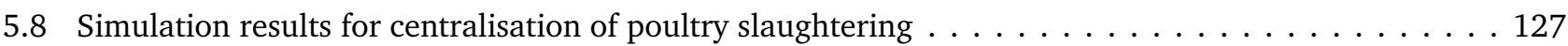

5.9 Appearing establishments' location and output after a 50\% centralisation of poultry slaughtering for the minimum transport performance solution (OptOptMin) $\ldots \ldots \ldots \ldots \ldots \ldots \ldots \ldots$

5.10 Krugman concentration indices for the poultry slaughtering industry's status quo and unrestricted minimum freight transport performance layout . . . . . . . . . . . . . . . 143

5.11 Optimal and status quo establishment sizes for the poultry slaughtering industry $\ldots \ldots \ldots \ldots 144$

5.12 Transport indicators for optimal and status quo industry layouts for poultry slaughtering $\ldots \ldots 146$

5.13 Freight transport performance regarding the impact of establishment size restrictions in poultry

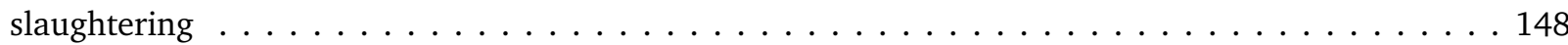

5.14 Commodity flow distances for the initial population in the automotive case . . . . . . . . . 159

5.15 Simulation results for vertical disintegration in the German automotive industry . . . . . . . . . 160

5.16 Solution ranges for different location probabilities during outsourcing in the automotive industry $\ldots 164$ 


\section{Introduction}

The introduction gives a brief overview of this thesis and its background by successively addressing the motivation, scope, and structure of the study. In addition, the research questions that determine the study's structure are given.

\subsection{Motivation}

The transport system plays a key role in national and international economic prosperity. It does not only offer mobility to people, it also bridges the spatial gap between locations of production and consumption for intermediates as well as finished products. In consequence, economic activity, especially in economies with a vital manufacturing industry, is a major determinant of freight transport.

This interdependence of economic activity and freight transport has been subject to research for a long time and still is until today. Already Smith (1776) identifies the division of labour as the major component for the wealth of nations, which directly depends on freight transport as expressed in "the division of labour is limited by the extent of the market" (Smith 1776, p. 18). Building upon this perception, more recent studies like Christopher (1992) emphasise that it is no longer single firms competing but systems of interdependent specialised companies, i.e. supply chains. On the physical level, these supply chains manifest as commodity flows between business establishments (Roorda et al. 2010).

However, these systems are not static but continuously adapt to changes in their environment (Chandra and Grabis 2007). For example, competition in industries that are prone to economies of scale often leads to a centralisation of production (Bain 1954). Such centralisations are expected to have a direct impact on freight transport demand (Kohn 2005). Addressing this kind of structural change, the centralisation of poultry slaughtering in Germany is analysed in the course of this study.

In addition, there are also other drivers of change that influence the structure of supply chains and the corresponding freight transport demand, e.g. caused by innovations in the production or product technology (Abele 2006) or adaptations in order to cope with increasing product complexity (Ro et al. 2007). Both kinds of drivers can be observed for example in the automotive industry. For this reason, part of this study addresses the automotive industry as an example of vertical disintegration caused by the modularisation of supply (Holweg and Pil 2004; Parry and Graves 2008).

Centralisation and vertical disintegration are examples of developments that have a direct impact on the underlying supply chains' establishments and material flows. This study coins the superordinate term change in the structure of supply chains for referring to this kind of phenomena.

The importance of developments on the level of supply chain structures regarding their impact on freight transport demand have gained attention from various authors in the area of freight transport research, e.g. Voordijk (1999), Drewes Nielsen et al. (2003), and Varschen et al. (2005). The growth in freight transport that is to be expected as a result of increases in the division of labour is also in the focus of public authorities, e.g. the German Federal Ministry of Transport (BMVI 2010). However, there are only few quantitative approaches in the area of freight transport research that address these effects. One of the first contributions in this direction is McKinnon and 
Woodburn (1996) who propose an aggregate parameter called handling factor for describing effects that relate to vertical disintegration of supply chains. More detailed quantitative approaches on this phenomenon are developed by Holzapfel and Vahrenkamp (1999) and Jäcker (1997). However, till today there is no approach that explicitly considers the structure of supply chains together with the underlying spatial pattern of production and consumption of commodities.

The same observation holds true for research on the interdependency of centralisation and freight transport. Here, existing studies mainly focus on the specific case of centralisation in logistics networks, e.g. Rodrigue et al. (2001) and Kohn (2005), leaving out the analysis of centralisation on the level of manufacturing establishments.

Existing comprehensive freight transport models only implicitly capture the interdependency of supply chain structures and freight transport demand by using rather aggregate approaches, especially those that follow the traditional 4-step-approach. Latest advances in modelling freight transport mainly focus on capturing logistics aspects (Liedtke 2006; Friedrich 2010; Liedtke and Friedrich 2012; Schröder et al. 2012; Davydenko 2015). Even in the cases in which the developed freight transport models explicitly consider business establishments and the relations between them, they are not applied for estimating the impact of changes in the population of establishments or their linkage, i.e. the supply chain structures (e.g. de Jong and Ben-Akiva 2007; Samimi 2010).

Hence, the question that is behind this study is as follows:

\section{How to estimate the impact \\ of changes in the structure of supply chains \\ on freight transport demand?}

This study's scope is derived directly from this question. The subsequent section illustrates how this study differs from existing approaches by explaining its scope by referring to focal elements, model characteristics, and examples used for the model application. Following the scope definition, a separate section addresses the study's overall structure and more detailed research questions, which are deduced from the central question formulated above.

\subsection{Scope of the Study}

Most existing applications of freight transport models focus on analysing the potential of state measures that directly influence key parameters of freight transport demand. In contrast, supply chain structures, i.e. the spatial distribution of supply and demand, are usually considered to be fixed and given. Hence, they are not subject to further analysis. In contrast, the scope of this study is defined as follows:

The analyses conducted within this study address the material dimension of supply chains and their structure, which consists of business establishment and linking commodity flows. The study's main objective is developing a quantitative model for estimating the impact of changes in the structure of supply chains on freight transport demand. The model development is framed by an interdisciplinary literature review that analyses existing approaches on modelling freight transport related characteristics of supply chains and their structure.

In order to account for the macroscopic nature of freight transport demand, the scope of the study adheres to the supply chains of entire sectors, or synonymously industries, not single supply chains of individual firms. Business establishment and commodity flows between them serve as basic elements for modelling the supply chain structures in the corresponding analyses.

The analysis of structural change relies on the comparison of static states that describe the before and after structural change configuration of supply chains at a sectoral scale. Regarding the model's temporal resolution, the 
static states describe annual flows as commonly used in the underlying statistics. The spatial scope for the example applications in this study is limited to the national level, under consideration of imports and exports, due to current data availability. In general, the developed model is also applicable on an international scale if suitable input data is available.

Since the assumptions required for simulating change in supply chain structures, especially regarding locations and assignment patterns, significantly influence the overall effect on freight transport demand, the model calculates a range of possible outcomes. This range is bounded by the absolute minimum and maximum, which is calculated by the application of linear programming. In addition, the model calculates the result for various probable configurations that lie within the absolute range.

The model's validity and capabilities are illustrated using two distinct example application in the scope of this study. The sector of poultry slaughtering serves as an example for analysing the centralisation of production. In contrast, the automotive industry is used in order to simulate the impact of vertical disintegration.

\subsection{Research Questions and Structure of the Study}

Following the central question behind the study, additional research questions are formulated below, which help to structure the various aspects that are relevant for finding answers on the superordinate question. Table 1.1 gives an overview of the study's chapters and the corresponding research questions. Answers to these question are given in chapter 6 (page 167).

Table 1.1: Chapters and corresponding research questions

\begin{tabular}{ll}
\hline Chapter & Research questions \\
\hline Chapter 1: Introduction & \\
\hline
\end{tabular}

Q1: How to define and categorise change in supply chain structures?

Chapter 2: Change in Supply Chain Structures

fer 3: Supply Chain Structures from the Macroscopic Perspective of Freight Transport

Q2: Which decisions determine the structure of a supply chain and how can they be modelled?

Q3: What is the current status of research on the interrelation of supply chains' structures and freight transport demand?

Q4: How far can existing statistics be used for identifying as well as forecasting the impact of changes in the supply chain structure on freight transport demand?

Q5: How do existing freight transport models capture the impact of changes in the structure of supply chains?

Chapter 4: Modelling Supply Chain Structures and Resulting Freight Transport Demand

Q6: How to build a quantitative model for estimating the impact of change in supply chain structures on freight transport demand?

Q7: How does centralisation of existing supply chains influence freight transport demand?

Chapter 5: Model Application: Supply Chain Structure Effects in the German Poultry and Automotive Industry

Q8: How does vertical disintegration of existing supply chains influence freight transport demand?

Q9: How can the impact of structural change on freight transport demand be mitigated by the application of state measures?

Chapter 6: Concluding Remarks 
The section at hand is part of chapter 1 , which gives the study's motivation and scope together with an overview on the overall structure of the thesis.

Chapter 2 defines material supply chains and their structure following a bottom-up approach. These two concepts are at the centre of the entire study. Next, possible changes in the structure of supply chains are introduced. The remaining part of the chapter continues with an interdisciplinary literature review of decisions and corresponding modelling approaches that relate to supply chain structures and their freight transport demand.

The following chapter 3 changes the perspective by perceiving freight transport as a macroscopic phenomenon. The corresponding analysis applies a top-down approach focussing on existing statistics in order to trace the impact of changes in the structure of supply chains on freight transport demand. Finally, existing comprehensive freight transport models are reviewed regarding their suitability for conducting analyses on the level of supply chain structures.

Chapter 4 introduces a new model for simulating the impact of change in supply chain structures on freight transport demand. The model description splits into a first part, which deals with the generation of an artificial but realistic landscape of business establishments and connecting commodity flows, and a second part, which addresses the procedures developed in order to simulate structural change within the supply chains of the initial population. Afterwards, technical specificities of the model's implementation are given. The chapter closes with a comparison of information needs for simulation structural change, the actual model design, and corresponding insights from the literature review.

Chapter 5 describes the application of the previously developed model. A first application addresses the case of centralisation in the German poultry industry. Based on first findings, potential freight transport related measures in the context of change in supply chain structures are developed and analysed based on the proposed model. The chapter continues with a model application that addresses vertical disintegration in the automotive industry. In this context, the model is applied for simulating the impact of state measures that influence the location choice of establishments.

The thesis closes with chapter $\mathbf{6}$, which gives a summary of the study, limitations as they occur in the context of the presented applications, and direct answers to the research questions denoted above. Finally, an outlook on further potential of the developed model and its application is given. 


\section{Change in Supply Chain Structures}

This chapter introduces the concept of material supply chains and illustrates the interrelation of their structure and freight transport demand following a bottom-up approach. In this way, the chapter lays the conceptual groundwork for the design of the developed model. It is organised as follows: The chapter starts with introducing the basic elements of the intended analysis, i.e. business establishments and commodity flows. In a next step, the corresponding meso-structures, i.e. material supply chains, are defined. Afterwards, the characteristics of the structure of these material supply chains are described. Building upon the concept of material supply chains, possible changes in their structure are categorised. The structural changes' potential impact on freight transport demand is discussed based on simplified examples. The chapter continues with an interdisciplinary literature review regarding existing approaches to the phenomenon of supply chains and their structures giving a brief understanding of decision problems and economic mechanisms that determine the shape of supply chains as relevant in the context of this work. Finally, the chapter closes with a conclusion that compares the insights gained from the literature review with the analytic requirements identified during the simplified examples.

\subsection{Elements of Material Supply Chains}

The following two sections define the central elements of supply chains, i.e. business establishments and commodity flows, which are at the core of the further analysis and model development.

\subsubsection{Business Establishments}

The intended analysis of changes in supply chains focusses on applications in manufacturing industries. This allows for imposing the assumption that any economic activity besides transport is carried out at a certain location in space using a certain facility. Following this perception, a business establishment is a physical entity that is defined by a set of facilities on a discrete compound with a corresponding spatial location. In colloquial language used synonymous used terms are site or location. In addition, factory or plant refer to specific types of business establishments.

On the organisational level, business establishments are run by economic actors usually denoted as firms or enterprises. In this regard, one firm can run one or multiple business establishments. In contrast, a business establishment belongs to only one firm in most cases.

The concept of using business establishments as relevant entities in freight transport modelling is not totally new. Hence, well-established frameworks for describing business establishments from literature are summarised before outlining an own conceptualisation for the application in the context of this work.

An exhaustive conceptual framework for describing business establishments has been contributed by Roorda et al. (2010). Hence, it is used as a basis for describing the fundamental attributes of business establishments in the following. Figure 2.1 shows a simplified entity-relationship diagram for business establishments and their attributes according to Roorda et al. (2010). 


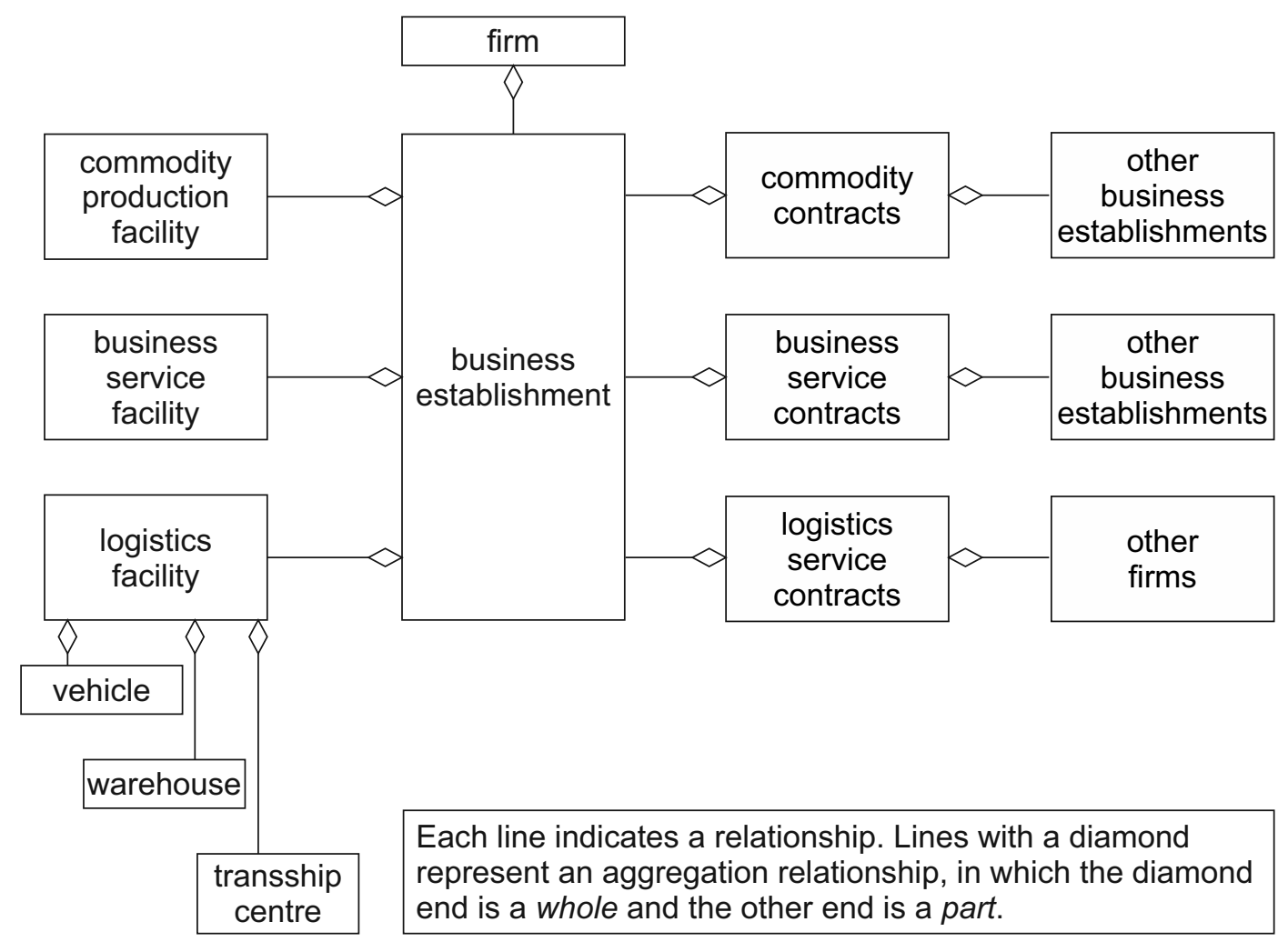

Figure 2.1: Business establishments and their attributes as entities for freight transport modelling according to Roorda et al. (2010)

In the illustrated concept, business establishments can have different types of facilities, or combinations thereof, to carry out their operations, i.e. for commodity production, business services, or logistics. Hence, these facilities are the physical attributes that determine a business establishment's capabilities in the framework of Roorda et al. (2010). For example, production capacities depend on the commodity production facilities whilst the availability of vehicles or warehouses is coupled to the establishments' logistics facilities. In addition, the different functionalities provided by the corresponding facilities give a first hint how business establishments' characteristics are connected to the different stages of an enhanced version of the traditional 4-step modelling approach.

Undoubtedly, size is an essential attribute of every business establishment. In this regard, the first question that arises is how to measure a business establishment's size. Considering the previous paragraph, suitable metrics could be based on the facilities available. The work of Colbe (1964) addresses the challenge of determining an optimal establishment size. This approach also contains an exhaustive discussion of the right metric. A first aspect for differentiation lies in applying an average value for a period of time, or distinct single or multiple values from points in time. For seasonal industries this difference becomes significant. A second differentiation addresses the question of which dimension to use. Here, Sombart (1902) and most authors dealing with the economics of business establishments after him, e.g. Löffelholz (1967), propose three categories:

Labour: In this case size is measured referring to the number of employees a business establishment has. This might either be a total number of all functional units or a specific number regarding employees occupied with a specific activity. Instead of using numbers of employees, it could also be referred to the number of hours worked or the like. German statistics often use total numbers of employees with social insurance per establishment for describing its size. A large advantage of statistics on employees is that they are broadly available. However, they 


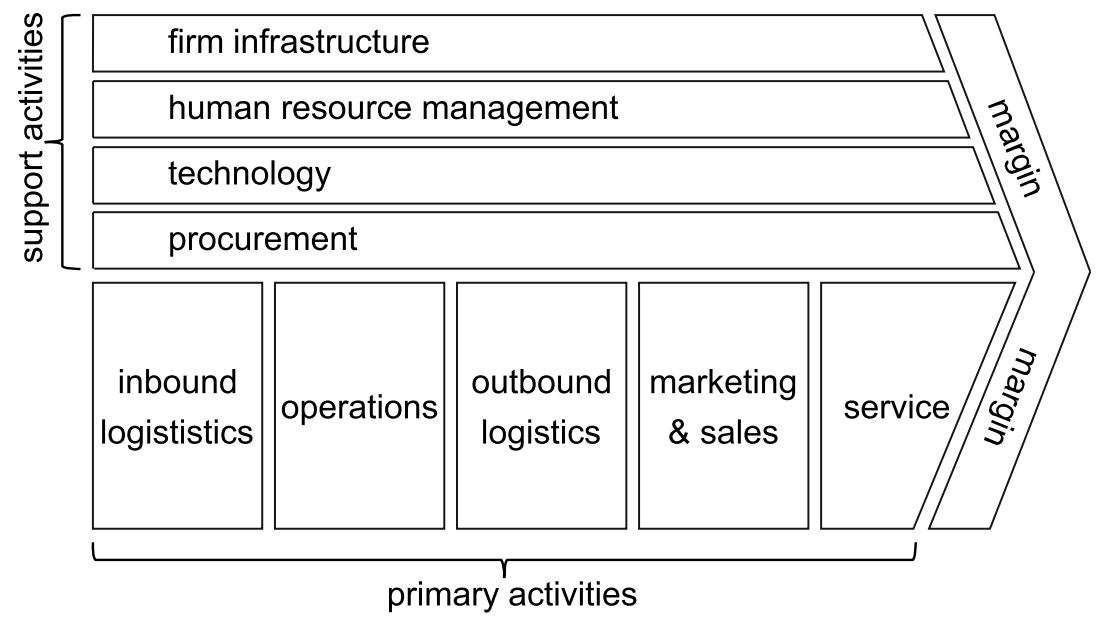

Figure 2.2: Value chain according to Porter $(1985$, p. 37)

become less meaningful the more automation is applied in an industry and the more it is prone to economies of scale due to characteristics of the production process (e.g. chemical industry).

Physical: Everything that can be physically measured and is related to a single business establishment falls into this category. For example, the area used for production is a relevant measure for business establishments engaging in logistics/warehousing as well as farming. Other references could be the volumes of input and output streams. For example, the number of vehicles produced at every car plant in Germany by year is available from commercial data providers such as Automobil Produktion (2014). Also, numbers of machinery or equipment and derived indicators belong into this category, like number of vehicles provided at a car rental station. Maximum production capacities regarding a specific (bottleneck) process are an example for indicators derived from the establishment's production facilities.

Financial: Turnover or net assets are examples for financial metrics. Most companies collect this data for reasons of taxes and controlling. Using financial data could be motivated by its availability since many companies are forced to publish at least parts of their data due to disclosure obligations. On the other hand, financial data is easily blurred by activities that have no physical equivalent at the considered business establishment. For example, the financial flow of a trade companies' headquarters is obviously coupled with the material turnover in its warehouses but it does not give any meaningful specific information regarding any of its establishments.

Regarding the further analysis of freight transport demand considering constraints imposed on business establishment level, labour based and physical metrics for establishment sizes are most suitable due to the rather direct relation to production volumes. However, the metric to be used in a specific analysis depends on the associated objective and data availability.

Business establishments do not exist isolatedly for themselves but they interact with other business establishments either for the procurement of supplies or for the sale of produced goods or provided services. In the concept of Roorda et al. (2010), established relationships between business establishments are formalised in contracts depicting the details for the agreed exchange. These contracts are the basis for material flows between establishments though they are of immaterial nature themselves. Looking at the organisational structure, business establishments are governed by a superordinate firm entity. These firms can either be small enterprises with a single establishment or huge corporations with numerous establishments. Obviously, being embedded into larger firm networks together with other establishments influences the overall decision making. 
Regarding the internal organisation of firms, Porter (1985) introduces the concept of the value chain as illustrated in figure 2.2. It is especially suitable for the intended analysis of supply chain structures because it emphasizes on the stepwise flow of material from source to customer within a single business unit. The value chain concept decomposes the operative processes into primary and supportive activities. However, not all activities denoted in the value chain concept can be found in every business establishment. Especially support activities may be carried out at specialised locations providing services to many establishments. For the later analysis of freight transport in supply chains, especially the activities procurement and technology together with inbound and outbound logistics are important for the further analysis since they determine the spatial pattern of material flows. An approach for capturing the decision-making that considers the different responsibilities and roles deduced from such activities using an explanatory agent-based model in the context of freight transport modelling is presented in Holmgren, Ramstedt, et al. (2012).

In summary, the relevant information regarding establishments' characteristics in the analysis of supply chain structures, material flows, and freight transport demand are:

- industry (sector)

- location

- size (e.g. employees, capacities, productive area, mostly used as proxy)

- volumes of input commodities

- volumes of output commodities

\subsubsection{Commodity Flows}

Obviously, business establishments produce and consume material, which requires bridging the spatial gap between locations of supply and demand by using freight transport in most cases. The smallest units of material exchange are shipments. They are the actual transported units as determined by the lot size choice during transport planning. In the context of freight transport modelling, this task is part of decision making on the level of logistics system (Roorda et al. 2010; Liedtke and Friedrich 2012; Schröder et al. 2012). In contrast, commodity flows are temporal aggregations of shipments between a combination of origin and destination location ignoring any logistics or infrastructure induced detours. In other words, the concept of commodity flows assumes direct transport distances and the flows' volumes correspond to cumulated flow volumes for a defined time span. Throughout this study, commodity flows are used as conceptual objects that describe material flows between specific business establishments for a certain time period. In this way, they serve as basic elements for the further analysis of interdependencies between economic activity and spatial flow patterns in supply chains. In summary, material flows give an answer to the question: Which amount of a specific commodity gets transported from a certain business establishment to another business establishment within a defined time period?

In this perception, a commodity flow is fully described by the following dimensions:

- origin establishment

- destination establishment

- commodity (type of good)

- flow volume

- reference period

Potentially, the locations of origin and destination establishment can be specified by any form of spatial reference. Depending on the representation of space in the application context this can be for example zone based information or geographic coordinates. Connecting origin and destination of commodity flows, loosely corresponds to the step of freight distribution in the traditional four-step-approach of transport modelling. 
The commodity-attribute is mostly self-explaining as this can obviously be described by relying on existing classifications as well as own definitions if required. The granularity of the applied classification significantly influences the resulting volumes of commodity flows.

The dimension measuring the flow volume consists of two elements: the information on the amount of material as expressed in weight or volume on the one hand and the information in which time span the amount flows on the other. In general, it is possible to used different dimensions of amount and reference periods within a single analysis but in most cases it is helpful to harmonize all flow volume information using the same time span within an analysis. For certain analyses, for example when looking at valued added, it might be required to include monetary value information into the specification of amount, e.g. by using value densities.

\subsection{Material-Flow-Based Definition of Supply Chains}

Above, business establishments are described as entities having physical as well as organisational attributes. Commodity flows for the exchange of goods connect these establishments such that network patterns are observable, which reflect the constraints imposed on establishment level, e.g. the demand for input materials.

In the discipline of business administration, these networks have been named supply chains, or supply networks in more recent publications. An overview of definitions is presented in Otto (2002). Regarding the definitions available there and in other publications, e.g. Christopher (1992) and Simchi-Levi et al. (2008), the formulation of Aitken (1998) proves most suitable for the scope of this study. It defines a supply chain as "a network of connected and interdependent organisations mutually and co-operatively working together to control, manage and improve the flow of materials and information from suppliers to end users".

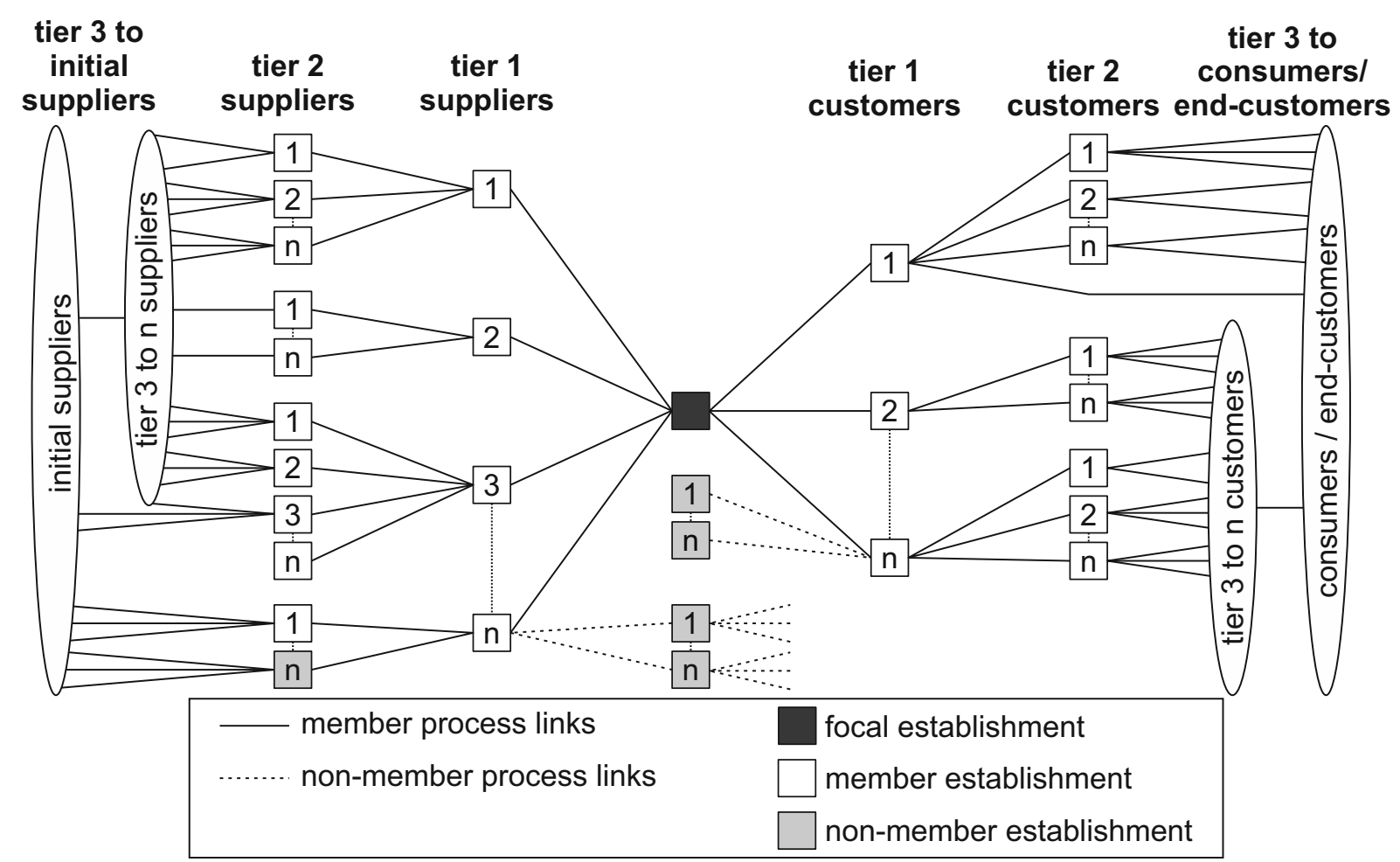

Figure 2.3: Supply chain network structure (adapted from Lambert, Cooper, and Pagh 1998) 
According to this definition, figure 2.3 shows a simplified supply chain structure from the perspective of a single focal business establishment. The depicted supply chain network structure also indicates that members of a certain supply chain, i.e. establishments participating in the integrated control and management, might also keep relations to non-member establishments that are outside the joint scope of the current supply chain. In consequence, a supply chain does not exist isolatedly but potentially overlaps with other chains.

Existing approaches to supply chains consider different kinds of flows between supply chain members. In this regard, typical flows (and flow directions) within supply chains are information (up- and downstream), material (downstream), and finance (upstream). However, for this study the scope is limited to material flows since information and financial flows are of subordinate importance in the intended context of freight transport demand.

For clarification, it is also helpful to distinguish between supply chains and transport chains. In this regard, Woxenius (2012) defines: "A transport chain focuses upon a consignment and extends over movement, physical handling and activities directly related to transport such as dispatch, reception, transport planning and control." Obviously, the distinguishing factor here is the scope of transport chains being solely on transport activities.

In order to distinguish from existing approaches, an autonomous definition, which is still based on the formulation cited above, is required for the further analysis. Hence, for context of this study, the concept of material supply chains is introduced according to the following definition:

Material supply chains are structures that are defined by a series of manufacturing establishments that are connected by material flows in order to gradually transform natural resources into finished products.

This definition of material supply chains emphasises on three major aspects: First, it exclusively considers material flows. This is a potentially strong simplification looking at the complex nature of economic interactions between suppliers and consumers of goods or services. However, this simplification is reasonable since the scope of the intended analysis is on the freight transport demand, which is assumed to be determined by the commodity flows of entire industries.

Second, the proposed definition refers to business establishments as entities that serve as the starting and ending locations of material flows. This accounts for the importance of exact geographic locations for origin and destination of physical flows regarding the further analysis in this study. In contrast, the broader definitions from the area of business administration usually refer to the interaction of organisations without explicit physical and spatial reference.

Third, the material-oriented definition includes the gradual transformation and stepwise production of final products. Here, it is assumed that the production of each establishments can be assigned to a specific stage in an idealised production process. Including this aspect into the definition accommodates for the division of labour across specialised industries and explicitly addresses a vertical structure of supply chains. Following this perception, a material supply chain is identified by starting at the final production stage for one specific product, which can also be an intermediate, and then including all upstream elements.

The simplified concept of transferring raw materials stepwisely into final products gives the impression of pure linearity in supply chains. However, for real-world scenarios, the occurrence of cyclic structures or flows skipping multiple intermediate stages forward or backward the idealised supply chain is not uncommon. Even if these cases are not captured in the examples of figure 2.5 and figure 2.6, the model design presented in chapter 4 is capable of dealing with non-linear supply chains.

As a last note, the terms supply chain and material supply chain are used synonymously in the remainder of the text, especially since the shorter version significantly increases readability in more complex statements. Hence, the reader may always think of material supply chains even if the text says supply chain. In any other case, the text specifies explicitly. 


\subsection{The Structure of Material Supply Chains}

In the sections above, supply chains and their elements have been laid out. The further analysis focusses on changes in the structure especially of material supply chains. Hence, a definition of structure within this context is required.

A colloquial definition of the term structure can be found in Merriam-Webster (2016a) saying it is the "organization of parts as dominated by the general character of the whole"1. In the context at hand, the general character of the whole is the supply chain scope delimited by the objective of jointly and stepwisely transforming inputs into outputs in order to manufacture a particular product. Obviously, the parts organised within the whole are business establishments and commodity flows, with commodity flows describing the material dimension of the relations between establishments. Hence, supply chain structure always refers to an abstract perception of an arrangement of establishments and their commodity flow relations.

In addition to the general definition of supply chain structure, a description of such a structure's characteristics and corresponding indicators is required in order to distinguish differing configurations. Below a brief overview of structural attributes is given.

In general, features of supply chains structures always refer to one of two possible dimensions, i.e. horizontal or vertical, according to Lambert and Cooper $(2000)^{2}$. In addition, the dimension of space should be included, especially regarding the intended analysis of freight transport demand.

The vertical dimension of supply chains stands for phenomena that refer to consecutive stages of the supply chain. In this context, each stage in the supply chain corresponds to a production step or set of steps that is always carried out a distinct establishment in an idealised production process as required for manufacturing the supply chain's final product. Getting back to the vertical dimension, there are two directions along the supply chain: downstream, from the initial suppliers towards end customers and upstream for the opposite direction.

In contrast, the horizontal dimension refers to phenomena that consider a single supply chain stage. Similar definitions can be found for example in Perry (1989), Werner (2013, pp. 118,123), and Christopher (2016, p. 245).

The vertical borders of a supply chain are defined by its range, i.e. the first and last production stages. The number of production stages gives information on the vertical structure within this range. These production stages are also called tiers as shown in figure 2.3 and numbered starting with 1 for suppliers located directly upstream from the final production stage. The total number of production changes is a key indicator for changes in the supply chain structure that result from vertical (dis)integration. Looking at the characteristics of the vertical linkage of supply chains on a sectoral scale, the connectedness describes the number of commodity flows between establishments of consecutive tiers.

Regarding the horizontal structure of a supply chain, a first hint is given by the number of establishments on each tier. However, the horizontal structure of a single supply chain is of little interest for analysing the interrelation with freight transport demand. In most cases, changes in the horizontal structure, e.g. centralisations, affect multiple supply chains. In consequence, the distribution of establishment sizes within the entire sector, i.e. all establishments producing the same output commodity, should be considered when analysing the impact of changes in the horizontal dimension. Such changes are often described as an increasing or decreasing industrial concentration, i.e. reduced or respectively higher number of establishments. Here, it is important to use the actual distribution of establishment sizes instead of averages since the latter might favour misleading results. For example, it is highly

$1 \quad$ This definition is highly similar to the concept of systems as denoted by Hall and Fagen (1956): "A system is a set of objects together with relationships between the objects and between their attributes."

2 Looking into the original publication by Lambert and Cooper (2000) one will find that it refers to the horizontal and vertical dimensions in supply chains inversely to the common definitions (Perry 1989; Werner 2013; Christopher 2016). In order to ensure consistency, this study harmonises any findings from literature according to the definitions given above. 
probable that a set consisting of few large establishments and many small ones leads to different patterns of freight transport demand than an equal number of establishments all being of average size.

In addition to horizontal and vertical characteristics, especially material supply chains have a spatial structure, which describes whether its members are in close proximity to each other, distributed across larger distances, or a mixture thereof.

As already adumbrated above, certain structural characteristics of supply chains are most expressive if they refer to entire industries instead of single chains, e.g. the number of establishments on a certain tier. Throughout the remainder of this study, the focus is on supply chains of entire sectors. Hence, whenever the text refers to changes in the supply chain structure, it is to be assumed that the expression refers to the supply chain structures of the whole sector.

Leading beyond the scope of the study at hand but nevertheless worth mentioning, the deeper analysis of industrial networks is addressed in the research area of network analysis, which provides a rich set of indicators for describing the characteristics of a network, i.e. a more detailed descriptions of structure (e.g. different types of measures for density or centrality, see for example Wasserman and Faust 1999 or Friedrich and Ottemöller 2011 for the potential of linking dynamic social network analysis and freight transport modelling). 


\subsection{Structural Change in Supply Chains}

Supply chain structures are not as static as they might appear during the previous section. They underlie permanent change. Be it a result of planned continuous improvement or the adaptation to the evolving environment. In this regard, a broad variety of political, organisational, or technological drivers for change can be identified. The following sections describe the nature and potential impact on freight transport of horizontal and vertical change. Afterwards, decisions and behaviour in the context of economic actors' supply chain management leading to rearrangements in the supply chain structure are described.

\subsubsection{Categories and Examples of Structural Change within Supply Chains}

Often, the adaptation processes carried out by the economic actors being part of supply chains leads to changes in the observable supply chain structure. Here, two categories of changes in the supply structure, i.e. horizontal and vertical, are to be identified. These are illustrated in figure 2.4.

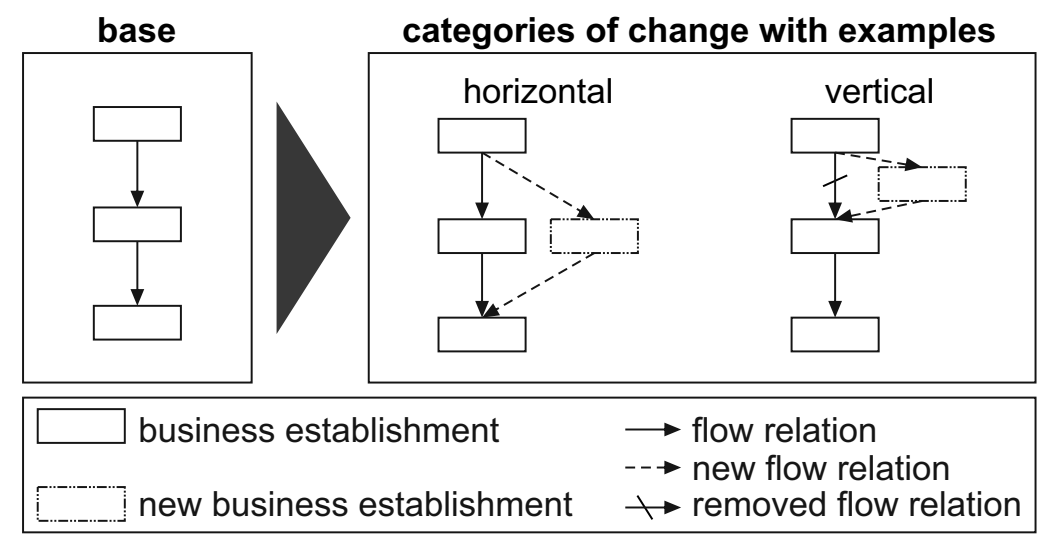

Figure 2.4: Categories of change in supply chain structures with examples

Vertical changes affect actors of consecutive stages of the supply chain, e.g. in the case of outsourcing of processes. Hence, they correspond to (dis)integrations of tiers. In contrast, horizontal changes are connected to changes to the composition of establishments on a single tier. As mentioned above, some manifestations of such restructurings are of organisational nature, therefore having no direct impact on the material flows and freight transport demand. Consequently, in the following only those changes in the structure of supply chains are of interest that directly manifest on the physical level. Here, physical level stands for the entire population of material flows and connected business establishments.

\section{Horizontal Changes}

Horizontal changes take place between actors of the same supply chain stage. Often, structural change in the horizontal dimension is driven by takeovers or alliances (Werner 2013, p. 123).

Figure 2.5 contains an example of centralisation. In the following, it is discussed in more detail in order to foster a better understanding of the interdependencies of horizontal changes and freight transport.

In the presented example, a certain amount of raw material is imported into the area of investigation. Here, it is processed within a two tier supply chain and delivered to a final consumption location in the end. The overall volume of material flow between the tiers is stable with a value of 100 units. In the base scenario, the material flow splits to provide inputs for two establishments that carry out the identical production step. In consequence, the 


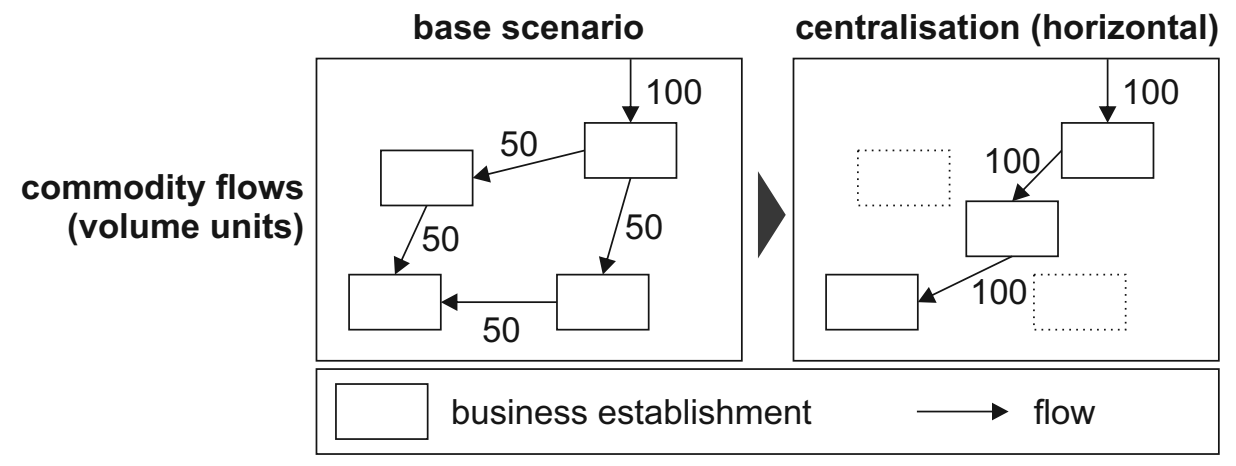

Figure 2.5: Example of changes in commodity flows in the case of centralisation

final consumption is served by two commodity flows each with a volume of 50 units. As shown in the figure, the overall freight transport volume in the investigation area for this setup is 300 units with a total of five commodity flows.

Now, a centralisation among the second tier establishments is assumed that leads to the emergence of a new production location that replaces the previous two establishments, e.g. in order to achieve economies of scale. Obviously, freight transport volume remains at a total of 300 units. The number of commodity flow is reduced to three flows now with an average volume of 100 units in contrast to a previous average of 60 units.

Most interesting from the perspective of the overall transport system is the development of freight transport performance. From the presented example, it is not recognisable which impact on transport performance will occur because there is no a priori information on the exact location of the new establishment available. Thus, possible (reasonable) locations must be considered. In the best case, the new location lies between the previous establishments and in this way even reduces overall transport performance. In contrast, one can also imagine that wage differences or subsidies influence the private decision makers to shift their production to a financially more advantageous but also more distant location at the price of higher freight transport performance. Potentially, the increased average commodity flow sizes, in the example from 50 to 100 units, lead to reductions in the transport rates per unit. This effect reduces the monetary deterrence of space, i.e. transport costs, that usually serves as a counterforce to the exploitation of wage differences. In consequence, relocations might become more attractive under the conditions of a more centralised production.

From the given case, it can be concluded that horizontal changes in supply chains may have a significant impact on freight transport. Already the presented example shows that it is impossible to find the single correct solution without further assumptions. Instead, a range of possible outcomes that depend on the intensity of assumptions made can be identified. Especially the spatial aspect of existing, vanishing, and newly appearing establishments requires a more complex modelling approach.

\section{Vertical Changes}

Vertical changes affect actors of consecutive stages of the supply chain. Often discussed phenomena in this regard are for example the outsourcing of production or assembly processes (Becker 2006; Göpfert and Grünert 2012; Werner 2013). In contrast to vertical change in the physical structure of supply chains, there are also developments in the organisational structure like takeovers of suppliers leading to vertical integration on the firm level. As defined above, such purely organisational phenomena are out of scope.

The value added (OECD 2013) or respectively the ratio of value added per output in monetary units (calculated as ratio $\left.=\frac{\sum \text { output }-\sum \text { input }}{\sum \text { output }}\right)$ is an often-cited indicator in the context of vertical change within supply chains, 
industries, and entire national economies. Since this indicator describes the supply chain structure from a financial perspective, the corresponding changes on the physical level are not unambiguous. Hence, different setups on the physical level may correspond to the same change in value added.

The effect of decreasing ratio of value added per output and its potentially negative impact on freight transport has been in the public debate quite some time (e.g McKinnon and Woodburn 1996; Rodrigue 2006) without scientifically satisfying and comprehensive answers (e.g. Holzapfel and Vahrenkamp 1993; Jäcker 1997; Holzapfel and Vahrenkamp 1999). A more detailed literature review, including the previously cited publications, is carried out in section 2.5.4, pp. 37-41.

As a starting point for overcoming this gap, the example in figure 2.6 shows how a decrease in the indicator ratio of value added can result from a vertical disintegration of physical production stages and how this might influence freight transport demand ${ }^{3}$.

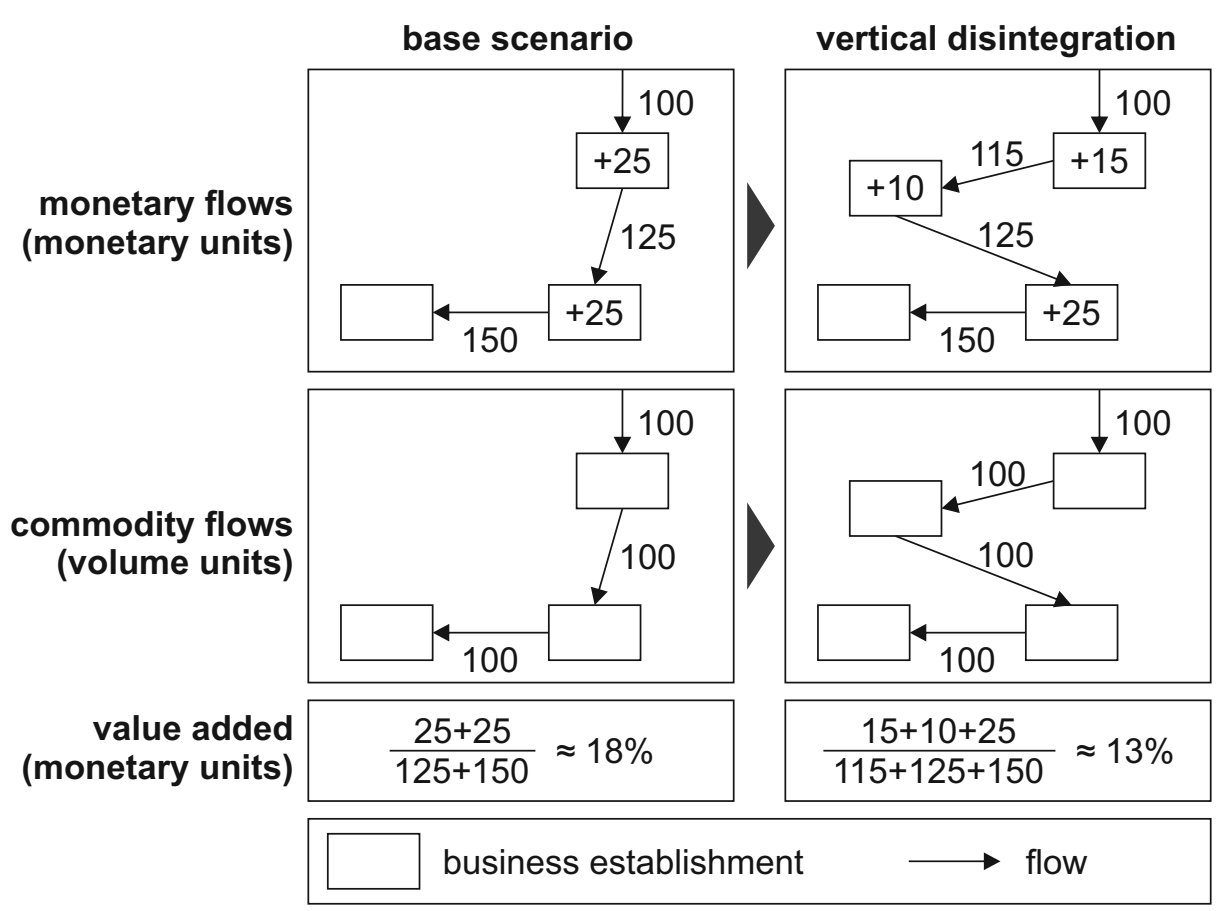

Figure 2.6: Example of changes in monetary flows and commodity flows in the case of vertical disintegration

The base scenario consists of three business establishments connected by a simple supply network, in this case a linear supply chain. The chain is driven by the demand of a consuming unit, e.g. a vehicle manufacturer's production site, which is supplied via a first-tier supplier that gets its inputs from a second tier supplier. The latter procures required raw materials from outside the focal area. Hence, the framing rectangle denotes the (spatial) boundary to the system under investigation.

In the upper part of the figure, all values correspond to monetary units. As described, this is only of limited usefulness in regard to analysing freight transport but it is required for analysing changes in the ratio of value added. The overall ratio of value added per output by summing up all procured inputs and outputs and dividing the difference by the total output. Hence, the value for this indicator is $\frac{50}{275} \approx 18 \%$ in the base scenario.

3 Apart from the disintegration of physical production, common effects that lead to a decrease in the ratio of value added are the outsourcing of service activities or increases in the value, respectively in the price, of intermediates. However, these phenomena do not directly influence freight transport. Section 5.2 contains more detailed information on these aspects using the German automotive industry as an example. 
Assuming a vertical disintegration such that the second tier supplier shifts part of its production to a new location, an additional tier is introduced into the supply chain and the financial as well as commodity flows change. The new setup is shown in the right part of figure 2.6.

First of all, the ratio of value added decreases to $\frac{50}{390} \approx 13 \%$. Thus, the assumed change reflects the intended reduction. From the physical perspective, routing the material flow between the suppliers of tier one and tier two via a new establishment, freight transport volume increases from 300 units to 400 units since transported goods are counted on every pickup. Consistently, the number of commodity flows rises by one.

Like in the case of centralisation, a prognosis of freight transport demand depends on various assumptions. In the best case freight transport performance could remain unchanged if the new business establishment is located along the previously taken transport route. In all other cases an increase in freight transport performance is inevitable. Summarising, it is to be concluded that vertical changes tend to have an impact on the ratio of value added as well as on freight transport demand. The high sensitivity to assumptions and the spatial nature of the problem require a more complex model for the further analysis of the actual impact on freight transport demand.

\section{Spatial Change}

In the public and scientific discussion of changes in supply chains, the relocation of production is usually part of the debate. Hence, an additional category for spatial changes appears to be required. In fact, most cases of relocations are intertwined with horizontal of vertical changes and should be addressed in that context.

Simply moving establishments to new locations without any further changes are out of scope for this work because they do not match the criteria of structural change on the level of establishments or commodity flows they only lead to changes in the distances of affected commodity flow relations. Nevertheless, it shall be mentioned that changes in the spatial setup influence freight transport demand. Figure 2.7 illustrates offshoring as an extreme case of spatial change.

Using the same base scenario as in the case of horizontal change, it is assumed that the importing establishment get moved to outside the original area of investigation. In consequence, the freight transport volume within the scope of analysis is reduced by 100 units. This counterintuitive effect is obviously a result of shifting volume out of the applied indicator's scope since the goods still need to be transported outside the focus area. From an economic perspective, the value added also changes. Depending on the value of the offshored production, an increase or decrease in the ratio of value added for the focal supply chain occurs. Like in the examples of horizontal and vertical change, any further analysis of changes in freight transport performance requires assumptions on the spatial layout.

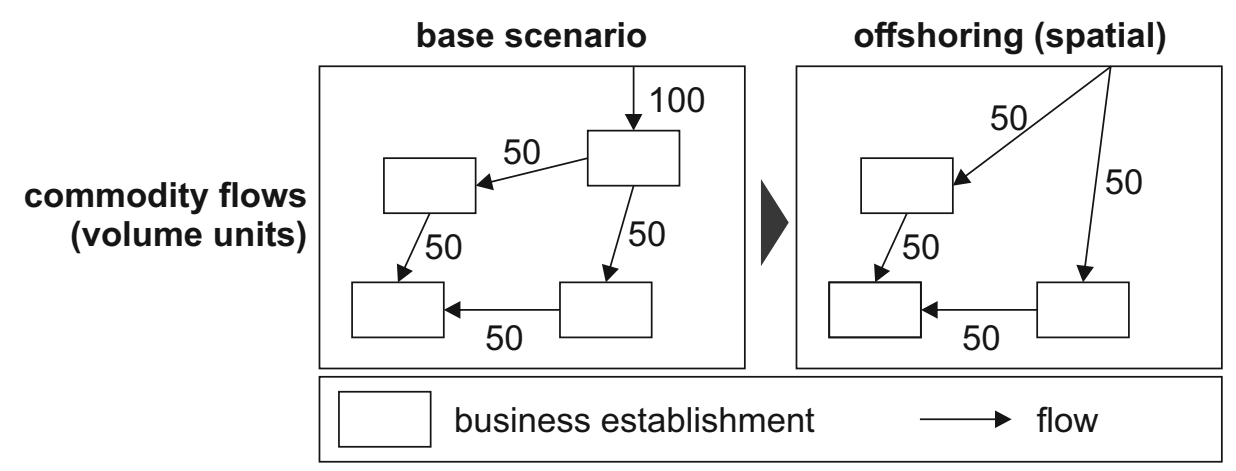

Figure 2.7: Example of changes in monetary flows and commodity flows in the case of spatial changes 
Consequently, spatial changes within given borders are neutral to value added but affect freight transport. In case of shifts across borders value added as well as indicators of freight transport demand will change. Spatial changes are addressed in the developed model, which is presented in chapter 4, as part of the previously described categories of horizontal and vertical change.

\subsubsection{Conclusions from the Examples of Change in the Structure of Supply Chains}

The different examples given above illustrate that changes in the structure of supply chains can have an impact on freight transport demand. The examples also show that is not possible to make any estimation on the actual impact without further information either derived from modelling efforts, if certain behaviour can be modelled endogenously, or assumptions. Derived from the given examples, these informations especially need to address the following aspects:

- before change:

- existing establishments: locations, input volumes, output volumes

- existing commodity flows: origins, destinations, volumes

- after change:

- existing establishments: locations, input volumes, output volumes

- appearing establishments: locations, input volumes, output volumes

- vanishing commodity flows: origins, destinations, volumes

- appearing commodity flows: origins, destinations, volumes

The subsequent literature review presents existing approaches on decision that relate to either one or multiple of the described aspects.

\subsection{Economic Decisions Influencing Supply Chain Structures from a Perspective of Freight Transport Demand}

The following sections provide a literature review regarding approaches on decisions of economic actors first on micro level and then on meso level. The literature review follows two purposes: First, the approaches from literature help to identify mechanisms that determine characteristics of supply structures and therefore should be reflected in the later model design and application. Second, the conducted literature review is used to summarise the status quo of research regarding the characteristics of supply chain structures and their relation to freight transport demand.

\subsubsection{Structure of the Literature Review}

All approaches included in the literature review address aspects that are relevant in the context of change in supply chain structures. In consequence, all the described decisions and phenomena are directly connected to the characteristics of either establishments, commodity flows, or both in the context of supply chain structures. Most of these decisions have a long-term, i.e. strategic, planning horizon (Fleischmann and Meyr 2003, p. 468; Günthner 2007, p. 331).

The broad range of research disciplines entangled with supply chain structures reaches from topics in business administration, logistics, via economics to transport and geography. Hence, finding a comprehensive as well as comprehensible categorisation for the intended literature review poses a challenging task. 
Table 2.1: Overview of supply-chain-structure-related decisions on establishment level (micro) and corresponding meso and macro phenomena

\begin{tabular}{|c|c|c|}
\hline micro & meso & macro \\
\hline $\begin{array}{l}\text { - location choice } \\
\text { - purchasing/sourcing } \\
\text { decisions } \\
\text { - target market choice }\end{array}$ & $\begin{array}{l}\text { - multi-facility location and } \\
\text { allocation problems }\end{array}$ & $\begin{array}{l}\text { - industry location } \\
\text { - (inter)national trade }\end{array}$ \\
\hline $\begin{array}{l}\text { - establishment size/capacity } \\
\text { choice }\end{array}$ & - horizontal cooperation & - horizontal industry structures \\
\hline - make or buy decision & $\begin{array}{l}\text { - number of tiers in the supply } \\
\text { chain }\end{array}$ & $\begin{array}{l}\text { - (national) value added } \\
\text { - vertical industry structures }\end{array}$ \\
\hline
\end{tabular}

By their content, most contributions can be distinguished by their focus on a single specific or a combination of decisions related to structural attributes, e.g. a ceteris paribus location choice or a parallel analysis of location choice and spatial price differences.

The scope, respectively scale, is a second aspect applied for categorising the different research objectives, i.e. single establishments (micro), groups of establishments (meso), or whole industries or (inter)national economies (macro).

An overview of the overall categorisation of decisions linked to supply chains structures and corresponding entries is given in table 2.1. For many phenomena listed in the table, the single entries stand for normative, descriptive or explanatory approaches in literature. For example, location choice is addressed normatively in land-use planning, descriptively in quantitative geography, and explanatorily in the new economic geography.

Following this structure, the literature overview below is partitioned into three parts. First, the framing role of supply chain management regarding this study's analysis of change in supply chain structures is summarised. Second, decisions on micro level are described, i.e. decision problem that relate to a specific aspect for a specific actor. The third part, approaches to supply chain structures from a meso and macro perspective presents literature that combines insights from the micro behaviour in order to analyse the potential outcome and driving forces if these decisions are made in parallel by larger numbers of actors.

\subsubsection{The Interrelation of Supply Chain Management, Supply Chain Structures, and Freight Transport}

The research area of supply chain management frames the entirety of decisions related to supply chain structures. The perception of supply chains as reasonably organised systems shapes the perception of economic activity through this study. Hence, this section aims at illustrating the direct relation between supply chain management and freight transport.

Today, it is broadly accepted that the competitive advantage depends on the excellence of all activities within a firm. Porter (1985) describes this principle and introduces the value chain concept, which structures material-flowbased firms' processes into strategic activities. Building upon these ideas, Christopher (1992) further develops this idea by clarifying that it is no longer isolated firms competing against each other. Instead, he puts networks of 
interdependent companies, i.e. supply chains, in this role. In this regard, Christopher (1992, p. 18) defines supply chain management as "the management of upstream and downstream relationships with suppliers and customers to deliver superior customer value at less cost to the supply chain as a whole". This formulation especially emphasises on the holistic and joint optimisation of involved suppliers and customers. The more specific formulation of SimchiLevi et al. (2008, p. 1) addresses the different tasks and objectives in the scope of supply chains: "Supply chain management is a set of approaches utilised to efficiently integrate suppliers, manufacturers, warehouses and stores, so that merchandise is produced and distributed at the right quantities, to the right locations, and the right time, in order to minimise system-wide costs while satisfying service level requirements".

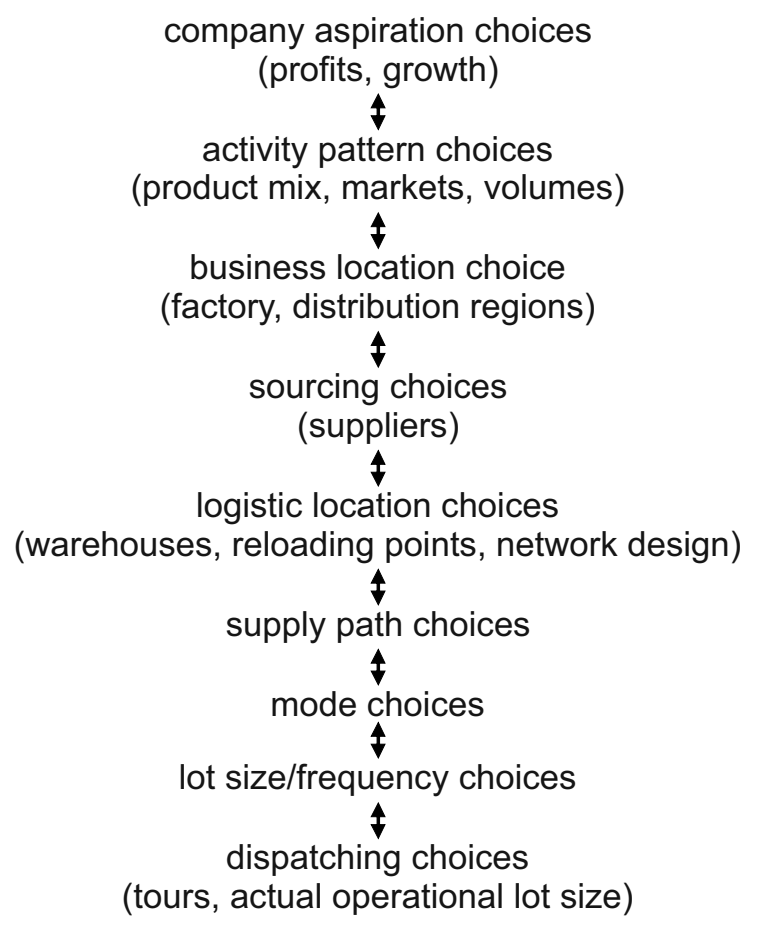

Figure 2.8: Hierarchy of corporate choices according to Friedrich (2010, p. 20)

A research stream from the area of supply chain management especially focusses on possible configurations of supply chains, e.g. Chandra and Grabis (2007). Here, a focus lies on developing strategies that match the continuously evolving environmental conditions. Following this dynamic perception, firms are systems of interdependent choices leading to permanent adaptation processes according to Siggelkow (2011). The dynamically evolving nature and limited predictability of environmental conditions leads Hedberg et al. (1976) to compare the stability of supply chains to "camping on see-saws" emphasising on the importance of flexibility and adaptability in economic planning and behaviour. From the perspective of freight transport demand, Hensher and Figliozzi (2007) emphasize on the relevance for considering rapid changes in freight transport modelling.

Regarding the dynamics of such changes in supply chains, literature from the area of supply chain management knows two opposite concepts: A first being "quantum change" (Khandwalla 1973), which corresponds to sudden and large changes. And a second kind, denoted as "piecemeal-incremental approaches" (Miller and Friesen 1982), which proposes rather slow processes that successively change the overall supply.

As the various definitions adumbrate, supply chain management addresses decision problem within an interdisciplinary environment for the benefit of various economic objective dimensions. In this regard, Friedrich (2010, p. 20) proposes a hierarchy of corporate choice levels for structuring the interrelation of economic decisions and freight transport demand as depicted in figure 2.8. Using the proposed hierarchy of choice levels for reference, 


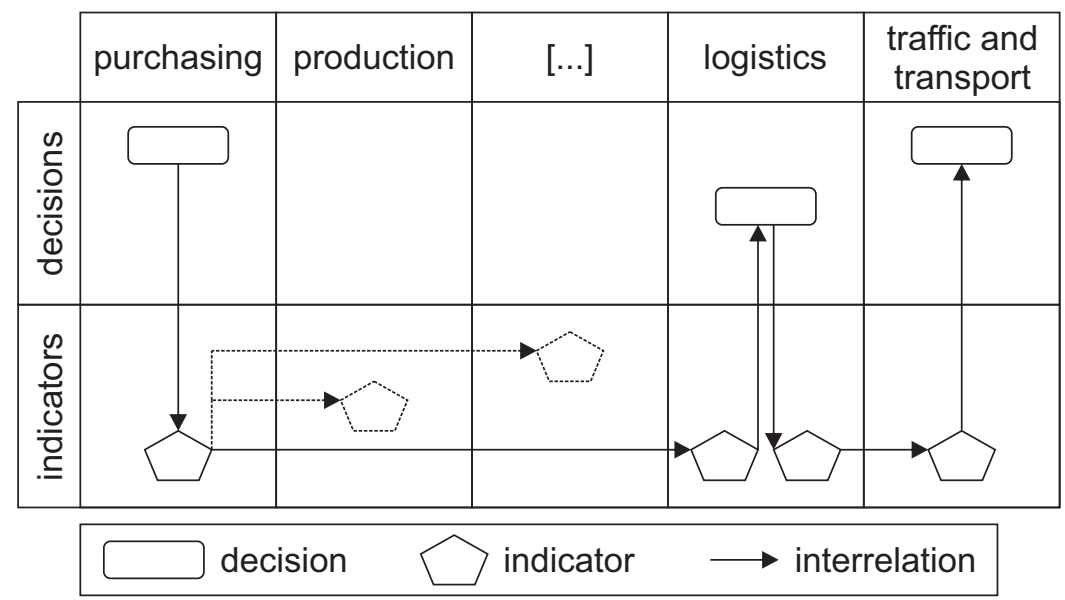

Figure 2.9: Framework for describing interdisciplinary interdependences of decisions (adapted from Boltze et al. 2015)

especially approaches on activity pattern choices, business location choices, and sourcing decisions receive further attention in the literature review below.

Also aiming at the interrelation of freight transport and economic decision making, Boltze et al. (2015) develop a more detailed framework that allows for describing interdisciplinary cause-effect-chains of decisions made in a specific subsystem of the supply chain and propagating to other areas. Their examples motivate for the interdisciplinary scope of the conducted literature review by emphasising how supply chain management and its various decision problems are interwoven with the freight transport system and its management. The conceptual framework is illustrated in figure 2.9.

In summary, reflecting the economic decision making in the analysis of supply chain restructurings is backed by research at the interface between supply chain management and freight transport. Though the dynamics of adaptation processes that lead to changes in the supply chain structure are out of scope for the analysis at hand, it is important to note that research from the area of supply chain managements underlines the dynamic and continuously adapting nature of supply chain structures.

After this brief preface on the general linkage between freight transport and supply chain management, the subsequent section leaves the abstract level and describes the various decisions on micro level that determine the configuration of supply chains and their structure.

\subsubsection{Decisions on Micro Level}

As mentioned, briefly describing the decisions that influence the emergence of supply chain structures on a micro level is a prerequisite before continuing with literature on the corresponding phenomena on a meso and macro level. These meso and macro modelling approaches often combine selected parameters from the micro level in order to account for potential tradeoffs. Hence, even if they are described separately on the micro level, most decisions are interrelated and mutually influenced by each other. Keeping this in mind, different micro decisions are addressed separately in the following for reasons of simplicity ${ }^{4}$.

The examples of change in supply chain structures have brought up central information needs for analysing the impact on freight transport demand. The first question asks where to find new business establishments (location

4 This is similar to the concept of constructional hierarchies that "decompose a complex system into simplified subsystems only for reasons of complexity, e.g. if no solution methods exist to solve a monolithic model of the complex system in a single step." (Schneeweiss 1999 according to Fleischmann and Meyr 2003) 
choice) and how to determine their output volumes capacity choice. Questions regarding the vertical supply structure are treated in the context of make or buy decision. The linkage between business establishments, i.e. the pattern of commodity flows, is a result of decisions taken in the context of purchasing and target market choice.

\section{Location Choice}

The importance of locational factors for the economic well-being of a firm has been subject to wide field of economic research in past (e.g. already in Smith 1776) and present (e.g. focussing on today's emerging markets in Jindra et al. 2016). Hence, the question of how to select a site has gained attention as well. Obviously, the location of establishments has a direct impact on the spatial structure of a supply chain.

Over time, a rich set of criteria has been collected. The following hierarchical list is a selection from MacCarthy and Atthirawong (2003), Mattfeld (2013), and Nehm et al. (2013) focussing on aspects that are especially relevant to the location of manufacturing establishments:

- geography

- distance to markets

- distance to suppliers

- climatic conditions

- availability of land

- infrastructure

- modes of transport

- quality and reliability of transport

- telecommunication systems

- educational and cultural offerings

- labour characteristics

- quality of labour force

- availability of labour force

- labour unions
- government and politics

- government stability

- subsidies or political support

- labour unions

- trade regulations

- environmental regulations

- costs

- wage rates

- transport costs

- energy costs

- land costs

- construction costs

The list contains soft as well as hard, i.e. quantifiable, factors (especially costs). Hence, the selection of a certain site should be based on methods that are capable of dealing with such complex multicriteria problems. Here, modern decision science proposes different approaches, e.g. the analytic hierarchy process (AHP) or analytic network process (ANP) (Saaty 2004). The process of selecting often is of a hierarchical structure with different criteria dominating on the different levels of decision, i.e. global, national, regional, and local. The importance of specific factors strongly depends on the sector under consideration. For example, knowledge intensive sectors like the pharmaceutical industry or information technology have negligible transport costs but highly depend on the availability of qualified labour. On the other hand, the processing of sugar beets must be carried out in proximity to the farming areas because of the products' low value density and resulting restrictions on affordable transport costs. In addition, firms may pursue manifold objectives when establishing new locations, e.g. entering new markets or reducing overall costs. 
Building upon Weber (1909), many mathematical optimisation problems have been formulated in order to find best locations in regard to quantifiable factors, especially costs, e.g. for transport. The model introduced in chapter 4 makes uses of approaches from the area of quantitative optimisation.

For the analysis of structural change in supply chains, locational attributes provide a source for assigning appearing establishments to locations. Thinking in the opposite direction, locational attributes can also be considered for selecting establishments that are prone to vanish in the course of restructurings due to their inferior locational attributes.

In addition, the presented location factors provide levers for policy measures that the location choice of firms, e.g. in order to improve employment or to mitigate the impacts of freight transport demand resulting from economic activity.

\section{Capacity Choice}

Determining optimal establishment sizes in terms of capacity is one of the major decisions regarding overall establishment characteristics. Obviously, it heavily depends on the demand for the produced good. Assuming market interactions, the volume of supply and demand are matched by a price mechanism (e.g. Marshall 1890). The longterm interdependency of establishments' sizes and locations, prices and demand are discussed in further detail in the following sections on meso and macro phenomena from a perspective of industry structures and industrial organisation.

If demand volumes and market shares are assumed to be fixed for the planning scope of a single firm, the capacity choice is directly connected to the number of facilities to open. Especially firms with a high market output need to decide for opening one or many establishments for producing the intended volume. For example, Bain (1954) discusses the importance of selecting a minimum-cost establishment size in order to avoid market entrance of new competitors. His results especially show how the optimal size differs between industries. An overview of methods used for descriptively finding such minimum efficient establishment sizes based on statistical census data is presented in Lyons (1980).

In contrast, there are also normative models for determining establishments' sizes, locations, and the allocation of suppliers and customers. An overview of available approaches planning problems considering multi-plant configurations can be found in Bhatnagar et al. (1993), Pirkul and Jayaraman (1998), and Melo et al. (2006).

Following this perspective, a central trade-off occurs between transport costs, fixed costs per facility, and the potential of economies of scale (Carlton and Perloff 2000, p. 39).

Section 5.1 focusses on the impact of centralisation, i.e. an increase in average establishment sizes, on freight transport demand in the industry of poultry slaughtering for Germany.

In addition, the capacity decision is interwoven with selecting a suitable technology ${ }^{5}$ that matches the intended output volume. Figure 2.10 illustrates how the superiority of the given average cost functions $A C_{1}$ and $A C_{2}$ depends on the achievable output volume. Even if $A C_{2}$ has a lower global minimum, $A C_{1}$ might be advantageous if demand does not allow for reaching the required amount. Also, smaller firms may be forced to apply $A C_{1}$ due to a lack of financial endowment and find ways to compensate for the cost disadvantage while a larger firm is capable of investing into rather costly technology that ensures lower average cost at large scale.

It is assumed that a technology describes the combination of input factors required for producing one unit of output and the accompanying cost of production. In economics the term production function is used synonymously. 


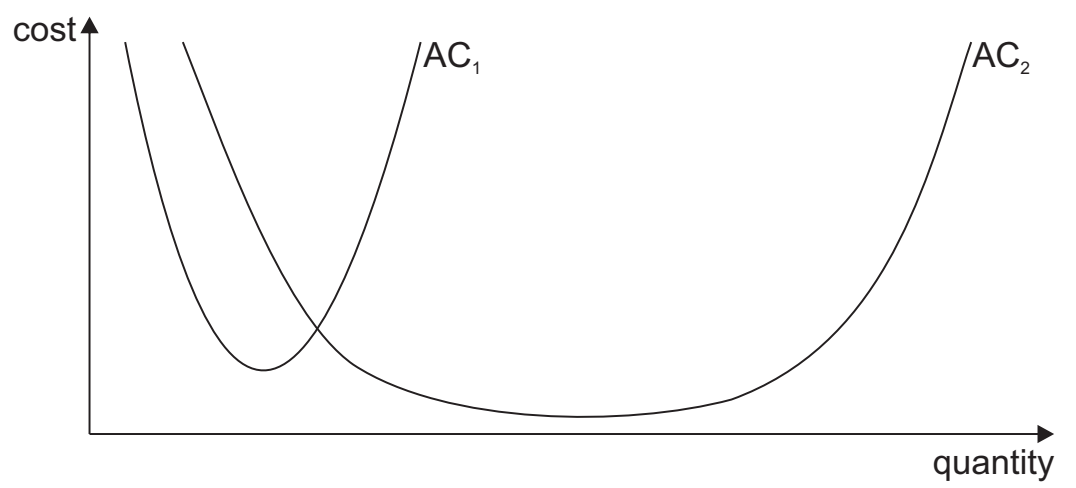

Figure 2.10: Average cost curves of different technologies (adapted from Carlton and Perloff 2000, p. 32)

A firm's number of establishment may also be determined by constraints imposed by suppliers or customers. For example, car plants might require levels of variant flexibility in a just-in-time environment that can only fulfilled by opening multiple customer specific sites.

As laid out above, the total demand for an industry's product, the available technologies (i.e. achievable economies of scale), and transport costs resulting from the location of demand and product characteristics determine the establishment sizes (i.e. horizontal structure) of an industry.

\section{Make or Buy Decision}

The decision on which parts to produce within the own establishments and which parts to buy from external suppliers belongs to the strategic level of a firms planning. According to Williamson (1985), this is a decision between three different governance structures: hierarchical if production is carried out within the firm and coordination is achieved through property rights, market if production is purchase from external and prices are used for the coordination of exchanges, and hybrid if a combination of both is applied. This leads to a range of possible degrees of outsourcing as illustrated in figure 2.11. For the context of changes in supply structure, especially those effects that are not simply of organisational nature (especially centre approach, cooperation).

Since the decision is fundamental to the firm's current and future prosperity, much research has been conducted on the various aspects of the make or buy decision. There are also different synonymous terms in literature, e.g. strategic outsourcing (Holcomb and Hitt 2007). In the following, the make or buy decision's key characteristics are presented in brief because it is closely connected to a supply chain's vertical structure, especially its number of tiers.

\begin{tabular}{|c|c|c|c|c|c|c|c|}
\hline insourcing & \multicolumn{3}{|c|}{ internal outsourcing } & \multicolumn{3}{c|}{ external outsourcing } \\
\hline $\begin{array}{c}\text { make } \\
\text { (own } \\
\text { manufac- } \\
\text { turing) }\end{array}$ & $\begin{array}{c}\text { centre } \\
\text { approach }\end{array}$ & $\begin{array}{c}\text { coope- } \\
\text { ration }\end{array}$ & $\begin{array}{c}\text { common } \\
\text { service } \\
\text { company }\end{array}$ & $\begin{array}{c}\text { capital } \\
\text { invest- } \\
\text { ment }\end{array}$ & $\begin{array}{c}\text { co- } \\
\text { working } \\
\text { formal co- } \\
\text { working } \\
\text { formal } \\
\text { agree- } \\
\text { ment }\end{array}$ & $\begin{array}{c}\text { spot } \\
\text { trans- } \\
\text { action }\end{array}$ \\
$\begin{array}{c}\text { only } \\
\text { hierarchy }\end{array}$ & & & & hybrid \\
\hline
\end{tabular}

Figure 2.11: Levels of outsourcing (Arnold 2000) 


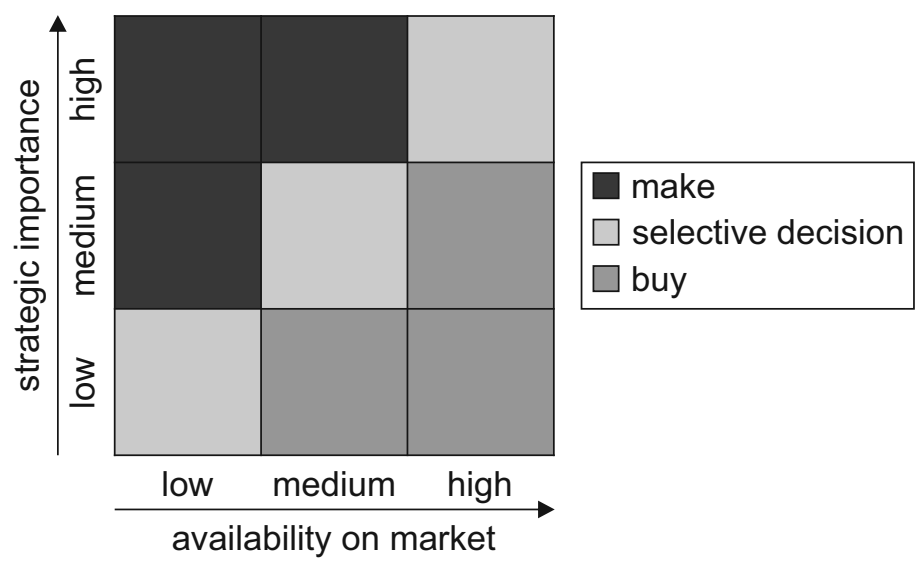

Figure 2.12: Make-or-buy portfolio (translated from Arnold et al. 2008, p. 280)

Most final products consist of combined or transformed inputs, which can be categorised depending on their relevance for the final product. Hence, there are auxiliary materials that are consumed during the production process (e.g. abrasives), generic suppliers (e.g. screws) and high end supplies that are competitively relevant components for the final product (e.g. communication and media systems in cars). Obviously, each of these product categories has a different weighting of decision factors during the make or buy decision. Over time, research as well as the application in practice have shown that there is a broad set of factors that need to be considered in the decision process. In this regard, McIvor et al. (1997) emphasize that the make or buy decision had been driven solely by the objective of lowest costs prior to the 1973-1974 oil crisis. In the aftermath, additional criteria gained more importance, like supply relations' risk exposure or quality aspects (Holweg and Pil 2004). Figure 2.12 shows a practical recommendation how to deal with the described types of supplies depending on their market availability. Besides manufacturing, the make or buy decision also applies to administrative and service activities. However, these are out of this study's scope since they are rather independent from material flows.

After describing the make or buy decision's background, the two major approaches for explaining and determining a firm's (vertical) scope are introduced below.

In economics, the question of a firm's boundaries are core to the research streams of industrial organisation and the theory of the firm. Within these communities, the transaction cost theory (Coase 1937) is a central concept for explaining a firm's scope. In the approach of Coase (1937), the first fundamental assumption is that each firm naturally reaches a certain size at which the internal provision of an additional transaction is as costly as buying the same product or service from the open market. The second major driver against the internal provision of goods lies in the risk of "diminishing returns to management". In this regard, it is assumed that bounded rationality leads to a decrease in the entrepreneurial capability of placing productive factors in the most beneficial uses under an increasing number of transactions. An example for the aim of reducing transactions can be found in the automotive industry. Here, among other concepts, supplier parks and modular sourcing have been introduced in order to reduce the number of first tier suppliers delivering directly to the car plants. Williamson (1985) has extended the transaction cost theory by distinguishing between costs that occur ex ante costs that occur before a transaction, e.g. for negotiating and contracting, and ex post that result from the transaction, e.g. for quality control. Section 5.2 contains an analysis of the potentially induced structural change and related changes in freight transport demand using the automotive supply chain as an example.

The resource based view (Penrose 1959; Barney 1991) is the second major framework for explaining a firm's scope. It focusses especially on competitive advantages and specific capabilities resulting from a firm's resources, which need to be immobile and heterogeneous across firms. In this regard, resources contribute to the competitive advantage if they are valuable (they exploit opportunities or neutralize threats for the firm), rare (they are not 
available at a significant number of other firms), imperfectly imitable (they cannot be obtained by competitors), and not substitutable (they cannot be replaced by equivalent substitutes) Barney (1991). Using the automotive industry as example again, carmakers increasingly rely on specialised suppliers in order to exploit their resources and capabilities, e.g. regarding navigation systems or engine control units. In this way, they avoid the risk of not achieving a competitive standing.

According to (Holcomb and Hitt 2007), the two streams for explaining the make or buy decision converge because surveys and field studies have shown that in practice a mixture of arguments is used for decision making. Hence, in the following, it is briefly described how different mechanism that rely on these concepts lead to restructurings of supply chains.

The simplest type of restructuring is "substitution-based outsourcing" (Gilley and Rasheed 2000), during which existing internal production is replaced with procuring intermediates from an external supplier. Cases in which a firm decides to purchase an intermediate from a supplier instead of investing into own capacities are denoted as abstention-based outsourcing. In both cases, production is shifted to an external location coordinated through market interactions.

The natural emergence of new markets for intermediates as a result of continuously ongoing specialisations within a firm is described in Jacobides and Winter (2005). Here, it is assumed that successful innovative developments within a firm leads to the creation of "embryonic forms of the vertical interface" due to organisational necessities. In the long run, these internal units increase their autonomy. Finally, they separate from the original firm in order to foster advantages in resources as well as transactional aspects as described above.

Another driver for the outsourcing of production activities are advances in standardisation leading to reductions in the transaction costs. For example, Richardson (1972) emphasises on the impact of standardised information exchange. Technical standards on intermediates also reduce the cost associated with purchasing on the open market. Hence, if the reduction in transaction cost becomes significant, firms will decide to replace their internal production with external provision.

In summary, this section describes the two approaches for explaining a firm's scope, i.e. transaction costs and competitive advantage due to its resources. Building upon these concepts, it has been shown how these concepts are relevant for the vertical supply chain structure and how changes in the decision parameters might trigger changes in the supply chain. Hence, for the given objective the overview on strategic outsourcing should suffice. More detailed subtleties, heterogeneous decision parameters, and sectoral specifics are laid out for the model application in the automotive industry in section 5.2.

\section{Purchasing (Sourcing Decisions)}

After deciding to buy a certain intermediate from an external supplier, the next challenge is selecting one or more suppliers as trading partners. Often, dominant objectives are total cost (transport, price, coordination), quality, and security of supply (Arnold et al. 2008, p. 270). In general, these objectives are mostly influenced by two dimensions (Zhaohui Zeng 2000). One parameter to decide upon is the distance between supplier and point of consumption, often reduced to a decision between global and local. The total number of suppliers for one specific part is a similarly important decision, i.e. single or multiple. From an economic perspective, single sourcing potentially offers better economies of scale while multiple sourcing reduces the risk of total supply disruptions and being overly dependant from a single supplier. Hence, risk and benefit play an important role when deciding for a sourcing strategy (Treleven and Bergman Schweikhart 1988). 
The actual sourcing strategy has a significant impact on the supply chain structure. It determines the spatial structure by selecting local or distant material sources. In addition, the number of suppliers per product directly influences the number of commodity flows between establishments, and in the aggregate the connectedness of industries (Liedtke (2006, p. 103) uses the term "idealness of supply trees").

\section{Target Market Choice}

A firm's potential of selecting its actual customers is limited in most markets. Nevertheless, it lies within the responsibilities of each firm to decide upon which spatial markets, e.g. regions or countries, to serve and which groups of customers, e.g. only business or only end consumers. In this regard, target market choice describes the counterpart, i.e. the opposite perspective, to the sourcing decision. Developing strategies and procedures for selecting target markets is part of research in the discipline of marketing (e.g. Kotler 1972 as a starting point for the different aspects of modern marketing). The more physical aspect of which customer to supply from which plant and which logistics structures to use is addressed in logistics research, especially distribution logistics (e.g. Friedrich, Tavasszy, et al. 2014 referring to the interrelation with freight transport). Target market related aspects can also play an important role in the location choice as already mentioned in the corresponding section above.

In the context of the overview at hand, this brief summary on target market choices is considered sufficient because the approaches on the other planning problems assume pull-oriented markets. In consequence, the customers' sourcing decisions are seen as most relevant for the establishment of exchange partnerships, respectively commodity flows. Nevertheless, the target market choice is addressed implicitly on the micro level especially as part of location choice and purchasing, and in the various approaches on meso/macro level that consider location and allocation choices.

\subsubsection{Approaches to Supply Chain Structures from a Meso and a Macro Perspective}

The previous sections describe decisions on micro level that directly influence the supply chain structure. Most of these decisions cannot be made without considering the surrounding (economic) actors. Research from manifold areas, e.g. industrial organisation, supply chain management, logistics, geography, operations research, and land use planning, aims at finding normative as well as descriptive models for the emergence of spatial economic structures using various approaches on different scales in order to accommodate for occurring interdependencies.

The following literature review summarises the major findings related to supply chain structures and their dynamics $^{6}$. Instead of using a disciplinary categorisation, the overview is organised by the central aspects for describing supply chain structures in the presented context:

- Horizontal industry structure: How to determine firm and establishment sizes on the level of an entire industry?

- Industry location: Where do establishments locate if the whole sector and neighbouring industries are also considered?

- Trade: How to estimate realistic spatial patterns of material flows at scales beyond single establishments?

- Location and allocation using optimisation problems: How to find combinations of establishment locations and corresponding material flows that correspond to lower and upper boundaries of the solution range?

6 As a matter of fact, in the context at hand is nearly impossible to adequately recognise the achievements at the level of detail they deserve, especially with a scientific background of logistics and freight transport modelling. Hence, the brief section aims at summarising the major findings and modelled mechanisms from the different research disciplines without claiming completeness. 
- (New) Economic Geopgraphy: Which combinations of establishment locations and spatial material flows are expected to emerge based on microeconomic reasoning?

- Vertical industry structure: How to group production steps vertically to form distinct tiers of supply chains?

The overview closes with two sections on research that analyses change in supply chain structures from the perspective of freight transport in particular, building a bridge to the subsequent chapter, which contains a top-down approach from an aggregate perspective on the phenomenon of freight transport. The content is mainly driven by the following questions:

- Vertical change and freight transport: What is the current status of quantitative approaches from the area of freight transport research on the interrelation of freight transport demand and vertical change in supply chain structures?

- Horizontal change and freight transport: What is the current status of quantitative approaches from the area of freight transport research on the interrelation of freight transport demand and horizontal change in supply chain structures?

For the reader, a remark on why the overview below is not structured into disjunct categories of macro and meso level might be helpful: Regarding the scale of research in the context of material supply chains, a meso perspective would contain all analyses that address multiple establishments and their characteristics in parallel. The distinguishing aspect to the superordinate macro level would be that meso studies focus on a proportion or selection from an industry with a joint but limited scope. In contrast, macro research would address entire economic systems. Unfortunately, in many cases the assignment of literature either to the meso or macro category is unclear. Therefore, such a categorisation is not applied below. In addition, a categorisation relying on combinations of question and scale would be sparsely populated due to the different disciplinary scopes of available research. Nevertheless, specific contributions are marked as having either a meso or macro scope whenever helpful.

\section{Horizontal Industry Structure}

The horizontal structure of industries has been addressed especially in economics. Here, it must be distinguished between two major streams, i.e. innovation economics and industrial organisation.

Starting with innovation economics, much research has been conducted on analysing the interdependency of the number of firms and the speed of technological progress. Even if not directly connected to the actual number and size of establishment, the number of firms at least determines the lowest bound for the number of establishments. Originally, Schumpeter (1942) put forward the hypothesis that stronger concentration of firms within an industry stimulates their innovation activities. In this context, Kamien and Schwartz (1982) develop an equilibrium based mathematical model from the perspective of a single firm. Their results support the Schumpeterian hypothesis.

Using a game theory approach, Dasgupta and Stiglitz (1980) propose a model that allows for determining the number of firms simultaneously with the budget spent on research and development. In contrast to earlier approaches, the game theory concept explicitly considers multiple, interdependent players. Due to a high level of behavioural freedom for the actors in their model, Dasgupta and Stiglitz (1980) cannot identify an unambiguous relationship between industry structure and budget invested for innovation.

Levin and Reiss (1984) extend the described approach (Dasgupta and Stiglitz 1980) by integrating spillover effects, i.e. implicit knowledge transfers between individuals. In this way, they are able to show the impact of technological exchange among economic actors. For the spatial structure of economic activity, this partially explains the tendency to spatial agglomeration within knowledge intensive industries. Here, research distinguishes between to types: Marshall/Arrow/Romer-externalities (Glaeser et al. 1992), i.e. spillovers between firms from the same sector on the 


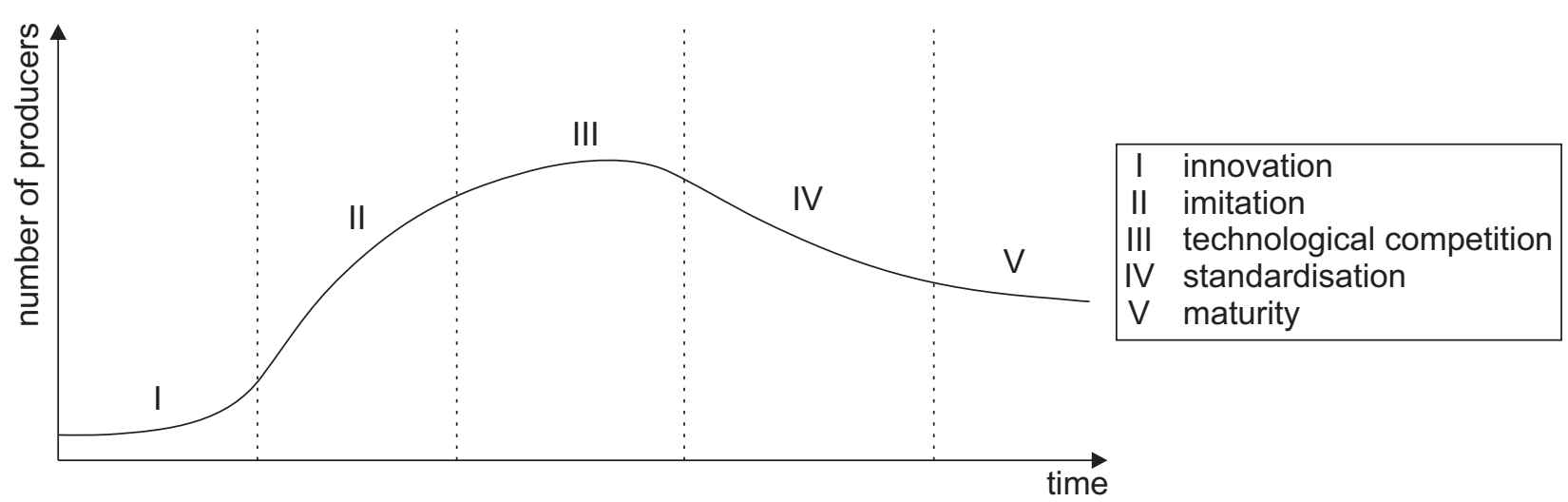

Figure 2.13: The five stages of new product industries (adapted from Mueller and Tilton 1969 and Gort and Klepper 1982)

one hand and Jacobs-externalities (Jacobs 1969), i.e. benefits resulting from the adjacency of firms from different sectors, on the other hand. Both being fostered by spatial proximity.

Summarising the insights on firm structures, models used for analysing the interdependency of industry structure and research and development activity do not allow for deducing a single structure because they reveal various stable configurations.

Industrial organisation is the second discipline of economics that focusses on industry structures. In this context, much work addresses industry structures from the perspective of contestability and resulting market structures, e.g. monopoly or perfect competition. Bain (1954) is a central contribution in this area, analysing the potential of economies of scale for different manufacturing in the United States based on documents and own survey data. The survey questions especially aimed at gathering information on minimal plant size required to achieve lowest unit costs, the productivity curve at smaller sizes, and the capital to establish a plant of most efficient size. The same information is collected considering firms. Hence, this approach distinguishes between firms and plants like it is proposed for the analysis of supply chain structures. Here, it is important to distinguish between economies of scale that appear on plant, i.e. manufacturing establishment, level due to increased efficiency of production processes at larger scale, and economies of scale on firm level that result from synergies on the level of supportive activities, e.g. central human resources services or purchasing. In the result, Bain (1954) finds different intensity of economies of scale across industries on plant as well as firm level. Nevertheless, he identifies a trend towards concentration across industries.

In more detail, the long-run trend towards concentration is explained in Mueller and Tilton (1969) and Gort and Klepper (1982) focussing on new product industries. They introduce five, structurally different, stages new product industries go through as illustrated in figure 2.13. Usually, in the first stage $(I)$, the number of producers is between one and three. The second phase (II) is characterised by a high number of market entries. After reaching a peak in phase III, competitors are forced to leave the market throughout phase IV. Mueller and Tilton (1969) propose that the speed of technological improvements decreases during phase II leading to an increase in the minimum efficient size of firm. As a result, the industry structure changes as firms and plants below the required efficiency level are forced out of the market. Finally, the industry reaches maturity in phase $V$ and the number of produces becomes rather stable. External shocks, e.g. due to new production technology or due to frictions on the demand side, might trigger shakeouts, according to phase III, also in rather mature industries. Examples for such externally triggered shakeouts are the collapse of the dot-com bubble (1999 to 2001) or consolidations in the aftermath of the recent financial crisis (2007 to 2009), e.g. in the banking sector. 


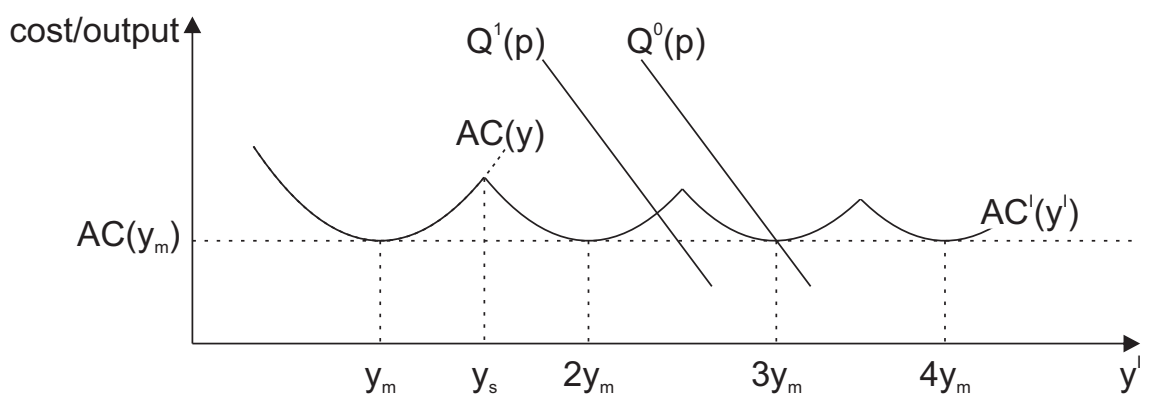

Figure 2.14: Average cost in an industry with multiple plants (Baumol 1982, p. 32)

Getting back to the idea of minimum efficient plant sizes (Bain 1954), Baumol (1982) addresses the contestability of markets and the industry structure based on average production cost assuming economies of scale on plant level. A key component of the analysis are average cost functions on industry level $\left(A C\left(y^{I}\right)\right)$ that are derived from plants' average cost curves $(A C(y))$ as illustrated in figure 2.10.

As shown, the first plant in the industry has minimum average costs when producing an amount of $y_{m}$. Once demand rises beyond the first plant's efficient capacity $y_{s}$, i.e. the output volume at which costs are no longer subadditive, a second plant will be opened and production volume split between them. Due to the U-shaped average cost curve on plant level (assuming identical plants), integer multiples of $y_{m}$ lead to unambiguous assignments of industry production to plants, e.g. when demand follows $Q^{0}(p)$. Unfortunately, real world demand is most likely to correspond to a curve that intersects $A C\left(y^{I}\right)$ somewhere between these multiples, e.g. like $Q^{1}(p)$. For these more realistic cases, Baumol (1982, p. 32) describes that no single stable industry structure can be determined and markets remain contestable under these circumstances. In addition, Baumol (1982, p. 36) proposes slightly changing the shape of the average costs curve on plant level such that it gets a flat bottom for certain range of output volume, which appears to be reasonable according to survey data. In consequence, the average cost function on industry level also becomes flat-bottomed. Looking at policy measures in such a situation, antitrust authorities can apply measures in order to increase the number of firms without social loss and without causing unsustainable industry structures (Baumol 1982, p. 40), an insight also helpful regarding measures that originate from transport planning.

As shown, research on the horizontal industry structure has shed light on the mechanisms that can be used for explaining the emergence of certain industry configurations and triggering forces for restructurings. In summary, none of the different modelling approaches is capable of unambiguously estimating a unique population of establishment sizes under given conditions. Hence, when modelling the change of supply structures, the horizontal industry structure must be assumed externally and should not be simulated endogenously.

\section{Industry Location}

As described above, a single establishment's location choice is potentially tightly interwoven with the location of suppliers, customers, and competitors. The research described below addresses the optimal location of economic activity from the perspective of a central planning unit for the entire economy based on economic reasoning.

The work by von Thünen (1990) (first published in 1826) presents a first model for the location of agricultural production based on economic fundamentals. The way it combines spatial aspects, multi-echelon production processes, and transport it must be seen as the earliest quantitative model that is similar to this study's scope on supply chain structures. His model assumes an isolated state with a central market as the location for the exchange of goods. Hence, the location of demand is given and fixed. From the centre outward the model determines circular zones, each with a distinct optimal agricultural activity. The soils fertility, and in consequence unit production cost, 


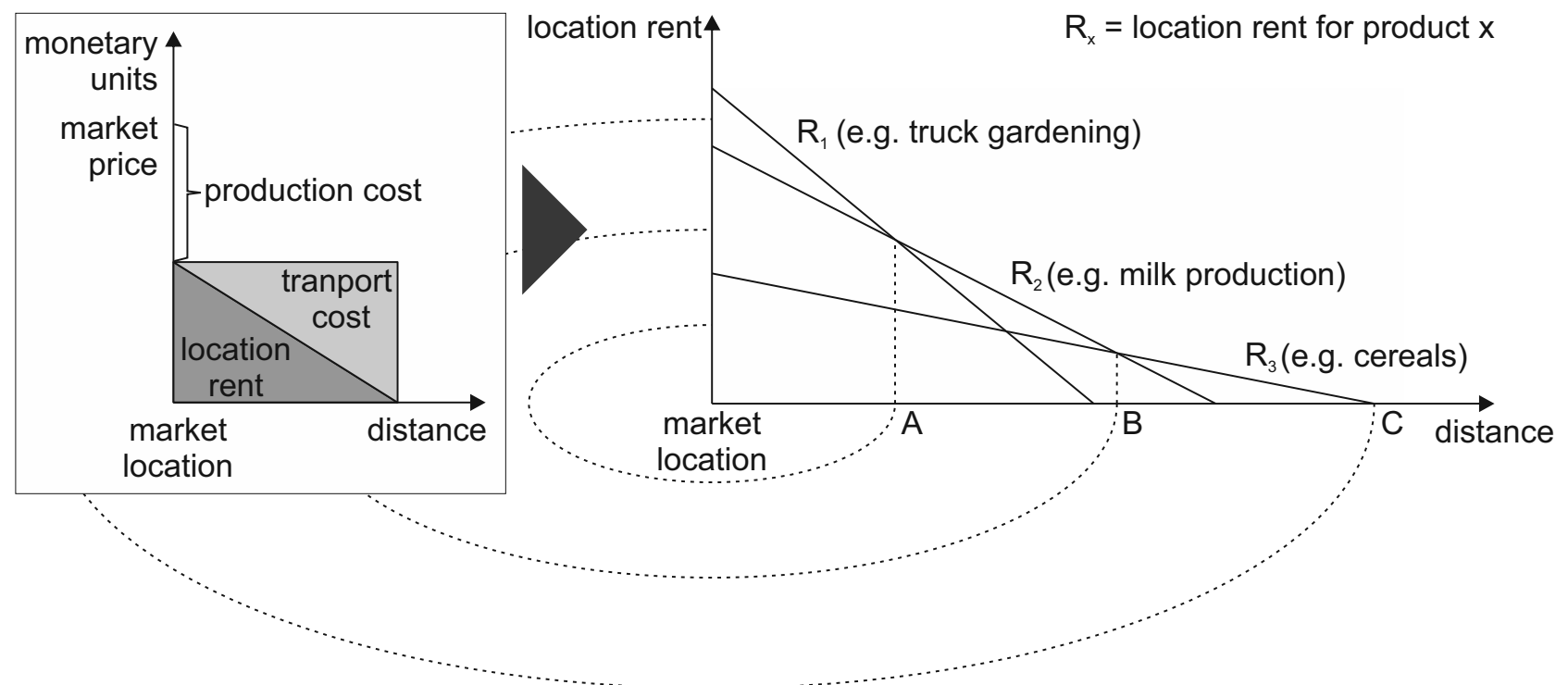

Figure 2.15: Composition of location rent and resulting von Thünen's rings for the location of agricultural production (von Thünen 1990 as quoted in Kulke 2013, p. 65, product examples from Beckmann 1968, p. 62)

are assumed equal among all locations. As depicted on the left side of figure 2.15, the model assumes a market price per commodity and a transport cost factor that depends on the products' transportability and perishability. Hence, for each product a location rent can be calculated as a function of distance to the central market (equation 2.1).

$$
l(d)=p-c^{\text {prod }}-c^{\text {trans }}(d)
$$

where:

$$
\begin{array}{ll}
l(d) & =\text { location rent at distance } d \\
p & =\text { market price per unit } \\
c^{\text {prod }} & =\text { production cost per unit } \\
c^{\text {trans }}(d) & =\text { transport cost per unit for distance } d
\end{array}
$$

At a certain distance, the location rent equals zero. This distance determines the state's outer boundary to wilderness. The resulting spatial pattern within the state boundaries is shown in figure 2.15. The strongly oversimplified model of von Thünen (1990) has been challenged on an empiric basis and proved applicability for the explanation of observable land-use patterns, especially if extended by additional market locations, efficient transport, and heterogeneous fertility of soil (Kulke 2013, pp. 66-67). However, even if it contains elements still found in later models of location choice at a meso or macro level, the model of von Thünen (1990) lacks especially a more suitable representation of transport and the consideration of manufacturing industries.

On a different level, Christaller (1980) (first edition published 1933) develops a model leading to geometrical structures for the location of cities, as well as economic activities. This kind of approach to spatial structures is also known as central place theory. Lösch (1940) extends the original approach by more soundly integrating economic principles in order to create an integrated theory of location choice and market areas especially for consumer demand (Blotevogel 2005). Criticising the extreme assumption of perfect geometric structures, Isard (1956) introduces additional forces like transport networks as sources of distortion. Still today, central place theory continues to influence normative land-use planning in Germany (Blotevogel 2005). However, the simplistic assumptions limit the applicability for this study's objective. 
The presented approaches on the location of economic activity give a first insight on the driving forces of location choice and resulting spatial patterns. However, the presented approaches on location choice on an industrial level are not suitable for applications in manufacturing industries or at the national scale due to the underlying simplifications. For the purpose of modelling location choice in supply chain structures, it is therefore recommended to rely on external assumptions or the optimisation problems described in the later section Location and Allocation using Optimisation Models (page 33).

\section{Trade}

Building upon the efforts described above, which focus on spatial structures, it is broadly accepted that the location of activity in space and the exchange of goods between these locations should be analysed using more integrated approaches:

"For (1) location cannot be explained unless at the same time trade is accounted for and (2) trade cannot be explained without the simultaneous determination of locations." (Isard 1956 as cited in Trautwein 2014).

Since locations of economic activity and connecting spatial commodity flows, i.e. trade, are fundamental characteristics of supply chain structures, this section is devoted to fundamental findings from the areas of trade modelling.

Trade models capture especially flows of goods resulting from the spatial aspects of supply and demand for goods. Building upon the idea of markets, they are developed to explain trade flows between countries and emerging prices considering various (immobile) factors, e.g. availability of workforce, capital and natural endowments. The majority of the developed models can be applied to interregional flows as well as international flows (e.g. Ohlin 1933). In general, trade models can be distinguished by which economic mechanisms they integrate and in which way market interaction and equilibria are modelled. On the side of endogenous mechanism, most models can be distinguished by either using the concept of comparative advantage (e.g. Ricardo 1817 and Ohlin 1933) or the integration of economies of scale.

One of the first trade models is presented in Ricardo (1817) by introducing the concept of comparative advantages between countries as explanatory variable for the emergence of trade. In the Ricardian model, each country has distinct technology functions for each good. The relative productivity for the two goods differs between the countries. Assuming free trade, each country will focus on producing the good for which it has the more efficient technology. In order to fulfil their demand for different goods, the two countries will exchange parts of their excess amounts in order to buy the required amount of the remaining good from the other country. Ricardo (1817) shows that in this situation both countries have the same set of goods as in the original situation but at a lower price together with additional production left for further export or consumption. Hence, the early and rather simple model by Ricardo (1817) predicts an overall increase in welfare for both economies as the major motivation for exchanging goods in free trade.

The next step in trade modelling was taken by Heckscher and Ohlin, published in Ohlin (1933), who provide a model that assumes identical production functions across countries and identical preferences but different endowments with capital and workforce. Capital and workforce are assumed to be immobile between countries. In contrast to the externally given comparative advantage formulated as different production functions in the Ricardian model, these are internalized by using capital and labour as parameters controlling for the shape of the production functions. Similar to Ricardo's model, the Heckscher-Ohlin model allows for finding profit-maximizing allocations of production factors and resulting trade flows. Despite various shortcomings in the model of Ohlin (1933), e.g. addressed in Leamer (1995) and Baldwin (2008), it still serves as a reference model when analysing international trade. 
Later designed general equilibrium models are based on the assumption of market clearance for all goods in a competitive economy. A condition that was first formulated in Walras (1874). Arrow and Debreu (1954) develop a mathematically sound formulation for a general equilibrium model and prove the existence of a solution that fulfils the required equilibrium conditions, i.e. market clearance and rationality in every agent's allocation choice. In contrast to earlier models, they integrate the idea that production is carried out by production units, e.g. firms (Decaluwé and Martens 1988).

Still, like Ohlin (1933), the model of Arrow and Debreu (1954) leaves out economies of scale. Addressing this limitation, Starrett (1978) develops the spatial impossibility theorem. It proves that there exists no competitive equilibrium involving the transport of goods between locations if space is homogeneous, transport is costly, and preferences are locally nonsatiated. In other words, if economic activity was infinitely divisible without loss of productivity, then transport would be minimized and production be spread according to demand. The real-world experience shows that there is no equal distribution neither for population nor economic activities. This limitation is addressed for example in the approaches of the new economic geography as described in one of the subsequent sections. Also, the fact that economic labour is not infinitely divisible without loss of productivity underlines the need for considering business establishments as basic elements of material supply chains.

In contrast to the before-mentioned economic models that apply concepts of rationality and utility maximisation for finding trade patterns, gravity models follow a different, i.e. descriptive, approach. The idea of modelling interaction across spaces similar to physical forces originates from geography (Reilly 1931). It incorporates the assumption that the intensity of interaction across space between two entities can be described by structural variables similar to masses of origin and destination and a deterrence function, which describes the hindering character of space to the interaction (Haggett 1968, p. 35). For example, the trade model of TRANS-TOOLS (freight model, described in detail in section 3.3.1) uses the formula below (Burgess, Chen, et al. 2008):

$$
T_{i j}=\alpha_{1} \cdot P_{i}^{\alpha_{2}} \cdot A_{j}^{\alpha_{3}} \cdot D_{i j}^{\alpha_{4}} \cdot e^{\alpha_{5} \cdot \gamma}
$$

where:

$$
\begin{array}{ll}
T_{i j} & =\text { the trade of a commodity group between country/region } \mathrm{i} \text { and } \mathrm{j} \text { in tonnes } \\
P_{i} & \text { the added value of the sector that supplies the commodity in country/region } \mathrm{i} \\
A_{j} & \text { the added value of the sector that consumes the commodity in country/region } \mathrm{j} \\
D_{i j} & \text { the distance between capital cities of country/region } \mathrm{i} \text { and } \mathrm{j} \text { as a proxy for the resistance on } \\
& \text { the trade } \\
= & \text { a dummy variable that captures economic co-operation between countries/regions or a } \\
& \text { specific position of (a group of) countries/regions } \\
\alpha_{1}, \alpha_{2}, \alpha_{3}, \alpha_{4}, \alpha_{5}= & \text { the model parameters }
\end{array}
$$

The presented efforts are potential solutions for the challenge of estimating flows of goods for an aggregate spatial resolution. The first category of models relies on endogenous mechanisms based on prices for the prediction of trade. A second more descriptive approach is contributed by gravity type models. Regarding the assignment of commodity flows on the level of business establishments, none of the presented approaches is directly applicable. In addition, the economic modelling approaches have a demand for spatially disaggregated input data. However, the presented trade models could be used for generating macroscopic flows that serve as aggregate constraints for commodity flows. 


\section{Location and Allocation using Optimisation Models}

Weber (1922, p. 9) (first edition published 1909) originally aims at forecasting future locations and transport flows for entire industries. Methodologically, he discusses the problem of location choice, finding three significant drivers: transport cost, labour cost, and agglomeration effects. Then, he conducts a deeper analysis for transport oriented location choices and develops what is known as Weber problem (also Fermat problem or Steiner-Weber problem) today. His model aims at finding a plant location that minimises transport cost under given locations of supply for intermediates and demand of customers.

First applications of formulations of the transport problem are developed in Hitchcock (1941) and Koopmans (1949) (for the mathematical formulation see section 4.5.2). In the conclusion, Koopmans (1949) recommends using the commodity flows as determined in the optimal solution of the transport problem as a benchmark for the location and interaction of industries.

Based upon this perception of the transport problem, Samuelson (1952) develops a model of spatial price equilibrium using linear programming. The model then is used for deducing rules on the impact of changes in the supplied volumes per region on the overall system including prices. Using a similar approach, Pitfield and Benabi (1982) propose using part of the transport problem's solution for determining location rents in the United Kingdom based on a rich dataset of actual freight flows provided by the British rail company. In the case of Pitfield and Benabi (1982), the solution of the applied transport problem shows a high degree of congruence with the real-world data especially for transport intensive commodity groups.

Also using linear optimisation, Kannegiesser and Günther (2014) and Kannegiesser, Günther, and Gylfason (2014) develop an approach for finding location and allocation patterns for the European automotive industry with the objective of minimising environmental impacts, e.g. $\mathrm{CO}_{2}$ emissions. Their results show that the result is mainly driven by the heterogeneous energy mixes provided by the different European countries and the resulting "optimal" location of energy intensive production steps.

In summary, literature shows that optimisation problems are already applied in the context of freight transport modelling. In contrast to the approaches described in the above sections Trade and Industry Location, the presented optimisation problems provide unique solutions regarding the location of establishments and allocation of commodity flows. However, it is to be considered that the optimisation problems purpose is to find minimum or maximum solutions. These do not need to be realistic. In contrast, the main purpose of the presented trade models is on estimating realistic spatial flow patterns. Apart from providing unique solutions, an additional advantage of the optimisation problems is that they are potentially capable of finding solutions on the level of business establishments and commodity flows as long as the number of variables remains in a solvable range. As mentioned above, the methodological subtleties and implemented formulations are described in more detail in the section on the developed model's second phase, which simulates change in supply chain structures (section 4.5.2, page 95).

\section{(New) Economic Geography}

Analysing the development of industrial structures and their spatial patterns is a central part of geography, especially its subdiscipline economic geography. Over time, multiple models of geographic industrialisation have been developed. An overview of available dynamic and static approaches can be found in Kulke (2013, pp. 85-201). The spatial model of geographic industrialisation by Storper and Walker (1989) (the following detailed description being based on Kulke 2013, p. 140), as shown in figure 2.16, is one example of qualitative dynamic models describing how industries (i.e. agglomerations of firms) develop over time regarding size and number of locations and their spatial distribution. 


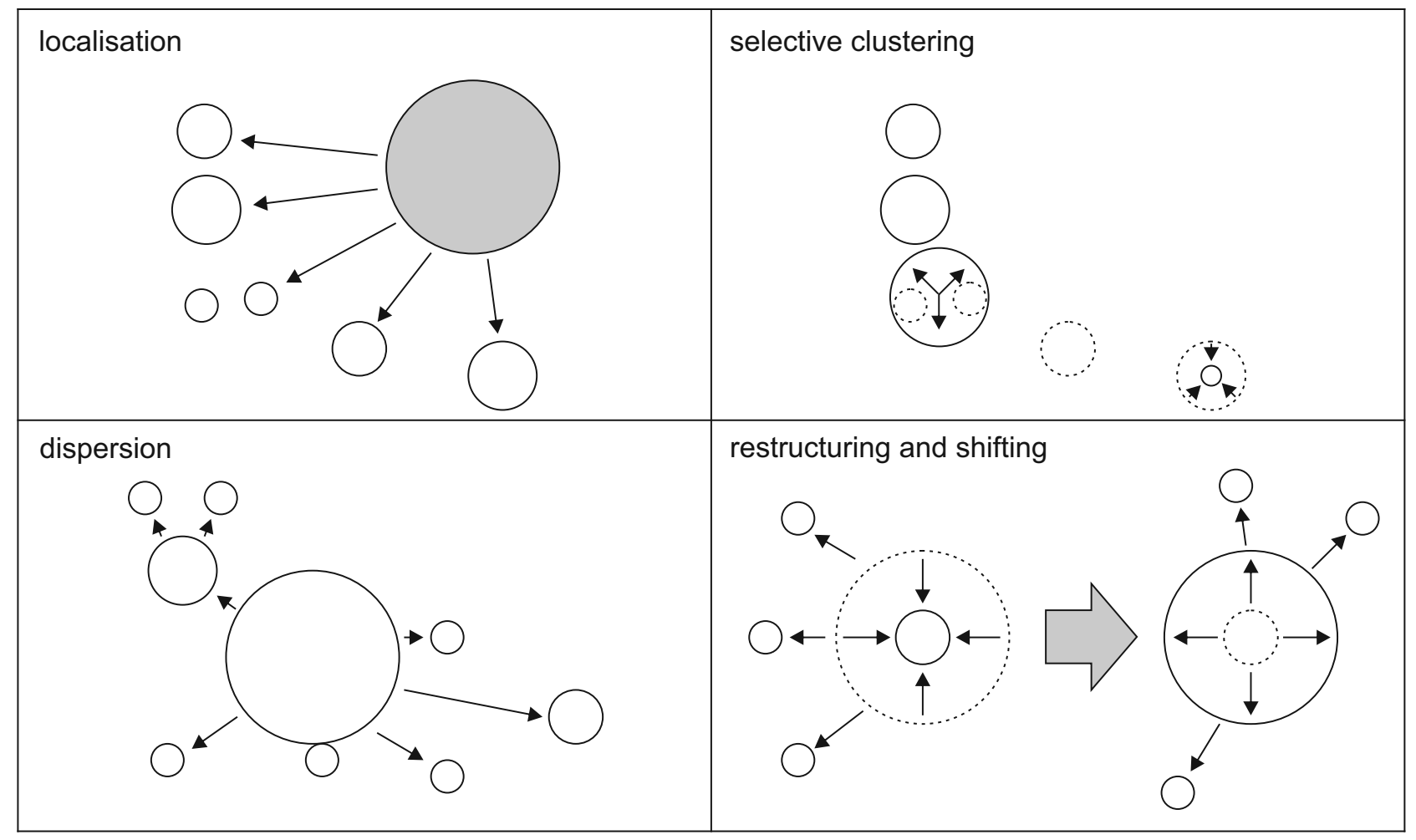

Figure 2.16: Spatial model of geographic industrialisation (Storper and Walker 1989, p. 71 as quoted in Kulke 2013)

Looking at the different phases of an emerging industry proposed in this very model (Storper and Walker 1989), location choice is hard to predict but to be expected most probably outside existing agglomerations during the initial emergence of a new industry. This first phase is denoted as localisation. The new locations of economic activity attract mobile production factors (e.g. labour and capital). This triggers concentration processes, certain locations grow whilst others decrease in size, as part of the second phase denoted as selective clustering. A phase of dispersion follows during which new locations spawn from the newly established industrial centres, e.g. for entering new markets. The maturing industry enters into the phase of restructurings and shifting, e.g. driven by innovations in the organisation or production processes. In summary, the described model underlines the dynamic character of continuously changing industry structures and supply chain structures.

Building upon the approaches presented above, i.e. industrial location choice, horizontal industry structures, and trade, a new subdiscipline emerged called new economic geography with Krugman (1991a) being seen as the starting point. This new research stream has gained much attention because it endogenously integrates many aspects that were modelled as external variables in existing approaches leading to the negligence of important interdependencies.

A major focus lies on the endogenous explanation for the occurrence of agglomerations as seen in the spatial structures of economy in the real-word. In this regard, Cronon (1992) distinguishes between first- and secondnature inequalities both being responsible for the unequal distribution of human activity in space. First-nature inequalities originate from the heterogeneity in natural endowments between different regions, e.g. regarding mineral resources, climate or geographic conditions like the availability of natural transport ways. In contrast, second-nature inequalities do only exist in consequence of human activity coping with the earlier first-nature conditions. Especially these should be endogenous to spatial economic models (Krugman 1998).

Hence, in contrast to previous approaches, the newer spatial economic models account for that "in the presence of increasing returns history matters" (Krugman 1979) or in other words that there might be lock-ins in the spatial 


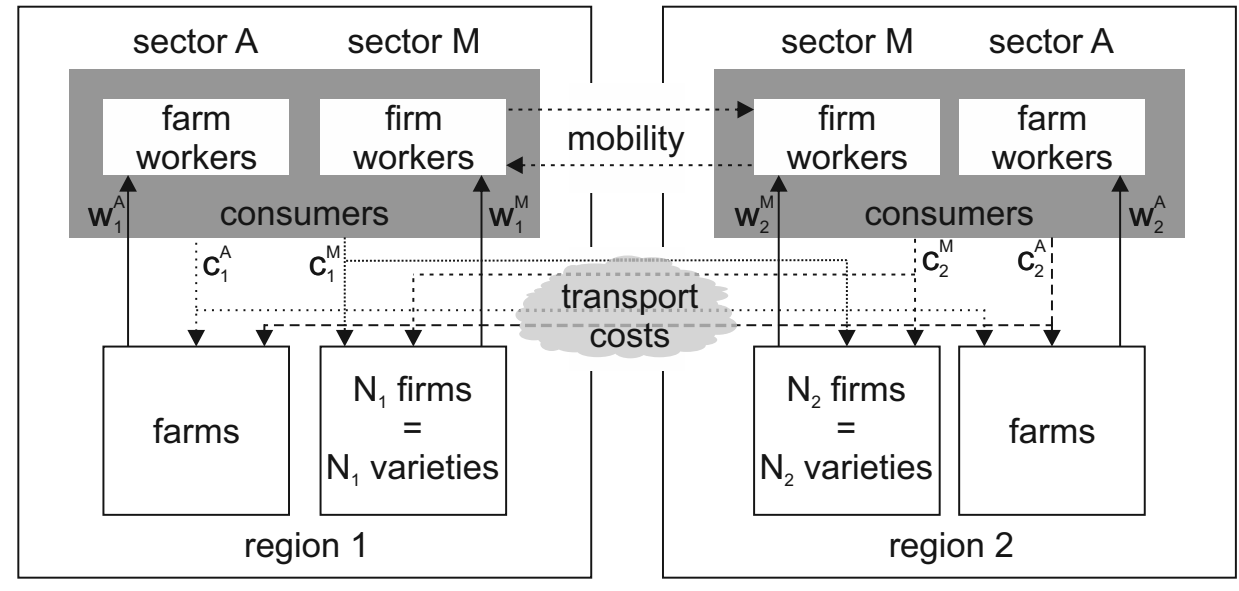

$\mathrm{w}=$ wage payments $($ income $) \quad \mathrm{c}=$ consumer spending

Figure 2.17: Structure of new economic geography's core model (simplified from Ehnts and Trautwein 2012)

pattern of economic activity due to its path-dependence (Arthur 1990; Arthur and Arrow 2004). As a result, new economic geography especially addresses two questions: "When is spatial concentration of economic activity sustainable? When is a symmetric equilibrium, without concentration, unstable?" (Fujita et al. 1999, p. 9).

The model proposed in Krugman (1991a) is the most comprehensive disaggregate approach on endogenously modelling the central aspects of supply chain structures, i.e. location of economic activity, spatial flow patterns, based on economic reasoning. Therefore, an overview of the modelled mechanisms and results of the spatial economic model proposed in Krugman (1991a) are presented in the following.

The applied modelling principle follows a general equilibrium and relies on invisible-hand processes that lead to the emergence of spatial structures (Krugman 1998). Hence, coordination is assumed to be achieved via market interactions according to monopolistic competition as described in Dixit and Stiglitz (1977). In the simplest case, two fundamentally different products are provided: A manufactured goods that is produced in different varieties, each variety being manufactured at only one specific plant and exchanged under monopolistic condition. The location and number of plants, and thereby varieties, is endogenous to the model. In contrast, a perfectly homogeneous agricultural good is provided under perfect competition serving as a residual. Regarding space, the described example considers two regions.

Production is assumed to be carried out at distinct facilities, which are not infinitely divisible without loss of productivity due to economies of scale. These facilities correspond to business establishments as described in the context of this study.

Regional demand considers spatially heterogeneous prices and local income, which depends on the local prices and production volumes. The utility function includes consumers' tendency of appreciating variety and consuming sets of heterogeneous products.

The only required input factors are specialised workforce. Krugman (1991b) assumes the agricultural workforce as given and immobile. Workers in manufacturing are assumed to be mobile. If their real wages are below average, they move to locations with higher real wages (Fujita et al. 1999, p. 62). This mechanism drives the (re)location of economic activity.

Instead of directly deriving static equilibria, the model assumes dynamic processes driven by accidental inequalities and the reactions of affected actors that may lead to stable states (Krugman 1998). In the given example with two regions, a growing concentration of manufacturing in one region caused by an initially small accidental decision 

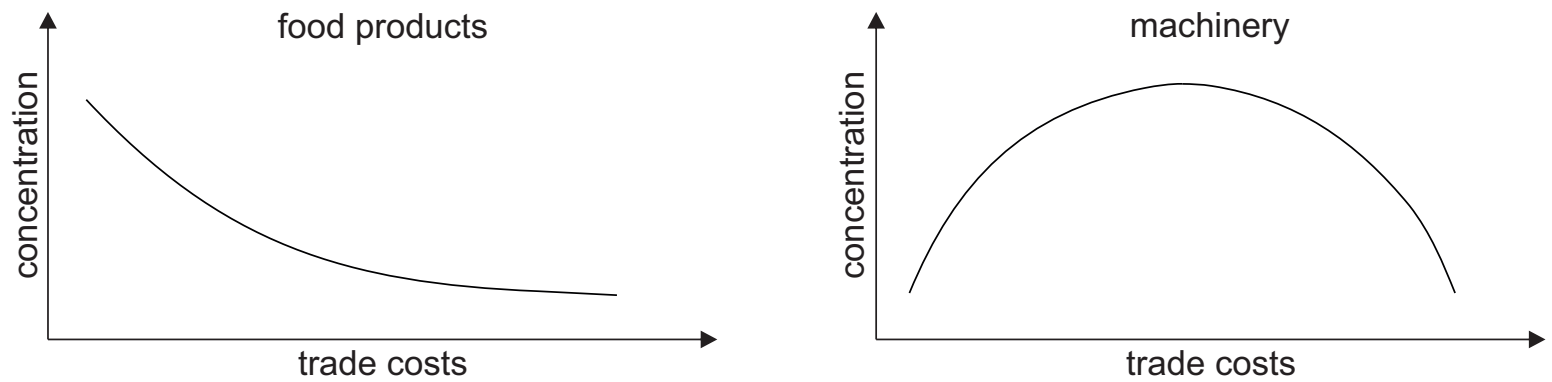

Figure 2.18: Industrial concentration in dependence of trade costs in comparison for example sectors with dominating comparative advantage (food products) and dominating economies of scale (machinery) as simulated by Forslid et al. (2002)

potentially triggers a positive feedback loop. As a result, the economy turns into a core-periphery geography even though it was perfectly homogeneous in the beginning (Krugman 1998). In the given example, it is a priori undecidable, which of the two regions will become the centre of manufacturing since the direction of stochastic fluctuations is unknown.

A major shortcoming of the original model from Krugman (1991a) is that it does not consider the importance of intermediates in manufacturing. In order to overcome this severe limitation, Venables (1996) extends the original model by adding an intermediate sector. The extended model shows that agglomeration as well as dispersion may be driven by the location choices of firms that are linked by intermediates. Combes et al. (2008, pp. 166-193) show that the forces induced by considering intermediates may replace the mobility of labour mechanism, which was fundamental in Krugman (1991a) but partially lacks empirical evidence.

Staying with intermediates and the impact of different mechanisms, Forslid et al. (2002) apply models from new economic geography in order to analyse the interrelation of industry characteristics and spatial concentration by using alternate model approaches, e.g. including or neglecting economies of scale or competitive advantage. Their model also contains the concept of intermediate goods produced in one and consumed by other sectors. The model results strongly differ depending on which of the mentioned aspects are considered. The results of a model application for the production of food and machinery, considering ten regions, thereof four representing western Europe, and assuming increasing returns to scale are illustrated in figure 2.18.

In summary, the existence of new economic geography's multiple equilibria contradicts earlier economic approaches focussing on unique and stable equilibrium states in economies with diminishing returns to scale. Besides transport costs, Krugman (1991a) identifies the intensity of economies of scale and the share of manufacturing in national income as key parameters for the emergence of spatial structures.

Arthur (1990) underlines the importance of path dependence and the impact of small random events during early stages of new industries' development. In this regard, the existence of inefficient but stable configurations is a significant result when seeing economic development under the premises of evolutionary processes. In addition, Arthur (1990) emphasizes that especially technology intensive industries are prone to economies of increasing returns and therefore experience intense positive feedbacks, which were out of scope of traditional research.

The (new) economic geography combines insights from different research disciplines leading to an integrated spatial disaggregate model that endogenously considers economies of scale, agglomeration effects, and path dependence. Unfortunately, the high complexity hinders the application on a larger scale as it would be required for the intended analysis of change in supply chain structures. Another limiting factor regarding applicability results from the lack of according input data. However, the findings regarding multiple equilibria and path-dependence support the later concept of estimating a range of possible outcomes based on different combinations of assumptions when analysing change in supply chain structures. 
Table 2.2: Schematic input output matrix from national accouting (simplified from Leontief 1936 and Kuhn 2010)

\begin{tabular}{|c|c|c|c|c|c|c|c|c|}
\hline & \multicolumn{3}{|c|}{ input to industries } & \multicolumn{3}{|c|}{ final expenditure } & \multirow[b]{2}{*}{ outpu } \\
\hline & & primary & secondary & tertiary & $D^{*}$ & $I^{*}$ & $E^{*}$ & \\
\hline \multirow{6}{*}{ 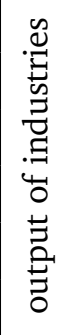 } & primary & & & & & & & \\
\hline & & & & & & & & \\
\hline & secondary & & & & & & & $\Sigma$ \\
\hline & & & & & & & & \\
\hline & tertiary & & & & & & & \\
\hline & & & & & & & & \\
\hline \multicolumn{5}{|c|}{ value added } & & & & \\
\hline \multicolumn{5}{|c|}{ imports } & & & & \\
\hline & output & \multicolumn{3}{|c|}{$\Sigma$} & & & & \\
\hline
\end{tabular}

\section{Vertical Industry Structure}

On an aggregate level, an economy's vertical structure can be captured using the concept of input output matrices (Leontief 1936). Table 2.2 shows the general structure of these matrices. Their main component, the matrix of intermediates, shows how the output of industries is consumed as input by downstream industries. Hence, shifts in the matrix reflect structural changes in the underlying economies, i.e. supply chains. For example, maturing national economies show a higher share of economic activity in the tertiary industries compared to developing countries. The appearance of new industries, e.g. as a result of outsourcing to specialised providers, would be captured by introducing a new pair of row and column in the matrix of intermediates. In the section related to the application of the structure model, it is further elaborated on the empiricism relevant for the Germany automotive industry (section 5.2).

Most of the input output tables published by public statistics offices consider financial flows due to challenges in the availability of consistent and uniform documentation of material flows. For multiple purposes, modelling freight transport and environmental studies being two of them, researchers try to derive physical input output matrices from known data (Hoekstra and van den Bergh 2006; Kowalski et al. 2007), e.g. by applying value density based transformations.

Originally, the input output model was intended for economic analysis on an aggregate level independently from the underlying geography. Over time, different approaches have been developed for estimating multi regional input output tables using methods like gravity or general equilibrium modelling (Ivanova 2014). Hence, this task shares similar challenges and solutions as the efforts described in the section on trade and trade modelling (section 2.5.4) and is therefore not further described here. An alternate approach using synthetic firm populations is presented in Abed et al. (2014).

The overall vertical industry structure is the outcome of the make or buy decisions of decentrally organised economic actors. Following such a behavioural perspective in contrast to the descriptive approaches above, Grossman and Helpman (2002) present a framework for deriving the vertical setup on industry level that is based on microeconomic reasoning. Motivated by an increasing volume of trade in intermediates for the United States (in fact an international trend as described in OECD 2013), Antràs and Helpman (2004) extend the approach to be able to analyse emergent organisational structures considering international trade in an environment with two countries. 
Their results show that an increase in wage differences as well as a reduction of trading costs leads to an increase of outsourcing and intra firm trade.

In summary, it is to be concluded that there are approaches on endogenously modelling the vertical structure of industries. However, in the context of analysing change in supply chain structures and corresponding freight transport demand it is recommended to consider these kinds of developments as externally given in order to keep overall complexity at a reasonable level.

The descriptive approaches from the area of input output matrices provide a suitable way for deriving input output relations on establishment level based on aggregate intersectoral trade data.

\section{Vertical Changes and Freight Transport}

This section focusses on quantitative research on the interrelation of vertical change in supply chain structures and freight transport demand. Here, there are mainly three contributions to be found (Jäcker 1997; Holzapfel and Vahrenkamp 1999; McKinnon, Browne, et al. 2012), which are discussed in rather high detail since they represent the status quo of research regarding this study's scope.

Jäcker (1997) analyses the impact of new production concepts, i.e. vertical change in supply chain structures, on freight transport using the electronics industry in Germany as an example. Having an economics background, a large part of Jäcker (1997) focusses on the importance of changes in transaction costs due to new technologies or different organisational structures for explaining changes in supply chain structures and freight transport in the long run. Restructurings are assumed to be coupled to the implementation of new production concepts, e.g. from the area of lean production. Based on empiricism, Jäcker (1997) also develops an aggregate model for forecasting freight transport assuming an increased vertical disintegration of supply chains.

In order to measure the adaptation of new production concepts in practice, Jäcker (1997) conducts a survey on establishment level for the German electronics industry. Among other topics, the survey especially addresses the prevalence of and shifts towards lean production methods. Here, an increasing number of establishments states to apply the concepts of modular sourcing and Just-In-Time deliveries. Especially the concept of modular sourcing has an effect on the vertical structure of the supply as illustrated in figure 2.19. The application in section 5.2 addresses the implications of this sourcing strategy and accompanying structural changes in particular.

After identifying the most relevant prevalent changes based on the survey data, Jäcker (1997) continues with developing an aggregate quantitative model on outsourcing as it appears when moving towards modular souring. For a first and rough estimation, he refers to the brief approach from Holzapfel and Vahrenkamp (1993) ${ }^{7}$ (Jäcker 1997, pp. 219-221) that uses a binomial approach for calculating the number of transport relations in a pyramidal

$7 \quad$ A very similar version of this publication in English language is Holzapfel and Vahrenkamp (1999).
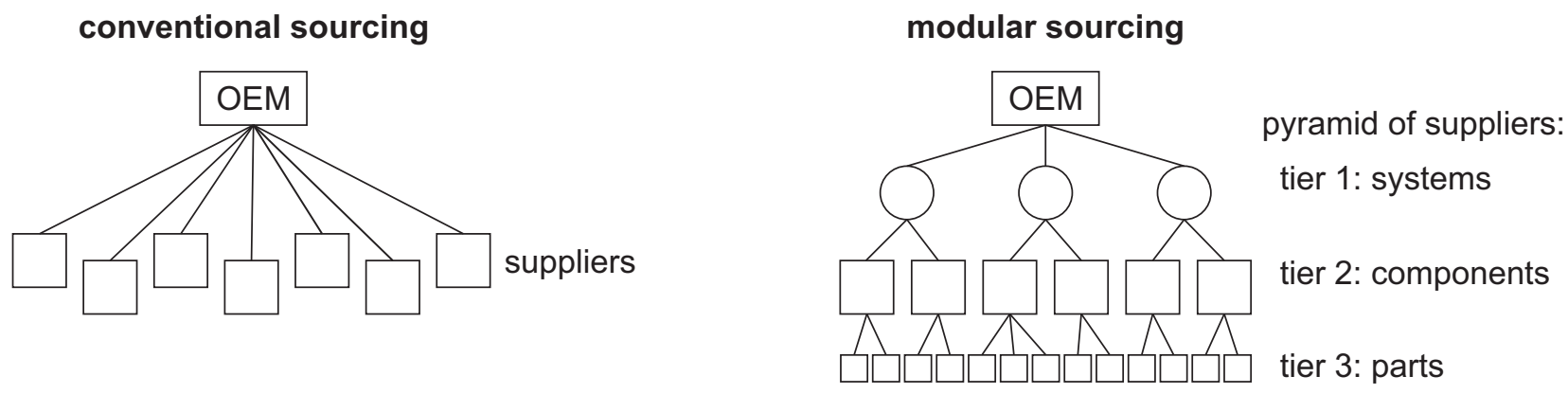

Figure 2.19: Pyramid structure of modular sourcing (adapted from Jäcker 1997, p. 40) 
supply structure. Holzapfel and Vahrenkamp (1999) propose using the number of transport relations as a proxy for transport volume. It is assumed that the number of supply relations per establishment is identical for all establishments in the pyramid. The corresponding formula (equation 2.3) is shown below:

$$
\text { nRelations }=\sum_{i=1}^{N-1}(\text { nSuppliers })^{i}=\frac{(\text { nSuppliers })^{N}-1}{(\text { nSuppliers })-1}-1
$$

where:

$$
\begin{array}{ll}
\text { nRelations } & =\text { number of transport relations } \\
N & =\text { number of tiers in supply pyramid } \\
i & =\text { index for tiers } \\
\text { nSuppliers } & =\text { number of relations to suppliers per establishment } \\
(\text { nSuppliers })^{i} & =\text { number of supply relations from tier } i+1 \text { to } i
\end{array}
$$

Spatial aspects, like the distance between an establishment and its suppliers, are left out. Hence, it is to be criticised that the developed aggregate formula tends to predict a misleading drastic increase in overall freight transport volume if value adding gets split and distributed across additional stages in the supply chain. The actual impact on the significantly more expressive indicator freight transport performance is to be expected much lower than the effect on freight transport volume.

Building upon this rather rough approach, Jäcker (1997) develops a model that stepwisely combines calculations regarding the number of transport relations under vertical disintegration, the impact of single sourcing, and shifts in transport distances. The calculations consider combinations of aggregate categories of establishment sizes and transport distances.

The model results of Jäcker (1997, p. 254) show a significant increase (85\%) of freight transport related vehicle mileage between 1991 and 1998 in the German electronics industry, the strongest driving force being vertical disintegration of supply chains. As pointed out by Jäcker (1997), it is important to note that the calculated numbers are upper boundaries due to the underlying assumptions. Also, the model does neither include explicit spatial information nor endogenous mitigation effects that would probably reduce the calculated model results.

Following a more general approach, McKinnon (2008) proposes a highly aggregate model for the identification of drivers that influence freight transport demand in order to find ways of reducing the demand for freight movement. Here, three major areas are identified: the amount and structure of production and consumption of material goods, the number of supply links connecting locations of production and consumption, and the average length of these links. Hence, the indicator "handling factor" (defined as tonnes lifted/weight of products) is introduced in order to describe effects coupled to the vertical structure, i.e. number of links. The spatial layout of supply chains is covered by the indicator denoted as "average length of haul". Analysis of trends and measures related to the described areas remain qualitative. A later application of the approach for forecasting the carbon footprint of road freight transport in 2020 is described in Piecyk and McKinnon (2010). The work of McKinnon (2008) mainly serves as a hint on the interdependence of supply chain structures and freight transport demand. However, the proposed approach is much to aggregate for deeper analysis.

In summary, from the existing approaches that consider vertical changes in the supply chain structure and freight transport demand, especially Jäcker (1997) gives a fruitful insight into the interdependence of new production concepts and freight transport demand. However, the developed model heavily relies on the extrapolation of existing categorised data, which has been collected for the German electronics industry. Hence, the model results 
leave out the interdependence of change in locations and material flow patterns when estimating freight transport demand. The model developed in this study explicitly addresses and overcomes these limitations.

\section{Horizontal Changes and Freight Transport}

In contrast to the vertical structure (Jäcker 1997 as described above), the impact of changes in the spatial and horizontal structure on the level of specific industries has not been in the focus of freight transport research, especially not on the level of micro states. However, some research has been conducted on an aggregate qualitative level.

In this regard, McKinnon and Woodburn (1996) analyse freight transport growth of the British food industry between 1983 and 1991 based on aggregate totals for the whole country. On the structural level they identify two levels of decision making in companies. The first being "structure of the logistical system" and the second being "pattern of sourcing and distribution". For the logistics structure they find a clear evidence for a trend of centralisation within the distribution systems, especially regarding the number of warehouses based on collected data. Looking at the size and number of facilities on the structural level of supply chains, the results are mixed, containing examples for as well as against an ongoing centralisation.

A similar approach is taken by Hesse and Rodrigue (2004) who especially focus on the role of logistics systems and their structures influence on freight transport demand, coining the term "transport geography". In an earlier contribution, Rodrigue et al. (2001) identify tendencies towards a centralisation of logistics system, i.e. by an increasing application of hub-and-spoke networks. Improvements in logistics are seen as drivers for supply relations across larger distances.

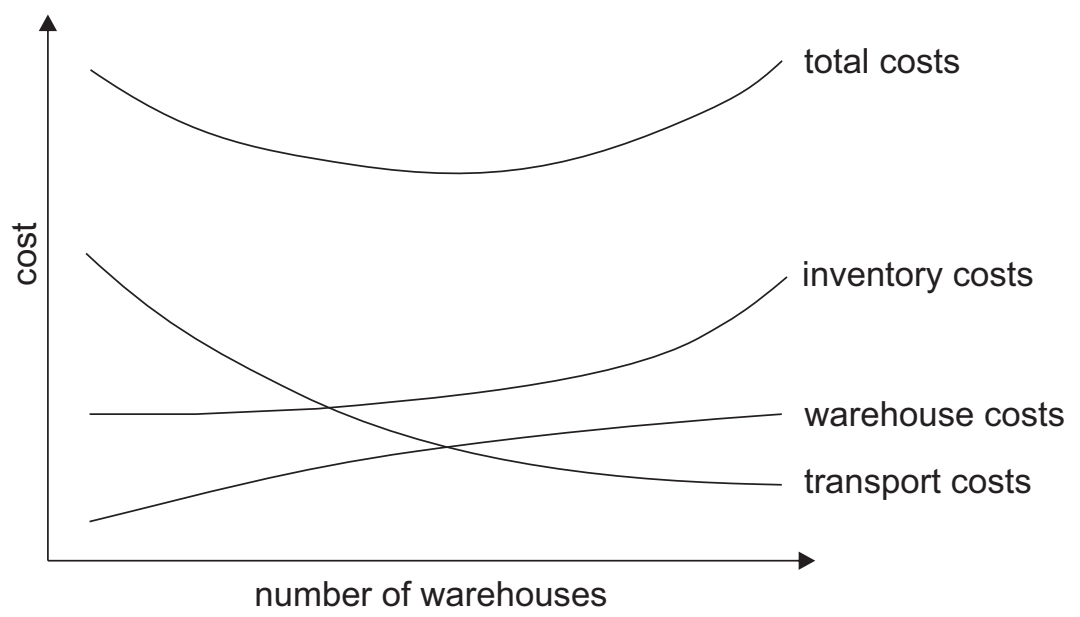

Figure 2.20: Logistics costs in dependence of the number of warehouses (not to scale, adapted from Coyle et al. 1988 , p. 277 according to Kohn 2005, p. 16)

A quantitative study on the impact of centralisation on freight transport is carried out in Kohn (2005). Focussing on $\mathrm{CO}_{2}$ emissions and freight transport performance, the impact of using a centralised warehouse for the European distribution is analysed, referring to the real-world case of a Swedish pump manufacturer. The economic reasoning based on the various types of costs occurring for the distribution of goods is show in figure 2.20. Regarding the impact on freight transport demand and environmental effects, the study does not conclude a clear ceteris paribus result for the impact of centralisation because a large set of relevant variables changes during the reorganisation. Nevertheless, it proposes a slight increase in freight transport performance due to the centralised logistics network. This effect is also addressed in Woxenius (2012) who proposes using directness as a key performance indicator for 
freight transport chains. In this work, he identifies two types detours of material flows in an economy: a first type that occurs as a result of the spatially disperse and multi-tier supply chains, and a second type that is induced by the structure of logistics systems. The subsequent parts of Woxenius (2012) focus on measures that influence detours in logistics systems, e.g. centralisation. Allen et al. (2012) follow a similar approach looking at the interdependency of freight transport and facility location regarding logistics especially in urban areas.

Summarising the treatment of horizontal change in supply structures research from the area of freight transport, several contributions consider centralisation as a relevant driver of freight transport demand. However, probably because of the adjacency of actual freight traffic and logistics, the focus mostly lies on centralisation within logistics systems, not on the underlying supply chains. Thus, it is to be concluded that there is a significant research gap regarding the interdependence of horizontal change in supply chain structures and freight transport demand.

\subsubsection{Conclusions from the Literature Review Regarding the Analysis of Supply Chain Structures on Micro and Meso Level}

The previous sections shed light on the decisions that shape supply chains structures from a micro perspective. The brief literature based discussion of each of these decisions illustrates their major input parameters and objectives as well as underlying mechanisms. As shown, most of the presented decisions depend on the outcome of other decisions made by the economic actor itself or by the environment.

Therefore, the literature review's second part focusses on research that addresses aspects of the emergence and change of supply chain structures from a macro perspective. The analysis of existing approaches supports the idea that supply chain structures are continuously influenced by forces that drive change, which adds to the relevance of the presented work. Apart from the work of Holzapfel and Vahrenkamp (1993), Holzapfel and Vahrenkamp (1999), and Jäcker (1997) the interdependency of supply chain structures and freight transport demand has not been addressed in quantitative research.

The presented different modelling approaches show relevant mechanisms that are in play when industry structures develop over time. They represent the status quo, i.e. best practice approaches, for dealing with specific aspects of the formation of supply chains. Hence, they constitute a kind of toolbox containing modelling concepts and methods that should be used when analysing supply chains and their economic environment if available workforce and manageable complexity were unlimited. Unfortunately, even those models that address single aspects of supply chain structures become difficult to handle. In addition, many of them do not produce single results but describe undecidable alternate path-dependent developments, which are determined by random minor events.

In summary, the analysis brings up the vast complexity of economic planning and decision making that should be reflected when designing a model for capturing change in supply chain structures. Given the efforts put into work for getting the presented partial approaches, it becomes obvious that the intended analysis of changes in supply chain structures requires limitations in the scope and framing concepts, e.g. by using scenario techniques for simulating different intensities and combinations of assumptions. How the insights gained from this literature review are integrated into the developed model is described in chapter 4 in the context of the actual model design.

Since the bottom-up approach described above is obviously limited when it comes to the analysis of supply chain structures and freight transport demand due to complexity and data availability, the following chapter changes the perspective. Hence, it follows a top-down approach starting with the aggregate macro phenomenon of freight transport and respective statistics and then digging deeper trying to identify the impact of changes in supply chain structures on freight transport demand. 


\section{Supply Chain Structures from the Macroscopic Perspective of Freight Transport}

The primary objective of this chapter is to define the freight transport system, the phenomenon of freight transport itself, and how to measure it. After introducing key indicators of freight transport demand, the development of freight transport is analysed based on statistical data following a top-down approach. The analysis especially addresses whether using statistical data sources suffices for quantifying the interdependence of freight transport demand and changes in supply chain structures. In this regard it is shown that the aggregate and distinct nature of different statistics and the negligence of spatial aspects requires a model based approach for further analysis. Hence, an overview of existing freight transport models is given emphasising on their capability of capturing influences that originate from changes in the supply chain structure. The chapter closes with deriving a research gap in the area of freight transport demand modelling regarding the analysis of change in supply chain structures.

\subsection{Characteristics of Transport}

Before starting with any analysis, it is necessary to get a mutual understanding of transport and its key characteristics. The general term transport stands for a variety of meanings across different research disciplines and everyday language. In the context of traffic and transport, which is referred to in this work, transport covers the movement (as an act or process of moving) of people, goods from one place to another. This definition is based on MerriamWebster (2016b). Similar according formulations can be found throughout literature. Contributions from the last years especially include the movement of information and energy (FGSV 2012, p. 23) since they are of growing importance to society and economy and because their transport follows a similar logic to that of passengers and goods. Speaking about the motivation or value of transport, it is widely agreed that transport does not have a value for its own. Instead, its value comes from the fulfilment of demand arising from social or economic activities. Hence, the demand for transport is a derived demand (Ortúzar and Willumsen 2011, p. 3) ${ }^{1}$. Figure 3.1 illustrates how the transport systems for moving people and goods are integrated into the socio-economic system that define the utility of transport.

Relying on specific infrastructure is a joint characteristic of the different types of transport mentioned above. Also, the different types of required infrastructure share major characteristics. Often, the application of certain means of transport is directly coupled to the type of infrastructure. In all cases, the provision of required infrastructure comes at the price of rather high investment costs and is usually neither affordable for nor fully exploited by single users. Hence, shared usage of infrastructure is widely practised, which allows for splitting costs among users. On the other hand, concurrent use of limited infrastructure capacity can lead to congestion for the users. Thus, for transport, there is an immanent trade-off between upfront investment costs for infrastructure and usage costs, e.g.

1 In fact, Rodrigue (2006) challenges this perception by emphasising today's strong integration of transport and logistics into supply chain management. The integrated consideration of economic activity and freight transport in this work partially accommodates for this argument. Nevertheless, the nature of freight transport demand remains derived. 


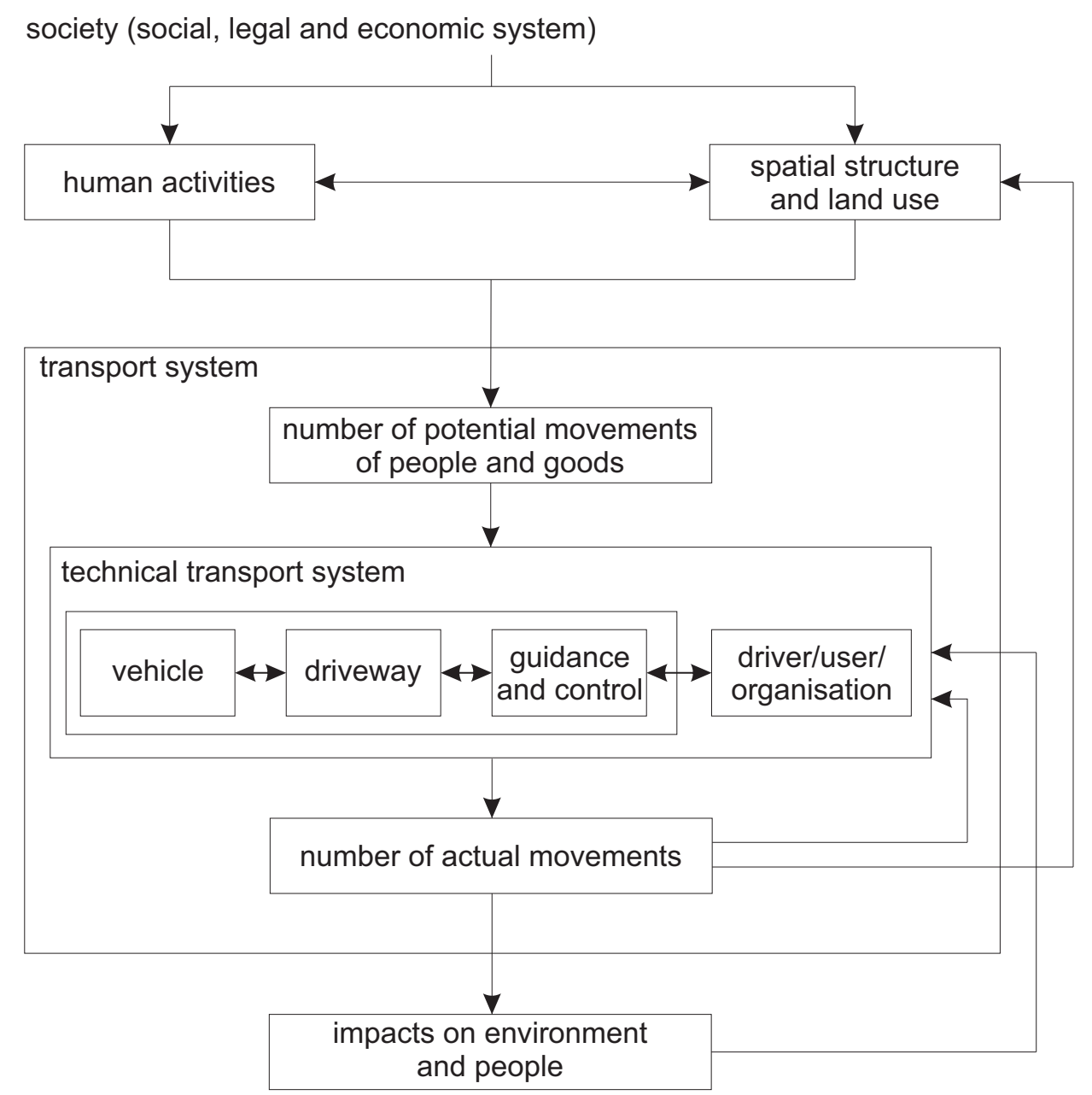

Figure 3.1: Socio-economic environment of transport according to Köhler (2014, p. 18)

congestion costs. As a consequence, transport planning is essential for the provision of infrastructure as well as operation under the condition of limited resources.

The previous paragraph has already sketched the characteristic of transport having a composite structure. Hence, the described types of transport all have in common that they are mostly perceived as aggregate phenomena that can be decomposed into single movements. Hence, many quantitative analyses follow a top-down approach and try to break down transport by categorisation using various observable dimensions. For certain paths of decomposition a direct disaggregation from the macro to the micro level is not possible due to the bundling and unbundling of potentially independent movements during their travel on the infrastructure (e.g. the micro-macro-gap in freight transport as described in Liedtke and Friedrich 2012).

Summarising the above, freight transport is the aggregate phenomenon of moving goods by making use of a combination of means of transport and public or private infrastructure. For the interaction with other types of transport, it is important to note that passenger transport and freight transport share the same infrastructure in large parts, e.g. roads or railways even if some parts are disjunct, e.g. passenger railway stations and freight terminals. 


\subsection{Characteristics of Freight Transport}

After briefly circumscribing transport in general, the scope is narrowed to freight transport in the following. Before starting into available statistics, a brief system analysis of freight transport is carried out that gives an understanding of how freight transport is determined by the interaction of various subsystems and how different indicators relate to them.

\subsubsection{System Analysis of Freight Transport Demand}

Visser et al. (1999) present a framework that emphasises the multi-layered nature of the transport system and the different actors involved. The overall framework is visualised in figure 3.2. Its concept is quite similar to the more simplified system description by Sjöstedt (2004), which is referred to in section 3.3. Visser et al. (1999) identify groups of actors, denoted as market participants, that take the roles of suppliers and consumers of goods or services on the different layers. Their interaction is coordinated through different markets or at least marketlike situations, which are called phenomena by the authors. The items to the respective exchange are collected under the title means. Coordinating and organising efforts for these markets are contributed by specific types of actors subsumed in the category of regulators.

Described roles, synonymously denoted as actors in the following, are distinguishable from one another because each of them serves a certain functionality or has a specific responsibility in the system. In other words, they are functional elements. The real-life actors fulfilling these requirements may combine one or more roles in a single organisation. Hence, the roles only give a functional structure and corresponding tasks, which then can be achieved in different organisational ways.

Assuming an overall pull-oriented economic system, the final demand for goods is provided by private consumers who purchase the full range of available products reaching from everyday products like groceries to infrequently bought items like electronic devices or cars. Thus, private consumption is the last stage of demand for goods and private consumers are the first group of actors to be identified as relevant for the overall freight transport system.

As laid out in the previous chapter on supply chain structures, in market economies, the supply for these goods is provided by private or public firms. The physical manifestations of these organisational firms are one or multiple business establishments. Hence, these business establishments are the actual locations of supply for goods produced at their facilities and the locations of demand for required inputs, i.e. intermediates or raw materials depending on the activities carried out in particular. The actual allocation of facilities to establishments is subject to the superordinate firm's planning scope. Hence, firms are abstract producers and consumers of goods while the business establishments are the actual physical entities of supply and demand. Depending on the level of aggregation and abstraction, both can be subsumed into the group of producers and consumers as depicted in figure 3.2.

So far, producers and consumers have been identified. They participate in trade according to their respective supply and demand for goods with the intention of maximising profits. Staying with the concept of Visser et al. (1999), this interaction may be supported by actors specialised in trading (traders). The outcome of this trading interaction are trade relations for goods between locations of supply and demand. Hence, a new demand arises, which is the demand for transport. The actors previously know as producers and consumers turn into shippers and receivers of cargo on this layer. The various characteristics of the traded goods lose their importance and their logistics and transport related requirements dominate. In the framework mentioned above, this is emphasised by changing the wording from goods to cargo. One could argue that this simplified idea of transport does not live up with 


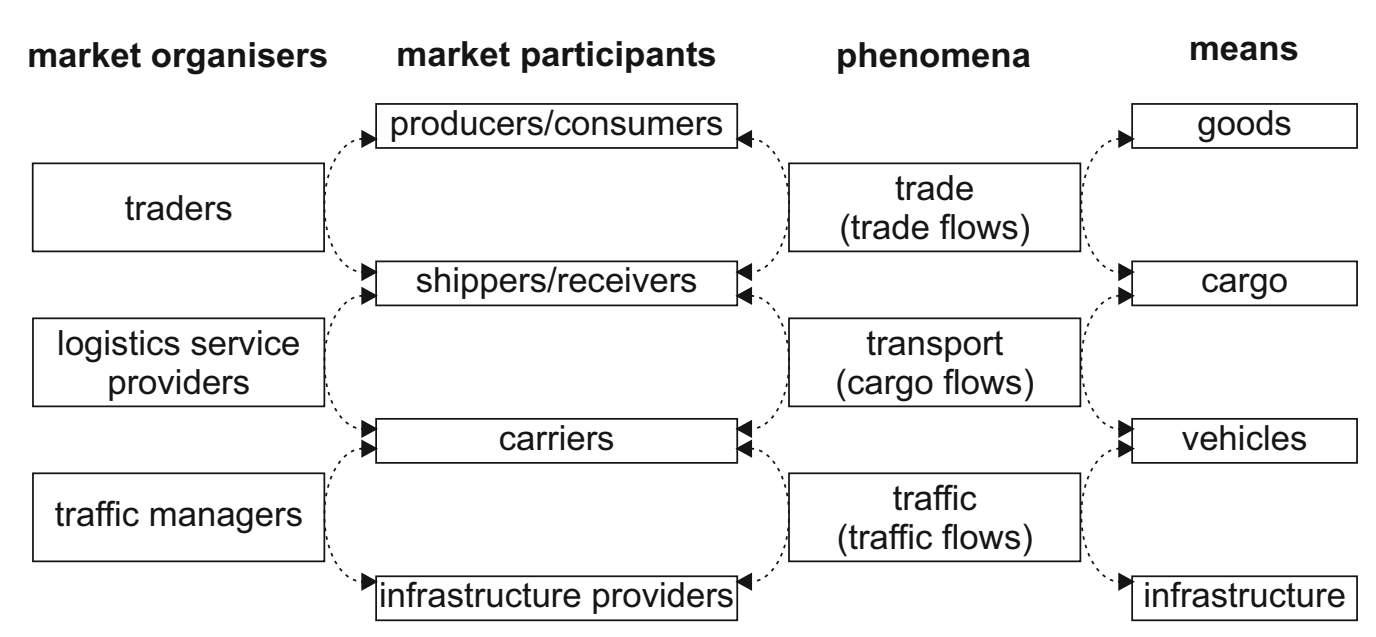

Figure 3.2: Subsystems of freight transport (adapted from Visser et al. 1999, pp. 45,47)

the actual complexity and extent of services of modern transport and logistics systems (Rodrigue 2006). For the intended analysis it is adequate to stick to the simplified perception of transport's and logistics' function ${ }^{2}$.

The actors providing the supply side to the demand for the transport of cargo are categorised as logistics service providers. In brief, actors of the type logistics service provider combine services supplied by carriers such that the demand for the transport of goods by shippers and receivers is fulfilled. This includes any possible set of combinations of transport legs relying one or multiple modes. Cargo from different shippers and different receivers may be bundled during transport in order to increase capacity utilisation and to achieve economies of scale. Hence, it is the planning and activity of logistics service providers that leads to the creation of logistics meso structures. These meso structures are accountable for the micro-macro gap, which renders the direct translation of cargo flows into vehicle flows impossible due to detours induced for bundling reasons (Liedtke and Friedrich 2012). A more vivid description of logistics service provider's role within the transport system can be found in Schröder et al. (2012).

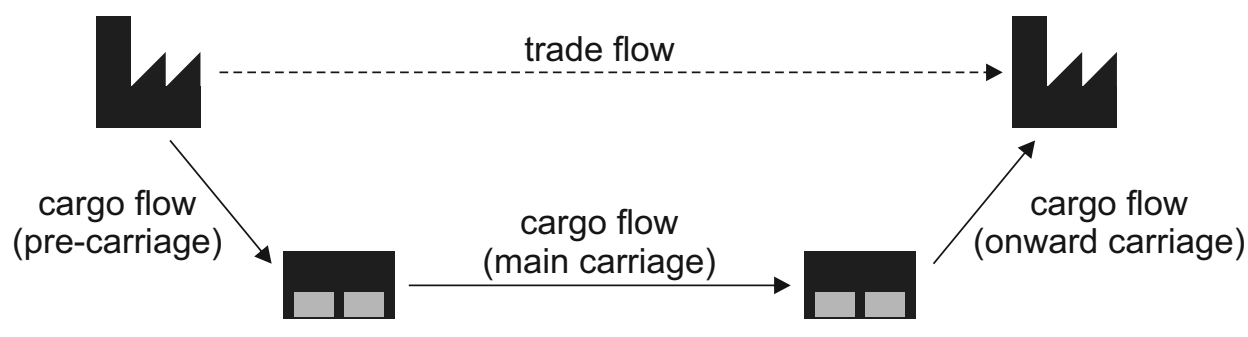

Figure 3.3: Example of trade flow and potential cargo flows for a multi-leg transport chain

Often, the transport chains organised by logistics service providers apply a combination of pre-carriage, main carriage and onward carriage as sketched in figure 3.3. On a macroscopic level, the aggregation of the illustrated microscopic trade flows, i.e. commodity flows, is denoted as production-consumption (PC) flows. In addition, the cargo flows of pre-carriage, main carriage, and onward carriagee translate into origin-destination (OD) flows (Nash 2015, p. 214). Obviously, PC flows are major determinants of OD flows. In the case of direct transport, OD and PC flows are even identical. However, in cases with multi-leg transport chains, spatial patterns and corresponding indicators of PC and OD flows differ significantly.

2 In order not to neglect the enormous heterogeneity within the logistics layer, it is referred to Klaus et al. (2011) for further information who present an exhaustive quantitative study of the various market segments in the European logistics markets. 
While the role of logistics service providers aims at the joint planning of different cargo transport demands, the physical transport is carried out by carriers. Hence, they turn the demand for transport of cargo into vehicle movements on infrastructure. Here, the vehicle tours' efficiency strongly depends on the transport demand (cargo), especially the sizes and spatial pattern of shipments. For example, a high number of small shipments with spatially disperse pickup and delivery locations leads to a rather low degree of capacity utilisation compared to direct transport of full truckloads with balanced backhauls. The entirety of freight vehicle movements constitutes the freight based share of traffic in the overall traffic flows, which additionally includes traffic from commercial passenger and private passenger and freight transport.

Regulation of traffic is organised by the general role of traffic managers. The actual actors that fill out this conceptual role are located at different levels within the hierarchy of public authorities ranging from municipal traffic departments to the federal ministry assigned to transport. Measures of traffic management are categorised into measures for traffic reduction, traffic shifting (spatial, temporal, and modal), and traffic control (Boltze 1996).

The supply for infrastructure is organised and managed by the infrastructure providers. In most cases, infrastructure providers are public authorities or at least under public regulation (public-private partnerships). This does not include infrastructure that is solely run for the benefit of single actors like warehouses or distribution centres of logistics service providers.

In the paragraphs above, the emergence of traffic is described from a linear straightforward perspective focussing on the underlying objectives of the different actors involved. In reality, the bottom-up emergence of traffic is not a one way road ${ }^{3}$. All the intermediate interactions are intertwined by feedback loops between the different layers that potentially influence the behaviour of the actors involved. Manheim (1980) sketches this interrelation by distinguishing between an activity system and a transport system mutually influencing each other through flows. For example, experiences made through vehicle movements in the traffic system are successively propagated from the carriers over logistics service providers to the shippers and receivers, respectively suppliers and consumers. For the case of carriers, they could experience congestions on the infrastructure that then translate into higher prices and durations for certain transport relations. In consequence, their customers, i.e. logistics service providers, might adapt their pricing schemes depending on the achievable capacity utilisation and balancing on certain relations in the long run. Changed costs structures in the transport market might influence producers and consumers to adapt their spatial trade patterns accordingly. More detailed examples of the interaction and causal loops between production, logistics, and transport can be found in Rühl, Freudenreich, et al. (2013).

In summary, freight transport demand needs to be defined as a complex phenomenon that subsumes different demands for movement, which occur in the subsystems of freight transport. As shown in figure 3.2, these demands refer to the movement of goods, cargo, or vehicles. Depending on the respective subsystem, the demand for movement may include specifics on a desired combination of parameters like origin, destination, route, time, amount, or costs (adapted from Gudehus 2005, p. 7). Changes within the demand of one subsystem are likely to influence the demand within the other linked subsystems. In addition, the occurring demands are interdependent with their corresponding supply. In this regard, it is worth mentioning that it is not ensured that the occurring demand is always completely fulfilled by the corresponding supply side. For example, limited capacities of transport infrastructure, vehicle availability, or freight transport oriented state measures may require adaptations in the desired movements.

The scope of this study lies on the freight transport demand expressed as a need for the movement of goods, which is determined by the underlying supply chain structures. Hence, whenever the text speaks of change in

\footnotetext{
3 In addition, an often neglected stream of material is to be found in the waste collection systems, which have the reverse direction of the forward economic system that produces and distributes goods to the final customer. Especially in the context of circular economies (Webster et al. 2013) these streams are of major importance when thinking about sustainable supply chain structures.
} 
freight transport demand due to changes in the supply chain structures, it primarily refers to the demand for goods movements described by trade flows, respectively commodity flows. However, as laid out above, any change on this level of demand is highly likely to incur adaptations in the demand within the other subsystems of freight transport as well. Therefore, it is reasonable to use the rather general term of freight transport demand even if the immediate change refers to the level of demand for the movement of goods.

\subsubsection{Indicators for Freight Transport Demand}

Before starting into the quantitative analysis of aggregate data, a brief summary of selected indicators is given, which is based on McKinnon (2008). The range of presented indicators reflects the different subsystems' characteristics within the overall freight transport system.

Freight Transport Volume ( $\left.\mathrm{t} / \mathrm{a}, \mathrm{m}^{3} / \mathrm{a}\right)$ : The indicator freight transport volume is also known by the term goods lifted (Zumkeller and Allsop 2003). It measures the amount of freight whenever it gets loaded onto any type of transport means. The amount can be measured using different dimensions, e.g. weight $(\mathrm{t})$ or volume $\left(\mathrm{m}^{3}\right)$. Usually, data on freight transport volumes refers to aggregates for time periods. If freight gets transported using a transport chain that consists of multiple legs, the freight transport volume is counted at every reloading. Even if some sources deviate from this interpretation and consolidate multiple countings in transport chains, changes in the number of stages of a supply chain directly affect the indicator for freight transport volume ${ }^{4}$.

Freight Transport Performance (tkm/a): The indicator of freight transport performance extends the pure transport volume by including the transport distance. It is calculated by summing the products of freight volume and distance per leg. Hence, freight transport performance is independent of the number of legs or stages of a supply chain but sensitive to the underlying distances. Therefore, it is especially useful for measuring the outcome of changes that influence the spatial pattern of freight transport.

Average Length of Haul $(\mathbf{k m})$ : The average length of haul is the indicator connecting freight transport volume and freight transport performance. It directly represents the average spatial gap to be bridged between pickup and delivery, which can be either locations of production or consumption or logistics facilities with transport-related functions.

Modal Split (\%): Modal split describes how (freight) transport is distributed across the different modes of transport. Hence, it is usually declared in percent. The modal split can be calculated on the basis of freight transport volume or freight transport performance, obviously leading to different results in most cases.

Vehicle Performance (vkm/a): Vehicle performance is calculated analogously to freight transport performance based on the distance travelled by vehicles per time span. In contrast to the previous indicators, vehicle performance is an indicator that refers to directly observable physical movements within the traffic system. In consequence, this indicator is especially useful for measuring the actual change in the traffic system that is induced by changes in the layout of supply chains.

$4 \quad$ See also the comments regarding the handling factor of McKinnon 2008 in section 2.5.4 and the formula for transport volume under vertical disintegration by Holzapfel and Vahrenkamp 1999 in section 2.4.1 
Vehicle Capacity Utilisation (\%): In addition to vehicle performance, the vehicle capacity utilisation allows for better describing to which extent the potential maximum transport capacity that corresponds to a given vehicle performance is used for actual transport, e.g. influenced by partial loads during collection trips or empty running for positioning trips.

\subsubsection{Top-down Analysis of Freight Transport Demand}

As it interacts with dynamically changing activity systems, freight transport itself evolves as well. In the past, slowly developing trends, e.g. the shift from production-based to service-based economies or European integration, as well as radical changes, e.g. the fall of the iron curtain, have influenced the shape of freight flows.

Below, changes in aggregate freight transport indicators are analysed following a top-down approach in order to check for their interrelation with changes in the supply chain structures. The analysis starts with the interdependence of total freight volume and economic activity. Afterwards, it continues with an analysis of the composition of freight transport demand by commodities ${ }^{5}$.

In the sections above and especially in the chapter on supply chain structures (chaper 2), it has been laid out that activity of microscopic economic entities leads to the emergence of freight transport demand. Hence, their must be a connection between economic activity and freight transport on aggregate level as well. This relation has been addressed by various authors, e.g. Meersman et al. (2010).

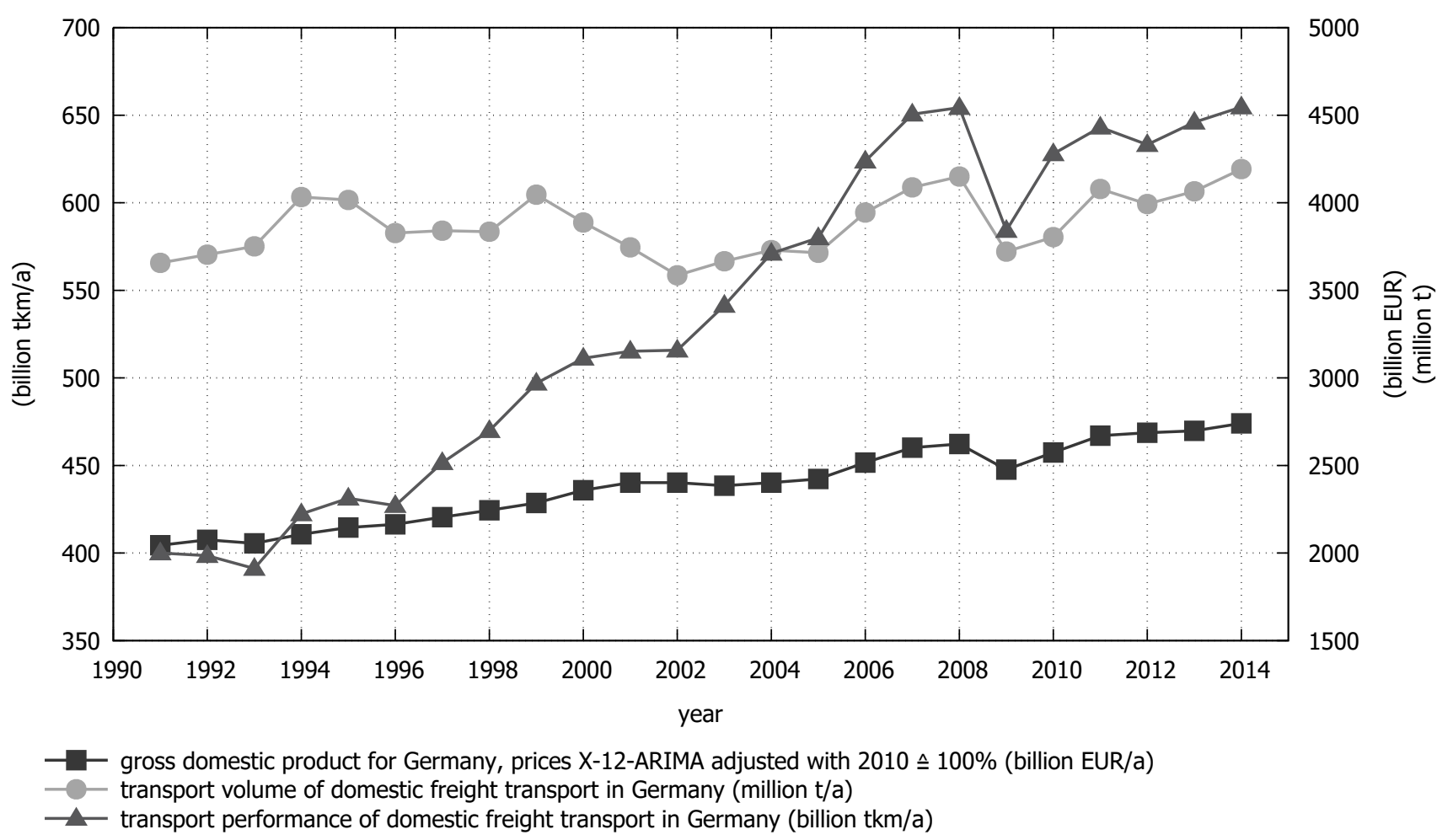

Figure 3.4: Development of gross domestic product and freight transport including rail, road, air, pipeline, and waterway transport in Germany. Data from Statistisches Bundesamt (2016c) and BMVBS (2015, pp. 241, 244).

\footnotetext{
5 Overviews of additional interrelations and driving effects, e.g. E-commerce, are presented in Aberle 2009, p. 91 and Kummer 2006, p. 105.
} 
On the national level, economic activity is often measured via the gross domestic product (GDP). The indicator aggregately measures production of an economy as a monetary value by summing the gross values added of all intermediate and final stages of residential units of production or synonymously services. This definition follows the definition of the OECD (Organisation for Economic Co-operation [sic] and Development) as presented in Lequiller and Blades (2014).

In figure 3.4, the development of freight transport performance, freight transport volume, and gross domestic product for Germany between 1991 and 2014 is shown. The published GDP data has already been normalised to real values with $2010=100 \%$, so that changes in nominal prices are accounted for. Comparing the growth rates, an average annual growth of $2.2 \%$ for freight transport performance is to be observed, $1.3 \%$ for GDP and $0.6 \%$ for freight transport volume. Considering these values, the growth of freight transport performance cannot be explained by the growth of freight transport volume without increases in the average transport distances, or changes in the value density.

Digging deeper, the available data also allows to analyse the development of transport volume and the average transport distance by mode as depicted in figure 3.5. For the period between the years 2002 and 2014, it is found as expected that the average transport distances for road and rail transport have increased. In consequence, the stagnation in transport volume is more than compensated for by the growth in distance regarding the impact on overall freight transport performance.

Regarding the underlying data, it is to be noted that it refers to origin-destination flows (OD), which leads to a multiple counting of freight volumes in the case of multi-leg transports. Analogously, the average distances consider the legs of pre-carriage, main carriage, and onward carriage as separate links. Hence, the shown average distances are not to be mixed up with those used in the later model applications for production-consumption relations (PC) in the context of commodity flows. The difference between OD and PC flows is also addressed in figure 3.3 and the accompanying text on page 46. The limitations that result from the origin-destination nature of the available statistical data hold also true for the analyses in the context of figure 3.4, figure 3.6, and figure 3.7.

On this aggregate level, it is not distinguishable, which reasons lead to the increase of aggregate distances. Possible direct explanations for the increase in transport distance are for example a simple increase of distance between domestic trading partners or an increasing amount of through traffic (BMVBS 2015, p. 208) as a result of an ongoing integration of European markets. In the following, additional data is used to analyse how the structure, i.e. the composition of transport volume by commodities, changes and how this in consequence influences the observed indicators.

The composition of industries within an economy changes with time passing. Early economies were dominated by agriculture before industrialisation started a shifting towards more technology based economies. In this regard, one of the latest appearances in the sectoral landscape has been the information and telecommunication industry. In contrast, traditional industries vanish or move to new locations, e.g. steelmaking withdrawing from Germany. Obviously, the sectors that have settled down in business mainly influence the economy's commodities transported.

In literature, changes in freight transport demand that arise from changes in the composition of the transported commodities are summarised under the term commodity structure effects (Aberle 2009, p. 91). Figure 3.6 shows the composition of commodities transported in 1999 and 2009 for Germany. For such a comparison, the classification of goods must remain unchanged and historic data must be available, which was ensured by selecting this specific time frame.

Comparing the values for transport volume by commodity for 1999 and 2009, largest changes occur for the share of transport volume for the commodity groups of quarry and pit, vehicles and machinery, and food and animal feed. In order to calculate the overall transport performance, the transport volume needs to be multiplied with 

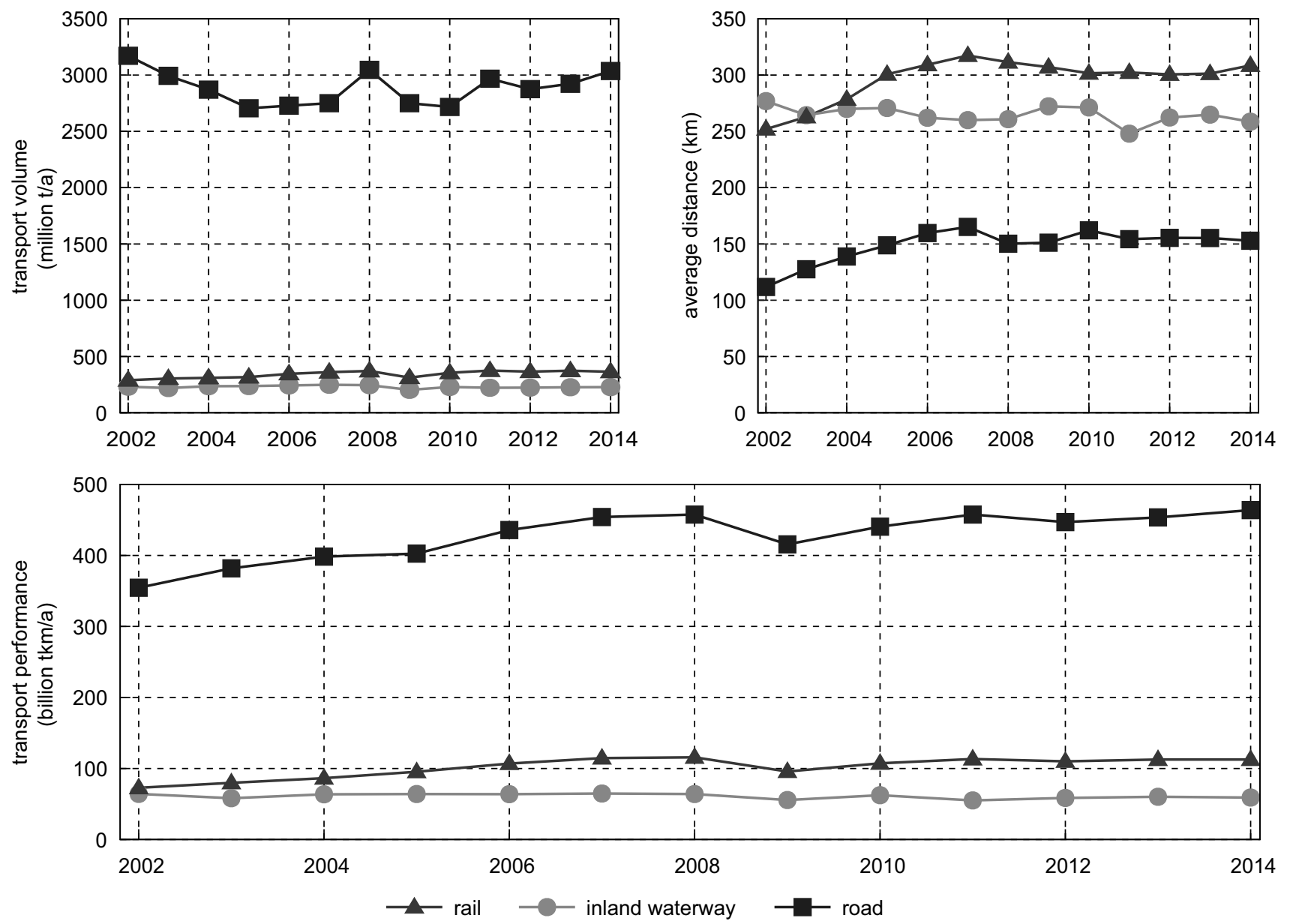

Figure 3.5: Growth of transport volume, transport distance, and transport performance by mode for Germany. Data for volume and performance from BMVBS (2015, pp. 241, 244), distance calculated.

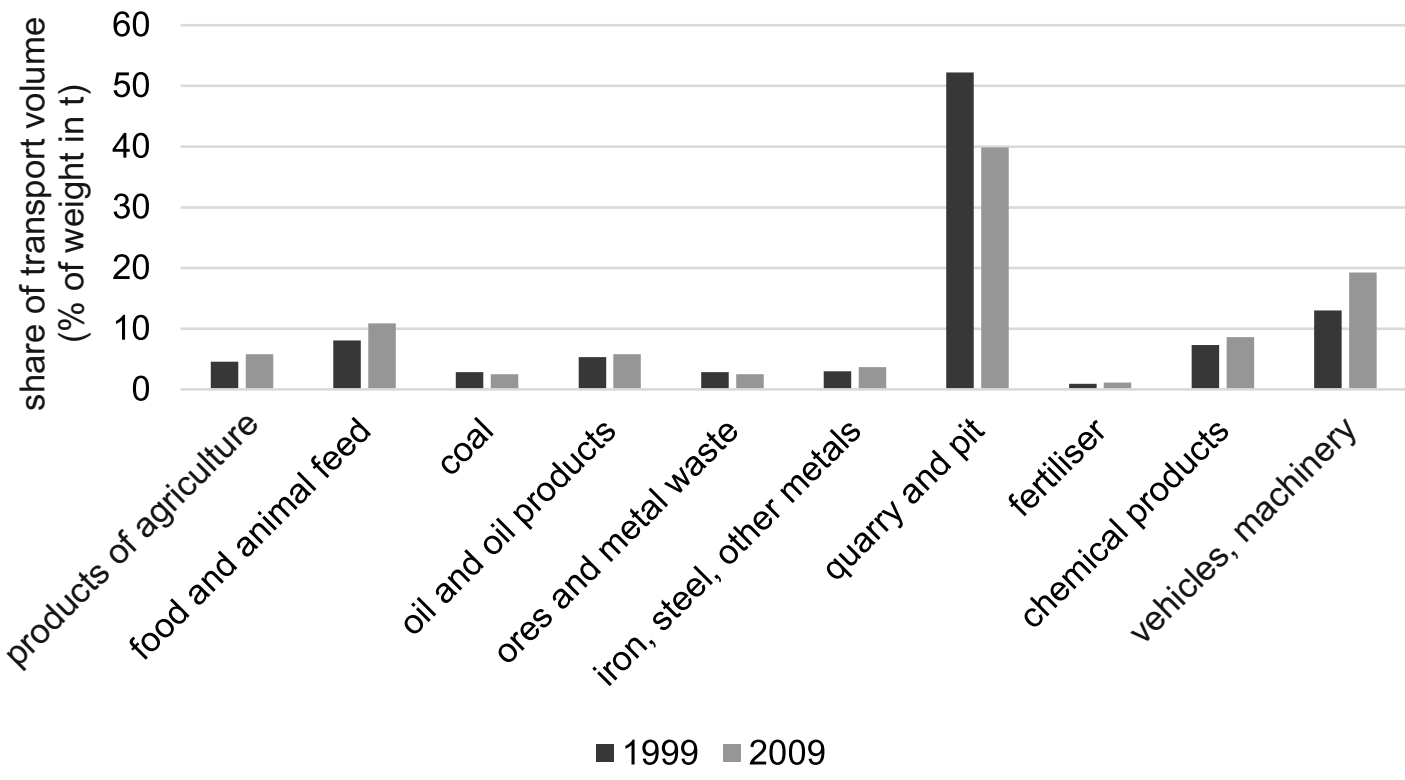

Figure 3.6: Transport volume by transported goods in Germany for the year 1999 and 2009. Data from BMVBS (2015, pp. 257, 258). 


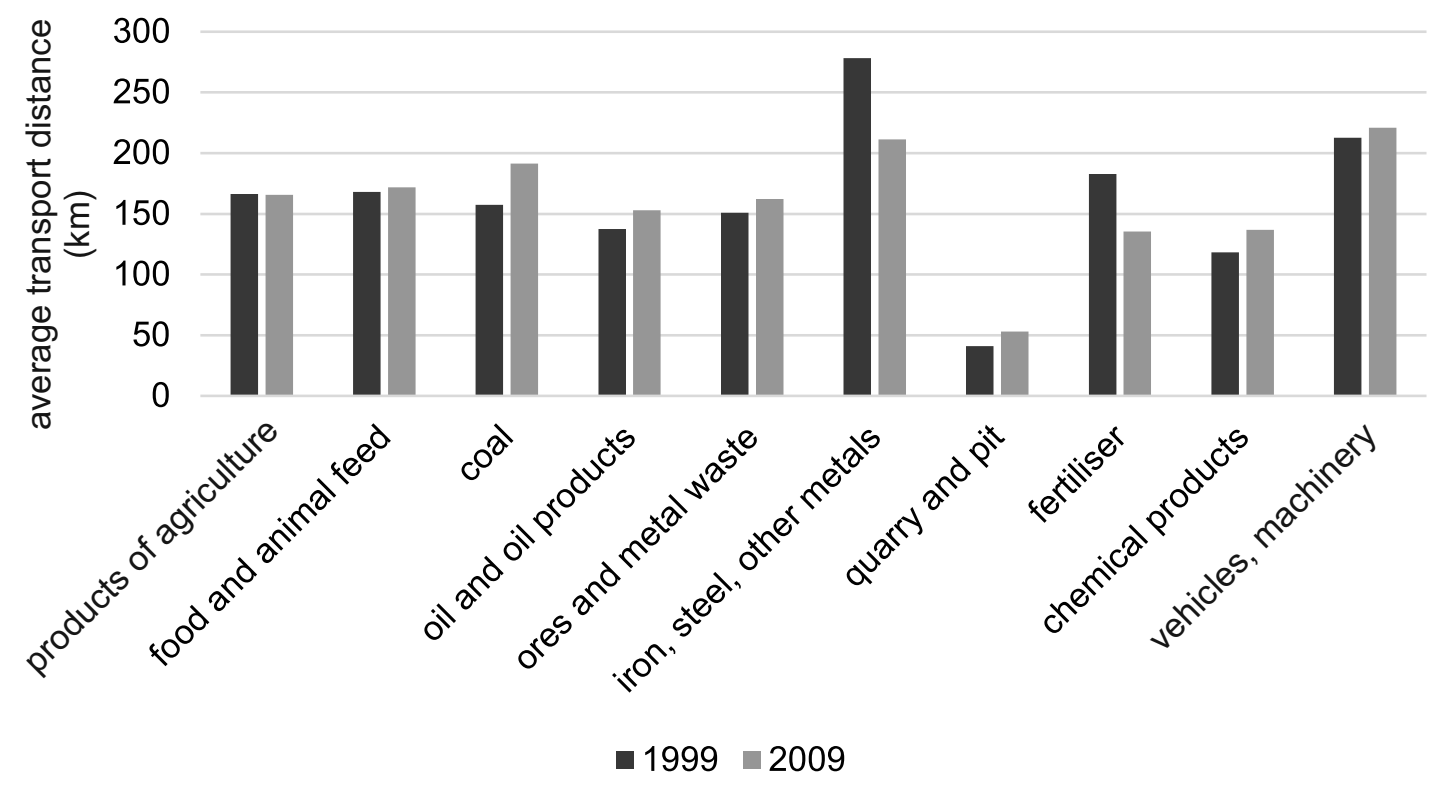

Figure 3.7: Average transport distances by transported goods in Germany for the years 1999 and 2009. Data from BMVBS (2015, pp. 264, 265).

Table 3.1: National accounting data on the German automotive industry for the years 2000 and 2010 (Statistisches Bundesamt 2014b)

\begin{tabular}{lrrr}
\hline indicator & 2000 (million EUR) & $\mathbf{2 0 1 0}$ (million EUR) & Growth (\%) \\
\hline production value of automotive industry & 211,897 & 285,180 & +35 \\
\hline inputs to automotive industry total (domestic) & 147,664 & 169,635 & +15 \\
thereof from automotive industry (domestic) & 70,609 & 86,210 & +22 \\
\hline inputs to automotive industry total (import) & 26,416 & 55,200 & +109 \\
thereof from automotive industry (import) & 6,720 & 26,265 & +291 \\
\hline
\end{tabular}

the corresponding distance by commodity and the results must be summed up. Looking at the average transport distances for all commodity groups, a range of $42 \mathrm{~km}$ to $278 \mathrm{~km}$ is found for the year 1999 as shown in figure 3.7.

Hence, it is obvious that changes in the composition of transport volume by commodities influences overall freight transport performance due to differences in the average transport distance. Additionally, the average transport distance per commodity group also changes. Thus, the data shows two interfering and overlying effects: a general change in the average distances per commodity and a change in the composition of freight volume by commodity with different average distances per commodity.

Potential explanations for these effects lie within developments in the structural and spatial layout of industries, their linkage among each other, and the respective trade patterns. Hence, in the following, the analysis of freight transport statistics above is extended to available economic information in order to find quantitative hints that support or contradict the hypotheses of structural change in supply chains leading to the described changes freight transport demand.

In order to reduce complexity to a traceable level, the following more detailed analysis focuses on a single example industry, which is the German automotive industry. Hence, any specific findings hold true only for this industry in particular but the general data sources and proposed analyses are applicable for other sectors as well. 
Table 3.2: Development of the number of business establishments in the German automotive industry from 1995 to 2012. Data from Statistisches Bundesamt (1995) and Statistisches Bundesamt (2012).

\begin{tabular}{rrrrrrrr}
\hline & \multicolumn{8}{c}{ number of business establishments with employees } \\
stage $^{*}$ & year & $\mathbf{2 0 - 4 9}$ & $\mathbf{5 0 - 9 9}$ & $\mathbf{1 0 0 - 4 9 9}$ & $\mathbf{5 0 0 - 9 9 9}$ & $\geq \mathbf{1 0 0 0}$ & total \\
\hline OEM & 1995 & 18 & 3 & 16 & 9 & 39 & 85 \\
OEM & 2012 & 18 & 12 & 22 & 16 & 41 & 109 \\
supplier & 1995 & 110 & 98 & 233 & 49 & 59 & 549 \\
supplier & 2012 & 189 & 173 & 363 & 86 & 56 & 867 \\
OEM & growth & $+/-0$ & +9 & +6 & +7 & +2 & +24 \\
supplier & growth & +79 & +75 & +130 & +37 & -3 & +318 \\
\hline
\end{tabular}

" Corresponds to NACE Rev. 2 Group 29.1 for OEM and 29.3 for supplier

As described in section 2.5.4, the vertical structure of industries is reflected in the input output matrices of national accounting. Looking at the national accounting data for the years 2000 and 2010 for the German automotive industry as shown in table 3.1, an overall increase in the industry's total production value is to be found. Obviously, this is accompanied by an increase in the value of intermediates procured. Part of the total volume of intermediates is provided by suppliers that are categorised as being part of the automotive industry as well. Supporting the hypotheses of vertical change in the supply chain structures, the share of the automotive parts procured in relation to all intermediates has significantly grown from 2000 to 2010. This effect holds true for domestic parts (from $\frac{70,609}{147,664}=48 \%$ to $\frac{86,210}{169,635}=58 \%$ ) but it is especially strong for imports (from $\frac{6,720}{26,416}=25 \%$ to $\frac{26,265}{55,200}=48 \%$ ). Comparing domestic and international procurement, the data shows that imports have grown much stronger than domestic intermediates. This is a hint that supply chains have been subject to spatial effects during the time considered as well. Unfortunately, the available data from national accounting does not allow for deeper disaggregation neither of industries nor space. At least, the data discussed above clearly suggest ongoing structural change for the automotive industry.

The statistics on the number of establishments by industry and size category provide another source of information related to supply chain structures. Table 3.2 shows the number of business establishments in the German automotive industry as categorised by number of employees and supply chain stage for the years 1995 and 2012. Here, the classification NACE Rev. 2 Group 29.1 represents manufacturers' car plants. Accordingly, it is assumed that Group 29.3 can be directly translated into suppliers from or close to tier one. Obviously, the data shows the largest growth in the number of small to mid-size business establishments, the strongest increase coming from suppliers in the category of 100-499 employees.

In combination with the hints from the national accounting data, this growth supports the existence of vertical supply chain effects. An observation that corresponds to changes resulting from the application concepts as presented in literature on the management of automotive supply chains. Potential reasons for the integration of additional business establishments into the supply chain are conventional outsourcing, modularisation of the assembly process or the increased procurement of complex, high value intermediates. A more comprehensive insight into these sectoral specifics is given in the context of the model application in chapter 5.2.

In summary, the analysis of freight transport statistics and economic data shows that freight transport demand changes and at the same time changes in the underlying supply chain structures occur. However, the aggregate nature of freight transport statistics and economic data together with the absence of spatial information limit its explanatory power regarding the quantitative interrelation of freight transport demand and supply chain structures. Hence, the further analysis of the relation between supply chains structures and freight transport demand requires the application of a model that is capable of capturing spatially disaggregate supply chains. 
Hence, the following section gives a brief introduction into the field of freight transport modelling. Next, an overview of different types of existing freight transport models is given in order to analyse their capability of capturing the impact of changes in the structure of supply chains on freight transport demand.

\subsection{Existing Freight Transport Models}

In order to do temporal and spatial analyses of freight transport leading far beyond available aggregate data, more complex freight transport models are required. First transport demand models were developed for the application in passenger transport (Martin et al. 1965; Hutchinson 1974). Directly applied to freight transport modelling, the traditional approach's four steps are as follows:

1. Generation: How much freight is generated where?

2. Distribution: Where does this freight go?

3. Modal Choice: Which means of transport are chosen?

4. Assignment: Which route is chosen?

In contrast to passenger transport, freight transport modelling requires models with higher complexity due to the manifold interaction between economic actors, logistics providers and the decentral nature of their organisation and coordination. Manheim (1980) sketches this interrelation by distinguishing between an activity system and a transport system mutually influencing each other through flows. In addition, the mentioned work describes several limitations of the traditional four-step-approach. Figure 3.8 shows how the four stages could be mapped into a layered perception of systems determining freight transport demand. According to Ottemöller and Friedrich (2016), the most severe limitations are the absence of decisions of actors, especially those related to logistics (e.g. transport lot size, distribution structures), the absence of interaction between modelling steps due to sequential modelling (e.g. increased costs caused by congestion, synergies from bundling transports) and information loss caused by aggregation (supply chains/networks, transport markets). In order to overcome these limitations, researchers have extended the 4-step-approach and also introduced new freight transport models. Due to the complex nature of freight transport modelling, most models focus on the implementation of new methods for modelling selected aspects like trade or logistics within a framework that still strongly resembles the 4-step-approach. Thus, the following section will make use of the four steps as a reference for locating the content and focus of existing models.

In the following, certain categories of models and example representatives are described. The first dimension for distinction is the aggregation level of the models either being aggregate or disaggregate. Aggregate models usually

traditional 4-stage transport modelling approach

\begin{tabular}{|l|}
\hline 4) Assignment \\
\hline 3) Mode Choice \\
\hline 2) Distribution \\
\hline 1) Generation \\
\hline
\end{tabular}

layer model of the transport system

\begin{tabular}{|c|c|}
\hline \multicolumn{2}{|c|}{ Traffic and Transport } \\
\hline \multicolumn{2}{|c|}{ Logistics } \\
\hline Production & Trade \\
\hline $\begin{array}{c}\text { Procurement of Intermediates } \\
\text { and Final Consumption }\end{array}$ \\
\hline
\end{tabular}

Figure 3.8: Comparison of the 4-step-approach and systems determining freight transport demand according to Sjöstedt (2004) 
work with a zonal spatial resolution leaving out details of single actors. Most of them are applied on a national or international scope. In contrast, disaggregate models focus on the distinct behaviour of single actors and take their decentral behaviour as a mechanism for the emergence of patterns. However, such disaggregate models are only applicable for a limited scope, e.g. local analyses, due to limitations in computability, which result from the high complexity and interdependency of decisions under consideration and the vast number of actors.

The model focus, i.e. the model objective, is another suitable point for distinction. Some models in the area of freight transport put special focus on certain aspects of freight transport demand like for example integrating logistics into aggregate models (e.g. Davydenko 2015) or improving the spatial flow modelling arising from trade (e.g. Ivanova 2014). Besides the aggregation level and model focus, the models can also be distinguished by the applied methods. For an overview see for example Thaller et al. (2016).

The set of freight transport models to be described below has been selected from the overview papers by de Jong, Gunn, and Walker (2004), Davidsson, Henesey, et al. (2005), Chow et al. (2010), Tavasszy, Ruijrok, et al. (2012), de Jong, Vierth, et al. (2013), and Taniguchi et al. (2014) and hints gained from discussions at scientific workshops and conferences. The set of described models is not exhaustive. Instead, the selection aims at covering a wide range of model types and modelling techniques in order to give an impression of the state of art in the field of freight transport modelling, especially regarding the integration of supply chain structures.

The overview mainly distinguishes between aggregate models that work on the level of abstract units independent from actual actors, and disaggregate models that explicitly consider the behaviour and characteristics of real-world decision-making entities.

\subsubsection{Aggregate Models}

\section{TRANS-TOOLS}

TRANS-TOOLS (TOOLS for TRansport forecasting ANd Scenario testing) is a transport network model that has been developed in order forecast the development of freight as well as passenger transport in the European Union and to assess the impact of policy measures on the overall transport system. It has been developed by an international consortium of researchers and consultants on behalf of the European Union. Due to the involved expertise and its strong resemblance to the 4-step-approach, it is chosen here as a best practice example of aggregate transport models, even though it has an international scope with a spatial resolution limited to the level of NUTS 2 zones. In Figure 3.9 the main model flow of TRANS-TOOLS is shown.

The economic module of TRANS-TOOLS is implemented as a spatial computable general equilibrium (SCGE) model called CGEurope. These models are spatial models that build upon general equilibrium market model, mathematically first formulated by Arrow and Debreu (1954). CGEurope (as depicted in Burgess, Becker, et al. 2005) considers demand and supply for households as well as firms of different sectors and with different regimes of competition. Goods can be traded across space but transport is costly for freight as well as passengers. The cost for transport is an output of the transport model. So, there is a loop for feeding the simulated cost from the transport model back into the economic model for the next iteration. By their nature, SCGE models are comparative-static, meaning that it is possible to calculate different equilibria by changing the inputs but impossible to dynamically simulate the transition from one equilibrium to another.

The output of the overall economic model is fed into the passenger model, which will be left out here, and the freight model. For the calculation of O/D freight flows, the freight model makes uses of a gravity based trade model called NEAC. It takes the output of the economic model for calculating trade flows for each O/D relation. More information on the applied gravity approach for modelling spatial interaction is described in the section on trade modelling (section 2.5.4) where the actual formulation is shown in formula 2.2 (p. 32). 


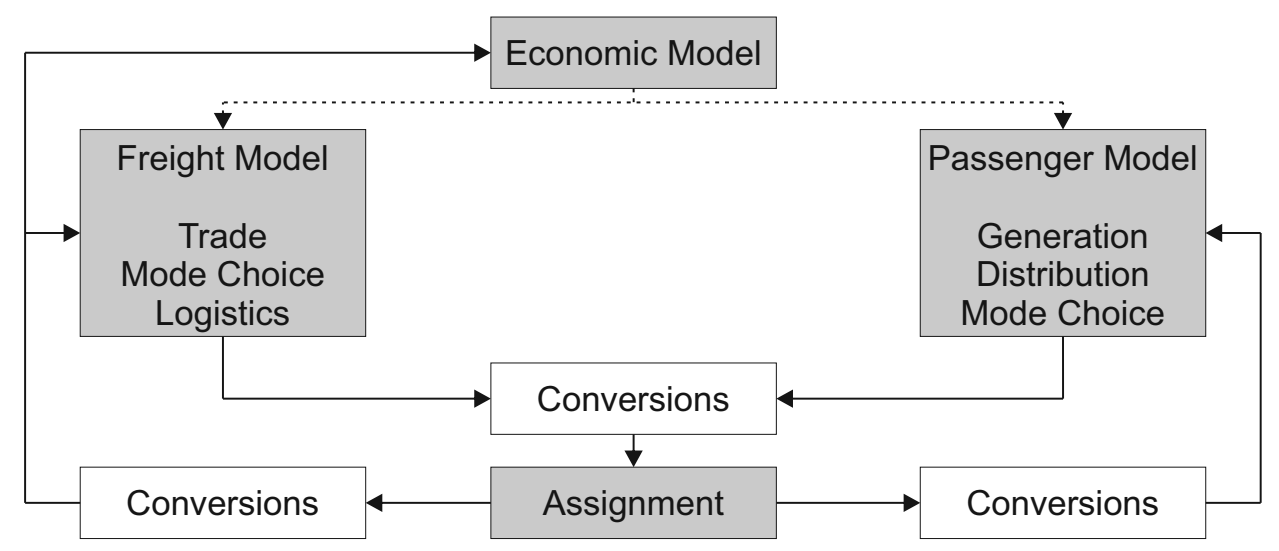

Figure 3.9: Model flow in TRANS-TOOLS as shown in Burgess, Chen, et al. (2008)

The last step of the NEAC module is mode choice. Here, a multinomial logit model (MNL as introduced in McFadden 1974) is applied, which distinguishes several explanatory variables per mode like time, cost and resistance of border crossings. Available modes are direct transport by any conventional means of transport as well as (intermodal) transport chains. So, the output of the overall NEAC module are production-consumption flow matrices per goods type and transport mode.

TRANS-TOOLS is based on the 4-step-approach but has an additional stage for logistics, which uses the SLAM (Spatial Logistics Appended Module) logic as laid out in detail in Tavasszy, Cornelissen, et al. (2001) and Chen et al. (2006). SLAM takes the trade flows between producing and consuming zones per mode as input and calculates origin-destination matrices for flows by constructing transport chains for the different modes. These transport chains consist of legs between producing zones, distribution centres and consuming zones. Hence, they define a routing through logistics systems with a one or two level layered distribution structure incorporating intermodal transport. The location of distribution centres to be used, in fact zones for the location of distribution centres, are determined heuristically. Methodologically, the assignment of freight to chains is done in a nested logit model per freight category. In this way, the SLAM module produces origin-destination vehicle flows per goods type and transport mode that consider detours due to routing of freight through logistics systems.

In the final stage of TRANS-TOOLS the assignment of passenger and freight flows is carried out together as required in order to capture congestion effects correctly. This is achieved by the application of probit-based models as presented in Daganzo and Sheffi (1977). The assignment step produces new travel times and in consequence new zonal accessibilities and transport costs, which are fed back into the freight, passenger and economic model.

In summary, TRANS-TOOLS shows, which steps are required for calculating spatial freight transport in a comprehensive aggregate model and which methods can be used for the particular model steps. The model flow also shows how feedback loops can be used for finding stable solutions if a sequential modelling approach is applied in an environment with strong interdependencies.

\section{ADA Structure in SAMGODS}

SAMGODS is a national freight transport model for Sweden. It follows a four-stage-approach that has been enhanced by a logistics module following the aggregate-disaggregate-aggregate (ADA) concept introduced by de Jong and Ben-Akiva (2007) and discussed in more detail in de Jong, Ben-Akiva, and Baak (2010). The key of ADA is that it relies on aggregate production to consumption flows (PC) and an aggregate traffic model (OD), which are connected by a disaggregate total logistics costs minimizing model that operates on firm level. The overall ADA structure for modelling freight transport is depicted in Figure 3.10 . 


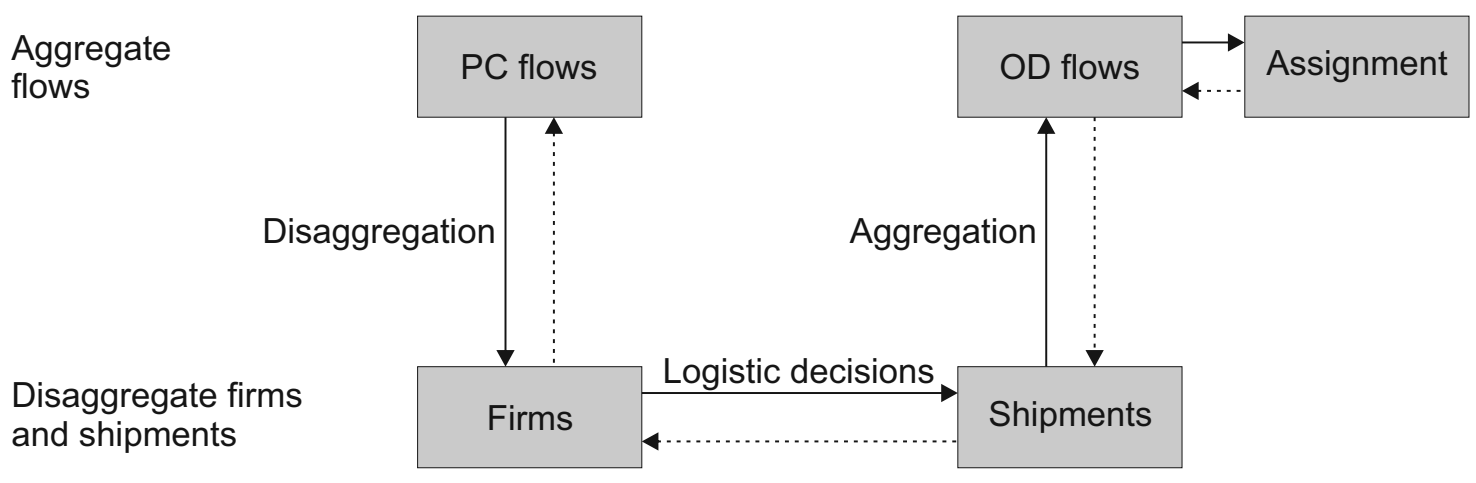

Figure 3.10: ADA structure for freight transport modelling as shown in de Jong, Ben-Akiva, and Baak (2010)

SAMGODS noticeably differs from comparable models in the way PC flows are modelled. In contrast to TRANSTOOLS, SAMGODS knows three different relations for PC flows. These are Producer to Wholesaler (PW), Producer to Consumer (PC), and Wholesaler to Consumer (WC) according to Edwards et al. (2008, p. 13). The decision for this structure is based on a commodity flow survey carried out for Sweden in 2001, which has shown that more than half of the recorded flows were sent from wholesalers showing these economic actors' structural importance for freight transport demand.

The included logistics model is another unique factor of SAMGODS. It aims at integrating lot size choice and logistics chain choice in an explanatory behavioural way in the model. The intended advantage of this disaggregate approach lies in the improved model sensitivity regarding policy assessment, since the model endogenously captures changes in the economic actors' behaviour as a reaction to changes induced by measures. This is a significant difference to other models that apply descriptive modelling methods in order to replicate observed logistics and transport behaviour.

Actually, the model does not contain single firms as entities but three categories of firm size for each sector and each zone. In this way, firm size heterogeneity can be considered and data amounts remain manageable (Edwards et al. 2008, p. 96). The last step before entering the logistics model is splitting up OD flows into firm to firm flows. This is done proportionally based on the relative amount of firms per size categories in the origin and destination zone (Edwards et al. 2008, p. 96). In the logistics module, shipment sizes and transport chain choice are determined for each firm to firm flow. Shipment size is optimised by using the Economic-Order-Quantity (EOQ) formula introduced by Harris (1913). The descriptive suitability of EOQ models for the discretisation of annual flows into shipments is demonstrated in Combes (2010) based on a commodity survey for France.

The transport chains generated in SAMGODS consist of one or more legs and allow for direct as well as intermodal transport by using transfer locations. In an iterative procedure, which updates the costs occurring on mutually used links in transport chains, consolidation of shipments is considered in the model. Initial costs are set by a forward-looking capacity utilisation, which is updated with the actually achieved utilisation following transport chain choices. This way of modelling avoids the pitfall of fixed load factors when translating freight or shipment flows into vehicle flows. So, the output of the logistics model is OD matrices for freight vehicles, which can be merged with passenger transport and fed into network assignment.

As described, the ADA approach is especially interesting because it emphasizes the importance of firm level decisions in freight modelling. Nevertheless, its implicit representation of firms limits its applicability for directly tracing the impact of changes in the supply chain structure. 


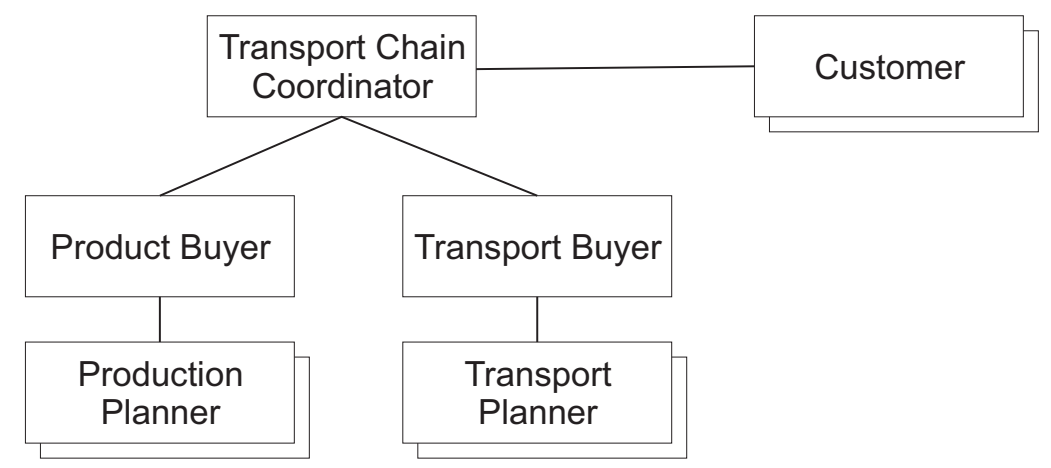

Figure 3.11: Agents used in decision layer of TAPAS according to Holmgren, Ramstedt, et al. (2012)

\subsubsection{Disaggregate Models}

Disaggregate models of freight transport first appeared on the urban level. An early approach can be found in the GOODTRIP model (Boerkamps et al. 2000), which uses supply chain structures and firm level economic behaviour for simulating urban freight transport and its changes triggered by drivers from economics, logistics, or traffic. In the following, selected disaggregate approaches to freight modelling are presented since they deliver an understanding of actors and decisions that are in play if freight transport is to be modelled on a micro level.

\section{TAPAS}

TAPAS (Transportation And Production Agent-based Simulator) is a model that was created for a micro simulation of supply chains combining production and transport decisions in a single tool (Davidsson, Holmgren, et al. 2008; Holmgren, Davidsson, et al. 2012; Holmgren, Ramstedt, et al. 2012). It is implemented as a multi-agent simulation. Hence, relevant real-world decision makers can be transferred into autonomously acting agents in the model.

This allows for example for the integration of an agent class production planner that allocates production orders to factories considering available production resources. Agents of the type transport planner supervise vehicle fleets and are responsible for the realisation of transport request. The coordination of production and transport is carried out by the transport chain coordinator by relying on the functionality offered by other agents in the model. The overall structure of agents in TAPAS in depicted in Figure 3.11.

As described, the agent-based approach allows for endogenously modelling complex decisions in autonomously acting agents. Additionally, these agents can be coupled in decentrally organised networks for the provision of required products. Also, the chosen type of dynamic simulation allows for analysis of system behaviour over time. On the other hand, the large number of autonomously acting agents leads to a high complexity in the overall communication and coordination requirements within the model. In consequence, the model application is limited to scenarios with a rather low complexity and small numbers of entities. Nevertheless, TAPAS is a good example of how the actors from real-life supply chains can be translated into an agent-based joint simulation of production and transport that is not limited to urban applications.

\section{Urban Distribution}

Wisetjindawat et al. (2006) introduce an innovative approach for improving freight generation and distribution by using the fractional split distribution method developed by Sivakumar and Bhat (2002) on a microscopic firm level in an urban environment.

In a first step, supply and demand of commodities are generated based on regression models that incorporate firm characteristics like industry type and location but also size indicators like number of employees or floor area. 
In a second step, commodity distribution is calculated based on probabilities for a customer selecting a certain combination of distribution channel, zone, and shipper applying mixed logit modelling. The according model calibration requires large amounts of data. For example, for the study of Wisetjindawat et al. (2006), a survey containing data on 46,000 firms from the Tokyo area (corresponding to $3 \%$ of all firms in this area) is used.

The enormous data requirements limit the approach in two different ways: Firstly, such data is often simply not available. Secondly, the model aims at reproducing existing structures. Hence, it is suitable for analyses that allow for assuming stable patterns. Especially when it comes to radical changes, for example in the logistics systems as assumed in Liedtke (2009) and Friedrich (2010), or relocations of establishments within the city (Moeckel 2007), the reliability of this model type is questionable.

\section{INTERLOG}

The INTERLOG model is an agent-based approach to freight modelling that focusses on the emergence of logistics patterns by using normative models for the description of agents' behaviour and markets for the overall coordination of supply and demand for transport. The model covers the full range of the four-step-approach but it is limited to the market of inter-regional less-than-truckload and mixed cargo transports. Therefore, it has a modular structure consisting of company generation, supplier choice, shipment-size choice, carrier choice and tour construction (Liedtke 2009, further details can be found in Liedtke 2006).

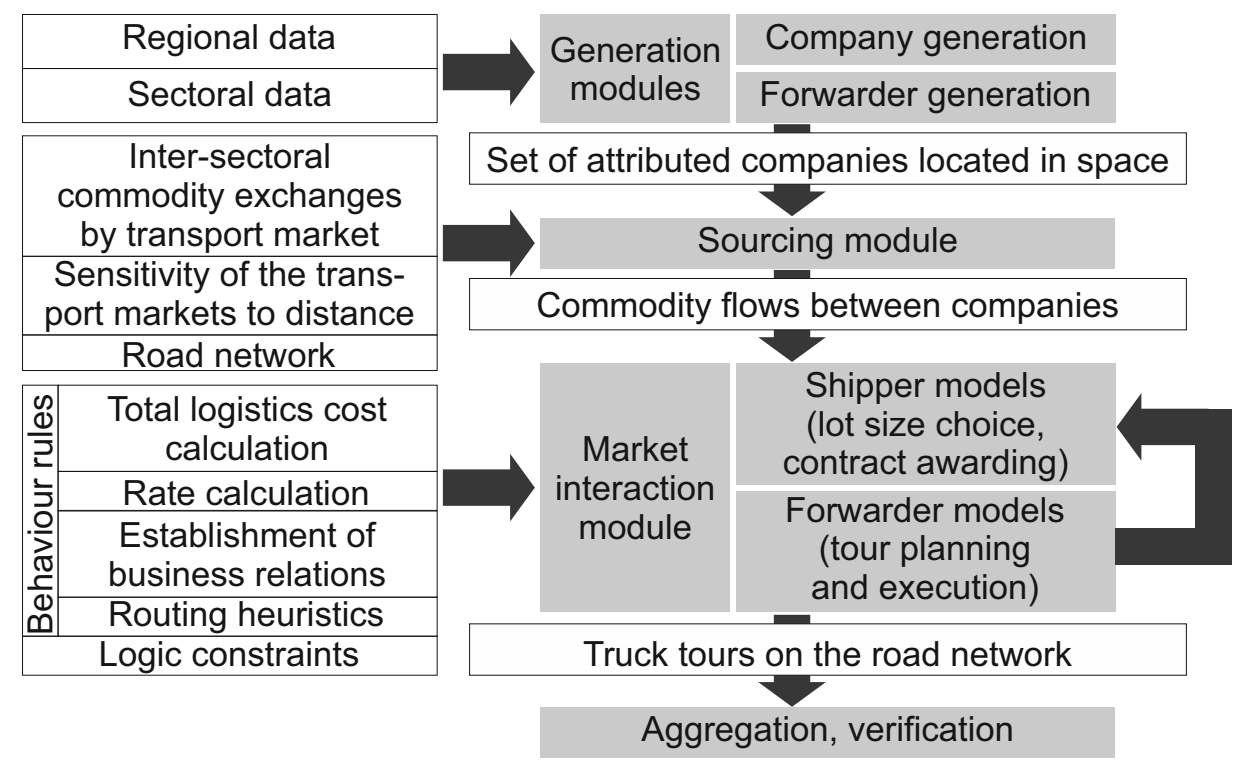

Figure 3.12: Simulation modules of INTERLOG (Liedtke 2009)

The model pays special attention to the generation of a realistic population of firms (factories and wholesalers acting as shippers and receivers) and forwarders from aggregate data. Hence, INTERLOG contains sophisticated procedures for the disaggregation of aggregate input data, e.g. using Monte Carlo methods. The overall model flow is also illustrated in figure 3.12 .

An artificial sourcing model is applied for creating commodity flows among these agents. The generation and sourcing procedure are required because disaggregate data is not available on the needed scale but the adequate consideration of firm characteristics and their heterogeneity is essential for the behavioural part of the model. The methods applied for linking business establishment in INTERLOG are adapted for the model developed in this study. 
The model focus is set on the dynamic simulation of a transport market that allows for coordinating shippers and forwarders using price mechanisms. In this way, INTERLOG endogenously models the emergence of logistics patterns, especially the specialisation of forwarders on certain relations. The conducted simulation studies show how the modelled degrees of freedom, mainly shipment size choice and forwarder selection, lead to evasive reactions of economic actors and therefore new patterns in the transport system in case restrictive measures are put into effect.

\section{SYNTRADE}

Friedrich (2010) describes SYNTRADE, which is a sectoral freight model for the food retailing industry, and its application to the German food supply. The overall structure, especially for generation and distribution, is similar to INTERLOG.

In SYNTRADE, limiting the scope to the German food retailing sector allows for the application of detailed inputouput-matrices that are distilled from a combination of public statistics and sectoral data sources, e.g. turnover statistics by sales channel and product group.

The model especially focusses on simulating the emergence of retailers' and logistic service providers' distribution systems regarding food products. For this purpose, SYNTRADE uses optimisation models from operations research in order to determine supply paths, lot sizes and especially warehouse locations. Simplified distribution tours for the warehouse outbound transport are included in the model as well. Thus, SYNTRADE is capable of endogenously calculating the total transport performance caused by the German food retailing.

The application of SYNTRADE for a peak oil scenario with doubled fuel cost for transport illustrates how the adaptation of the distribution system is capable of absorbing a large share of the expected impact. This result emphasizes the importance of behaviour sensitive, explanatory models when it comes to prognoses of system reactions under significant changes in the environment. The high level of detail in the SYNTRADE model and data requirements limit the manageable model scope to one focal industry and supply firms from neighbouring sectors.

The model developed in the study at hand applies adapted versions of the establishment generation procedures as described in the context of SYNTRADE.

\section{MATSim Freight}

MATSim Freight is a freight oriented enhancement of MATSim, which originally is an multi-agent simulation of passenger transport. The focus of MATSim is on modelling dynamic traffic flows and mobility behaviour in networks.

Agents, which are capable of planning their daily mobility behaviour, form the core of the MATSim modelling approach. Their plans are fed into a traffic network simulation. Here, the joint execution of all plans leads to congestion in the network and the agents are informed about the performance of their original plan. Based on these experiences, agents can adapt their planning to the found conditions for a next simulation run. Several iterations of planning and simulation lead to stable traffic patterns in the network. For more information see for example Balmer et al. (2005).

The extension MATSim Freight uses the same concept for implementing freight transport relevant agents into the model. Therefore, Schröder et al. (2012) introduce the Shipper Agent, which acts as sender and receiver of shipments, Transport Service Provider Agent, which constructs transport chains using suitable transshipment facilities and the actual transport service provided by Carrier Agents, which carry out the transport plan and therefore experience the performance of the initial plans and forward these informations to their contracted partners. In this way, an iterative adaptation of contracts and transport plans leads to stable freight transport.

A significant strength of this approach lies in the endogenous modelling of consolidation, and therefore economies of scale, resulting from the joint transport of shipments on the vehicle level. Referring to the 4-step-approach, 
MATSim freight provides a promising approach for the mode choice and assignment step including aspects from (distribution) logistics. Due to the early stage of development, the endogenous generation and distribution of freight transport demand is not considered adequately. Finally, it is worth mentioning that in contrast to the other models presented here, executables and source code of MATSim's core as well as extensions are fully available online as open source.

\section{FAME}

FAME (Freight Activity Microsimulation Estimator) is a framework for modelling freight transport, which goes down to the level of firms on the demand side. The framework encompasses five modules. These are firm generation, supply chain replication, logistics decisions, shipment forecasting, and network analysis.

The implementation of FAME addressed here, as presented in Samimi (2010), only consists of the first four modules, since the focus of this work lies on the determination of shipment size and the preceding modelling steps.

Firm generation is based on fuzzy categories defined by distinguishing characteristics location, sector, and size. For creating the actual artificial firm population that is used throughout the model, FAME utilises existing aggregate statistics for the United States. Within this population, firms get linked by commodity flows in the supply chain replication step. Connections between firms are established relying on suitability measures for potential links according to a previously defined rule set. Afterwards, the determined annual flows are split up into shipments. Here, a shipment size model is used that makes use of a set of explanatory variables and an iterative proportional fitting to match observed commodity flow data. Mode choice between rail and road is implemented in the form of a discrete choice (probit) model, which has recently been improved (Samimi et al. 2014).

The major contribution of FAME lies in the activity-oriented modelling on the firm level. The overall model is largely based on a descriptive approach that aims at reproducing observed data. Hence, the applicability might be limited in scenarios with fundamental changes in the overall structures.

\subsubsection{Land-Use Transport Interaction (LUTI) Models}

Besides transport modelling, the question of the interrelation of spatial (economic) structures and (freight) transport is addressed in so called land-use transport interaction (LUTI) models. These models include a wide range of forces that shape the location and spatial interaction of actors, especially in densely populated areas.

Wegener (2004) describes the development of urban space as being driven by change processes of different speed, i.e. very slow change for infrastructure networks and land use, slow change for workplaces and housing, fast change for employment and population, very fast change for goods transport and travel. Hence, LUTI models try to cover a broad range of driving forces leading to an enormous complexity and limiting the application area. Typical elements that are considered in LUTI models are shown in figure 3.13.

Belonging to the research group of Wegener (2004), Moeckel (2007) presents a microsimulation of business relocation and firmography, which represent parts of the land-use transport feedback cycle. The chosen approach on location choice incorporates the access to intermediate goods but leaves out the consideration of actual commodity flows. Hence, the approach of Moeckel (2007) partially shares challenges with the study at hand, e.g. generation of an artificial population of establishments, but also significantly differs by leaving out the explicit consideration material flows between these establishments. 


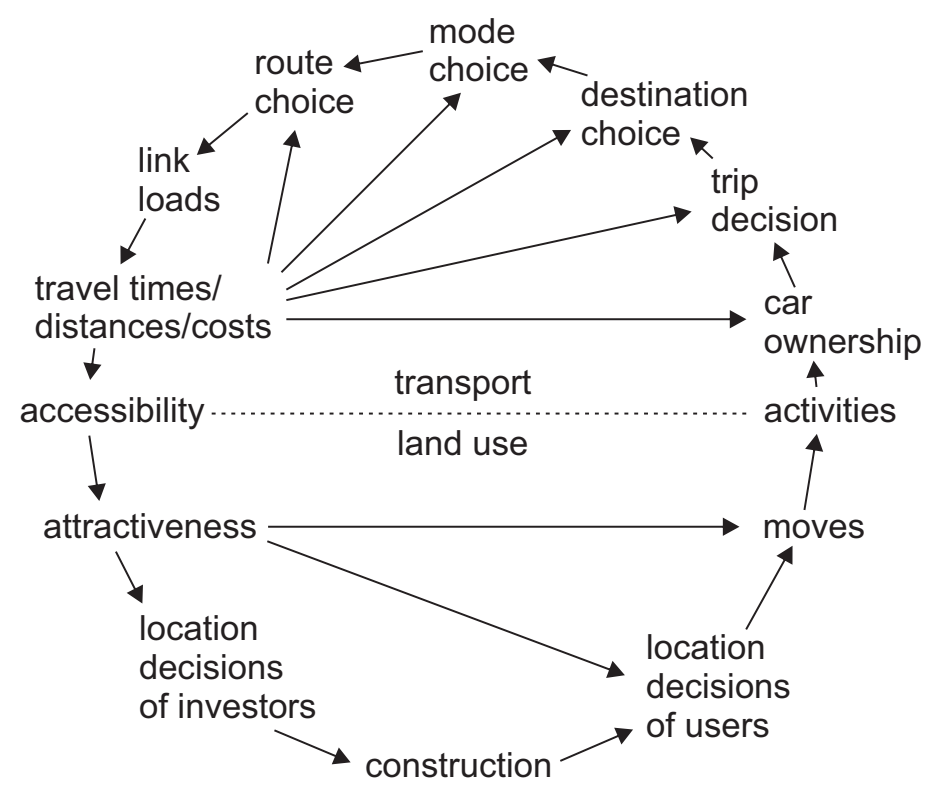

Figure 3.13: Land-use transport feedback cycle (Wegener 2004, p. 129)

In summary, the strength of LUTI models lies on describing shifts in the locational and transport pattern on an intraregional level (Schoemakers and van der Hoorn 2004). In addition, even on the intra-regional level the predictive capabilities are considered reliable only for household and service activities, not industrial activity (Schoemakers and van der Hoorn 2004). This also holds true for recent efforts that apply microscopic simulation, e.g. Nicolai and Nagel (2015).

\subsection{Conclusions and Findings from the Area of Freight Transport}

The aggregate freight transport data and accompanying data on the economic structure support the hypothesis of ongoing change in the supply chain structures influencing freight transport demand. However, the aggregate nature of the available statistical information does not allow for further analysis. This limitation could be overcome by the application of a model that is capable of simulating supply chain structures and their transport demand according to the given data.

Looking at models that could potentially fill this gap, the full range of different freight transport modelling approaches has been presented in the literature review above. Traditionally, the analysis of freight transport follows a macro perspective using a top-down approach. In order to overcome resulting shortcomings, recent developments in freight transport modelling focus on the bottom-up approaches (e.g. de Jong, Gunn, Walker, and Widell 2002; Liedtke 2009; Roorda et al. 2010), which become more and more applicable due to advances in modelling methods, computational performance, and data availability. In this regard, meso-structures emerging from economic behaviour of (decentrally organised) actors have gained attention, especially for the case of logistics structures (Liedtke and Friedrich 2012; Schröder et al. 2012; Tavasszy, Ruijrok, et al. 2012). Nevertheless, the scope of these disaggregate approaches remains limited to effects that occur on the higher levels of the transport system, leaving out dynamics within the overall economic structure and spatial pattern of production and consumption.

However, various authors emphasise the importance of developments on the level of supply chain management for explaining the development of freight transport demand (e.g. McKinnon and Woodburn 1996; Jäcker 1997; Drewes Nielsen et al. 2003; Kohn 2005; BMVI 2010) and describe the need for further analysis. Regarding this gap, only few quantitative, microscopic studies of the meso-structures on the first stages of freight generation and 


\begin{tabular}{|c|c|c|c|c|c|}
\hline $\begin{array}{l}\text { Decision } \\
\text { problem }\end{array}$ & $\begin{array}{l}\text { Typical modelling } \\
\text { challenges }\end{array}$ & \multicolumn{3}{|c|}{ Tyical techniques employed } & $\begin{array}{l}\text { This study's } \\
\text { approach }\end{array}$ \\
\hline $\begin{array}{l}\text { Production and } \\
\text { consumption }\end{array}$ & $\begin{array}{l}\text { trip generation, } \\
\text { facility location, } \\
\text { freight/economy } \\
\text { linkage }\end{array}$ & \multirow[t]{2}{*}{$\begin{array}{l}\text { LUTI ('70s) and } \\
\text { SCGE ('90s) } \\
\text { models }\end{array}$} & \multicolumn{2}{|c|}{$\begin{array}{l}\text { trip generation and } \mathrm{I} / \mathrm{O} \text { models } \\
\text { ('70s) }\end{array}$} & \multirow{2}{*}{$\begin{array}{l}\text { rule based } \\
\text { generation of } \\
\text { disaggregate } \\
\text { supply chain } \\
\text { structures and } \\
\text { simulation of } \\
\text { change }\end{array}$} \\
\hline Trade & $\begin{array}{l}\text { international trade, } \\
\text { value to volume } \\
\text { conversion }\end{array}$ & & $\begin{array}{l}\text { gravity and } \\
\text { synthetic } O / D \\
\text { models ('70s) }\end{array}$ & \multirow[t]{4}{*}{$\begin{array}{l}\text { agent based } \\
\text { simulation } \\
\text { models ('90s) }\end{array}$} & \\
\hline $\begin{array}{l}\text { Logistics } \\
\text { services }\end{array}$ & $\begin{array}{l}\text { inventory location, } \\
\text { supply chain } \\
\text { management }\end{array}$ & \multicolumn{2}{|c|}{ logistics choice models ('90s) } & & \\
\hline $\begin{array}{l}\text { Transportation } \\
\text { services }\end{array}$ & $\begin{array}{l}\text { choice of mode, } \\
\text { intermodal } \\
\text { transport, } \\
\text { light goods vehicles }\end{array}$ & $\begin{array}{l}\text { simple trip } \\
\text { conversion factors } \\
\text { ('70s), discrete } \\
\text { choice ('90s) }\end{array}$ & \multirow[t]{2}{*}{$\begin{array}{l}\text { multimodal } \\
\text { networks ('80s) }\end{array}$} & & \\
\hline $\begin{array}{l}\text { Network and } \\
\text { routing }\end{array}$ & $\begin{array}{l}\text { routing and } \\
\text { congestion, } \\
\text { tour planning, } \\
\text { city access }\end{array}$ & $\begin{array}{l}\text { network } \\
\text { assignment ('80s), } \\
\text { simulation ('90s) }\end{array}$ & & & \\
\hline
\end{tabular}

Figure 3.14: Freight modelling challenges and corresponding approaches adapted from Tavasszy (2008)

distribution, i.e. supply chains or supply networks, have been conducted in the area of freight transport modelling so far. First advances for considering such behaviour-driven structures can be found for example in Wisetjindawat et al. (2006) or Samimi (2010). Still, there is no work combining the microscopic modelling of supply chain structures and corresponding material flows with identified drivers of change on this very level regarding the impact on freight transport demand.

In summary, the review shows that none of the existing freight transport models can be directly applied for analysing the interrelation of supply chains structures and freight transport demand. Especially the approaches of Liedtke (2006), Wisetjindawat et al. (2006), de Jong and Ben-Akiva (2007), Friedrich (2010), and Samimi (2010) emphasise the importance of integrating elements from the level of supply chain structures, i.e. business establishments and commodity flows, into freight transport modelling.

Regarding the applicability of existing approaches in this study, Tavasszy (2008) gives an overview of decisions problems that need to be considered when modelling freight transport and corresponding state of the art modelling solutions as shown in figure 3.14 (page 63). From this overview, especially the decision problems denoted as production and consumption and trade are relevant for the scope of this study. Hence, selected approaches and procedures that are applied in the described models have been adapted to be used in the developed model on supply chain structures.

The following chapter describes the developed model in detail. It also contains an overview of modelling challenges as identified on the examples in section 2.4 and corresponding approaches from literature that are used in the developed model. 


\section{Modelling Supply Chain Structures and Resulting Freight Transport Demand}

As laid out in the previous chapters, the detailed analysis of the impact of changes in the supply chain structures on freight transport requires a spatial model working on the microscopic level of business establishments. This chapter explains the overall structure, applied modelling approaches and implemented procedures for model developed for this purpose. Before developing or describing a model, it is helpful to discuss what is part of the model and what is not. Hence, this chapter starts with a brief description of the model scope before introducing the overall model workflow and then deep diving into its components. It closes with the models' technical details.

\subsection{Model Requirements and Scope}

The model objective is analysing the impact of changes in the supply chain structure of industries on freight transport demand, especially freight transport performance. In the selected approach, this is done by a static comparison of a before and after population of business establishments and commodity flows between them.

The primary model application is simulating centralisation as an example of horizontal structural change. In addition, the model is capable of capturing a downstream outsourcing of a certain production step, which is an example of vertical change. The overall model design, modelled entities and relations, and controllable parameters are designed to match the challenges imposed by these two focal applications.

Regarding the resolution of economic entities, the model needs to reach down to the level of business establishments because the structural changes that are to be analysed occur on this level.

The impact of structural change on freight transport manifests in changes in the assignment of material flows between suppliers and customers. Therefore, the assignment of flows is core to the developed model and must be controllable. Consequently, it is required to capture commodity flows at the level of inter-establishment relations.

In this regard, the possible assignments of commodity flows heavily depend on the availability of suitable establishments. Hence, the characteristics of establishments entering or leaving the population are of major importance. Therefore, the model must be capable of distinguishing various size distributions of appearing or vanishing establishments.

Obviously, trade structures significantly differ between industry relations and commodities exchanged, which leads to the requirement of distinguishing between different industries, respectively sectors, producing and consuming different types of goods, i.e. commodities, in the model.

As shown in chapter 2, any analysis of changes in the supply chain structures on the impact on freight transport demand must be carried out considering the spatial dimension. Since data is only available by zones, i.e. regions, the spatial model will also only distinguish between zones as locations and distances between them. The actual spatial resolution depends on the input data's level of zonal disaggregation. 
Closely connected to the question of spatial resolution, the question of spatial boundaries delimiting the system of interest arises. In principle, the developed formal model does not imply any type of spatial borders by its nature. Instead, the availability of data and computability of the resulting problem size are the only limits. For the intended analyses, the spatial boundary for the location of establishments and flows is set to Germany because the focus lies on the impact on national freight transport performance. In this context, international effects still can be simulated by assuming establishment locations in zones directly located at the corresponding borders.

The intended analysis compares static configurations. Therefore, the model describes totals regarding a defined time span. Since most statistic data refers to annual periods, the presented model applications rely on total values for one year. The model only delivers two distinct system configurations for comparison. It does not contain any elements that depict a dynamic transition from one state to the other.

In the chapter on freight transport (chapter 3) it is laid out that the trade relations and resulting material flows between establishments are on one of the first and most basic layers of the freight transport system. For the translation into actual vehicle movements on infrastructure, many more logistics and transport systems need to be considered. The latter systems are out of this model's scope. Hence, the model's output is a lower bound for freight transport performance neglecting any detours resulting from transport necessities. This has two advantages: on the one hand, it is a way of making complexity controllable. On the other hand, it allows focussing on the direct influence of structural change on the lower bounds of freight transport demand as delimited by direct transport and vehicles' maximum capacity utilisation. Including more systems would only blur this immediate impact. For example, incurred changes in the distribution of shipment sizes could either lead to better bundling potential in logistics systems and a reduction in vehicle mileage or just have the opposite effect. Such an analysis would require sophisticated logistics and vehicle tour modelling, which is out of scope for this work. Changes in the composition of shipments or lot sizes are out of scope as well. Nevertheless, the presented model's output of establishments and connecting commodity flows can be used for improving the steps of freight generation and distribution in fully developed traditional freight transport demand models.

\subsection{Overview of the Model's Workflow}

The single tasks resulting from the model approach presented above are shown in figure 4.1. They are the basis for the actual modular model implementation. This chapter's structure largely follows the depicted workflow. The paragraphs below give a brief overview of the overall model flow before diving into each steps' details.

The developed model starts with a first phase, which is of descriptive nature. It aims at generating an artificial industry landscape that is consistent with available aggregate statistical information. This first phase is inevitable because exhaustive data is not available at the required level of detail, especially not on discrete supply chain structures. Methodically, the first model phase applies a combination of stochastic generation and directed choice procedures.

In the second model phase, the previously generated business establishments and commodity flows serve as a starting point for the simulation of structural change in the artificial networks. The implemented model procedures are capable of simulating vertical and horizontal structural changes under given assumptions. In this second model phase, approaches from linear programming as well as stochastic approaches are used. In this way, it is possible to analyse how the level of freedom in the assumptions influences the range of possible model results.

Even though they are not explicitly mentioned in the model's workflow in figure 4.1, the model also contains a fully automated reporting module that calculates a set of key indicators and generates more complex analyses like geographic visualisations for each model run or entire batches of simulations. 


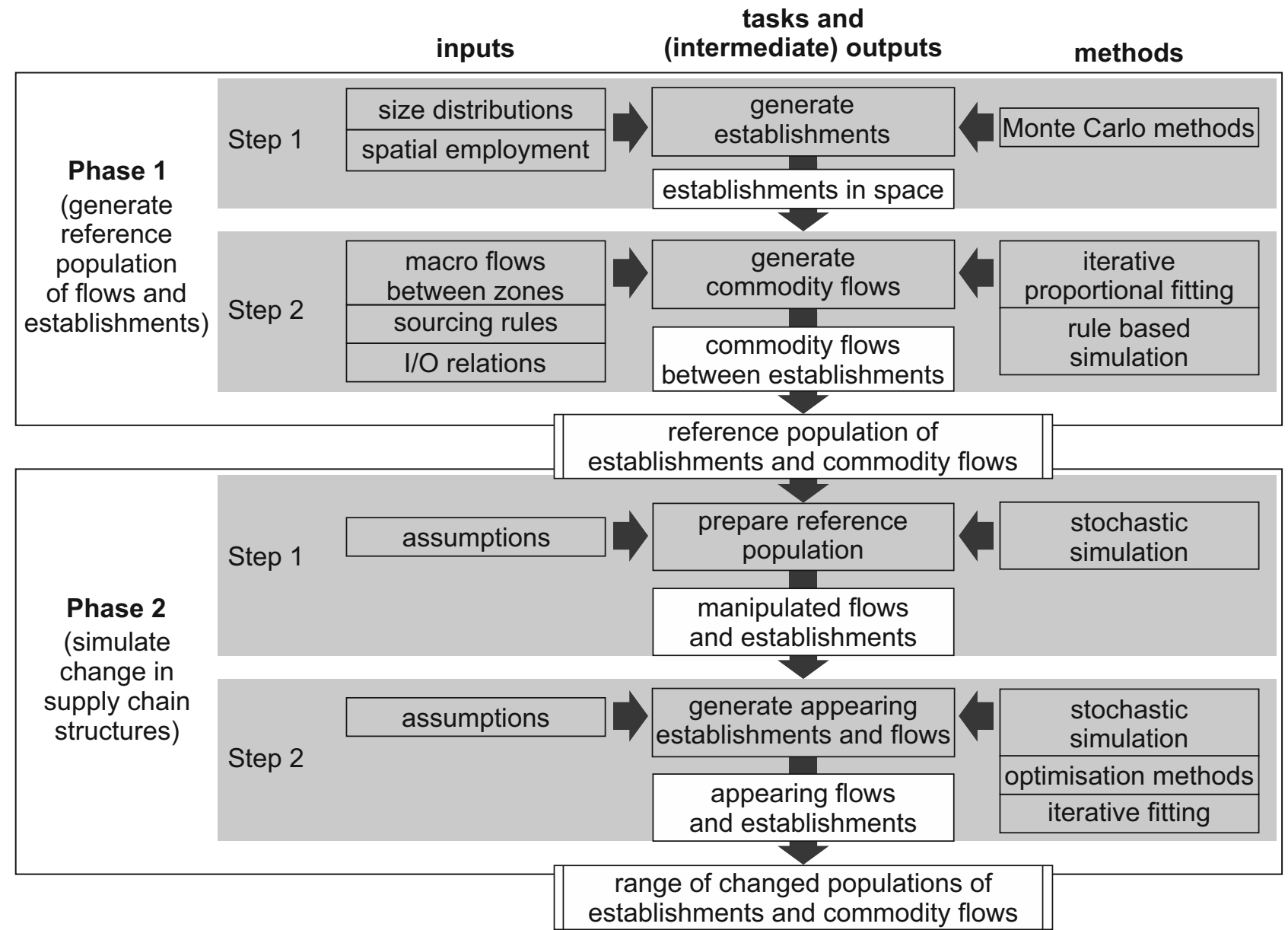

Figure 4.1: Schematic workflow applied for simulating changes in supply chain structures with according inputs, outputs, and methods

\subsection{Focal Model Elements and Their Attributes}

In the following, the fundamental model elements with their most important attributes and functions in the model are introduced. These elements are implemented as objects in the actual Java model.

\section{Business Establishments}

Business establishments are perceived as entities in space at which input commodities are transformed into output commodities, which can potentially serve as inputs for establishments of the next supply chain stage. The relation of inputs per output is described by an assumed technology. Establishments themselves are fully described by location, sector, and size. The assignment of an establishment to a certain sector is based on the produced output commodity, which in consequence leads to homogeneity of output throughout a sector. In the model applications at hand, the technology is identical for all establishments within a sector. Together, an establishment's size and technology define the volume produced and the required volumes of input commodities.

Consequently, the establishments serve as locations determining origins and destinations of commodity flows thereby imposing certain restrictions on the flows in the model: On establishment level, the total volume of each input commodity is split into multiple batches each served by a different supplier. In this way, the establishments' characteristics influence the commodity flows' size. In addition, the number of suppliers per commodity and establishments determines the density of inter-sectoral supply networks. The linkage of commodity flows and establishments is illustrated in figure 4.2. Since all commodity flows begin and end at business establishments, 


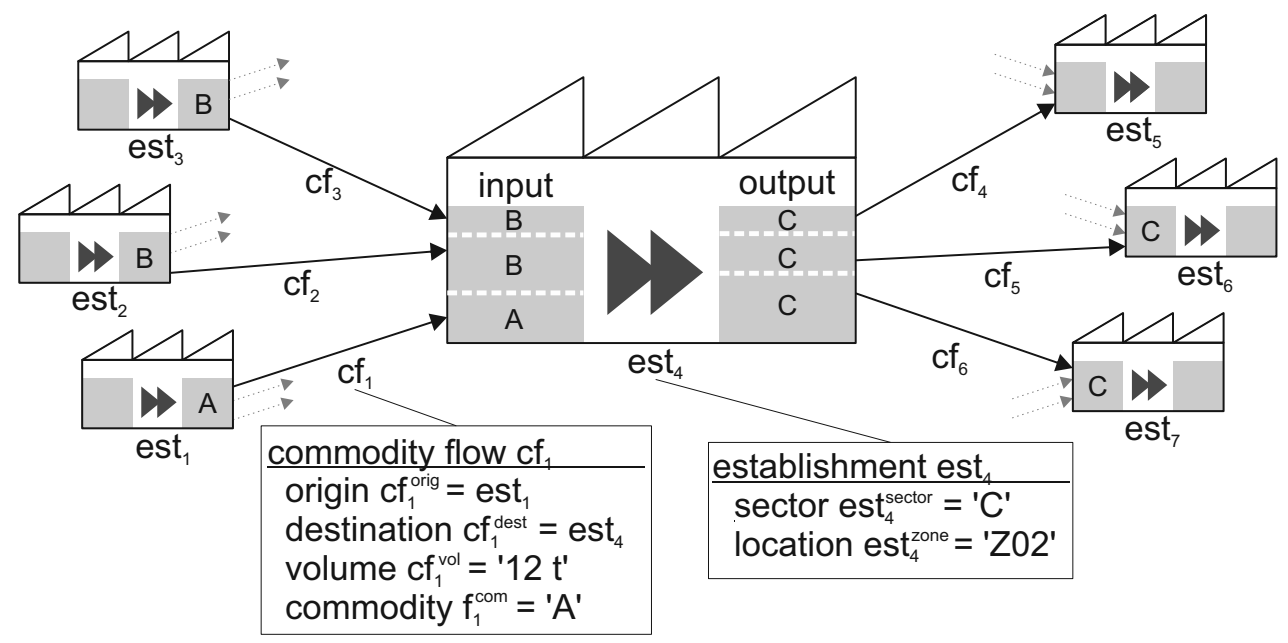

Figure 4.2: Business establishments with their fundamental attributes and commodity flows modelled as objects

it is establishments that frame the analysed supply network. They serve as kind of source of sources at the very beginning of supply chain by producing a first output commodity that does not require any further inputs. The termination of supply chains is modelled by establishments whose output is not consumed by any other entity.

\section{Commodity Flows}

Commodity flows are the main target of the analysis since they describe the actual demand for freight transport. As described, they are the model elements that describe the material flows between business establishments. Therefore, every commodity flow has attributes for the type of good, i.e. commodity, a tuple of origin and destination, and a flow rate. The flow rate is also referred to as size in the following even though this term might slightly neglect the temporal aspect as induced by using a reference period for analysis.

\section{Macro Flows}

The model also contains a second concept of material flows, which is called macro flow. These are illustrated in figure 4.3. Like commodity flows, macro flows have a distinct commodity, a flow rate (size), and a combination of origin and destination. In contrast to commodity flows, they are of aggregate nature, i.e. they do not start and end at establishments but zones. Another difference is that macro flows are not part of the modelled system but serve as input data used to create consistency between the artificial population of commodity flows and material flows observed in reality and documented in statistics. Sources for actual macro flows by commodity are regional commodity flow matrices often published by statistical offices or transport authorities.

\section{Zone based Model of Space and Distance}

The applied concept of space is an essential component for understanding the model. Instead of using a continuous pane for locating establishment and flows, the model divides space into zones. Hence, any assignment to locations in the model is an assignment to a certain zone. The decision for using such a zonal system is driven by most statistics relying to the same type of spatial reference. For the presented model application, a resolution according to NUTS 3 (Nomenclature des unités territoriales statistiques) is used. Here, the zones' average diameter is approximately $60 \mathrm{~km}$. 


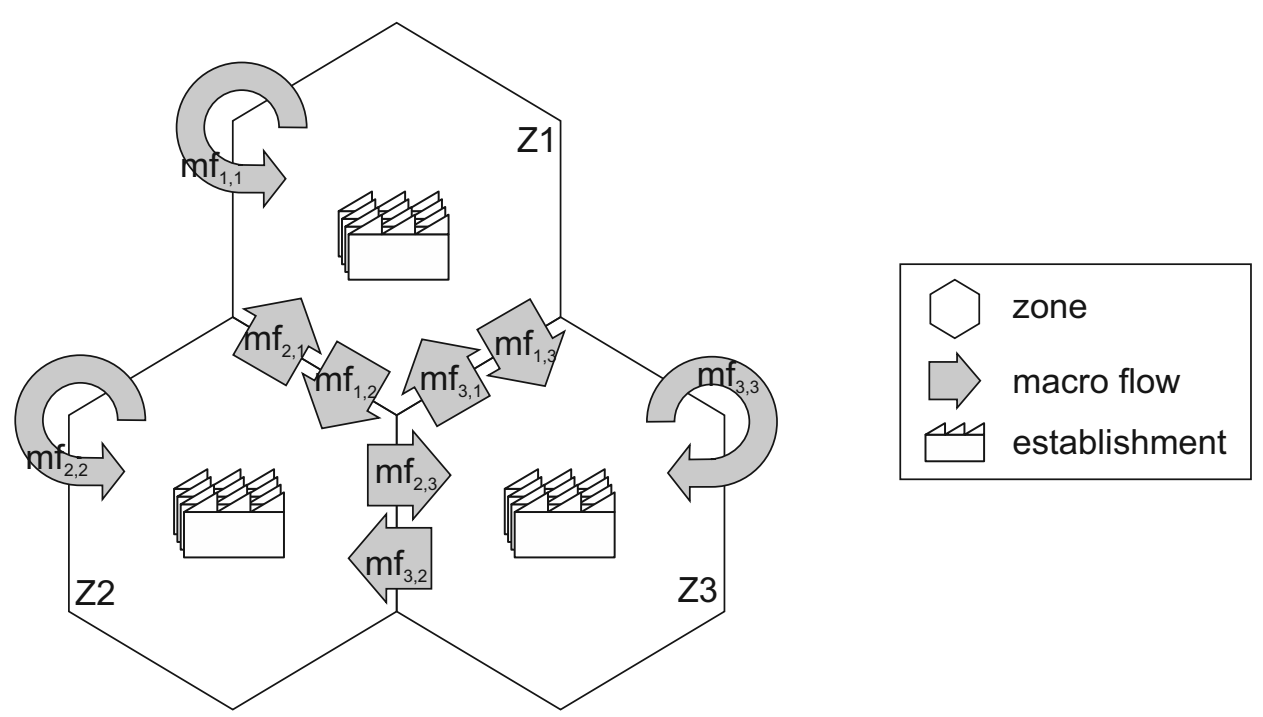

Figure 4.3: Example of macro flows for a single commodity in a zonal space model

\subsection{Generating the Reference Population of Flows and Establishments (Phase 1)}

The following sections address the first phase of the model, i.e. the initial generation of business establishments, the calculation of total inputs and outputs, the breakdown of total input amounts into discrete flows and the linking of these flows to supplying establishments.

\subsubsection{Overview of the Generation Procedure}

The procedures implemented for the first phase aim at ensuring consistency with real-world supply networks. Therefore, they especially address the following objectives:

- realistically heterogeneous sizes of establishments

- plausible establishment locations

- establishments' input and output volumes according to available statistics

- parameter-controlled number of suppliers per establishment and commodity

- parameter-controlled sizes for inter-establishment flows

- aggregates of inter-establishment commodity flows consistent with available macro flows for ensuring realistic spatial flow patterns

These objectives are reflected in the external input considered by the model when generating establishments (listed in table 4.1) and commodity flows (listed in table 4.2) in the first model phase.

The model starts with generating a population of establishments either by loading them from a distinct list, as recommended in Moeckel (2007, p. 28) for considering highly specific spatial patterns, or if such a source is not available by disaggregating statistics on the distribution of establishment sizes and a spatial distribution, e.g. of employment, as applied in Liedtke (2006) and Friedrich (2010). According to the determined establishment sizes, volumes of input and output commodities are set for every establishment based on productivity factors derived from production statistics or input-output matrices. Hence, a realistic population of establishments is generated, which serves as input for the second step of generating commodity flows. 
Table 4.1: External inputs required for stochastically generating the initial population of establishments

\begin{tabular}{|c|c|}
\hline Parameter & Description \\
\hline$f_{s}(e m p)$ & probability density for establishments' sizes (employees), specific to sector $s$ \\
\hline$n E m p^{s}$ & number of employees in sector $s$ \\
\hline$n E m p_{i}^{s}$ & number of employees in sector $s$ for zone $i$ \\
\hline$n E s t^{s}$ & number of establishments in sector $s$ \\
\hline prodFactor $_{s}$ & $\begin{array}{l}\text { productivity factor describing the volume of output produced per unit of establish- } \\
\text { ment size (e.g. employee) in sector } s\end{array}$ \\
\hline $\operatorname{inpFac}_{c, s}$ & $\begin{array}{l}\text { input factor describing the volume of commodity } c \text { required for producing one unit of } \\
\text { output for sector } s\end{array}$ \\
\hline
\end{tabular}

Table 4.2: External inputs required for generating the initial population of commodity flows

\begin{tabular}{ll}
\hline Parameter & Description \\
\hline $\operatorname{dispFac}_{c, s}$ & $\begin{array}{l}\text { dispersion factor for flows of commodity } c \text { to sector } s \text { used for calculating the number } \\
\text { of incoming commodity flows per input commodity for every establishment }\end{array}$ \\
$\alpha_{c, s}$ & $\begin{array}{l}\text { Lorenz asymmetry parameter for commodity flows of commodity } c \text { to establishments } \\
\text { in sector } s \text { used for calculating the distribution of flow sizes among flows of the same } \\
\text { commodity ending at the same establishment }\end{array}$ \\
$\beta_{c, s}$ & $\begin{array}{l}\text { distribution parameter describing the impact of establishment sizes on the distribu- } \\
\text { tion of inter sector links regarding input commodity } c \text { for sector } s\end{array}$ \\
$M F_{c}$ & sets of macro flows for each commodity $c$ to be used for fitting commodity flows
\end{tabular}

The generation of commodity flows relies on constraints on establishment level that determine the total number of suppliers per establishment, the applied equations are adapted from Liedtke (2006), and the distribution of volumes supplied by each relation. In this way, commodity flows are created that have a known volume and destination establishment. In the next step, suppliers are assigned to each commodity flow serving as origin establishment. Here, consistency with real-world spatial flow patterns is ensured by fitting the generated commodity flows into macroscopic flows as provided by transport planning offices. The sections below describe the procedures applied for generating the initial population of establishments and commodity flows in more detail.

\subsubsection{Generating an Artificial Population of Establishments (Phase 1, Step 1)}

As described, business establishments are at the core of the entire model. Exact data on whole populations of establishments are not available in most cases. Instead, public statistics contain information on certain distribution parameters, e.g. number of establishments by size categories (measured by employees) and sector. Hence, the model requires procedures that are capable of generating an artificial population of establishments according to the given aggregate data. For this purpose, the model contains two fundamentally different methods for generating populations of establishments: 


\section{Reading Establishments from External File}

The most direct way of using realistic populations of business establishments is loading exact data on establishment level from an external file into the model. This is especially helpful for applications with singular traffic generators whose locations and output are well known. Often, sectoral surveys are available for this purpose. For example, Automobil Produktion (2011) contains detailed information regarding output and location of car plants of the automotive industry.

\section{Generating Establishment Sizes by Stochastic Simulation}

If no exact disaggregate source is available, establishments need to be generated according to aggregate data, which is often provided by the national statistical offices.

In literature, this task is referred to as generation of synthetic populations in transport modelling. Many older and also very recent publications originate from the area of passenger transport modelling because it has a longer tradition using a disaggregate modelling paradigm. For example, the work of Saadi et al. (2016) proposes using Markov models in this context. Barthelemy and Toint (2013) present an approach for generating a spatially distributed population of households. An overview of different techniques can be found in Janssens et al. (2014). According to their work, generation procedures can be divided into two categories: Iterative Proportional Fitting (IPF) and Combinatorial Optimisation (CO). The IPF approach uses a given sample and applies proportionals fittings to the matrix elements until they correspond to intended row and column totals. In contrast, the CO approach aims at entropy maximisation by iteratively replacing individuals in a randomly generated population until a bestfit population is found. A comparison of these major techniques regarding the generation of a population of firms has been carried out by Ryan et al. (2009) finding general applicability for both methods but recommending CO because of its higher accuracy when synthesising the small benchmark population. A similar study has provided by Klein and Altenburg (2013) who verify the applicability of a Monte Carlo generation procedure for establishments referring to a limited area of northern Germany.

Since there is no initial sample available for the model applications at hand, the implemented procedure for the generation of business establishments uses concepts from the combinatorial optimisation approach. The actual implemented algorithms are largely adapted from Liedtke (2006) and Friedrich (2010) because they have developed procedures especially considering the availability of data for Germany.

For the intended model, three characteristics are required for every business establishment: sector, size and location. Statistics on establishment sizes are mostly only available on the national level. Hence, it is required two combine sector-specific information on establishment size distributions with spatial data, like employment statistics, if the spatial resolution has a granularity finer than national. For this purpose, the model applies a two stage procedure for generating an artificial set of establishments sector by sector. In the first step, a stochastic simulation of establishment sizes is carried out, leading to the creation of according establishment entities. In the second step, these establishments are assigned to locations in space by using a greedy bin packing heuristic. Both steps are carried out separately for every sector whose establishments are not provided by an external file. If the available statistical data are incomplete, often as a result of data being removed for privacy reasons, these gaps need to be filled in the course of external data preparations.

The resulting artificial establishments have attributes (sector, employees, location) such that their aggregation corresponds to the aggregate statistics used as input. Based on these structural characteristics, the amount of output and the correspondingly required inputs can be calculated. This section closes with describing these calculations because they constitute the last steps of the generation procedure. 


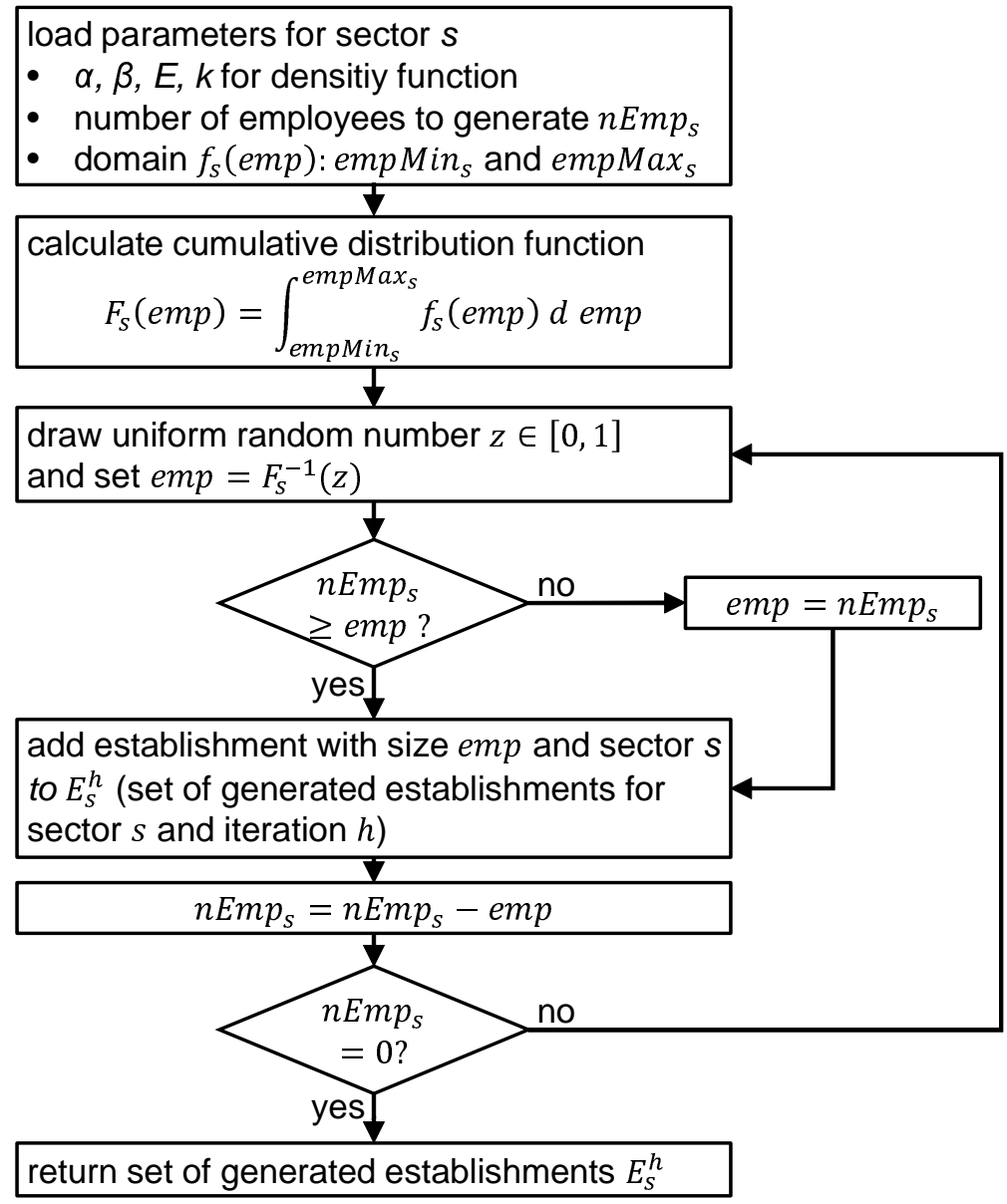

Figure 4.4: Process chart for establishment generation by Monte Carlo simulation

The decision of expressing establishment size by number of employees has been made because of data availability. In order to increase consistency and thereby comprehensibility, the following paragraphs refer to number of employees as proxy for size. Hence, the terms are used synonymously. Nevertheless, it is important to note that the procedures presented are not limited to the sole usage of employment statistics. Alternative measures of establishment size, which might be more suitable for certain applications, are discussed in chapter 2.

For the presented model, two types of stochastic simulation for the establishment generation are implemented. The first method uses a Monte Carlo approach with a continuous density function for generating a set of establishments of heterogeneous sizes whose attributes correspond to given statistical distributions. The second approach produces establishments based on the assumption of uniform distributions within discrete size categories. This is especially suitable for ensuring congruence with statistics for sectors that have significant leaps in the distribution of establishment sizes. In the following, the Monte Carlo approach is described first. Secondly, the category based procedure is introduced. The section closes with a description of the spatial assignment procedure, which is used for both cases of establishment generation.

\section{Using a Continuous Density Function for Establishment Generation}

The Monte Carlo approach has the advantage that it is capable of producing a realistically smooth distribution of establishment sizes based on categorised data from statistics. In this way, methodologically imposed leaps at category borders can be avoided. Also, applying continuous functions allows for considering various distributions of values within categories other than uniform distributions, which is desirable looking at the available data. 
For the Monte Carlo approach, a density function (equation 4.1, page 73) is fitted to match establishment statistics (e.g. Statistisches Bundesamt 2013a) by varying the distribution parameters using a goal seeking procedure that aims at minimising the deviation between the share of establishments and employees per category regarding the fitted distribution and statistical data. The fitting is carried out as part of external data preparations. Only the resulting distribution parameters are fed into the actual model. The assumed density function is proposed by Liedtke (2006). The fitting procedure is described in more detail in Friedrich (2010, pp. 104-105) but omitted here because it is not part of the implemented Java model.

The actual generation of establishments is carried out sector by sector as described in figure 4.4 (page 72). Based on the sector-specific density functions and accompanying parameters, the size of establishments is determined by generating uniformly distributed random values $z, z \in[0,1]$ and finding the corresponding value of the inverse cumulative distribution function $F_{s}^{-1}(z)$. Next, it is checked whether the determined size exceeds the remaining number of employees to be assigned. If so, the size is reduced to the remaining number $e m p=n E m p_{s}$ and the procedure finishes for this sector.

$$
f_{s}(e m p)=\frac{1}{N} \cdot \frac{\left(\frac{e m p}{E}\right)^{\delta}}{\left(\frac{e m p}{E}+k\right)^{\gamma}}
$$

with:

$$
N, \gamma, \delta, k, E \in \mathbb{R}^{+}
$$

where:

$$
\begin{array}{ll}
f_{s}(e m p) & =\text { probability density, specific to sector } s \\
e m p & =\text { employees } \\
\gamma, \delta, k & =\text { distribution parameter } \\
E & =\text { scaling parameter } \\
N \quad & =\text { normalising factor }
\end{array}
$$

In most statistics on establishment sizes, the largest category is defined as an open interval. This conflicts with the numerical approximation of the distribution function requiring an upper limit. Hence, reasonable upper limits are defined as part of the external fitting process of the density function.

New establishment sizes are drawn until the intended number of employees in the sector $n E m p_{s}$ has been fully assigned. Testing the implemented generation procedure has shown that for some simulation runs the random number generator produces sequences of numbers that lead to very skew sets of establishments regarding the intended total number of establishments in the sector. In order to avoid using such unintendedly skew sets of establishments, multiple candidate sets of establishments are produced for every sector and evaluated by a scoring function. The best scoring set of establishments per sector is chosen and stored for later usage in the model. The iterative generation and scoring procedure is depicted in figure 4.5 (page 74).

The approach described above works best if statistics show a continuous and rather even distribution of establishment sizes (e.g. suppliers in the automotive industry), which is a direct consequence of using function 4.1. In other sectors, like slaughtering of poultry, the approach shows poor accuracy when simulating establishment sizes due to leaps and multiple peaks in the statistically observed distribution.

These shortcomings of the presented procedure could be reduced by assuming a bimodal (multimodal) density function different from 4.1. Applying such a function would require significantly more efforts in the step of data 


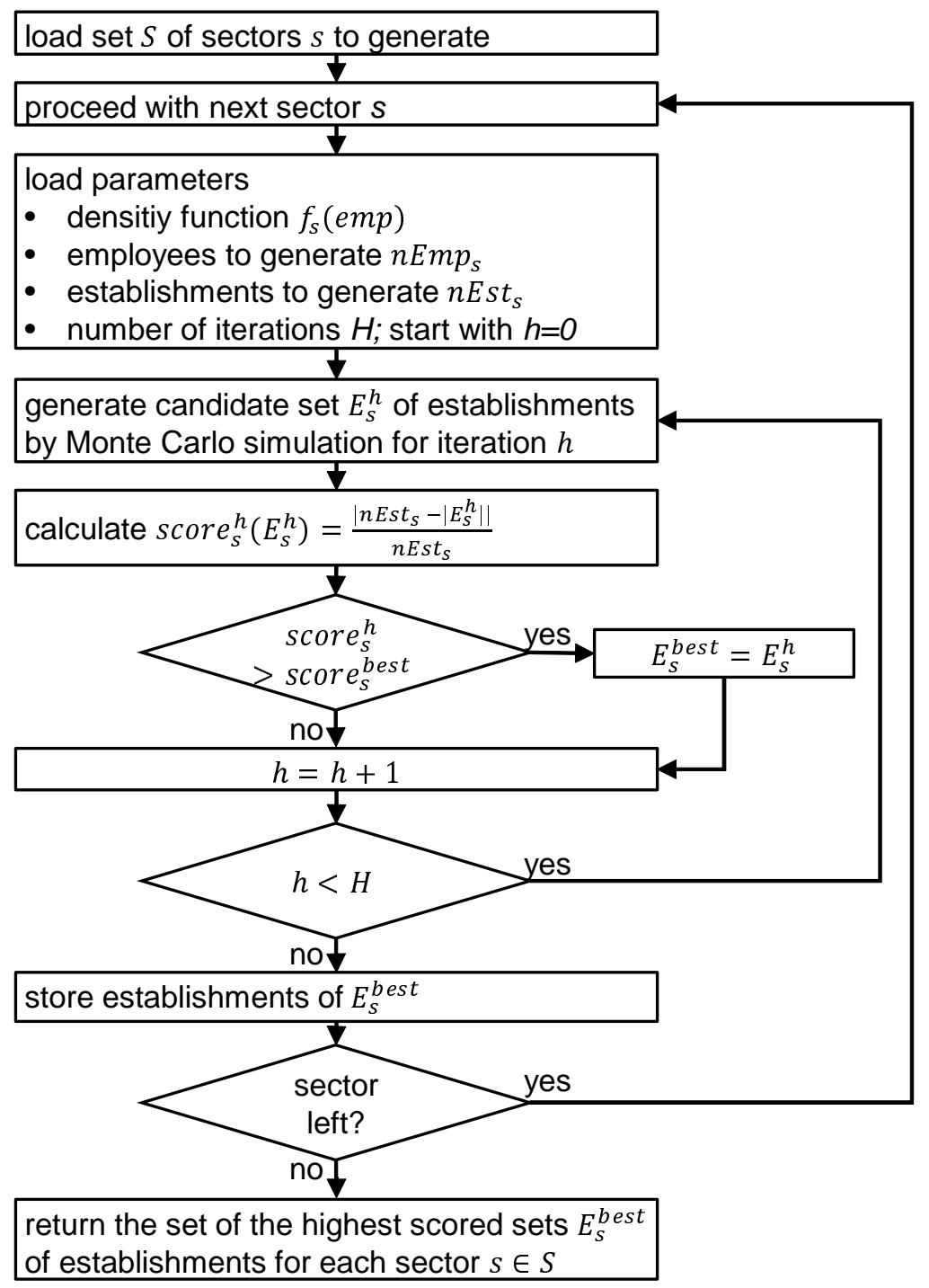

Figure 4.5: Process chart for the scoring of candidate sets of business establishments 
preparation and fitting but keep the advantages of the continuous approach in combination with the Monte Carlo procedure, i.e. heterogenous sets of generated sizes and smooth transitions between categories while keeping consistency with available statistics.

For simplicity and in order to be able to directly control for parameters relevant for simulating centralisation, an alternative approach is developed and implemented in the model, which is based on the categories (intervals) given in establishment size statistics.

\section{Using a Discrete Interval Distribution for Establishment Generation}

As laid out above, certain sectors, like slaughtering of poultry, show rather uneven distributions of sizes with very strong accumulations at the upper and lower ends. Hence, a second procedure has been implemented in the model that is more suitable for distributions with multiple peaks and significant leaps between size categories. In addition, this interval based procedure allows for generating sets of establishments with direct control of average establishment size and number of establishments independently from stochastic influences. This is especially advantageous in applications in which it is required to precisely control for the parameters relevant for centralisation effects. Still, a certain degree of heterogeneity is ensured by assuming uniform distributions within every interval of the size categories given in statistics. The developed procedure is described in detail in the following.

The interval based generation procedure starts similar to the Monte Carlo approach described above by loading the required information for the sector to be processed. The corresponding flowchart is depicted in figure 4.6. The information required as input is a set of size categories (intervals) with their upper and lower boundaries $\left[\operatorname{intMin}_{i}\right.$, int Max $_{i}$ ) limiting the allowed establishment sizes, information on the number of employees intEmp $_{i}$ and number of establishments intEst $t_{i}$ to be generated per interval $i$. A typical set of intervals would be $[0 ; 10),[10,50),[50,249),[\geq 250)$.

For every interval, establishment sizes emp are determined iteratively using a uniformly distributed random number $z \in[0,1]$ and calculating $\mathrm{emp}=\operatorname{int}_{\mathrm{Min}}+z \cdot\left(\right.$ intMax $\left._{i}-\mathrm{int}_{\mathrm{Min}}\right)$ until the desired number of establishments has been generated. For every drawn establishment size it must be ensured that it leaves enough remaining employees intEmp $p_{i}$ for the remaining number of establishments to be generated intEst $t_{i}$. Therefore, the maximum allowed establishment size is calculated as $e m p_{\text {max }}=i n t E m p_{i}-\left(i n t E s t_{i}-1\right) \cdot i n t M i n_{i}$ is calculated assuming that $i n t E m p_{i}$ and intEst $t_{i}$ are updated on every iteration so that they count the number of employees and establishment that still need to be assigned.

Equation 4.2 shows a slightly different formulation of this constraint emphasizing on the total number of employees to be assigned for the current interval intEmptotal and those already assigned in this interval $\sum_{h=1}^{j} e m p_{h}$. The formula gives the maximum size $e m p_{\max }^{j+1}$ for the generation of the interval's $j+1$ th establishment.

$$
e m p_{\max }^{j+1}=\left(i n t E m p_{i}^{\text {total }}-\sum_{h=1}^{j} e m p_{h}\right)-\left(i n t E s t_{i}^{\text {total }}-j-1\right) \cdot i n t M i n_{i}
$$

where:

$$
\begin{array}{ll}
e m p_{\max }^{j+1} & =\text { maximum establishment size for iteration } j+1 \\
i n t E m p_{i}^{\text {total }} & =\text { total number of employees in interval } i \\
e m p_{h} & =\text { size of establishment } h \text { already generated for current interval } \\
i n t M i n_{i} & =\text { lower boundary for current interval }
\end{array}
$$

If the drawn establishment size is larger than the allowed maximum $e m p_{\max }$, it is set to the maximum value $e m p=e m p_{\max }$. As a consequence, the remaining establishments will be forced to have sizes of 
load parameters

- intervals' ranges [intMin ${ }_{i}$, intMax in $_{i}$ )

- employees per interval intEmpi

- establishments per interval intEst $t_{i}$

\begin{tabular}{|c|}
\hline oroceed with next interval $i$ \\
\hline 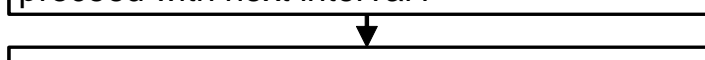 \\
\hline $\begin{array}{l}\text { calculate } \\
\qquad e m p_{\max }=\operatorname{intEmp}_{i}-\left(\text { intEst }_{i}-1\right) \cdot \min _{i} \\
\frac{1}{\downarrow}\end{array}$ \\
\hline
\end{tabular}

draw uniform random number $z \in[0,1]$ and calculate

$e m p=\operatorname{intMin}_{i}+\mathrm{z} \cdot\left(\right.$ intMax $_{i}-$ intMin $\left._{i}\right)$

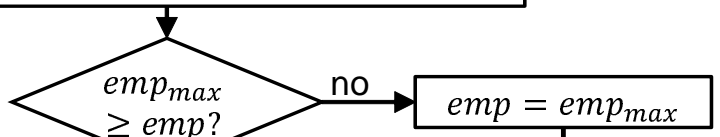

$\longrightarrow$ emp?

yes

add establishment with size emp and sector $s$

to set of generated establishments

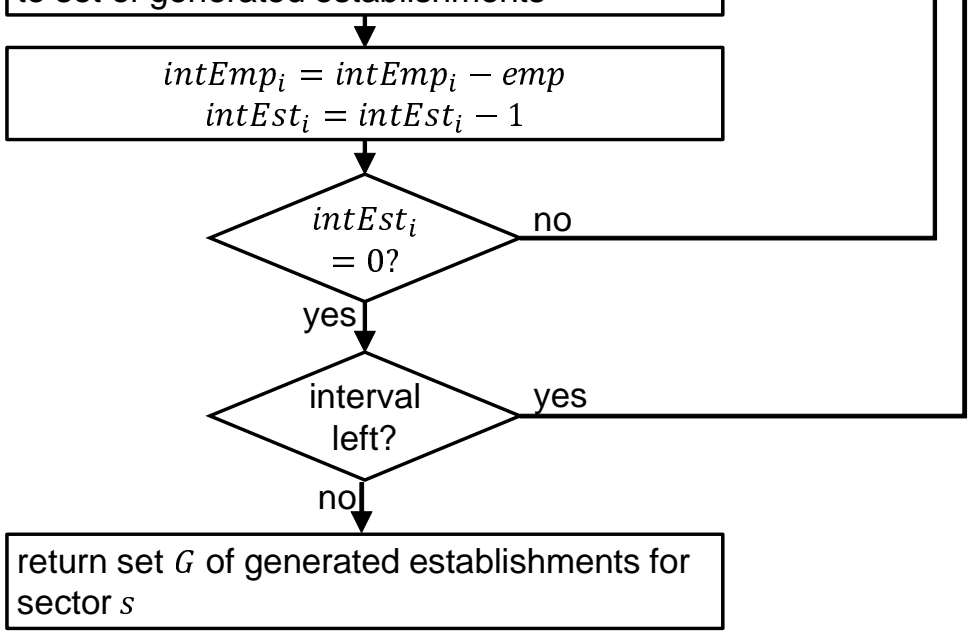

Figure 4.6: Process chart for the generation of establishments using a discrete interval based distribution 
then $e m p=\operatorname{int} M i n_{i}=e m p_{\max }$ in the subsequent iterations for this interval. After generating all establishments for all size intervals for the respective sector, the procedure returns the set of generated establishments.

\section{Assigning Generated Establishments to Spatial Locations}

The establishments generated either by Monte Carlo simulation or in the interval based procedure so far have information on their size (number of employees) and the sector they belong to. Their location still needs to be determined. Common data sources for the spatial layout of an industry are employment statistics by zones. For the case of farming, far more spatial data is available, e.g. on the area used for grain growing or the number of animals kept for livestock farming by zone. In order to ensure the transferability of the model, the implemented spatial assignment procedure is capable of using any type of such zonal data. The only prerequisite is a fitting of the indicator used for establishment size and spatial assignment in the input data before feeding it into the model.

The spatial assignment procedure requires a set $E$ of establishments to be assigned with each having a certain size, e.g. employees. In addition, a set $Z$ describing the spatial distribution of the size indicator by zone, e.g. spatial employment statistics, is required. Figure 4.7 shows a flowchart of the implemented algorithm. The objective is to assign establishments to zones such that the resulting assignment does not conflict with the number of employees per zone depicted in the spatial distribution data. Hence, a method similar to a greedy bin packing heuristic is applied.

It starts by selecting the largest establishment to be assigned est ${ }_{v} \in E$. Next, all zones that have enough free capacity zone ${ }_{i}^{c a p} \geq e s t_{v}^{s i z e}$ are selected. Afterwards, a random choice is carried out among all potential zones for selecting the zone to place the establishment. This random element prevents the algorithm from producing a biased assignment by always putting the largest establishments into the largest zones.

After selecting the zone for the current establishment $e s t_{v}$, the remaining free capacity of the selected zone gets updated zone $e_{r n d}^{c a p}=z o n e_{r n d}^{c a p}-e s t_{v}^{s i z e}$. If no zone with enough remaining capacity can be found, the establishment gets added to the set for postponed assignment $P$. In any case, the establishment gets removed from the set of establishments to be assigned and the algorithm continues with the next largest establishment $e s t_{v+1} \in E$.

Once the set $E$ of establishments to assign is empty, the algorithm continues with assigning the establishments that have been for postponed assignment $e t_{v} \in P$. Here, the remaining establishments are iteratively put into the zone with the largest remaining capacity zone $e_{\max }^{c a p}$ following a descending order of establishment sizes. Once all establishment have been linked to a zone, the algorithm terminates and the found assignment is returned.

The separate treatment of postponed establishment leads to deviations from the spatial input data but ensures consistency in the size distribution within the population. For the given analyses this is preferable. Testing the implemented method with different data has shown that the share of establishments and employees assigned by the treatment of residuals tends to be insignificant. Most populations contain a high number of very small establishments, which fit into the remaining capacities during the last iterations. If priority was on fulfilling the spatial constraints, residual establishment could be split up and fit into the remaining zones. In general, the problem of residual establishments occurs because of using a heuristic, which provides a suitable solution within reasonable time. Applying exact methods, i.e. a form of bin packing problem here, is not required since the deviations caused from the heuristic are negligible. Also, exact methods might not be able to find a solution in acceptable time. In addition, an exact solution would also not be unique since it is to be expected that there are multiple assignments that lead to a perfect match of statistical data and establishment locations. 


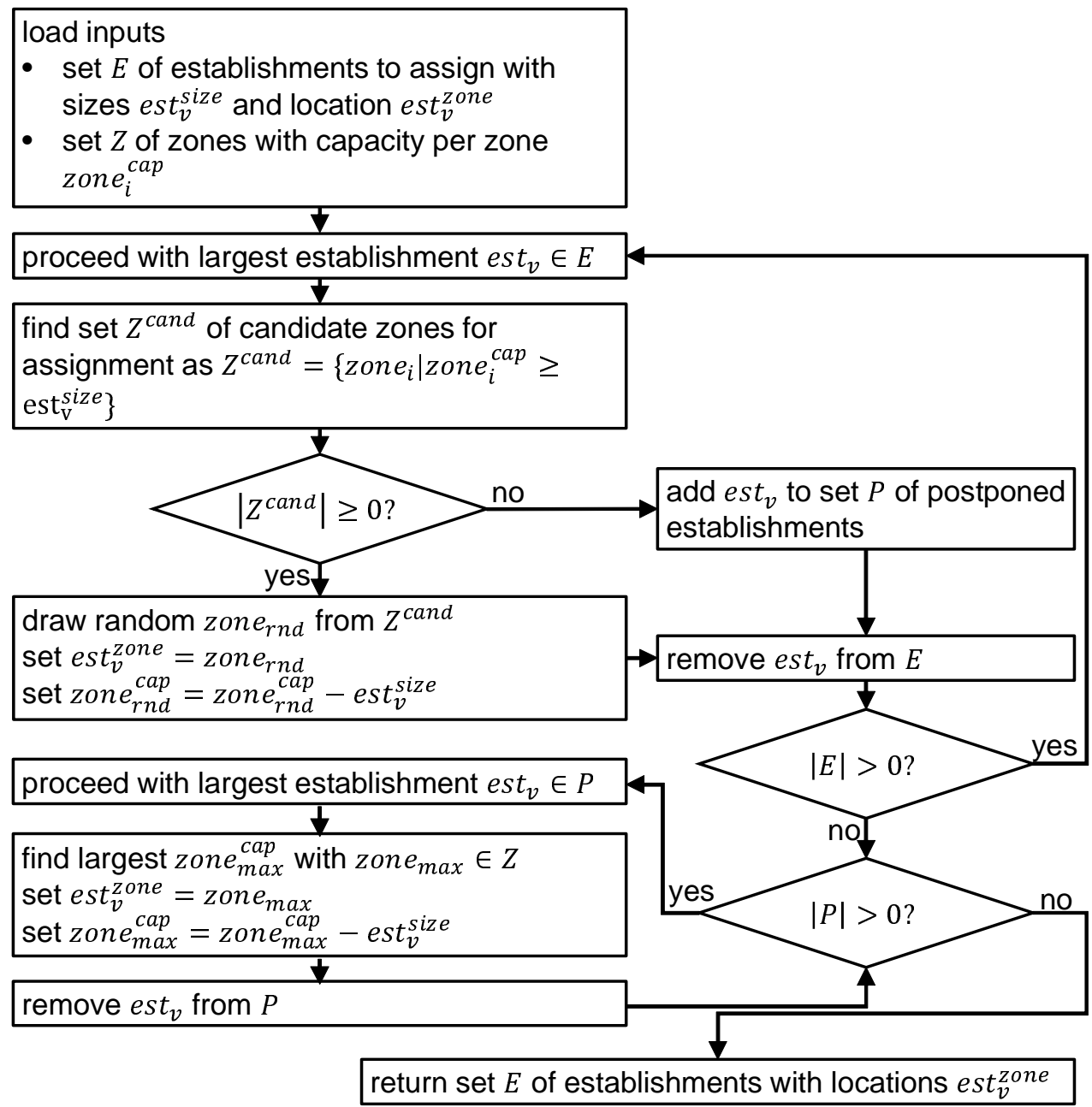

Figure 4.7: Flowchart for the spatial assignment of establishments 


\section{Calculating the Output Volumes of Establishments}

After all establishments for all sectors have been generated and located in space, their output and accordingly required inputs are calculated. The model assumes that every establishment provides a single type of output, which is determined by its sector affiliation. The sector also determines the technology used for the production of outputs, which depicts the amount of inputs required. Hence, in the model, a sector is defined by homogeneity of outputs and the technology used for their production. The output calculation is based on sector est ${ }_{v}^{\text {sector }}$ and size $e s t_{v}^{\text {size }}$ of the establishment. The implemented model uses a linear function $f\left(\right.$ est $_{v}^{\text {sector }}$, est $\left.t_{v}^{\text {size }}\right)=$ est $_{v}^{\text {out }}=$

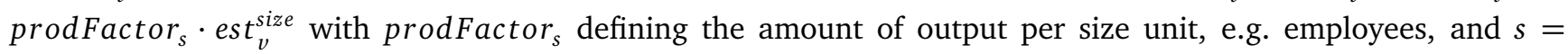
est $t_{v}^{\text {sector }}$.

Values for the parameter prodFactor $r_{s}$ are defined for every sector in an external file based on production statistics. For certain applications where suitable data is available for calibration, the model allows for extending the implemented functions such that they show superadditivity (economies of scale) or subadditivity (diseconomies of scale) instead of a pure linear relation. Alternatively, this aspect could be addressed by using output directly as size parameter in the generation process instead of e.g. employees.

\section{Calculating the Input Volumes of Establishments}

The required inputs per establishment are determined by the amount of the establishment's output and its sector, respectively its technology. The technology defines which types of goods $(c \in C)$ and which amounts (inpFac $c, s$ ) are required for the production of one output unit of sector $s$. Hence, for every input commodity required, every establishment is assigned the needed amount by calculating $e s t_{v}^{i n p_{c}}=i n p F a c_{c, s} \cdot$ est $_{v}^{\text {out }}$. Like productivity, the input factors are provided by an external file. The empiricism regarding these parameters is described in the chapter 5 because it directly depends on the actual application.

\subsubsection{Generating Commodity Flows between Establishments (Phase 1, Step 2)}

The previous sections describe how establishments are generated in the model. The following sections focus on how the commodity flows connecting these establishments are produced.

\section{Fitting of Macro Flows}

A major challenge for freight transport modelling is ensuring congruence of the modelled system and the real world. Whilst there are multiple data sources available regarding establishments' characteristics, only few countries, e.g. the United States of America or Sweden, conduct detailed commodity flow surveys, which provide valuable information for modelling disaggregate freight flows. Unfortunately, there are no comparable sources on freight flows in Germany. Nevertheless, a macroscopic freight flow matrix is published as part of the federal transport planning for Germany (Schubert et al. 2014), which can be used as a source on the actual spatial pattern of freight flows.

In order to ensure consistency of the modelled flows with the aggregate data, the model uses the interzonal macro flows as constraints when creating the inter-establishment micro flows. Since the model only contains a subset of the aggregate flows, the macro data needs to be fitted to the production and consumption volumes as determined by the generated establishments. The procedure follows the approach of Furness (1962). It works as follows:

The macro fitting is carried out for every commodity being input or output of the generated establishments. In a first step, the row and column totals for a zonal production-consumption (PC) matrix are calculated for the commodity 


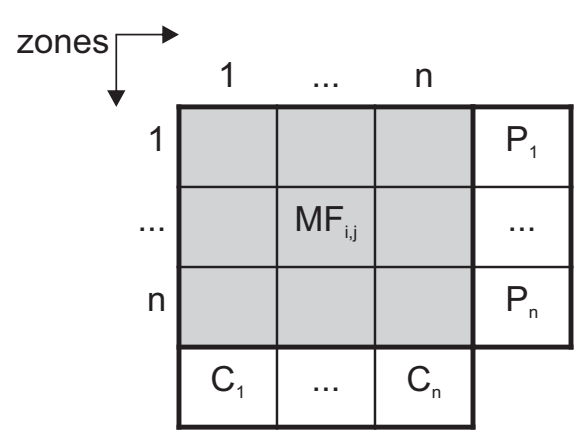
where:
$\mathrm{P}_{\mathrm{i}}=$ production in zone $\mathrm{i}$
$\mathrm{C}_{\mathrm{j}}=$ consumption in zone $\mathrm{j}$
$\mathrm{MF}_{\mathrm{i}, \mathrm{j}}=$ macro flow from zone $\mathrm{i}$ to $\mathrm{j}$

Figure 4.8: Schematic production-consumption matrix of macro flows

considered. Figure 4.8 illustrates the variables used for the PC matrices. In this context, consumption stands for the consumption of intermediates by establishments as well as for the consumption of private households.

$$
\begin{aligned}
& P_{i}^{c}=\sup _{i}^{c}=\sum_{\left\{e s t_{v} \mid e s s_{v}^{\text {sector }}=c \wedge \text { est } t_{v}^{\text {zone }}=i\right\}} \operatorname{est}_{v}^{\text {out }} \\
& C_{j}^{c}=\operatorname{dem}_{j}^{c}=\sum_{\left\{e s t_{v} \mid e s t_{v}^{z o n e}=j\right\}} e s t_{v}^{i n p_{c}}
\end{aligned}
$$

where:

$$
\begin{array}{ll}
P_{i}^{c}=\sup _{i}^{c} & =\text { production volume of commodity } c \text { in zone } i \text { (i.e. supply) } \\
C_{j}^{c}=\text { dem }_{j}^{c} & =\text { consumption volume of commodity } c \text { in zone } j \text { (i.e. demand) } \\
\text { est }_{v} & =\text { establishment object } v \\
\text { est } t_{v}^{\text {inp }} & =\text { input of commodity } c \text { for establishment } v \\
\text { est } t_{v}^{\text {out }} & =\text { output of establishment } v \\
\text { est } t_{v}^{\text {sector }} & =\text { sector, i.e. output commodity, of establishment } v \\
\text { est }_{v}^{\text {zone }} & =\text { zone of establishment } v
\end{array}
$$

For every commodity used in the model, an external parameter defines to which commodity from the macro data it shall be fitted. For most applications, the resolution of commodities in the model is higher than provided by the aggregate data source. Hence, it might happen that different commodities in the model refer to the same aggregate commodity flow pattern, e.g. meat products and vegetables both assigned to macro flows of the category food products and luxury foods. Even in these cases the model will match micro and macro flows for different micro commodities separately. At first thought, parallel assignment of such micro flows would give better considerations to the constraints imposed by the macro data, it becomes clear at second thought that the degrees of freedom would not change significantly because production and consumption per micro commodity are still determined by the generated establishments. So, this simplification in the fitting procedure cannot significantly influence the results' overall quality.

As described, row and column totals are calculated for the generated establishments. Now, the macro PC matrices need to be fitted so that their row and column totals correspond to those in the model by altering the matrix elements. In transport modelling, the iterative procedure proposed by Furness (1962) is well established for this purpose. Hence, an extensive description of the procedure is omitted here and only a short overview on the iterative process is given using the original nomenclature for the variables. The Java implementation of the Furness method used within the model has been provided by Andreas Balster. Briefly, it works as follows: 
In turns, table elements are adjusted following row and column constraints in separate steps in order to match target row and column totals. For the row iteration, current totals $P_{i}^{n}$ are computed. Hereupon, a compensating factor $p_{i}^{n}$ is calculated considering for the target totals $P_{i}^{*}$ for every row such that $p_{i}^{n}=P_{i}^{*} / P_{i}^{n}$. The actual row iteration is carried out by updating every element with $t_{i j}^{n+1}=t_{i j}^{n} \cdot p_{i}^{n}$. The updated table $T^{n+1}$ is used as input for the subsequent column iteration, starting with calculating the new column totals $C_{j}^{n+1}$. The compensating factors for the columns are derived analogously to the row factors by $c_{j}^{n+1}=C_{j}^{*} / C_{j}^{n+1}$. Finally, the table elements are updated by calculating $t_{i j}^{n+2}=t_{i j}^{n+1} \cdot c_{j}^{n+1}$. The iteration stops once the deviations $\sum_{i \in I}\left|P_{i}^{*}-P_{i}^{n}\right|$ and $\sum_{j \in J}\left|C_{j}^{*}-C_{j}^{n}\right|$ are sufficiently small or a maximum number of iterations has been reached.

The output of the macro flow fitting are PC tables for every commodity that correspond to the inter-zonal row and column totals of the modelled establishments and also show the same spatial flow structure as the available macro flow statistics. These generated tables serve as a central input for the subsequent generation of micro flows.

\section{Creating Commodity Flows}

The procedure outlined below produces commodity flows between the previously generated establishments according to the fitted macro PC tables. Conceptionally, the overall flow assignment follows a sourcing perspective, i.e. each commodity flow's destination establishment is already fixed at the moment of its creation. A suitable origin establishments is selected afterwards considering statistical constraints. Hence, this is not to be mistaken for an endogenous model of the sourcing decision. Instead, in this context, the sourcing perspective refers to the way of creating commodity flows by technically following an upstream logic.

The procedure applied has two distinct steps: First, the total input volumes per commodity and establishment are split into discrete batches determining commodity flow sizes. Second, for every batch a supplier is selected from the population of generated establishments. In this context, batch describes the amount of commodity delivered by one supplier. The term batch is not to be mixed up with delivery lot sizes or shipment sizes as used in freight transport. In the presented model, batch size and the generated flow size are identical except for cases when stricter constraints require adaptations during the later assignment procedure.

\section{Discretisation of Input Volumes}

In the generation process, the establishments have been assigned total volumes of input per commodity. The procedure presented in this section is used to split these total volumes into single batches, which get assigned to suitable suppliers in the next step.

One aspect of producing a realistic population of commodity flows is reflecting a realistic distribution of flow sizes. For this reason, the model relies on a Pareto-like distribution when splitting total input volumes per establishment and commodity (est $t_{v}^{i n p_{c}}$ ) into single batches. The cumulated Pareto distribution is described in equation 4.5. This approach has also been used in Friedrich (2010, p. 112).

$$
F(x)=1-\left(\frac{x_{\min }}{x}\right)^{k}, x>x_{\min }
$$

If normalised such that $F\left(x_{\max }=100 \%\right)$, the cumulated Pareto function corresponds to the Lorenz curve (Gudehus 2005, p. 134). In consequence, the calculation of the actual batch sizes per input commodity relies on the parametrised function for a Lorenz curve proposed by Gudehus (2005, p. 137). The exact formulation is depicted in equation 4.6. 
For the applied Lorenz curve, the dimension $p^{N}$ measures the cumulated share of the count of intended flows. The dimension $p^{M}$ stands for the cumulated share of total input volume to be assigned. The parametrisation of the Lorenz curve and the calculation of batch sizes is carried out consecutively and separately sector by sector.

$$
\begin{gathered}
p_{k}^{M}=1+\frac{\left(2-\left(1-\alpha_{c, s}\right)^{2}\right) \cdot p_{k}^{N}-\sqrt{4 \cdot\left(p_{k}^{N}\right)^{2}-4 \cdot\left(p_{k}^{N}\right)^{2} \cdot\left(1-\alpha_{c, s}\right)^{2}+\left(1-\alpha_{c, s}\right)^{4}}}{\left(1-\alpha_{c, s}\right)^{2}} \\
p_{k}^{N}=k \cdot \frac{1}{\text { est }_{v}^{\text {suppliers }}} \\
c f_{k}^{\text {vol }}=\operatorname{est}_{v}^{\text {inp }} \cdot\left(p_{k}^{M}-p_{k-1}^{M}\right)
\end{gathered}
$$

with:

$$
\begin{aligned}
p_{0}^{M} & =0 \\
k & \in\left[1, \text { est }_{v}^{\text {suppliers }_{c}}\right] \\
\alpha_{c, s} & \in[0,1)
\end{aligned}
$$

where:

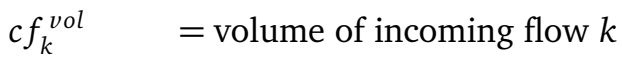

$$
\begin{aligned}
& \text { est } t_{v} \text { in } p_{c}=\text { total incoming volume of commodity } \mathrm{c} \text { for establishment } v \\
& \text { est }_{v}^{\text {suppliers }}=\text { number of suppliers for establishment } v \text { for flows of commodity type } c \\
& k \quad=\text { index of commodity flow } k \\
& p_{k}^{N} \quad=\text { cumulated proportion of number of commodity flows including flow } k \\
& p_{k}^{M} \quad=\text { cumulated proportion of commodity amounts of flows including flow } k \\
& \alpha_{c, s} \quad=\text { Lorenz asymmetry parameter for flow relation of commodities of type } c \text { to industry } s \\
& \left(s=e s t_{v}^{\text {sector }}\right)
\end{aligned}
$$

Figure 4.9 illustrates how a uniform splitting of $p^{M}$, assuming an example number of flows $(n=4)$, leads to a population of different volumes, respectively batch or commodity flow sizes, which are consistent with the intended distribution. In the figure, the different lengths of the arrows $\left(f_{1}, \ldots, f_{4}\right)$ sketched alongside the $p^{M}$-axis represent the variety of relative volumes per batch expressed as a share of the total required input volume. In addition, the different graphs in the figure show how different values for $\alpha$ lead to different shapes of the Lorenz curve and in consequence to different distributions of batch sizes. For example, $\alpha=0.0$ produces a uniform set of sizes.

Aside from the volume of inputs, a target number of suppliers est $v_{v}^{\text {suppliers }_{c}}$ for every commodity $c$ and establishment est $_{v}$ is required for the application of the Pareto-discretisation. The actual outcome of the assignment procedure might differ because the greedy sequential assignment of flows might require additional or fewer suppliers due to the distribution of remaining free output capacity at potential supplying establishments or zonal flow restrictions.

Including a variable on the number of suppliers per commodity and establishment into the model is motivated by the requirement to capture different degrees of connectedness between sectors. In this regard, Liedtke (2006, p. 103) uses the term "idealness of supply trees" and introduces a formula similar to equation 4.9, which includes a parameter called dispersion factor $\operatorname{dispFac}_{c, s}$, which describes the degree of connectedness between the industry producing commodity $c$ and the consuming industry $s$. 


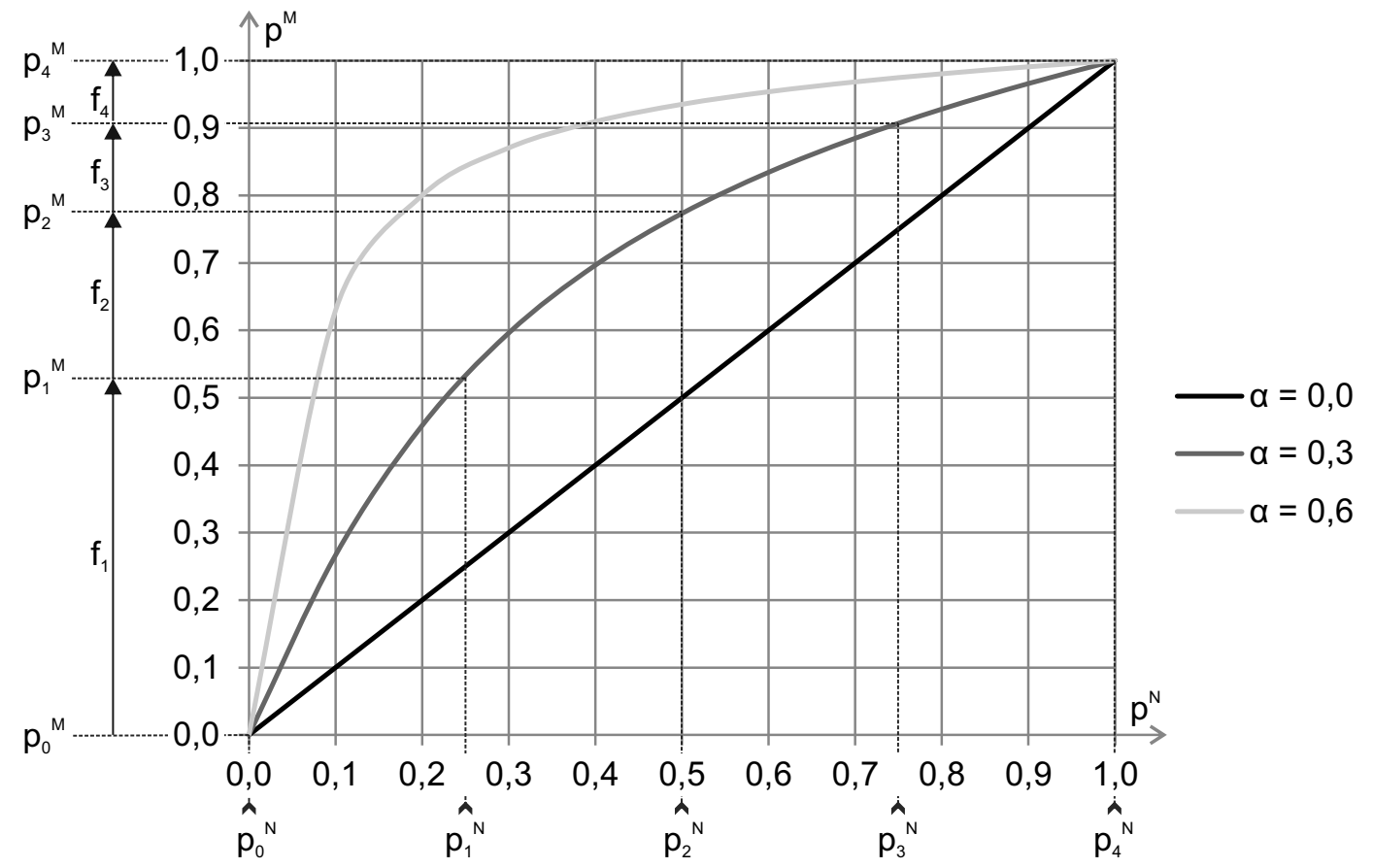

Figure 4.9: Example of using the Lorenz curve function (equation 4.6) for discretisation

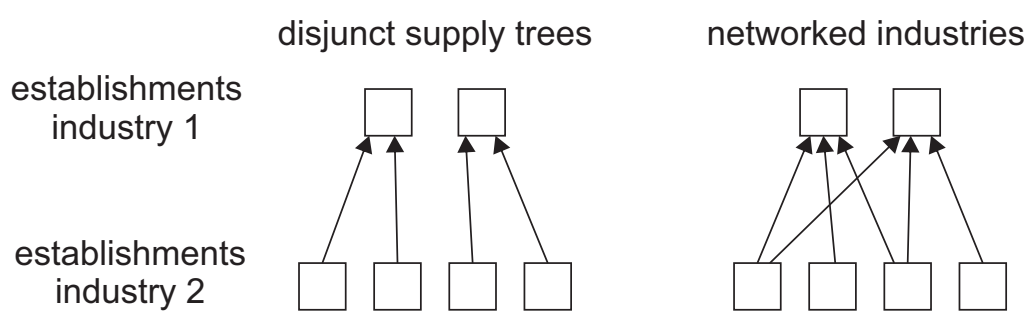

Figure 4.10: Connectedness within supply chains based on Liedtke (2006, p. 103).

$$
\text { est }_{v}^{\text {suppliers }_{c}}=\left\lceil n E s t_{c} \cdot n E s t_{s} \cdot \operatorname{dispFac}_{c, s} \cdot \frac{\left(\text { est }_{v}^{\text {out }}\right)^{\beta_{c, s}}}{\sum_{\left\{e s t_{v} \in E \mid \text { est }_{v}^{\text {sector }}=e s t_{v}^{\text {sector }}\right\}}\left(\text { est }_{v}^{\text {out }}\right)^{\text {beta }_{c, s}}}\right\rceil
$$

with:

$$
\begin{aligned}
\operatorname{dispFac}_{c, s} & \in[0,1] \\
\beta_{c, s} & \in \mathbb{R}
\end{aligned}
$$

where:

$\operatorname{dispFac}_{c, s}=$ dispersion factor for flows of commodity type $c$ to industry $s$

est $t_{v}^{\text {out }} \quad=$ production of establishment $v$

est ${ }_{v}^{\text {suppliers }}$ s $_{c}=$ number of suppliers of commodity $c$ for establishment $v$

nEst $_{c} \quad=$ number of establishments in supplying industry $c$

$n E s t_{s} \quad=$ number of establishments in receiving industry $\left(s=e s t_{v}^{s e c t o r}\right)$

$\beta_{c, s} \quad=$ distribution parameter describing the impact of establishment sizes on the distribution of inter sector links 
The formula used in the model at hand shows certain improvements compared to Liedtke (2006). The most important enhancements are the integration of establishment output est $t_{v}^{\text {out }}$ and the consideration of total sector output $\sum_{\left\{\text {est }_{v} \mid \text { est }\right.}^{\text {sector }=e s t_{v}^{\text {sector }\}}}\left(\text { est }_{v}^{\text {out }}\right)^{\beta}$ as well as a smoothing parameter $\beta$ to describe how strong an establishment's size influences its number of suppliers compared to the overall sector output.

The actual procedure for calculating the target number of suppliers is carried out as follows. For each commodity $c$, it finds the number $n E s t_{c}$ of establishments providing this very commodity. Based on externally defined values for the dispersion factor $\operatorname{dispFac} c$ cor the current sectoral relation and the distribution parameter $\beta_{c, s}$, a target number of suppliers is calculated for every establishment in the consuming sector. Applying the ceiling function in the respective formula (equation 4.9) ensures that at least a minimum number of one supplier is set for every commodity. This is repeated for all commodities so that every establishment is assigned a target number of suppliers $\left(\right.$ est $_{v}^{\text {suppliers }_{c}}$ ) for each of its input commodities.

After the target number of suppliers has been set, commodity flow sizes are determined by discretisation of total input commodity volumes per establishment. The overall input volume of a certain commodity $c$ for a certain establishment is denoted by est $t_{v}^{i n p_{c}}$. This volume is to be split into $k \in\left\{1, \ldots\right.$, est $\left._{v}^{\text {suppliers }}{ }_{c}\right\}$ separate batches to be served by different suppliers leading to a set of heterogeneous commodity flows ending at the current establishment $\left(c f_{k}^{\text {dest }}=e s t_{v}\right)$. For this purpose, the Lorenz curve function (equation 4.6) is cut into uniform segments with upper borders $p_{k}^{N}$ for every $k$. The resulting difference $p_{k}^{M}-p_{k-1}^{M}$ determines the share of batch $k$ regarding the required overall input of the current commodity. Hence, the absolute size of batch $k$, and the according commodity flow volume $c f_{k}^{v o l}$, is calculated by multiplying the establishment's required amount $e s t_{v}^{i n p_{c}}$ with the share denoted by the segment's difference in the Lorenz curve function $\left(p_{k}^{M}-p_{k-1}^{M}\right)$. The parameter for the Lorenz asymmetry factor $\alpha_{c, s}$ is provided externally.

In this section it has been laid out how the number of suppliers per establishment is determined for each input commodity and how this number of suppliers translates into corresponding commodity flows. The following section describes how the actual supplying establishments are selected for each batch.

\section{Assigning Supplier Establishments to Commodity Flows}

All previous steps have been preparations for the final step of producing commodity flows between establishments as described in this section. These micro flows are created by determining a supplying establishment for each batch of input commodity as generated in the previous step. The procedure for selecting supply establishments aims at ensuring consistency with the fitted inter-zone flow constraints and the establishments' output capacities. Any relaxations required to deal with exceptional states of the algorithm and their impact are addressed in more detail during the step by step explanation of the applied procedure. Before diving into the steps of the assignment process, the constraints considered are explained in more detail since the developed algorithm is based on best fulfilling these conditions:

Constraint 1: Required Volumes of Input Commodities for every Establishment: As described, the focal entity for the assignment process are commodity flows of inputs with each having a distinct commodity type and size. In order to achieve consistency regarding the relation of input and output on establishment level, all commodity flows need to be assigned to a supplying establishment. Consequently, assigning all commodity flows leads to inter-establishment flows that fulfil the requirement regarding total input volumes per commodity as well. The corresponding necessary condition is expressed in equation 4.10.

$$
\sum_{\left\{c f_{k} \mid c f_{k}^{c o m}=c \wedge c f_{k}^{\text {dest } \left._{=}=s t_{v}\right\}}\right.} c f_{k}^{v o l}=e s t_{v}^{\text {input }_{c}}, \forall e s t_{v} \in E, \forall c \in C
$$


where:

$$
\begin{aligned}
& c f_{k}^{\text {com }}=\text { commodity of commodity flow } k \\
& c f_{k}^{\text {dest }}=\text { destination establishment of commodity flow } k \\
& c f_{k}^{\text {vol }}=\text { volume of commodity flow } k \\
& \text { est } v_{v}=\text { establishments from the set of all establishments } E \\
& C \quad=\text { set of all commodities with } c f_{k}^{\text {com }}=c \text { and } c \in C \\
& E \quad=\text { set of all establishments }
\end{aligned}
$$

Constraint 2: Output Capacities of Establishments: In addition to the input constraints, supplying establishments can only provide an amount of output commodities below or equal to their output capacity as determined during the calculation of throughputs (equation 4.11).

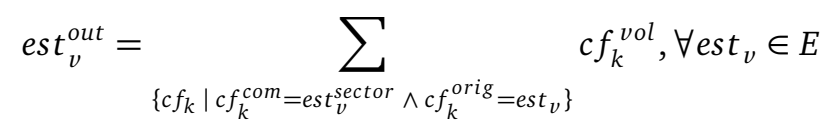

where:

$c f_{k}^{\text {com }}=$ commodity of commodity flow $k$

$c f_{k}^{\text {orig }}=$ origin establishment of commodity flow $k$

$c f_{k}^{\text {vol }}=$ volume of commodity flow $k$

est ${ }_{v}^{\text {out }}=$ output capacity of establishment $v$

$E \quad=$ set of all establishments

Constraint 3: Flow Volume per Commodity and Zonal Relation according to Fitted Macro Flows: As laid out above, consistency with real-world spatial freight flow patterns is ensured by considering available macro flow data in the supplier selection process. Hence, after assigning all commodity flows of input commodities to suppliers, the sum of all inter-establishment flows' volume for a certain zone-to-zone relation should be equal to the corresponding fitted macro flow. This condition should hold true for each commodity and each inter-zone relation as formulated in equation 4.12.

$$
m f_{l}^{\text {vol }}=\sum_{\left\{c f_{k} \mid c f_{k}^{\text {origZone }}=m f_{l}^{\text {origZone }} \wedge c f_{k}^{\text {destZone }}=m f_{l}^{\text {destZone }} \wedge c f_{k}^{\text {com }}=m f_{l}^{\text {com }}\right\}} c f_{k}^{\text {vol }}, \forall m f_{l} \in M F
$$

where:

$$
\begin{array}{ll}
c f_{k}^{\text {com }} & =\text { commodity of commodity flow } k \\
c f_{k}^{\text {vol }} & =\text { volume of commodity flow } k \\
c f_{k}^{\text {origZone }} & =\text { origin zone of commodity flow } k \\
c f_{k}^{\text {destZone }} & =\text { origin zone of commodity flow } k \\
m f_{l}^{\text {com }} & =\text { commodity of macro flow } l \\
m f_{l}^{\text {vol }} & =\text { volume of macro flow } l \\
m f_{l}^{\text {origZone }} & =\text { origin zone of macro flow } l \\
m f_{l}^{\text {destZone }} & =\text { origin zone of macro flow } l \\
M F & =\text { set of all macro flows }
\end{array}
$$


Similar to the assignment of establishments to zones, the applied algorithm is of greedy and partially stochastic nature. Hence, it might run into a state that does not allow for a complete allocation of commodity flows considering the entirety of all given constraints. Therefore, the algorithm consists of a first part that produces an assignment that is fully consistent with the imposed constraints and a second part that stepwisely relaxes the constraints in order to assign any residual flows as well.

Algorithm Part 1: Maximum Constraint Supplier Selection: In the supplier selection algorithm, the set of generated establishments provides the potential suppliers serving as origin establishment for the commodity flows. In addition, the fitted macro flows must be loaded in order to consider the restrictions they imply on the spatial linkage of establishments. The assignment procedure is carried out for all commodities used within the model by assigning one commodity at a time. Figure 4.11 shows the corresponding flowchart.

The iteration starts with selecting the largest unassigned commodity flow $c f_{k}$ for the current commodity $\left(c f_{k}^{\text {com }}=\right.$ c). In the next step, the algorithm identifies all zones (zone $e_{i}$ ) that could contain a potential supplier for the current commodity flow according to the restrictions imposed by the macro flows. These zones are stored in a set $(Z)$. Accordingly, the necessary condition is that the macro flow volume allows for the assignment of a commodity flow larger or equal to the current flow's size and the macro flow ends in the zone of the current commodity flow's destination establishment $\left(Z=\left\{\right.\right.$ zone $_{i} \mid$ zone $_{i}=m f_{l}^{\text {origZone }} \wedge m f_{l}^{\text {com }}=c f_{k}^{\text {com }} \wedge m f_{l}^{\text {vol }} \geq c f_{k}^{\text {vol }} \wedge m f_{l}^{\text {destZone }}=$ $\left.c f_{k}^{\text {destZone }}\right\}$ ).

Based on the potential locations of suppliers, candidate suppliers are identified whose locations are in the determined zones and that have enough free output capacity $\left(E_{\text {cand }}=\left\{e s t_{\text {cand }} \mid e s t_{\text {cand }}^{\text {sector }}=c f_{k}^{\text {com }} \wedge\right.\right.$ est cand $_{\text {cand }}^{\text {ou }} \geq$ $\left.c f_{k}^{v o l} \wedge e s t_{\text {cand }}^{z o n e} \in Z\right\}$ ). In addition, a consuming establishment can only have one commodity flow per commodity type and supplier establishment. If no candidate supplier can be found that fulfils the various conditions $\left(\left|E_{\text {cand }}\right|=0\right.$ ), a selection procedures with relaxed constraints is carried out as described in a distinct section below (p. 86).

In case multiple establishments are available as potential suppliers, a random establishment $e t_{\text {rnd }}$ is drawn from these. This stochastic element is included in order to avoid a bias resulting from the descending iteration order of commodity flows. Using a greedy bin packing heuristic without stochastic elements, the descending iteration order potentially induces undesired patterns by always assigning the largest flows to the largest establishments. Mixing the two paradigms, the random drawing process could apply a weighting based on the (free) capacity of available establishments. Again, this approach would tend to produce specific patterns. Without data on the actual distribution of flow sizes between establishment sizes, it cannot be decided whether a weighted random choice would improve the result quality. The same argument holds true for the application of a more sophisticated appraisal function for the selection of suppliers. For these reasons, the current model does not apply weighting within the random selection of supplier establishments.

After the stochastic decision for the current commodity flow's supplier, the supplier's free output capacity gets reduced by the current flow's size (est $t_{r n d}^{\text {out }}=e s t_{r n d}^{\text {out }}-c f_{k}^{\text {vol }}$ ). Also, the corresponding macro flow's remaining unassigned volume gets reduced $\left(m f_{l}^{v o l}-c f_{k}^{v o l}\right)$. Finally, the commodity flow gets removed from the set of unassigned flows.

Algorithm Part 2: Relaxed Constraint Supplier Selection: The commodity flows whose assignment was not possible due to the macro flow and establishment capacity constraints in the first part of the supplier selection algorithm are processed according to the routine shown in the flowchart of figure 4.12. Regarding the required input parameters all parameters and sets of entities from the first part of the procedure are also valid in this second 


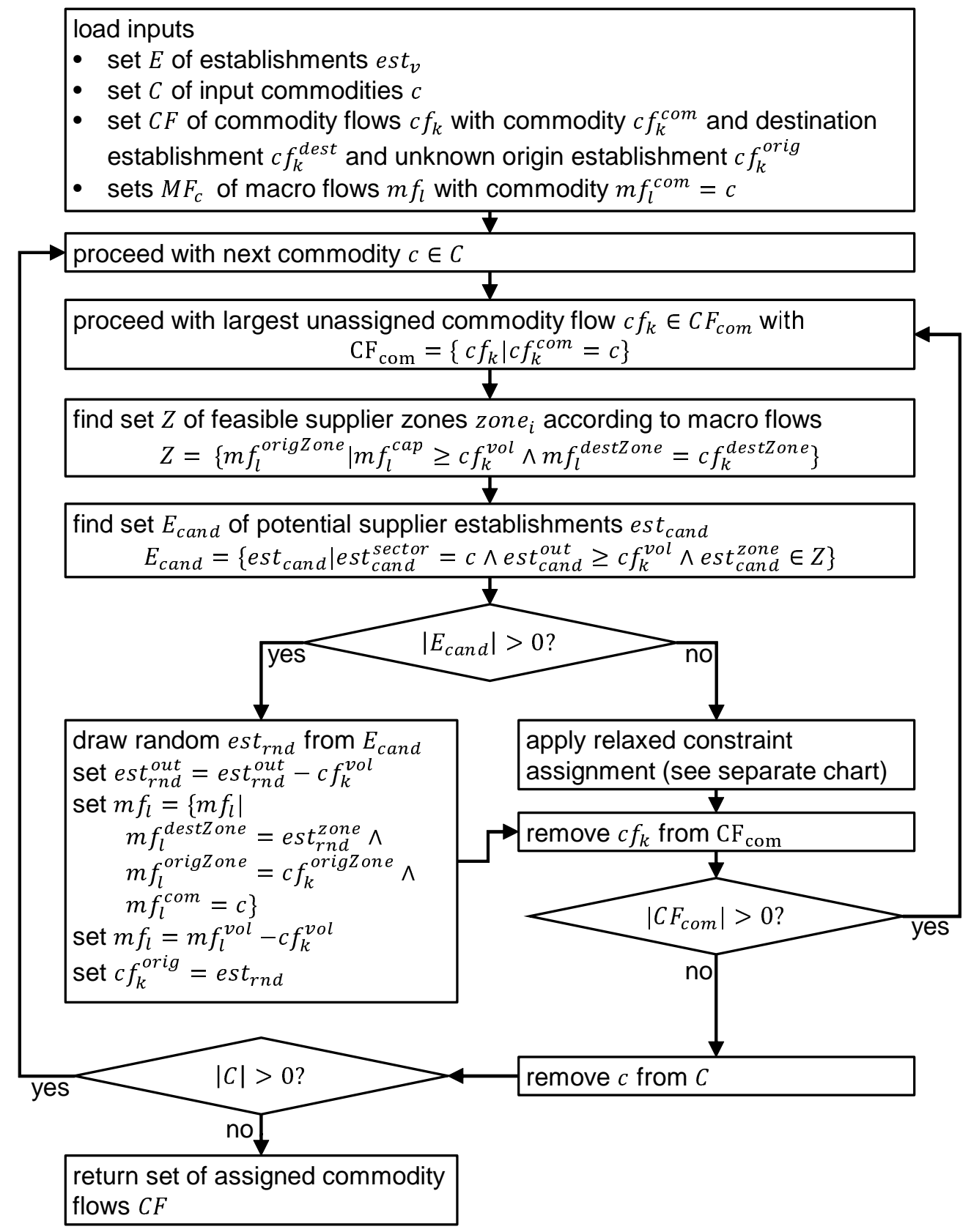

Figure 4.11: Flowchart for the assignment of suppliers to commodity flows

part. The later described model applications show that the overall volume of commodity flows that undergo this postponed assignment is negligibly small.

As described, the relaxed constraint procedure is carried out whenever no combination of supplier establishment and macro flow with enough remaining capacity regarding the current commodity flow's volume is available. Hence, the algorithm searches for the combination of macro flow and establishment providing the largest possible capacity $\left(\operatorname{cap}_{\max }=\max \left(\min \left(e s t_{v}^{\text {out }}, m f_{l}^{\text {cap }}\right)\right)\right)$. This preserves the spatial macro flow pattern at the price of relaxing the commodity flow size distribution. If such a combination is found, the current flow is resized to match the available maximum capacity. For the residual amount of the original volume, a new flow $c f_{\text {new }}$ is added to the set $C F_{\text {com }}$ for later assignment $\left(c f_{\text {new }}^{v o l}=c f_{k}^{v o l}-c a p_{\max }\right)$. Finally, the resized commodity flow is assigned to the identified supplier establishment and the corresponding macro flow's free capacity is reduced (not shown in the chart in figure 4.12 for reasons of clarity). 


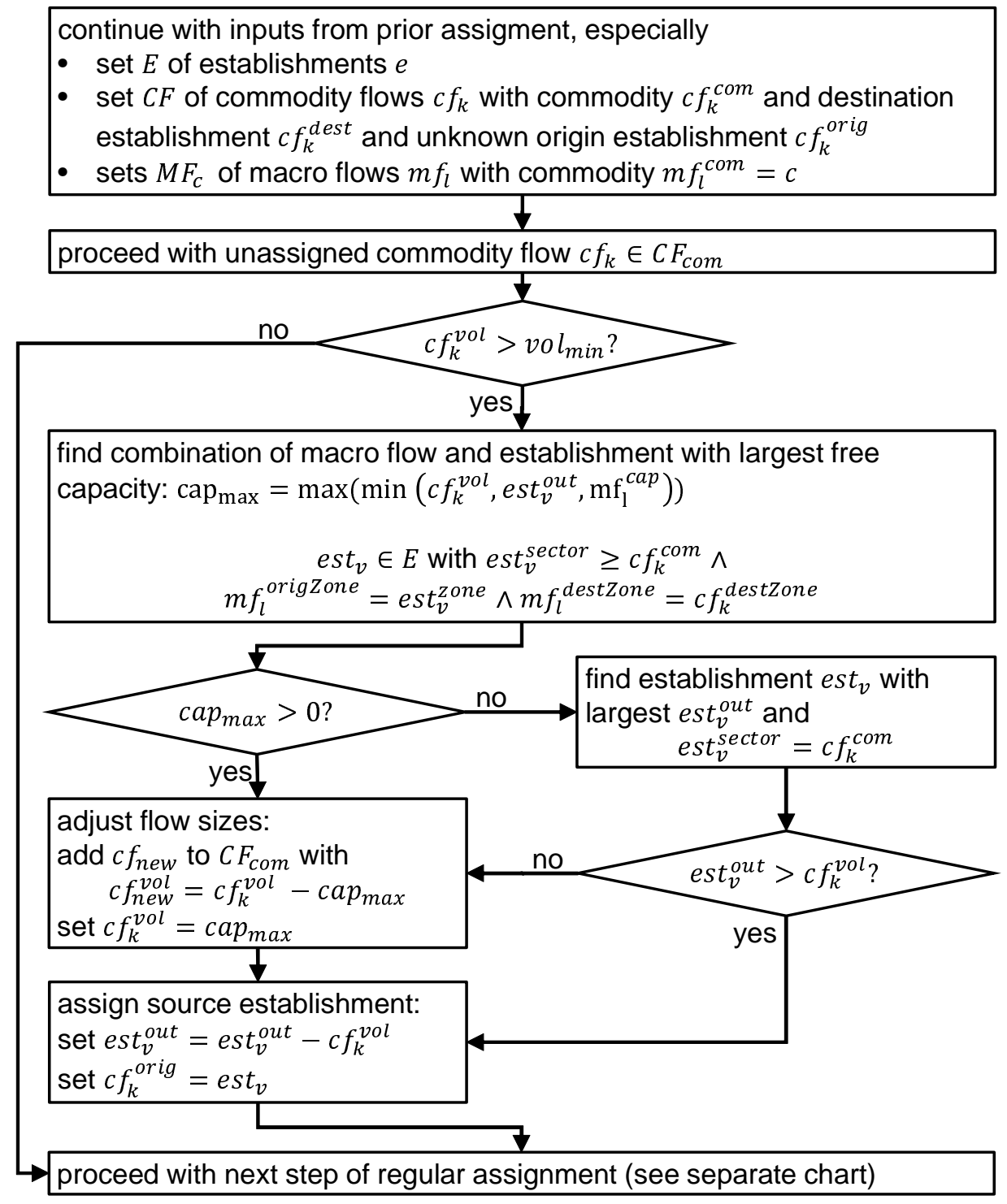

Figure 4.12: Flowchart for the relaxed constraint supplier selection

In case no valid combination of macro flow and establishment is available, the macro flow constraint gets relaxed and the algorithm searches for the establishment with the largest free output capacity. If the largest free capacity is below the current commodity flow's volume, the flow size is adjusted according to the procedure described in the paragraph above.

Ignoring the size constraint, it is now possible to match the current commodity flow's size with the establishment with the largest free output capacity. Accordingly, the current flow is resized so that it equals the available maximum capacity $\left(c f_{k}^{v o l}=e s t_{v}^{\text {out }}\right.$ ) and a new commodity flow is added for assignment with the remaining volume. In any case, the current commodity flow gets linked to a supplier establishment $\left(c f_{k}^{\text {orig }}=e s t_{v}\right)$ and is removed from the set of flows to be assigned.

After describing the actual relaxed contraint assignment of flows, the applied relaxations' necessity and their impact on the output are discussed in brief. First of all, it is important to note that the algorithm has been designed to give priority to fulfilling all restrictions imposed on the level of the establishments' input and output volumes. This is desirable because data on establishment sizes and their probable throughput are available and valued reliable. Especially for the case of horizontal change, the establishment parameters are at the core for describing the assumed 
changes. Hence, relaxations regarding the corresponding restrictions in the initial generation of establishments and flows would induce an unwanted blurring. Therefore, the applied procedures are capable of ensuring maximum consistency between artificial entities and the according input statistics on establishment level.

The developed algorithm first relaxes the commodity flow size constraints while preserving establishment and macro flow conditions. This is motivated by the potential influence of commodity flows' spatial patterns on the later simulation of changes in the supply chain structure and the availability and reliability of macro flow data for Germany.

However, the sequential assignment and deviations that result from the macro flow fitting lead to the necessity of assigning a negligible share of commodity flows while ignoring the macro flow constraints. As described above, the algorithm selected the establishment with the largest free output capacity as supplier. If possible, the current commodity flow's volume is unchanged. The chosen way of selecting the establishment with the largest free output capacity preserves large flows, at the price of creating small residuals. The latter have the benefit of having a high chance of directly finding a suitable supplier in the subsequent procedure.

The relaxed constraint assignment also allows for assigning multiple commodity flows to the same supplier. This accounts for unfavourable earlier assignments that lead to tiny residual capacities in the later process. After all commodity flows have been assigned, these multiple flows are consolidated such that there is only a single commodity flow between each pair of supplier and consumer establishment.

In summary, the developed algorithm contains a first part that assigns discrete batches of input commodities to supplier establishment considering the restrictions coming from available macro flows, establishments' throughput requirements and flow size distributions. For commodity flows that cannot be assigned during this first part of the algorithm, there is a second procedure that successively allows for the relaxation of constraints in order to allow for the complete assignment of the required volume of commodities. Ignoring the constraints might have a small influence on the overall model outcome even if the spatial pattern imposed by macro flows is preserved as far as possible. Numerical information on the commodity volumes assigned by using the relaxed procedures and the resulting deviation is provided for the application scenarios in the corresponding sections 5.1 and 5.2.

The recently described creation of commodity flows between establishments requiring input and suppliers is the last step of the model's initial phase. Subsequently, the generated population of artificial establishments and commodity flows will be used to simulate changes in their supply chain structures.

\subsection{Simulation of Change in Supply Chain Structures (Phase 2)}

This section focusses on how changes in the supply chain structure are applied to the previously generated population of artificial establishments and commodity flows between them. In the following, this set of flows and establishments is referred to as reference or initial population.

\subsubsection{Overview of Implemented Structure Effects and corresponding Model Procedures}

In general, the simulation of change always follows a two step procedure: First, alterations are applied to the establishments and connected flows within the reference population in order to free enough space for the creation of new patterns according to the specified change. This first step is best compared to the image of cutting out or unravelling of commodity flow networks. Second, the population of establishments is updated so that it corresponds to the intended change. Afterwards or in parallel, depending on the chosen type of simulation, the updated establishments get connected by new commodity flows according to the updated restrictions. This second step can 


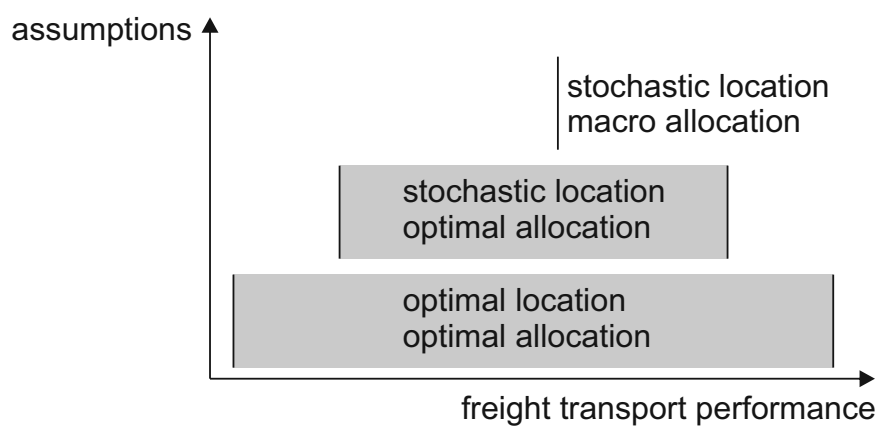

Figure 4.13: Range logic for dealing with different levels of constraints induced by assumptions

be seen as a kind of stitching or welding the lose ends of the supply networks together. The result is an altered population, which then can be compared to the reference population. The microscopic result data allows for a broad set of detailed analysis with freight transport performance being the most important indicator for the overall comparison.

\section{Using a Range Logic for Dealing With Assumptions}

By nature, simulating structural change requires certain strong assumptions (see also section 2.4.2, page 17), significantly influencing the model result. Whilst some parameters are determined by the structural change itself, further assumptions need to be made, especially regarding the following aspects in the case of centralisation:

1. Which business locations vanish?

2. Which new business locations appear?

3. How are they interconnected with Linkage of commodity flows?

Logically, the welding of supply networks for vertical change faces similar challenges regarding assumptions as in the horizontal case. For vertical changes these are assumptions on:

1. Which business locations outsource tasks?

2. Which new business locations appear?

3. How are they interconnected with commodity flows?

The solution used for coping with these challenges is calculating a range of different solutions by using mathematical models that are capable of finding maximum and minimum values for freight transport under given assumptions. Hence, the model does not calculate a single result but determines a range of possible outcomes under the given structural change in the supply chain structure.

For this purpose, the model contains different approaches with different levels of assumptions for estimating the possible impact. Applying methods from operations research and transport modelling, successively replacing degrees of freedom for the solution with assumptions, possible solution ranges can be calculated depending on the intensity of assumptions applied. Figure 4.13 summarises the interdependency of procedures and assumptions, and the resulting range of solutions. For now, it is only important to consider the overall concept in order to understand the different implemented procedures. The impact on the quantitative model result is described in further detail for each model application. 

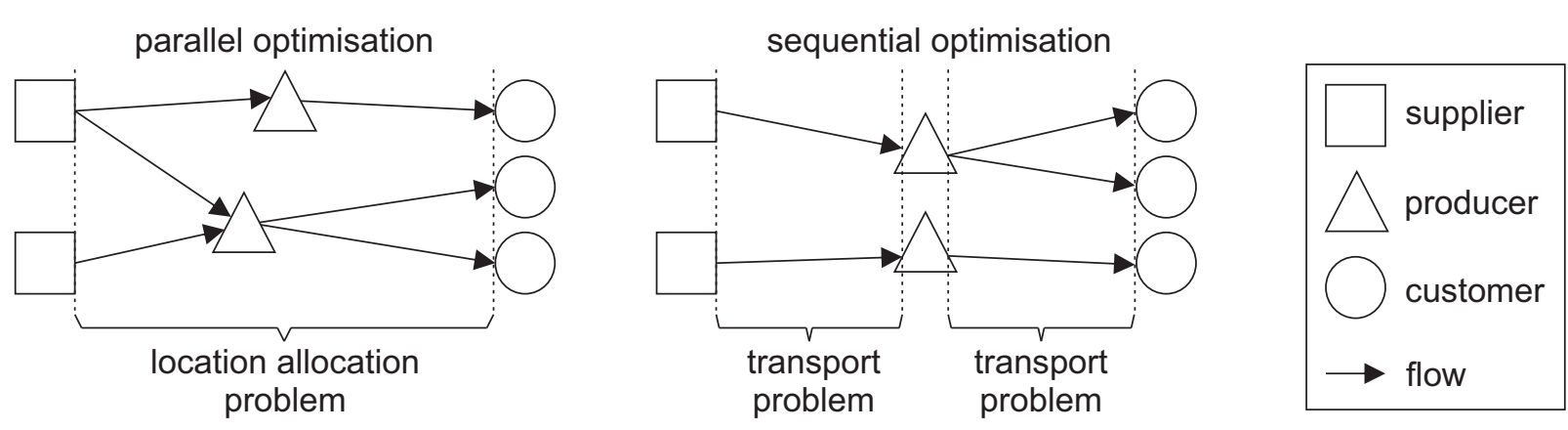

Figure 4.14: Comparing the application of sequential transport problems and a parallel location allocation problem for the assignment of flows

Parallel Location Allocation Problem: The procedure with the fewest assumptions applies an optimisation problem for locating establishments and assigning flows in parallel. This approach has its origin in the area of operations research. In the model at hand, an adapted formulation is used to find a set of establishments and flows fulfilling the restrictions of the assumed structural change with either a minimum or maximum value for the arising freight transport performance by simply exchanging the objective function into minimisation or maximisation. Due to including establishment locations into the optimisation, no assumptions are required regarding this aspect. Establishment sizes are also unrestricted. In consequence, the parallel consideration leads to the widest range of possible solutions. Hence, the location allocation problem determines the minimum and maximum freight transport possible under the given structural change.

Stochastic Location and Transport Problem: In contrast to the parallel assignment, this approach combines a stochastic location algorithm for the establishments with a problem formulation from operations research, now limited to assigning commodity flows. In consequence, the solution space is reduced to a less wide range. The different scopes of the parallel and sequential problem formulation are also illustrated in figure 4.14.

Stochastic Location and Macro Flow Fitting: Finally, this approach relies on the same stochastic location of establishments as described above. But instead of using methods from operations research for the creation of commodity flows, the macro flow fitting is applied similar to the procedure used during the generation of the reference population. Hence, this solution not only contains assumptions on the location and size of establishments but also on spatial flow patterns, i.e. by extrapolating flow matrices from before the structural change. In consequence, the high number of assumptions leads to a single solution instead of a range.

For assumptions that are not tackled directly by successively applying the three different procedures described above, repeated simulation cycles and sensitivity analyses are carried for the actual applications, e.g. for coping with the impact of selecting a certain set of disappearing business locations for centralisation or selecting a set of establishments for outsourcing in the case of outsourcing. The actual problem formulations applied in the model are explained in more detail in the subsequent sections.

\subsubsection{Simulating Horizontal Change}

This section deals with the procedures implemented in the model for simulating horizontal change within supply chain structures as defined in section 2.4.1. Centralisation is used as an illustrative example for horizontal effects when explaining the applied algorithms without loss of generality. 
Table 4.3: Parameters required for the simulation of centralisation, i.e. for describing the structural change itself (1) and necessary assumptions (2)

\begin{tabular}{|c|c|c|}
\hline \multicolumn{2}{|r|}{ Parameter } & \multirow{3}{*}{$\begin{array}{l}\text { Description } \\
\text { output commodity of the centralising sector } \\
\text { number of establishments in the focal sector after centralisation }\end{array}$} \\
\hline 1 & $p^{*}$ & \\
\hline & nFocalEsts & \\
\hline \multirow[t]{8}{*}{2} & locationChoice & $\begin{array}{l}\text { selects the procedure for locating establishments that appear as a result } \\
\text { of centralisation, i.e. optimal (using either location allocation problem) } \\
\text { or stochastic (using probabilities for establishments' sizes and locations) }\end{array}$ \\
\hline & assignmentProcedure & $\begin{array}{l}\text { selects the procedure for reassigning commodity flows after applying } \\
\text { structural change, i.e. optimal (using either location allocation problem } \\
\text { or transport problem) or macro (using macro flow fitting) }\end{array}$ \\
\hline & centralisationDegree & $\begin{array}{l}\text { share of establishments to be removed from centralising sector in ini- } \\
\text { tial population (centralisationDegree }=1 \text { if assigmentProcedure }= \\
\text { optimal and locationChoice }=\text { optimal) }\end{array}$ \\
\hline & assignmentSense & $\begin{array}{l}\text { selects the sense for assignment, i.e. minimise or maximise transport } \\
\text { performance (only applicable if assignmentProcedure }=\text { optimal) }\end{array}$ \\
\hline & $f_{s}(e m p)$ & $\begin{array}{l}\text { probability density for appearing establishments' sizes, specific to sector } \\
s=p^{*} \text { (only applicable if locationChoice }=\text { stochastic) }\end{array}$ \\
\hline & $P_{i}^{\text {locate }}$ & $\begin{array}{l}\text { probabilities by zone for the location of appearing establishments (only } \\
\text { applicable if locationChoice = stochastic) }\end{array}$ \\
\hline & $P_{i}^{\text {remove }}$ & probabilities by zone for the removal of focal establishments \\
\hline & $M F_{c}$ & $\begin{array}{l}\text { sets of macro flows for each commodity } c \text { to be used for fitting during } \\
\text { reassignment (only applicable if assigmentProcedure }=\text { macro) }\end{array}$ \\
\hline
\end{tabular}

As defined above, horizontal effects relate to those changes in the supply chain structures of an industry that are caused by changes in the configuration of establishments on the same stage of an idealised supply chain. Taking centralisation as an example, such a horizontal phenomenon would be a reduction in the total number of establishment on a certain stage of the sectoral supply chain and a resulting increase in the average size of these establishments, size measured by production volume. In the following, the establishments belonging to the affected supply chain stage are denoted as focal establishments.

The overall process for simulating horizontal changes is illustrated in figure 4.15 for the example case of centralisation. As shown, the procedure starts with selecting establishments belonging to the focal industry from the reference population that will be removed in order to give space to a population of establishments that is consistent with the assumed structural change. Additionally, the commodity flows linked to the deleted establishments are removed as well. With this step, the manipulation of the initial population finishes and the model continues with stitching the supply networks back together. This requires either resizing remaining establishments of the focal industry or generating new establishments in order to ensure consistency in the overall production volume. Afterwards or in parallel, depending on the chosen approach, input and output commodity flows need to be assigned for the appearing or respectively resized establishments. The algorithmic details of every step are explained in the sections below.

\section{Preparing the Reference Population of Establishments for Horizontal Changes (Phase 2, Step 1)}

The fundamental assumption for the simulation of structural changes in the context at hand is that only the structure and spatial pattern of establishments and flows may undergo changes. Total production and consumption 
(1) select and remove vanishing establishments $\begin{array}{llc}\text { supplying } & \begin{array}{c}\text { centralising } \\ \text { industry }\end{array} & \begin{array}{c}\text { consuming } \\ \text { industries }\end{array}\end{array}$

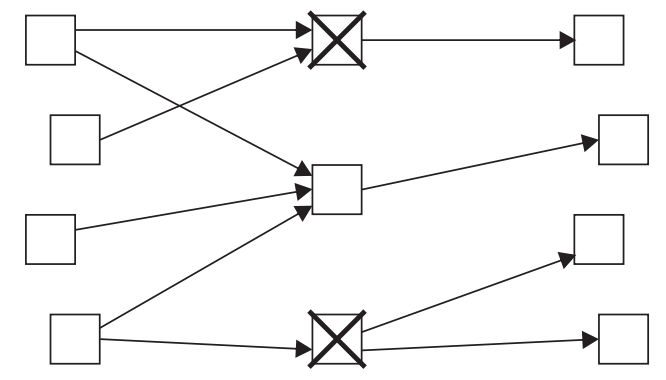

(3) generate appearing establishments supplying centralising consuming industries industry industries

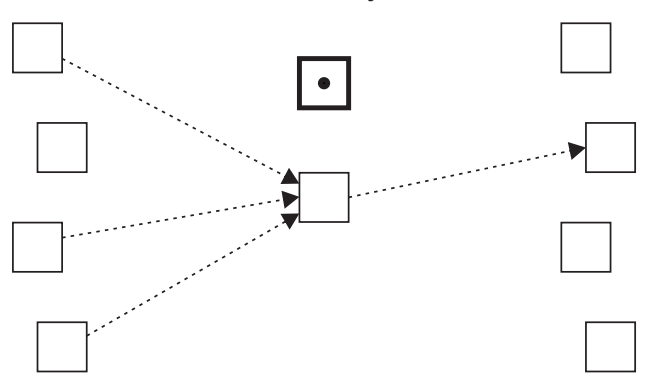

(2) remove corresponding flows

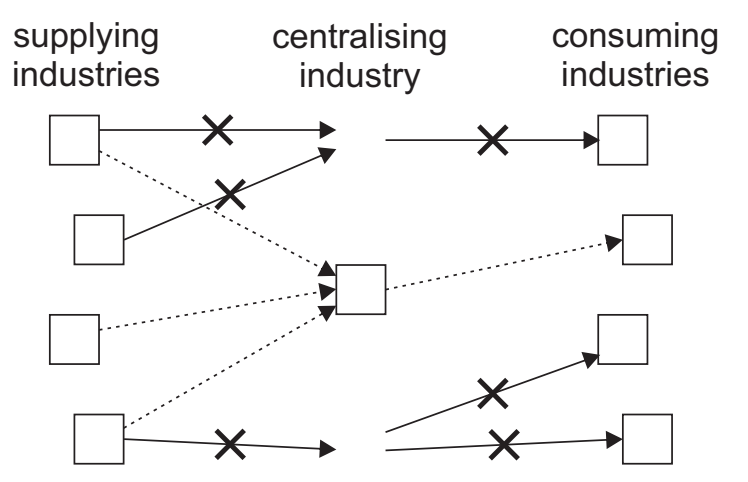

(4) generate corresponding flows supplying centralising consuming industries industry

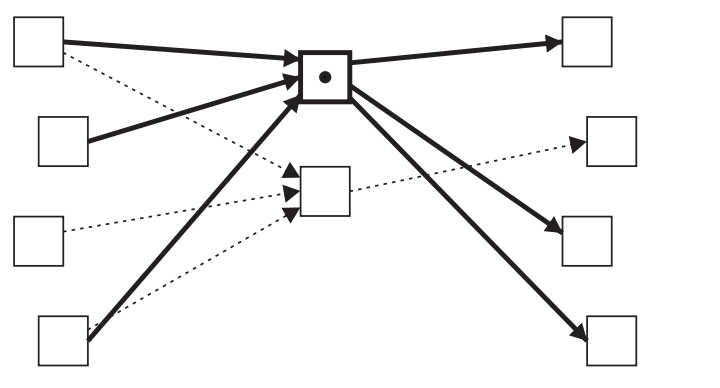

$\rightarrow$ commodity flow $\square$ business establishment

Figure 4.15: Example of the model procedure for simulating centralisation 
volumes have to remain untouched to achieve a ceteris paribus, i.e. all other things being equal or held constant, comparability. In this way, the chosen approach enables tracing any changes in the overall freight transport demand back to the simulated changes in the structure.

Obviously, simulating horizontal changes requires a reassignment of a certain share of output from the focal reference establishments if the overall throughput is assumed to remain stable. Hence, a certain set of establishments needs to be removed from the reference population in order to create space for the creation of a new population of focal establishment that corresponds to the intended characteristics of the horizontal effect assumed.

The question of how many establishments are to be removed limits the degree of freedom for creating a centralised population. Here, one extreme solutions would be to remove only as many establishments as required to fulfil the given number of establishments after the centralisation and assign the free capacity fully to the remaining establishments, which requires additional assumptions. In any case, this solution allows for the smallest range of possible results. In contrast, the largest range of results becomes possible if all establishments of the focal industry are to be removed and the total production is taken over by newly appearing establishments that fulfil the centralisation constraints. Hence, the model provides a parameter to control for the share of establishments to be removed and a second parameter to control how much of the removed capacity gets assigned to the remaining establishments. The impact of different combinations of these parameters are discussed in the sections on the example applications (section 5.1 and section 5.2).

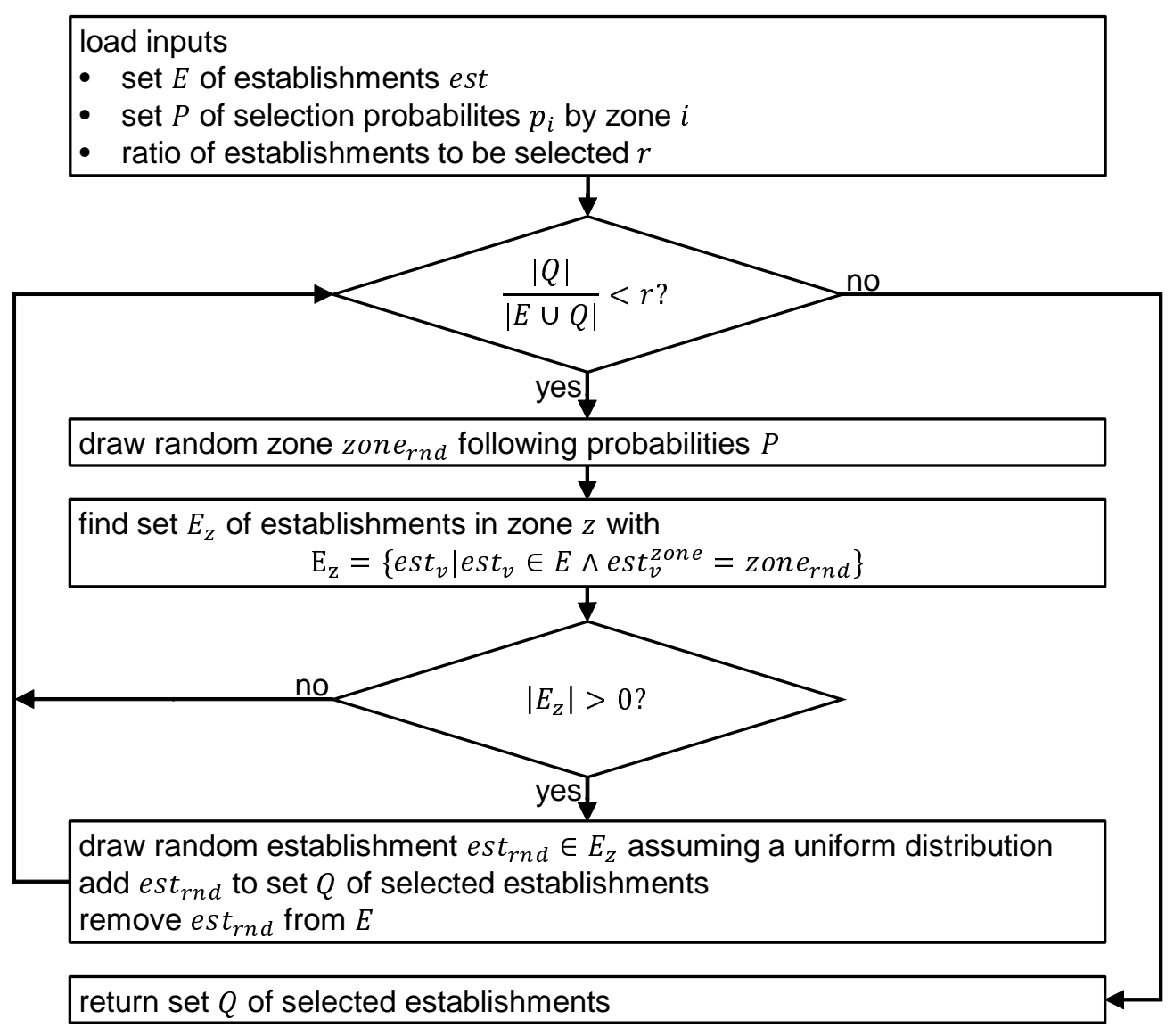

Figure 4.16: Selecting establishments considering selection probabilities by zone

In summary, the purpose of the first part of the procedure is to select and remove focal establishments together with connected commodity flows in order to give way for the subsequent application of structural change by manipulating remaining establishments or creating new ones. 
Hence, the model first selects establishments from the reference population that are going to be removed. As shown in figure 4.16, the implemented establishment selection procedure requires a set of establishments, information on selection probabilities by zone and the share of establishments to be selected. The actual selection procedure is implemented as a two stage stochastic process, which first draws a random zone and in a second step randomly selects an establishment from the previously chosen zone. The selected establishments are stored in a set $Q$, which is returned once the desired ratio $r$ of establishments has been selected.

For the selected establishments, all connected commodity flows are removed and the linked establishments are updated. Establishments that receive commodity flows from removed establishments lose these supply. In consequence, they need to increase their demand for the inputs as described in equations 4.13. On the other hand, establishments that deliver to vanishing establishments need to increase their available supply of produced commodities as denoted in equation 4.14.

$$
\begin{aligned}
\text { est }_{v}^{\text {input }} & =e s t_{v}^{\text {input }}+c f_{k}^{v o l}, \forall c f_{k}: c f_{k}^{\text {orig }}=e s t_{v} \wedge e s t_{v} \in Q \wedge c f_{k}^{\text {dest }}=e s t_{v} \text { with } c=c f_{k}^{\text {com }} \\
\text { est } t_{v}^{\text {out }} & =e s t_{v}^{\text {out }}+c f_{k}^{v o l}, \forall c f_{k}: c f_{k}^{\text {dest }}=e s t_{v} \wedge e s t_{v} \in Q \wedge c f_{k}^{\text {orig }}=e s t_{v}
\end{aligned}
$$

where:

$c f_{k}^{\text {com }}=$ commodity of commodity flow $k$

$c f_{k}^{\text {dest }}=$ destination establishment of commodity flow $k$

$c f_{k}^{\text {orig }}=$ origin establishment of commodity flow $k$

$c f_{k}^{\text {vol }}=$ volume of commodity flow $k$

est $_{v}^{\text {input }_{c}}=$ unassigned but required input volume of commodity $c$ at establishment $v$

est $t_{v}^{\text {out }} \quad=$ unassigned available output volume of at establishment $v$

$Q \quad=$ set of selected establishments

The result of the procedure described above is a population of establishments, which now have unfulfilled demand for inputs and unassigned output capacities. Hence, the next steps in the procedure need to close the gaps incurred.

\section{Generate Appearing Establishments and Commodity Flows for Horizontal Changes}

\section{(Phase 2, Step 2)}

As mentioned in the introduction to this section, there are three approaches to closing the created gap between supply and demand considering effects of horizontal change in the supply chain structures. Each of them is explained in detail in the following.

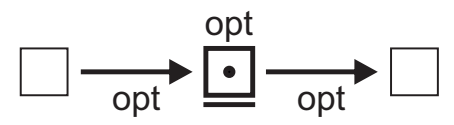

\section{Optimal Location and Optimal Flow Assignment}

Closing the gaps in the supply chains requires two steps: First, manipulating the population of establishments such that the overall production and consumption volumes are met by compensating for the precedingly removed establishments. Again, these manipulations have to be in line with the assumed changes in the overall structure, i.e. the intended number of establishments in the case of simulating a centralisation. For the parallel location and supplier choice in the model, it is assumed that the remaining focal establishments do not change their size.This is motivated by the intention of finding the maximum range of possible outcomes without further assumptions. In consequence, the vanishing establishments' capacity must be fully compensated by establishments newly created 
according to the solution of the optimisation problem. This assumption also significantly reduces complexity of the applied optimisation problem. Possible influences on the result are discussed after presenting the mathematical formulation of the problem. When applying one of the sequential reassignment procedures, the corresponding parameters are considered.

The Location Allocation Problem: The location allocation problem's formulation is based on Geoffrion and Graves (1974) and Sharma and Berry (2007). The latter coins the term single stage capacitated warehouse location problem (SSCWLP) because the formulation has originally been developed for optimising a system of distribution centers for multiple plants and customers in a multi commodity environment. Due to adaptations applied and because the term location allocation problem emphasizes on the parallel choice, the work at hand sticks to this name. Also, it is important to note that the optimisation is not applied on a single firm but on the entirety of all establishments of a certain (sub)sector and neighbouring industries in contrast to the original application area.

Being a mixed linear integer problem, the location allocation problem is NP-hard, which leads to limitations in the feasible problem size due to superpolynomial growth of the required computation time. The pipeline of software used for solving the optimisation problems in the model is described in the section on technical specifics of the model implementation (section 4.6.2).

In the given context, the location allocation problem is used to find a combination of establishments and flows minimising or maximising total freight transport performance according to the restrictions resulting from the overall industrial landscape and an assumed alteration of supply chain structures. The optimisation problem developed from the original SSCWLP works as follows:

$$
\text { minimise } \sum_{c \in C} \sum_{i \in Z} \sum_{j \in Z} f_{i, j}^{c} \cdot d_{i, j}
$$

subject to:

$$
\begin{aligned}
\sum_{j \in Z} f_{i, j}^{c} & =\sup _{i}^{c}, \forall i \in Z, \forall c \in C \backslash\left\{p^{*}\right\} \\
\sum_{i \in Z} f_{i, z}^{c} & =x_{z} \cdot \operatorname{inpFac} c \cdot \sum_{j \in Z} f_{z, j}^{p}, \forall z \in Z, \forall c \in C \backslash\left\{p^{*}\right\}, p=p^{*} \\
\sum_{i \in Z} f_{i, j}^{p} & =\operatorname{dem}_{j}^{p}, \forall j \in Z, p=p^{*} \\
\sum_{z \in Z} x_{z} & =n \\
f_{i, j}^{c} & \in \mathbb{R}^{\geq 0}, \forall i, j \in Z, \forall c \in C \\
\operatorname{inpFac} c & \in \mathbb{R}^{\geq 0}, \forall c \in C \\
n & \in \mathbb{N}^{>0} \\
x_{z} & \in\{0,1\}
\end{aligned}
$$


where:

$Z \quad=$ set of all zones indexed by $i, j$, and $z$

$C=$ set of commodities $c$

$p^{*} \quad=$ the specific commodity $p^{*} \in C$ that is produced by the focal establishments

$d_{i, j} \quad=$ distance from zone $i$ to $j$

$f_{i, j}^{c} \quad=$ amount of commodity $c$ transported from $i$ to $j$

inpFac ${ }^{c}=$ amount of input commodity $c$ required per output unit $p$

$\sup _{i}^{c} \quad=$ supply of commodity $c$ at zone $i$

$\operatorname{dem}_{j}^{p} \quad=$ demand for commodity $p$ at zone $j$

$x_{z} \quad=$ binary variable on opening establishment at $z$

$n \quad=$ total number of facilities to open

The objective function considers overall freight transport performance as calculated by the weighted sum of all occurring commodity flows and relation-specific distances as shown in equation 4.15. The distances are assumed to be identical for all commodities. Flow volumes of commodities $f_{i, j}^{c}$ refer to a certain relation from zone $i$ to $j$ and a certain commodity $c$. The commodity produced by the focal establishments is denoted as $p^{*}$ with $p^{*}$ being a specific element of the set $C$ of all commodities. This is important because certain restrictions only apply to commodity $p^{*}$ or all but $p^{*}$.

Condition 4.16 ensures that the supply for input commodities $\left(c \in C \backslash\left\{p^{*}\right\}\right)$ gets fully assigned. Analogously, the fulfilment of the entire demand for produced commodities $p^{*}$ is formulated in 4.18. The values for supply and demand are determined by the free output capacities and required inputs of the establishments that have lost their trading partners during the removal procedure depicted above aggregated to the level of zones.

The number $n$ of establishments to open is depicted in 4.22. Hence, this variable ensures the restriction coming from the simulated structural change, i.e. the stronger the centralisation, the smaller the number of establishments to open. The applied model is uncapacitated in order to cover the absolute minimum and maximum values regarding freight transport. Capacity constraints for the focal establishments could easily be introduced by a condition of the type $\sum_{j \in Z}$ dem $_{z, j}^{p} \leq \max C a p a c i t y, \forall z \in Z$.

The process of transforming inputs into outputs at establishments is reflected in equation 4.17. It uses an input factor inpFac ${ }^{c}$ that depicts which amount of a certain commodity $c$ is required for producing a unit of output commodity $p^{*}$, which is identical to the technology assumed during the generation of the reference population of establishments and flows (section 4.4.2).

The binary variable $x_{z}$ ensures that only locations that have been assigned an establishment $\left(x_{z}=1\right)$ are allowed to carry out any transformation of inputs into outputs and serve demand. The decision for allowing only one establishment per location does not limit the solution space in any way because of the created establishments being uncapacitated, transformation processes being linear, and all distances being equal for establishments at the same location.

The equations for the location allocation problem do not contain any decision variables for the actual establishments size. They are simply not required because establishment sizes are determined by sums of output product flows per establishment, respectively per zone $\left(\sum_{z \in Z} \sum_{j \in Z} f_{z, j}^{p}\right)$.

The integration of the optimisation model into the overall model procedure, i.e. the preparation of input data, the solving process, and the result extraction, is described in the later section 4.6 .2 because it is identical for all optimisation models applied and not specific to the location allocation problem. 


\section{Sequential Location and Supplier Choice}

In contrast to the previously described location allocation problem, the following procedures use a sequential approach for closing the gaps in the supply networks while simulating structural changes. Hence, in a first step establishments are generated such that they correspond to the assumed change. Afterwards, in a second step, commodity flows between potential suppliers and consumers of commodities are generated using an optimisation problem. Alternatively, the flows are created by the application of a macro flow fitting in a procedure similar to the generation of flows in the first phase of the model.

Preparing the Population of Focal Establishments: The preparation of the focal establishments' population is required in order to compensate for the reduction in total production capacities resulting from the previous removal of a certain share of focal establishments. The compensation can be achieved by resizing the remaining establishments, by generating new establishments, or by a combination of both. Thus, the model includes a parameter describing the share of production to be taken over by resizing remaining establishments.

In the case of remaining establishments taking over a share of production, every remaining establishment gets a share of the production to be redistributed according to its share to the overall remaining focal establishments' output. Based on the new output capacities, the volumes for required input commodities are updated corresponding to calculation of throughput described in section 4.4.2.

The other part of the production is provided by establishments that need to be generated according to the restrictions from the change in supply chain structures, denoted as appearing establishments. The generation of these establishments can be carried out by any of the procedures presented in section 4.4 .2 or combinations thereof, which includes using probability distribution for Monte Carlo simulation, lists of establishment sizes with stochastic location choice, or list of establishments with externally given size and location. The stochastic assignment of these establishments to locations relies on externally provided selection probabilities for every zone $\left(p_{\text {appearing, } i}\right)$. In this way, it is possible to reproduce current spatial employment patterns or to simulate specific spatial layouts representing the impact of certain, e.g. political, measures on location choice and in consequence on freight transport performance. The calculation of throughput relies on the same procedures as depicted in section 4.4.2.

After the population of focal establishments has been prepared, the locations of supply and demand for commodities are known so that the overall model process continues with determining the connecting flows either be applying an optimisation problem, i.e. the transport problem, or a macro flow based procedure.

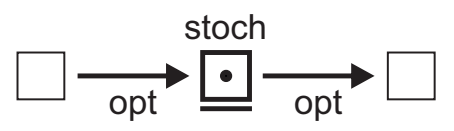

Optimal Supplier Assignment using the Transport Problem: Again, an optimisation problem is used for connecting supply and demand. In the previously described location allocation problem, there is a trade-off between moving closer to supply on the one hand and demand on the other. In contrast, when applying the transport problem, the locations of focal establishments have already been set in the previous step. Therefore, it is possible to apply a separate transport problem for each commodity considered because the assignments of the different commodities do not have any influence on each other.

A first formulation of the transport problem as a linear program has been presented by Hitchcock (1941). From a computational complexity perspective, the transport problem has the favourable characteristic that it can be solved efficiently for most cases, e.g. using the Simplex algorithm. Hence, the approach using the transport problem remains applicable even for scenarios in which the location allocation problem cannot be solved due to too large 
numbers of entities. The mathematical formulation of the transport problem used in the model at hand is described below.

$$
\text { minimise } \sum_{i \in Z} \sum_{j \in J} f_{i, j} \cdot d_{i, j}
$$

subject to:

$$
\begin{array}{r}
\sum_{j \in Z} f_{i, j}=\sup _{i}, \forall i \in Z \\
\sum_{i \in Z} f_{i, j}=\operatorname{dem}_{j}, \forall j \in Z \\
f_{i, j} \in \mathbb{R}^{\geq 0}, \forall i, j \in Z
\end{array}
$$

where:

$$
\begin{array}{ll}
d_{i, j} & =\text { distance from zone } i \text { to zone } j \\
f_{i, j} & =\text { amount of commodity transported from } i \text { to } j \\
\sup _{i} & =\text { supply of commodity available in } i \\
\operatorname{dem}_{j} & =\text { demand for commodity in } j \\
Z \quad & =\text { set of locations } i \text { and } j \text { of supply and demand }
\end{array}
$$

The objective function 4.24 describes that overall transport performance, which is calculated by multiplying flow volume $f_{i, j}$ with the relation specific distance $d_{i, j}$, shall be minimised leading to a lower bound of freight transport performance. For the upper bound, minimisation is replaced with maximisation.

Like the parallel location allocation problem, the transport problem requires a condition that ensures that supply gets fully assigned (equation 4.25) and that the entirety of demand is fulfilled (equation 4.26). The transport problem's integration into the overall model is described in section 4.6.2 together with the location allocation problem.

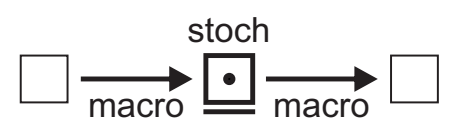

Supplier Choice using Macro Flow Fitting: The application of the previously described optimisation problems allows for determining upper and lower bounds for transport performance resulting from different intensity of assumptions limiting the solution space. Hence, an approach that produces a most probable outcome in between the upper and lower bounds is still required.

The approach presented in the section at hand provides such a solution by extrapolating the current spatial flow patterns for creating commodity flows among the manipulated population of establishments. This task is very similar to the linking of establishments in the initial model phase. Therefore, the procedure applied for the changed population of establishments is identical to the approach already used in the initial generation of inter-establishment flows that is described in section 4.4.3.

In order to reuse the already implemented procedures, focal establishments that have not been removed but been resized are treated specifically. For each of them, a new establishment of the size that just corresponds to the increase in size is created. The new establishments have identical attributes but differ in size as described. In other words, they are treated like extensional establishments of the previous at the same location.

In brief, the manipulations of the focal establishment population lead to changes in the production-consumption matrices of the commodities serving as input or output to the altered establishments. According to equation 4.13 
and 4.14, the available output and required inputs on establishment level have been updated in the previous step of manipulating the reference population. Hence, the volumes to be reassigned for supply and demand by zone can be calculated as denoted in equations 4.28 and 4.29 .

$$
\begin{aligned}
& P_{i}^{c}=\sup _{i}^{c}=\sum_{\left\{e s t_{v} \mid e s t_{v}^{z \text { one }}=i \wedge \text { est }_{v}^{\text {sector }}=c\right\}} e s t_{\nu}^{\text {out }}, \forall i \in Z, \forall c \in C \\
& C_{i}^{c}=\operatorname{dem}_{i}^{c}=\sum_{\text {est } \left._{v} \mid e s t_{v}^{z \text { one }}=i\right\}} e s t_{v}^{i n p_{c}}, \forall i \in Z, \forall c \in C
\end{aligned}
$$

where:

$$
\begin{array}{ll}
P_{i}^{c}=\sup _{i}^{c} & =\text { production volume of commodity } c \text { in zone } i \text { (i.e. supply) } \\
C_{j}^{c}=\text { dem }_{j}^{c} & =\text { consumption volume of commodity } c \text { in zone } j \text { (i.e. demand) } \\
\text { est }_{v} & =\text { establishment object } v \\
\text { est }_{v}^{\text {inp }} & =\text { input of commodity } c \text { for establishment } v \\
\text { est } t_{v}^{\text {out }} & =\text { output of establishment } v \\
\text { est }_{v}^{\text {sector }} & =\text { sector, i.e. output commodity, of establishment } v \\
\text { est }_{v}^{\text {zone }} & =\text { zone of establishment } v
\end{array}
$$

The new row and column totals are fitted to an externally defined set of macro flows. This can either be the same set that was used for the initial fitting or, if required for certain scenarios, a different set.

The subsequent micro flow generation relies on the industry characteristics that have been determined during the initial generation. Hence, flow size distribution parameters remain unchanged. This is motivated by the requirement of ingapplying a ceteris paribus manipulation when simulating changes in the supply chain structure. 


\subsubsection{Simulating Vertical Change}

Vertical changes represent the second category of structural change covered in the developed model. As described above, vertical changes affect business establishments of consecutive stages of an idealised supply chain. In consequence, the simulation procedure for this category of effects must be different from the one applied for horizontal cases. Still, many subroutines can be reused.

The implemented and presented procedure for simulating vertical changes focusses on the case of disintegration of supply chains, often denoted by the less precise term outsourcing (for the exact definition see section 2.4.1). This choice is motivated by the case of vertical disintegration being addressed in multiple approaches from the area of freight transport (Jäcker 1997; Holzapfel and Vahrenkamp 1999; Varschen et al. 2005; McKinnon, Browne, et al. 2012) but so far without the application of suitable spatial quantitative analysis. Especially for the automotive industry, vertical disintegration is a major side effect of applying new production strategies that rely on modular sourcing (Doran 2003; Becker 2006; Göpfert and Grünert 2012).

Modelling vertical effects needs to be rather application specific leading to a low level of transferability. It is not possible to implement a procedure in such an abstract way that it would become possible to simulate vertical disintegration and the antipodal effect of vertical integration with the identical program logic. This is a result of the two effects not being instances of the same logic problem with different parameter values but having a totally different resolution logic with different parameters and different sets of assumptions: Integration implies removing establishments of a certain stage, whilst disintegration requires adding a new stage with new establishments, leading to significantly different roles of the affected surrounding establishments.

In the following, a brief overview of the different steps for simulating vertical disintegration is given before diving into the details of the developed procedures. Like the simulation of horizontal effects, the procedure for vertical change relies on the reference population of establishments and commodity flows generated in the initial model phase (section 4.4).

As shown in figure 4.17, the simulation of change starts with selecting establishments that outsource a certain activity to a new establishment leading to vertical disintegration of the supply chain. Coherently, the selection of establishments that outsource is limited to establishments belonging to the before-hand defined outsourcing sector. In the next step, the selected establishments' output commodity flows are removed from the reference population of flows. Additionally, the outsourcing establishments' technology is altered such that they produce an intermediate commodity. At this stage, the manipulation of the reference population finishes and the model proceeds with stitching together the supply networks under the changed conditions. Hence, new establishments need to appear that transform the new intermediate into the outsourcing industry's final product. Also, the appearing establishments' output needs to be assigned to the establishments of the consuming industries in order to achieve consistency with the reference situation. These appearing establishments form an additional intermediate stage, i.e. tier, in the supply chain. Depending on the selected procedure, the generation of new establishments and flows can be carried out in parallel or in sequence. The parameters considered for simulating vertical disintegrations are summarised in table 4.4 .

\section{Preparing the Reference Population for Vertical Changes (Phase 2, Step 1)}

As described above, the implemented procedures for simulating vertical changes in the supply chain structures exclusively focus on the case of vertical disintegration. Hence, the initial population of establishments and flows needs to manipulated such that previous output flows get rerouted via new establishments. This requires selecting a certain share of establishments that will transfer their last step of production to an external establishment. The 
(1) select outsourcing establishments outsourcing industry

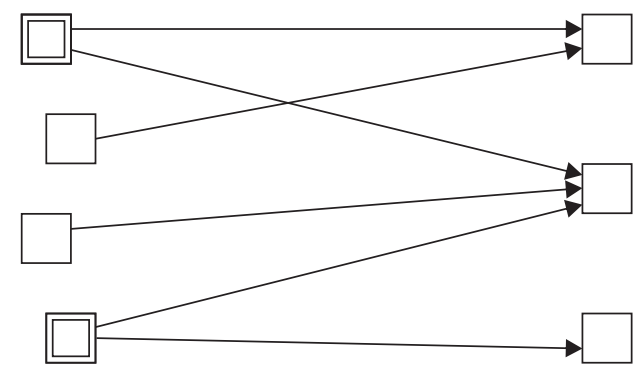

(3) generate appearing establishments outsourcing industry

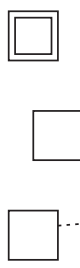

$$
\text { new }
$$
industry

\section{consuming} industries
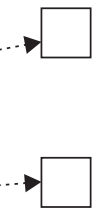

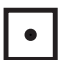

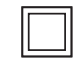

(2) remove corresponding flows

$\begin{array}{cc}\begin{array}{c}\text { outsourcing } \\ \text { industry }\end{array} & \begin{array}{c}\text { consuming } \\ \text { industries }\end{array}\end{array}$

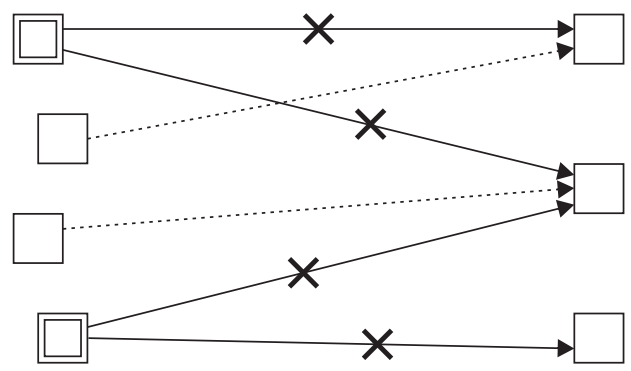

(4) generate corresponding flows outsourcing new industry industry consuming industries

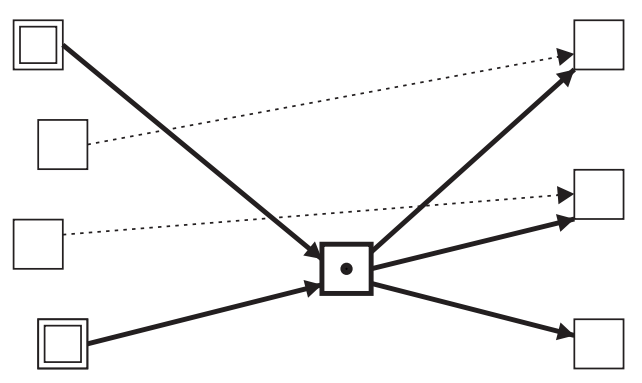

business establishment

Figure 4.17: Example of the model procedure for simulating vertical disintegration 
Table 4.4: Parameters required for the simulation of outsourcing, i.e. for describing the structural change itself (1) and necessary assumptions (2)

\begin{tabular}{|c|c|c|}
\hline \multicolumn{2}{|r|}{ Parameter } & \multirow{2}{*}{$\begin{array}{l}\text { Description } \\
\text { output commodity of the outsourcing sector }\end{array}$} \\
\hline 1 & $p^{*}$ & \\
\hline & outsourcingDegree & $\begin{array}{l}\text { share of establishments from the outsourcing sector that actually do outsource } \\
\text { part of their production }\end{array}$ \\
\hline & $p^{\text {new }}$ & sector that appears as a result of outsourcing \\
\hline & nAppearingEsts & $\begin{array}{l}\text { number of establishments that appear as a result of outsourcing (belonging to } \\
\text { sector } p^{\text {new }} \text { ) }\end{array}$ \\
\hline \multirow[t]{7}{*}{2} & locationChoice & $\begin{array}{l}\text { selects the procedure for locating establishments that appear as a result of } \\
\text { outsourcing, i.e. optimal (using either location allocation problem) or stochastic } \\
\text { (using probabilities for establishments' sizes and locations) }\end{array}$ \\
\hline & assignmentProcedure & $\begin{array}{l}\text { selects the procedure for reassigning commodity flows after applying struc- } \\
\text { tural change, i.e. optimal (using either location allocation problem or transport } \\
\text { problem) or macro (using macro flow fitting) }\end{array}$ \\
\hline & assignmentSense & $\begin{array}{l}\text { selects the sense for assignment, i.e. minimise or maximise transport perfor- } \\
\text { mance (only applicable if assignmentProcedure = optimal) }\end{array}$ \\
\hline & $f_{s}(e m p)$ & $\begin{array}{l}\text { probability density for appearing establishments' sizes, specific to sector } s= \\
p^{\text {new }} \text { (only applicable if locationChoice = stochastic) }\end{array}$ \\
\hline & $P_{i}^{\text {outsource }}$ & $\begin{array}{l}\text { probabilities by zone for selecting the establishments from the reference popu- } \\
\text { lation that do the outsourcing }\end{array}$ \\
\hline & $P_{i}^{\text {locate }}$ & $\begin{array}{l}\text { probabilities by zone for the location of appearing establishments (only appli- } \\
\text { cable if locationChoice = stochastic) }\end{array}$ \\
\hline & $M F_{c}$ & $\begin{array}{l}\text { sets of macro flows for each commodity } c \text { to be used for fitting during reassign- } \\
\text { ment (only applicable if assigmentProcedure = macro) }\end{array}$ \\
\hline
\end{tabular}

selection of establishments for this purpose is achieved by a directed random choice with selection probabilities by zone as described in the section on horizontal changes, especially figure 4.16. For the selected establishments, the output commodity flows are removed such that the origin establishments have unassigned output capacity and the destination establishments have unfulfilled demand for inputs. This corresponds to the logic of equations 4.13 and 4.14 .

In contrast to the case of centralisation, the outsourcing requires a change in the outsourcing establishments' technology. Hence, the selected establishments' technology and sector are updated so that they produce the same volume as before but a different commodity. The new output commodity serves as single input commodity for the newly appearing establishments that carry out the new task of finalising the intermediates into the original product. In other words, the original commodity flows of final product are split into two supply relations, i.e. intermediate product and final product. In summary, the preparation of the initial population returns a set of establishments, which provide unassigned output capacity of a new intermediate commodity, and establishments that have unfulfilled demand for the original output commodity. These need to be connected via newly appearing establishments that carry out the outsourced production step. 


\section{Generate Appearing Establishments and Commodity Flows for Vertical Changes}

(Phase 2, Step 2)

Obviously, the procedures for closing the previously created gaps in the supply networks need to generate establishments, which carry out the outsourced processes, and commodity flows for the required intermediates as well as the final products. Since the overall population of establishments can be divided into suppliers, consumers, and focal establishments, the assignment procedures described in the section on horizontal changes can be reused if suitable data preparations are applied. In other words, focal establishments now take the role of centralised establishments. Hence, the same three different approaches for generating establishments and assigning flows are available. Their application in the case of vertical effects is described below, assuming that the general problem formulations are known or can be looked up in the corresponding sections on horizontal changes (see section 4.5.2).

\section{Optimisation Problems for Modelling Purposes}

Again, optimisation problems are used for finding the minimum and maximum boundaries for freight transport performance under the assumed structural change. The linear optimisation problems are integrated into the overall model procedure as laid out in section 4.6.2.

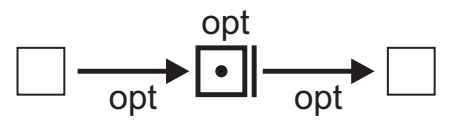

Location Allocation Problem: Without any assumptions on the locations of the establishments appearing as a result of the vertical disintegration, the location allocation problem is used to find establishment locations and commodity flows in parallel. In this way, there is a maximum degree of freedom, which allows for finding the absolute minimum and maximum values of freight transport performance possible under the given spatial distribution of supply of intermediates and demand for final products.

The mathematical formulation of the location allocation problem is identical to the one used in the horizontal case (equations 4.15 to 4.23 , page 96 ) with minor changes in the meaning of certain parameters. When applied for scenarios of vertical disintegration, the parameter $n$ stands for the number of facilities to be created due to the outsourcing of production. In addition, the specific commodity $p^{*}$ denotes the output commodity of the additional production stage, i.e. of the appearing establishments. The new output of the outsourcing establishments is denoted by a sole $c \in C$. All other parameters and variables keep their meaning.

\section{Sequential Location and Supplier Choice}

Increasing the number of assumptions, the location of appearing establishments can be simulated independently from the generation of corresponding commodity flows. The required procedures are laid out below, first explaining the generation of appearing establishments, second describing the two different approaches for creating the corresponding commodity flows.

Preparing the Population of Focal Establishments: In contrast to the simulation of centralisation for which it is possible that remaining establishments take over additional production capacities by resizing, it is excluded that any existing establishment takes over the outsourced activity in the vertical case. This would directly contradict the assumed vertical disintegration. Nevertheless, such a pattern can still be simulated if the generated new establishments are assigned to locations that already have establishments of the outsourcing industry.

The generation of new establishments relies on the procedure depicted in section 4.4.2. The overall output capacity of these new establishments is identical to the output capacity of the outsourcing establishments that now only 
provide an intermediate product. The technology for the newly created establishment is assigned as described in section 4.4.2 as well. Here, it is assumed that the volumes of intermediates required as input is identical to the volume of produced final goods.

The externally provided location probabilities for new establishment allow analyses similar to those sketched in the horizontal case, especially regarding specific politically influenced location patterns or the integration of expert knowledge for certain scenarios.

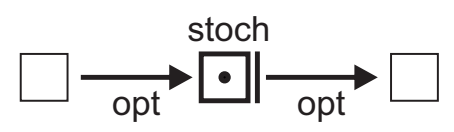

Optimal Supplier Choice using the Transport Problem: After the locations of supply and demand for intermediates and final goods have been determined by the establishment generation, the minimum and maximum freight transport performance for the given spatial layout are determined using the transport problem. The actual mathematical formulation is described in equations 4.24 to 4.27. Due to the independence of inbound and outbound commodity flows, as explained in the section on applying the transport problem in the case of centralisation, the transport problem gets solved separately for every commodity in the case of vertical changes as well.

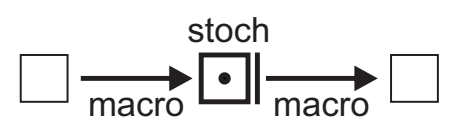

Supplier Choice using Macro Flow Fitting: Alternatively to the application of optimisation models for reassigning commodity flows, the model is capable of extrapolating spatial flow patterns from before the vertical change in the supply structures in order to match the altered locations of supply and demand. For this purpose the procedure introduced as macro flow fitting is used. Here, the given macro flows are fitted to the row and column totals of the PC matrix resulting from the simulated structural change. Like in the horizontal case, the procedure applied for generating the initial population of commodity flows can be reused (section 4.4.3).

\subsection{Technical Specifics of the Implemented Model}

The following sections shed some light on the technical side of the implemented model. After giving an overview of the general architecture, the subsequent sections provide more detailed information on the software applied for solving optimisation problems, the treatment of stochastic procedures in the model, and reporting components.

\subsubsection{Overall Architecture of the Implemented Model}

The overall model is implemented in Java (ORACLE 2016). Running a batch or single simulation requires a single command line call with reference to a configuration file. Subsequently, the called program controls each step including calling external optimisation software and the delivery of detailed and aggregate reports of the results. For some functionality, the model includes third party libraries, which are all available as free and open software. Hence, they can be retrieved from common public Maven repositories ${ }^{1}$. In this way, the traceability and reusability of the developed procedures is ensured. In addition, an interface is implemented, which allows for using commercial software for solving linear and mixed integer problems since the available free and open source software revealed significant shortcomings when solving mixed integer linear problems.

1 Apache Maven (https://maven.apache.org/) is a software project management tool. In the context of this work, it is used for the provision and management of third party libraries by referring to (public) repositories that collect and catalogue (third-party) software libraries (e.g. https://repo1.maven.org/maven2/). 
The configuration file referenced in the program call contains all information on the structural change to be applied and input data to use. For each externally defined aspect the model expects a separate file. The implemented model is capable of reading and writing different file types, e.g. comma separated values for large amounts of numerical data or the Microsoft Excel Format (.xlsx) for certain parameter definitions. The required Excel functionality is provided by the Apache POI library (Apache 2016b).

The overall implementation follows common design patterns like object orientation and encapsulation. The internal organisation of sets of objects heavily relies on data structures like maps, lists and combinations thereof. Using this collection based approach allows for using highly efficient lambda expressions ${ }^{2}$ when manipulating or aggregating the stored objects. Whenever possible, the modelled objects contain direct references to the objects they relate to, e.g. commodity flow objects have direct references to their origin and destination establishment objects. In this way, the data structures reflect the discrete and sparse nature of the analysed supply networks. For the organisation of sorted lists, the implementation partially relies on functionality provided by the GlazedLists library (Wilson et al. 2015). The provided implementation of sorted lists has the advantage that they remain sorted even if elements are manipulated.

In the model, most numerical values are defined as being of the type double. This broadly used data type has a limited precision for storing real numbers due to its binary nature. In consequence, the algorithms for basic mathematical operations contain elements that lead to decreases in the precision of the result depending on the actual values of the operands. Hence, the common commutative properties of addition and multiplication do not hold fully true for calculations with double values. For example, summing the same numbers in different orders leads to slight variations in the result. These effects also occur in the model at hand especially when algorithms iterate over unordered data structures like sets. Throughout the model these fluctuations are neutral to the overall procedure but they become important when it comes to finding feasible solutions to the applied optimisation problems. Besides from impairing the feasibility of optimisation problems, which the model takes care of as described below, these fluctuations do not cause significant deviations in the output.

\subsubsection{Software Pipeline Applied for Preparing and Solving Optimisation Problems}

Setting up and solving the optimisation problems described in the sections above requires certain preparations and a rather advanced pipeline of different software as shown in figure 4.18.

First, the parameter values required for the solving the optimisation problem need to be determined, especially values of supply, demand, and the cost matrix. Therefore, supply and demand are aggregated to the level of zones based on the current population of business establishment. In this way, problem size is significantly reduced without influencing the model result because the applied distance matrix only has a resolution of zones. Hence, aggregating supply and demand per zone does not lead to changes in the freight transport performance of the solution. The optimisation model requires an exact equality of supply and demand volumes. The overall model procedure may lead to very small deviations for reasons described above. In order to perfectly balance supply and demand, an additional location is introduced ensuring feasibility for the problem at hand. The corresponding elements in the cost matrix are set so that they are significantly larger than any other element in the matrix when minimising freight transport performance or significantly smaller than the other elements in cases of maximisation. Setting this kind of penalty costs ensures that only residual amounts get assigned to the balancing locations. Later, when the found solution is parsed back into the supply chain model, these flows are ignored.

2 Lambda expressions are anonymous functions allowing for the in-place definition of procedures that are capable of using parallelisation functionality provided by the Java framework 
control file

(Python)

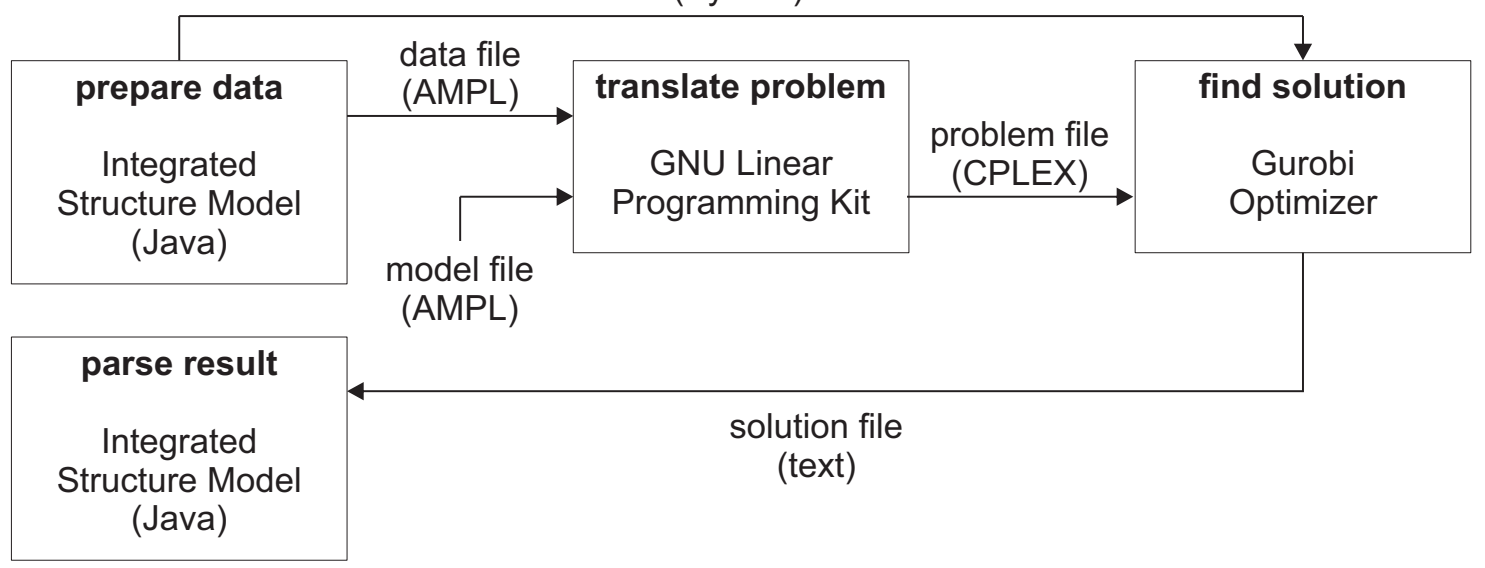

Figure 4.18: Implemented control and data flow for solving optimisation problems

The determined parameter values are written into a data file according to AMPL (A Mathematical Programming Language), which is consistent with GNU MathProg in large parts. The problem statement is formulated in AMPL as well but stored in a separate model file. Together they are fed into the GNU Linear Programming Kit (GNU 2012), which combines the input information and translates the given problem with its parameters into a single problem file according to the IBM CPLEX (IBM 2016) definitions for linear problems.

The produced problem file is fed into the solver provided by the commercial Gurobi Optimizer (Gurobi 2016) software. The actual solving process is controlled by a Python script, which is generated and executed by the developed Java model. Among others, the script contains information on the optimisation sense, computation time limits, and the desired optimality gap. The two latter parameters are especially relevant for solving the mixed integer linear location allocation problem. The applied solution procedure first finds an optimal solution whilst ignoring the integer constraints. In a second, and more time consuming phase, the algorithm searches for a solution that considers the integer constraint starting on the first phase's result. The given time limit defines how long this search is allowed to take. The optimality gap imposes a stop criterion regarding the relative deviation of the current solution compared to the relaxed solution. The found optimal solution is fed back into the Java model, which parses the result and then continues with the further model process.

The chosen pipeline of different software offers some major advantages: In cases where no commercial solver is available, the overall model remains functional since the GNU Linear Programming Kit can be used as a fallback solution with significantly less performance. However, this leads to infeasibility for the problem instances used in the application scenarios described later. In the opposite case, if a more capable software becomes available the translated problem file can easily be fed into any other solver. Aside from computational aspects, storing the linear problem formulations in separate files instead of integrating them directly into the Java source code increases transparency as well as maintainability.

\subsubsection{Application of Simulation Batches for Assessing the Influences of Stochastic Elements}

The model contains several algorithms with stochastic elements as described throughout the sections on the initial generation and manipulation of establishments. First, these random based procedures are used in order to avoid a bias induced by the iteration order of model entities. In addition, stochastic procedures are applied for the disaggregation of aggregate statistics. Last but not least, directed random driven selection procedures are applied 
when certain shares of the overall population need to be selected without any further specifications of selection criteria, e.g. when selecting establishments for removal in the first step of simulating horizontal changes.

In order to compensate for influences on the result induced by stochastic processes, the model control flow allows for running iterative loops of the same step with identical input data but with changing sequences of random numbers. For example for the simulation of centralisation, the processes for the removal of establishments is isolated for repetition purposes. The consequent step of recreating establishments is encapsulated as well. Hence, the model carries out a predefined number of combinations of removal and recreation. The resulting output is stored in a detailed report for every single run and a summarising report is generated aggregating the outcome of the batch's single runs.

\subsubsection{Reporting and Visualisation Components}

For logging the overall simulation process, the model uses the Apache Log $4 \mathrm{j} 2$ framework (Apache 2016a). Each relevant population of commodity flows as well as establishments is also saved to comma separated files in order to allow for traceability of results. In addition, Geovisualisations of the model results are created using GeoTools The Open Source Java GIS Toolkit (Open Source Geospatial Foundation 2016) and embedded into an HTML report for each simulation run. This report also contains additional visualisations like histograms and Lorenz curve charts, which are generated by calls to custom gnuplot scripts (Williams et al. 2015).

\subsection{Model Validation and Verification}

The model presented in this chapter clearly belongs to the category of static stochastic simulations since it imitates static states of a real-world system by applying stochastic elements in the simulation process. In consequence, the recommendations of Law and Kelton (1991) are pertinent. In their comprehensive handbook of modelling and simulation, they especially emphasize the tasks of verification and validation as being of crucial importance at different stages of the model development and application as illustrated in figure 4.19. In this context, validation asks whether the model shows the same characteristic behaviour as the actual system while verification asks whether the programmed software is identical to the underlying conceptual model. In the following, it is discussed how the accompanying challenges as identified by Law and Kelton (1991, pp. 299-307) are addressed for the model at hand.

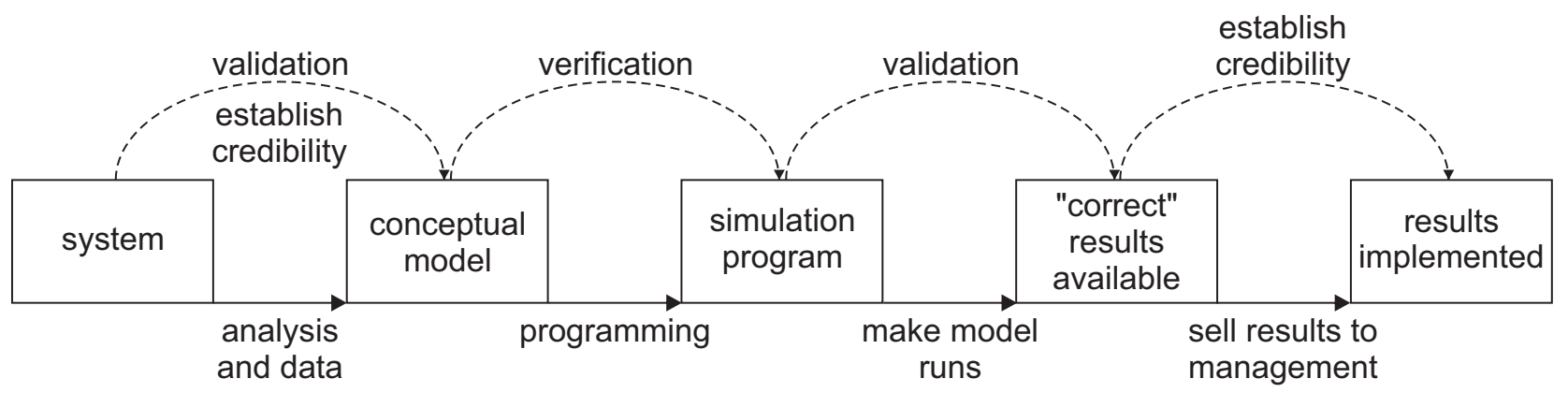

Figure 4.19: Validation as part of the model development and application (Law and Kelton 1991, p. 299)

In a first step of the model development and application process, it is required to translate the system of interest into a conceptual model that is suitable for the modelling purpose, i.e. the question(s) to be answered by the overall simulation study, and that adequately describes elements, relations, and behaviour of the original system. 
For the presented model, this step has been carried out using a literature based system analysis as documented in section 2.5 and section 3.3. In addition, data from the presented applications has been used as well. The conceptual model's validation then has been ensured by presentations and discussions with practitioners from the food industry and scientists with a freight transport background.

The next challenge lies in the verification of the software that has been programmed according to the conceptual model's specifications. Here, consistency has been ensured by applying an agile development approach together with continuous testing of any incrementally added functionality throughout the development process. In this way, each version of the model's components has been tested for its own functionality as well as its interaction with the overall model framework.

After the programming work has been finished, the overall model needs to be tested in order to validate its results. In the case at hand, this is achieved by a partial validation based on the results of the model application results as described in section 5.1.7 (page 129) for a centralisation and in section 5.2.4 (page 157) for the case of vertical disintegration. Here, partial validation means, that the results are checked for consistency and plausibility regarding expected effects, sensitivities, and fluctuations across repeated model runs.

\subsection{Conclusions Regarding Information Needs, Model Design, and Literature Findings}

The examples of change in supply chain structures given in chapter 2 illustrate, which information is required for estimating the corresponding impact on freight transport (see especially section 2.4.2, page 17). The section below discusses the identified challenges, especially how they are addressed in literature, and how this is reflected in the developed model.

\section{Model Phase 1: Before Change}

The before change population of establishments and commodity flows is generated due to a lack of data on this level of disaggregation. Hence, the challenge for the model's first phase is finding a realistic micro state that is consistent with the existing aggregate statistics. This is achieved by determining suitable attributes regarding the two main model elements of business establishments and commodity flows.

\section{Establishments}

The model is capable of using given lists of establishments with full information on location, input, and output volumes, e.g. from commercial data providers. According to Moeckel (2007, p. 61) this is especially helpful in cases with highly specific patterns. Alternatively, the model provides a stochastic generation procedure that combines a Monte Carlo based approach for simulating establishment sizes with a bin packing heuristic for assigning the generated establishments to space. This combination of methods, which uses statistics on establishment sizes and spatial distribution of employment, is also used in Liedtke (2006) and Friedrich (2010). The vertical linkage within supply chains, i.e. volumes of input and output commodities, is based on aggregate input-output matrices as proposed by Leontief (1936).

\section{Commodity Flows}

The challenge of determining commodity flows between the previously generated establishments lies in finding realistic combinations of origin, destination, and transported volume. Here, the model uses a new procedure that relies on given macro flows serving as constraints on the aggregate flow volumes per spatial relation. This 
procedure requires a fitting of the given matrices to the current case, which is achieved using the method of Furness (1962). The number of commodity flows and their sizes is mainly determined by constraints on establishment level considering a Pareto distribution for incoming commodity flows (Friedrich 2010) together with parameters describing the connectedness between sectors similar to the approach of Liedtke (2006).

\section{Model Phase 2: After Change}

The model's second phase aims at finding the potential impact on freight transport demand in the case of change in the supply chain structures from the first phase. Hence, this part of the model cannot rely on reproducing statistical data but needs to estimate possible or potential solution range based on assumptions. Potentially, part of the assumptions can be replaced by endogenous modelling of behaviour at the price of increased model complexity. The paragraphs below briefly summarise how the model deals with the according challenges and how this is motivated by literature, especially regarding the extremely high degrees of freedom.

\section{Establishments}

The simulation of change immanently requires information on locations and sizes of establishments that appear or that exist and are to be adapted. Literature on the horizontal structure of industries (Dasgupta and Stiglitz 1980; Baumol 1982), shows that it is not possible to find a unique solution regarding establishment sizes. In addition, the results from the new economic geography (Krugman 1991b; Forslid et al. 2002) illustrate that the location of economic activity tends to show a strong path dependency, which is driven by small random events. In consequence, there is a broad range of different stable location patterns. However, it is impossible to decide a priori, which of the possible spatial patterns will appear. Nevertheless, various factors influencing location choice on micro level can be identified (MacCarthy and Atthirawong 2003; Mattfeld 2013; Nehm et al. 2013).

For coping with these information needs on establishment level, the model heavily relies on assumptions and stochastic elements instead of additional endogenous modelling. The model provides a first option for determining sizes and locations of establishments when simulating change by using externally given lists of establishments. The second option consists on a combining assumptions, e.g. spatial location probabilities or size distributions, together with stochastic simulation. Here, a repeated simulation under identical assumptions accounts for the inherent ambiguity by identifying reasonable solution ranges. The option of applying spatial probabilities for selecting existing establishments as well as for locating appearing establishments allows for considering single or combinations of factors relevant for location choice.

\section{Commodity Flows}

Spatial flow patterns can be estimated descriptively using trade models (Ohlin 1933; Arrow and Debreu 1954; Burgess, Chen, et al. 2008) or normatively using optimisation models (Hitchcock 1941; Koopmans 1949). For the latter, it is also possible to consider location choice within the optimisation (Geoffrion and Graves 1974; Sharma and Berry 2007).

The developed model uses two completely different approaches for estimating spatial flows patterns under assumed change in the supply chain structures. For finding the absolute possible range, optimisation models are applied that minimise or maximise freight transport. Using no further assumptions, it is possible to determine establishment locations, sizes, and the assignment of flows in parallel, which corresponds to the strongest impact possible regarding freight transport performance. The model is also capable of finding minimum or maximum solution for flow between establishments with given sizes and locations. The increased number of assumptions leads to a more narrow solution range compared to the parallel optimisation. In addition, the model provides the option 
to apply an extrapolation of current macro flow patterns, i.e. a matrix fitting procedure based on Furness (1962), to estimate the spatial flows under structural change. This procedure is selected as a simplified representative for the application of more sophisticated trade models.

In summary, the model deals with the uncertainties regarding the simulation of change by the application of different degrees of assumptions, repeated stochastic simulation, and optimisation models for finding absolute solution ranges under the given assumptions. 


\section{Model Application: Supply Chain Structure Effects in the German Poultry and Automotive Industry}

This chapter contains two example applications of the model developed in the previous chapters. In order to cover the different types of structural change that can occur in supply chains, two distinct examples have been selected for application: The centralisation of the poultry supply chain, i.e. farming, slaughtering, and processing, serves as an example of horizontal change. In contrast, the outsourcing of production in the relation of tier-1 supplier and car plants is used as an example of vertical change. Both examples are based on data from the actual industries as they exist in Germany.

\subsection{Centralisation of Germany Poultry Slaughtering}

As described, this first section focusses on analysing the interrelation of centralisation effects within the supply chains around poultry slaughtering in Germany and freight transport demand. It is organised as follows: Since the poultry supply chain is rather specific but shares characteristics with other supply chains of the food industry, it is worthwhile to start with a brief overview of the overall food sector in Germany before the analysis dives into the details of the poultry supply chains as required for the actual example application. Next, an overview of data sources used as input data for the model is given. Afterwards, the scenario constructed for the model application is described and first insights are discussed in order to foster the understanding of the modelled system's dynamics. In the next step, the developed model is validated based on detailed results for a specific case of centralisation. Using the insights gained so far, measures that could be applied in the context of centralisation in order to positively influence the change freight transport demand are developed and their impact is analysed. The section closes with conclusions from the model application regarding centralisation in the German poultry supply chain.

\subsubsection{Overview of the German Food Industry}

The reliable supply with food is essential to the well-being of any population. In developed economies, this crucial task is fulfilled by a complex system of private actors within a strict legal frame. In most cases, the private actors involved are organised in multi-echelon supply chains. These start with primary activities like crop farming or animal breeding. The hereby gained raw products are partially already consumable and a certain share is provided directly to the end customers. A larger proportion enters into manufacturing and value-adding processes carried out by specialised economic actors.

Following this perception, the food industry can be further divided into subsystems, each having specialised supply chains for producing a certain good. The sectoral interrelation of food products is depicted in figure 5.1. The figure shows two major characteristics of the food industry: First, food products follow a stepwise refinement process from the production of raw materials in the outer areas, which are then being propagated along intermediate types of goods to the end consumer. The supply chain for poultry, which will be in the centre of the analysis in the following sections, is highlighted. Second, the figure emphasizes the interdependence across supply chains for 
different products due to the overlap of raw materials and intermediates. In consequence, changes in the structure of one of these supply chains also have an effect on the indirectly linked chains, e.g. in terms of freight transport or supply risks.

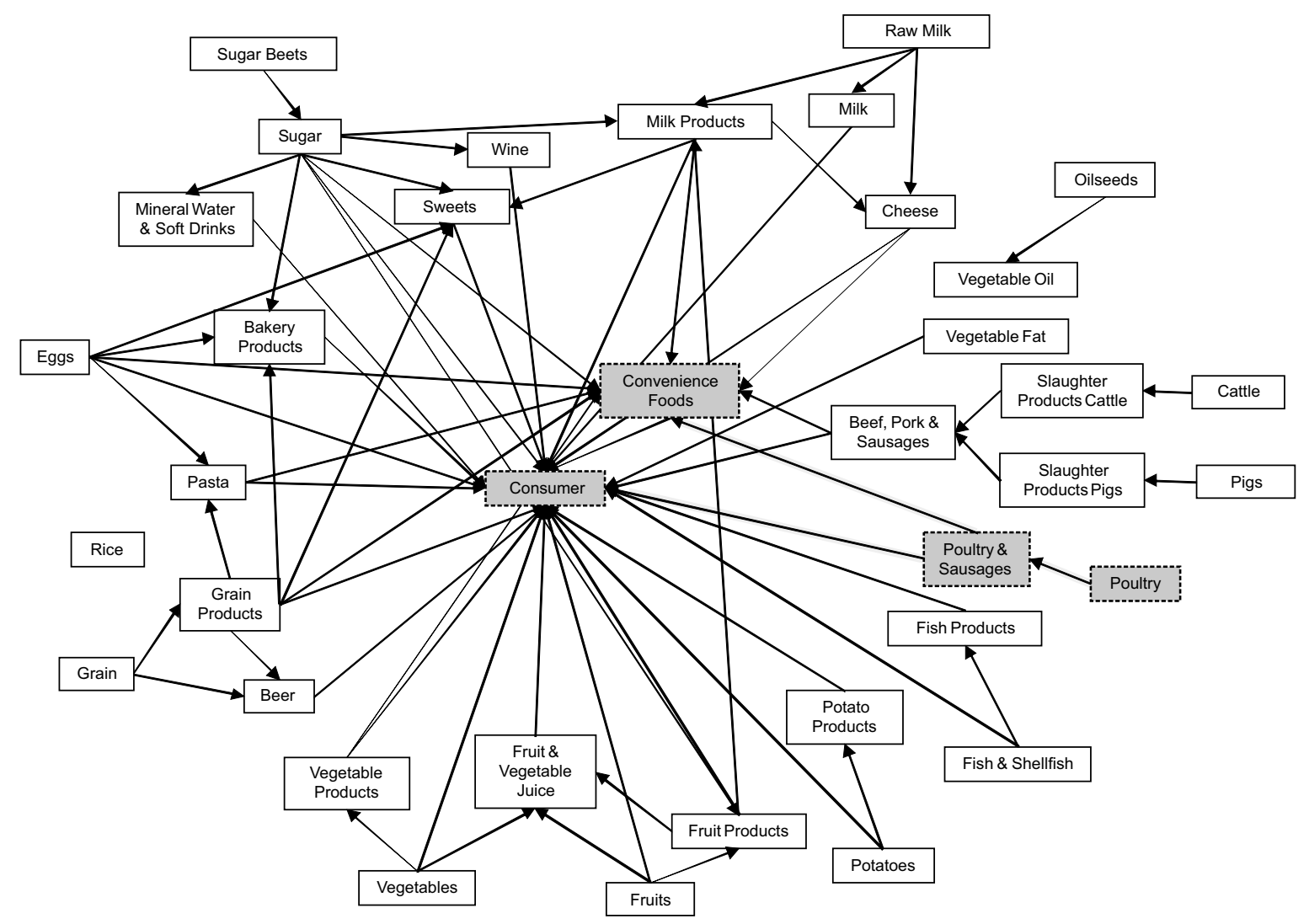

Figure 5.1: Sectoral supply-consumption chains for food products as developed in the SEAK project (Balster et al. 2016). The stages of the poultry supply chain are highlighted.

Looking at the number of different entities to be considered in these areas, Hemmerling and Pascher (2012) list a number of 292,500 establishments for the agricultural supply in Germany in 2011 with $72 \%$ thereof also being active in livestock farming. For the subsequent stage in the supply chain, which is food processing, table 5.1 gives an impression of the composition of the overall 37,564 business establishments and their size distribution by the number of employees. The data show that across all branches a large proportion of business establishments belong into the category of smallest establishments having only one to nine employees. In this regard, Hemmerling and Pascher (2012) describe an ongoing trend of consolidation leading to the emergence of fewer but larger establishments.

Once, the products have reached a consumer-ready processing grade, they are fed into specialised distribution systems. The food retailing companies have established a dense network of points-of-sale, providing their customers with a wide range of differentiated products. As a result, the retailers make use of warehouses close to the final demand for bundling, buffering and commissioning purposes. The inbound logistics into the warehouses is usually organized and carried out by logistics service providers. The outbound logistics from the warehouse to the pointsof-sale is optimized by the retailer since its efficiency is a significant competitive factor in this sector. For a detailed model of these logistics system see Friedrich (2010).

After giving an overview on the overall food industry, the following paragraphs continue with its specifics and first insights related to freight transport demand. 
Table 5.1: Business establishments (count and number of employees) of the German food industry by produced goods and size category. Data from Statistisches Bundesamt (2014a).

\begin{tabular}{|c|c|c|c|c|c|c|c|c|c|c|}
\hline \multirow[b]{4}{*}{ industry (WZ 2008) } & \multicolumn{10}{|c|}{ establishments } \\
\hline & \multirow{2}{*}{\multicolumn{2}{|c|}{ total }} & \multicolumn{8}{|c|}{ thereof with employees } \\
\hline & & & \multicolumn{2}{|c|}{$0-9$} & \multicolumn{2}{|c|}{$10-49$} & \multicolumn{2}{|c|}{$50-249$} & \multicolumn{2}{|c|}{$>=250$} \\
\hline & count & empl. & count & empl. & count & empl. & count & empl. & count & empl. \\
\hline $\begin{array}{l}10.1 \text { slaughtering and } \\
\text { meat processing }\end{array}$ & 12,882 & 151,182 & 9,914 & 27,689 & 2,430 & 45,541 & 469 & 48,202 & 69 & 29,750 \\
\hline 10.2 fish processing & 250 & 7,048 & 168 & 368 & 59 & 1,468 & 15 & 1,775 & 8 & 3,437 \\
\hline $\begin{array}{l}10.3 \text { fruit and veg- } \\
\text { etable process- } \\
\text { ing }\end{array}$ & 845 & 28,496 & 534 & 1,027 & 174 & 4,243 & 109 & 11,675 & 28 & 11,551 \\
\hline $\begin{array}{l}10.4 \text { prod. of oils and } \\
\text { fats }\end{array}$ & 197 & 5,359 & 148 & 186 & 17 & 458 & 28 & 3,196 & 4 & 1,519 \\
\hline 10.5 milk processing & 831 & 37,613 & 585 & 642 & 94 & 2,404 & 109 & 13,536 & 43 & 21,031 \\
\hline $\begin{array}{l}10.6 \text { mills, prod. of } \\
\text { starch }\end{array}$ & 788 & 13,230 & 622 & 1,100 & 101 & 2,092 & 56 & 5,990 & 9 & 4,048 \\
\hline $\begin{array}{l}10.7 \text { prod. of bak- } \\
\text { ery products and } \\
\text { pasta }\end{array}$ & 16,189 & 265,568 & 11,498 & 33,757 & 3,664 & 74,551 & 875 & 89,860 & 152 & 67,400 \\
\hline $\begin{array}{l}10.8 \text { prod. of other } \\
\text { food products }\end{array}$ & 2,057 & 96,073 & 1,354 & 2,594 & 337 & 7,826 & 270 & 31,304 & 96 & 54,349 \\
\hline $\begin{array}{l}10.9 \text { prod. of ani- } \\
\text { malfeed }\end{array}$ & 801 & 15,050 & 556 & 837 & 174 & 4,046 & 63 & 6,133 & 8 & 4,034 \\
\hline $\begin{array}{l}11.0 \text { prod. of bever- } \\
\text { ages }\end{array}$ & 2,724 & 61,009 & 1,964 & 2,824 & 481 & 11,090 & 226 & 22,293 & 53 & 24,802 \\
\hline total & 37,564 & 680,628 & 27,343 & 71,024 & 7,531 & 153,719 & 2,220 & 233,964 & 470 & 221,921 \\
\hline
\end{tabular}

As described in Ottemöller and Friedrich (2016), the high number of products and points of sale in the food sector leads to a large number of commodity flows with low volumes, especially in the outbound distribution to the point of sale. Here, the shipment sizes between two locations are usually smaller than or at best equal to a full truckload. Perishability and heterogeneity of food products favour smaller but more frequent shipments for intermediate products as well. As a result, intermediate and consumer-ready food commodities have a high affinity to the mode of road transport, which makes the food sector almost entirely reliant on road transport.

Between the different stages of processing, freight transport is required for conveying intermediates towards the subsequent processing plants. The strong dependence on road transport is also reflected in transport statistics. According to BMVBS (2015, p. 257), in 2014, the transport of agricultural products contributed 7\% to the overall road freight transport performance in Germany (285.9 billion tkm/a in total). The transport of consumer goods for short-term usage, which includes not only food products but also textiles, clothing, leather and leather products, and paper and print products, contributed $24 \%$. The modal split shows a share of $69 \%$ for road transport of agricultural products and 89\% for consumer goods, both calculated on the basis of freight transport performance (BMVBS 2015, p. 271).

Even if the food industry follows national peculiarities, the exchange of intermediates and final products with international partners is of growing importance. The composition of imports and exports is strongly driven by different competitive advantages due to geographic, e.g. climatic, conditions or path dependent specialisations. Regarding food products, the largest net imports for Germany are oilseeds, fruits, vegetables, wine, and fish. While Germany's largest net exports are potatoes, mineral water and soft drinks, beer, and sugar (values from Statistisches Bundesamt 2016a). 
Like other industries, the food sector and its structure are not static but continuously evolving. In the area of logistics, especially warehousing, trends like digitalisation and automation change the framing conditions on operational as well as strategic level. Additional driving forces lie in the internationalisation of trade in intermediates and final goods, e.g. by the formation of an internal market in the European Union or trade agreements with other nations. All of these trends are reflected in changes in the supply chain structure of the food industry.

In this regard, Hemmerling and Pascher (2012, pp. 93-117) analyse the size distribution of business establishments for different branches of farming in the European Union and Germany. Their study shows that there is a significant dominance of large establishments for most branches leading to a large concentration for many European countries. The according numbers for Germany show a similar picture but with a slightly less strong concentration compared to other European states. This leaves space for a further concentration within certain branches in Germany. According to Hemmerling and Pascher (2012), such a development is supported by increasing needs for exploiting economies of scale due to international competition as a result of liberalised trade. The interdependence of economies of scale and the horizontal industry structure is also addressed in section 2.5.4 (page 27).

Tracing the development of establishment sizes in statistical data is difficult due to multiple changes in the classification of economic activity on the one hand and changes in the categorisation of establishment sizes on the other. For these reasons, it is referred to a data excerpt provided to the author by the German federal statistics office. This dataset covers the time span from 1977 to 1994. The industry categorisation refers to SYPRO codes (Systematik im Produzierenden Gewerbe), a precursor to the newer system of the current WZ 2008 (Klassifikation der Wirtschaftszweige), which today especially aims at the harmonisation of classifications across the European Union.

Figure 5.2 shows the development of the total number of establishments in the food industry (thick line, right vertical axes) and the development of establishment numbers in selected subcategories (left vertical axes). First of all, the overall number of establishments in the food industry significantly decreases in the depicted period. The sharp increase from 1988 to 1989 is induced by the German reunification. The overall trend of decreasing establishment numbers is reflected in most of the shown subcategories, e.g. in slaughtering or in the meat industry. Nevertheless, there are exceptions to the rule, like shown for the production of baked goods, which shows a total increase in the establishment numbers for the observed time span.

The overall decrease in the number of establishments could simply be the result of an overall shrinking of the food industry. In fact, the data clearly contradicts this hypotheses as it shows a continuous growth in the industry's turnover by $73 \%$ in the time from 1977 to 1994 . Hence, it is worthwhile to take a look into the development of average establishment sizes as illustrated in figure 5.3. Here, most of the industrial subcategories show an increase in the average establishment size, which can also be observed for the entire food industry. Again, there are exception to the rule like the production of long-life baked products, which reveals a decrease in the average establishments size. Also, the available data's focus on employment as a proxy for establishment size do not allow for direct analysis of changes in productivity, e.g. caused by technological progress.

In summary, the decreasing number of establishments together with the increasing average establishment size and growth in overall turnover hint towards ongoing centralisation within many subcategories of the food industry. In the following, the case of the poultry supply chain, consisting of poultry farming, slaughtering, and processing, is presented in detail in order to analyse how the identified trend towards centralisation influences freight transport demand. 


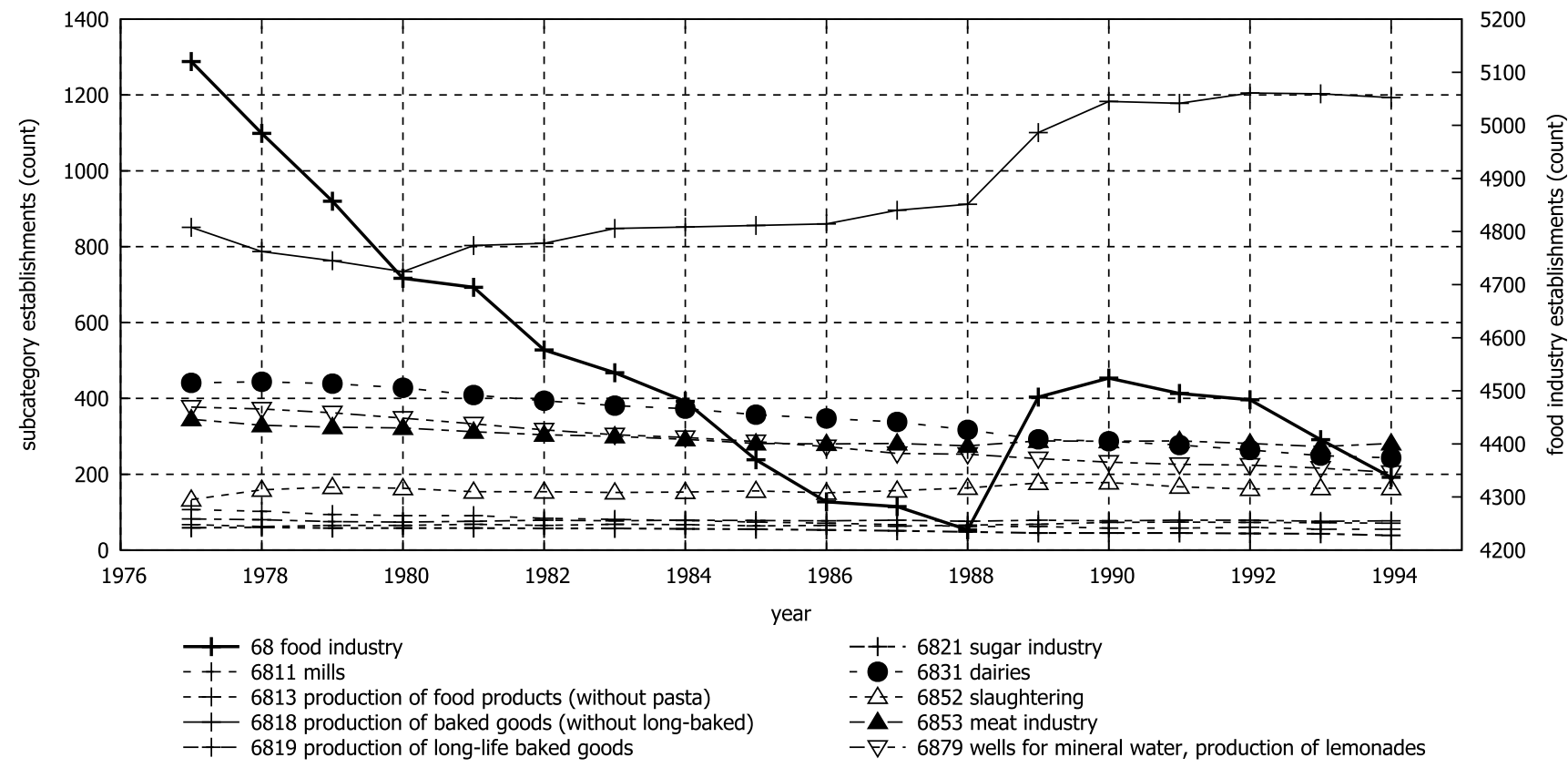

Figure 5.2: Development of average establishment sizes in the German food industry and selected subcategories thereof denoted by their SYPRO codes. Data provided by custom report from German Federal Statistical Office (Statistisches Bundesamt). Time range selected because of multiple changes in underlying categorisations in more recent years.

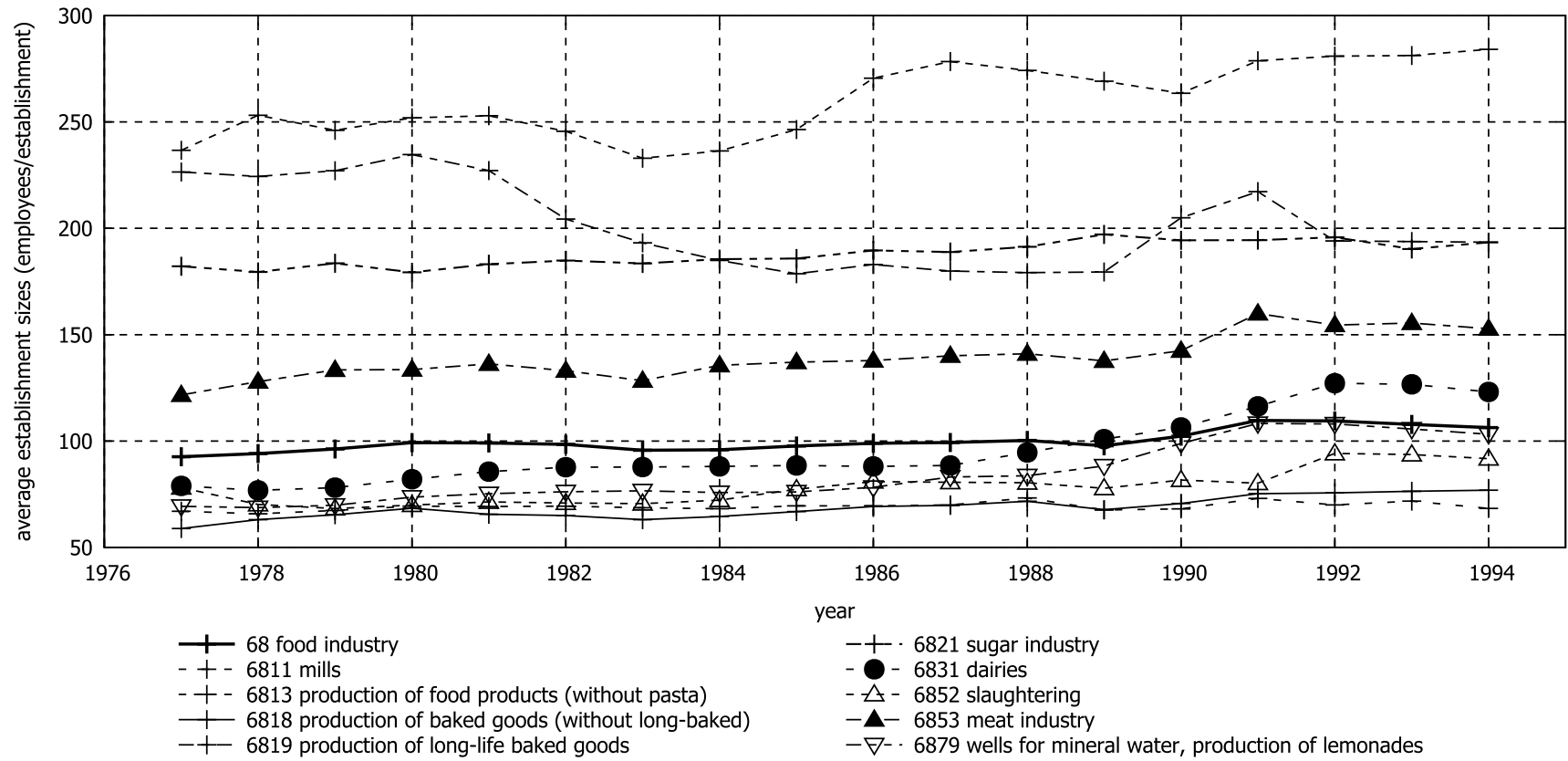

Figure 5.3: Development of the number of establishments in the German food industry and selected subcategories thereof denoted by their SYPRO codes. Data provided by custom report from German Federal Statistical Office (Statistisches Bundesamt). Time range selected because of multiple changes in underlying categorisations in more recent years. 


\subsubsection{System Analysis of Poultry Supply Chains in Germany}

The above analysis of the food industry has identified a certain trend of centralisation in this very sector and shown that it is especially visible in the supply chains of slaughtering. In order to create a manageable scope of analysis that also fulfils the requirement of data availability, the supply chain of poultry production in Germany is selected for an example application of the developed model. The centralisation is assumed to take place in the production stage of slaughtering. In other words, poultry slaughtering is considered the focal industry for the following application.

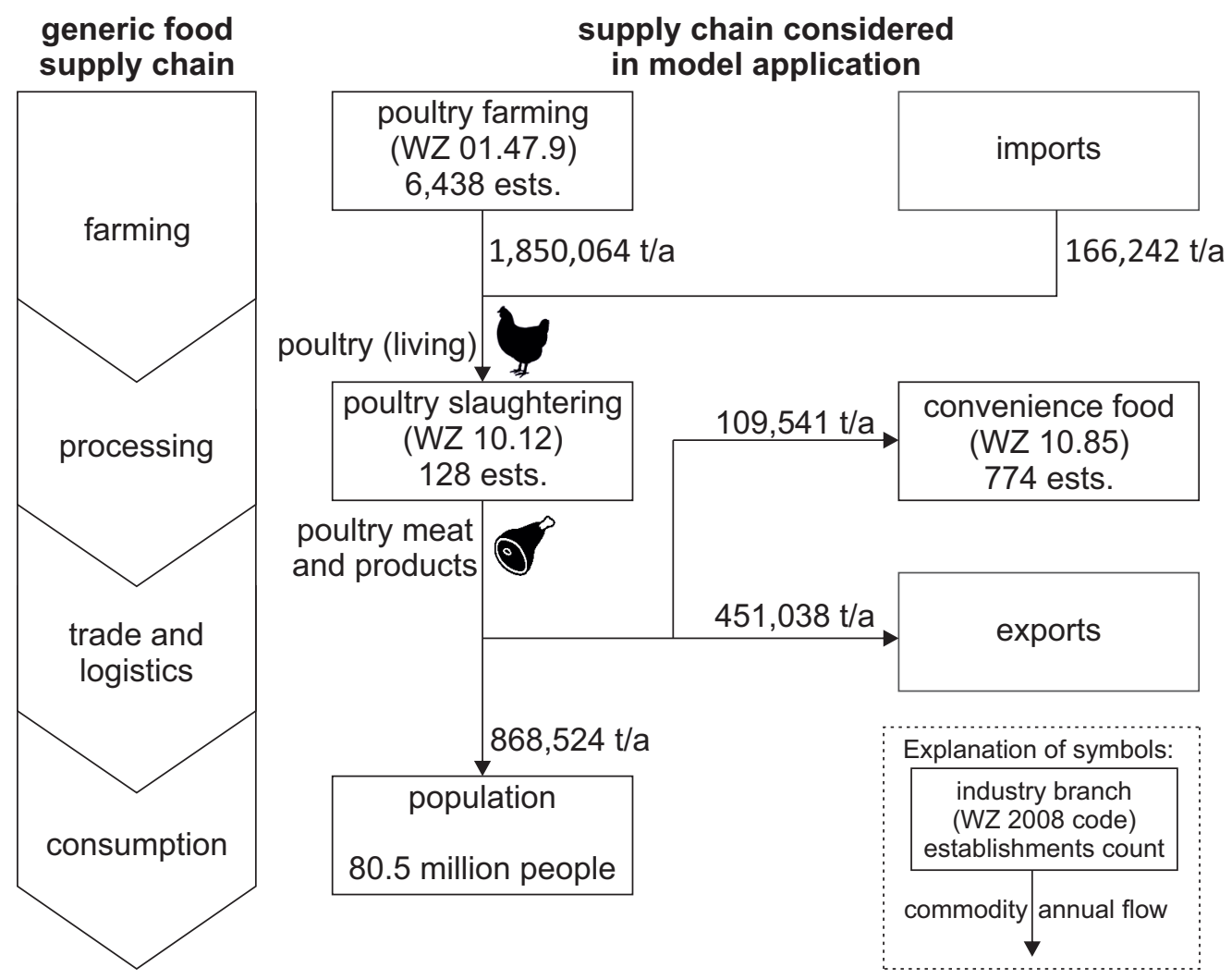

Figure 5.4: Poultry supply chain considered in model application. Industry classifications according to WZ 2008 (Klassifikation der Wirtschaftszweige), total flow volumes adapted from Balster et al. (2016).

In this context, poultry is mainly the aggregate of chicken and turkey. Hence, whenever required, input data is harmonised to match this aggregation. The corresponding poultry supply chain is illustrated in figure 5.4. As shown, the scope of analysis begins with the farming of poultry. The earlier stage of hatching is left out. This is motivated by the fact that for the intended way of analysis only the freight flows among the industries directly connected to the focal stage are affected by changes in the supply chain structure. This focal stage, i.e. poultry slaughtering, consumes inputs from the farming of poultry and delivers its products to the industry producing convenience foods and to the population. Regarding the suppliers, a share of roughly $8 \%$ is provided by non-domestic suppliers, i.e. imports. Analogously, part of the focal industry's output, approximately $32 \%$, gets exported. In total, poultry slaughtering produces meat with a weight of 1.4 million t/a from an annual supply of living animals of about 2.0 million $\mathrm{t} / \mathrm{a}$.

So far, the organisational and aggregate flow structure of the poultry supply chain have been described. As discussed in the previous chapters, the corresponding spatial layout is also of major importance. Thus, the spatial structure of the considered domestic industries is shown in the maps of figure 5.5 and figure 5.6. 

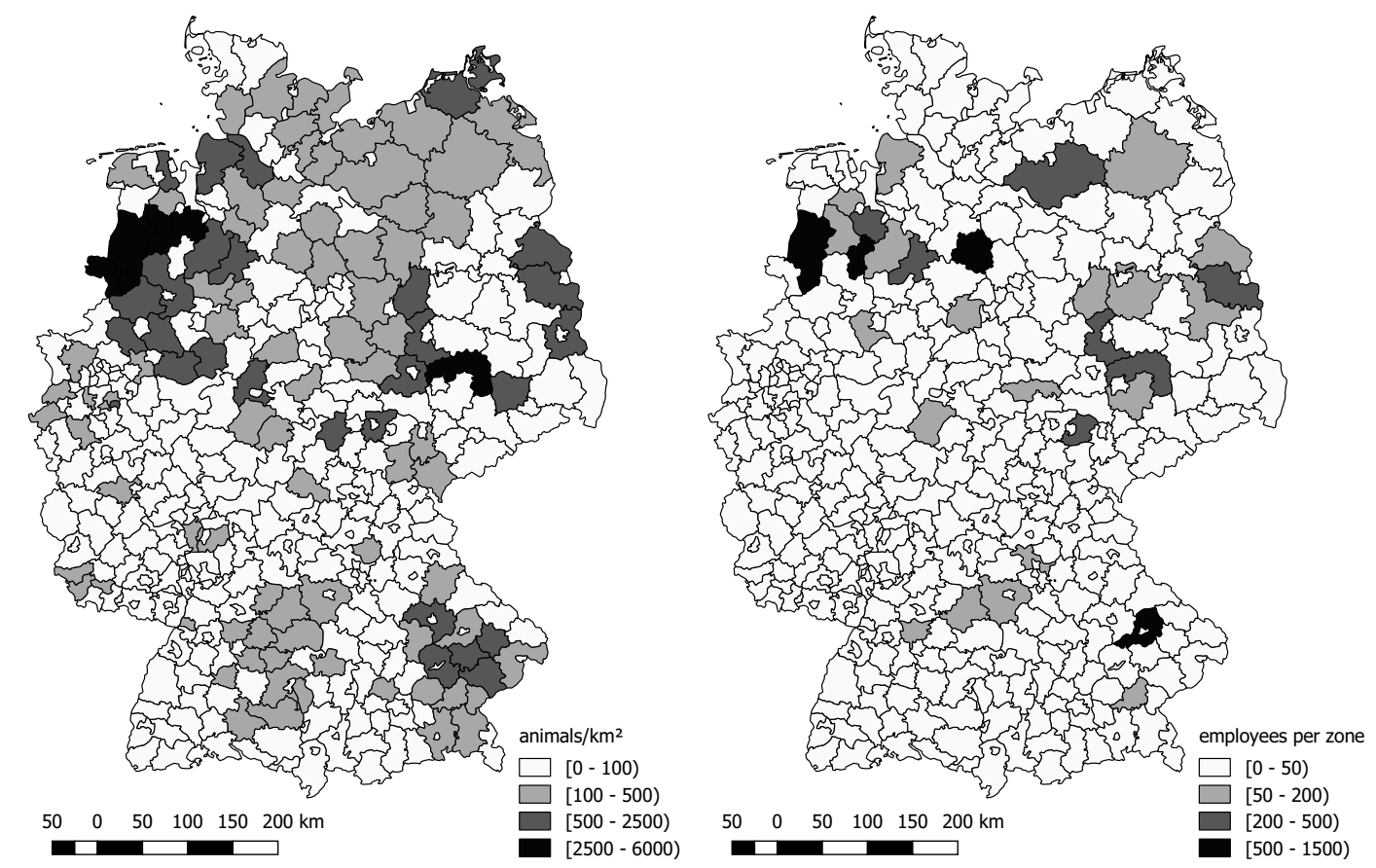

Figure 5.5: Density maps of poultry farming (left, animals $/ \mathrm{km}^{2}$, data from Hessisches Statistisches Landesamt 2015) and poultry slaughtering (right, employees/zone, data from Statistisches Bundesamt 2013b) for Germany

Visually, the maps already adumbrate rather concentrated spatial industry patterns, i.e. an unequal distribution of employment across the entirety of available zones. In addition to a pure visual analysis, Krugman (1991b) proposes using an index (equation 5.1) that describes the distribution of one industry in relation to the distribution of all employees. This index has been named Krugman concentration index in the aftermath.

Mathematically, the Krugman concentration index is defined as follows (adapted from Krugman 1991b; Vogiatzoglou 2006):

$$
\operatorname{CONC}^{s}=\sum_{i \in I}\left|\frac{n E m p_{i}^{s}}{\sum_{i \in I} n E m p_{i}^{s}}-\frac{\sum_{s \in S} n E m p_{i}^{s}}{\sum_{s \in S} \sum_{i \in I} n E m p_{i}^{s}}\right|
$$

where:

$$
\begin{array}{ll}
\operatorname{CONC}^{s} & =\text { Krugman concentration index for sector } s \\
n E m p_{i}^{s} & =\text { number of employees in sector } s \text { in zone } i \\
s & =\text { index for specific sector } s \text { from the set of all sectors } S \\
i & =\text { index for specific zone } i \text { from the set of all zones } I
\end{array}
$$

For the application at hand, the formulation has been adapted for using a proxy distribution $s^{*}$ as reference instead of the originally applied entirety of all employees:

$$
\operatorname{CONC}^{s}=\sum_{i \in I}\left|\frac{n E m p_{i}^{s}}{\sum_{i \in I} n E m p_{i}^{s}}-\frac{n E m p_{i}^{s^{*}}}{\sum_{i \in I} n E m p_{i}^{s^{*}}}\right|
$$

where:

$$
n E m p_{i}^{s^{*}}=\text { proxy distribution } s^{*}
$$



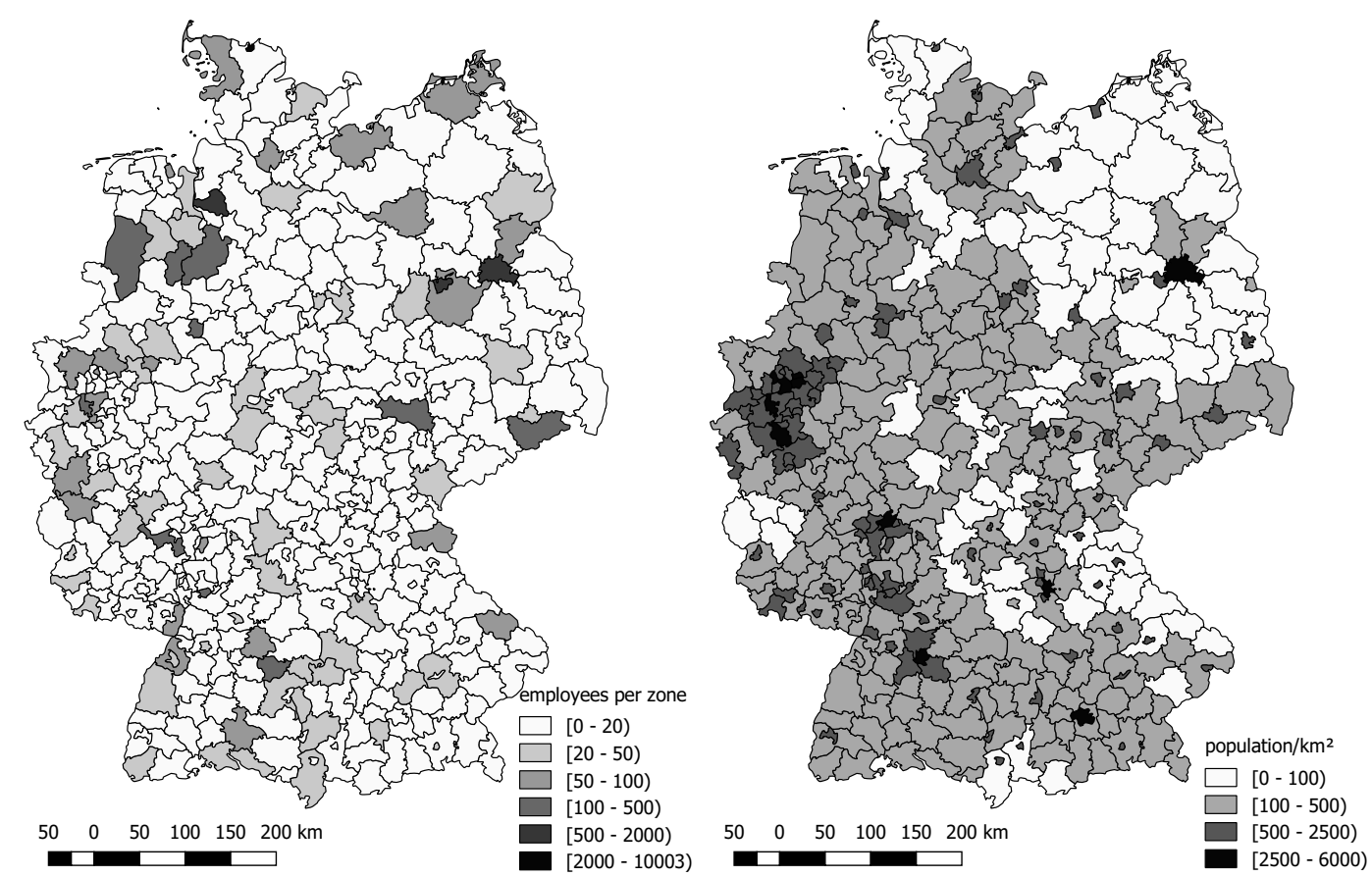

Figure 5.6: Map of employees in convenience food production (left, data from Statistisches Bundesamt 2013b) and population density (right, data from Statistisches Bundesamt 2016b) in Germany

The index takes the value of $\operatorname{CONC}^{s}=2$ if the industry $s$ has a fully distinct spatial pattern in relation to the proxy distribution $s^{*}$. Thus, $\operatorname{CONC}^{s}=2$ identifies a maximum of spatial concentration. In cases where industry $s$ and proxy $s^{*}$ are fully congruent the index shows a value of $C O N C^{s}=0$ signalising a minimum concentration.

Table 5.2: Krugman concentration index for the poultry supply chain's industries in Germany (calculated according to equation 5.2)

\begin{tabular}{lccc}
\hline industry $s$ & \multicolumn{3}{c}{ CONC $^{\text {s }}$ for } \\
poultry farming (WZ 01.47.9) & 1.46 & 1.44 & 1.21 \\
poultry slaughtering (WZ 10.12) & 1.79 & 1.78 & 1.65 \\
convenience food (WZ 10.85) & 1.44 & 1.49 & 1.54 \\
population & 0 & 0.55 & 0.78 \\
\hline
\end{tabular}

Table 5.2 shows the values for the Krugman concentration index of the various industries involved in the poultry supply chain. First, the index values are calculated using the population's spatial distribution as reference. Next, a second calculation applies a perfectly uniform distribution across zones as reference. Finally, the industrial distribution is compared to the distribution of the zones' areas. Here it can be observed that the land intensive activity of farming and the closely connected slaughtering of poultry show the best match if compared to the zones' area. In contrast, the production of convenience food best corresponds to the distribution of the population, which itself has the best congruence if matched with the uniform distribution. This is reasonable since one objective when determining the shape of zones is creating zones with approximately equal numbers of inhabitants. The Krugman index is also used for describing simulation results in later sections of this chapter. 


\subsubsection{Overview of Data Sources Used for Modelling the Poultry Supply Chain}

As laid out in chapter 4, the initial phase of the developed model aims at generating an artificial landscape of business establishments and commodity flows that corresponds to the real-world situation. Hence, this phase of the model particularly requires suitable input data. The following table 5.3 shows which sources the values for the various model parameters originate from.

The table distinguishes between the generated industry landscapes, i.e. the population of business establishments from the various stages of the assumed supply chain, and the commodity flows, i.e. the flows of material that are required for fulfilling the demand and supply of final goods and intermediates. Finally, there are general inputs that provide information on the framing conditions, especially the spatial system.

The parameters given in the column model input are introduced in more detail in table 4.1 (p. 70) and table 4.2 (p. 70) in the context of the actual model description. The actual values used during the model application are shown in appendix A (page 197).

Table 5.3: Overview of input data used for modelling the poultry supply chain

\begin{tabular}{|c|c|c|}
\hline area & model input & data source \\
\hline \multirow[t]{4}{*}{$\begin{array}{l}\text { industry } \\
\text { landscape }\end{array}$} & $\begin{array}{l}\text { business } \quad \text { establishment } \\
\left(f_{s}(e m p), n E m p^{s}, n E s t^{s}\right)\end{array}$ & $\begin{array}{l}\text { statistical data on establishment sizes (Statis- } \\
\text { tisches Bundesamt 2015) }\end{array}$ \\
\hline & location of business establishments $\left(n E m p_{i}^{s}\right)$ & $\begin{array}{l}\text { statistical data on employment by zones } \\
\text { (Statistisches Bundesamt 2013b), animal } \\
\text { stock by zones (Hessisches Statistisches Lan- } \\
\text { desamt 2015), and population by zones } \\
\text { (Statistisches Bundesamt 2016b) }\end{array}$ \\
\hline & $\begin{array}{l}\text { establishment input and output volumes } \\
\left(\text { prodFactor }_{s}, \text { inpFac }_{c, s}\right)\end{array}$ & $\begin{array}{l}\text { statistical data on sectoral linkage provided by } \\
\text { research project SEAK (Balster et al. 2016) }\end{array}$ \\
\hline & $\begin{array}{l}\text { foreign trade partners and corresponding vol- } \\
\text { umes }\end{array}$ & $\begin{array}{l}\text { statistical trade data (Statistisches Bundesamt } \\
\text { 2016a) }\end{array}$ \\
\hline \multirow{3}{*}{$\begin{array}{l}\text { commodity } \\
\text { flows }\end{array}$} & commodity flow sizes $\left(\alpha_{c, s}\right)$ & estimated \\
\hline & $\begin{array}{l}\text { number of suppliers per establishment and } \\
\text { commodity (dispFac c } c, s, \beta_{c, s} \text { ) }\end{array}$ & estimated \\
\hline & macro flows $\left(M F_{c}\right)$ & $\begin{array}{l}\text { statistical data from German federal transport } \\
\text { plan (BMVI 2014) }\end{array}$ \\
\hline \multirow[t]{2}{*}{ general } & spatial zone system $\left(z o n e_{i}\right)$ & public geo data (GeoBasis-DE/BKG 2016) \\
\hline & road network based distance matrix $\left(d_{i, j}\right)$ & public data (eurostat 2016) \\
\hline
\end{tabular}

As described, distances are taken from eurostat (2016). This source measures the distance between two NUTS 3 (Nomenclature des unités territoriales statistiques) zones by taking the road network distance between the political centres of the zones. Distances within zones are not considered in the source. Therefore, they are assumed as the average distance between to points within a circle area as described in Friedrich (2010, p. 68). Accordingly, the formula applied for calculating the intra-zone distances is $d_{i, i}=0.63 \cdot \sqrt{z \text { one } e_{i}^{\text {area }}}$.

\subsubsection{Overview of Application Scenario Poultry}

After describing the prerequisites for the application, it is now time to start into the actual model application. Given the poultry supply chain as depicted in figure 5.4, it shall now be analysed how a centralisation on the stage of 
slaughtering influences overall freight transport demand. The populations of upstream suppliers and downstream consumers remain unchanged in order to ensure ceteris paribus conditions as far as possible. However, it is inevitable to apply changes to the commodity flows connecting suppliers and consumers as far as they connected to focal establishments that are involved in the centralisation. Figure 5.7 gives an overview of the affected commodity flows and establishments together with the assumptions required for simulating centralisation. Even if already discussed in chapter 4, it is helpful to summarise the different assumptions since they are key to understanding the different solution methods and range of results in the following.

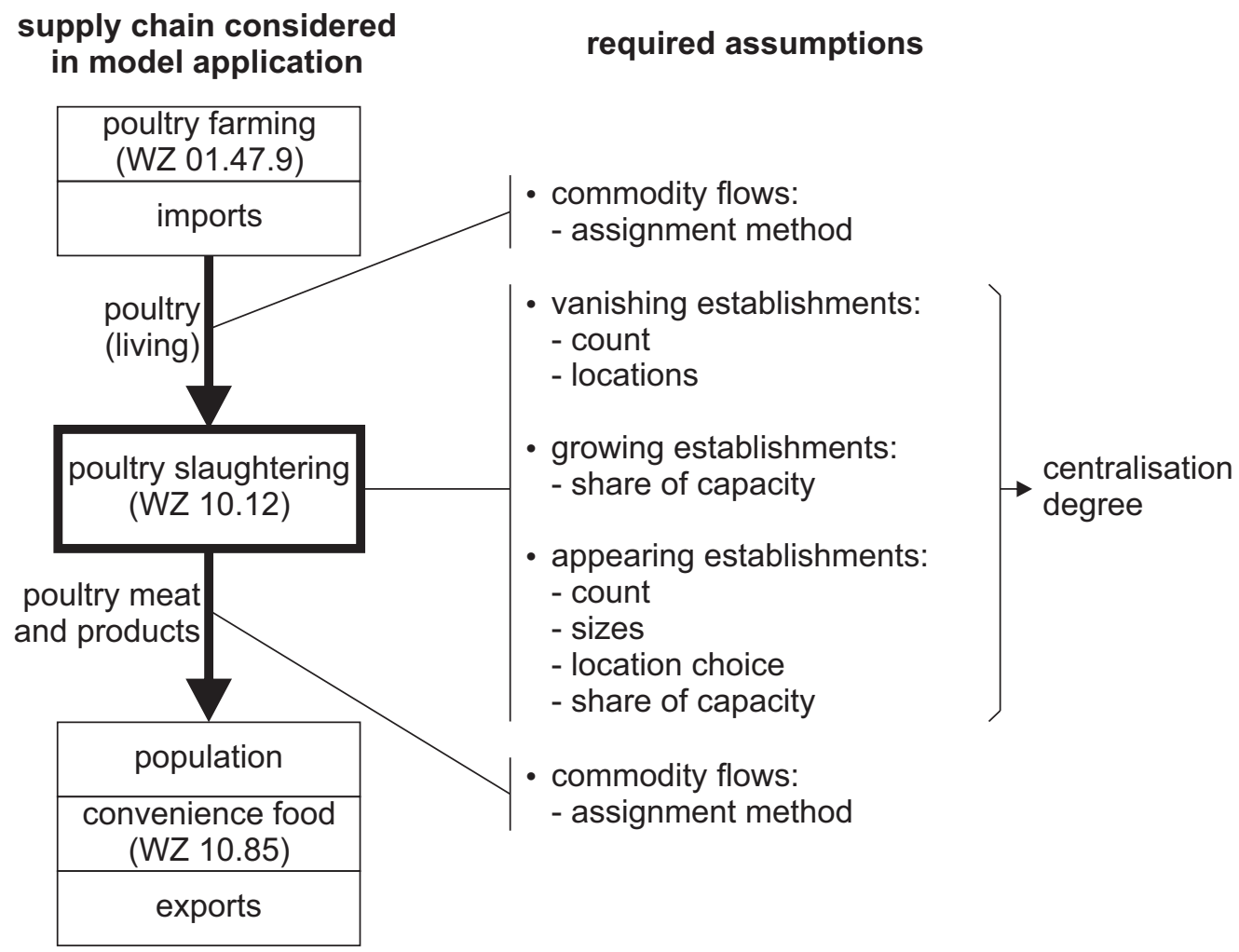

Figure 5.7: Overview of poultry supply chain for application and required assumptions for centralisation

As shown, most assumptions are required in the area of the centralising industry's establishments. Since overall industry output is considered to remain unchanged, certain establishments will need to be removed from the population in order to achieve a reduction in the number of establishments according to the assumed centralisation. These establishments are called vanishing establishments in the following. In the next step, there are two fundamentally different possibilities for reassigning the vanishing establishments' capacity. Either the remaining establishments can grow or the capacity is assigned to establishments that are newly created due to the optimisation calculus of economic actors. The latter are called appearing establishments. Obviously, the count, sizes, and locations of appearing establishments significantly influence the impact on freight transport demand. It is also possible to split the unassigned capacity between growing establishments and appearing establishments. The assumptions on the level of commodity flows are mostly determined by choosing the assignment method, and assignment sense if optimisation models are to be applied.

\subsubsection{Simulation Results of Model Phase 1}

This section addresses the output of the model's first phase for the analysis for centralisation in the German poultry industry. The actual outcome as well as its validity are discussed. The spatial layout of the corresponding initial 
population of focal establishments and their flow relations, i.e. the output of model phase 1, are visualised in the map shown in figure 5.8 (page 124).

In this map and all following maps, establishments are located at the spatial centre of gravity of the respective zones. If more than one establishment is located in the same zone, the additional objects are aligned circularly around the centre. Flow relations are drawn connecting zone centres if there exists at least one input or output commodity flow between the zones that is larger than $0.1 \mathrm{t} / \mathrm{a}$.

Getting back to the actual content of figure 5.8, the establishments' locations reflect the distribution of employment from the statistical input, which has been illustrated in figure 5.5. In the status quo, core areas of poultry slaughtering can be identified in the north, east, and south of Germany. The large number of commodity flows and their macro flow based assignment leads to a very dense network of flow relations covering all of Germany. Even if the visualisation of these flow relations do not give much insight on themselves, they are still helpful for comparing the overall pattern to the structural changes in the flow patterns of the later model results for phase 2 .

Regarding the quality of the first phase's output, the fit of generated commodity flows and framing macro flows is of major importance. Thus, for each generated initial population of commodity flows and establishments a deviation measure is calculated per commodity as described below.

First, commodity flows are aggregated by zone to zone relations, i.e. by calculating a matrix $T^{c}$ for each commodity $c$ with entries $t_{i, j}^{c}$ for the aggregate flows from zone $i$ to $j$ corresponding to:

$$
t_{i, j}^{c}=\sum_{\left\{c f_{k} \mid c f_{k}^{\text {origZone }}=i \wedge c f_{k}^{\text {destZone }=j \wedge}\right.} c f_{k}^{c \text { com }=c\}} f_{k}^{\text {vol }}
$$

where:

$t_{i, j}^{c} \quad=$ aggregate commodity flow volume for the relation from zone $i$ to $j$

$c f_{k}^{\text {vol }} \quad=$ volume of commodity flow $k$

$c f_{k}^{\text {origZone }}=$ origin zone of commodity flow $k$

$c f_{k}^{\text {destZone }}=$ origin zone of commodity flow $k$

Now, the deviation $d e v^{c}$ can be calculated for each commodity by comparing the aggregate zone flows and the input macro flows:

$$
d e v^{c}=\sum_{i \in I} \sum_{j \in J}\left|t_{i, j}^{c}-m f_{l}^{\nu o l}\right| \text { with } m f_{l}^{\text {origZone }}=i \wedge m f_{l}^{\text {destZone }}=j \wedge m f_{l}^{\text {com }}=c
$$

where:

$d e v^{c} \quad=$ deviation measure for commodity $c$

$t_{i, j}^{c} \quad=$ aggregate commodity flow volume for the relation from zone $i$ to $j$

$m f_{l}^{\text {vol }} \quad=$ volume of macro flow $l$

$m f_{l}^{\text {origzone }}=$ origin zone of macro flow $l$

$m f_{l}^{\text {destZone }}=$ origin zone of macro flow $l$

$m f_{l}^{\text {com }}=$ commodity of macro flow $l$ 


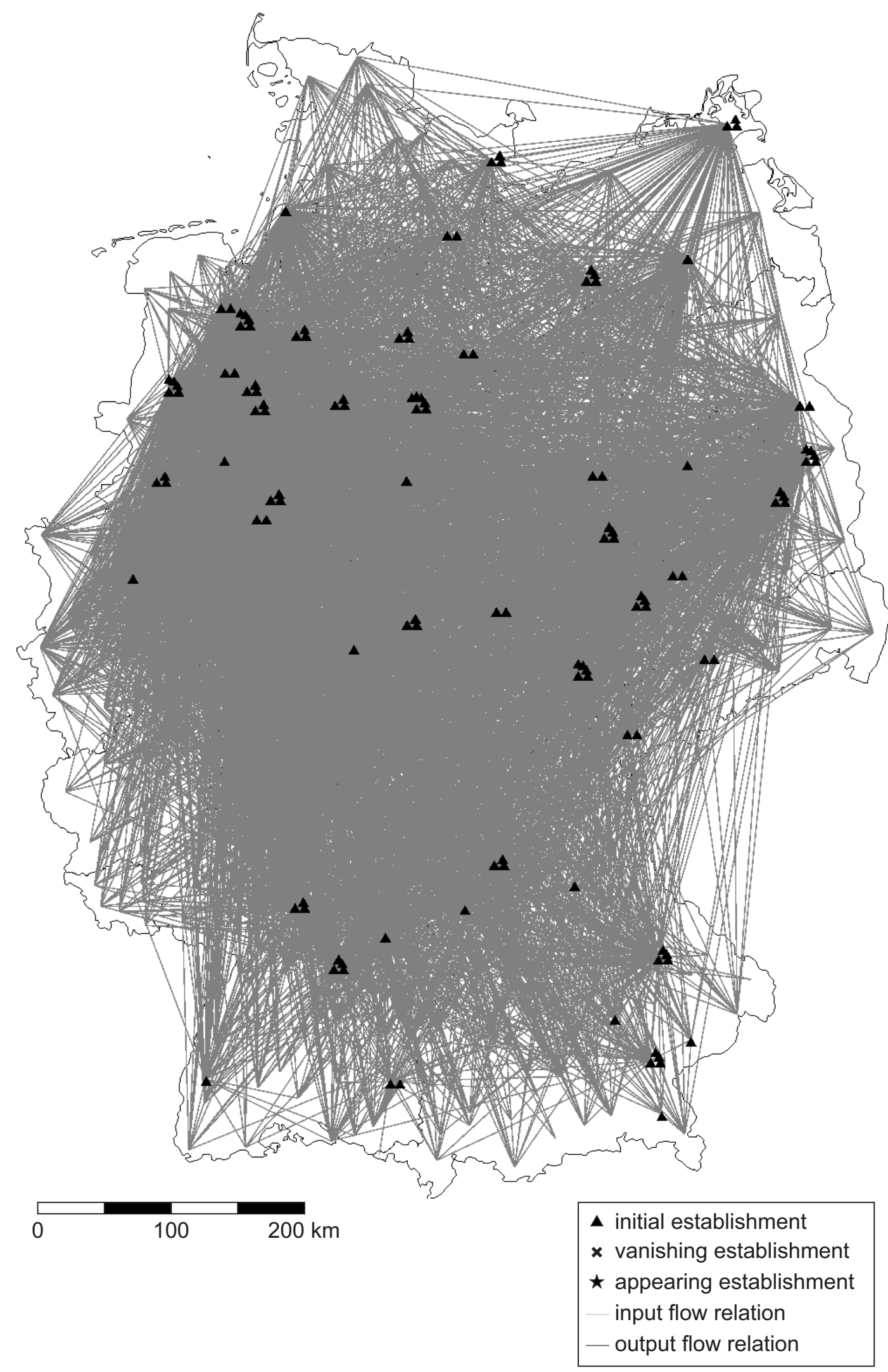

Figure 5.8: Map showing the initial 128 focal establishments of poultry slaughtering with their flow relations 
Table 5.4: Average distances for macro flow and commodity flow populations after model phase 1

\begin{tabular}{ccc}
\hline & \multicolumn{2}{c}{ average distance (km) } \\
output commodity of sector & macro flows & commodity flows \\
\hline WZ 01.47.9 & 175.9 & 177.5 \\
WZ 10.12 & 279.8 & 280.7 \\
\hline
\end{tabular}

Table 5.5: Number of commodity flows per sector relation after model phase 1

\begin{tabular}{c|cccc}
\hline origin & \multicolumn{4}{|c}{ \# commodity flows to receiving sectors } \\
sector & WZ 10.12 & WZ 10.85 & export & population \\
\hline WZ 01.47.9 & 8256 & & & \\
WZ 10.12 & & 7129 & 85 & 7326 \\
\hline
\end{tabular}

Finally, the values of $d e v^{c}$ are normalised by setting the absolute deviation in relation to the overall volume of the current commodity $\operatorname{devNorm}{ }^{c}=\frac{d e v^{c}}{\sum_{\left\{c f_{k} \mid c f_{k}^{c o m}=c\right\}} c f_{k}^{v o l}}$. Applying this normalised measure, the values for devNorm ${ }^{c}$ are in the range of $0.6 \%$ to $1.2 \%$ for the presented cases, which proves a high conformity of commodity flows and macro flow restrictions as intended.

Obviously, the measure $\operatorname{devNorm^{c}}$ only considers the difference in the flow volumes of inter zone relations but leaving out the corresponding distances, it does not explicitly account for the spatial nature of the underlying configuration of flows. Using transport performances instead of volumes would introduce a weighting based on the distance covered by the relations. However, using transport performances would raise new pitfalls, e.g. the question of how suitable the usage of absolutes would be. Therefore, the spatial aspect is controlled for by comparing the average distances of the generated commodity flows and the corresponding macro flows patterns as shown in table 5.4. Clearly, the difference between the average distance of macro flows and generated flows is acceptably low with a relative deviation of less than $1 \%$.

Apart from the generated commodity flow population's spatial structure, its characteristics on establishment level need to be looked at in order to verify its plausibility. Table 5.5 shows the total number of generated commodity flows by sector relations. Compared to the aggregate flow scenario for the poultry supply chain (figure 5.4), the sectoral relations are reflected correctly on the level of commodity flows.

However, the depicted aggregate numbers only give a hint on the generated supply network's numerical complexity resulting from a total number of 22,796 commodity flows. In order to verify the overall plausibility, table 5.6 disaggregates the number of flows per sectoral relation on the level of receiving establishments. This answers the question of how many suppliers per consumed commodity an establishment has. Looking at the data regarding establishments of poultry slaughtering (WZ 10.12), the min column entry shows that there is at least one establishment that has 2 incoming commodity flows for living poultry (from WZ 01.47.9). The max value denotes that there is also at least one other establishments that has 290 incoming commodity flows of this type. The overall average number of incoming flows per establishment for this sectoral relation is 64.5.

The opposite perspective is taken in table 5.7, which describes the number of outgoing commodity flows per establishment and sector relation. Hence, the data answers the question of how many customers does one establishment serve per consuming sector. Taking the commodity flows from establishments of poultry slaughtering (WZ 10.12) to export, the table's data finds a minimum of 0 (zero) commodity flows and a maximum of 5 commodity flows on establishment level. The corresponding average value of 0.7 shows only a certain share of establishments provides part of their output to export. 
Table 5.6: Incoming commodity flows per establishment by sector relation after model phase 1

\begin{tabular}{|c|c|c|c|c|c|c|c|c|c|c|c|c|}
\hline \multirow{3}{*}{$\begin{array}{l}\text { origin } \\
\text { sector }\end{array}$} & \multicolumn{12}{|c|}{ \# incoming commodity flows per establishment in receiving sector ${ }^{1}$} \\
\hline & \multicolumn{3}{|c|}{ WZ 10.12} & \multicolumn{3}{|c|}{ WZ 10.85} & \multicolumn{3}{|c|}{ export } & \multicolumn{3}{|c|}{ population } \\
\hline & $\min$ & $\max$ & avg & $\min$ & $\max$ & avg & $\min$ & $\max$ & avg & $\min$ & $\max$ & avg \\
\hline WZ 01.47 .9 & 2 & 290 & 64.5 & & & & & & & & & \\
\hline WZ 10.12 & & & & 1 & 32 & 9.2 & 5 & 17 & 9.4 & 1 & 41 & 18.2 \\
\hline
\end{tabular}

${ }^{1}$ minimum (min), maximum (max), and average (avg) number of incoming commodity flows per establishment and sector relation as observed in the generated population

Table 5.7: Outgoing commodity flows per establishment by sector relation after model phase 1

\begin{tabular}{|c|c|c|c|c|c|c|c|c|c|c|c|c|}
\hline \multirow{3}{*}{$\begin{array}{l}\text { origin } \\
\text { sector }\end{array}$} & \multicolumn{12}{|c|}{ \# outgoing commodity flows per establishment in origin sector ${ }^{1}$} \\
\hline & \multicolumn{3}{|c|}{ WZ 10.12} & \multicolumn{3}{|c|}{ WZ 10.85} & \multicolumn{3}{|c|}{ export } & \multicolumn{3}{|c|}{ population } \\
\hline & $\min$ & $\max$ & avg & $\min$ & $\max$ & avg & $\min$ & $\max$ & avg & $\min$ & $\max$ & avg \\
\hline WZ 01.47.9 & 1 & 110 & 3.7 & & & & & & & & & \\
\hline WZ 10.12 & & & & 1 & 184 & 55.7 & 0 & 5 & 0.7 & 1 & 245 & 18.2 \\
\hline
\end{tabular}

${ }^{1}$ minimum (min), maximum (max), and average (avg) number of outgoing commodity flows per establishment and sector relation as observed in the generated population

Unfortunately, there is no data available on the actual number of commodity flows between establishments of the poultry slaughtering supply chain in Germany. Therefore, in the current situation the best option to check the model validity in this regard is to check the plausibility of results.

Overall, the number of flow relations on establishment level are reasonable. The only unexpectedly high value occurs for the maximum number of flows of 110 between an establishment of poultry farming (WZ 01.47.9) to slaughtering (WZ 10.12) as shown in table 5.7. Looking at the detailed simulation output, the high value can be identified as a unique anomaly that results from the assignment procedure applied for residual input volumes. Regarding the intended analysis, this behaviour is acceptable due to the unique occurrence and the fact that the macro flows constraints, which follow actual data and should therefore be valued higher, are met. However, in case the developed model was to be applied in the context of robustness analysis of supply networks, special attention needs to be paid to this kind of effect in the generation procedure.

However, in case real-world data becomes available for calibration and validation in the future it should be used in the developed model for validating the model output in addition to the currently applied plausibility checks. The model's design accounts for the consideration of such data in the parametrisation of commodity flow structures as described in section 4.4.3 (page 81).

\subsubsection{Simulation Results of Model Phase 2}

In order to give an overview of the overall model dynamics and result ranges, a large quantity of simulation batches that covers the possible variations in the assumptions for simulating centralisation within the supply chain structures generated in model phase 1 has been conducted. The results are shown in table 5.8.

Here, the first column serves as an aggregate indicator for the degree of centralisation in the industry. Since this assumption significantly influences the simulation results, it is used for sorting the result data. The second column 
shows the count of vanishing establishments. This assumption determines the degree of freedom for simulating a population of establishments that fulfils the intended centralisation characteristics. The values given in the column for the count of appearing establishments can be directly calculated from the centralisation degree and the count of vanishing establishments. Nevertheless, for reasons of comprehensibility and traceability these values are disclosed explicitly. The fourth column shows which share of the vanishing establishments' capacity is assigned to appearing establishments.

Table 5.8: Simulation results for centralisation of poultry slaughtering ${ }^{1}$ (initially 637 million tkm/a and 128 focal establishments; ranges for change are extreme values, respectively median values, as observed during $10 \mathrm{x}$ 10 loops for stochastic influences regarding vanishing and appearing establishments)

\begin{tabular}{|c|c|c|c|c|c|c|}
\hline \multirow[b]{2}{*}{$\begin{array}{l}\text { centralisation } \\
\text { degree }^{1}(\%)\end{array}$} & \multicolumn{2}{|c|}{ assumptions } & \multirow[b]{2}{*}{$\begin{array}{c}\text { appearing } \\
\text { establ. } \\
\text { capacity } \\
(\%)\end{array}$} & \multicolumn{3}{|c|}{ change in transport performance ${ }^{2}$} \\
\hline & $\begin{array}{l}\text { establ. } \\
\text { vanishing } \\
\text { (count) }\end{array}$ & $\begin{array}{l}\text { establ. } \\
\text { appearing } \\
\text { (count) }\end{array}$ & & $\begin{array}{c}\text { OptOpt }^{3} \\
{[\mathrm{~min} ; \max ]} \\
(\%)\end{array}$ & $\begin{array}{l}\text { StochOpt }{ }^{4} \\
{[\text { min; max }]} \\
(\%)\end{array}$ & $\begin{array}{c}\text { StochMacro }^{5} \\
\text { [median] } \\
(\%)\end{array}$ \\
\hline 0 & 0 & 0 & 0 & {$[-]$} & {$[-35 ;+142]$} & {$[+/-0]$} \\
\hline 25 & 32 & 0 & 0 & {$[-]$} & {$[-16 ;+59]$} & {$[+6]$} \\
\hline 25 & 64 & 32 & 100 & {$[-38 ;+185]$} & {$[-20 ;+125]$} & {$[+24]$} \\
\hline 25 & 128 & 96 & 100 & {$[-66 ;+275]$} & {$[-28 ;+183]$} & {$[+24]$} \\
\hline 50 & 64 & 0 & 0 & {$[-]$} & {$[-18 ;+108]$} & {$[+17]$} \\
\hline 50 & 96 & 32 & 100 & {$[-51 ;+236]$} & {$[-24 ;+157]$} & {$[+30]$} \\
\hline 50 & 128 & 64 & 100 & {$[-65 ;+275]$} & {$[-28 ;+183]$} & {$[+24]$} \\
\hline 75 & 96 & 0 & 0 & {$[-]$} & {$[-9 ;+154]$} & {$[+42]$} \\
\hline 75 & 128 & 32 & 100 & {$[-60 ;+275]$} & {$[-29 ;+182]$} & {$[+24]$} \\
\hline 99 & 128 & 1 & 100 & {$[+38 ;+235]$} & {$[+78 ;+221]$} & {$[+150]$} \\
\hline
\end{tabular}

${ }^{1}$ centralisation degree $(\%)=\frac{\text { \#establ. before-\#establ. after }}{\text { \#establ. before }} \cdot 100$

2 change in transport performance $(\%)=\frac{t p^{a f t e r}-t p^{b e f o r e}}{t p^{b e f o r e}} \cdot 100$

${ }^{3}$ location choice: optimal; flow assignment: optimal

${ }^{4}$ location choice: stochastic; flow assignment: optimal

${ }^{5}$ location choice: stochastic; flow assignment: macro flows

In contrast to the previously described columns containing information on the assumptions, the columns five to seven contain the corresponding numerical model output. The output values are expressed as relative change in the aggregate indicator transport performance $(t p)$. Here, the simulation result is put in relation to the initial transport performance before centralisation $\left(\triangle t p=\frac{t p^{a f t e r}-t p^{b e f o r e}}{t p^{b e f} \text { ore }} \cdot 100 \%\right)$.

The column OptOpt contains the simulation results for applying the facility location problem for a parallel optimisation of location and flow assignment for the appearing establishments. In contrast, the column StochOpt assumes a stochastic location choice followed by an optimal assignment. In both cases, OptOpt and StochOpt, the optimisation models is applied for minimisation as well as maximisation. Therefore, the table contains a minimum and maximum value for each assignment method.

The last column StochMacro gives the results for a simulation of centralisation that is based on stochastic location choice for appearing establishments together with a flow assignment according to macro flow patterns like applied

In contrast to the simulation results below, imports and exports have not been considered separately in the underlying model runs. 
during the first model phase. Due to the stochastic elements in the model, the StochMacro values show fluctuations between different simulation runs with identical input parameters. Therefore, the table discloses the median value of the calculated model results for this assignment method since it is more robust against outliers, which might occur as a result of seldom extreme combinations of stochastic elements.

After describing the meaning of the various columns, the following paragraphs discuss first insights based on the presented data.

The assumptions of the first and last row of table 5.8 represent two rather extreme parameter assumptions. The first row actually gives a lower bound if all commodity flows from the initial assignment were replaced with an optimal assignment among an unchanged population of focal establishments.

In contrast, the last row describes an opposite extreme case by assuming that all focal establishments vanish and the production of the entire industry is carried out by a single appearing establishment. The OptOpt solution gives the absolute range of change in freight transport performance that can be induced by the location choice of that single establishment. It is shown that such a strong reduction in the number of establishments must lead to an increase in freight transport performance. For the solution belonging to StochOpt and StochMacro the only source for variation lies in the stochastic location choice since all flows need to be routed through the single establishment in any case leaving no freedom for different flow assignments. Hence, for a given location the values the minimum, maximum and median value for StochOpt and StochMacro are equal. Accordingly, the disclosed results' variations between these columns solely originate from the stochastic location of the single appearing establishment.

Looking further at general tendencies across the different rows of the table, the data show that a higher number of appearing establishments leads to a wider range of the minimum and maximum solution if optimisation is applied in the assignment as done for the columns of OptOpt and StochOpt. This behaviour is plausible since in these cases the optimisation models have a higher degree of freedom during reassignment. In this regard, it is also coherent that there are no values for the combination of optimal location choice and optimal assignment if the centralisation degree is achieved with an appearing establishment count of zero.

In addition, comparing the ranges calculated for OptOpt and StochOpt, the results show that if the count of disappearing and appearing establishments are high enough, the minimum and maximum values take similar values for different centralisation degrees. The explanation for this behaviour lies in the fact that from the perspective of the optimisation problems, the different assumptions still allow for the same solution space.

The various values disclosed for the StochMacro solutions show a certain tendency for a higher degree of centralisation leading to a higher degree of growth in freight transport performance, especially for the cases without appearing establishments. In fact, a more solid analysis of this relationship is not possible solely based on the median values. This topic is addressed in more detail in the subsequent sections of this chapter.

Before continuing with the deeper analysis of an assumed centralisation degree of $50 \%$, it is worthwhile to give a short remark on the technical side of the data discussed above.

Each number in the table represents a simulation batch consisting of 100 combinations, i.e. ten different selections of vanishing establishments and ten sets of appearing establishments. This multiplicative interdependency together with the linear growth in the number of simulated parameter combinations and the assignment procedures' inherent complexity lead to a computation time of approximately 60 hours for the entire table using an Intel i3570K Quadcore CPU at 3.4 Ghz with 16 GB RAM, 64 bit OS, Java 1.864 bit, and SSD storage for input and output. However, these 100 combinations only make up a tiny share of the combinatoric possibilities. Regarding the disappearing establishments, there are $\left(\begin{array}{c}128 \\ 64\end{array}\right)=2.4 \cdot 10^{37}$ possible combinations for selecting 64 disappearing establishments from a population of 128 according to the multinomial coefficient. For locating 64 appearing establishments, there are $\left(\begin{array}{c}402+64-1 \\ 64\end{array}\right)=4.4 \cdot 10^{79}$ possible combinations since multiple establishments can be assigned to 


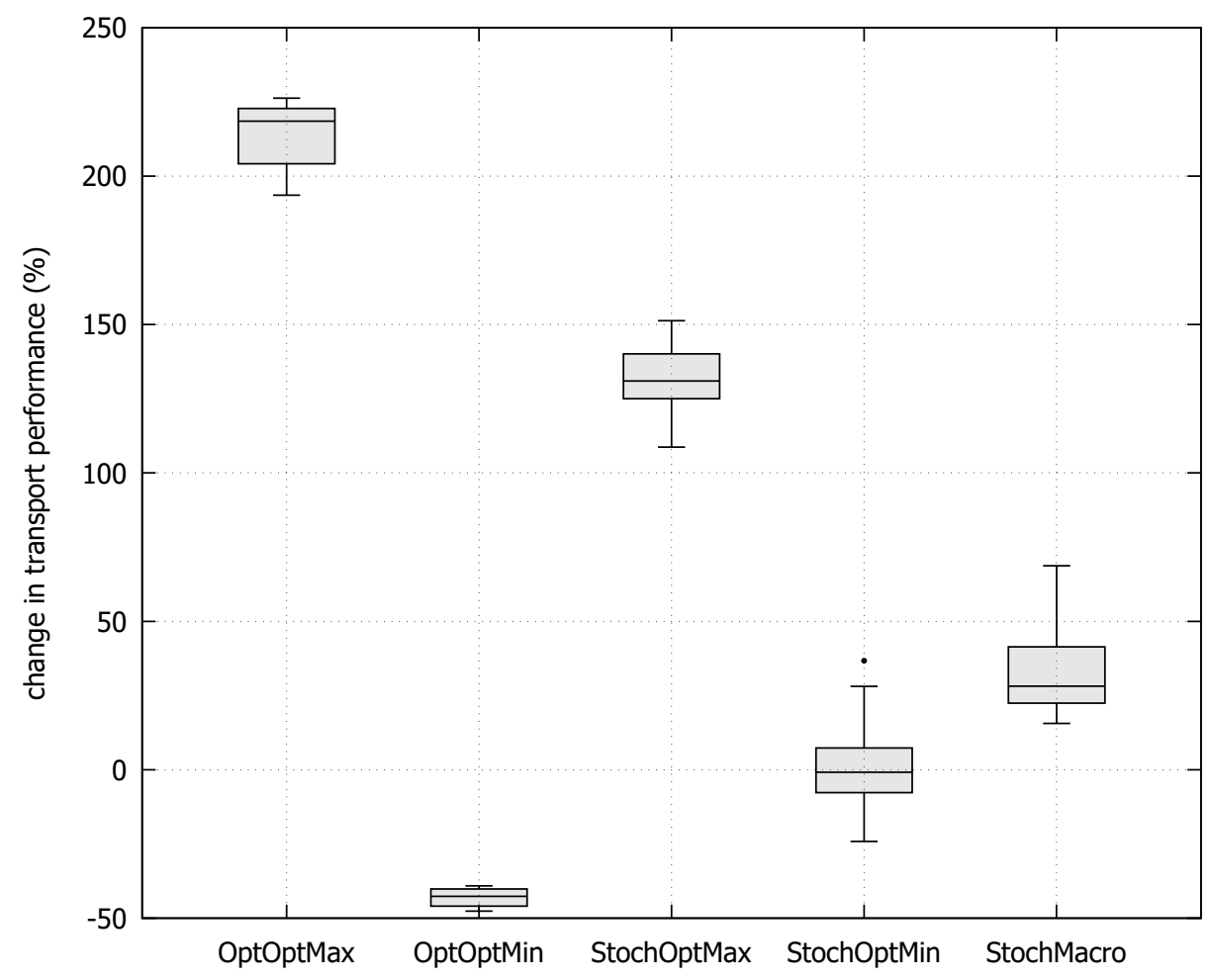

Figure 5.9: Boxplot aggregating the simulation results for a centralisation degree of $50 \%$, a count of 96 vanishing establishments, 32 appearing establishments, and a capacity share of $100 \%$ for the appearing establishments

the same zone but the order of assignment does not play any role. Hence, there are $2.4 \cdot 10^{37} \cdot 4.4 \cdot 10^{79}=1.04 \cdot 10^{117}$ possible configurations taking the two procedures together.

\subsubsection{Partial Validation Based on Detailed Results from Model Phase 2}

In order to validate the model and to get a better understanding of the interrelation of the various model results. The following paragraphs and figures give a detailed insight into the simulation results under the assumption of a 50\% centralisation degree, 96 vanishing establishments, 32 appearing establishments, and an appearing establishments' capacity of 100\%, which is identical to the assumptions shown in row 6 in table 5.8 .

To begin with, figure 5.9 contains a boxplot that illustrates the different solution ranges for the different combinations of assumptions regarding location choice, assignment method, and assignment sense. In the diagram, the boxes cover the 0.25 quantiles around the median value, which itself is represented as a horizontal line in the box. The whiskers extend for a range of up to 1.5 times the boxes' height (interquartile range). Outliers that reach beyond this range are marked with dots.

The boxplot clearly shows that the combination of an optimal location choice with an optimal assignment (OptOptMax and OptOptMin) leads to the most extreme result values. This is plausible with the original intention of finding the absolute maximum range for possible outcomes considering only the assumptions on the underlying change in the supply chain structure.

The next combination of boxes in the diagram stands for the combination of a stochastic location choice and optimal assignment (StochOptMax and StochOptMin). Here, the gap between the solutions of the minimisation and 
maximisation is smaller than in the first case. The stochastic location choice leaves a lower degree of freedom for the optimisation, which is limited to finding a maximum or minimum assignment of flows.

The last box in the chart visualises the simulation outcome if a stochastic location choice and a flow assignment according to macro flows are assumed (StochMacro). As expected, these results lie within the range of the StochOptMin and StochOptMax solution. In this regard, it is especially interesting that there is an overlap in the range of StochOptMin and StochMacro. It is important to note that the overlap appears for different simulation runs, i.e. stochastic combinations that lead to the highest values in the minimisation and different stochastic combinations that incur the lowest values for the macro flow assignment. However, the overlap emphasizes that the applied realworld macro flow patterns are closer to a minimum optimal solution than to a worst case, worst case especially from the perspective of a freight transport planner aiming at low transport performances. This is especially reasonable since it corresponds to the assumption of an economic optimisation calculus of the involved actors. However, the minimisations' solution ranges also show that a centralisation of production could lead to a reduction of transport performance, illustrated by negative values in the boxplot, if a central planning could assign flow relations and perfect substitutability of input as well as output commodities was assumed. The sections below shed light on the various solutions that are behind the presented boxplot.

In order to simulate the assumed centralisation degree of 50\%, a certain share of establishments, in this case 96 , need to be removed from the initial population. The map in figure 5.13 (page 134) depicts one example of the location and flow relations of these vanishing establishments. Here again, the map is intended to give an overview of the overall spatial setup of establishments and flow relations and to remind of the simulation procedure's order of steps. The overlapping pattern of flows prohibits any deeper analysis based on the shown map.

After removing the vanishing establishments and their commodity flows from the initial population, the model closes the incurred gaps in the supply networks by applying different adaptation, location, and assignment procedures. The maps shown in figure 5.14 to figure 5.18 (pages 135 to 139) visualise the different spatial setups that belong to the results described in the context of the boxplot in figure 5.9.

The first spatially visualised result shown in figure 5.14 depicts the establishments and flow relations that are the outcome of the OptOptMin solution method. Clearly, the optimisation leads to a rather uniform geographic distribution of establishments if output capacities are ignored. If the spatial distribution of capacities is taken into account, a stronger spatial concentration appears. Since the applied location allocation optimisation problem is uncapacitated, the distribution of output and number of establishments by size categories, illustrated in figure 5.10 and figure 5.11, can be used for underlining the shift towards stronger concentration of the industry. Figure 5.10 emphasizes on how the output is shifted to establishments that fall into a previously unpopulated size category. Combined with the count of establishments in this large size category as shown in figure 5.11, it becomes clear that the uncapacitated location allocation problem suggests the creation of few large establishments accompanied by some smaller sites.

The establishment locations that correspond to this size distribution, respectively the optimal location allocation problem, are visualised in the map of figure 5.12. Here, a concentration of larger establishments in the northern half of Germany can be observed. The according flow assignment is illustrated in figure 5.14. In contrast to the dense and overlapping flow pattern of the initial population, establishments now have very limited spatial reach for their suppliers and customers.

The opposite flow pattern is calculated for the maximum solution of the location allocation problem as shown in figure 5.15. As described by the objective function, the establishment locations take the largest distance possible from the supply and consumption areas, which must be at the border of the survey area, i.e. Germany. Even if this extreme solution is rather of theoretical than practical importance for the underlying problem, an interesting side 


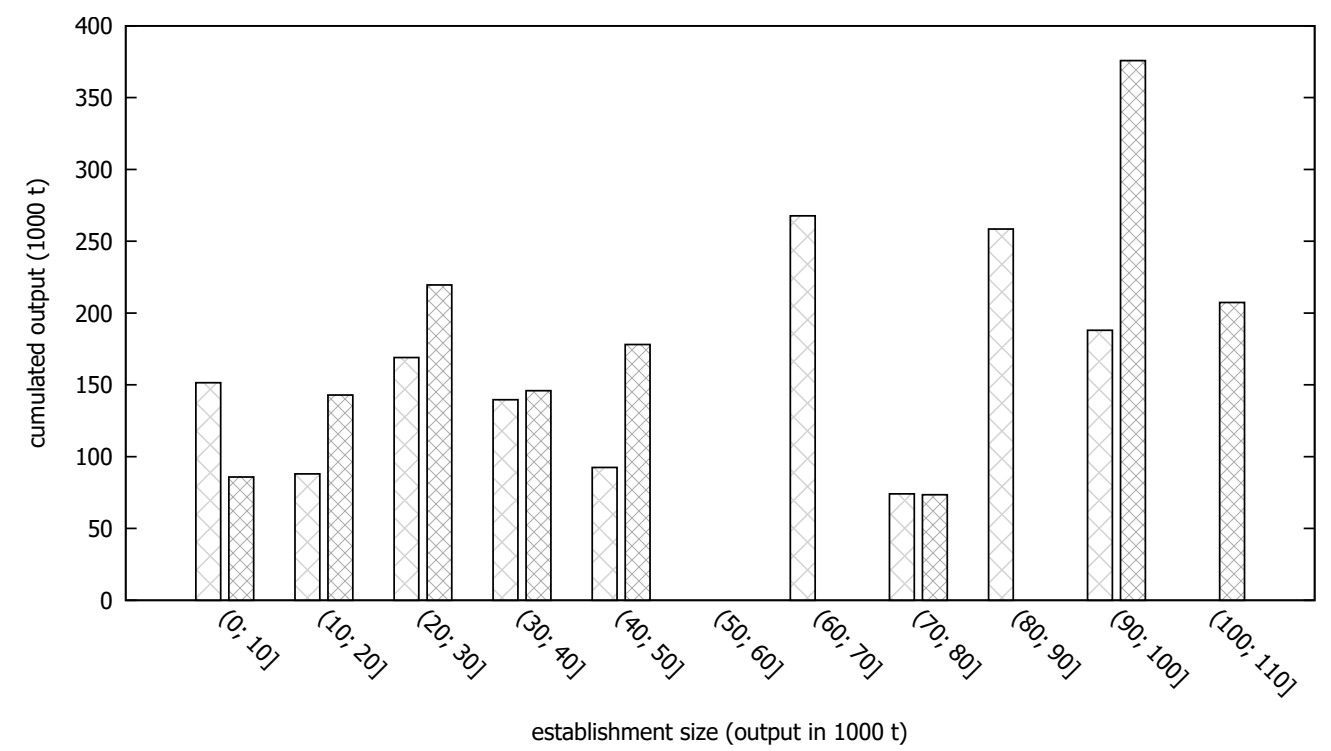

before $\square$

Figure 5.10: Establishment output by size categories before and after a $50 \%$ centralisation poultry slaughtering with 32 appearing and 96 vanishing establishments for the OptOptMin solution

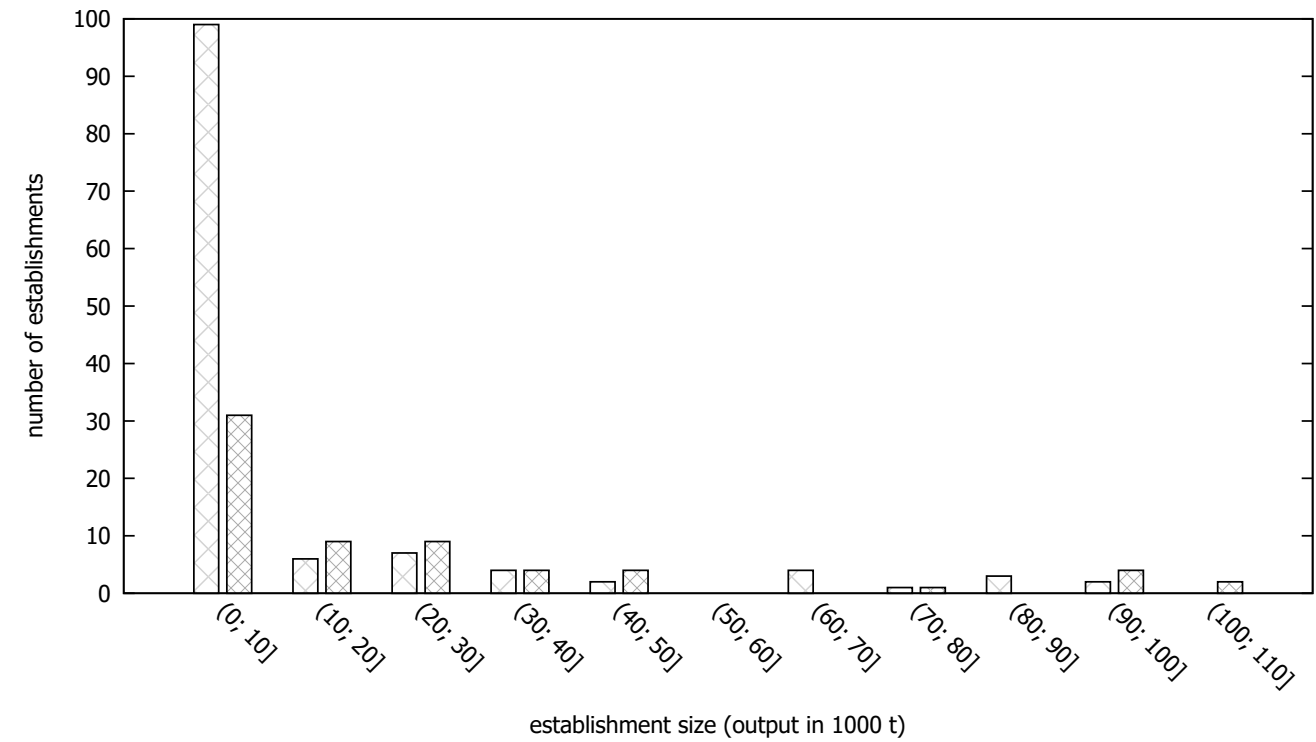

before $\square$
after $\square \square$

Figure 5.11: Establishment count by size categories before and after a $50 \%$ centralisation poultry slaughtering with 32 appearing and 96 vanishing establishments for the OptOptMin solution

fact is that already 13 locations are enough to provide maximum distances to the zones of supply and demand for inputs and outputs of poultry slaughtering in Germany.

Leaving the optimal location choice behind, figure 5.16 illustrates a minimum flow pattern that is achievable if establishment sizes and locations have already been determined by stochastic simulation or further external assumptions. In this very case, a uniform probability is assumed for all zones. Due to capacity constraints and stochastic location choice, the appearing establishments show more overlapping and larger distances in their flow relations if compared to the above solution with optimal location choice. 


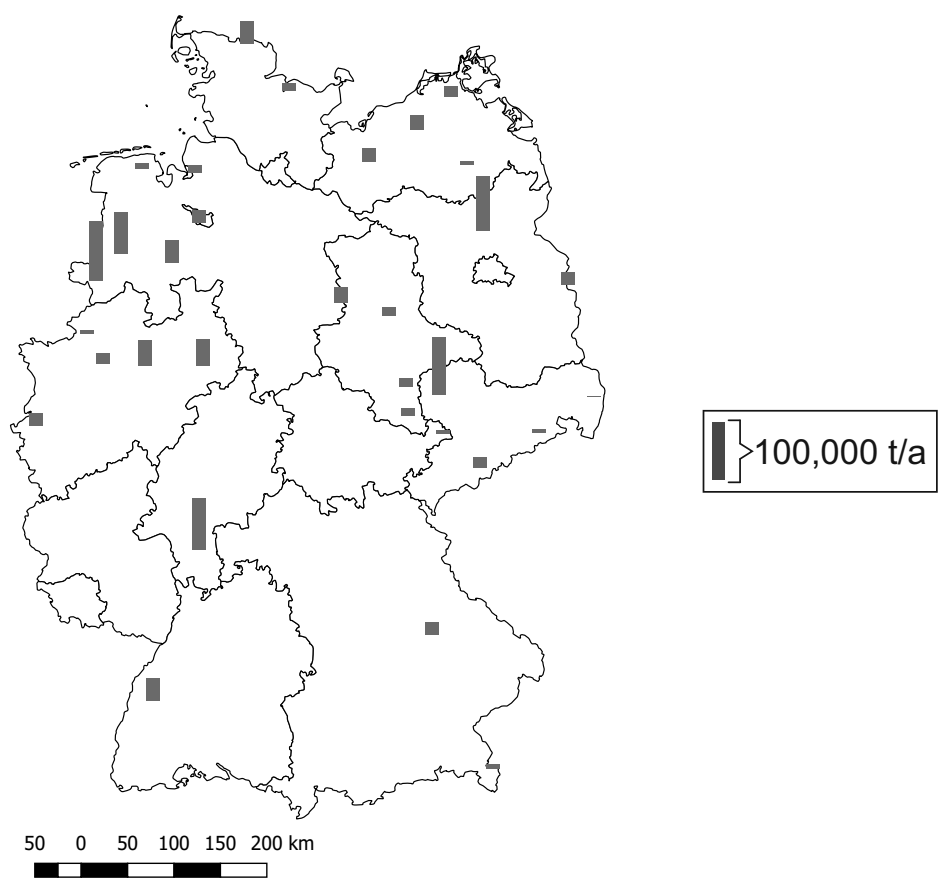

Figure 5.12: Spatial distribution of appearing establishments' sizes after a $50 \%$ centralisation of poultry slaughtering with 32 appearing and 96 vanishing establishments for the OptOptMin solution. Exact locations and sizes are given in table 5.9 (page 133).

The corresponding maximum solution shows a distinct flow pattern as well. It is visualised in figure 5.17 Here, the objective of realising maximum distances leads to strong overlaps but since the establishment locations are fixed, so are the maximum distances and output capacities. In consequence, the spatial flow pattern significantly deviates from that of the maximum solution for the location allocation problem.

As the last of the series, figure 5.18 shows the spatial relations for a flow assignment that is based on real-world macro flows. Hence, as expected, a similar dense and overlapping flow structure can be observed as it is shown for the initial population (figure 5.8).

Together, the overview and detailed results show that the model is valid. In other words, the different example results show that the various components of the model work as expected and produce plausible results. 
Table 5.9: Appearing establishments' location and output after a 50\% centralisation of poultry slaughtering with 32 appearing and 96 vanishing establishments for the minimum transport performance solution (OptOptMin)

\begin{tabular}{|c|c|c|c|c|}
\hline$\#$ & AGS & location name & output $(1000 t / a)$ & cumulated share (\%) \\
\hline 1 & 03456 & Grafschaft Bentheim, Landkreis & 105 & 10.30 \\
\hline 2 & 14713 & Leipzig, Kreisfreie Stadt & 102 & 20.27 \\
\hline 3 & 12065 & Oberhavel, Landkreis & 96 & 29.70 \\
\hline 4 & 06411 & Darmstadt, Kreisfreie Stadt & 91 & 38.63 \\
\hline 5 & 03454 & Emsland, Landkreis & 74 & 45.81 \\
\hline 6 & 05774 & Paderborn, Kreis & 47 & 50.45 \\
\hline 7 & 05915 & Hamm, Kreisfreie Stadt & 45 & 54.85 \\
\hline 8 & 03460 & Vechta, Landkreis & 40 & 58.79 \\
\hline 9 & 01001 & Flensburg, Kreisfreie Stadt & 39 & 62.64 \\
\hline 10 & 08317 & Ortenaukreis, Landkreis & 39 & 66.47 \\
\hline 11 & 03154 & Helmstedt, Landkreis & 27 & 69.09 \\
\hline 12 & 13072 & Rostock, Landkreis & 27 & 71.71 \\
\hline 13 & 13004 & Schwerin, Kreisfreie Stadt & 24 & 74.06 \\
\hline 14 & 03401 & Delmenhorst, Kreisfreie Stadt & 23 & 76.33 \\
\hline 15 & 09362 & Regensburg, Kreisfreie Stadt & 23 & 78.57 \\
\hline 16 & 12053 & Frankfurt (Oder), Kreisfreie Stadt & 23 & 80.77 \\
\hline 17 & 05370 & Heinsberg, Kreis & 22 & 82.94 \\
\hline 18 & 14521 & Erzgebirgskreis, Landkreis & 20 & 84.86 \\
\hline 19 & 13073 & Vorpommern-Rügen, Landkreis & 20 & 86.78 \\
\hline 20 & 05562 & Recklinghausen, Kreis & 19 & 88.61 \\
\hline 21 & 15003 & Magdeburg, Kreisfreie Stadt & 16 & 90.20 \\
\hline 22 & 15088 & Saalekreis, Landkreis & 16 & 91.73 \\
\hline 23 & 04012 & Bremerhaven, Kreisfreie Stadt & 14 & 93.11 \\
\hline 24 & 15084 & Burgenlandkreis, Landkreis & 14 & 94.46 \\
\hline 25 & 01002 & Kiel, Kreisfreie Stadt & 13 & 95.71 \\
\hline 26 & 03462 & Wittmund, Landkreis & 10 & 96.65 \\
\hline 27 & 09172 & Berchtesgadener Land, Landkreis & 8 & 97.46 \\
\hline 28 & 05554 & Borken, Kreis & 7 & 98.11 \\
\hline 29 & 16077 & Altenburger Land, Landkreis & 6 & 98.73 \\
\hline 30 & 14628 & Sächsische Schweiz-Osterzgebirge, Landkreis & 6 & 99.32 \\
\hline 31 & 13071 & Mecklenburgische Seenplatte, Landkreis & 6 & 99.89 \\
\hline 32 & 14626 & Görlitz, Landkreis & 1 & 100.00 \\
\hline
\end{tabular}




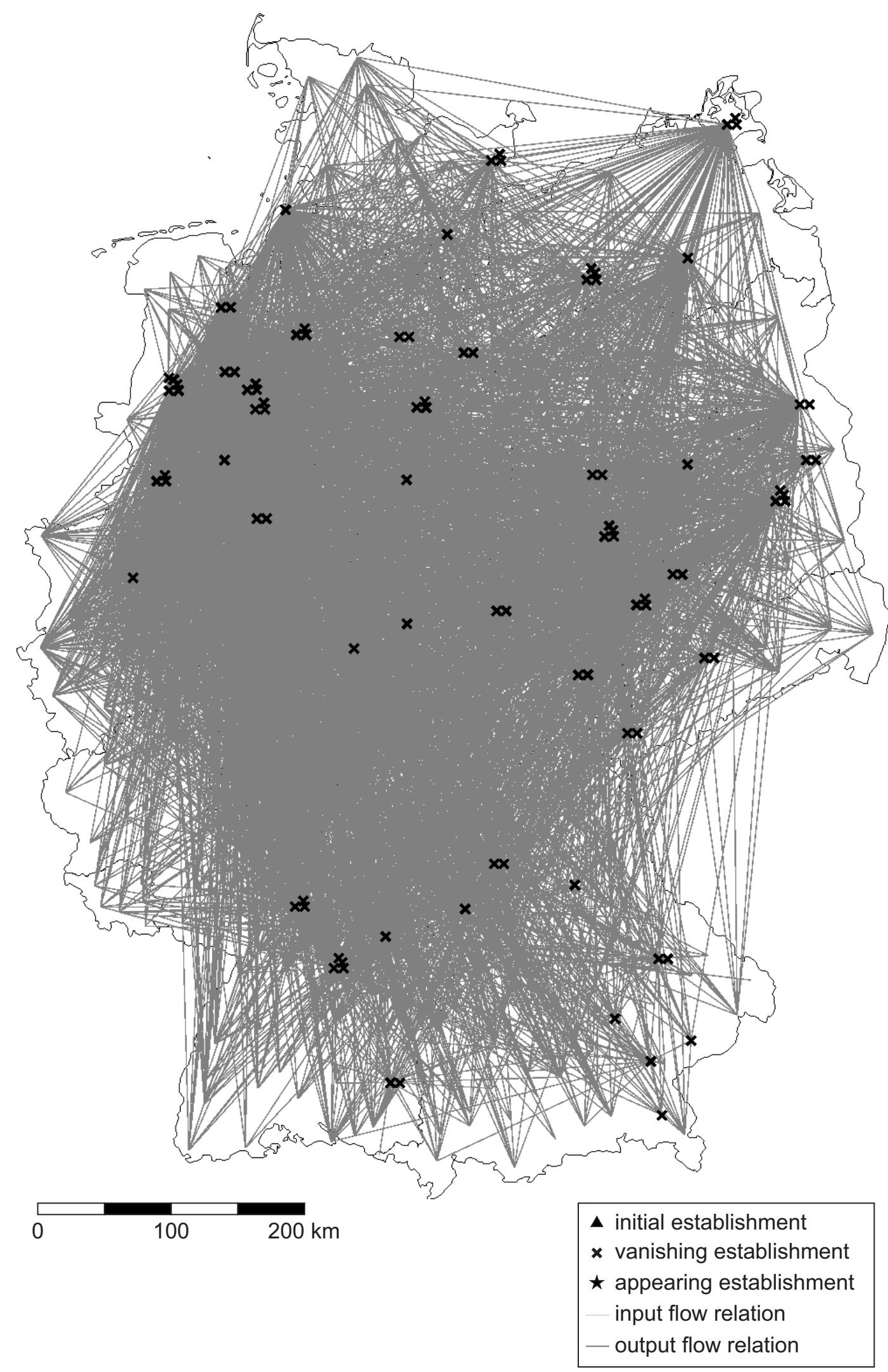

Figure 5.13: Map showing the 96 focal establishments (poultry slaughtering) that vanish during centralisation and corresponding flow relations 


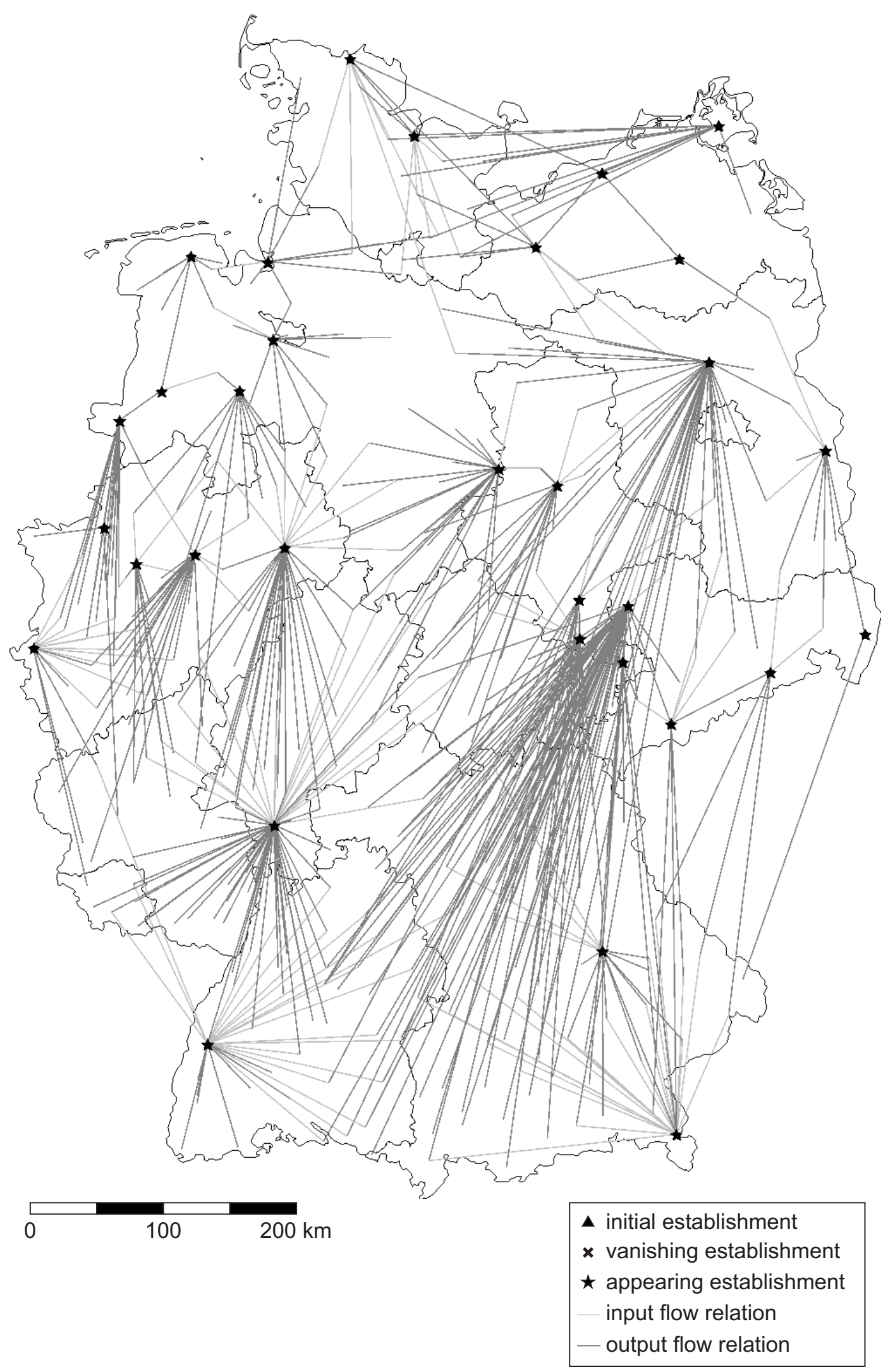

Figure 5.14: Map showing the up to 32 establishments that appear during centralisation of poultry slaughtering if optimal location choice, optimal assignment, and minimisation are assumed (OptOptMin) 


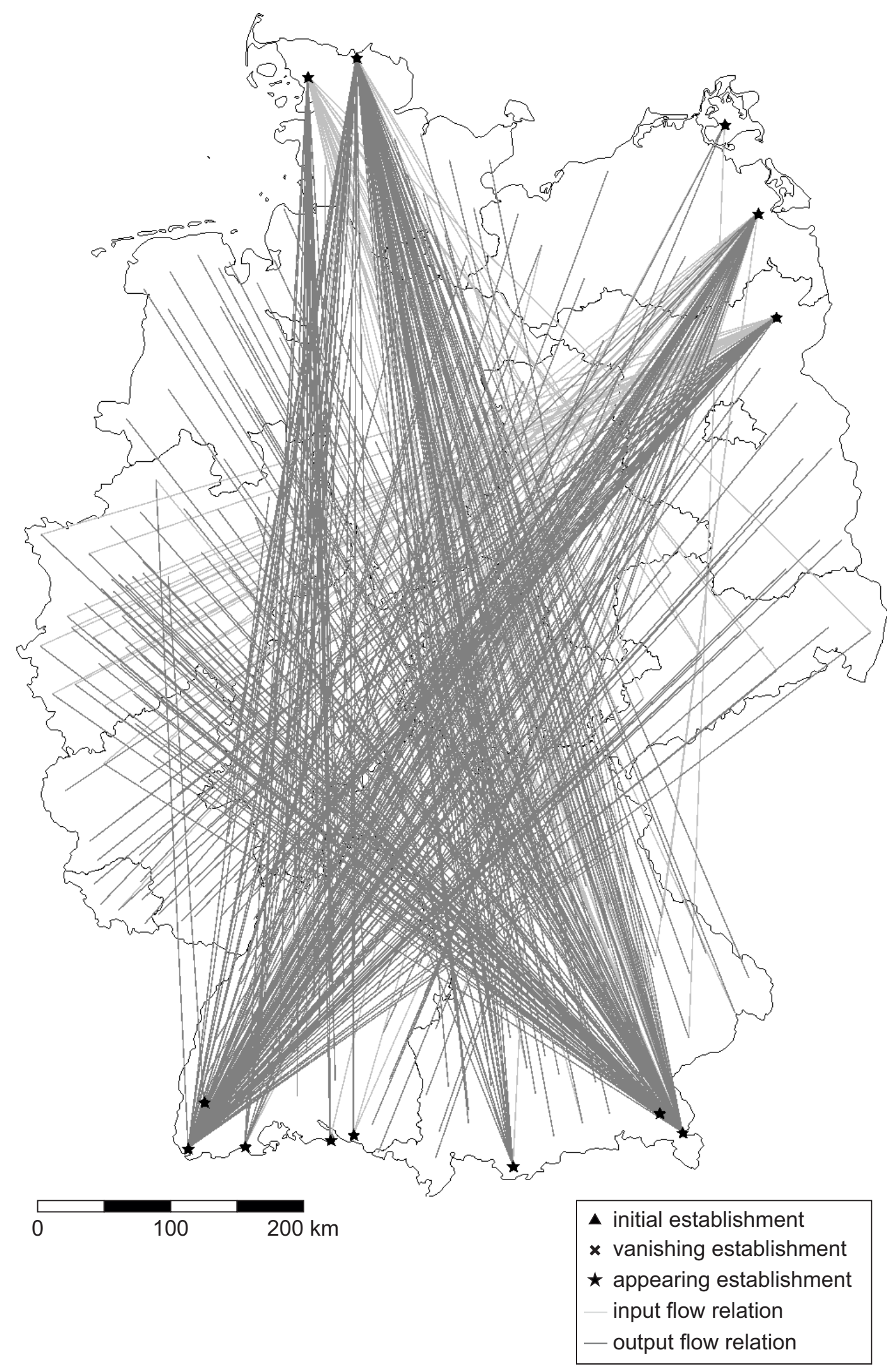

Figure 5.15: Map showing the up to 32 establishments that appear during centralisation of poultry slaughtering if optimal location choice, optimal assignment, and maximisation are assumed (OptOptMax) 


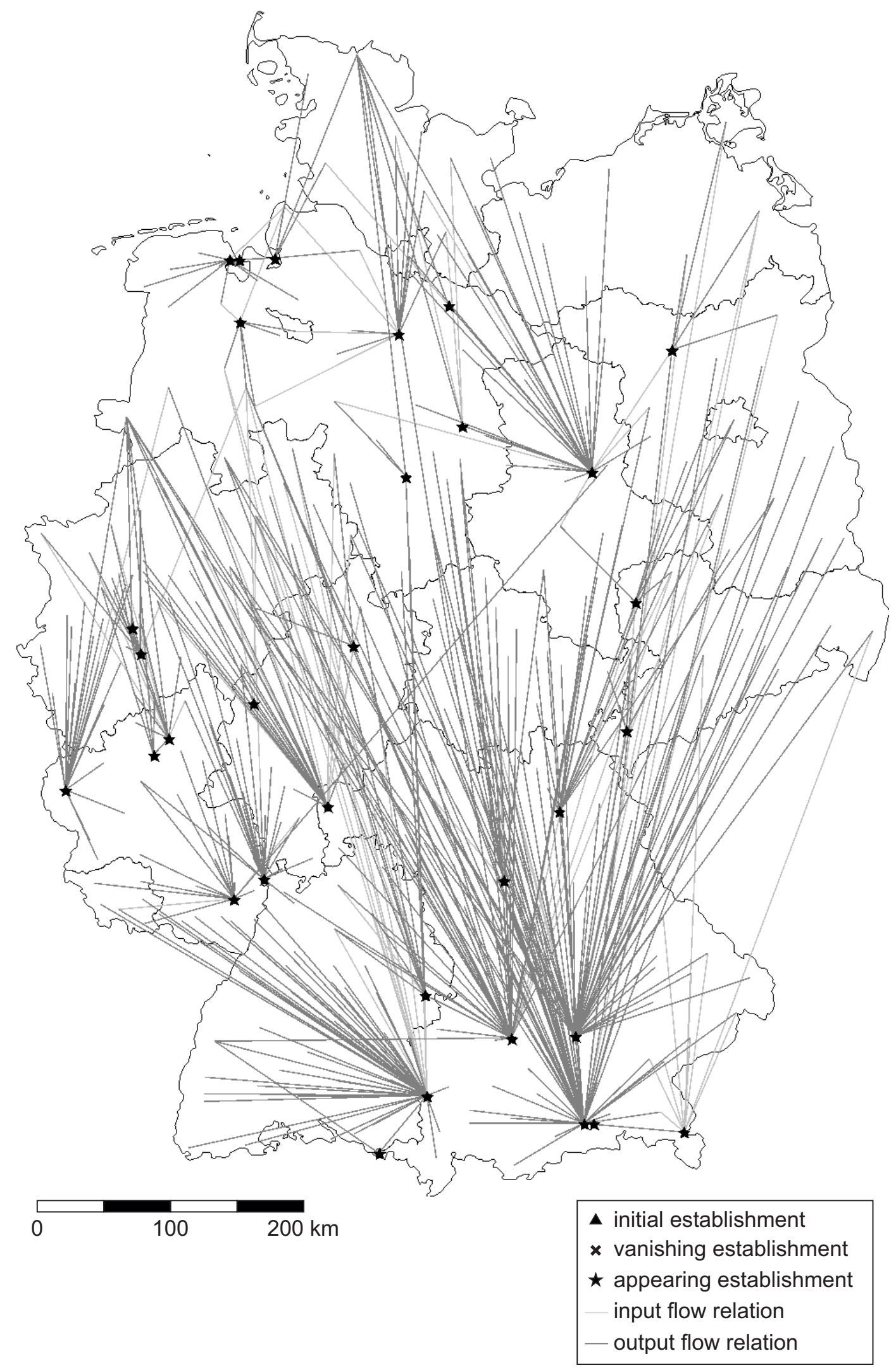

Figure 5.16: Map showing the 32 establishments that appear during centralisation of poultry slaughtering if stochastic location choice, optimal assignment, and minimisation are assumed (StochOptMin) 


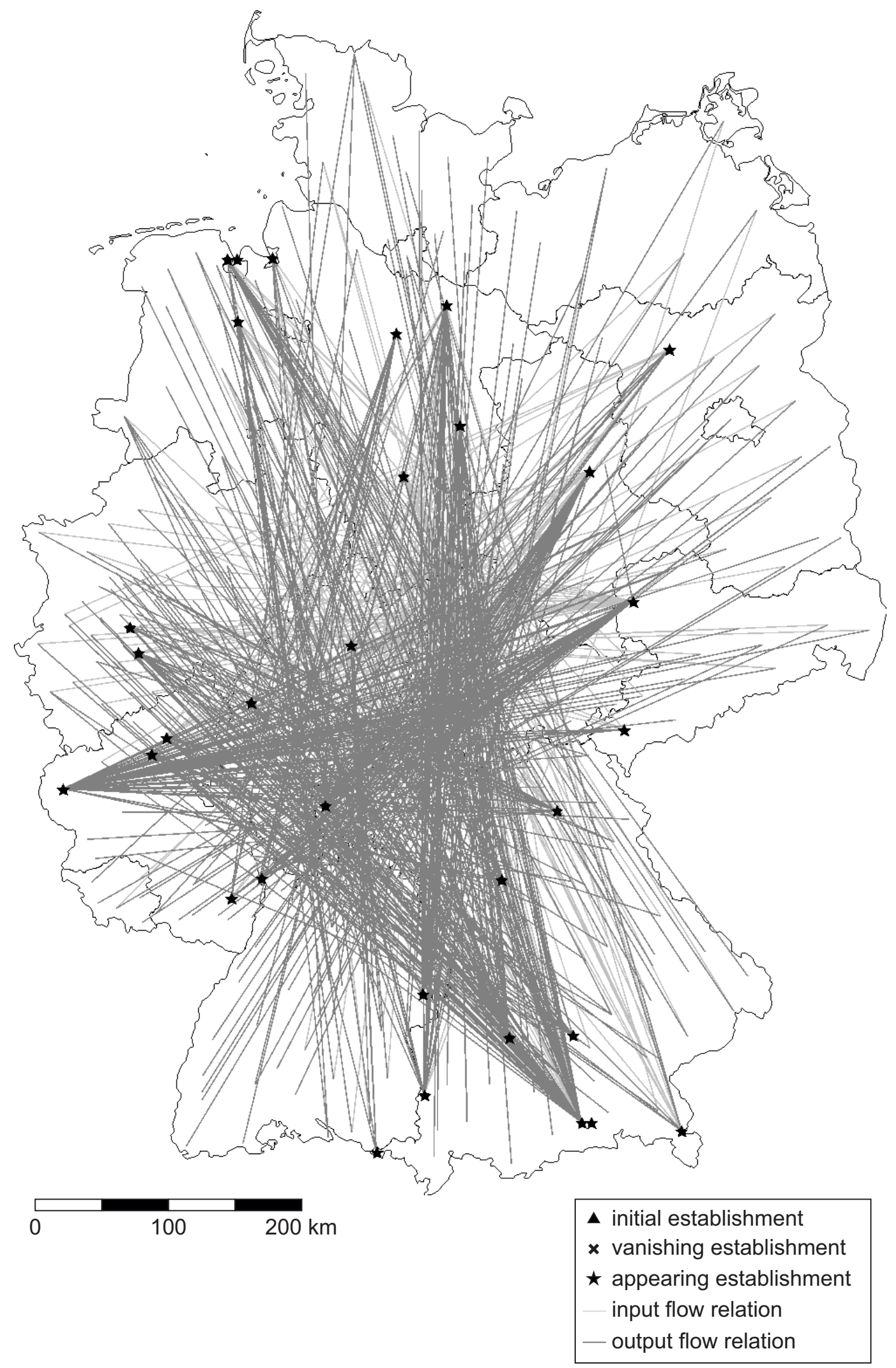

Figure 5.17: Map showing the 32 establishments that appear during centralisation of poultry slaughtering if stochastic location choice, optimal assignment, and maximisation are assumed (StochOptMax) 


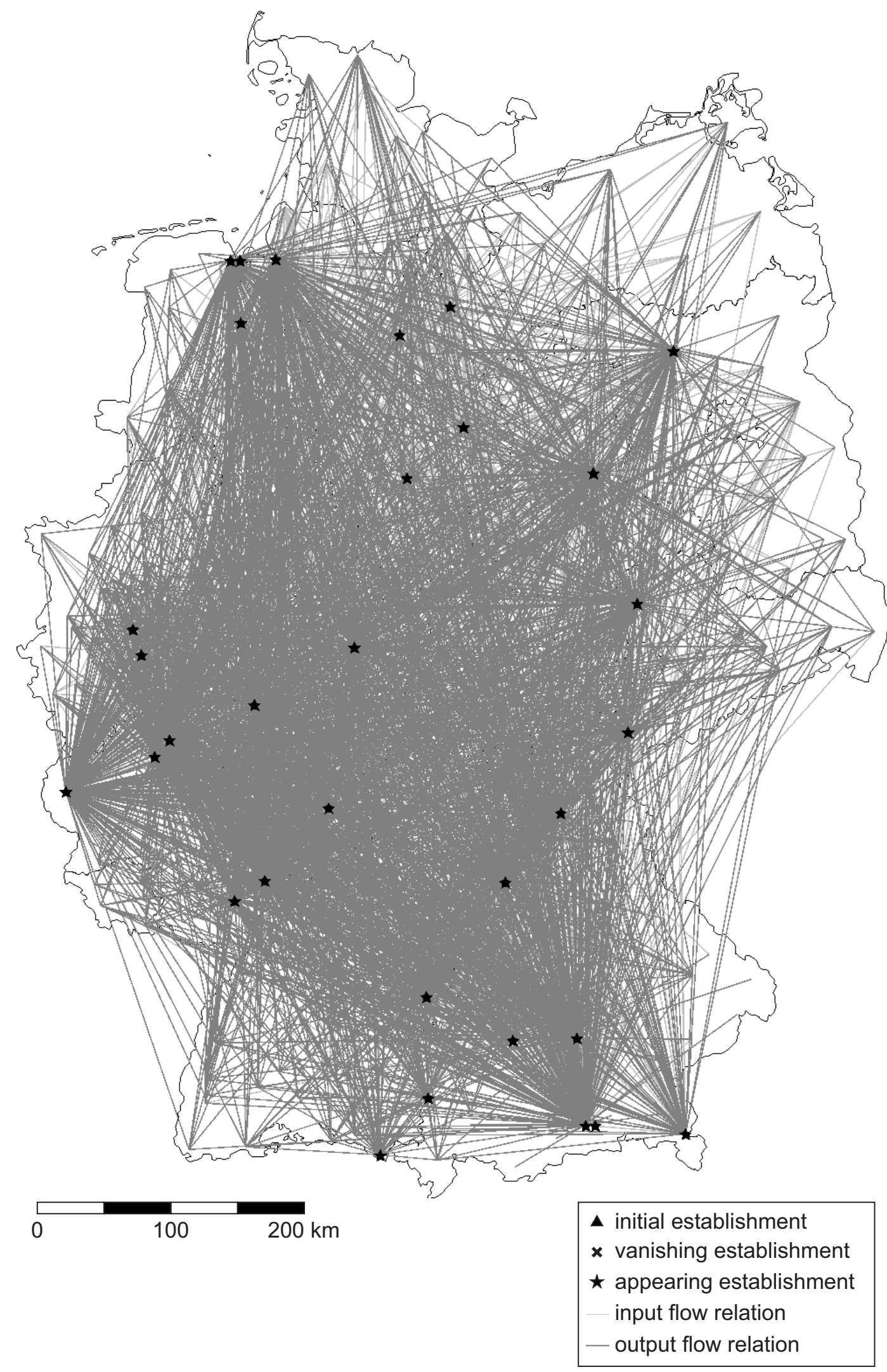

Figure 5.18: Map showing the 32 establishments that appear during centralisation of poultry slaughtering if stochastic location choice and macro flow assignment are assumed (StochMacro) 


\subsubsection{Potential Freight Transport Demand Related Measures in the Context of Supply Chain Restructurings}

From the perspective of transport planning and spatial planning the question arises whether the ongoing change in supply chain structures should be accompanied by regulative measures in order to foster positive and avoid negative effects, which would also pose the challenge of comparably measuring and balancing the heterogeneous kinds of possible impacts.

Interfering with the decision making and behaviour of involved actors is at the core of traffic and transport planning and management with the objective of ensuring the functioning and sustainability of the overall transport system. Here, the recent approach of freight transport demand management especially addresses opportunities for mitigating positive and negative effects of freight transport by applying bundles of transport management measures (Rühl and Boltze 2017). Typically, the corresponding measures are categorised by their objective:

- reducing traffic

- shifting traffic (spatial, temporal, modal)

- controlling traffic

Literature contains a wide range of possible measures for influencing freight transport, e.g. regional sourcing initiatives, temporal vehicle bans, speed limits, or spatially differentiated road pricing. Most of these measures interfere with parameters that are relevant to the decisions that determine supply chain structures as described in section 2.5. In consequence, it is to be expected that most freight transport oriented state measures at least indirectly influence supply chain structures. Examples of such cause-effect chains in the area of production, logistics, and traffic can be found in Boltze et al. (2017).

However, the developed model shows that supply chain structure effects are determined by the characteristics of disappearing establishments, appearing establishments, and the corresponding commodity flows. Hence, it is reasonable to limit the scope to those measures that directly influence these parameters. Referring to the above classification, measures that relate to establishment characteristics or the assignment of commodity flows in the context of change in supply chain structures, clearly belong into the categories of reducing traffic and shifting traffic (spatial).

In the context of supply chain structures, there are also state measures that potentially cause an increase in freight transport demand for the benefit of objectives beyond the transport system. However, the freight transport related impact of these measures depends on their influence on the characteristics on establishments and commodity flows. Example measures, especially for the context of the German poultry industry, are given below:

- disappearing establishments

- protecting establishments at locations with overall low economic prosperity

- protecting small establishments to increase product diversity

- appearing establishments

- favouring appearing establishments at locations with currently overall low economic power

- limiting appearing establishments' sizes and locations to avoid the creation of single points of failure

- assignment of commodity flows

- limiting the maximum or average distance of appearing establishments' commodity flows

- requiring the assignment of at least two suppliers per consuming location to create redundancy

It is important to emphasize that these measures are of hypothetical nature. They are supposed to illustrate immanent degrees of freedom that could potentially be used for interfering with the objective of meeting economic, transport, or risk related targets. The evaluation of the described measures' applicability faces two major chal- 
lenges: first, a limited direct transferability of model results in general; and second, an even more severe limitation lies in the legal requirements of potential measures. Addressing especially the second challenge, the following paragraphs give a brief overview of possible links to the existing regulatory framework for spatial planning in Germany.

Regarding the current legal situation, probably none of the measures above could be directly applied in Germany since they all heavily interfere with the entrepreneurial freedom guaranteed in the constitution (Grundgesetz article 12). An additional obstacle is to be found in the spatially and hierarchically distributed responsibility of responsible authorities. For example, regarding measures related to location choice in the presented context, the application scope would always require joint planning on the national level. However, the spatial planning system in Germany is hierarchically and federally organised as described in Scholl et al. (2007). Looking at the capabilities of the spatial planning law (Raumordnungsgesetz, ROG), which is pertinent to the national level, it does not offer any possibility for enforcing any specific location of a specific industry. The same holds true for the corresponding plans on the level of federal states (Landesentwicklungspläne). However, incentive based measures, e.g. subsidies for settling at certain locations, could be justifiable with the argument of pursuing objectives related to sustainable land-use. In this regard, the Raumordnungsgesetz defines "spatial structures are to be designed such that negative effects of traffic are reduced and additional traffic is avoided." (translated from Raumordnungsgesetz chapter 1 section 2 subsection 2 sentence 3, original version from 22.12.2008, last amendment from 31.08.2015).

If anyhow immediate regulatory interaction with private location choice is possible, only land-use planning on the level of municipalities (Flächennutzungsplan and Bauleitplan) could be used for enforcing desired restrictions on size or location of appearing establishments. Accordingly, recommendations and strategies for the location of industrial establishments can be found in literature, mostly focussing on freight transport intensive sectors like logistics, e.g. Allen et al. (2012) or Vallée (2012). However, discussions with experts from the corresponding local authorities have shown that the municipality often pursues own objectives, e.g. increasing local tax incomes as well as the availability of workplaces, that potentially conflict with the intended measures as desirable on the national level ${ }^{2}$.

In contrast to location choice, there already exists regulatory legislation on the level of commodity flow assignment for the slaughtering industry. Motivated by animal welfare during transport, the European Union has established Council Regulation (EC) No 1/2005 of 22 December 2004 on the protection of animals during transport (European Commision 2005), which sets a maximum journey time of eight hours for living animals that should not be exceeded. Loading and unloading already count into the journey time with an assumed minimum duration of one hour per procedure. Hence, the remaining four hours of journey time leave a distance of $360 \mathrm{~km}$ assuming a rather high average transport speed of $60 \mathrm{~km} / \mathrm{h}$. However, poultry is currently still excluded from this regulation as long as transported living poultry gets supplied with water and fodder if the journey time exceeds 12 hours, or 72 hours for living chicken (Chapter 5 of Annex I Council Regulation (EC) No 1/2005). In general, it is possible to extend the allowed journey time for all animals by measures that aim at improving animal welfare during transport. On the other hand, certain organic and sustainable food initiatives' certificates require shorter transport times for living animals, e.g. four hours for Bioland (Bioland 2016).

In summary, it is described above as at least difficult to interfere regulatorily with economic actors' decision making and resulting freight transport demand. This holds especially true for the sketched measures that directly relate to supply chain structures on a national scale. However, as a matter of fact, there already is a broad range of regulatory standards being applied that comes from areas like traffic and transport planning and management or animal welfare. Regarding the concept of freight transport demand management, soft measures like promoting

2 In general, it is also debatable whether public authorities should interfere with economic decision making as long as the pertinent regulations concerning common standards, e.g. regarding safety, environment, and society, are met. However, any further discussion in this direction is left untouched for the scope of this work. 
and supporting regional sourcing (e.g. as listed in Rühl and Boltze 2017), might be applicable especially when they share economic actors' objectives. Hence, it might be worthwhile to think about room for manoeuvres regarding potential measures and their impacts on freight transport demand as adumbrated in the section below.

\subsubsection{Model Applications for Impact Analysis of Example State Measures}

After giving potential measures in the section above, this section now illustrates how the developed model can be applied in the context of an impact assessment for measures that influence the supply chain structures. The impact assessment only considers freight transport. Hence, when thinking about the applicability of theses measures, it is to be remembered that freight transport demand is only one aspect within a broad set of target dimensions for the application of state measures. For analysis, three separate situations are considered successively:

- As a starting point, a first analysis shows how the German poultry industry's establishments would be shaped if a central planning unit minimised overall freight transport performance.

- A second analysis is carried out for the application of a measure that restricts establishment sizes.

- Finally, a third study shows how freight transport performance changes if the entire industry was shifted abroad.

\section{Optimal Industry Layout for Poultry Slaughtering in Germany (Sector WZ 10.12)}

Before thinking about the design of actual measures, it is worth thinking about the underlying system with the intention of finding a hypothetical ideal setup. In this context, this would be a setup of the poultry supply chain that leads to minimum freight transport performance.

The presented model is capable of finding such a combination of establishment sizes, locations and commodity flows for poultry slaughtering. This is achieved by simulating a change in the supply chain structure that assumes a complete vanishing of establishments and allows for an unlimited number of appearing establishments. Applying these assumptions, the minimising solution with optimal location choice and optimal assignment of flows finds an industry layout that delivers the absolute minimum freight transport performance. Hence, this solution could be used as a benchmark for assessing measures that influence the industry's freight transport demand.

The corresponding solution for the poultry slaughtering industry is illustrated on the right side of figure 5.19. The map uses bars for describing the spatial distribution of production volumes as required for achieving a minimum freight transport performance. As adumbrated in the map and verified by the detailed model output data (appendix B.1), the optimal layout proposes a combination of few large establishments and many very small sites.

In numbers, the fourteen largest establishments account for more than $50 \%$ of the entire sector's production volume, while the other $50 \%$ are provided by an additional number of 183 establishments. However, the optimal solution also recommends a stronger spatial dispersion of production compared to the status quo, which is shown on the left side of figure 5.19 .

The corresponding distribution of output volumes across establishments size categories is shown in figure 5.20. Together, the spatial distribution of production and the distribution of output across establishment size categories show, that the optimal solution proposes the creation of overall slightly smaller and spatially more distributed establishments. This is also reflected in lower values of the Krugman concentration indices for the optimal solution compared to the current layout as shown in table 5.10. 

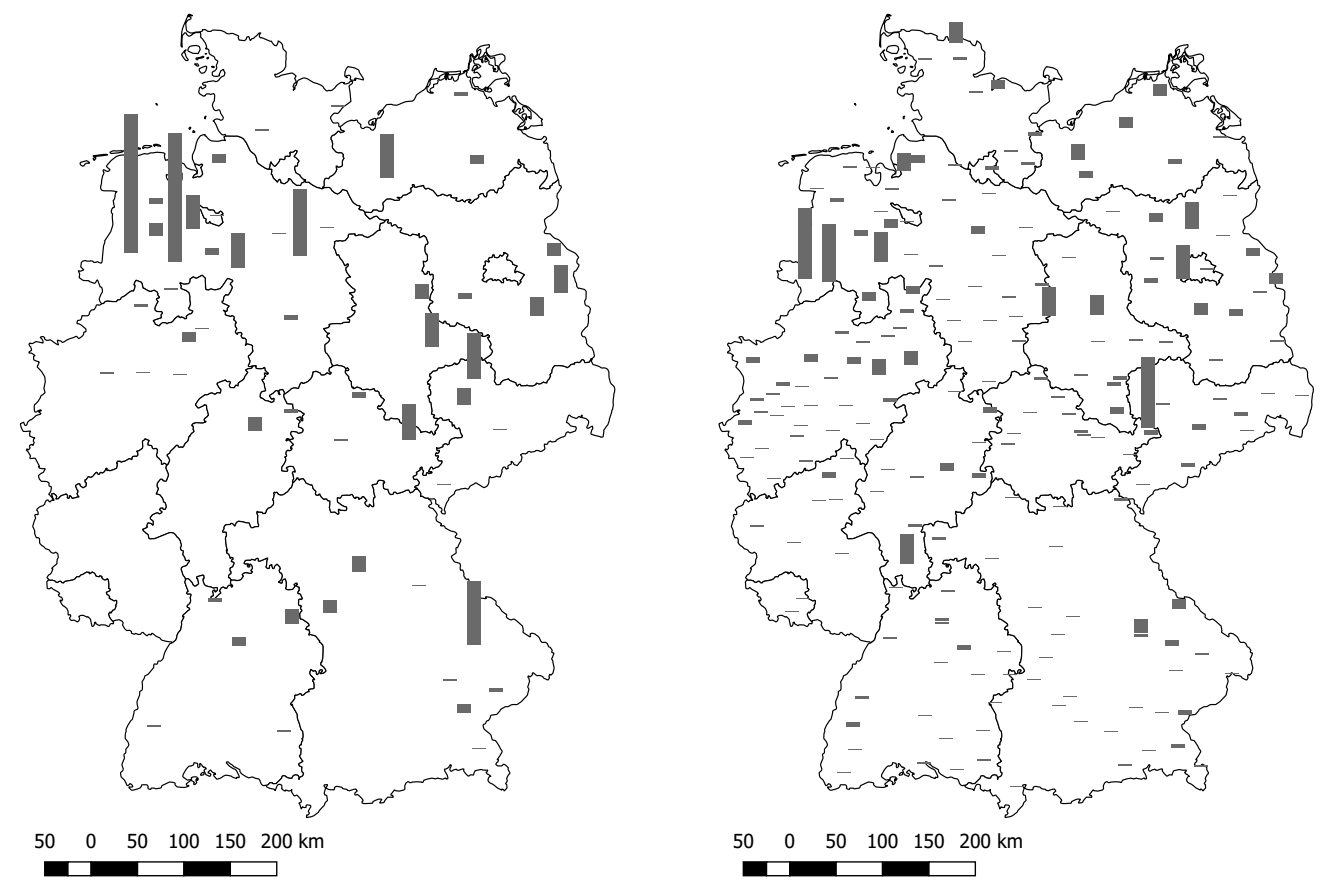

$100,000 \mathrm{t} / \mathrm{a}$

Figure 5.19: Poultry slaughtering's spatial layout and output for status quo (left) and minimum transport performance situation without restrictions (right). Bars represent annual output on zone level. Their scaling is identical for both maps. For numerical information see section B.1 (page 209).

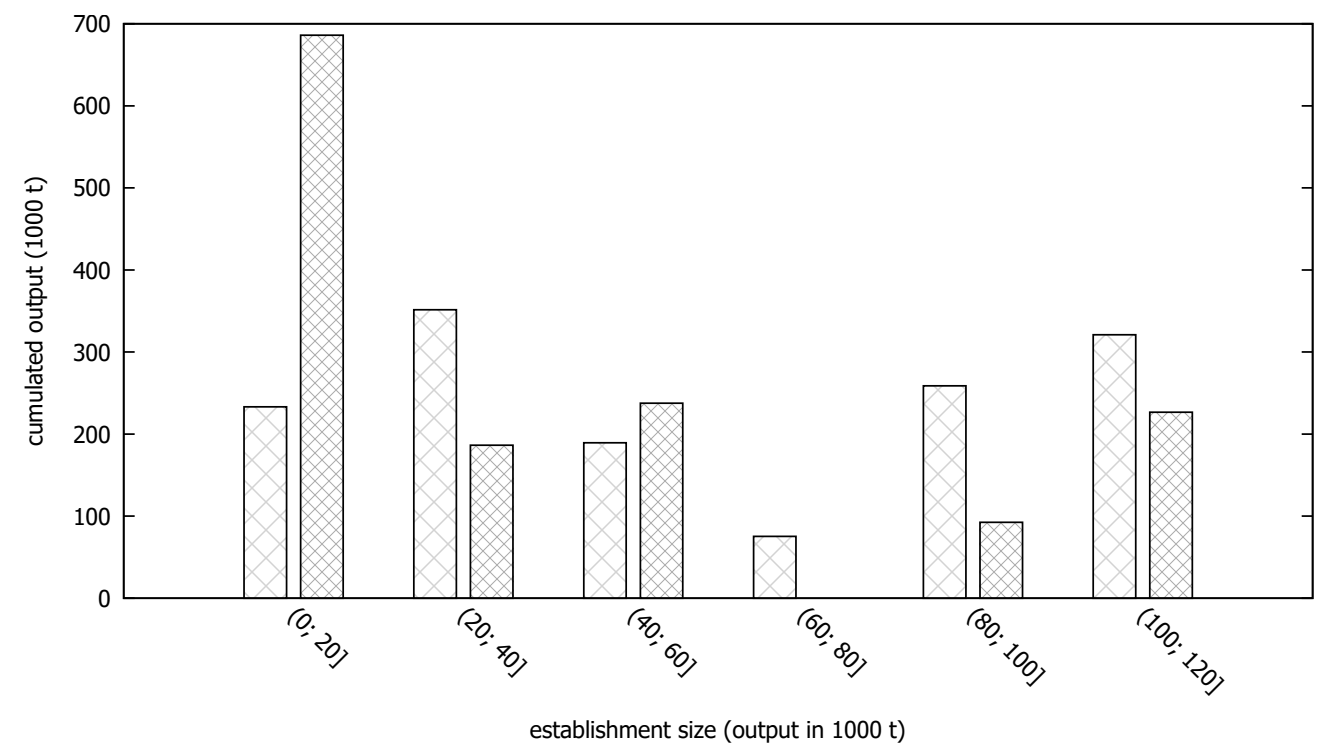

before $\square$
after $\square \square$

Figure 5.20: Barchart comparing the distribution of establishment outbut by size categories in status quo (before) and optimal layout without further restrictions (after)

Table 5.10: Krugman concentration indices (calculated according to equation 5.2) for the poultry slaughtering industry's (WZ 10.12) status quo and unrestricted minimum freight transport performance layout

\begin{tabular}{l|ccc}
\hline & \multicolumn{3}{|c}{ CONC $^{\text {for }}$} \\
solution & $s^{*}=$ population & $s^{*}=$ uniform distribution & $s^{*}=$ area \\
\hline status quo & 1.79 & 1.78 & 1.65 \\
minimum transport performance & 1.41 & 1.37 & 1.37 \\
\hline
\end{tabular}


Leaving behind the assumption of an unrestricted number of establishments, the next interesting question is, how optimal establishment sizes and respectively the optimal spatial distribution of production changes, if the number of establishment locations is reduced, i.e. different degrees of centralisation are assumed.

To start with, table 5.11 shows how establishments are distributed across size categories by output for various degrees of centralisation, i.e. different number of establishments in the industry. For reference, the status quo distribution is included in the first row.

As already presented for the unrestricted optimal solution, the optimal solutions with reduced establishments counts also all propose the creation of larger establishments if compared to the status quo. Looking at the data, the required production volumes are taken from the category of establishments with the lowest annual output. Comparing the different solutions, the pattern of creating few but large establishments for a minimum transport pattern seems to be robust for the given layout of the surrounding industries.

Table 5.11: Optimal and status quo establishment sizes for the poultry slaughtering industry (WZ 10.12) if assuming different numbers of establishments

\begin{tabular}{|c|c|c|c|c|c|c|c|}
\hline \multicolumn{2}{|c|}{ assumptions } & \multicolumn{6}{|c|}{ number of establishments with output $(1000 \mathrm{t})$} \\
\hline solution & \# ests. $^{1}$ & $(0 ; 30]$ & $(30 ; 60]$ & $(60 ; 90]$ & $(90 ; 120]$ & $(120 ; 150]$ & $(150 ; 180]$ \\
\hline status quo & 128 & 112 & 9 & 4 & 3 & & \\
\hline $\min$. t. p. ${ }^{2}$ & unrestricted & 187 & 7 & & 3 & & \\
\hline $\min$. t. p. ${ }^{2}$ & 128 & 118 & 6 & 1 & 3 & & \\
\hline $\min$.t. p. ${ }^{2}$ & 64 & 52 & 7 & 2 & 3 & & \\
\hline $\min$. t. p. ${ }^{2}$ & 32 & 14 & 11 & 2 & 3 & 1 & 1 \\
\hline
\end{tabular}

However, it is still possible that the large establishments' locations significantly differ between the assumed establishment counts. Therefore, the spatial distribution of production is visualised for all solutions in figure 5.21. For reference, a map showing the distribution in the status quo is included in the bottom right of the figure.

The visual comparison of the optimal layouts shows that the spatial distribution of production is rather stable for the different solutions. Especially the solutions with 128 and 64 establishments show a high degree of congruence. Only the solution with 32 establishments slightly differs from the previous two by recommending significantly larger establishments in the south east and south west areas. In summary, the analysis shows that optimal spatial distribution for the poultry industry is rather robust against changes in the total number of establishments. Hence, the presented spatial structures could serve as a desirable target when developing measures with the intention of minimising freight transport.

So far, only the structural parameters and their impact on the optimal solutions have been discussed, i.e. establishment sizes and establishment locations, but the according values for freight transport demand have been ignored. Thus, this paragraph gives a brief insight into selected indicators for the different solutions presented above. The analysis is based on the information presented in table 5.12.

The indicator longest input distance gives the maximum distance that living poultry (WZ 01.47.9) needs to be transported in the assumed solution. Analogously, the indicator longest output distance describes how far the products of poultry slaughtering (WZ 10.12) need to be transported at maximum in order to supply the production 

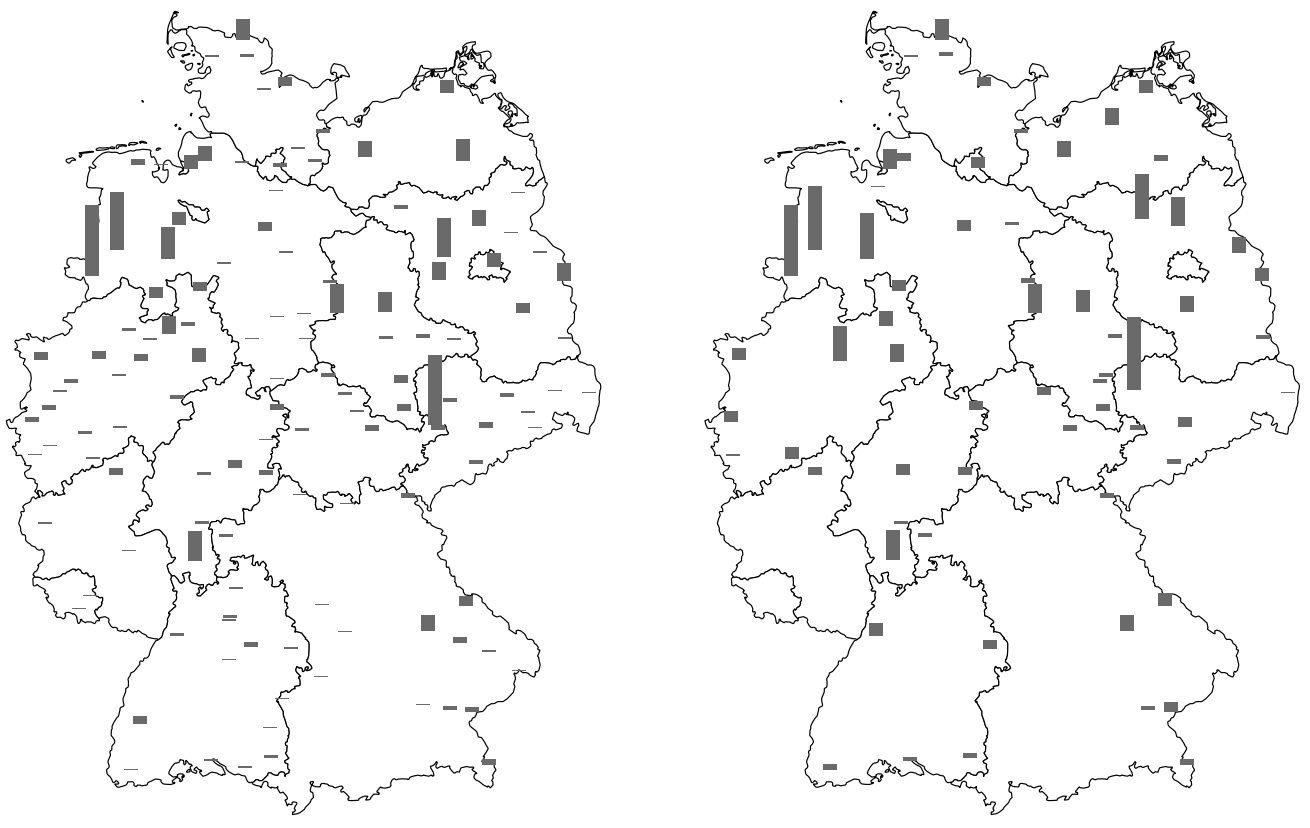

$100,000 \mathrm{t} / \mathrm{a}$

$\begin{array}{llllll}50 & 0 & 50 & 100 & 150 & 200 \mathrm{~km}\end{array}$

$50 \quad 0 \quad 50 \quad 100 \quad 150 \quad 200 \mathrm{~km}$
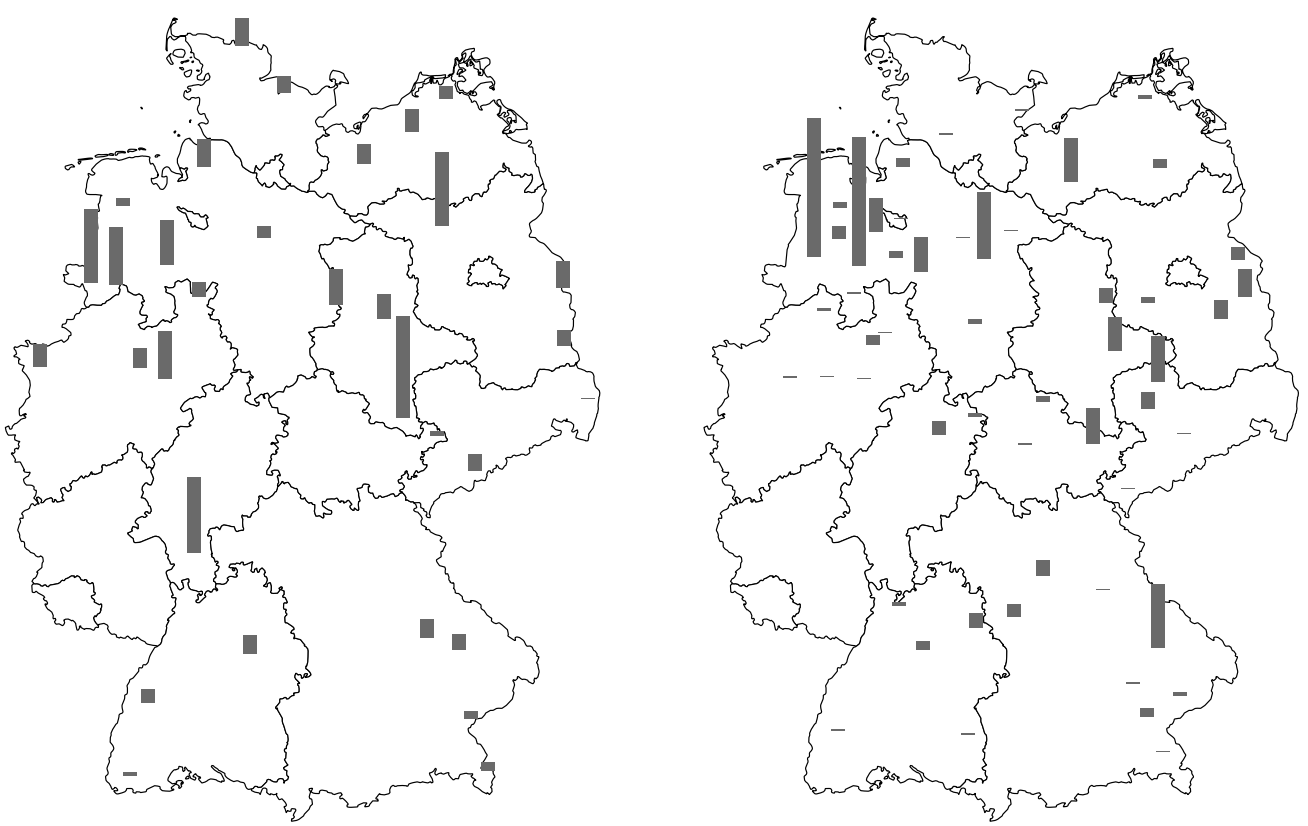

$\begin{array}{llllll}50 & 0 & 50 & 100 & 150 & 200 \\ \mathrm{~km}\end{array}$

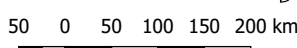

D.

Figure 5.21: Poultry slaughtering's (sector WZ 10.12) spatial layout and output for minimum transport performance using 128 (top left), 64 (top right), and 32 (bottom left) establishments. Status quo included for reference (bottom right). Bars represent annual output on zone level. Their scaling is identical for all maps. Corresponding data in appendix, tables B.2 to B.4. 
Table 5.12: Transport indicators for optimal and status quo industry layouts for poultry slaughtering (sector WZ 10.12) if assuming different numbers of establishments. Corresponding maps in figure 5.21 (page 145).

\begin{tabular}{|c|c|c|c|c|c|}
\hline \multicolumn{3}{|c|}{ assumptions } & \multirow{2}{*}{$\begin{array}{r}\text { longest input } \\
\text { distance } \\
(\mathrm{km})\end{array}$} & \multirow{2}{*}{$\begin{array}{r}\text { longest output } \\
\text { distance } \\
(\mathrm{km})\end{array}$} & \multirow{2}{*}{$\begin{array}{r}\text { total freight } \\
\text { transport performance } \\
(\text { million tkm/a) }\end{array}$} \\
\hline location choice & assignment & \# ests. ${ }^{1}$ & & & \\
\hline status quo & macro flows & 128 & 914 & 1154 & 776 \\
\hline status quo & optimal $^{2}$ & 128 & 397 & 680 & 490 \\
\hline optimal $^{2}$ & optimal & unrestr. & 139 & 725 & 310 \\
\hline optimal & optimal & 128 & 143 & 765 & 312 \\
\hline optimal & optimal & 64 & 227 & 785 & 321 \\
\hline optimal & optimal & 32 & 346 & 681 & 346 \\
\hline
\end{tabular}

${ }^{1}$ total number of establishments

${ }^{2}$ optimal $=$ minimum freight transport performance

of convenience food, the population, and exports. Finally, the indicator total freight transport performance gives an insight on the overall freight transport demand for the respective solution.

In the status quo, maximum input and output distances are rather high with $914 \mathrm{~km}$ and $1154 \mathrm{~km}$. Overall freight transport performance is 776 million tkm for this setup. Using the status quo spatial distribution of production but optimal assignment of commodity flows, freight transport performance could be brought down to 490 million tkm. In the solution with optimal location choice, optimal assignment, and no restrictions on establishments sizes, maximum input and output distances could be reduced down to $139 \mathrm{~km}$ and $725 \mathrm{~km}$. This would also lead to an overall reduction in freight transport performance to 310 million tkm.

For the optimal solutions with a limited number of establishments, the results show an increase in the maximum input distance while the maximum output distances remain rather stable. This is a direct result of the centralisation, which leads to the removal of decentral establishments that are in the proximity of low volume supply regions. In consequence, overall freight transport performance also rises, compared to the unrestricted solution, when the number of establishments is reduced. However, in every optimal solution freight transport performance remains less than half of the value in the status quo.

The analysis has brought up expected as well as unexpected results regarding parameters that are potentially relevant when designing measures for the reduction of overall freight transport, i.e. the indicator of freight transport performance. Regarding the spatial distribution of poultry slaughtering, a stronger dispersion is desirable compared to the current situation. However, the calculated optimal solutions propose the creation of a certain number of significantly larger establishments. Ideally, these should be accompanied by a number of small establishments. If the number of establishments needs to be reduced for any external reasons, this should be done at the cost of smaller establishments of freight transport performance shall remain as low as possible. However, any reduction in the number of establishments leads to an increase of freight transport performance in the optimal solutions. Summarising the findings above, the final assessment of measures that limit establishment sizes requires additional studies since simply setting maximum establishment sizes is not always reasonable if overall freight transport demand shall be reduced as shown in the examples.

Regarding measures that address transport distances, the optimal solutions give lower bounds for required distances for supply or consumption relations. The results clearly show that the number of establishments has a strong influence on the achievable maximum input transport distances if overall minimum freight transport perfor- 
mance is intended. Findings in this regard are especially helpful if the interest is on measures that aim at the animal welfare by enforcing harder limits on transport durations. However, the presented optimal solutions only give an insight on the possible minima. In consequence, they are of limited transferability for real-world applications.

Talking about limitations, it is essential to remember that the presented solutions do not consider any kind of costs related to the opening and running of establishments, which is especially relevant for real-world situations in which economies of scale play an important role for economic decision making. Furthermore, the model results do not consider the translation of commodity flows (PC) into vehicle movements (OD). Especially the smaller establishments proposed in the optimal solution have a high potential of requiring less than truckload transports, which are highly probable to cause significant amounts of empty running or detours for bundling reasons. In addition, the described application of the optimisation models assumes perfect substitutability of goods within sectors and unbounded rationality of all parties involved. Real-world experience shows that these are rather strong assumptions. However, those kinds of assumptions are inevitable for any study in this area.

\section{Impact of Establishment Size Restrictions}

In the previous section, it has been analysed how establishment sizes and locations should be chosen for poultry slaughtering in Germany if it was optimised by a central planning unit with the objective of achieving minimum freight transport performance.

Taking as a starting point the previously gained insight that a mixed population consisting of some large and a certain number of smaller establishments leads to minimum freight transport if they are located at the optimum locations and assigned optimal flows patterns, this section analyses how the model result changes if the optimal solution's establishment sizes are used but stochastic location choice in combination with minimising flow assignment or macro flow assignment is assumed. In addition, the impact of a measure that limits maximum establishments sizes is simulated in order to find out how it influences the range of resulting freight transport performance. A priori, it is expected that limiting maximum establishment sizes avoids the occurrence of extremely unfavourable layouts regarding freight transport performance.

Table 5.13 contains the results of the simulation studies that were carried out in this regard. The general setup is identical to the application above, which was used to identify optimal establishment sizes and spatial structures (data in appendix A). The number of establishments in poultry slaughtering (WZ 10.12) is set to 128. For the cases with restrictions on establishment sizes, overall production is assigned equally to the focal establishments. A relocation and reassignment of the entire focal industry is assumed in order to eliminate influences coming from the otherwise required selection of vanishing establishments. For comparability, the corresponding optimal solution is given in the first row of the table. In order to account for the stochastic character of the assumed undirected location choice, 100 simulation runs have been carried out per row, i.e. for each combination of assumptions. For the application at hand, optimisation solely stands for a minimisation of freight transport performance. On the one hand, this improves clarity of simulation results, on the other hand assuming a maximisation calculus would lead far beyond a reasonable worst case in the given context.

As expected, the results show that limiting establishments' sizes leads to lower values for freight transport performance if the corresponding indicators are compared directly for the restricted and unrestricted solutions. In other words, not only the overall solution range (values of $\min$ and $\max$ ) is lower for the restricted solutions but also the average and median values. Due to the partial overlap of the solution ranges, no strictly dominant solution can be identified. However, based on the lower values for median and average values the restriction of establishment sizes appears to be advantageous under the assumed circumstances. 
Table 5.13: Freight transport performance regarding the impact of establishment size restrictions for a count of 128 establishments in poultry slaughtering (WZ 10.12).

\begin{tabular}{|c|c|c|c|c|c|c|}
\hline \multicolumn{3}{|c|}{ assumptions } & \multicolumn{4}{|c|}{$\begin{array}{l}\text { observed simulation results } \\
\text { freight transport performance (million tkm/a) }\end{array}$} \\
\hline location choice & flow assignment & establishment sizes & $\min$ & $\max$ & average & median \\
\hline optimal $^{1}$ & optimal & optimal & 312 & 312 & 312 & 312 \\
\hline stochastic & optimal & unrestricted $^{2}$ & 534 & 901 & 713 & 706 \\
\hline stochastic & macro & unrestricted $^{2}$ & 862 & 1243 & 1039 & 1030 \\
\hline stochastic & optimal & restricted & 496 & 792 & 631 & 633 \\
\hline stochastic & macro & restricted & 827 & 1065 & 953 & 950 \\
\hline
\end{tabular}

${ }^{1}$ optimal assuming minimisation of freight transport performance

${ }^{2}$ unrestricted corresponds to sizes from OptOptMin solution with 128 establishments as described in table B.2

Regarding generalisability ${ }^{3}$, it must be noted that the given results only hold true for the given assumptions, which contain significant limitations compared to real-world situations. It is highly improbable that real-world actors will apply a fully stochastic location choice. For example, Friedrich (2010) shows that the logistics systems of food retailing can be explained following and optimisation calculus. However, it is also reasonable to assume bounded rationality and not transport optimal planning for real-world decision makers. In this regard, the presented results for a central holistic optimisation on the one hand and partially stochastic decision making with restrictions on the other describe the two diametric findings on the impact of restricting establishment sizes. For the design of actual freight transport demand oriented measures, it is highly recommended considering both findings. In this regard, the results show a valuable degree of transferability regarding actual real-world situations.

\section{Impact of a Spatial Shift of the Entire Industry}

Potentially, any regulatory intervention might lead to evasive reactions by the industry. Regarding the industry of poultry slaughtering, a very extreme reaction would be a complete offshoring, i.e. the relocation of the entire industry to foreign countries. This section briefly illustrates how the developed model can be used in order to simulate the impact on freight transport demand if such a shift took place.

For the application at hand, it is assumed that only the slaughtering industries relocates its establishments. The farming of poultry and the consuming sectors remain unchanged. Regarding the plausibility of these assumptions, the farming of poultry strongly depends on the availability of suitable land, especially for the disposal of animal waste as manure, which strongly reduces its mobility potential. Regarding the consumers of poultry meat, they are expected to show rather low sensitivity for a relocation since poultry meat and its transport account only for a part of their overall costs. Hence, the assumption of stable framing industries is reasonable especially for short to medium time horizons.

Regarding the application scenario, it is required to adapt the aggregate intersectoral flow volumes. It is assumed that neither living poultry is imported nor poultry meat is exported since production gets offshored completely. For the new location of poultry slaughtering it is assumed that the industry moves to those countries that currently export living poultry to Germany. The distribution of production among these countries follows the distribution of imports (table A.2, page 206).

3 Generalisability meaning "universal laws of nature that hold true without exception" according to Finfgeld-Connett (2010) and transferability standing for applicability of selected findings in new situations if situations are similar enough (adapted from Hellström 2008). 
The analysis focusses on the directly caused domestic freight transport. Therefore, it suffices to use the existing spatial system and locate offshored production to those zones that contain the corresponding border crossings. In consequence, this approach does not consider transport on foreign territory or induced through traffic.

For the scenario at hand, the overall freight transport volume sums up to 2.8 million t/a. Using the status quo industry landscape together with the adaptations regarding import and export, the initial model phase finds a solution according to the given macro flows with a freight transport performance of 603 million tkm/a. Leaving the establishments unchanged but optimising flow assignment, this value could be reduced to 375 million tkm/a.

Based on this initial solution, the simulation of spatial shift leads to an increase of freight transport to 860 million tkm/a if commodity flow assignment follows macro flow constraints. Applying optimal flow assignment with the objective of minimising freight transport performance, the model finds a value of 583 million tkm/a. The map in figure 5.22 shows the spatial flow pattern for the minimal freight transport performance solution. Due to the locations of shifted establishments being defined externally, the parallel location allocation optimisation is not applicable here.

In summary, this section proves the developed model's applicability in the context of complete or partial international spatial shifts of industries. In addition, the simulation results show that the complete offshoring is highly probable to cause an increase in freight transport performance. However, there is a slight overlap of solution ranges, which means that an optimisation in the flow assignment could theoretically compensate for the offshoring's potentially increasing effect. 


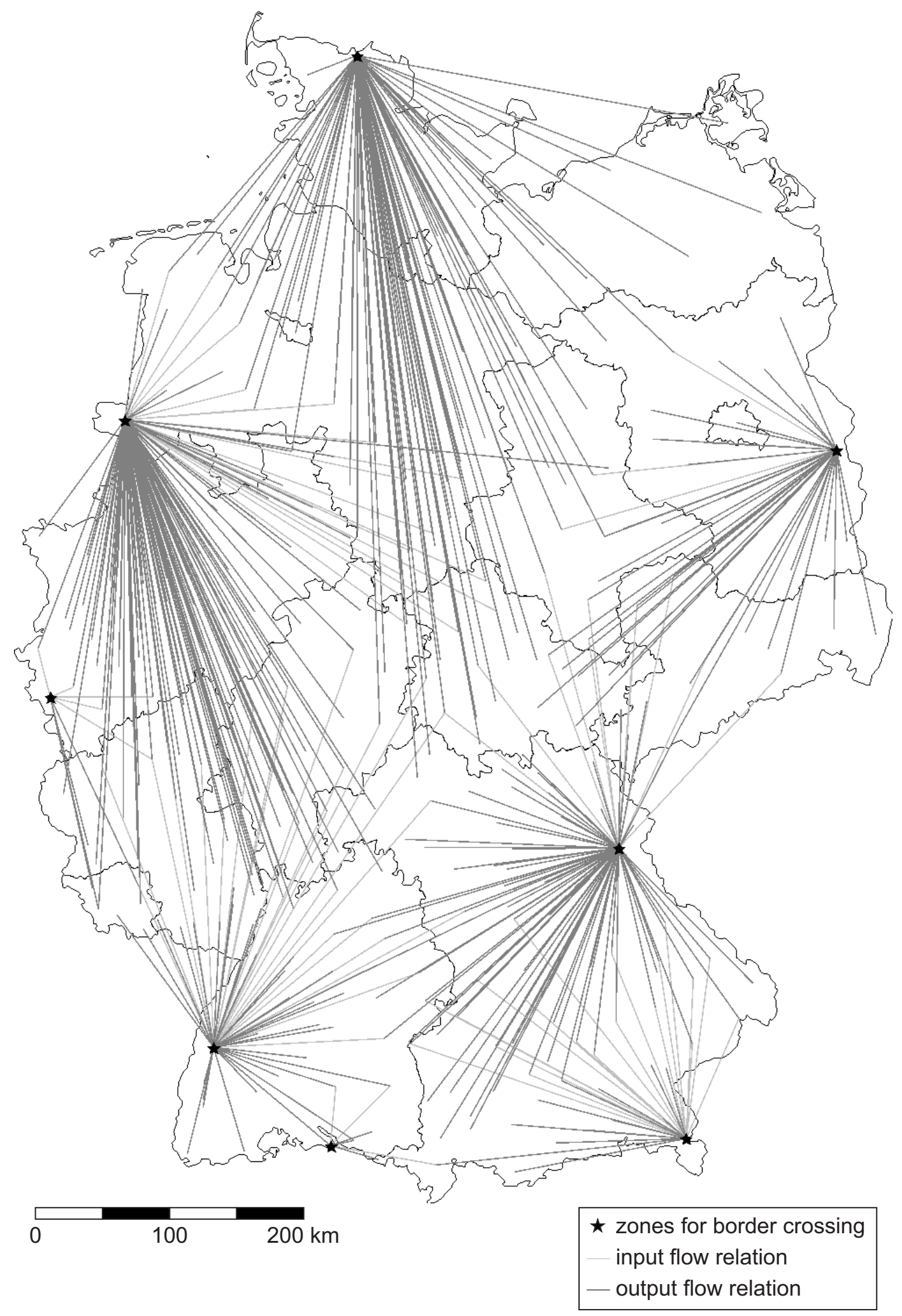

Figure 5.22: Map showing the domestic freight flows resulting from freight transport performance minimisation in the case of complete offshoring of poultry slaughtering (WZ 10.12). Assignment of volumes according to import data in table A.2 (page 206) in appendix. 


\subsubsection{Conclusions From the Example Applications in the German Poultry Industry}

The previous sections analyse a centralisation, i.e. reduction in the number of establishments, on the stage of slaughtering in the German poultry industry and its effect on freight transport demand. Summing up, the corresponding model applications produce several insights:

In a first step, the overall setting of the German poultry supply chains is introduced. Next, an overview of the relation between the different simulation methods regarding location choice and assignment of flows is given. In addition, first numerical results are presented that already show the influence of the different parameter combinations, which result from the various degrees of freedom in the model. Here, it is identified that a centralisation of poultry slaughtering potentially leads to an increase in freight transport performance. However, as long as there is a suitable range in the degrees of freedom for the optimisation problems, a transport optimised location of establishments or respectively assignment of commodity flows can compensate for this effect.

Digging deeper into the results in a next step, the model's first phase, which generates the initial artificial landscape before the application of any change, is validated by plausibility checks and comparing the generated commodity flow patterns with the externally given macro flows.

Analogously, a 50\% centralisation is used to validate the simulation of horizontal changes during the model's second phase. Therefore, the outcomes of the location allocation procedure (OptOpt), stochastic location choice and optimal assignment (StochOpt), and stochastic location choice and macro flow assignment (StochMacro) are discussed and visualised. The presented simulation results show that the model's second phase components work as expected, and in consequence the developed model is to be considered valid.

Analysing the different model results, it is to be found that there are various drivers for the growth of freight transport performance when simulating centralisation. The minimum transport solutions show that it is desirable to locate establishments of poultry slaughtering closer to the supply for inputs, which leads to higher distances in the output relations, due to the weight relation of input per output of approximately $2 / 1$. In addition, a centralisation, i.e. a reduction in the number of establishments below the optimal count, incurs an increase of freight transport demand since the locations of supply and demand remain unchanged, which in consequence requires longer transport distances for inputs and outputs. Another driver of freight transport performance is to be found in the location choice of appearing establishments. The model identifies the corresponding optimal locations but also shows the outcome when assuming probability driven location choices that may result from tradeoffs between factors within and beyond the freight transport system.

Based on these insights, the applicability of measures that influence the outcome of freight transport demand under changing supply chain structures are discussed, finding a general difficulty resulting from the necessity of interfering with independent economic decision making, given legal conditions, and a federal hierarchy of responsibilities at least for Germany. Nevertheless, freight transport oriented measures are applied in the realworld, motivating for a further analysis of potential measures that could be applied in the context of centralisation in the German poultry industry.

The corresponding model application shows that in an optimal industry setup, a population of large focal establishments together with a number of disperse establishments at the right locations provides a solution with lowest freight transport performance on the level of freight transport demand for goods. Challenging this result, the subsequent simulation of a measure that restricts maximum establishment sizes shows that limiting establishment sizes leads to lower average and median transport performance if not optimal but stochastic choice is assumed. Hence, these two different outcomes should be considered when it comes to the design of actual freight transport demand oriented measures. 
Finally, in a last application scenario it is simulated how an offshoring of the entire poultry slaughtering industry influences the corresponding domestic freight transport performance. This scenario illustrates the developed model's direct applicability for this kind of analysis. In addition, it is shown how the offshoring potentially leads to an increase in domestic freight transport performance. 


\subsection{Vertical Disintegration in the German Automotive Industry}

The section at hand addresses structural change in the form of vertical disintegration in the German automotive industry. This example application primarily serves as a proof of concept that the developed model is also capable of simulating vertical disintegration, which is a specific type of vertical change. In consequence, the section on the automotive industry is rather brief omitting details or variations that are not essential for proving the model's functionality. Nevertheless, the impact of vertical disintegration is described and fundamental insights gained from the example application are discussed whenever significant. The section is organised as follows: It starts with a description of developments in the automotive industry in order to derive the motivation for the further analysis of vertical disintegration and its interrelation with freight transport demand. Afterwards, the German automotive industry is systematised and an overview of data sources used in the context of the model application is given. Next, the scope of analysis and required assumptions for the application are defined. The next subsection addresses the outcome of the model's first phase and its validity. The discussion of the model's second phase's output starts with an overview of the range of results for different assumptions and their interrelations. For validation purposes, the results for a specific case are discussed in greater detail afterwards. The section closes with the conclusions that can be drawn from the example application in the automotive industry.

\subsubsection{Developments in the German Automotive Industry as a Motivation for Further Analysis}

The automotive sector is a vital and continuously developing industry in Germany (Garcia Sanz et al. 2007). It is an early adopter regarding new production concepts like just in time transports or modular sourcing (Collins et al. 1997). These developments in the organisation of production networks and production strategies are always accompanied by changes in the spatial structures of the industry. For example, Dyer (1996) compares the different spatial layouts of the automotive industry in Japan and the USA finding a direct interrelation of economic performance and spatial structure of supply networks. Kannegiesser and Günther (2014) and Kannegiesser, Günther, and Gylfason (2014) pursue a similar question in the context of the European research project LogMan (Logistics \& Manufacturing trends and sustainable transport), i.e. they develop an optimisation model on an international scale that aims at minimising the overall $\mathrm{CO}_{2}$ footprint the automotive industry considering the energy consumption of production and transport processes.

An often-cited indicator for the ongoing change within industries and national economies is the value added (OECD 2013) or respectively the ratio of value added per output in monetary units (calculated as ratio $=\frac{\sum \text { output }-\sum \text { input }}{\sum \text { output }}$ ). Looking at the German automotive industry, a significant decline of this indicator between 1967 and 2000 can be observed, stabilising around $20 \%$ in the following years as depicted in figure 5.23. The potentials and possible limitations for future development are still under discussion (Göpfert and Grünert 2012).

The decrease in the ratio of value added can be explained by causes that are potentially neutral to freight transport demand, e.g. a rise of the procured intermediates due to technological advances. However, part of the effect is related to modifications in the supply chain due to the implementation of new production and procurement principles, especially modular sourcing (see figure 2.19 on page 38), which often requires the establishment of specialized supplier sites in proximity to the manufacturing plants (Becker 2006; Parry and Graves 2008). Knorst (2004) especially emphasizes the effect of reducing complexity in car plants' supply relations if intermediate supplier sites are established that combine incoming spare parts to assembly ready modules. Shifting steps of production of assembly to (potentially new) establishments downstream the supply chain is called vertical disintegration or respectively outsourcing in the following. This change in the vertical supply structure is also addressed in section 2.4.1 (page 14) and further discussed based on statistical data for the automotive industry in the context of table 3.2 (page 53). 


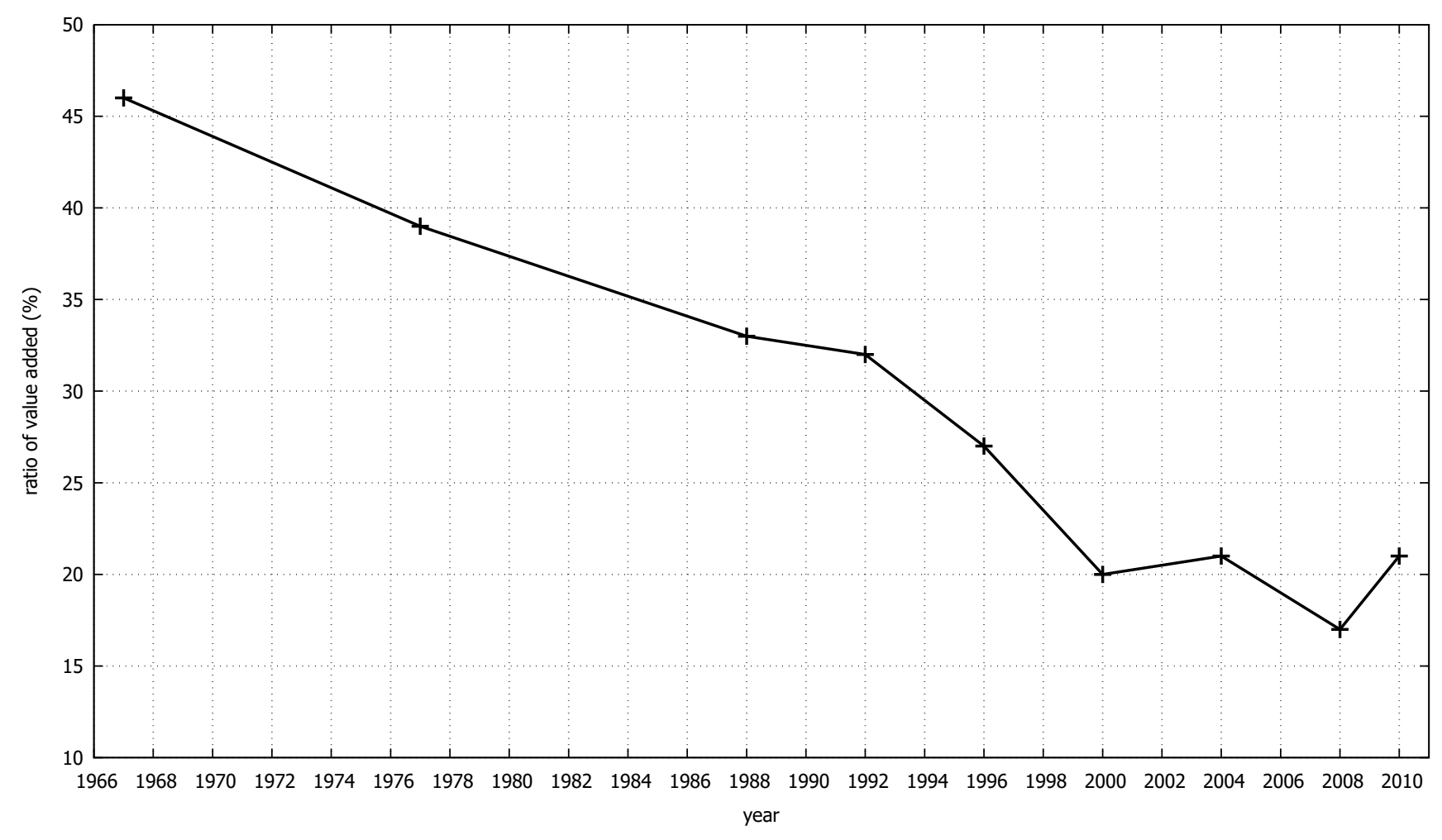

Figure 5.23: Ratio of value added in the German automotive industry. Based on data fom from VDA (2012).

However, the already discussed data does not give any insight on the impact of vertical disintegration on freight transport demand. Hence, the sections below give a first approach on how the developed model of supply chain structures and freight transport demand can be applied to simulate the range of possible outcomes based on the example of the German automotive industry.

\subsubsection{System Description and Data Sources Used for Scenario Construction}

The automotive industry can be structured into multi-echelon supply networks that are delimited by the assembly of vehicles at car plants. According to Klug (2010, p. 122) and others, there is a first tier of suppliers that deliver assembly ready modules directly to car plants. Suppliers for components are located on the neighbouring upstream stage of the supply chain, denoted as tier-2. With an increasing number of echelons between the current stage and the car plant, the type of produced goods gets more and more general, such that tier- 3 consists of suppliers that provide rather general parts for the subsequent production stages. The supply chains end at suppliers of raw materials, often denoted as tier- $n$.

For the model application at hand, only the supply relation between tier-1 and car plant is considered as shown in figure 5.24. This limited vertical scope suffices for the intended analysis of vertical disintegration since the location and sizes of outsourcing establishments on tier-1 as well as car plants are considered to remain unchanged. The numbers of vehicles produced per car plant in the application correspond to actual numbers for the year 2008 as provided by Automobil Produktion (2008). The total volume of commodity flows from tier-1 suppliers to car plants is estimated as $1 \mathrm{t}$ /vehicle, which is in a reasonable regarding the average weight of vehicles produced in 2008 being $1.5 \mathrm{t}$ (icct 2016, p. 60) and the sectoral relation as described in the input-output matrix (Statistisches Bundesamt 2014b) and statistics on consumed inputs by sectors (Statistisches Bundesamt 2009). In addition, due to the model's linearity and the consideration of a single commodity only, the model's spatial output is independent from the assumed volume. Regarding the calculated freight transport volumes and performance, only their scale is 


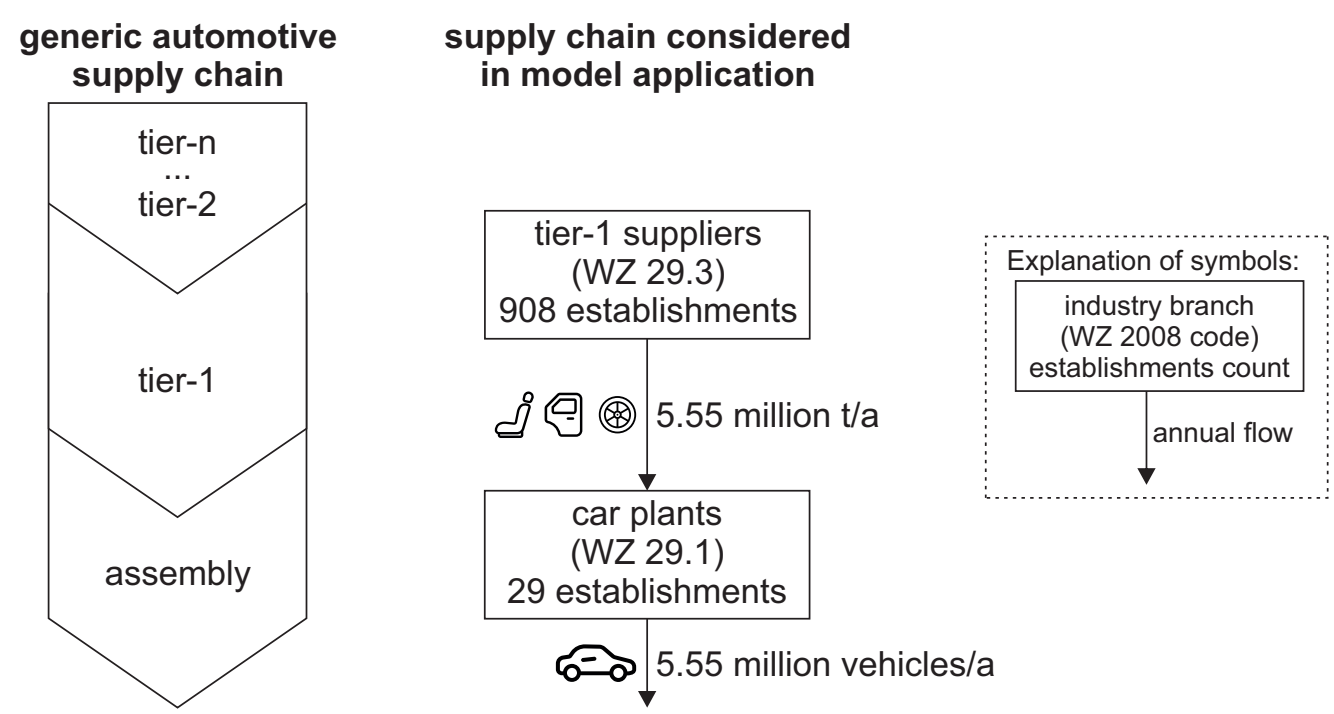

Figure 5.24: Automotive supply chain considered in model application for vertical disintegration. Industry classifications according to WZ 2008 (Klassifikation der Wirtschaftszweige), total flow volumes adapted from Automobil Produktion (2008)

influenced proportionally. In consequence, relative indicators of change that compare initial and simulated values are independent of the actual overall volume.

Regarding required model inputs, the locations and output volumes of car plants are taken from Automobil Produktion (2008). Suppliers are generated by combining spatial employment statistics (Statistisches Bundesamt 2013b) and statistical information on establishment sizes (Statistisches Bundesamt 2013a). Here, the industry classification WZ 2008 uses code 29 for the production of vehicles and parts thereof, with code 29.1 representing the actual production of vehicles and code 29.3 for the production of tier-1 suppliers.

Macro flow patterns are extracted from BMVI (2014) based on the data for NST 2007 section 12, which is a joint category for parts for vehicles as well as produced vehicles.

Parameters determining flow sizes are assumed reasonably due to the lack of comprehensive real-world data. The zoning system and distance metrics are identical to the application in the poultry industry (table 5.3). An overview of input data used in the automotive application is also given in table C.1 in the appendix (page 221).

The spatial setup of the tier-1 suppliers (left) and car plants (right) in Germany is shown in figure 5.25. The visualisation clearly shows a concentration of the supplying industry in the west and south of Germany. Looking at the 29 car plants and their locations, they are rather distributed in Germany without any unique pattern. However, this does not lead to an equal distribution of vehicle production in space. In fact, the enormous volumes manufactured at each of the limited number of car plants leads to a pattern of scattered locations with highly concentrated demand for input commodities, i.e. singular attractors of freight transport. In addition, the car plants do not only serve as drains for input materials but also as singular sources for produced vehicles, which then need to be distributed according to the different target markets. However, the distribution of vehicles and vertical disintegration within the upstream supply chain are independent and therefore not considered in the application at hand.

\subsubsection{Scope of Analysis and Required Assumptions}

As described above, the scope of analysis is limited to the relation of current tier- 1 suppliers and car plants. Hence, the model's first phase needs to generate an initial population that consists of establishments from these industries 

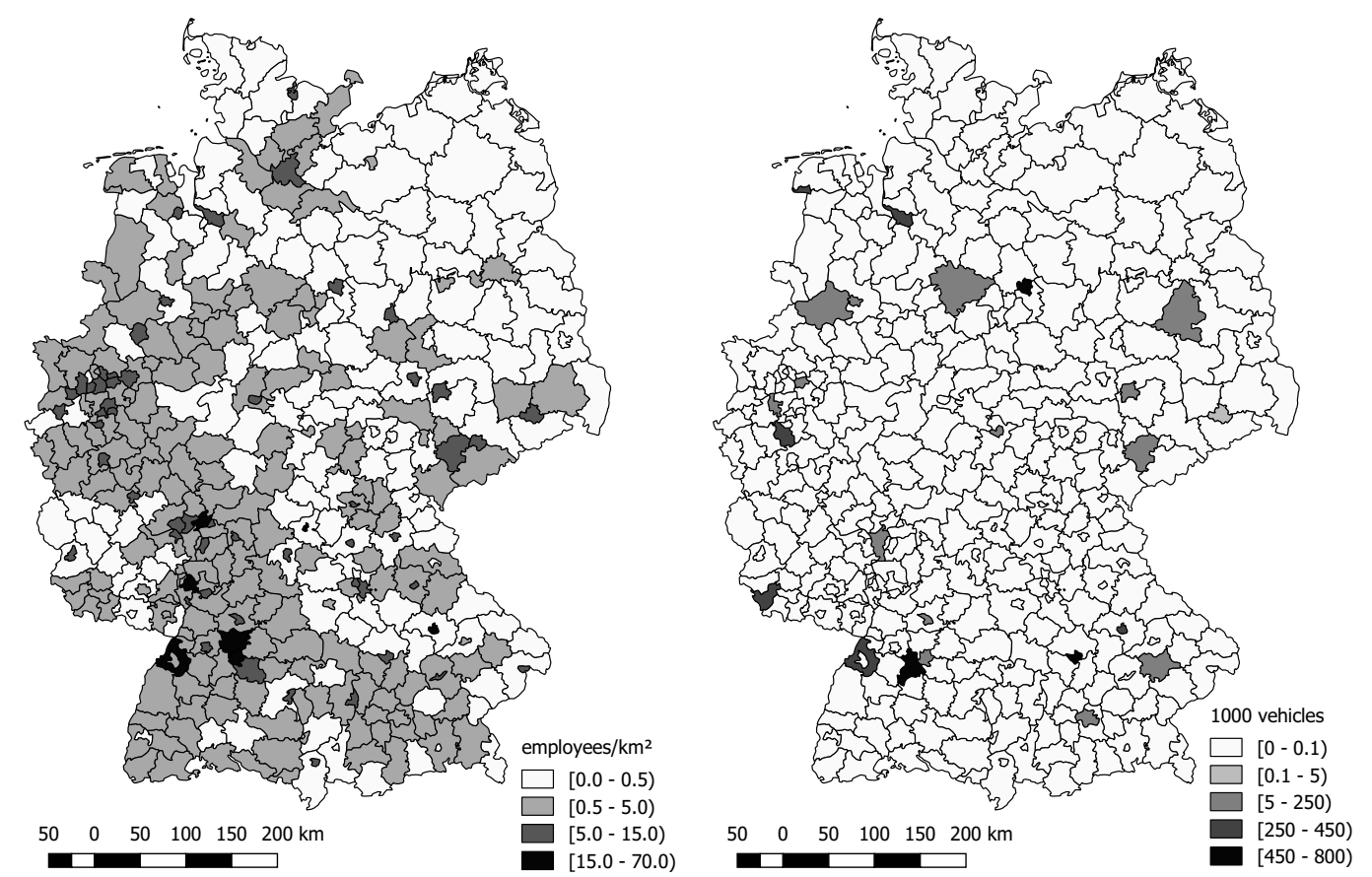

Figure 5.25: Density maps of automotive suppliers (left, employees $/ \mathrm{km}^{2}$, data from Statistisches Bundesamt 2013b) and assembly (right, 1000 vehicles produced annually/zone, data from Automobil Produktion 2008) for Germany

and commodity flows between them. As illustrated in figure 5.26, vertical disintegration of production is simulated based on this initial population.

It is assumed that the decision for the outsourcing of production is determined per supplying establishment. If a supplying establishment is decided to undergo outsourcing in the model, all of its outgoing commodity flows need to be rerouted via an establishment of a newly appearing stage of the supply chain. Hence, the first assumption to be made is the selection of outsourcing establishments, especially their count and locations.

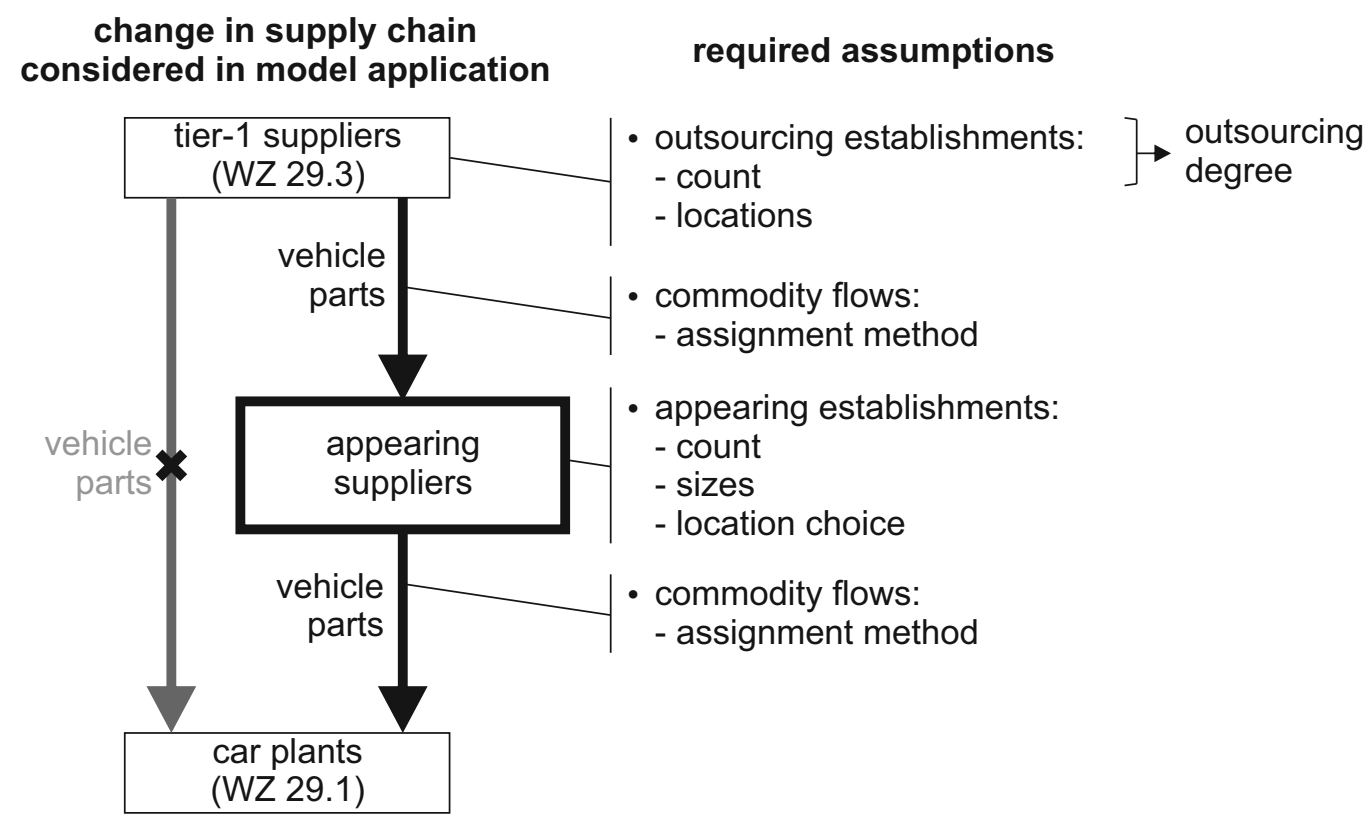

Figure 5.26: Overview of change in automotive supply chain for application and required assumptions 
A second set of assumptions addresses the appearing establishments' characteristics, i.e. their total count, their sizes and locations. While the total number of appearing establishments needs to be given externally, sizes and locations can be either given externally, simulated stochastically, or be the result of optimisation.

The assignment of commodity flows to and from appearing establishments can be achieved either according to given macro flows or optimisation. Like in the case of centralisation, the optimisation can address location and allocation in parallel (OptOpt) or combine stochastic location choice with optimal assignment of commodity flows (StochOpt). The optimisation models minimise or respectively maximise freight transport performance (e.g. StochOptMin or StochOptMax).

Now, after describing input data and required assumptions, the following section addresses the validation of the model's first phase's output before continuing with a discussion of the results regarding the impact of vertical disintegration as simulated in the model's second phase in a subsequent section.

\subsubsection{Partial Validation For the Output of Model Phase 1}

The artificial landscape of establishments and commodity flows generated in the model's first phase is shown in the map of figure 5.27. Even if the crowded and overlapping commodity do not allow for much analytical insight, the locations of generated establishments for suppliers as well as car plants clearly represents the spatial distribution of the statistical input data as visualised in figure 5.25.

Looking at the generated commodity flows, they show an average distance of $273 \mathrm{~km}$. The corresponding macro flow data shows an average distance of $260 \mathrm{~km}$, which corresponds to a deviation in the average distance of input data and generated flows of $4.6 \%$. The difference in average distances is to be explained by the sparse pattern of destination zones that results from low number of car plants but each attracting enormous volumes. In addition, the macro flows do not only contain unassembled parts but also the distribution of produced vehicles, which requires flows that are potentially diametrical to the inbound flows of input materials. In summary, a deviation of below $5 \%$ is acceptable since the intended analysis especially addresses the impact of structural change and therefore only requires a structurally realistic reference population and not a perfectly matching representation of real-world conditions.

Regarding the plausibility of flows on establishment level, the number of outgoing flows per establishment is between 1 and 22 with an average of 5.7 flows. On the receiving side, car plants have between 50 and 265 incoming commodity flows with an average number of 177.6 flows. If compared with data available from case studies, e.g. Corsten and Gabriel (2004) and Iddink (2010), these values are within a reasonable range.

Due to the disaggregate and specific approach used in the application at hand, it is possible to compare the generated population of establishments and especially commodity flows to case studies from literature. For example, Flender (2010) provides a snapshot of data on incoming transports, i.e. shipments, for a car plant in Wolfsburg, which corresponds to zone 03103 in the spatial system used in the application at hand. However, it is important to distinguish between commodity flows and shipments. In the model at hand, commodity flows represent annual flow volumes. Hence, they are annual aggregations of shipments on a certain transport relation. Remembering this difference, it is helpful to compare transport volumes by distance from the case study with the simulated data for commodity flows. In addition, it is also to be noted that the case study data has been extracted from a three dimensional chart, leading to sufficient precision for conclusions on the overall plausibility but obviously only with limited accuracy. Thus, the comparison task below should be seen as an interesting approach of using new sources for validation instead of a final assessment of the model output's quality. 


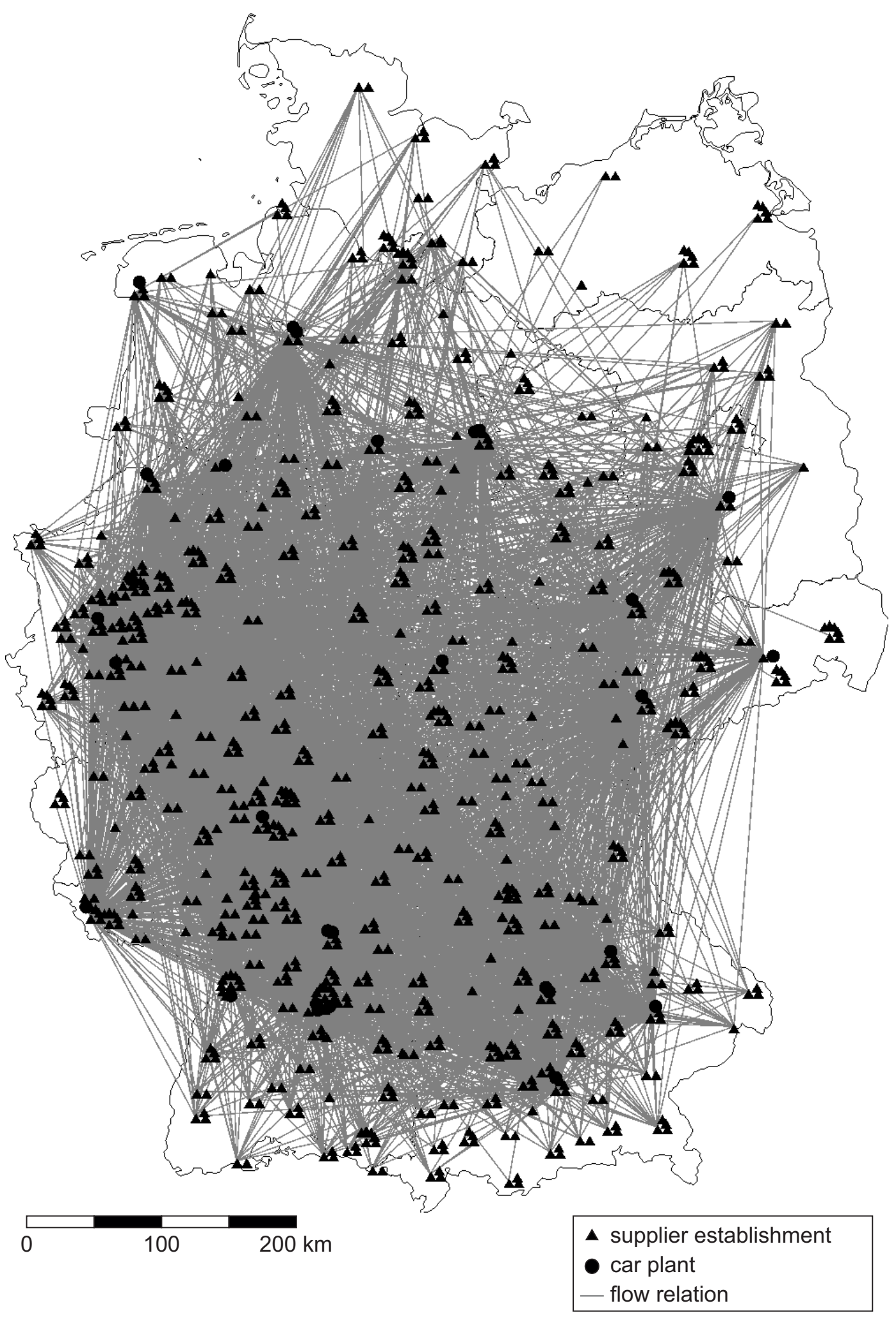

Figure 5.27: Map of tier-1 suppliers, car plants, and flow relations after model phase 1 
Table 5.14: Commodity flow distances for the initial population in the automotive case. Distance categories and case study data from Flender $(2010$, p. 153).

\begin{tabular}{|c|c|c|c|}
\hline \multirow[b]{2}{*}{ distance category $(\mathrm{km})$} & \multicolumn{3}{|c|}{$\begin{array}{l}\text { relative share of freight transport volume (\%) } \\
\text { case study } \\
\text { simulated }\end{array}$} \\
\hline & to 03103 & aggregate & to 03103 \\
\hline$[0-150)$ & 30 & 36 & 21 \\
\hline$[150-400)$ & 18 & 38 & 54 \\
\hline$[400-500)$ & 42 & 10 & 11 \\
\hline$\left[500-700^{1}\right)$ & 10 & 16 & 14 \\
\hline
\end{tabular}

${ }^{1}$ for the column of simulated aggregates, this category extends to $1000 \mathrm{~km}$

Table 5.14 contains a side by side comparison of the case study (Flender 2010) and the simulated data. The analysis of average distances finds a value of $293 \mathrm{~km}$ for the case study, $273 \mathrm{~km}$ for the simulation's aggregate, and $302 \mathrm{~km}$ for commodity flows ending in zone 03103. The data in table 5.14 allows for a deeper analysis of the deviations by distance categories. Especially for the categories [150 - 400) and [400 - 500) large differences between case study and simulation can be observed. However, if the rather small category [400 - 500) was combined with its lower neighbour to form a new section [150 - 500), the deviation would reduce significantly. The values for the combined category would be $60 \%$ for the case study, $58 \%$ for the aggregate flows, and $55 \%$ for the simulated flows to zone 03103.

The study of Flender (2010) does not explicitly disclose whether the data refers to production-consumption, i.e. commodity flows of the model result, or origin-destination, i.e. cargo as transported by vehicles, flows. As laid out earlier (page 46), OD and PC flows may differ significantly in the case of consolidated transports. However, Iddink (2010, p. 100) finds that the major share of deliveries within the automotive industry is carried out as direct transports. Hence, considering the fact that the case study data uses an arbitrary snapshot of transport data on the level of shipments together with an unfavourable categorisation, the comparison with the model's first phase's output does not show systematic differences, even if the simulated aggregate data slightly overestimates the shortest and widest distance categories. Adjusting the categorisation to form a medium distance category, its share is rather equal for case study and simulated data. The comparison of case study data and commodity flows ending in zone 03103 show a larger overall deviation if compared to the simulation's aggregate.

In summary, the distribution of the generated commodity flows' volume by distance categories is to be assumed as valid even if there clearly are deviations in the direct comparisons with the case study data of Flender (2010), which is just a direct consequence of using the macro flow patterns for NST-2007 section 12 from BMVI (2014) for the assignment of commodity flows.

Thus, overall plausibility for the first phase's output has been ensured. The section below continues with insights on the corresponding model's second phase's output, i.e. the simulation of vertical disintegration. 


\subsubsection{Example Results from the Model's Second Phase in the Case of Vertical Disintegration}

This section gives a brief overview of selected results if vertical disintegration is simulated for the establishments and commodity flows generated in the model's first phase. As a reminder, the vertical disintegration is assumed as the outsourcing of production tasks in the relation of tier-1 suppliers and car plants using the German automotive industry as an example. The simulation of outsourcing requires three major assumptions, which are described in more detail in the context of figure 5.26:

1. Which supplier establishments do apply outsourcing?

2. Which new intermediate establishments do appear?

3. How are commodity flows assigned between outsourcing establishments, appearing establishments, and car plants?

In this regard, table 5.15 contains the various model outputs that result from different combinations of the assumptions described above. All results for the second phase use the identical population of generated establishments and commodity flows as input. The solutions with stochastic location choice assume equally sized appearing establishments like applied in the application on centralisation in the poultry supply chain (section 5.1.9, page 147).

Table 5.15: Simulation results for vertical disintegration in the German automotive industry (initially 1513 million $\mathrm{tkm} / \mathrm{a}$; ranges for change are extreme values, respectively median values, as observed during 10 $\times 10$ loops for stochastic influences regarding selection of outsourcing and appearing establishments. The number of 29 appearing establishments allows for exactly one supplier per car plant.)

\begin{tabular}{|c|c|c|c|c|}
\hline \multicolumn{2}{|c|}{ assumptions } & \multicolumn{3}{|c|}{ change in transport performance } \\
\hline $\begin{array}{l}\text { outsourcing } \\
\text { degree }^{1}(\%)\end{array}$ & $\begin{array}{l}\text { establ. } \\
\text { appearing } \\
\text { (count) }\end{array}$ & $\begin{array}{c}\text { OptOpt }^{2} \\
\text { [min; max] } \\
\text { (\%) }\end{array}$ & $\begin{array}{c}\text { StochOpt }^{3} \\
{[\min ; \max ]} \\
(\%)\end{array}$ & $\begin{array}{c}\text { StochMacro }^{4} \\
\text { [median] } \\
(\%)\end{array}$ \\
\hline 50 & 1 & {$[+67 ;+228]$} & {$[+72 ;+175]$} & {$[+117]$} \\
\hline 50 & 10 & {$[-27 ;+300]$} & {$[+1 ;+191]$} & {$[+67]$} \\
\hline 50 & 20 & {$[-32 ;+300]$} & {$[-14 ;+198]$} & {$[+59]$} \\
\hline 50 & 29 & {$[-36 ;+300]$} & {$[-16 ;+202]$} & {$[+54]$} \\
\hline 50 & 40 & {$[-36 ;+300]$} & {$[-17 ;+207]$} & {$[+49]$} \\
\hline 50 & 80 & {$[-37 ;+300]$} & {$[-22 ;+202]$} & {$[+47]$} \\
\hline 50 & 160 & {$[-37 ;+300]$} & {$[-24 ;+199]$} & {$[+45]$} \\
\hline 50 & 320 & {$[-37 ;+300]$} & {$[-24 ;+200]$} & {$[+43]$} \\
\hline 50 & 402 & {$[-37 ;+300]$} & {$[-25 ;+201]$} & {$[+43]$} \\
\hline $\begin{array}{l}{ }^{1} \text { outsourcing } \\
{ }^{2} \text { location choi } \\
{ }^{3} \text { location choi }\end{array}$ & $\begin{array}{l}\text { gree }(\%)= \\
\text { : optimal; fl } \\
\text { stochastic; }\end{array}$ & $\begin{array}{r}\text { upplying establ. that } \\
\text { \#supplying } \\
\text { v assignment: } \\
\text { ow assignment: }\end{array}$ & $\begin{array}{l}\text { pply outsourcing } \\
\text { stabl. } \\
\text { timal } \\
\text { optimal }\end{array}$ & \\
\hline${ }^{4}$ location ch & stochasti & $N$ assignmen & lacro flows & \\
\hline
\end{tabular}

The first column contains the assumption on which share of original tier-1 establishments applies outsourcing. Even if this share is fixed, the model simulates different combinations of outsourcing establishments by using stochastic selection processes. The second column gives the number of establishments that appear in order to carry out the outsourced production tasks. Location choice and the determination of production volumes for 
these establishments depends on the selected simulation procedure. In this regard, the column headings OptOpt, StochOpt, and StochMacro follow the same logic as in table 5.8 (page 127).

Looking at the combination of optimal location choice and optimal assignment flows (OptOpt), the simulation results show that already 10 appearing establishments provide enough freedom to the optimisation models for finding the highest value for freight transport possible $(+300 \%)$. Sticking to this column (OptOpt), the results show that a higher number of appearing establishments allows for lower overall freight transport performance ($37 \%$ ). For reaching the absolute minimum with a precision of $0.1 \%$, a number of 40 to 80 appearing establishments already suffices.
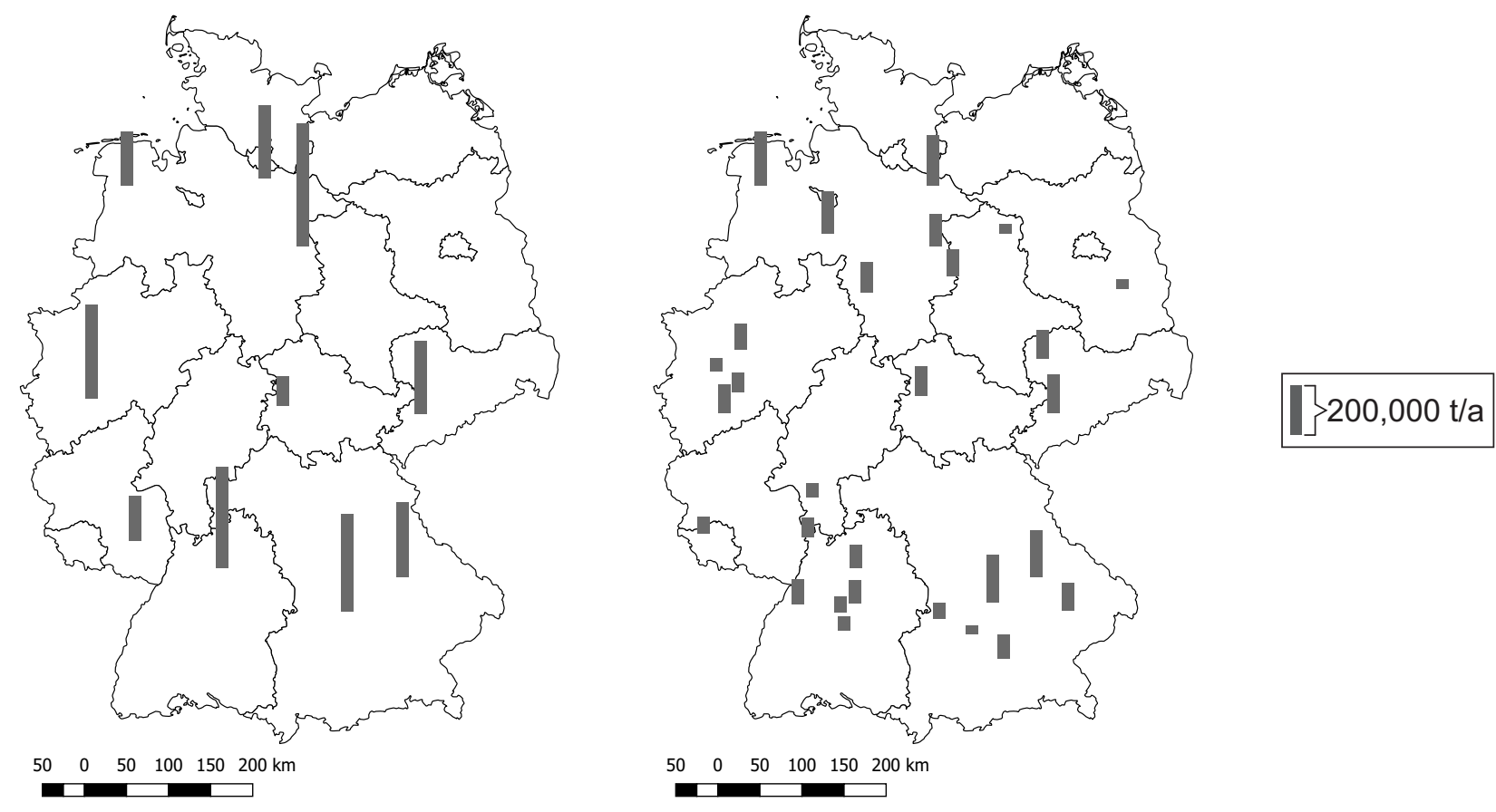

Figure 5.28: Appearing establishments' spatial layout and output for different numbers of appearing establishments ( $\mathrm{n}=10$ left, $\mathrm{n}=29$ right) and minimum transport performance solutions (OptOptMin). Bars represent annual output. Their scaling is identical for both maps.

Figure 5.28 visualises the spatial distribution of establishments and their sizes for the transport minimal solutions with a number of 10 and 29 appearing establishments. The assumption of 29 appearing establishments would allow for creating one establishment per car plant. Appendix D (page 239) contains example maps illustrating the optimal location of establishment and corresponding flow relations for all counts of appearing establishments ( 1 - 402) given in table 5.15 .

For the combination of stochastic location choice and optimal assignment (StochOpt), the results remain within the ranges of the parallel optimisation solutions (OptOpt). The maximum values for the StochOpt maximum results are rather stable around $+200 \%$. Regarding the lower boundary of results, a higher number of appearing establishments leads to lower minimum transport performance. It is especially interesting to note that optimal flow assignment is potentially capable of limiting the increase of freight transport performance caused by outsourcing with stochastic location choice to $+1 \%$ if at least 10 appearing establishments are assumed. Mathematically, even a reduction of freight transport performance is possible.

The values of the last column, stochastic location choice with macro flow assignment (StochMacro), show a decline in the medians of additional freight transport performance caused by outsourcing with a rising number of establishments. As described above, this pattern is prevalent in the minimising optimal solutions as well. Hence, under 
the given assumptions, a higher number of appearing establishments is desirable in order to reduce the growth of freight transport performance as induced by vertical disintegration. However, the results also show that optimisation during location choice or flow assignment suffice to prevent any growth. In consequence, it is to be reasoned that outsourcing does not necessarily translate into increased overall freight transport performance. Hence, there is a potential for the application of state measures that aim at mitigating the impact on freight transport in the case of vertical disintegration.

\subsubsection{Partial Validation of the Model's Second Phase for the Case of Vertical Disintegration}

In order to check the plausibility of the model's second phase's results, the solutions for a vertical disintegration with 29 appearing establishments is analysed in more detail below. For this purpose, figure 5.29 shows a boxplot of the different simulation outputs if a number of 29 appearing establishments is assumed. The visualisation follows the same rules as described for figure 5.9 (page 129).

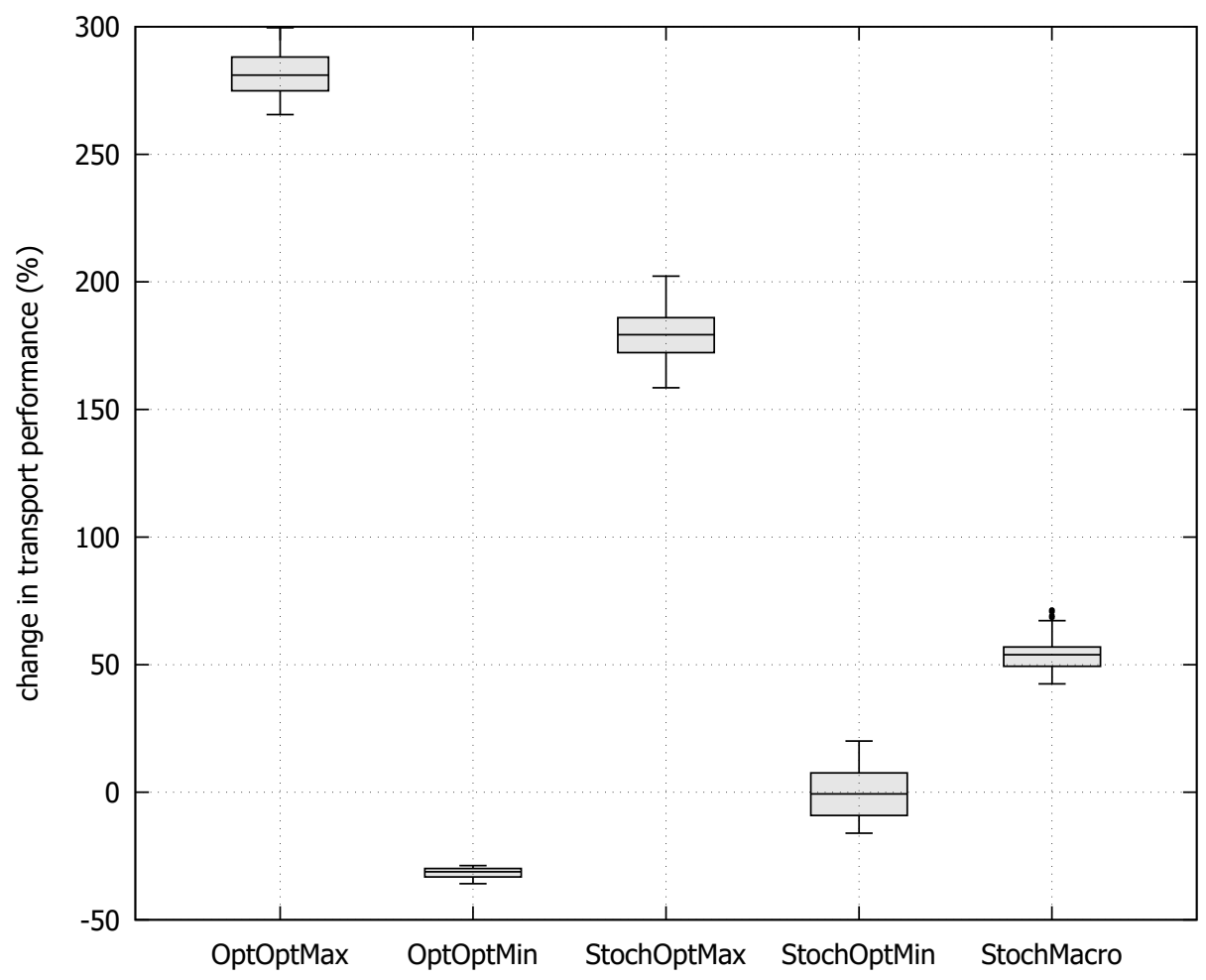

Figure 5.29: Boxplot aggregating the simulation results for an outsourcing degree of $50 \%$ and a count of 29 appearing establishments

As expected, the OptOptMin and OptOptMax solutions frame the overall solution range. The vertical range of solutions for OptOptMin as well as OptOptMax results from the stochastic influence of selecting a share of $50 \%$ of supplying establishment to participate in outsourcing.

The corridor of possible outcomes narrows if stochastic location choice is assumed (StochOptMin and StochOptMax) due to the reduced degree of freedom remaining for optimisation. In addition to the information given in table 5.15, the boxplot shows how the possible outcomes of the StochOptMin solutions stretch around the $+/-0 \%$ mark with the median value being slightly in the negative range $(-1.3 \%)$. 
Regarding the StochMacro solution, the boxplot illustrates that the simulation produces a rather densely populated range of values around the median value with few outliers.

For a visual representation of the underlying simulation output, appendix D (page 234) contains example maps illustrating appearing establishments' locations and flow relations for each combination of location choice and flow assignment in the case of 29 appearing establishments. Overall, the solutions' spatial patterns are similar to those of the application in the poultry centralisation if comparing the outcome of the same combination of location choice and flow assignment method. In consequence, it is to be concluded that the simulation model's second phase's methods for simulating vertical disintegration in the supply chain structure produce plausible spatial patterns of establishments and flow relations.

Together, the comparison of solution ranges depending on the chosen assumption together with a plausibility check of the corresponding spatial patterns based on the generated maps, the model's second phase's overall output in the case of vertical disintegration proves reasonable and valid.

\subsubsection{Impact Assessment for Measures That Influence Appearing Establishments' Locations}

The results presented in table 5.15 above show that the possible range for an increase in freight transport demand in the case of 29 appearing establishment is $[-36 \% ;+300 \%]$ as described by the OptOptMin and OptOptMax solution.

Hence, for cases in which location choice is not assumed to be optimal, the simulation results must be within this range. However, without further analysis it is unclear how specific location patterns influence the actual outcome within the wrapping range.

The developed model accounts for analyses of this kind by providing the parameter $p_{\text {appearing, }}$, which can be used for influencing the spatial distribution of appearing establishments. For example, figure 5.30 illustrates the distribution of location probabilities, if the probabilities $p_{\text {appearing, } i}$ for each zone $i$ are calculated proportionally from the number of employees in manufacturing in each zone (left) or if their multiplicative inverse (normalisingFactor $\cdot 1 / p_{\text {appearing }, i}$ ) is used (right). The according employment data is included in the appendix in table C.3.

These two distribution serve as examples for two diametrical location policies: In order to produce clusters of competency and to exploit spillover effects (Dasgupta and Stiglitz 1980; Levin and Reiss 1984, details on page 27), in this case especially Marshall/Arrow/Romer-externalities (Glaeser et al. 1992), it is economically reasonable to follow the current spatial distribution of employment in manufacturing and co-locate with existing establishments. In contrast, state decision making may pursue just the opposite objective and aim at creating workplaces in economically weaker regions by subsidies or similar measures as already discussed above in the context of poultry supply chains (page 140). In this case, establishments should be located especially in regions with currently low employment, which is expressed by using the reciprocal value of the proportional employment numbers.

Table 5.16 collects the results for the simulation of vertical disintegration with 29 appearing establishments if the employment based distributions are used. For comparison, the table also includes the simulation results for the case of using a uniform distribution for locating appearing establishments. Only solutions with stochastic location choice are included in the analysis as required by the assumptions described above. Furthermore, only transport minimal assignment StochOptMin and macro flow assignment Stoch are applied, which is suitable since economic calculus during vertical disintegration should reasonably lead to solutions between a minimal solution and the status quo flow pattern but not a maximisation of freight transport.

Regarding the minimal transport solutions (StochOptMin) in table 5.16, the data show that the location probabilities according to the current spatial pattern of employment in manufacturing produce the lowest values for freight 

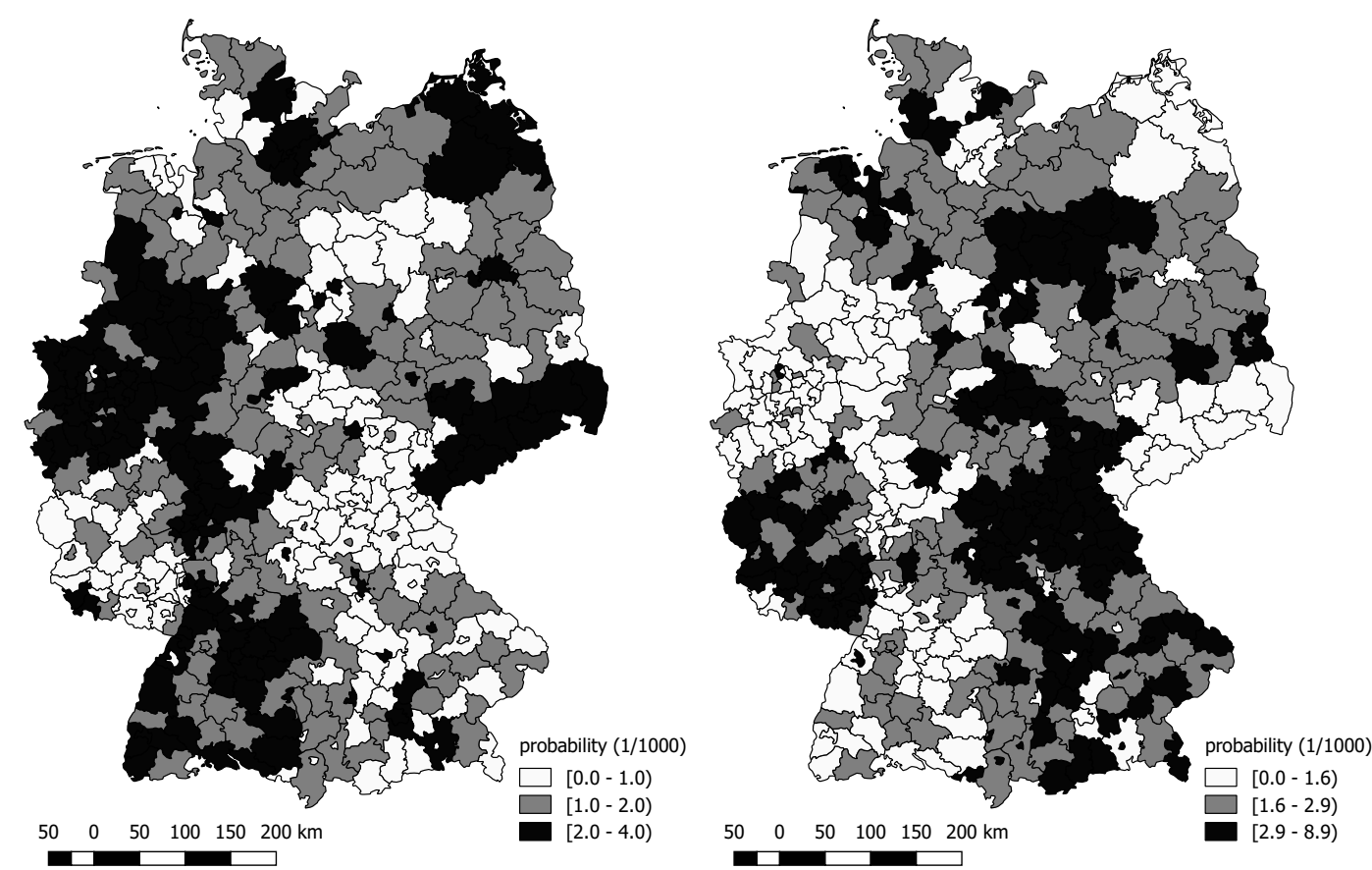

Figure 5.30: Location probabilities by zone proportional to employment in manufacturing (left) and its normalised reciprocal value (right)

Table 5.16: Solution ranges for different location probabilities for the assumption of 29 appearing establishments during outsourcing in the automotive industry

\begin{tabular}{l|ccc|cccc}
\hline \multirow{2}{*}{ assumptions } & \multicolumn{4}{|c}{ observed change in freight transport performance (\%) } \\
& \multicolumn{3}{c}{ StochOptMin } & \multicolumn{4}{c}{ StochMacro } \\
location probabilities & min & median & max & min & median & max \\
\hline uniform distribution & -16 & -1 & +20 & +42 & +54 & +71 \\
employment manufacturing & -18 & -6 & +7 & +42 & +51 & +63 \\
reciprocal employment manufacturing & -12 & +4 & +20 & +42 & +55 & +66 \\
\hline
\end{tabular}

transport performance. In contrast, using the reciprocal values as probabilities leads to the highest values in freight transport demand. Here, it is especially interesting that in the case of reciprocal value the median value becomes significantly positive $(+4)$ while the optimisation models are capable of finding solutions that reduce freight transport performance in the majority of cases for the other spatial distributions (medians -1 and -6 ).

Continuing with the results for macro flow assignment (StochMacro), a similar interrelation of the observed values is to be found. Again, the solution for location choice according to manufacturing's employment generates the lowest values for freight transport performance. However, the impact of using the reciprocal values is less strong compared to the case with optimal assignment. Hence, comparing the different simulation results for macro flows assignment, especially the low deviation of median values, no outstanding best solution can be identified.

Summarising the results for the transport minimal and macro flow assignment, a location pattern according to the employment in manufacturing qualifies to be most suitable for the objective of minimising freight transport performance. 


\subsubsection{Conclusions from the Example Applications in the German Automotive Industry}

In summary, the model applications in the context of vertical disintegration within the German automotive industry produce several insights:

First of all, the application gives a brief insight into the German automotive industry and developments that have the potential of influencing freight transport demand. Subsequently, vertical disintegration, i.e. introducing an additional stage to the existing supply chains, is selected for further analysis. Here, it is assumed that a new type of establishment gets inserted between tier-1 suppliers and car plants, which is conceptually similar to supplier parks.

The simulation of vertical disintegration in the German automotive industry verifies the developed model's applicability for vertical changes in supply chain structures. The corresponding simulation results show that there is a wide range of possible outcomes regarding the impact on freight transport performance for the case of vertical disintegration. The corridor of results can be narrowed by using assumptions on the number of establishments that take over the outsourced production, their location choice, and the assignment of commodity flows.

The presented application also shows how comprehensive public statistics can be used together with sectoral information, e.g. from case studies providing sector specific statistical data. In addition, it is shown how data from case studies can be used for plausibility checks and model validation, especially for the first model phase, i.e. the generation of a reference population of establishments and commodity flows. The validation of the model's second phase's output proves that the model works as expected when simulating vertical disintegration, which is a representative of vertical change in supply chain structures.

Regarding insights on more fundamental interdependencies, the model results propose that a higher number of appearing establishments leads to lower increases in freight transport performance under the given conditions and assumptions. For cases with optimal location choice and optimal flow assignment it is even possible to reduce freight transport compared to the initial situation. However, it is to be remembered that this solution is of theoretical nature and only considers production-consumption flows and neither origin-destination flows nor actual vehicle movements.

Finally, it is also demonstrated that the developed model is capable of simulating the impact of measures that influence location choice of appearing establishments. Here, it is shown that locating appearing establishments according to the current spatial pattern of the manufacturing sector shows the lowest increases of freight transport performance for the assumed vertical disintegration. 


\section{Concluding Remarks}

This chapter starts with a brief summary of the study that also addresses the insights gained regarding the research questions formulated in chapter 1. Afterwards, the main limitations of the developed model and its example applications are given in order to increase transparency and identify potential for further improvements. The chapter closes with a brief outlook.

\subsection{Summary and Contributions to the Research Questions}

The study starts with a brief introduction into the motivation, scope, and structure of the thesis. The corresponding Chapter 1 sketches the research gap that exists between qualitative analyses on the interrelation of supply chain structures and freight transport demand on the one hand and aggregate comprehensive freight transport models on the other.

Laying a basis for the remainder of the study, chapter 2 follows a bottom-up approach and answers research question Q1: How to define and categorise change in supply chain structures? In this regard, it is necessary to distinguish between the definition of material supply chains that this study refers to from the various interpretations of the general term supply chain. In brief, material supply chains are structures that are defined by a series of manufacturing establishments that are connected by material flows. Hence, supply chains are seen as organisations of establishments and commodity flows that are dominated by the general character of successively producing a certain good. It is assumed that each establishment can be assigned to a defined stage in the supply chain that represents a particular step of production. Following this perception, supply chain structures have a vertical dimension that stretches along the successive stages and the respective establishments. Hence, changes in the supply chain structure that directly affect the order of stages in the supply chain belong into the category of vertical changes (e.g. vertical disintegration). In contrast, the horizontal dimension addresses the characteristics of establishments on the same stage. Thus, changes that directly influence the configuration of establishments on a single stage of supply chains are categorised as horizontal changes (e.g. centralisation).

In addition, chapter 2 addresses research question Q2: Which decisions determine the structure of a supply chain and how can they be modelled? The conducted interdisciplinary literature review shows that there is a broad set of choices that directly influence the structure of supply chains. In this regard, the overall structure of an entire sector's supply chains is not the outcome of a central unit's comprehensive planning process but a result of independently behaving economic actors, which each follow a certain optimisation calculus. Regarding the importance for modelling supply chain structures, each of the approaches presented in this study's literature review provides insight on at least one of the developed model's central aspects: size and location of establishments, assignment of commodity flows. In literature there are normative as well as descriptive approaches on the according decision problems. These approaches can be further distinguished by the quantity of focal actors, i.e. single (micro), several (meso), or many (macro). The actual scope heavily depends of the corresponding study's objective. In addition, the various approaches can be categorised as describing decision problems that exclusively focus on a single aspect, e.g. the distribution of establishment sizes in the horizontal industry structure (descriptive, macro), or as decision problems that consider multiple decision variables in parallel, e.g. multi facility location allocation 
problems (normative, meso). In summary, the interdisciplinary literature review clearly shows that the vast amount of potentially interdependent decisions and decision variables cannot be endogenously modelled in full detail in order to simulate supply chain structures and their freight transport demand at maximum detail following a bottom-up approach.

Finally, chapter 2 also sheds light on research question Q3: What is the current status of research on the interrelation of supply chains' structures and freight transport demand? In research, it is broadly accepted that freight transport demand and supply chain structures are interrelated. Few comprehensive freight transport models already contain elements that explicitly consider supply chain structures based on business establishments and commodity flows. However, studies that directly address the impact of changes in the supply chain structure on freight transport demand are very rare. In addition, existing quantitative approaches focus on very specific cases, e.g. centralisation within a certain logistics system, or are of rather aggregate nature and do not adequately consider the spatial dimension. Thus, there is no quantitative modelling approach that combines establishments and commodity flows, i.e. the central elements of material supply chains, and a disaggregate representation of space for analysing the interdependence of supply chain structures and freight transport demand. The study at hand addresses this gap.

Changing the perspective, chapter 3 addresses freight transport as a macroscopic phenomenon by following research question Q4: How far can existing statistics be used for identifying as well as forecasting the impact of changes in the supply chain structure on freight transport demand? The top-down analysis of existing statistics allows for the identification of certain aggregate trends, e.g. a growth in the average distance of freight transport. Available more detailed data helps to identify additional developments that are less obvious, e.g. shifts in the mix of transported goods by volume. Extending the scope beyond directly transport related data, economic statistics shed light on aspects related to supply chain structures, e.g the development of establishment sizes within sectors or the linkage between industries. However, the different statistics exist separately and do not allow for an integrated analysis as it would be required for tracing changes that result from developments on the level of supply chain structures. The largest obstacles are the lack of a spatial resolution and a potential overlay of various drivers that remain indistinguishable. Hence, quantitative models are needed for further analysis of changing supply chain structures and freight transport demand.

For this reason, chapter 3 raises research question Q5: How do existing freight transport models capture the impact of changes in the structure of supply chains? In brief, the corresponding the literature review of existing comprehensive freight transport finds that even if there are models that apply supply chain concepts, none of them is directly applicable for the intended analysis. The aggregate nature of comprehensive freight transport models that follow the traditional 4-step-approach does not allow for a direct consideration of changes in the structure of supply chains. More recent approaches aim at integrating supply chain aspects by introducing business establishments and commodity flows as relevant elements to freight transport models. However, there is no study to be found in literature that applies quantitative freight transport models in order to analyse the impact of changes in the supply chain structure on freight transport demand. Most applications of comprehensive models that forecast future freight transport rely on aggregate changes that combine various overlapping developments based on external assumptions or integrated economic modules. Hence, existing comprehensive freight transport models are not suitable for an isolated analysis of the impact of changes in the structure of supply chains on freight transport demand. Still, existing models provide a rich set of concepts and methods that are transferable for the purpose of modelling supply chain structures and their freight transport demand.

Chapter 4 describes the model specifically developed for simulating the impact of change in supply chain structures on freight transport demand. Hence, it gives an answer to research question Q6: How to build a quantitative model for estimating the impact of change in supply chain structures on freight transport demand? Analysing the interrelation of supply chain structures and freight transport demand requires spatially disaggregate data on the level 
of business establishments and commodity flows. Since this kind of data is not available from existing statistics, it is necessary to make use of a realistic but artificially generated industry landscape for the analysis. Therefore, the developed approach proposes using two distinct phases for modelling. A first phase uses data from various available sources in order to generate a population of establishments and commodity flows that is congruent with real-world conditions. Here, the developed model relies on adapting and recombining well-established approaches from existing freight transport models. In a next step, the second model phase takes the generated population as input for the simulation of change in supply chain structures. Applying changes directly to the generated population instead of using adjustments in the input data in combination with complete regeneration is required in order to clearly distinguish between the influence of structural change and stochastic model elements. The simulation of change heavily depends on assumptions regarding changes in the population of existing establishments, appearing establishments, and the assignment of commodity flows among these. The developed approach proposes to account for this challenge by providing alternative combinations of simulation procedures, i.e. for calculating the absolute mathematically possible solution range as well as calculating narrowed solution ranges that result from a higher degree of assumptions. Methodologically, the developed model applies a combination of optimisation and stochastic simulation for this task. Technically, the major part of the model is implemented in Java while using external libraries for specific tasks, e.g. solving linear problems or geovisualisation. In summary, the developed approach proposes to address the requirements that result from the intended analysis and the availability of data by using distinct procedures for generating an initial industry landscape and for simulating structural change while using business establishments and commodity flows as central model elements together with a disaggregate resolution of space.

Chapter 5 describes two distinct applications of the previously developed model. The first application addresses research question Q7: How does centralisation of existing supply chains influence freight transport demand? The corresponding analyses are carried out for the case of centralisation on the supply chain stage of slaughtering in the German poultry industry. Overall, the simulation results suggest that such a centralisation, i.e. a reduction in the number of establishments on a particular stage of the supply chain, is likely to cause an increase in freight transport performance. The simulation results also show that a transport optimised location of establishments together with a suitable assignment of commodity flows is capable of compensating for this impact, at least in theory. This wide range of possible outcomes is a consequence of the high degree of freedom that results from the need of further assumptions on the actual parameters of the centralisation that is to be analysed. Hence, the model application for estimating the outcome of a centralisation of supply chain structures mainly shows how the simulation's output depends on given assumptions and how changes in the assumptions influence the simulation's results. In order to derive concrete recommendations on real-world applications more research on framing conditions that limit the range of assumptions is required. However, the simulation of centralisation in the poultry industry gives valuable insight on the overall system behaviour under this kind of structural change. The results lay special emphasis on the essential role of the spatial dimension.

The second model application of chapter 5 focusses on vertical disintegration using the example of the German automotive industry in order to give an answer to research question Q8: How does vertical disintegration of existing supply chains influence freight transport demand? Similar to the case of centralisation, the simulation of vertical integration produces a wide range of possible outcomes for the example scenario. However, the corridor of results can be narrowed by using assumptions on the number of establishments that take over the outsourced production, their location choice, and the assignment of commodity flows. Overall, the model results propose that a higher number of appearing establishments results in lower increases in freight transport performance in general. Also, it is theoretically possible to reduce freight transport compared to the initial situation if optimal location choice and optimal flow assignment are assumed. In summary, the results show that vertical disintegration does not 
necessarily lead to increases in freight transport performance. However, regarding real-world scenarios, the actual impact depends on the location choice and commodity flow assignment of the involved actors.

For both cases, i.e. centralisation and vertical disintegration, chapter 5 applies the developed model for impact analysis regarding the potential of state measures according to research question Q9: How can the impact of structural change on freight transport demand be mitigated by the application of state measures? For the case of centralisation in the German poultry industry, the simulation results show that lowest freight transport performance could be achieved by a population of large focal establishments together with a number of disperse establishments at the right locations. Relaxing the assumption on optimal location choice, the simulation shows that the enforcement of a measure that limits establishment sizes leads to lower average and median transport performance for stochastic combinations of appearing establishments' locations. Hence, these two different simulation outcomes do not allow for a single best recommendation regarding sizes restrictions. However, both results should be considered when it comes to the design of actual freight transport demand oriented measures.

For the case of vertical disintegration in the German automotive industry, it is estimated how a measure that interferes with the location choice of appearing establishments influences overall freight transport performance. Comparing fully stochastic location choice, location according to current employment patterns, or according to their inverse, the simulation results indicate that increases of freight transport performance are to be expected the lowest if appearing establishments settle according to the current spatial pattern of the manufacturing sector. Despite the advantage of generating the lowest increase in freight transport, the proposed solution might interfere with competing objectives that are also relevant for developing state measures.

Taking the different impact analyses together, the simulation results presented in chapter 5 show that it is possible to develop measures that positively influence the impact on freight transport demand in case of changes in the structure of supply chains. However, the assessment of potential measures in order to derive concrete recommendations requires the consideration of objectives beyond the freight transport system.

Summing up the main findings of the overall study, it first of all gives an interdisciplinary overview of decisions and existing modelling approaches in the context of supply chain structures. For deeper analysis, the study introduces a quantitative disaggregate model for estimating the impact of changes in the structure of supply chains on freight transport demand. Its application in two different sectors for two different kinds of structural change exemplarily illustrates the quantitative interrelation of supply chain structures and freight transport demand. In addition, the analysis of hypothetical state measures shows potential ways of mitigating the impact of changes in supply chain structures on freight transport demand. 


\subsection{Limitations of the Developed Model and Example Applications}

By nature, models are simplified representations of real-world systems. Availability of data, the need for a reduction of details, and limited capacities for model creation inevitably lead to imperfections in every model that is developed. Therefore, it has to be ensured that the model's shortfalls do not interfere significantly with the modelling purpose. Validity and plausibility checks conducted during the model application address this challenge. In addition, transparency on existing limitations helps to prevent wrong interpretations of the model's results and unsuitable model applications. Also, the limitations offer a starting point for future improvement. Therefore, the most significant limitations of the developed model and the given applications are described below.

\section{Appearing Establishments' Sizes}

As shown in the impact assessment for measures that limit appearing establishments' sizes in the case of centralisation (section 5.1.9), the change in freight transport demand significantly depends on the sizes of appearing establishments and their distribution. A similar challenge exists in cases of centralisation in which a share of the production is assigned to already existing establishment thereby leading to their growth. Here, the model contains different approaches for the assignment like proportional growth or packing procedures that merge remaining and deleted establishments for the simulation of growth. An endogenous determination of probable establishment size distribution would require the creation of a comprehensive economic model that considers for example economies of scale, which would lead far beyond the scope of the model at hand. A more detailed description of aspects that were to be considered can be found in section 2.5.4 on existing models for determining the horizontal structure of industries. In order to account for this influence, the model provides an interface for loading externally given distributions of establishment sizes especially for appearing establishments. In this way it is possible to combine the insights from economic models on horizontal industry structure into the developed model.

\section{Macro Flow Assignment Despite Structural Change}

The simulation of change is at the core of the model's second phase. A main characteristic of the applied procedure of macro flow fitting using the method of Furness (1962) is that it preserves existing spatial flow patterns. On the one hand, this is desirable since it is to be assumed that appearing establishments show a behaviour similar to the current situation. On the other hand, it is to be questioned whether especially for the assignment of flows to new sites economic actors are not rather prone to changes in their behaviour due to economic reasoning and optimisation calculus. However, this challenge is immanent to any descriptive model, which uses parameter values from the status quo for prognosis, e.g. values on preferences in discrete choice models, values for deterrence of distance in gravity models, or technical coefficients in the input-output model. The model at hand accounts for this challenge by applying optimisation models that calculate the mathematically possible range of solutions, which then allows for a better judgement on the macro flow based solution. An alternative solution to account for fundamental changes in the modelled system is using normative models for describing the behaviour of relevant actors since the objective of optimisation remains stable and changes in the decisions' input parameters can be studied using sensitivity analyses as done for example in Friedrich (2010).

\section{Aggregate Commodity Categorisation of Macro Flows}

Another unfavourable aspect of using externally given macro flow data for the spatial assignment of commodity flows is the aggregate categorisation of the data currently available for Germany (BMVI 2014). In the application on vertical disintegration in the automotive industry, the respective macro flow category (NUTS-2007 section 12) contains vehicles as well as parts thereof, two types of commodities that tend to have diametrical flow directions. In the application this leads to a deviation in the average distances of macro flows and generated commodity flows. 
Here, a direct improvement can be achieved by using more disaggregate input data as soon as it becomes available. Since this is currently not the case, the generated commodity flows distribution of distances is compared with a data set from the case study of Flender (2010) finding that the average distance of generated flows lies between the average distance of the case study and the macro flows. Hence, the overall distribution is to be assumed suitable for the study's objective of analysing the impact of change in supply chain structures.

\section{Perfect Substitutability of Commodities}

The developed model assumes perfect substitutability of commodities of the same category. In the case of poultry, this is a very suitable assumptions. The category of living poultry could be subdivided into chicken and turkey and then be further specified into conventional and organic. However, these subcategories' spatial patterns and commodity characteristics are congruent. For the automotive industry, this is different. Blackening in the employment data used for locating supplier establishments (Statistisches Bundesamt 2013b) limits disaggregation to the level of WZ2008 29.3 production of vehicle parts, which is an aggregate for the manufacturing of highly different commodities, e.g. car seats, engines, or tires. In addition, these parts are highly specific for each produced vehicle type. In consequence, the assumption of perfect substitutability, which results from the availability of data, is a limitation for the given application in the automotive industry. However, there are several possible solutions: One way of addressing substitutability is to adjust the algorithms used for simulating vertical change so that they pay more attention to preserving the existing relations between suppliers and car plants. Alternatively, using more detailed data that distinguishes between the suppliers for specific components as available from sectoral sources like Automobil Produktion (2011) allows to avoid the challenge of perfect substitutability. Alternatively, an artificial subcategorisation could be applied to the currently used data leading to a similar result as using sectoral sources but avoiding the limitations of proprietary data.

\section{Availability of Data for Commodity Flow Constraints}

As described throughout the study, the developed model uses constraints on establishment level for the determination of commodity flow sizes. In the given application, the commodity flows' aggregate spatial patterns follow the constraints imposed by the corresponding macro flows. However, currently there is no comprehensive data on the size distribution of commodity flows available in Germany. Therefore, these parameters have been estimated with the objective of plausibility. For the automotive industry, case studies (Corsten and Gabriel 2004; Iddink 2011) are used as points of reference. Also, commodity flow surveys exist for example for Sweden or the US (de Jong and Ben-Akiva 2007). Therefore, it is reasonable that the developed model provides parameters for considering such data in case it becomes available for the described application or the model is to be applied in an environment with suitable commodity flow surveys. In the meantime, case studies help to ensure consistency and plausibility.

\section{Translation of Commodity Flows Into Vehicle Movements}

The developed model estimates freight transport performance based on commodity flows in supply chains. However, the system analysis of freight transport illustrates that the actual vehicle performance also depends on effects caused by logistics systems and the traffic system. For the applications in the poultry and automotive industry, the limited scope is less severe since most transports are carried out as direct transports. In addition, the applied distance matrix already considers road network distances. However, small commodity flows, which occur especially for the set of small establishments proposed by the minimum transport solutions, might require shipments at the size of partial loads and thereby induce detours for bundling reasons and empty running on the level of vehicle movements. Hence, the calculated solutions' optimality on the level of commodity flows does not necessarily provide minimum solutions on the level of vehicle performance. The presented model does also not include mode choice, though it might be helpful for a final assessment of effects since a long distance transport of large 
volumes by train might be environmentally superior to a mid-range road transport. These aspects are especially relevant when transferring insights from the calculated optimal solutions to real world applications. Overcoming the described limitations requires the application of additional modelling efforts that explicitly consider logistics systems as well as tour patterns on vehicle level based on the populations of establishments and commodity flows estimated in the presented model.

\subsection{Outlook}

This study introduces a model for simulating the impact of changes in the supply chain structure on freight transport demand on the disaggregate level of business establishments and commodity flows. In this way, the developed model addresses the gap between aggregate and mainly qualitative approaches on the interdependence of supply chain structures and freight transport demand and existing freight transport demand models that do no explicitly consider driving developments from the level of supply chains.

Regarding future work derived from this study, especially two directions are possible besides immediate enhancements of the presented applications, e.g by using more data for validation and calibration, by increasing the number of simulation cycles, or by simulating the impact of additional state measures.

The first opportunity for further research results from the direct applicability of the developed model for analysing the effect of change in the supply chain structures of additional sectors on the corresponding freight transport demand. The model's sectoral transferability is demonstrated in this study by using the examples of centralisation in the poultry industry and vertical disintegration in the automotive industry in Germany. Besides sectoral transferability, widening the spatial scope, e.g. for assessing structural change on a European level, offers a similarly extended application of the current model. Both options, additional sectors or larger spatial scope, mainly require the gathering, consolidation, and preparation of input data, which is then to be applied with the current model.

A second direction for further development lies in integrating the developed modelling approach with a comprehensive freight transport model in order to address effects that might become visible on the level of logistics systems or vehicle movements on infrastructure. However, this task is expected to be rather challenging since it requires major adaptations to any existing freight model as well as to the model implemented in this study. Apart from technical necessities, additional challenges are imposed when the interactions of actors reach beyond the currently limited scope of specific sectors. Hence, even if the study at hand contributes to the improvement of freight transport models by providing first insight on the interrelation of supply chain structures and freight transport demand, it is still a long way to fully integrate these microscopic phenomena into the macroscopic scope of comprehensive freight transport models. 


\section{List of Symbols}

The table below provides a collection of the variables used throughout this work. Variables used solely locally for controlling the program flow are excluded from this list. For reasons of clarity regarding the model related variables, symbols that are only used in the context of the literature review in chapters 2 and 3 are left out as well.

Conceptionally, the construction of symbols follows two approaches: Complex objects having multiple attributes are denoted by giving the type of the object, a subscript for the unique index and and a superscript for the current attribute (object Type $e_{\text {uniqueIndex }}^{\text {attribute }}$. Therefore, the description in the table below refers to the given attribute. Hence, these lines are marked by $A$ in the column Type.

In contrast, simple numerical values not belonging to complex objects are denoted by a variable name that already stands for the value information. A combination of subscript and superscript is used for reference if values are specific (e.g. $\sup _{i}^{g}$ ). This notation from linear programming is used for reasons of simplification and readability. The corresponding entries in the table are marked by $V$ in the column Type.

In addition, the names of relevant mathematical functions are given denoted as type $F$.

The table also lists the letters used for referring to specific types of index sets (type $I$ ). Here, upper case letters stand for the actual set and lower case letters stand for the elements $(q \in Q)$.

The list is sorted by the symbol in a descending alphabetical order. The ordering first considers the object or variable name, then the superscript, and last the subscript.

\begin{tabular}{llc}
\hline Symbol & Description & Type \\
\hline$\alpha_{c, s}$ & Lorenz asymmetry parameter for commodity flows of commodity $c$ to sector $s$ & $\mathrm{~V}$ \\
$c$ & commodity index & $\mathrm{I}$ \\
$C$ & set of commodities & $\mathrm{I}$ \\
$C_{i}^{c}$ & consumption volume of commodity $c$ in zone $i$ as used in & $\mathrm{V}$ \\
& production-consumption $(\mathrm{PC})$ matrix (equal to $d e m_{i}^{c}$ ) & \\
$c a p_{\text {max }}$ & maximum free capacity of the combination of supplier establishment's output & $\mathrm{V}$ \\
& and corresponding macro flow & $\mathrm{O}$ \\
$c f_{k}$ & commodity flow object $k$ & $\mathrm{~A}$ \\
$c f_{k}^{\text {com }}$ & commodity of commodity flow $k$ & $\mathrm{~A}$ \\
$c f_{k}^{\text {dest }}$ & destination establishment of commodity flow $k$ & $\mathrm{~A}$ \\
$c f_{k}^{\text {destZone }}$ & destination zone of commodity flow $k$ & $\mathrm{~A}$ \\
$c f_{k}^{\text {vol }}$ & volume of commodity flow $k$ & $\mathrm{~A}$ \\
$c f_{k}^{\text {orig }}$ & origin establishment of commodity flow $k$ & $\mathrm{~A}$ \\
$c f_{k}^{\text {origzone }}$ & origin zone of commodity flow $k$ &
\end{tabular}




\begin{tabular}{|c|c|c|}
\hline Symbol & Description & Type $^{*}$ \\
\hline $\operatorname{CONC}^{s}$ & Krugman concentration index for sector $s$ & $\mathrm{~V}$ \\
\hline$d_{i, j}$ & distance from zone $i$ to $j$ & $\mathrm{~V}$ \\
\hline $\operatorname{dem}_{i}^{c}$ & demand for commodity $c$ in zone $i$ & A \\
\hline$d e v^{c}$ & $\begin{array}{l}\text { deviation measure for the fit of commodity flows and macro flows for } \\
\text { commodity } c\end{array}$ & $\mathrm{~V}$ \\
\hline devNorm ${ }^{c}$ & normalised version of deviation measure $d e v^{c}$ & $\mathrm{~V}$ \\
\hline $\operatorname{dispFac}_{c, s}$ & dispersion factor for flows of commodity $c$ to sector $s$ & A \\
\hline$E_{s}$ & set of establishments in sector $s$ & I \\
\hline emp & number of employees & $\mathrm{V}$ \\
\hline empMax & maximum establishment size (employees) in sector $s$ & $\mathrm{~V}$ \\
\hline empMin & minimum establishment size (employees) in sector $s$ & $\mathrm{~V}$ \\
\hline$e s t_{v}^{i n p_{c}}$ & input volume of commodity $c$ of establishment $v$ & A \\
\hline$e s t_{v}^{\text {out }}$ & output volume of establishment $v$ & A \\
\hline est $t_{v}^{\text {sector }}$ & sector of establishment $v$ & A \\
\hline$e s t_{v}^{s i z e}$ & size of establishment $v$ & A \\
\hline$e_{t}^{\text {suppliers }_{c}}$ & number of suppliers for commodity $c$ for establishment $v$ & A \\
\hline$e s t_{v}^{z o n e}$ & zone of establishment $v$ & A \\
\hline$f_{i, j}$ & $\begin{array}{l}\text { amount of commodity transported from zone } i \text { to } j \text { (exclusively used in linear } \\
\text { programs that consider a single commodity) }\end{array}$ & $\mathrm{V}$ \\
\hline$f_{i, j}^{c}$ & $\begin{array}{l}\text { amount of commodity } c \text { transported from zone } i \text { to } j \text { (exclusively used in } \\
\text { linear programs that consider multiple commodities) }\end{array}$ & $\mathrm{V}$ \\
\hline$f_{s}(e m p)$ & density function for establishment sizes measured in employees for sector $s$ & $\mathrm{~F}$ \\
\hline$F_{s}(e m p)$ & $\begin{array}{l}\text { cumulative distribution function for establishment sizes measured in } \\
\text { employees for sector } s\end{array}$ & $\mathrm{~F}$ \\
\hline G & set of generated establishments & I \\
\hline$h$ & counter for iterations & I \\
\hline$H$ & maximum number of iterations & V \\
\hline$i$ & zone index & I \\
\hline$I$ & set of zones & I \\
\hline inpFac ${ }^{c}$ & $\begin{array}{l}\text { input factor describing the volume of commodity } c \text { required for producing one } \\
\text { unit of output for the focal sector (exclusively used in linear programs of } \\
\text { optimisation problems) }\end{array}$ & $\mathrm{V}$ \\
\hline $\operatorname{inpFac}_{c, s}$ & $\begin{array}{l}\text { input factor describing the volume of commodity } c \text { required for producing one } \\
\text { unit of output for sector } s\end{array}$ & $\mathrm{~V}$ \\
\hline intEmp $p_{i}$ & $\begin{array}{l}\text { number of employees to be assigned for interval } i \text { using the interval based } \\
\text { generation procedure }\end{array}$ & $\mathrm{V}$ \\
\hline
\end{tabular}




\begin{tabular}{|c|c|c|}
\hline Symbol & Description & Type $^{*}$ \\
\hline intEst $_{i}$ & $\begin{array}{l}\text { number of establishments to be generated for interval } i \text { using the interval } \\
\text { based generation procedure }\end{array}$ & $\mathrm{V}$ \\
\hline $\operatorname{int} \operatorname{Min}_{i}$ & $\begin{array}{l}\text { minimum establishment size for interval } i \text { using the interval based generation } \\
\text { procedure }\end{array}$ & $\mathrm{V}$ \\
\hline intMax & $\begin{array}{l}\text { maximum establishment size for interval } i \text { using the interval based generation } \\
\text { procedure }\end{array}$ & $\mathrm{V}$ \\
\hline$j$ & zone index & I \\
\hline$J$ & set of zones & I \\
\hline$k$ & commodity flow index & I \\
\hline$K$ & set of commodity flows & I \\
\hline$l$ & macro flow index & I \\
\hline$L$ & set of macro flows & I \\
\hline$m f_{l}$ & macro flow object $l$ & $\mathrm{O}$ \\
\hline$m f_{l}^{c o m}$ & commodity of macro flow $l$ & A \\
\hline$m f_{l}^{\text {destZone }}$ & destination zone of macro flow $l$ & A \\
\hline$m f_{l}^{v o l}$ & volume of macro flow $l$ & A \\
\hline$m f_{l}^{\text {orig }}$ & origin zone of macro flow $l$ & A \\
\hline$m f_{l}^{\text {origZone }}$ & origin zone of macro flow $l$ & A \\
\hline$M F_{c}$ & set of macro flows for commodity $c$ & I \\
\hline$n E m p^{s}$ & number of employees in sector $s$ & $\mathrm{~V}$ \\
\hline$n E m p_{i}^{s}$ & number of employees in sector $s$ in zone $i$ & $\mathrm{~V}$ \\
\hline$n E s t^{s}$ & number of establishments in sector $s$ & $\mathrm{~V}$ \\
\hline$n E s t_{i}^{s}$ & number of establishments in sector $s$ in zone $i$ & $\mathrm{~V}$ \\
\hline$p_{\text {appearing }, i}$ & probability appearing establishment to be located in zone $i$ & $\mathrm{~V}$ \\
\hline$p^{*}$ & $\begin{array}{l}\text { specific commodity type } p^{*} \text { produced by focal establishments (exclusively } \\
\text { used in linear programs of optimisation problems) }\end{array}$ & $\mathrm{V}$ \\
\hline$p_{i}$ & $\begin{array}{l}\text { probability to select zone } i \text {, e.g. for removing establishments during the } \\
\text { simulation fo centralisation }\end{array}$ & $\mathrm{V}$ \\
\hline$P_{i}^{c}$ & $\begin{array}{l}\text { production volume of commodity } c \text { in zone } i \text { as used in } \\
\text { production-consumption (PC) matrix (equal to } \sup _{i}^{c} \text { ) }\end{array}$ & $\mathrm{V}$ \\
\hline prodFactor $_{s}$ & $\begin{array}{l}\text { productivity factor describing the volume of output produced per unit of } \\
\text { establishment size in sector } s\end{array}$ & $\mathrm{~V}$ \\
\hline$s$ & sector & $\mathrm{V}$ \\
\hline$S$ & set of sectors & $\mathrm{V}$ \\
\hline $\sup ^{c}$ & supply for commodity $c$ & $\mathrm{~V}$ \\
\hline $\sup _{i}^{c}$ & supply for commodity $c$ in zone $i$ & $\mathrm{~V}$ \\
\hline
\end{tabular}




\begin{tabular}{llc}
\hline Symbol & Description & Type $^{*}$ \\
\hline$t_{i, j}^{c}$ & $\begin{array}{l}\text { aggregate commodity flow volume for the relation from zone } i \text { to } j \text { and } \\
\text { commodity c }\end{array}$ & $\mathrm{V}$ \\
$v$ & establishment index & $\mathrm{I}$ \\
$w$ & establishment index & $\mathrm{I}$ \\
$z$ & zone index & $\mathrm{I}$ \\
$Z$ & set of zones & $\mathrm{I}$ \\
$z$ one $e_{i}$ & zone object $i$ & $\mathrm{O}$ \\
$z$ cone $e_{i}^{\text {cap }}$ & capacity of zone with index $i$ & $\mathrm{~A}$ \\
\hline
\end{tabular}

" Definition of types:

$\begin{array}{ll}\text { A } & \text { attribute of complex object } \\ \text { F } & \text { function } \\ \text { I } & \text { letter used for indexing } \\ \text { O } & \text { complex object } \\ \text { V } & \text { numerical value not part of any object (primitive data type) }\end{array}$




\section{List of Abbreviations}

\begin{tabular}{|c|c|c|}
\hline Abbreviation & Meaning & Description \\
\hline AGS & $\begin{array}{l}\text { Amtlicher Gemeindeschlüssel. Official } \\
\text { Municipality Key. }\end{array}$ & $\begin{array}{l}\text { Used as classification of statistical units. } \\
\text { Partially congruent with NUTS. }\end{array}$ \\
\hline AMPL & A Mathematical Programming Language. & Used for linear programming. \\
\hline BMVI & $\begin{array}{l}\text { Bundesministerium für Verkehr und digitale } \\
\text { Infrastruktur. Federal Ministry of Transport } \\
\text { and Digital Infrastructure. }\end{array}$ & \\
\hline GDP & Gross domestic product. & \\
\hline LUTI & Land-use/transport interaction. & \\
\hline NACE & $\begin{array}{l}\text { Nomenclature statistique des activités } \\
\text { économiques dans la Communauté } \\
\text { européenne. }\end{array}$ & Classification of economic activity. \\
\hline NST-2007 & $\begin{array}{l}\text { Nomenclature uniforme des marchandises } \\
\text { pour les statistiques de transport. Standard } \\
\text { goods classification for transport statistics. } \\
\text { Revision } 2007 .\end{array}$ & \\
\hline NUTS 3 & $\begin{array}{l}\text { Nomenclature des unités territoriales } \\
\text { statistiques. Classification of Territorial Units } \\
\text { for Statistics. }\end{array}$ & $\begin{array}{l}\text { Level } 3 \text { corresponds to small regions with a } \\
\text { diameter of approximately } 60 \mathrm{~km} \text { in } \\
\text { Germany. Partially congruent with AGS. }\end{array}$ \\
\hline OD matrix & Origin-destination matrix & $\begin{array}{l}\text { Corresponds to cargo flows as transported by } \\
\text { vehicles. }\end{array}$ \\
\hline OECD & $\begin{array}{l}\text { Organisation for Economic Co-operation and } \\
\text { Development. }\end{array}$ & \\
\hline OEM & Original Equipment Manufacturer. & $\begin{array}{l}\text { Used for referring to car manufacturers in } \\
\text { this study. }\end{array}$ \\
\hline PC matrix & Production-consumption matrix. & Corresponds to trade flows. \\
\hline SCGE & Spatial computable general equilibrium. & \\
\hline VDA & $\begin{array}{l}\text { Verband der Automobilindustrie. German } \\
\text { Association of the Automotive Industry. }\end{array}$ & \\
\hline WZ 2008 & $\begin{array}{l}\text { Klassifikation der Wirtschaftszweige, Ausgabe } \\
\text { 2008. German Classification of Economic } \\
\text { Activities, Edition } 2008 .\end{array}$ & \\
\hline
\end{tabular}




\section{Bibliography}

Abed, Omar, Tom Bellemans, Sungjin Cho, Gerrit K. Janssens, Davy Janssens, and Geert Wets (2014). "A Bottom up Approach to Estimate Production-consumption Matrices from a Synthetic Firm Population Generated by Iterative Proportional Updating". In: Transportation Research Procedia 1.1, pp. 49-56. Issn: 23521465. Dor: 10.1016/j. trpro.2014.07.006.

Abele, Eberhard (2006). Handbuch globale Produktion. München [u.a.]: Hanser. IsBn: 3-446-40610-7.

Aberle, Gerd (2009). Transportwirtschaft: Einzelwirtschaftliche und gesamtwirtschaftliche Grundlagen. 5., überarb. und erg. Aufl. Wolls Lehr- und Handbücher der Wirtschafts- und Sozialwissenschaften. München: Oldenbourg. ISBN: 9783486579512.

Aitken, James M. (1998). Supply chain integration within the context of a supplier association. Ph.D. Thesis: Case studies of four supplier associations. Cranfield University.

Allen, J., M. Browne, and T. Cherrett (2012). "Investigating relationships between road freight transport, facility location, logistics management and urban form". In: Journal of Transport Geography 24, pp. 45-57. DoI: 10.1016/ j.jtrangeo.2012.06.010.

Antràs, Pol and Elhanan Helpman (2004). "Global Sourcing". In: Journal of Political Economy 112, pp. 552-580. URL: http://dx.doi.org/10.1086/383099.

Apache (2016a). Apache Log4j 2. Version 2.1. uRL: http://logging.apache.org/log4j/2.x/ (visited on 06/29/2016).

Apache (2016b). Apache POI: HSSF and XSSF for Excel Documents. Version 1.6.0. uRL: https://poi.apache.org/ overview.html (visited on 06/29/2016).

Arnold, Dieter, Heinz Isermann, Axel Kuhn, Horst Tempelmeier, and Kai Furmans, eds. (2008). Handbuch Logistik (VDI-Buch) (German Edition). 3., neu bearb. Springer.

Arnold, Ulli (2000). "New dimensions of outsourcing: A combination of transaction cost economics and the core competencies concept". In: European Journal of Purchasing \& Supply Management 6.1, pp. 23-29. IssN: 09697012. Dor: 10.1016/S0969-7012(99)00028-3.

Arrow, Kenneth J. and Gerard Debreu (1954). "Existence of an Equilibrium for a Competitive Economy". In: Econometrica 22.3, pp. 265-290. ISSN: 00129682. DoI: 10.2307/1907353. uRL: http://www.jstor.org/stable/1907353.

Arthur, W. Brian (1990). "Positive Feedbacks in the Economy". In: Scientific American 262.2, pp. 92-99. Issn: 00368733. DOI: 10.1038/scientificamerican0290-92.

Arthur, W. Brian and Kenneth J. Arrow (2004). Increasing returns and path dependence in the economy. [Nachdr.] Economics, cognition, and society. Ann Arbor: Univ. of Michigan Press. IsBn: 978-0-472-06496-0.

Automobil Produktion (2008). Sonderausgabe Internationale OEM Produktionsstandorte. Landsberg: mi, verlag moderne industrie.

Automobil Produktion (2011). Automobil-Zulieferer in Deutschland 2011/2012. Landsberg: mi, verlag moderne industrie.

Automobil Produktion (2014). Sonderausgabe - Global Automotive Business 2014. Landsberg: mi, verlag moderne industrie.

Bain, Joe S. (1954). "Economies of Scale, Concentration, and the Condition of Entry in Twenty Manufacturing Industries". In: The American Economic Review 44.1, pp. 15-39. Issn: 00028282. 
Baldwin, Robert E. (2008). The development and testing of Heckscher-Ohlin trade models: A review. The Ohlin lectures. Cambridge, Mass.: MIT Press. IsBn: 978-0-262-02656-7.

Balmer, M., B. Raney, and K. Nagel (2005). "Adjustment of activity timing and duration in an agent-based traffic flow simulation". In: Progress in activity-based analysis. Ed. by H. J. P. Timmermans. Amsterdam, Boston, Oxford: Elsevier. ISBN: 0080445810.

Balster, Andreas, Hanno Friedrich, Ole Ottemöller, and Kevin Rolko (2016). Schlussbericht zum Teilprojekt Quantitative Modellierung der Lebensmittelversorgung in Deutschland des Verbundprojektes SEAK. URL: http://www.seakprojekt.de/download/SEAK-Bericht-Teilvorhaben-IfV.pdf (visited on 11/29/2016).

Barney, J. (1991). “Firm Resources and Sustained Competitive Advantage”. In: Journal of Management 17.1, pp. 99120. ISSN: 0149-2063. DoI: 10.1177/014920639101700108.

Barthelemy, Johan and Philippe L. Toint (2013). "Synthetic Population Generation Without a Sample". In: Transportation Science 47.2, pp. 266-279. ISSN: 00411655, 15265447. DoI: 10.1287/trsc.1120.0408.

Baumol, William J. (1982). "Contestable Markets: An Uprising in the Theory of Industry Structure". In: The American Economic Review 72.1, pp. 1-15. Issn: 00028282.

Becker, Thomas (2006). Quo Vadis Zulieferpark? Neue Zusammenarbeitsmodelle in der automobilen Zulieferkette. Hamburg: Verlag Dr. Kovač. IsBn: 3830024193.

Beckmann, Martin (1968). Location theory. New York: Random House. IsBN: 0394300416.

Bhatnagar, Rohit, Pankaj Chandra, and Suresh K. Goyal (1993). "Models for multi-plant coordination”. In: European Journal of Operational Research 67.2, pp. 141-160. Dor: 10.1016/0377-2217(93)90058-U.

Bioland (2016). Bioland-Richtlinien für die Verarbeitung. Fleisch und Fleischerzeugnisse. Version of 22.11.2016. URL: http:// www. bioland.de/fileadmin/dateien/HP_Dokumente/Richtlinien/2016-11 - 22_Fleisch_und_ Fleischerzeugnisse.pdf (visited on 01/17/2017).

Blotevogel, Hans Heinrich (2005). "Zentrale Orte”. In: Handwörterbuch der Raumordnung. Ed. by Ernst-Hasso Ritter. Hannover: Akademie für Raumforschung und Landesplanung, pp. 1307-1315. ISBN: 978-3-88838-555-1.

BMVBS, ed. (2015). Verkehr in Zahlen. 44. Jg. Hamburg: Deutscher Verkehrs-Verlag. IsBN: 978-3-87154-493-4.

BMVI (2010). Freight Transport and Logistics Masterplan. Berlin: German Federal Ministry of Transport. uRL: http: //www.bmvi.de/SharedDocs/EN/Publikationen/masterplan- freight- transport- and-logistics.pdf?__blob = publicationFile (visited on 11/29/2016).

BMVI (2014). Prognose der deutschlandweiten Verkehrsverflechtungen 2030. Güterverkehrsmatrizen. URL: http:// daten.clearingstelle-verkehr.de/276/ (visited on 11/29/2016).

Boerkamps, Jeroen, Arjan van Binsbergen, and Piet Bovy (2000). "Modeling Behavioral Aspects of Urban Freight Movement in Supply Chains". In: Transportation Research Record: Journal of the Transportation Research Board 1725, pp. 17-25. ISSN: 0361-1981. DoI: 10.3141/1725-03.

Boltze, Manfred (1996). "Intermodales Verkehrsmanagement". In: Internationales Verkehrswesen 48.1+2, pp. 1118.

Boltze, Manfred, Frederik Rühl, Ulrich Berbner, and Hanno Friedrich (2015). "The Interdisciplinary Decision Map - A Reference Model for Production, Logistics and Traffic". In: TRB 94th Annual Meeting. 11-15 Jan 2015. Washington DC. Washington DC, United States: Transportation Research Board.

Boltze, Manfred, Frederik Rühl, Ulrich Berbner, and Hanno Friedrich (2017). "The Interdisciplinary Decision Map: A Reference Model for Production, Logistics and Traffic". In: Dynamic and Seamless Integration of Production, Logistics and Traffic. Ed. by Eberhard Abele, Manfred Boltze, and Hans-Christian Pfohl. Berlin, Heidelberg: Springer Verlag, pp. 31-49. IsBN: 978-3-319-41095-1.

Bundesagentur für Arbeit (2013). Sozialversicherungspflichtig Beschäftigte nach Wirtschaftsabteilungen und -gruppen der WZ 2008. Stichtag 30.06.2012. Reihe Arbeitsmarkt in Zahlen - Beschäftigungsstatistik. Nürnberg.

Burgess, A., J.F.F. Becker, et al. (2005). Deliverable 1. TRANS-TOOLS (TOOLS for TRansport forecasting ANd Scenario testing) Deliverable 1. Funded by 6th Framework RTD Programme. Delft, Netherlands: TNO Inro. 
Burgess, A., M. Chen, M. Snelder, N. Schneekloth, A. Korzhenevych, E. Szimba, M. Kraft, M. Krail, O. Nielsen, C. Hansen, A. Martino, D. Fiorello, P. Christidis, and A. Vilcan (2008). Final Report TRANS-TOOLS (TOOLS for TRansport forecasting ANd Scenario testing) Deliverable 6. Funded by 6th Framework RTD Programme. Delft, Netherlands: TNO Inro.

Carlton, Dennis W. and Jeffrey M. Perloff (2000). Modern industrial organization. 3rd ed. The Addison-Wesley series in economics. Reading, Mass.: Addison-Wesley. IsBn: 0321011457.

Chandra, Charu and Janis Grabis (2007). Supply chain configuration: Concepts, solutions and applications. New York: Springer. ISBN: 978-0-387-68155-9.

Chen, T. M. et al. (2006). Deliverable 3: Report on model specification and calibration results TRANS-TOOLS (TOOLS for TRansport forecasting ANd Scenario testing) Deliverable3. Funded by 6th Framework RTD Programme. Delft, Netherlands: TNO Inro.

Chow, Joseph Y., Choon Heon Yang, and Amelia C. Regan (2010). "State-of-the-Art of Freight Forecast Modeling: Lessons Learned and the Road Ahead". In: Transportation: Planning, Policy, Research, Practice 37.6, pp. 10111030.

Christaller, Walter (1980). Die zentralen Orte in Süddeutschland: E. ökonomisch-geographische Untersuchung über d. Gesetzmäßigkeit d. Verbreitung $u$. Entwicklung d. Siedlungen mit städtischen Funktionen. 3., unveränd. Aufl., reprograf. Nachdr. d. 1. Aufl., Jena 1933. Darmstadt: Wissenschaftliche Buchges. IsBn: 3534044665.

Christopher, Martin (1992). Logistics and supply chain management: Strategies for reducing costs and improving services. London: Financial Times and Pitman Pub. ISBN: 0273034154.

Christopher, Martin (2016). Logistics \& supply chain management. Fifth edition. Harlow, England: Pearson. ISBN: 1292083794.

Coase, R. H. (1937). "The Nature of the Firm". In: Economica 4.16, pp. 386-405.

Colbe, Walther Busse (1964). Die Planung der Betriebsgröße. Vol. 7. Betriebswirtschaftliche Beiträge. Wiesbaden and s.1.: Gabler Verlag. IsBn: 978-3-663-14792-3. DOI: 10.1007/978-3-663-14792-3. uRL: http://dx.doi.org/10. 1007/978-3-663-14792-3.

Collins, Robert, Kimberly Bechler, and Silvio Pires (1997). "Outsourcing in the automotive industry: From JIT to Modular Consortia”. In: European Management Journal 15.5, pp. 498-508. Issn: 02632373. DoI: 10.1016/S02632373(97)00030-3.

Combes, Francois (2010). "Estimation of the Economic Order Quantity Model Using the ECHO Shipment Database". In: European Transport Conference, 2010. Ed. by Association for European Transport.

Combes, Pierre-Philippe, Thierry Mayer, and Jacques-François Thisse (2008). Economic geography: The integration of regions and nations. Princeton, N.J. and Woodstock, Oxfordshire: Princeton University Press. IsBN: 9780691139425.

Corsten, Daniel and Christoph Gabriel, eds. (2004). Supply Chain Management erfolgreich umsetzen: Grundlagen, Realisierung und Fallstudien. 2nd ed. Berlin: Springer. ISBN: 3540005862.

Coyle, John J., Edward J. Bardi, and C. John Langley (1988). The management of business logistics: A supply chain perspective. New York, NY, USA: West Publishing.

Cronon, William (1992). Nature's metropolis: Chicago and the Great West. New York: W.W. Norton. IsBn: 0393308731.

Daganzo, Carlos F. and Yossef Sheffi (1977). "On Stochastic Models of Traffic Assignment". In: Transportation Science 11.3, pp. 253-274. Issn: 00411655, 15265447.

Dasgupta, Partha and Joseph Stiglitz (1980). "Uncertainty, Industrial Structure, and the Speed of R\&D". In: The Bell Journal of Economics 11.1, p. 1. ISSN: 0361915X. Dor: 10.2307/3003398.

Davidsson, Paul, Lawrence Henesey, Linda Ramstedt, Johanna Törnquist, and Fredrik Wernstedt (2005). "An analysis of agent-based approaches to transport logistics". In: Transportation Research Part C: Emerging Technologies 13.4, pp. 255-271. IssN: 0968090X. DOI: 10.1016/j.trc.2005.07.002. 
Davidsson, Paul, Johan Holmgren, Jan A. Persson, and Linda Ramstedt (2008). "Multi agent based simulation of transport chains". In: Proceedings of the 7th international joint conference on Autonomous agents and multiagent systems - Volume 2. Vol. 2. Richland and USA: International Foundation for Autonomous Agents and Multiagent Systems, pp. 1153-1160. ISBN: 978-0-9817381-1-6.

Davydenko, Igor (2015). Logistics Chains in Freight Transport Modelling: Ph.D. Thesis. Delft University of Technology. DOI: $10.13140 /$ RG.2.1.2371.9843.

de Jong, Gerard and Moshe Ben-Akiva (2007). "A micro-simulation model of shipment size and transport chain choice". In: Transportation Research Part B: Methodological 41.9, pp. 950-965. IssN: 01912615. Dor: 10.1016/j. trb.2007.05.002.

de Jong, Gerard, Moshe Ben-Akiva, and Jaap Baak (2010). Method Report - Logistics Model in the Swedish National Freight Model System (Version 2). Den Haag, Netherlands: SIGNIFICANCE.

de Jong, Gerard, Hugh Gunn, and Warren Walker (2004). "National and International Freight Transport Models: An Overview and Ideas for Future Development". In: Transport Reviews 24.1, pp. 103-124. Dor: 10.1080/ 0144164032000080494.

de Jong, Gerard, Hugh Gunn, Warren Walker, and Jenny Widell (2002). Study on ideas on a new national freight model system for Sweden. Santa Monica, CA: RAND. Isbn: 0-8330-3327-1.

de Jong, Gerard, Inge Vierth, Lóránt Tavasszy, and Moshe Ben-Akiva (2013). "Recent developments in national and international freight transport models within Europe”. In: Transportation 40.2, pp. 347-371. Issn: 0049-4488. DoI: 10.1007/s11116-012-9422-9. uRL: http://dx.doi.org/10.1007/s11116-012-9422-9.

Decaluwé, Bernard and André Martens (1988). "CGE modeling and developing economies: A concise empirical survey of 73 applications to 26 countries". In: Journal of Policy Modeling 10.4, pp. 529-568. Issn: 01618938. DoI: 10.1016/0161-8938(88)90019-1.

Dixit, Avinash K. and Joseph E. Stiglitz (1977). "Monopolistic Competition and Optimum Product Diversity". In: The American Economic Review 67.3, pp. 297-308. ISSN: 00028282. DoI: 10.2307/1831401. uRL: http://www. jstor.org/stable/1831401.

Doran, Desmond (2003). "Supply chain implications of modularization". In: International Journal of Operations \& Production Management 23.3, pp. 316-326.

Drewes Nielsen, Lise, Per Homann Jespersen, Tina Petersen, and Leif Gjesing Hansen (2003). "Freight transport growth: a theoretical and methodological framework". In: European Journal of Operational Research 144, pp. 295-305.

Dyer, Jeffrey H. (1996). "Specialized Supplier Networks as a Source of Competitive Advanteag: Evidence from the Auto Industry”. In: Strategic Management Journal 17.4, pp. 271-291.

Edwards, Henrik, John Bates, and Henrik Swahn (2008). Swedish Base Matrices Report.Estimates for 2004, estimation methodology, data, andprocedures. Frösön, Sweden.

Ehnts, Dirk and Hans-Michael Trautwein (2012). "From New Trade Theory to New Economic Geography: A Space Odyssey". In: OEconomia 2012.01, pp. 35-66. Issn: 2113-5207. Dor: 10.4074/S2113520712011036.

European Commision (2005). Council Regulation (EC) No 1/2005 of 22 December 2004 on the protection of animals during transport and related operations and amending Directives 64/432/EEC and 93/119/EC and Regulation (EC) No 1255/97. URL: http://eur-lex.europa.eu/legal-content/EN/TXT/?uri=CELEX:32005R0001 (visited on 01/07/2016).

eurostat (2016). Distance (in $\mathrm{km}$ ) between nuts regions. URL: http://ec. europa.eu/eurostat/tercet/flatfiles.do (visited on 07/04/2016).

FGSV (2012). Begriffsbestimmungen. Teil: Verkehrsplanung, Strassenentwurf und Strassenbetrieb. Ausgabe 2012. Ausgabe 2012. Vol. 220 Ausg. 2012. FGSV. Köln: Forschungsgesellschaft für Strassen- und Verkehrswesen FGSV. ISBN: 978-3-86446-024-1. 
Finfgeld-Connett, Deborah (2010). "Generalizability and transferability of meta-synthesis research findings". In: Journal of advanced nursing 66.2, pp. 246-254. ISsN: 0309-2402. DoI: 10.1111/j.1365-2648.2009.05250.x..

Fleischmann, B. and H. Meyr (2003). "Planning Hierarchy, Modeling and Advanced Planning Systems". In: Supply chain management. Ed. by A. G. de Kok and S. C. Graves. Vol. 11. Handbooks in operations research and management science. Amsterdam and Boston: Elsevier, pp. 457-523. IsBn: 0444513280.

Flender, Heiko (2010). Modellgestützte Analyse zur Optimierung von Transportnetzwerken: Evaluation der Potenziale zentral geplanter Transporte in der Versorgungslogistik der Automobilindustrie. Dortmund: Verl. Praxiswissen. IsBN: 3869750359.

Forslid, Rikard, Jan I. Haaland, and Karen Helena Midelfart Knarvik (2002). “A U-shaped Europe?” In: Journal of International Economics 57.2, pp. 273-297. Dor: 10.1016/S0022-1996(01)00155-6.

Friedrich, Hanno (2010). Simulation of logistics in food retailing for freight transportation analysis: Dissertation. Karlsruhe: Karlsruhe Institute of Technology. URL: http://digbib.ubka.uni-karlsruhe.de/volltexte/1000020602 (visited on 01/07/2017).

Friedrich, Hanno and Ole Ottemöller (2011). "Transferring Methods From Social Dynamic Network Analysis To Freight Transportation”. In: Proceedings of: THE 16TH INTERNATIONAL CONFERENCE OF HONG KONG SOCIETY FOR TRANSPORTATION STUDIES. 17 - 20 Dec 2011. Ed. by HKSTS. Hong Kong, China.

Friedrich, Hanno, Lóránt Tavasszy, and Igor Davydenko (2014). "Distribution Structures". In: Modelling Freight Transport. Elsevier, pp. 65-87. IsBN: 9780124104006. Dor: 10.1016/B978-0-12-410400-6.00004-5.

Fujita, Masahisa, Paul R. Krugman, and Anthony Venables (1999). The spatial economy: Cities, regions and international trade. Cambridge, Mass.: MIT Press. IsBn: 0262062046.

Furness, K. P. (1962). Trip forecasting. Paper presented at a seminar on the use of computers 15 in traffic planning. Unpublished. London.

Garcia Sanz, Francisco J., Klaus Semmler, and Johannes Walther, eds. (2007). Die Automobilindustrie auf dem Weg zur globalen Netzwerkkompetenz: Effiziente und flexible Supply Chains erfolgreich gestalten. Berlin: Springer. ISBN: 978-3-540-70787-5.

GeoBasis-DE/BKG (2016). Verwaltungsgebiete 1:250.000. Ed. by Dienstleistungszentrum des Bundes für Geoinformation und Geodäsie. URL: http://www.bkg.bund.de (visited on 11/29/2016).

Geoffrion, A. M. and G. W. Graves (1974). "Multicommodity distribution system design by Benders decomposition". In: Management Science 5.20, pp. 822-844.

Gilley, K. M. and A. Rasheed (2000). "Making More by Doing Less: An Analysis of Outsourcing and its Effects on Firm Performance". In: Journal of Management 26.4, pp. 763-790. issn: 0149-2063. Dor: 10.1177/ 014920630002600408.

Glaeser, Edward L., Hedi D. Kallal, José A. Scheinkman, and Andrei Shleifer (1992). "Growth in Cities”. In: Journal of Political Economy 100.6, pp. 1126-1152. Dor: 10.2307/2138829.

GNU (2012). GLPK (GNU Linear Programming Kit). Version 4.32. URL: https://www.gnu.org/software/glpk/ (visited on $06 / 29 / 2016)$.

Göpfert, Ingrid and Marc Grünert (2012). "Logistiknetze der Zukunft: Das neue Hersteller-Zuliefer-Verhältnis in der Automobilindustrie". In: Logistik der Zukunft. Ed. by Ingrid Göpfert. Wiesbaden: Gabler, pp. 139-178. IsBN: 3834922846.

Gort, Michael and Steven Klepper (1982). "Time Paths in the Diffusion of Product Innovations". In: The Economic Journal 92.367, p. 630. IssN: 00130133. Dor: 10.2307/2232554.

Grossman, G. M. and E. Helpman (2002). "Integration versus Outsourcing in Industry Equilibrium". In: The Quarterly Journal of Economics 117.1, pp. 85-120. ISSN: 0033-5533. Dor: 10.1162/003355302753399454.

Gudehus, Timm (2005). Logistik: Grundlagen, Strategien, Anwendungen. 3., neu bearb. Aufl. SpringerLink: Springer e-Books. Berlin [u.a.]: Springer. IsBN: 3-540-24113-2. 
Günthner, Willibald A. (2007). Neue Wege in der Automobillogistik: Die Vision der Supra-Adaptivität. VDI-Buch. Berlin, Heidelberg: Springer-Verlag Berlin Heidelberg. IsBn: 978-3-540-72404-9.

Gurobi (2016). Gurobi Optimizer. Version 6.5. uRL: http://www.gurobi.com/ (visited on 06/29/2016).

Haggett, Peter (1968). Locational analysis in human geography. London: Edward Arnold. ISBN: 9780713151794.

Hall, A. D. and R. E. Fagen (1956). "DEFINITION OF SYSTEM". In: General Systems 1, pp. 18-28.

Harris, F. W. (1913). "How Many Party to Make at Once". In: Factory, The Magazine of Management 10.152, pp. 135136.

Hedberg, Bo L. T., Paul C. Bystrom, and William H. Starbuck (1976). "Camping on Seesaws: Prescriptions for a Self-Designing Organization”. In: Administrative Science Quarterly 21.1, p. 41. IssN: 00018392. DoI: 10.2307/ 2391877.

Hellström, Tomas (2008). "Transferability and Naturalistic Generalization: New Generalizability Concepts for Social Science or Old Wine in New Bottles?” In: Quality \& Quantity 42.3, pp. 321-337. Issn: 0033-5177. DoI: 10.1007/ s11135-006-9048-0.

Hemmerling, Udo and Peter Pascher (2012). Situationsbericht 2012/13: Trends und Fakten zur Landwirtschaft. Berlin: Deutscher Bauernverband e.V. IsBN: 978-3-9812770-4-3.

Hensher, David and Miguel Andres Figliozzi (2007). "Behavioural insights into the modelling of freight transportation and distribution systems". In: Transportation Research Part B: Methodological 41.9, pp. 921-923. ISsN: 01912615. DOI: 10.1016/j.trb.2007.04.002.

Hesse, Markus and Jean-Paul Rodrigue (2004). "The transport geography of logistics and freight distribution". In: Journal of Transport Geography 12.3, pp. 171-184. DoI: 10.1016/j.jtrangeo.2003.12.004.

Hessisches Statistisches Landesamt (2015). Sonderauswertung für GENESIS:Tabelle 116-33-4 (Landwirtschaftliche Betriebe mit Viehhaltung und Zahl der Tiere nach Tierarten - Stichtag - regionale Tiefe: Kreise und krfr. Städte, Stichtag 1. März 2010).

Hitchcock, Frank L. (1941). "The Distribution of a Product from Several Sources to Numerous Localities". In: Journal of Mathematics and Physics 20.1-4, pp. 224-230. Issn: 00971421. Dor: 10.1002/sapm1941201224.

Hoekstra, Rutger and Jeroen C.J.M. van den Bergh (2006). "Constructing physical input-output tables for environmental modeling and accounting: Framework and illustrations". In: Ecological Economics 59.3, pp. 375-393. ISSN: 09218009. Dor: 10.1016/j.ecolecon.2005.11.005.

Holcomb, Tim R. and Michael A. Hitt (2007). "Toward a model of strategic outsourcing". In: Journal of Operations Management 25.2, pp. 464-481. Dor: 10.1016/j.jom.2006.05.003.

Holmgren, Johan, Paul Davidsson, Jan A. Persson, and Linda Ramstedt (2012). "TAPAS: A multi-agent-based model for simulation of transport chains". In: Simulation Modelling Practice and Theory 23, pp. 1-18. ISSN: 1569190X. DOI: 10.1016/j.simpat.2011.12.011.

Holmgren, Johan, Linda Ramstedt, Paul Davidsson, and Jan A. Persson (2012). "Multi-Agent-Based Simulation for Analysis of Transport Policy and Infrastructure Measures". In: Proceedings of the 14th International Conference on Principles and Practice of Multi-Agent Systems. Springer.

Holweg, Matthias and Frits K. Pil (2004). The second century: Reconnecting customer and value chain through build-to-order: moving beyond mass and lean production in the auto industry. Cambridge, Mass: MIT Press. ISBN: 0262582627.

Holzapfel, H. and R. Vahrenkamp (1993). "Bemerkungen zum Zusammenhang der steigenden Arbeitsteilung mit dem Verkehrsaufwand". In: Informationsdienst des Instituts für ökologische Wirtschaftsforschung 8.2, pp. 6-7.

Holzapfel, Helmut and Richard Vahrenkamp (1999). "An appraisal of decreased depth of production on traffic demand: development of a model". In: World Transport Policy \& Practice 5.2, pp. 18-20.

Hutchinson, B.G. (1974). Principles of urban transport systems planning. Washington: Scripta Book Co. ISBN: 0070315396. 
IBM (2016). IBM CPLEX Optimizer. URL: http://www-03.ibm.com/software/products/de/ibmilogcpleoptistud (visited on 06/29/2016).

icct (2016). EUROPEAN VEHICLE MARKET STATISTICS - Pocketbook 2015/16. Berlin. URL: http://www.theicct.org/ sites/default/files/publications/ICCT_EU-pocketbook_2015.pdf (visited on 01/20/2017).

Iddink, Ute (2010). Erklärungsmodell zur Ableitung des Wirtschaftsverkehrs in Produktionsnetzwerken. 1st ed. München: Verl. Dr. Hut. IsBn: 978-3-86853-425-2.

Iddink, Ute (2011). "Improving freight transport models by integration of logistics and procurement figures". In: ed. by Transportation Research Board. Washington, D.C: Transportation Research Board.

Isard, Walter (1956). Location and space-economy: A general theory relating to industrial location, market areas, land use, trade, and urban structure. Cambridge, Mass: M.I.T. Press. IsBn: 0262090015.

Ivanova, Olga (2014). "Modelling Inter-Regional Freight Demand with Input-Output, Gravity and SCGE Methodologies". In: Modelling freight transport. Ed. by Lorant A. Tavasszy and Gerard de Jong. Elsevier insights. London: Elsevier. isBn: 978-0-12-410400-6.

Jäcker, Andreas (1997). Verkehrliche Wirkungen neuer Produktionskonzepte: Eine theoretische und empirische Analyse am Beispiel der deutschen Elektroindustrie. Vol. Heft 143. Beiträge aus dem Institut für Verkehrswissenschaft an der Universität Münster. Göttingen: Vandenhoeck \& Ruprecht. IsBN: 3525858841.

Jacobides, Michael G. and Sidney G. Winter (2005). "The co-evolution of capabilities and transaction costs: Explaining the institutional structure of production". In: Strategic Management Journal 26.5, pp. 395-413. IssN: 0143-2095. Dor: 10.1002/smj.460.

Jacobs, Jane (1969). The economy of cities. Vintage international. New York: Random House. URL: https://books. google.de/books?id=GgyxAAAAIAAJ.

Janssens, Davy, Ansar-Ul-Haque Yasar, and Luk Knapen, eds. (2014). Data Science and Simulation in Transportation Research. IGI Global. ISBN: 9781466649200. DoI: 10.4018/978-1-4666-4920-0.

Jindra, Björn, Sohaib S. Hassan, and Uwe Cantner (2016). "What does location choice reveal about knowledgeseeking strategies of emerging market multinationals in the EU?" In: International Business Review 25.1, pp. 204220. ISSN: 09695931. DOI: 10.1016/j.ibusrev.2014.11.008.

Kamien, Morton I. and Nancy L. Schwartz (1982). Market structure and innovation. Cambridge surveys of economic literature. Cambridge, MA: Cambridge Univ. Press.

Kannegiesser, M. and H.-O. Günther (2014). "Sustainable development of global supply chains—part 1: Sustainability optimization framework". In: Flexible Services and Manufacturing Journal 26.1-2, pp. 24-47. IssN: 1936-6582. DOI: 10.1007/s10696-013-9176-5.

Kannegiesser, Matthias, Hans-Otto Günther, and Ólafur Gylfason (2014). "Sustainable development of global supply chains-part 2: Investigation of the European automotive industry". In: Flexible Services and Manufacturing Journal 26.1-2, pp. 48-68. Issn: 1936-6582. Dor: 10.1007/s10696-013-9177-4.

Khandwalla, P. N. (1973). "Viable and Effective Organizational Designs of Firms". In: Academy of Management Journal 16.3, pp. 481-495. issn: 0001-4273. Dor: 10.2307/255008.

Klaus, Peter, Christian Kille, and Martin Schwemmer (2011). Top 100 in European transport and logistics services: Market sizes, market segments and market leaders in the European logistics industry. 4. Ed. 2011/2012. Hamburg: DVV Media Group. IsBN: 9783871544521.

Klein, Timotheus and Sven Altenburg (2013). "Synthese von Wirtschaftsstrukturen mit r88-Structurama". In: Wirtschaftsverkehr 2013. Ed. by Uwe Clausen and Carina Thaller. Berlin, Heidelberg: Springer Berlin Heidelberg, pp. 16-31. ISBN: 978-3-642-37600-9. DoI: 10.1007/978-3-642-37601-6\{_\}2.

Klug, Florian (2010). Logistikmanagement in der Automobilindustrie: Grundlagen der Logistik im Automobilbau. VDI-Buch. Berlin, Heidelberg: Springer-Verlag Berlin Heidelberg. ISBN: 978-3-642-05293-4.

Knorst, Peter (2004). "Ford: Lean Manufacturing and Supply". In: Supply Chain Management erfolgreich umsetzen. Ed. by Daniel Corsten and Christoph Gabriel. Berlin: Springer, pp. 73-86. IsBN: 3540005862. 
Köhler, Uwe (2014). Einführung in die Verkehrsplanung: Grundlagen, Modellbildung, Verkehrsprognose, Verkehrsnetze. Stuttgart: Fraunhofer IRB Verlag. ISBN: 9783816790419.

Kohn, Christofer (2005). Centralisation of distribution systems and its environmental effects. Linköping: Linköping University. IsBN: 91-85299-71-5.

Koopmans, Tjalling C. (1949). "Optimum Utilization of the Transportation System". In: Econometrica 17, pp. 136146. ISSN: 00129682. DOI: 10.2307/1907301.

Kotler, Philip (1972). "A Generic Concept of Marketing”. In: Journal of Marketing 36.2, p. 46. Issn: 00222429. DoI: $10.2307 / 1250977$.

Kowalski, Jan S., Gernot T. Liedtke, Axel Schaffer, and Spiering Spiering (2007). "The Importance of Material Flow Analysis for Commodity Transport Demand and Modelling". In: Romanian Journal of Regional Science 1, pp. 1732.

Krugman, Paul (1991a). "Increasing Returns and Economic Geography". In: Journal of Political Economy 99.3, pp. 483-499. Dor: 10.1086/261763.

Krugman, Paul R. (1979). "Increasing returns, monopolistic competition, and international trade". In: Journal of International Economics 9.4, pp. 469-479. DoI: 10.1016/0022-1996(79)90017-5.

Krugman, Paul R. (1991b). Geography and trade. 1st MIT Press pbk. ed. Gaston Eyskens lecture series. Leuven, Belgium and Cambridge, Mass.: Leuven University Press and MIT Press. IsBn: 9780262610865.

Krugman, Paul R. (1998). “WHAT'S NEW ABOUT THE NEW ECONOMIC GEOGRAPHY?” In: Oxford Review of Economic Policy 14.2, pp. 7-17. ISSN: 0266903X. Dor: 10.2307/23606492. uRL: http://www.jstor.org/stable/ 23606492.

Kuhn, Andreas (2010). Input-Outputrechnung im Überblick. Wiesbaden: Statistisches Bundesamt.

Kulke, Elmar (2013). Wirtschaftsgeographie. 5., aktualisierte Aufl. Vol. 2434. UTB. Paderborn and Paderborn: UTB and Schöningh Paderborn. IsBn: 9783825240165.

Kummer, Sebastian (2006). Einführung in die Verkehrswirtschaft. Vol. 8336 : Betriebswirtschaftslehre. UTB. Wien: Facultas.wuv. IsBN: 3825283364.

Lambert, Douglas M. and Martha C. Cooper (2000). "Issues in Supply Chain Management". In: Industrial Marketing Management 29.1, pp. 65-83. Issn: 00198501. DoI: 10.1016/S0019-8501(99)00113-3.

Lambert, Douglas M., Martha C. Cooper, and Janus D. Pagh (1998). "Supply Chain Management: Implementation Issues and Research Opportunities". In: The International Journal of Logistics Management 9.2, pp. 1-20. IssN: 0957-4093. DOI: 10.1108/09574099810805807.

Law, Averill M. and W. David Kelton (1991). Simulation Modeling and Analysis (McGraw Hill Series in Industrial Engineering and Management Science). 2nd ed. McGraw-Hill College.

Leamer, E. E. (1995). The Heckscher-Ohlin Model in Theory and Practice: Princeton Studies in International Economics. Leontief, Wassily W. (1936). "Quantitative Input and Output Relations in the Economic Systems of the United States". In: The Review of Economics and Statistics 18.3, pp. 105-125. ISSN: 00346535, 15309142. DoI: 10.2307/ 1927837.

Lequiller, F. and D. Blades (2014). Understanding National Accounts. OECD Publishing. IsBN: 9789264214620. DoI: 10.1787/9789264214637-en.

Levin, Richard and Peter C. Reiss (1984). In: $R \& D$, patents, and productivity. Ed. by Zvi Griliches. National Bureau of Economic Research conference report. Chicago: University of Chicago Press, pp. 175-208. IsBN: 0-226-308847.

Liedtke, Gernot (2006). An actor-based approach to commodity transport modelling: Dissertation. Baden-Baden: Nomos. IsBN: 3832921419.

Liedtke, Gernot (2009). "Principles of micro-behavior commodity transport modeling". In: Transportation Research Part E: Logistics and Transportation Review 45.5, pp. 795-809. ISSN: 1366-5545. Dor: 10.1016/j.tre.2008.07.002. URL: http://www.sciencedirect.com/science/article/pii/S1366554509000507. 
Liedtke, Gernot and Hanno Friedrich (2012). "Generation of logistics networks in freight transportation models". In: Transportation 39.6, pp. 1335-1351. ISSN: 0049-4488. DOI: 10.1007/s11116-012-9386-9. uRL: http://dx.doi. org/10.1007/s11116-012-9386-9.

Löffelholz, Josef (1967). Repetitorium der Betriebswirtschaftslehre: Völlig neubearbeitete und erweiterte Buchausgabe. 2. überarbeitete Auflage. Wiesbaden and s.l.: Gabler Verlag. IsBn: 978-3-663-13075-8. Dor: 10.1007/978-3-66313075-8. URL: http://dx.doi.org/10.1007/978-3-663-13075-8.

Lösch, August (1940). Die räumliche Ordnung der Wirtschaft: Eine Untersuchung über Standort, Wirtschaftsgebiete und internationalem Handel. Jena: Fischer.

Lyons, Bruce (1980). "A New Measure of Minimum Efficient Plant Size in UK Manufacturing Industry". In: Economica 47.185, p. 19. Dor: $10.2307 / 2553165$.

MacCarthy, B. L. and W. Atthirawong (2003). "Factors affecting location decisions in international operations a Delphi study". In: International Journal of Operations \& Production Management 23.7, pp. 794-818. DoI: 10. 1108/01443570310481568.

Manheim, Marvin L. (1980). Fundamentals of transportation systems analysis. 3rd ed. Vol. 4. Cambridge: MIT Press. ISBN: 9780262632898.

Marshall, Alfred (1890). PRINCIPLES OF ECONOMICS. London: Macmillan and Co.

Martin, Brian V., Frederick W. Memmott, and Alexander J. Bone (1965). Principles and techniques of predicting future demand for urban area transportation. Cambridge: Massachusetts Institute of Technology Press.

Mattfeld, Dirk (2013). Logistiknetzwerke: Modelle fur standortwahl und tourenplanung. [Place of publication not identified]: Springer Gabler. ISBN: 978-3-8349-2269-4.

McFadden, Daniel L. (1974). "Conditionial logit analvsis of qualitative choice behavior". In: Frontiers in econometrics. Ed. by Paul Zarembka. Economic theory and mathematical economics. New York: Academic Press, pp. 105135. ISBN: 0127761500.

McIvor, R. T., P. K. Humphreys, and W. E. McAleer (1997). "A strategic model for the formulation of an effective make or buy decision". In: Management Decision 35.2, pp. 169-178. Issn: 0025-1747. Dor: 10.1108/ 00251749710160331.

McKinnon, Alan Campbell (2008). "The potential of economic incentives to reduce CO2 emissions from goods transport". In: International Transport Forum on Transport and Energy. Ed. by OECD.

McKinnon, Alan Campbell, Michael Browne, and Anthony E. Whiteing (2012). Green logistics: Improving the environmental sustainability of logistics. Second edition. London and Philadelphia: Kogan Page. IsBN: 0749466251.

McKinnon, Alan Campbell and Allan Woodburn (1996). "Logistical Restructuring and Freight Traffic Growth: An Empirical Assessment”. In: Transportation 23, pp. 141-161. Issn: 0049-4488.

Meersman, Hilde, Eddy van de Voorde, and Thierry Vanelslander (2010). "It's all about economics!" In: Maritime Policy \& Management 37.3, pp. 175-177. Issn: 0308-8839. DoI: 10.1080/03088831003700553.

Melo, M. T., S. Nickel, and F. Saldanha da Gama (2006). "Dynamic multi-commodity capacitated facility location: A mathematical modeling framework for strategic supply chain planning". In: Computers \& Operations Research 33.1, pp. 181-208. ISSN: 03050548. DOI: 10.1016/j.cor.2004.07.005.

Merriam-Webster (2016a). Structure. URL: http://www.merriam-webster.com/dictionary (visited on 03/29/2016). Merriam-Webster (2016b). Transport. URL: http://www.merriam-webster.com/dictionary (visited on 03/29/2016). Miller, Danny and Peter H. Friesen (1982). "Structural Change and Performance: Quantum versus PiecemealIncremental Approaches". In: The Academy of Management Journal 25.4, pp. 867-892. IssN: 00014273. DoI: $10.2307 / 256104$.

Moeckel, Rolf (2007). Business location decisions and urban sprawl: A microsimulation of business relocation and firmography. Vol. 126. Dortmunder Beiträge zur Raumplanung / Blaue Reihe. Dortmund: IRPUD. ISBN: 978-388211-160-6. 
Mueller, Dennis C. and John E. Tilton (1969). "Research and Development Costs as a Barrier to Entry". In: The Canadian Journal of Economics 2.4, p. 570. Issn: 00084085. Dor: 10.2307/133844.

Nash, Chris, ed. (2015). Handbook of research methods and applications in transport economics and policy. Handbooks of research methods and applications. Cheltenham: Edward Elgar Publishing. IsBn: 9780857937926. URL: http://search.ebscohost.com/login.aspx?direct=true\&scope $=$ site\&db=nlebk\&AN=1075223.

Nehm, Alexander, Uwe Veres-Homm, Annemarie Kübler, and Michael Lorenz (2013). Logistikimmobilien - Markt und Standorte 2013: Deutschland, Österreich, Schweiz, Belgien und Niederlande. Stuttgart: Fraunhofer-Verl. IsBN: 9783839606131.

Nicolai, T. and K. Nagel (2015). "Integration of agent-based transport and land use models". In: Integrated transport \& land use modeling for sustainable cities. Ed. by Michel Bierlaire. Lausanne: EPFL Press. IsBN: 9780415729109.

OECD (2013). Interconnected economies: Benefiting from global value chains. Paris: Organisation for Economic Cooperation and Development. ISBN: 9789264189560. URL: http://www.keepeek.com/Digital-Asset-Management/ oecd/science-and-technology/interconnected-economies_9789264189560-en\#page3.

Ohlin, Bertil (1933). Interregional and international trade. 3rd ed. Harvard economic studies. Cambridge, Mass.: Harvard Univ. Press 1957.

Open Source Geospatial Foundation (2016). GeoTools The Open Source Java GIS Toolkit. Version 2.7. URL: http: //geotools.org/ (visited on 06/29/2016).

ORACLE (2016). Java. Version 1.8. URL: https:// www. java.com/de/download/faq/java8 . xml (visited on 06/29/2016).

Ortúzar, Juan de Dios and Luis G. Willumsen (2011). Modelling transport. 4th ed. Oxford: Wiley-Blackwell. ISBN: 9780470760390.

Ottemöller, Ole and Hanno Friedrich (2016). "Opportunities of sectoral freight transport demand modelling". In: Case Studies on Transport Policy 4.1, pp. 9-12. Issn: 2213624X. DoI: 10.1016/j.cstp.2015.08.003.

Otto, Andreas (2002). Management und Controlling von Supply Chains: Ein Modell auf der Basis der Netzwerktheorie. Vol. 290. Neue betriebswirtschaftliche Forschung. Wiesbaden: Deutscher Universitätsverlag. ISBN: 3663107167. DOI: 10.1007/978-3-663-10716-3. uRL: http://dx.doi.org/10.1007/978-3-663-10716-3.

Parry, Glenn and Andrew Graves, eds. (2008). Build to order: The road to the 5-day car. London: Springer. IsBN: 9781848002241.

Penrose, Edith Tilton (1959). The theory of the growth of the firm. New York: John Wiley and Sons.

Perry, Martin K. (1989). "VERTICAL INTEGRATION: DETERMINANTS AND EFFECTS". In: Handbook of industrial organization. Ed. by Richard Schmalensee and Robert Willig. Vol. 10. Handbooks in economics. Amsterdam: Elsevier, pp. 185-255. IsBn: 0444704345.

Piecyk, Maja I. and Alan C. McKinnon (2010). "Forecasting the carbon footprint of road freight transport in 2020". In: International Journal of Production Economics 128.1, pp. 31-42. Dor: 10.1016/j.ijpe.2009.08.027.

Pirkul, Hasan and Vaidyanathan Jayaraman (1998). "A multi-commodity, multi-plant, capacitated facility location problem: Formulation and efficient heuristic solution”. In: Computers \& Operations Research 25.10, pp. 869-878. ISSN: 03050548. DOI: 10.1016/S0305-0548(97)00096-8.

Pitfield, D. E. and B. Benabi (1982). "British location rents: An interpretation of the dual transportation problem for commodity flows". In: Transportation Planning and Technology 7.4, pp. 243-265. ISSN: 0308-1060. Dor: 10. 1080/03081068208717227.

Porter, Michael E. (1985). Competitive advantage: Creating and sustaining superior performance. New York and London: Free Press and Collier Macmillan. IsBn: 0684841460.

Reilly, William J. (1931). The law of retail gravitation. New York, NY, USA: Knickerbocker Press.

Ricardo, David (1817). The Principles of Political Economy and Taxation. London: John Murray.

Richardson, G. B. (1972). “The Organisation of Industry”. In: The Economic Journal 82.327, p. 883. Issn: 00130133. DOI: $10.2307 / 2230256$. 
Ro, Young K., Jeffrey K. Liker, and Sebastian K. Fixson (2007). "Modularity as a Strategy for Supply Chain Coordination: The Case of U.S. Auto". In: IEEE Transactions on Engineering Management 54.1, pp. 172-189. ISSN: 0018-9391. DOI: 10.1109/TEM.2006.889075.

Rodrigue, Jean-Paul (2006). "Challenging the derived transport-demand thesis: geographical issues in freight distribution". In: Environment and Planning A 38.8, pp. 1449-1462. ISSN: 0308-518X. Dor: 10.1068/a38117.

Rodrigue, Jean-Paul, Brian Slack, and Claude Comtois (2001). "Green Logistics (The Paradoxes of)". In: Handbook of logistics and supply-chain management. Ed. by Ann Brewer, Kenneth Button, and David A. Hensher. Vol. 2. Handbooks in transport. Amsterdam and New York: Pergamon. IsBn: 0-08-043593-9.

Roorda, Matthew J., Rinaldo Cavalcante, Stephanie McCabe, and Helen Kwan (2010). "A conceptual framework for agent-based modelling of logistics services". In: Transportation Research Part E: Logistics and Transportation Review 46.1, pp. 18-31. Issn: 1366-5545.

Rühl, Frederik and Manfred Boltze (2017). "Freight Transport Demand Management: Influencing the Freight Transport Demand Within Traffic Management". In: Dynamic and Seamless Integration of Production, Logistics and Traffic. Ed. by Eberhard Abele, Manfred Boltze, and Hans-Christian Pfohl. Berlin, Heidelberg: Springer Verlag, pp. 163-184. ISBN: 978-3-319-41095-1. DOI: 10.1007/978-3-319-41097-5\{_\}9. uRL: http://dx.doi.org/10.1007/ 978-3-319-41097-5_9.

Rühl, Frederik, Tobias Freudenreich, Ulrich Berbner, Ole Ottemöller, Hanno Friedrich, and Manfred Boltze (2013). "Production, logistics, and traffic: a systematic approach to understand interactions". In: Selected Proceedings of the 13th World Conference on Transport Research (WCTR). Ed. by World Conference on Transport Research Society.

Ryan, Justin, Hanna Maoh, and Pavlos Kanaroglou (2009). "Population Synthesis: Comparing the Major Techniques Using a Small, Complete Population of Firms”. In: Geographical Analysis 41.2, pp. 181-203. Issn: 00167363. Dor: 10.1111/j.1538-4632.2009.00750.x.

Saadi, Ismaill, Ahmed Mustafa, Jacques Teller, Bilal Farooq, and Mario Cools (2016). "Hidden Markov Model-based population synthesis". In: Transportation Research Part B: Methodological 90, pp. 1-21. ISsN: 01912615. DoI: 10.1016/j.trb.2016.04.007.

Saaty, Thomas L. (2004). "Decision making - the Analytic Hierarchy and Network Processes (AHP/ANP)". In: Journal of Systems Science and Systems Engineering 13.1, pp. 1-35. ISSN: 1004-3756. DOI: 10.1007/s11518-0060151-5.

Samimi, Amir (2010). A behavioral mode choice microsimulation model for freight transportation in the U.S. Dissertation at University of Illinois at Chicago. Ann Arbor, Minnesota: ProQuest LLC. IsBn: 9781124137698.

Samimi, Amir, Abolfazl Mohammadian, Kazuya Kawamura, and Zahra Pourabdollahi (2014). "An activity-based freight mode choice microsimulation model". In: Transportation Letters 6.3, pp. 142-151. IssN: 1942-7867. DoI: 10.1179/1942787514Y.0000000021.

Samuelson, Paul A. (1952). "Spatial Price Equilibrium and Linear Programming". In: The American Economic Review 42.3, pp. 283-303. Issn: 00028282.

Schneeweiss, Christoph (1999). Hierarchies in Distributed Decision Making. Berlin, Heidelberg: Springer Berlin Heidelberg. ISBN: 978-3-662-03830-7.

Schoemakers, Arnout and Toon van der Hoorn (2004). "LUTI modelling in the Netherlands: Experiences with TIGRIS and a framework for a new LUTI model". In: European Journal of Transport and Infrastructure Research 4.3, pp. 315-332.

Scholl, Bernd, Hany Elgendy, and Markus Nollert (2007). Raumplanung in Deutschland - Formeller Aufbau und zukünftige Aufgaben: Spatial planning in Germany - Formal structure and future tasks. Vol. 35. Schriftenreihe des Instituts für Städtebau und Landesplanung an der Universität Karlsruhe (TH). Karlsruhe: Universitätsverlag. ISBN: 9783866441620 . 
Schröder, Stefan, Michael Zilske, Gernot Liedtke, and Kai Nagel (2012). "Computational Framework for Multiagent Simulation of Freight Transport Activities". In: TRB 91st Annual Meeting Compendium of Papers DVD. Ed. by Transportation Research Board. Washington, D.C: Transportation Research Board.

Schubert, Markus, Stefanos Kotzagiorgis, Bernd Butz, Walter Schneider, and Markus Leible (2014). Verkehrsverflechtungsprognose 2030 - Los 3: Erstellung der Prognose der deutschlandweiten Verkehrsverflechtungen unter Berücksichtigung des Luftverkehrs. Ed. by Bundesministerium für Verkehr und digitale Infrastruktur. uRL: http: //daten.clearingstelle-verkehr.de/276/3/Datensatzbeschreibung\%20G\%C3\%83\%C2\%BCterverkehr.pdf (visited on 08/04/2016).

Schumpeter, Joseph A. (1942). Capitalism, socialism and democracy. New York, NY, USA: Harper.

Sharma, R.R.K. and V. Berry (2007). "Developing new formulations and relaxations of single stage capacitated warehouse location problem (SSCWLP): Empirical investigation for assessing relative strengths and computational effort". In: European Journal of Operational Research 177.2, pp. 803-812. Dor: 10.1016/j.ejor.2005.11.028.

Siggelkow, Nicolaj (2011). "Firms as Systems of Interdependent Choices". In: Journal of Management Studies 48.5, pp. 1126-1140. ISSN: 00222380. DoI: 10.1111/j.1467-6486.2011.01010.x.

Simchi-Levi, David, Philip Kaminsky, and Edith Simchi-Levi (2008). Designing and managing the supply chain: Concepts, strategies, and case studies. 3rd ed. Mcgraw-Hill/Irwin series operations and decision sciences. Boston: McGraw-Hill/Irwin. ISBN: 9780071107501.

Sivakumar, Aruna and Chandra Bhat (2002). "Fractional Split-Distribution Model for Statewide Commodity-Flow Analysis". In: Transportation Research Record: Journal of the Transportation Research Board 1790, pp. 80-88. IssN: 0361-1981. DoI: 10.3141/1790-10.

Sjöstedt, L. (2004). "A conceptual framework for analyzing policy-maker's and industry roles". In: Barriers to Sustainable Transport. Ed. by Piet Rietveld. London: Tylor and Francis Group.

Smith, Adam (1776). An Inquiry into the Nature and Causes of the Wealth of Nations. London: W. Strahan and T. Cadell.

Sombart, Werner (1902). Der moderne Kapitalismus. Leipzig: Duncker \& Humblot.

Starrett, D. (1978). "Market allocations of location choice in a model with free mobility". In: Journal of Economic Theory 17, pp. 21-37.

Statistisches Bundesamt (1995). Betriebe, Tätige Personen und Umsatz des Verarbeitenden Gewerbes sowie des Bergbaus und der Gewinnung von Steinen und Erden nach Beschäftigtengrößenklassen. Ed. by German Federal Statistical Office. Wiesbaden.

Statistisches Bundesamt (2009). Material- und Wareneingangserhebung im Verarbeitenden Gewerbe sowie im Bergbau und in der Gewinnung von Steinen und Erden. Ed. by German Federal Statistical Office. Wiesbaden.

Statistisches Bundesamt (2012). Betriebe, Tätige Personen und Umsatz des Verarbeitenden Gewerbes sowie des Bergbaus und der Gewinnung von Steinen und Erden nach Beschäftigtengrößenklassen. Ed. by German Federal Statistical Office. Wiesbaden.

Statistisches Bundesamt (2013a). Betriebe, Tätige Personen und Umsatz des Verarbeitenden Gewerbes sowie des Bergbaus und der Gewinnung von Steinen und Erden nach Beschäftigtengrößenklassen. Ed. by German Federal Statistical Office. Wiesbaden.

Statistisches Bundesamt (2013b). Sonderauswertung. Beschäftigte nach Kreisen: Sozialversicherungspflichtig Beschäftigte nach Wirtschaftsabteilungen und -gruppen der WZ 2008; Regierungsbezirke, Kreise und kreisfreie Städte (regionale Abgrenzung nach dem Arbeitsortprinzip); Stichtag 30.06.2012. Ed. by German Federal Statistical Office. Wiesbaden.

Statistisches Bundesamt (2014a). Sonderauswertung. Betriebe nach Wirtschaftsabteilungen und Größenklassen der sozialversicherungspflichtig Beschäftigten im Berichtsjahr 2012. Registerstand: 31.05.2014. Wiesbaden.

Statistisches Bundesamt (2014b). Volkswirtschaftliche Gesamtrechnungen. Ed. by German Federal Statistical Office. Wiesbaden. 
Statistisches Bundesamt (2015). Betriebe nach Wirtschaftsklassen und Größenklassen der sozialversicherungspflichtig Beschäftigten im Berichtsjahr 2012. Sonderauswertung des Unternehmensregisters. Ed. by German Federal Statistical Office. Wiesbaden.

Statistisches Bundesamt (2016a). Aus- und Einfuhr (Außenhandel): Deutschland, Jahre, Land, Warenverzeichnis (8Steller). GENESIS-Online Datenbank. Tabelle 51000-0015. Wiesbaden.

Statistisches Bundesamt (2016b). Genesis Tabelle 12411-0014. Bevölkerung: Kreise, Stichtag; Stichtag 31.12.2012; ed. by German Federal Statistical Office. Wiesbaden.

Statistisches Bundesamt (2016c). Volkswirtschaftliche Gesamtrechnungen. Bruttoinlandsprodukt ab 1970. Vierteljahresund Jahresergebnisse. Ed. by German Federal Statistical Office. Wiesbaden.

Storper, Michael and Richard Walker (1989). The capitalist imperative: Territory, technology, and industrial growth. Oxford, UK and New York, NY, USA: B. Blackwell. IsBN: 978-0-631-16533-0.

Taniguchi, Eiichi, Russel G. Thompson, and Tadashi Yamada (2014). "Recent Trends and Innovations in Modelling City Logistics". In: Procedia - Social and Behavioral Sciences 125.1, pp. 4-14. IssN: 1877-0428. DoI: 10.1016/j. sbspro.2014.01.1451. uRL: http://www.sciencedirect.com/science/article/pii/S187704281401489X.

Tavasszy, Lóránt A. (2008). "Freight modelling: an overview of international experiences". In: Freight demand modeling. Ed. by Kathleen L. Hancock. Washington, D.C.: Transportation Research Board. IsBN: 978-0-309-113076.

Tavasszy, Lóránt A., C. E. Cornelissen, and E. Huijsman (2001). "FORECASTING THE IMPACTS OF CHANGING PATTERNS OF PHYSICAL DISTRIBUTION ON FREIGHT TRANSPORT IN EUROPE". In: Selected proceedings of the 9th World Congress on Transport Research, 22 - 27 July 2001, Seoul Korea. Ed. by Chang-Ho Park, J. R. Cho, and J. Oh. World Conference on Transport Research Society. ISBN: 0080442749.

Tavasszy, Lóránt A., Kees Ruijrok, and Igor Davydenko (2012). "Incorporating logistics in freight transport demand models: State-of-the-art and research opportunities". In: Transport Reviews 32.2, pp. 203-219. Dor: 10.1080/ 01441647.2011.644640.

Thaller, Carina, Benjamin Dahmen, Gernot Liedtke, and Hanno Friedrich (2016). "Freight Transport Demand Modelling". In: Commercial Transport. Ed. by Uwe Clausen, Hanno Friedrich, Carina Thaller, and Christiane Geiger. Lecture Notes in Logistics. Springer International Publishing. ISBN: 978-3-319-21265-4.

Trautwein, Hans-Michael (2014). "Der Traum vom Allgemeinen Gleichgewicht im Raum". In: Studien zur Entwicklung der ökonomischen Theorie XXIX. Ed. by Hans-Michael Trautwein. Vol. 115,29. Schriften des Vereins für Socialpolitik, Gesellschaft für Wirtschafts- und Sozialwissenschaften : N.F. Berlin: Duncker \& Humblot, pp. 337371. ISBN: 9783428143849.

Treleven, Mark and Sharon Bergman Schweikhart (1988). "A risk/benefit analysis of sourcing strategies: Single vs. multiple sourcing". In: Journal of Operations Management 7.3-4, pp. 93-114. DoI: 10.1016/0272-6963(81) 90007-3.

Vallée, Dirk (2012). Leitfaden Logistik. Vol. 16. E-Paper der ARL. Hannover: Akademie für Raumforschung und Landesplanung. ISBN: 978-3-88838-734-0.

Varschen, Christian, Astrid Gühnemann, and Barbara Lenz (2005). "Produktionsveränderungen und Güterverkehrsnachfrage - Ergebnisse von Einzelfallanalysen". In: Wirtschaftsverkehr 2005. Ed. by Uwe Clausen. Logistik, Verkehr und Umwelt. Dortmund: Verlag Praxiswissen and Verl. Praxiswissen, pp. 33-47. IsBn: 3-89957-29-4. URL: http://elib.dlr.de/21009/.

VDA (2012). Tatsachen und Zahlen. 1969-2012. Ed. by Verband der Automobilindustrie. Berlin: Verband der Automobilindustrie.

Venables, Anthony J. (1996). "Equilibrium Locations of Vertically Linked Industries". In: International Economic Review 37.2, p. 341. ISSN: 00206598. DOI: 10.2307/2527327. 
Visser, Johan, Arjan van Binsbergen, and Toshinori Nemoto (1999). "URBAN FREIGHT TRANSPORT POLICY AND PLANNING". In: City logistics I. Ed. by Eiichi Taniguchi and Russell G. Thompson. Vol. 1. City logistics. Kyoto: Institute of Systems Science Research, pp. 39-69. IsBN: 4998076701.

Vogiatzoglou, Klimis (2006). "Agglomeration or dispersion? Industrial specialization and geographic concentration in NAFTA". In: Journal of international economic studies 20.(3), pp. 89-102. ISSN: 0911-1247.

von Thünen, Johann Heinrich (1990). Der isolierte Staat in Beziehung auf Landwirtschaft und Nationalökonomie. Neudr. nach der Ausg. letzter Hand, Rostock Leopold, 1842 / eingeleitet von Heinrich Waentig, 5., unveränd. Aufl. Aalen: Scientia-Verlag. IsBN: 3511092183.

Voordijk, Hans (1999). "Logistical Restructuring of Supply Chains of Building Materials and Road Freight Traffic Growth”. In: International Journal of Logistics Research and Applications 2.3, pp. 285-304. ISSN: 1367-5567. DOI: 10.1080/13675569908901586.

Walras, Léon (1874). Éléments d'économie politique pure: ou, Théorie de la richesse sociale. Lausanne: Corbaz.

Wasserman, Stanley and Katherine Faust (1999). Social network analysis: Methods and applications. Vol. 8. Structural analysis in the social sciences. Cambridge: Cambridge Univ. Press. IsBn: 9780521387071.

Weber, A. (1922). Ueber den Standort der Industrien. 2nd edition. Vol. Bd. 1. J.C.B. Mohr (Paul Siebeck).

Weber, Alfred (1909). Über den Standort der Industrien. Tübingen: JCB Mohr.

Webster, Ken, Jocelyn Blériot, and Craig Johnson, eds. (2013). A new dynamic: Effective business in a circular economy. 1. ed. Cowes (Isle of Wight): Ellen MacArthur Foundation. IsBN: 0992778417.

Wegener, Michael (2004). "Overview of Land Use Transport Models". In: Handbook of Transport Geography and Spatial Systems. Ed. by David A. Hensher, Kenneth J. Button, Kingsley E. Haynes, and Peter R. Stopher. Vol. 5. Handbooks in transport. Emerald Group Publishing Limited, pp. 127-146. IsBN: 978-0-080-44108-5. DoI: 10. 1108/9781615832538-009.

Werner, Hartmut (2013). Supply Chain Management: Grundlagen, Strategien, Instrumente und Controlling. 5th ed. Wiesbaden: Springer Gabler. ISBN: 978-3-8349-3769-8. uRL: http://link.springer.com/book/10.1007/978-38349-3769-8.

Williams, Thomas, Colin Kelley, Russel Lang, Dave Kotz, John Campbell, Gershon Elber, and Alexander Woo (2015). gnuplot. Version 5.0.0. URL: http://www.gnuplot.info/ (visited on 06/29/2016).

Williamson, Oliver E. (1985). The economic institutions of capitalism: Firms, markets, relational contracting. New York, NY: Free Press. IsBN: 002934820X.

Wilson, Jesse, James Lemieux, Holger Brands, Kevin Maltby, and Rob Eden (2015). GlazedLists. Version 1.9.1. URL: http://www.glazedlists.com/ (visited on 06/29/2016).

Wisetjindawat, Wisinee, Kazushi Sano, and Shoji Matsumoto (2006). "Commodity Distribution Model Incorporating Spatial Interactions for Urban Freight Movement". In: Transportation Research Record: Journal of the Transportation Research Board 1966, pp. 41-50. ISSN: 0361-1981. DOI: 10.3141/1966-06.

Woxenius, Johan (2012). "Directness as a key performance indicator for freight transport chains". In: Research in Transportation Economics 36.1, pp. 63-72. IssN: 07398859. DoI: 10.1016/j.retrec.2012.03.007.

Zhaohui Zeng, Amy (2000). "A synthetic study of sourcing strategies". In: Industrial Management \& Data Systems 100.5, pp. 219-226. ISSN: 0263-5577. DOI: 10.1108/02635570010304798.

Zumkeller, Dirk and Richard E. Allsop (2003). PONS kleines Fachwörterbuch Verkehrswesen: Englisch-Deutsch, Deutsch-Englisch. Vollst. Neuentwicklung, 1. Aufl. Stuttgart: Klett Sprachen. IsBN: 3125182786. 
Appendices 


\section{A Input Data for Model Application in Poultry Slaughtering}

Table A.1: Data used for locating establishments in the model application for poultry slaugthering ( $\left.n m p_{i}^{s}\right)$. Sources: Balster et al. (2016), Statistisches Bundesamt (2013b), Hessisches Statistisches Landesamt (2015), and Statistisches Bundesamt (2016b).

\begin{tabular}{|c|c|c|c|c|}
\hline $\begin{array}{r}\text { zone } \\
\text { (AGS) }\end{array}$ & $\begin{array}{r}\text { WZ 01.47.9 } \\
\text { (animals) }\end{array}$ & $\begin{array}{r}\text { WZ } 10.12 \\
\text { (employees) }\end{array}$ & $\begin{array}{r}\text { WZ } 10.85 \\
\text { (employees) }\end{array}$ & $\begin{array}{r}\text { population } \\
\text { (persons) }\end{array}$ \\
\hline 01001 & 0 & 0.00 & 10003 & 83462 \\
\hline 01002 & 0 & 0.00 & 0 & 239866 \\
\hline 01003 & 0 & 0.00 & 0 & 211713 \\
\hline 01004 & 0 & 0.00 & 0 & 76951 \\
\hline 01051 & 282990 & 0.00 & 0 & 132965 \\
\hline 01053 & 318364 & 0.00 & 0 & 187905 \\
\hline 01054 & 0 & 0.00 & 68 & 162237 \\
\hline 01055 & 0 & 15.49 & 5 & 197882 \\
\hline 01056 & 0 & 0.00 & 84 & 298826 \\
\hline 01057 & 1167332 & 0.00 & 35 & 126721 \\
\hline 01058 & 318364 & 0.00 & 0 & 268058 \\
\hline 01059 & 212243 & 0.00 & 9 & 194911 \\
\hline 01060 & 565980 & 0.00 & 0 & 261988 \\
\hline 01061 & 247616 & 19.07 & 0 & 130135 \\
\hline 01062 & 176869 & 0.00 & 0 & 232911 \\
\hline 02000 & 0 & 0.00 & 0 & 1734272 \\
\hline 03101 & 0 & 0.00 & 49 & 245798 \\
\hline 03102 & 0 & 0.00 & 15 & 98095 \\
\hline 03103 & 0 & 0.00 & 0 & 121758 \\
\hline 03151 & 70748 & 0.00 & 0 & 171015 \\
\hline 03152 & 35374 & 0.00 & 0 & 247988 \\
\hline 03153 & 0 & 0.00 & 15 & 138655 \\
\hline 03154 & 0 & 0.00 & 38 & 90391 \\
\hline 03155 & 70748 & 0.00 & 1 & 135418 \\
\hline 03156 & 0 & 0.00 & 0 & 75245 \\
\hline 03157 & 0 & 0.00 & 1 & 130047 \\
\hline 03158 & 35374 & 0.00 & 17 & 120117 \\
\hline 03241 & 106122 & 0.00 & 9 & 1112675 \\
\hline 03251 & 1167332 & 72.70 & 219 & 209671 \\
\hline 03252 & 0 & 0.00 & 13 & 148532 \\
\hline 03254 & 70748 & 51.25 & 0 & 275330 \\
\hline
\end{tabular}




\begin{tabular}{|c|c|c|c|c|}
\hline $\begin{array}{r}\text { zone } \\
\text { (AGS) }\end{array}$ & $\begin{array}{r}\text { WZ } 01.47 .9 \\
\text { (animals) }\end{array}$ & $\begin{array}{r}\text { WZ } 10.12 \\
\text { (employees) }\end{array}$ & $\begin{array}{r}\text { WZ } 10.85 \\
\text { (employees) }\end{array}$ & $\begin{array}{r}\text { population } \\
\text { (persons) }\end{array}$ \\
\hline 03255 & 0 & 0.00 & 6 & 72459 \\
\hline 03256 & 1273453 & 370.65 & 0 & 120225 \\
\hline 03257 & 70748 & 0.00 & 1 & 156039 \\
\hline 03351 & 141495 & 723.43 & 0 & 175706 \\
\hline 03352 & 3714238 & 97.73 & 0 & 197433 \\
\hline 03353 & 141495 & 0.00 & 40 & 240548 \\
\hline 03354 & 0 & 0.00 & 0 & 48928 \\
\hline 03355 & 0 & 0.00 & 0 & 175640 \\
\hline 03356 & 0 & 0.00 & 654 & 110816 \\
\hline 03357 & 813595 & 0.00 & 0 & 161780 \\
\hline 03358 & 530606 & 4.77 & 0 & 135772 \\
\hline 03359 & 212243 & 0.00 & 9 & 195779 \\
\hline 03360 & 106122 & 5.96 & 6 & 92801 \\
\hline 03361 & 0 & 0.00 & 0 & 132129 \\
\hline 03401 & 0 & 0.00 & 17 & 73588 \\
\hline 03402 & 0 & 0.00 & 0 & 49751 \\
\hline 03403 & 0 & 0.00 & 48 & 158658 \\
\hline 03404 & 0 & 0.00 & 1 & 155625 \\
\hline 03405 & 0 & 0.00 & 52 & 76545 \\
\hline 03451 & 35374 & 60.78 & 0 & 118489 \\
\hline 03452 & 813595 & 0.00 & 2 & 186673 \\
\hline 03453 & 7782213 & 134.67 & 22 & 160033 \\
\hline 03454 & 2617654 & 1492.15 & 213 & 312855 \\
\hline 03455 & 141495 & 0.00 & 3 & 97327 \\
\hline 03456 & 3537370 & 0.00 & 0 & 133652 \\
\hline 03457 & 0 & 0.00 & 2 & 164202 \\
\hline 03458 & 990464 & 356.35 & 25 & 125413 \\
\hline 03459 & 1414948 & 25.03 & 0 & 350444 \\
\hline 03460 & 3855733 & 1383.69 & 313 & 133462 \\
\hline 03461 & 0 & 0.00 & 40 & 89126 \\
\hline 03462 & 0 & 0.00 & 1 & 56362 \\
\hline 04011 & 35374 & 4.77 & 0 & 546451 \\
\hline 04012 & 0 & 0.00 & 0 & 108323 \\
\hline 05111 & 0 & 0.00 & 343 & 593682 \\
\hline 05112 & 0 & 0.00 & 17 & 486816 \\
\hline 05113 & 70748 & 0.00 & 1 & 566862 \\
\hline 05114 & 0 & 0.00 & 2 & 222026 \\
\hline 05116 & 70748 & 0.00 & 0 & 255087 \\
\hline 05117 & 0 & 0.00 & 0 & 166654 \\
\hline 05119 & 0 & 0.00 & 16 & 210005 \\
\hline 05120 & 35374 & 0.00 & 0 & 109352 \\
\hline 05122 & 0 & 0.00 & 0 & 155316 \\
\hline 05124 & 0 & 0.00 & 0 & 342885 \\
\hline 05154 & 1131959 & 0.00 & 3 & 301977 \\
\hline
\end{tabular}




\begin{tabular}{|c|c|c|c|c|}
\hline $\begin{array}{r}\text { zone } \\
\text { (AGS) }\end{array}$ & $\begin{array}{r}\text { WZ } 01.47 .9 \\
\text { (animals) }\end{array}$ & $\begin{array}{r}\text { WZ } 10.12 \\
\text { (employees) }\end{array}$ & $\begin{array}{r}\text { WZ } 10.85 \\
\text { (employees) }\end{array}$ & $\begin{array}{r}\text { population } \\
\text { (persons) }\end{array}$ \\
\hline 05158 & 141495 & 0.00 & 72 & 477397 \\
\hline 05162 & 106122 & 0.00 & 38 & 439225 \\
\hline 05166 & 212243 & 0.00 & 0 & 295448 \\
\hline 05170 & 282990 & 0.00 & 53 & 458329 \\
\hline 05314 & 0 & 0.00 & 14 & 309869 \\
\hline 05315 & 141495 & 0.00 & 0 & 1024373 \\
\hline 05316 & 35374 & 0.00 & 25 & 159926 \\
\hline 05334 & 0 & 0.00 & 0 & 542833 \\
\hline 05358 & 106122 & 0.00 & 50 & 258651 \\
\hline 05362 & 0 & 0.00 & 10 & 454792 \\
\hline 05366 & 176869 & 0.00 & 71 & 187724 \\
\hline 05370 & 636727 & 0.00 & 0 & 247827 \\
\hline 05374 & 106122 & 0.00 & 0 & 271332 \\
\hline 05378 & 0 & 0.00 & 0 & 277997 \\
\hline 05382 & 176869 & 0.00 & 0 & 580588 \\
\hline 05512 & 0 & 0.00 & 0 & 116498 \\
\hline 05513 & 0 & 21.45 & 11 & 257607 \\
\hline 05515 & 0 & 0.00 & 3 & 296599 \\
\hline 05554 & 424485 & 0.00 & 0 & 363819 \\
\hline 05558 & 1096585 & 0.00 & 33 & 215087 \\
\hline 05562 & 0 & 0.00 & 72 & 615778 \\
\hline 05566 & 353737 & 26.22 & 0 & 434170 \\
\hline 05570 & 813595 & 0.00 & 29 & 272832 \\
\hline 05711 & 0 & 9.53 & 478 & 328314 \\
\hline 05754 & 2511533 & 101.30 & 15 & 351624 \\
\hline 05758 & 176869 & 0.00 & 0 & 249147 \\
\hline 05762 & 70748 & 0.00 & 0 & 143709 \\
\hline 05766 & 0 & 0.00 & 2 & 346496 \\
\hline 05770 & 318364 & 0.00 & 5 & 309990 \\
\hline 05774 & 1874806 & 0.00 & 17 & 296135 \\
\hline 05911 & 0 & 0.00 & 0 & 362213 \\
\hline 05913 & 0 & 0.00 & 0 & 572087 \\
\hline 05914 & 0 & 0.00 & 0 & 186243 \\
\hline 05915 & 70748 & 0.00 & 73 & 176440 \\
\hline 05916 & 0 & 0.00 & 0 & 154563 \\
\hline 05954 & 176869 & 0.00 & 0 & 324223 \\
\hline 05958 & 176869 & 0.00 & 0 & 263720 \\
\hline 05962 & 0 & 0.00 & 16 & 419976 \\
\hline 05966 & 35374 & 0.00 & 17 & 135523 \\
\hline 05970 & 0 & 0.00 & 0 & 275594 \\
\hline 05974 & 459859 & 5.96 & 8 & 296029 \\
\hline 05978 & 176869 & 7.15 & 45 & 392940 \\
\hline 06411 & 0 & 0.00 & 79 & 147925 \\
\hline 06412 & 0 & 0.00 & 19 & 687775 \\
\hline
\end{tabular}




\begin{tabular}{|c|c|c|c|c|}
\hline $\begin{array}{r}\text { zone } \\
\text { (AGS) }\end{array}$ & $\begin{array}{r}\text { WZ } 01.47 .9 \\
\text { (animals) }\end{array}$ & $\begin{array}{r}\text { WZ } 10.12 \\
\text { (employees) }\end{array}$ & $\begin{array}{r}\text { WZ } 10.85 \\
\text { (employees) }\end{array}$ & $\begin{array}{r}\text { population } \\
\text { (persons) }\end{array}$ \\
\hline 06413 & 0 & 0.00 & 16 & 116945 \\
\hline 06414 & 0 & 0.00 & 0 & 272636 \\
\hline 06431 & 0 & 0.00 & 1 & 261695 \\
\hline 06432 & 3961854 & 0.00 & 16 & 284413 \\
\hline 06433 & 0 & 0.00 & 1 & 254883 \\
\hline 06434 & 0 & 0.00 & 15 & 228098 \\
\hline 06435 & 353737 & 0.00 & 1 & 403134 \\
\hline 06436 & 0 & 0.00 & 11 & 226113 \\
\hline 06437 & 0 & 0.00 & 3 & 96648 \\
\hline 06438 & 0 & 0.00 & 2 & 336265 \\
\hline 06439 & 0 & 0.00 & 3 & 180911 \\
\hline 06440 & 0 & 0.00 & 8 & 293940 \\
\hline 06531 & 70748 & 0.00 & 33 & 253041 \\
\hline 06532 & 70748 & 0.00 & 12 & 252106 \\
\hline 06533 & 0 & 0.00 & 14 & 169904 \\
\hline 06534 & 247616 & 0.00 & 0 & 241279 \\
\hline 06535 & 0 & 0.00 & 5 & 106947 \\
\hline 06611 & 0 & 0.00 & 1 & 192874 \\
\hline 06631 & 141495 & 0.00 & 0 & 216093 \\
\hline 06632 & 0 & 0.00 & 3 & 120165 \\
\hline 06633 & 848969 & 0.00 & 28 & 234206 \\
\hline 06634 & 141495 & 143.02 & 24 & 180279 \\
\hline 06635 & 0 & 0.00 & 15 & 157293 \\
\hline 06636 & 141495 & 40.52 & 0 & 100913 \\
\hline 07111 & 0 & 0.00 & 0 & 109779 \\
\hline 07131 & 0 & 0.00 & 37 & 125837 \\
\hline 07132 & 35374 & 0.00 & 10 & 129166 \\
\hline 07133 & 0 & 0.00 & 15 & 155306 \\
\hline 07134 & 0 & 0.00 & 0 & 81135 \\
\hline 07135 & 0 & 0.00 & 11 & 63475 \\
\hline 07137 & 742848 & 0.00 & 20 & 210035 \\
\hline 07138 & 35374 & 0.00 & 12 & 179812 \\
\hline 07140 & 0 & 0.00 & 36 & 101002 \\
\hline 07141 & 35374 & 0.00 & 25 & 121838 \\
\hline 07143 & 0 & 0.00 & 17 & 198852 \\
\hline 07211 & 0 & 0.00 & 38 & 106544 \\
\hline 07231 & 0 & 0.00 & 0 & 110833 \\
\hline 07232 & 0 & 0.00 & 19 & 95946 \\
\hline 07233 & 70748 & 0.00 & 58 & 61073 \\
\hline 07235 & 0 & 0.00 & 9 & 143893 \\
\hline 07311 & 0 & 0.00 & 0 & 47035 \\
\hline 07312 & 0 & 0.00 & 9 & 97112 \\
\hline 07313 & 0 & 0.00 & 0 & 43641 \\
\hline 07314 & 0 & 0.00 & 0 & 160179 \\
\hline
\end{tabular}




\begin{tabular}{|c|c|c|c|c|}
\hline $\begin{array}{r}\text { zone } \\
(\mathrm{AGS})\end{array}$ & $\begin{array}{r}\text { WZ 01.47.9 } \\
\text { (animals) }\end{array}$ & $\begin{array}{r}\text { WZ } 10.12 \\
\text { (employees) }\end{array}$ & $\begin{array}{r}\text { WZ } 10.85 \\
\text { (employees) }\end{array}$ & $\begin{array}{r}\text { population } \\
\text { (persons) }\end{array}$ \\
\hline 07315 & 0 & 0.00 & 0 & 202756 \\
\hline 07316 & 0 & 0.00 & 0 & 52268 \\
\hline 07317 & 0 & 0.00 & 0 & 40267 \\
\hline 07318 & 0 & 0.00 & 0 & 49764 \\
\hline 07319 & 0 & 0.00 & 0 & 79727 \\
\hline 07320 & 0 & 0.00 & 0 & 34064 \\
\hline 07331 & 0 & 0.00 & 4 & 125173 \\
\hline 07332 & 0 & 0.00 & 9 & 130927 \\
\hline 07333 & 0 & 0.00 & 14 & 75508 \\
\hline 07334 & 0 & 0.00 & 72 & 124889 \\
\hline 07335 & 0 & 0.00 & 10 & 104443 \\
\hline 07336 & 0 & 0.00 & 11 & 71766 \\
\hline 07337 & 0 & 0.00 & 0 & 108752 \\
\hline 07338 & 0 & 0.00 & 0 & 148079 \\
\hline 07339 & 35374 & 0.00 & 175 & 202222 \\
\hline 07340 & 0 & 0.00 & 16 & 97180 \\
\hline 08111 & 0 & 0.00 & 8 & 597939 \\
\hline 08115 & 0 & 0.00 & 12 & 367208 \\
\hline 08116 & 0 & 0.00 & 0 & 508577 \\
\hline 08117 & 0 & 0.00 & 169 & 247835 \\
\hline 08118 & 0 & 88.19 & 13 & 516748 \\
\hline 08119 & 106122 & 0.00 & 81 & 408827 \\
\hline 08121 & 0 & 0.00 & 21 & 117531 \\
\hline 08125 & 106122 & 0.00 & 7 & 324543 \\
\hline 08126 & 389111 & 0.00 & 8 & 107498 \\
\hline 08127 & 672101 & 162.09 & 10 & 186928 \\
\hline 08128 & 0 & 0.00 & 42 & 129842 \\
\hline 08135 & 35374 & 0.00 & 35 & 127608 \\
\hline 08136 & 35374 & 0.00 & 4 & 306484 \\
\hline 08211 & 0 & 0.00 & 22 & 52585 \\
\hline 08212 & 0 & 0.00 & 1 & 296033 \\
\hline 08215 & 247616 & 0.00 & 0 & 427106 \\
\hline 08216 & 0 & 0.00 & 68 & 222472 \\
\hline 08221 & 0 & 0.00 & 308 & 150335 \\
\hline 08222 & 0 & 0.00 & 0 & 294627 \\
\hline 08225 & 176869 & 0.00 & 17 & 141847 \\
\hline 08226 & 141495 & 40.52 & 13 & 527287 \\
\hline 08231 & 0 & 0.00 & 35 & 116425 \\
\hline 08235 & 0 & 0.00 & 0 & 150709 \\
\hline 08236 & 0 & 0.00 & 3 & 192092 \\
\hline 08237 & 0 & 0.00 & 18 & 115055 \\
\hline 08311 & 0 & 0.00 & 12 & 218043 \\
\hline 08315 & 35374 & 0.00 & 0 & 247711 \\
\hline 08316 & 0 & 17.88 & 3 & 157399 \\
\hline
\end{tabular}




\begin{tabular}{|c|c|c|c|c|}
\hline $\begin{array}{r}\text { zone } \\
\text { (AGS) }\end{array}$ & $\begin{array}{r}\text { WZ } 01.47 .9 \\
\text { (animals) }\end{array}$ & $\begin{array}{r}\text { WZ } 10.12 \\
\text { (employees) }\end{array}$ & $\begin{array}{r}\text { WZ } 10.85 \\
\text { (employees) }\end{array}$ & $\begin{array}{r}\text { population } \\
\text { (persons) }\end{array}$ \\
\hline 08317 & 141495 & 0.00 & 27 & 411700 \\
\hline 08325 & 0 & 0.00 & 7 & 135553 \\
\hline 08326 & 0 & 0.00 & 12 & 204585 \\
\hline 08327 & 0 & 0.00 & 2 & 132476 \\
\hline 08335 & 176869 & 0.00 & 30 & 270568 \\
\hline 08336 & 106122 & 0.00 & 50 & 220606 \\
\hline 08337 & 0 & 0.00 & 16 & 163699 \\
\hline 08415 & 0 & 0.00 & 13 & 274691 \\
\hline 08416 & 0 & 0.00 & 18 & 214894 \\
\hline 08417 & 70748 & 0.00 & 0 & 184658 \\
\hline 08421 & 0 & 0.00 & 14 & 117977 \\
\hline 08425 & 106122 & 0.00 & 26 & 187123 \\
\hline 08426 & 176869 & 15.49 & 16 & 187747 \\
\hline 08435 & 70748 & 0.00 & 38 & 205843 \\
\hline 08436 & 70748 & 0.00 & 7 & 272425 \\
\hline 08437 & 141495 & 0.00 & 73 & 127272 \\
\hline 09161 & 0 & 0.00 & 0 & 127886 \\
\hline 09162 & 0 & 0.00 & 0 & 1388308 \\
\hline 09163 & 0 & 0.00 & 35 & 59935 \\
\hline 09171 & 459859 & 0.00 & 0 & 106515 \\
\hline 09172 & 0 & 0.00 & 5 & 101875 \\
\hline 09173 & 0 & 0.00 & 0 & 120664 \\
\hline 09174 & 0 & 0.00 & 0 & 142021 \\
\hline 09175 & 0 & 0.00 & 4 & 131011 \\
\hline 09176 & 0 & 0.00 & 2 & 125039 \\
\hline 09177 & 70748 & 0.00 & 0 & 128289 \\
\hline 09178 & 35374 & 0.00 & 30 & 166286 \\
\hline 09179 & 35374 & 0.00 & 0 & 205194 \\
\hline 09180 & 0 & 0.00 & 17 & 84710 \\
\hline 09181 & 0 & 0.00 & 0 & 114223 \\
\hline 09182 & 247616 & 0.00 & 15 & 94759 \\
\hline 09183 & 318364 & 91.77 & 0 & 107363 \\
\hline 09184 & 0 & 0.00 & 5 & 325744 \\
\hline 09185 & 35374 & 0.00 & 14 & 91783 \\
\hline 09186 & 0 & 0.00 & 0 & 118349 \\
\hline 09187 & 0 & 0.00 & 0 & 247133 \\
\hline 09188 & 0 & 0.00 & 25 & 129530 \\
\hline 09189 & 176869 & 1.19 & 1 & 169464 \\
\hline 09190 & 0 & 0.00 & 20 & 129568 \\
\hline 09261 & 0 & 0.00 & 11 & 65322 \\
\hline 09262 & 0 & 0.00 & 5 & 49038 \\
\hline 09263 & 0 & 0.00 & 14 & 45099 \\
\hline 09271 & 70748 & 0.00 & 12 & 114733 \\
\hline 09272 & 0 & 0.00 & 4 & 77817 \\
\hline
\end{tabular}




\begin{tabular}{|c|c|c|c|c|}
\hline $\begin{array}{r}\text { zone } \\
\text { (AGS) }\end{array}$ & $\begin{array}{r}\text { WZ 01.47.9 } \\
\text { (animals) }\end{array}$ & $\begin{array}{r}\text { WZ } 10.12 \\
\text { (employees) }\end{array}$ & $\begin{array}{r}\text { WZ } 10.85 \\
\text { (employees) }\end{array}$ & $\begin{array}{r}\text { population } \\
\text { (persons) }\end{array}$ \\
\hline 09273 & 0 & 0.00 & 0 & 113996 \\
\hline 09274 & 70748 & 23.84 & 22 & 148862 \\
\hline 09275 & 141495 & 0.00 & 8 & 184905 \\
\hline 09276 & 35374 & 0.00 & 70 & 76329 \\
\hline 09277 & 212243 & 39.33 & 11 & 117437 \\
\hline 09278 & 424485 & 680.52 & 0 & 96667 \\
\hline 09279 & 35374 & 0.00 & 16 & 91267 \\
\hline 09361 & 0 & 0.00 & 10 & 41578 \\
\hline 09362 & 0 & 0.00 & 3 & 138296 \\
\hline 09363 & 0 & 0.00 & 0 & 41684 \\
\hline 09371 & 0 & 3.58 & 6 & 103352 \\
\hline 09372 & 389111 & 0.00 & 11 & 125620 \\
\hline 09373 & 0 & 0.00 & 0 & 127145 \\
\hline 09374 & 0 & 0.00 & 10 & 95849 \\
\hline 09375 & 318364 & 0.00 & 0 & 184344 \\
\hline 09376 & 1804059 & 0.00 & 9 & 142947 \\
\hline 09377 & 0 & 0.00 & 59 & 73923 \\
\hline 09461 & 0 & 0.00 & 14 & 70863 \\
\hline 09462 & 0 & 0.00 & 0 & 71482 \\
\hline 09463 & 0 & 0.00 & 1 & 41022 \\
\hline 09464 & 0 & 0.00 & 0 & 44461 \\
\hline 09471 & 0 & 0.00 & 6 & 143758 \\
\hline 09472 & 0 & 0.00 & 0 & 104901 \\
\hline 09473 & 106122 & 0.00 & 1 & 87006 \\
\hline 09474 & 0 & 0.00 & 0 & 113331 \\
\hline 09475 & 0 & 0.00 & 5 & 97873 \\
\hline 09476 & 0 & 0.00 & 0 & 69095 \\
\hline 09477 & 0 & 0.00 & 11 & 73211 \\
\hline 09478 & 35374 & 0.00 & 0 & 67109 \\
\hline 09479 & 0 & 0.00 & 0 & 74599 \\
\hline 09561 & 0 & 0.00 & 6 & 39684 \\
\hline 09562 & 0 & 0.00 & 14 & 105412 \\
\hline 09563 & 0 & 0.00 & 0 & 118358 \\
\hline 09564 & 0 & 0.00 & 0 & 495121 \\
\hline 09565 & 0 & 0.00 & 100 & 39137 \\
\hline 09571 & 247616 & 133.48 & 0 & 178289 \\
\hline 09572 & 0 & 170.43 & 6 & 131227 \\
\hline 09573 & 0 & 0.00 & 0 & 113959 \\
\hline 09574 & 35374 & 0.00 & 0 & 164564 \\
\hline 09575 & 106122 & 0.00 & 18 & 97409 \\
\hline 09576 & 35374 & 0.00 & 39 & 123168 \\
\hline 09577 & 0 & 0.00 & 13 & 92187 \\
\hline 09661 & 0 & 0.00 & 37 & 67681 \\
\hline 09662 & 0 & 0.00 & 1 & 52098 \\
\hline
\end{tabular}




\begin{tabular}{|c|c|c|c|c|}
\hline $\begin{array}{r}\text { zone } \\
\text { (AGS) }\end{array}$ & $\begin{array}{r}\text { WZ } 01.47 .9 \\
\text { (animals) }\end{array}$ & $\begin{array}{r}\text { WZ } 10.12 \\
\text { (employees) }\end{array}$ & $\begin{array}{r}\text { WZ } 10.85 \\
\text { (employees) }\end{array}$ & $\begin{array}{r}\text { population } \\
\text { (persons) }\end{array}$ \\
\hline 09663 & 0 & 0.00 & 0 & 124577 \\
\hline 09671 & 389111 & 0.00 & 8 & 172575 \\
\hline 09672 & 0 & 0.00 & 10 & 103124 \\
\hline 09673 & 0 & 0.00 & 0 & 80224 \\
\hline 09674 & 0 & 0.00 & 0 & 84226 \\
\hline 09675 & 0 & 0.00 & 0 & 87899 \\
\hline 09676 & 0 & 0.00 & 0 & 127944 \\
\hline 09677 & 0 & 0.00 & 23 & 126496 \\
\hline 09678 & 35374 & 0.00 & 9 & 112857 \\
\hline 09679 & 0 & 0.00 & 20 & 158026 \\
\hline 09761 & 0 & 0.00 & 11 & 272699 \\
\hline 09762 & 0 & 0.00 & 12 & 41570 \\
\hline 09763 & 0 & 0.00 & 0 & 64625 \\
\hline 09764 & 0 & 0.00 & 3 & 41551 \\
\hline 09771 & 0 & 0.00 & 0 & 127250 \\
\hline 09772 & 35374 & 0.00 & 5 & 239004 \\
\hline 09773 & 35374 & 0.00 & 23 & 93122 \\
\hline 09774 & 0 & 0.00 & 13 & 120130 \\
\hline 09775 & 35374 & 0.00 & 35 & 165270 \\
\hline 09776 & 0 & 0.00 & 0 & 78641 \\
\hline 09777 & 0 & 0.00 & 0 & 134118 \\
\hline 09778 & 0 & 0.00 & 47 & 136383 \\
\hline 09779 & 35374 & 0.00 & 24 & 128939 \\
\hline 09780 & 35374 & 0.00 & 22 & 149457 \\
\hline 10041 & 70748 & 0.00 & 30 & 326638 \\
\hline 10042 & 0 & 0.00 & 47 & 103520 \\
\hline 10043 & 0 & 0.00 & 16 & 134099 \\
\hline 10044 & 0 & 0.00 & 1 & 196611 \\
\hline 10045 & 0 & 0.00 & 14 & 144291 \\
\hline 10046 & 106122 & 0.00 & 20 & 89128 \\
\hline 11000 & 0 & 0.00 & 1260 & 3375222 \\
\hline 12051 & 0 & 0.00 & 576 & 71149 \\
\hline 12052 & 0 & 0.00 & 0 & 99913 \\
\hline 12053 & 0 & 0.00 & 0 & 58537 \\
\hline 12054 & 0 & 0.00 & 0 & 159456 \\
\hline 12060 & 35374 & 0.00 & 54 & 173193 \\
\hline 12061 & 1733312 & 197.84 & 0 & 160314 \\
\hline 12062 & 176869 & 0.00 & 31 & 107649 \\
\hline 12063 & 141495 & 0.00 & 11 & 153294 \\
\hline 12064 & 2087048 & 134.67 & 5 & 186925 \\
\hline 12065 & 141495 & 0.00 & 14 & 202162 \\
\hline 12066 & 282990 & 0.00 & 12 & 115212 \\
\hline 12067 & 247616 & 293.19 & 0 & 177047 \\
\hline 12068 & 9833888 & 0.00 & 4 & 99125 \\
\hline
\end{tabular}




\begin{tabular}{|c|c|c|c|c|}
\hline $\begin{array}{r}\text { zone } \\
\text { (AGS) }\end{array}$ & $\begin{array}{r}\text { WZ 01.47.9 } \\
\text { (animals) }\end{array}$ & $\begin{array}{r}\text { WZ } 10.12 \\
\text { (employees) }\end{array}$ & $\begin{array}{r}\text { WZ } 10.85 \\
\text { (employees) }\end{array}$ & $\begin{array}{r}\text { population } \\
\text { (persons) }\end{array}$ \\
\hline 12069 & 0 & 56.02 & 99 & 204388 \\
\hline 12070 & 212243 & 0.00 & 68 & 78799 \\
\hline 12071 & 0 & 0.00 & 9 & 120178 \\
\hline 12072 & 212243 & 0.00 & 15 & 159686 \\
\hline 12073 & 141495 & 0.00 & 34 & 122484 \\
\hline 13003 & 0 & 0.00 & 14 & 202887 \\
\hline 13004 & 35374 & 0.00 & 1 & 91264 \\
\hline 13071 & 3042138 & 90.58 & 0 & 264261 \\
\hline 13072 & 530606 & 0.00 & 0 & 210732 \\
\hline 13073 & 636727 & 40.52 & 99 & 223718 \\
\hline 13074 & 459859 & 0.00 & 53 & 155801 \\
\hline 13075 & 1096585 & 0.00 & 2 & 239291 \\
\hline 13076 & 1556443 & 466.00 & 0 & 212373 \\
\hline 14511 & 0 & 0.00 & 8 & 241210 \\
\hline 14521 & 0 & 0.00 & 1 & 355275 \\
\hline 14522 & 530606 & 7.15 & 16 & 317204 \\
\hline 14523 & 389111 & 5.96 & 48 & 236227 \\
\hline 14524 & 247616 & 0.00 & 12 & 330294 \\
\hline 14612 & 0 & 0.00 & 26 & 525105 \\
\hline 14625 & 389111 & 0.00 & 7 & 310898 \\
\hline 14626 & 106122 & 0.00 & 5 & 264673 \\
\hline 14627 & 1061211 & 0.00 & 16 & 244717 \\
\hline 14628 & 106122 & 0.00 & 174 & 245927 \\
\hline 14713 & 0 & 0.00 & 0 & 520838 \\
\hline 14729 & 601353 & 182.35 & 11 & 259207 \\
\hline 14730 & 9833888 & 493.41 & 0 & 198629 \\
\hline 15001 & 247616 & 0.00 & 2 & 84606 \\
\hline 15002 & 0 & 0.00 & 0 & 231440 \\
\hline 15003 & 0 & 0.00 & 0 & 229924 \\
\hline 15081 & 318364 & 0.00 & 0 & 86878 \\
\hline 15082 & 1025838 & 356.35 & 0 & 168475 \\
\hline 15083 & 3820359 & 0.00 & 20 & 174001 \\
\hline 15084 & 176869 & 0.00 & 215 & 186081 \\
\hline 15085 & 636727 & 0.00 & 19 & 223094 \\
\hline 15086 & 2617654 & 151.36 & 38 & 92367 \\
\hline 15087 & 176869 & 0.00 & 0 & 144735 \\
\hline 15088 & 919717 & 0.00 & 0 & 189217 \\
\hline 15089 & 353737 & 0.00 & 20 & 201210 \\
\hline 15090 & 70748 & 0.00 & 8 & 116666 \\
\hline 15091 & 212243 & 0.00 & 0 & 130699 \\
\hline 16051 & 0 & 0.00 & 0 & 203485 \\
\hline 16052 & 0 & 0.00 & 0 & 95384 \\
\hline 16053 & 0 & 0.00 & 0 & 106915 \\
\hline 16054 & 0 & 0.00 & 0 & 35967 \\
\hline
\end{tabular}




\begin{tabular}{rrrrr}
\hline $\begin{array}{r}\text { zone } \\
\text { (AGS) }\end{array}$ & $\begin{array}{r}\text { WZ 01.47.9 } \\
\text { (animals) }\end{array}$ & $\begin{array}{r}\text { WZ 10.12 } \\
\text { (employees) }\end{array}$ & $\begin{array}{r}\text { WZ 10.85 } \\
\text { (employees) }\end{array}$ & $\begin{array}{r}\text { population } \\
\text { (persons) }\end{array}$ \\
\hline 16055 & 0 & 0.00 & 0 & 63236 \\
16056 & 0 & 0.00 & 0 & 41744 \\
16061 & 70748 & 0.00 & 32 & 101312 \\
16062 & 282990 & 0.00 & 0 & 85921 \\
16063 & 495232 & 0.00 & 0 & 127227 \\
16064 & 672101 & 0.00 & 29 & 104947 \\
16065 & 35374 & 57.21 & 0 & 78618 \\
16066 & 70748 & 0.00 & 0 & 126208 \\
16067 & 353737 & 17.88 & 38 & 135376 \\
16068 & 0 & 0.00 & 0 & 71005 \\
16069 & 0 & 0.00 & 8 & 65540 \\
16070 & 0 & 0.00 & 0 & 109531 \\
16071 & 530606 & 0.00 & 1 & 82016 \\
16072 & 0 & 0.00 & 7 & 57802 \\
16073 & 0 & 0.00 & 14 & 111463 \\
16074 & 0 & 382.57 & 0 & 84282 \\
16075 & 0 & 0.00 & 8 & 84435 \\
16076 & 0 & 0.00 & 5 & 103297 \\
16077 & 35374 & 0.00 & 0 & 94749 \\
\hline
\end{tabular}

Table A.2: Location of import and export volumes in poultry supply chain. Sources: Balster et al. (2016) and Statistisches Bundesamt (2016a).

\begin{tabular}{rrr}
\hline $\begin{array}{r}\text { zone } \\
\text { (AGS) }\end{array}$ & $\begin{array}{r}\text { import, treated as WZ 01.47.9 } \\
\text { (animals) }\end{array}$ & $\begin{array}{r}\text { export } \\
(\mathbf{t})\end{array}$ \\
\hline 01001 & 2536148 & 26146 \\
03456 & 3386808 & 590 \\
05334 & 102774 & 12828 \\
07211 & 0 & 87705 \\
08317 & 865581 & 43197 \\
08335 & 56354 & 9101 \\
09172 & 286875 & 76304 \\
09374 & 1365387 & 17637 \\
12053 & 1320459 & 177530 \\
\hline
\end{tabular}

Table A.3: Productivity factors ( prodFactor $_{s}$ ) for poultry supply chain (calculated).

\begin{tabular}{crc}
\hline sector & output factor & unit \\
\hline WZ 01.47.9 & 0.017 & $t /($ animal $\cdot a)$ \\
WZ 10.12 & 149.253 & $t /($ employee $\cdot a)$ \\
WZ 10.85 & 1.000 & $t /($ employee $\cdot a)$ \\
export & 1.000 & $1 / a$ \\
population & 1.000 & $t /($ person $\cdot a)$ \\
\hline
\end{tabular}


Table A.4: Intersectoral linkage for poultry supply chain $\left(\operatorname{inpFac}_{c, s}\right)$. Sources: Balster et al. (2016) and Statistisches Bundesamt (2016a).

\begin{tabular}{ccc}
\hline output from sector $(c)$ & input to sector $(s)$ & input per output unit \\
\hline WZ 01.47 .9 & WZ 10.12 & 1.41 \\
WZ 10.12 & WZ 10.85 & 5.47 \\
WZ 10.12 & population & 0.011 \\
WZ 10.12 & export & 1.00 \\
\hline
\end{tabular}

Table A.5: Commodity flow parameters for poultry supply chain (estimated).

\begin{tabular}{ccrcc}
\hline from sector $(c)$ & to sector $(i)$ & $\operatorname{dispFac}_{c, s}$ & $\alpha_{c, s}$ & $\beta_{c, s}$ \\
\hline 01.47 .9 & 10.12 & 0.04 & 0.2 & 0.6 \\
10.12 & population & 0.10 & 0.2 & 0.1 \\
10.12 & 10.85 & 0.08 & 0.2 & 0.1 \\
10.12 & export & 0.10 & 0.2 & 0.1 \\
\hline
\end{tabular}




\section{B Detailed Simulation Results for Poultry Slaughtering Application}

Table B.1: Establishments' locations and output for optimal layout of poultry slaughtering (sector WZ 10.12) without restrictions, descending sorting based on annual output. For further information see section 5.1.9 (page 142).

\begin{tabular}{rrlrr}
\hline$\#$ & AGS & location name & output (t/a) & cumulated share (\%) \\
\hline 1 & 14713 & Leipzig, Kreisfreie Stadt & 113376 & 7.93 \\
2 & 03456 & Grafschaft Bentheim, Landkreis & 113328 & 15.86 \\
3 & 03454 & Emsland, Landkreis & 92430 & 22.33 \\
4 & 12054 & Potsdam, Kreisfreie Stadt & 53199 & 26.05 \\
5 & 03460 & Vechta, Landkreis & 48269 & 29.43 \\
6 & 06411 & Darmstadt, Kreisfreie Stadt & 47056 & 32.72 \\
7 & 03154 & Helmstedt, Landkreis & 45373 & 35.90 \\
8 & 12065 & Oberhavel, Landkreis & 43675 & 38.95 \\
9 & 01001 & Flensburg, Kreisfreie Stadt & 32643 & 41.24 \\
10 & 15003 & Magdeburg, Kreisfreie Stadt & 31089 & 43.41 \\
11 & 04012 & Bremerhaven, Kreisfreie Stadt & 29030 & 45.45 \\
12 & 13004 & Schwerin, Kreisfreie Stadt & 25201 & 47.21 \\
13 & 05974 & Soest, Kreis & 24695 & 48.94 \\
14 & 05774 & Paderborn, Kreis & 22267 & 50.50 \\
15 & 09375 & Regensburg, Landkreis & 21424 & 51.99 \\
16 & 13073 & Vorpommern-Rügen, Landkreis & 18541 & 53.29 \\
17 & 12072 & Teltow-Fläming, Landkreis & 18152 & 54.56 \\
18 & 13072 & Rostock, Landkreis & 17547 & 55.79 \\
19 & 12053 & Frankfurt (Oder), Kreisfreie Stadt & 16368 & 56.94 \\
20 & 09372 & Cham, Landkreis & 16217 & 58.07 \\
21 & 03458 & Oldenburg, Landkreis & 13867 & 59.04 \\
22 & 01002 & Kiel, Kreisfreie Stadt & 13864 & 60.01 \\
23 & 03404 & Osnabrück, Kreisfreie Stadt & 13359 & 60.95 \\
24 & 12068 & Ostprignitz-Ruppin, Landkreis & 13184 & 61.87 \\
25 & 05562 & Recklinghausen, Kreis & 13023 & 63.78 \\
26 & 03358 & Heidekreis, Landkreis & 12896 & 64.58 \\
27 & 03352 & Cuxhaven, Landkreis & 12859 & 65.43 \\
28 & 12064 & Märkisch-Oderland, Landkreis & 12117 & 66.25 \\
29 & 05770 & Minden-Lübbecke, Kreis & 11768 & 67.08 \\
30 & 06535 & Vogelsbergkreis, Landkreis & 11767 & 6.58 \\
31 & 15084 & Burgenlandkreis, Landkreis & & \\
32 & 13076 & Ludwigslust-Parchim, Landkreis & & \\
& & & & \\
& & & & \\
\hline
\end{tabular}




\begin{tabular}{|c|c|c|c|c|}
\hline \# & AGS & location name & output $(t / a)$ & cumulated share $(\%)$ \\
\hline 33 & 05915 & Hamm, Kreisfreie Stadt & 10500 & 69.31 \\
\hline 34 & 12061 & Dahme-Spreewald, Landkreis & 10496 & 70.05 \\
\hline 35 & 05154 & Kleve, Kreis & 9315 & 70.70 \\
\hline 36 & 14522 & Mittelsachsen, Landkreis & 9148 & 71.34 \\
\hline 37 & 09263 & Straubing, Kreisfreie Stadt & 8920 & 71.97 \\
\hline 38 & 06636 & Werra-Meißner-Kreis, Landkreis & 8825 & 72.58 \\
\hline 39 & 07138 & Neuwied, Landkreis & 8822 & 73.20 \\
\hline 40 & 03453 & Cloppenburg, Landkreis & 8238 & 73.78 \\
\hline 41 & 13071 & Mecklenburgische Seenplatte, Landkreis & 8011 & 74.34 \\
\hline 42 & 08119 & Rems-Murr-Kreis, Landkreis & 7990 & 74.90 \\
\hline 43 & 09171 & Altötting, Landkreis & 7989 & 75.46 \\
\hline 44 & 05370 & Heinsberg, Kreis & 7571 & 75.98 \\
\hline 45 & 06631 & Fulda, Landkreis & 7566 & 76.51 \\
\hline 46 & 16077 & Altenburger Land, Landkreis & 7561 & 77.04 \\
\hline 47 & 08316 & Emmendingen, Landkreis & 7480 & 77.57 \\
\hline 48 & 12051 & Brandenburg an der Havel, Kreisfreie Stadt & 6939 & 78.05 \\
\hline 49 & 02000 & Hamburg, Kreisfreie Stadt & 6730 & 78.52 \\
\hline 50 & 15088 & Saalekreis, Landkreis & 6539 & 78.98 \\
\hline 51 & 03457 & Leer, Landkreis & 6494 & 79.44 \\
\hline 52 & 14521 & Erzgebirgskreis, Landkreis & 6302 & 79.88 \\
\hline 53 & 05758 & Herford, Kreis & 6034 & 80.30 \\
\hline 54 & 09189 & Traunstein, Landkreis & 5880 & 80.71 \\
\hline 55 & 15002 & Halle (Saale), Kreisfreie Stadt & 5645 & 81.10 \\
\hline 56 & 01003 & Lübeck, Kreisfreie Stadt & 5461 & 81.49 \\
\hline 57 & 05958 & Hochsauerlandkreis, Kreis & 5459 & 81.87 \\
\hline 58 & 14612 & Dresden, Kreisfreie Stadt & 5233 & 82.24 \\
\hline 59 & 05112 & Duisburg, Kreisfreie Stadt & 5039 & 82.59 \\
\hline 60 & 03103 & Wolfsburg, Kreisfreie Stadt & 4626 & 82.91 \\
\hline 61 & 09464 & Hof, Kreisfreie Stadt & 4621 & 83.23 \\
\hline 62 & 09661 & Aschaffenburg, Kreisfreie Stadt & 4619 & 83.56 \\
\hline 63 & 16062 & Nordhausen, Landkreis & 4522 & 83.87 \\
\hline 64 & 16055 & Weimar, Kreisfreie Stadt & 4502 & 84.19 \\
\hline 65 & 08317 & Ortenaukreis, Landkreis & 4481 & 84.50 \\
\hline 66 & 06413 & Offenbach am Main, Kreisfreie Stadt & 4208 & 84.80 \\
\hline 67 & 05515 & Münster, Kreisfreie Stadt & 4200 & 85.09 \\
\hline 68 & 05166 & Viersen, Kreis & 4132 & 85.38 \\
\hline 69 & 12063 & Havelland, Landkreis & 4003 & 85.66 \\
\hline 70 & 08125 & Heilbronn, Landkreis & 3803 & 85.93 \\
\hline 71 & 01053 & Herzogtum Lauenburg, Kreis & 3787 & 86.19 \\
\hline 72 & 01059 & Schleswig-Flensburg, Kreis & 3781 & 86.46 \\
\hline 73 & 09362 & Regensburg, Kreisfreie Stadt & 3779 & 86.72 \\
\hline 74 & 11000 & Berlin, Kreisfreie Stadt & 3462 & 86.96 \\
\hline 75 & 14627 & Meißen, Landkreis & 3454 & 87.20 \\
\hline 76 & 14729 & Leipzig, Landkreis & 3424 & 87.44 \\
\hline 77 & 09172 & Berchtesgadener Land, Landkreis & 3407 & 87.68 \\
\hline
\end{tabular}




\begin{tabular}{|c|c|c|c|c|}
\hline \# & AGS & location name & output $(t / a)$ & cumulated share (\%) \\
\hline 78 & 05116 & Mönchengladbach, Kreisfreie Stadt & 3367 & 87.92 \\
\hline 79 & 01054 & Nordfriesland, Kreis & 3361 & 88.15 \\
\hline 80 & 16065 & Kyffhäuserkreis, Landkreis & 3360 & 88.39 \\
\hline 81 & 05114 & Krefeld, Kreisfreie Stadt & 3359 & 88.62 \\
\hline 82 & 12071 & Spree-Neiße, Landkreis & 3359 & 88.86 \\
\hline 83 & 03256 & Nienburg (Weser), Landkreis & 3354 & 89.09 \\
\hline 84 & 15001 & Dessau-Roßlau, Kreisfreie Stadt & 3317 & 89.33 \\
\hline 85 & 05711 & Bielefeld, Kreisfreie Stadt & 3289 & 89.56 \\
\hline 86 & 05754 & Gütersloh, Kreis & 3220 & 89.78 \\
\hline 87 & 03357 & Rotenburg (Wümme), Landkreis & 3071 & 90.00 \\
\hline 88 & 03153 & Goslar, Landkreis & 3047 & 90.21 \\
\hline 89 & 06531 & Gießen, Landkreis & 2941 & 90.41 \\
\hline 90 & 08212 & Karlsruhe, Stadtkreis & 2939 & 90.62 \\
\hline 91 & 01058 & Rendsburg-Eckernförde, Kreis & 2938 & 90.83 \\
\hline 92 & 08335 & Konstanz, Landkreis & 2767 & 91.02 \\
\hline 93 & 12062 & Elbe-Elster, Landkreis & 2661 & 91.21 \\
\hline 94 & 03462 & Wittmund, Landkreis & 2638 & 91.39 \\
\hline 95 & 03359 & Stade, Landkreis & 2519 & 91.57 \\
\hline 96 & 15087 & Mansfeld-Südharz, Landkreis & 2384 & 91.73 \\
\hline 97 & 09182 & Miesbach, Landkreis & 2340 & 91.90 \\
\hline 98 & 16063 & Wartburgkreis, Landkreis & 2328 & 92.06 \\
\hline 99 & 12067 & Oder-Spree, Landkreis & 2257 & 92.22 \\
\hline 100 & 03461 & Wesermarsch, Landkreis & 2226 & 92.37 \\
\hline 101 & 03157 & Peine, Landkreis & 2216 & 92.53 \\
\hline 102 & 15091 & Wittenberg, Landkreis & 2142 & 92.68 \\
\hline 103 & 05315 & Köln, Kreisfreie Stadt & 2107 & 92.83 \\
\hline 104 & 05913 & Dortmund, Kreisfreie Stadt & 2099 & 92.97 \\
\hline 105 & 16068 & Sömmerda, Landkreis & 2099 & 93.12 \\
\hline 106 & 01062 & Stormarn, Kreis & 2099 & 93.27 \\
\hline 107 & 05314 & Bonn, Kreisfreie Stadt & 2099 & 93.41 \\
\hline 108 & 16071 & Weimarer Land, Landkreis & 2098 & 93.56 \\
\hline 109 & 08225 & Neckar-Odenwald-Kreis, Landkreis & 2098 & 93.71 \\
\hline 110 & 08121 & Heilbronn, Stadtkreis & 2077 & 93.85 \\
\hline 111 & 08436 & Ravensburg, Landkreis & 2075 & 94.00 \\
\hline 112 & 13075 & Vorpommern-Greifswald, Landkreis & 2044 & 94.14 \\
\hline 113 & 09271 & Deggendorf, Landkreis & 2005 & 94.28 \\
\hline 114 & 07232 & Eifelkreis Bitburg-Prüm, Landkreis & 1999 & 94.42 \\
\hline 115 & 05570 & Warendorf, Kreis & 1914 & 94.56 \\
\hline 116 & 16056 & Eisenach, Kreisfreie Stadt & 1873 & 94.69 \\
\hline 117 & 15089 & Salzlandkreis, Landkreis & 1817 & 94.81 \\
\hline 118 & 14523 & Vogtlandkreis, Landkreis & 1815 & 94.94 \\
\hline 119 & 16053 & Jena, Kreisfreie Stadt & 1798 & 95.07 \\
\hline 120 & 08437 & Sigmaringen, Landkreis & 1708 & 95.19 \\
\hline 121 & 05111 & Düsseldorf, Kreisfreie Stadt & 1682 & 95.30 \\
\hline 122 & 09779 & Donau-Ries, Landkreis & 1681 & 95.42 \\
\hline
\end{tabular}




\begin{tabular}{|c|c|c|c|c|}
\hline$\#$ & AGS & location name & output $(t / a)$ & cumulated share $(\%)$ \\
\hline 123 & 09262 & Passau, Kreisfreie Stadt & 1681 & 95.54 \\
\hline 124 & 08222 & Mannheim, Stadtkreis & 1680 & 95.66 \\
\hline 125 & 12073 & Uckermark, Landkreis & 1679 & 95.77 \\
\hline 126 & 03353 & Harburg, Landkreis & 1679 & 95.89 \\
\hline 127 & 08435 & Bodenseekreis, Landkreis & 1677 & 96.01 \\
\hline 128 & 06632 & Hersfeld-Rotenburg, Landkreis & 1677 & 96.13 \\
\hline 129 & 05124 & Wuppertal, Kreisfreie Stadt & 1675 & 96.24 \\
\hline 130 & 15081 & Altmarkkreis Salzwedel, Landkreis & 1587 & 96.35 \\
\hline 131 & 03255 & Holzminden, Landkreis & 1550 & 96.46 \\
\hline 132 & 05374 & Oberbergischer Kreis, Kreis & 1511 & 96.57 \\
\hline 133 & 03401 & Delmenhorst, Kreisfreie Stadt & 1488 & 96.67 \\
\hline 134 & 14625 & Bautzen, Landkreis & 1260 & 96.76 \\
\hline 135 & 14628 & Sächsische Schweiz-Osterzgebirge, Landkreis & 1260 & 96.85 \\
\hline 136 & 05358 & Düren, Kreis & 1260 & 96.94 \\
\hline 137 & 08426 & Biberach, Landkreis & 1260 & 97.03 \\
\hline 138 & 05162 & Rhein-Kreis Neuss, Kreis & 1259 & 97.11 \\
\hline 139 & 08111 & Stuttgart, Stadtkreis & 1259 & 97.20 \\
\hline 140 & 09561 & Ansbach, Kreisfreie Stadt & 1259 & 97.29 \\
\hline 141 & 08336 & Lörrach, Landkreis & 1259 & 97.38 \\
\hline 142 & 08136 & Ostalbkreis, Landkreis & 1259 & 97.47 \\
\hline 143 & 14626 & Görlitz, Landkreis & 1258 & 97.55 \\
\hline 144 & 09463 & Coburg, Kreisfreie Stadt & 1258 & 97.64 \\
\hline 145 & 10043 & Neunkirchen, Landkreis & 1258 & 97.73 \\
\hline 146 & 05334 & Städteregion Aachen, Kreis & 1221 & 97.82 \\
\hline 147 & 16076 & Greiz, Landkreis & 1127 & 97.89 \\
\hline 148 & 05962 & Märkischer Kreis, Kreis & 1016 & 97.97 \\
\hline 149 & 12070 & Prignitz, Landkreis & 937 & 98.03 \\
\hline 150 & 05113 & Essen, Kreisfreie Stadt & 847 & 98.09 \\
\hline 151 & 05316 & Leverkusen, Kreisfreie Stadt & 845 & 98.15 \\
\hline 152 & 03403 & Oldenburg (Oldb), Kreisfreie Stadt & 845 & 98.21 \\
\hline 153 & 09177 & Erding, Landkreis & 844 & 98.27 \\
\hline 154 & 08417 & Zollernalbkreis, Landkreis & 844 & 98.33 \\
\hline 155 & 10041 & Regionalverband Saarbrücken, Landkreis & 840 & 98.39 \\
\hline 156 & 09183 & Mühldorf a. Inn, Landkreis & 840 & 98.44 \\
\hline 157 & 06533 & Limburg-Weilburg, Landkreis & 840 & 98.50 \\
\hline 158 & 06532 & Lahn-Dill-Kreis, Landkreis & 840 & 98.56 \\
\hline 159 & 09673 & Rhön-Grabfeld, Landkreis & 840 & 98.62 \\
\hline 160 & 03257 & Schaumburg, Landkreis & 839 & 98.68 \\
\hline 161 & 09773 & Dillingen a.d. Donau, Landkreis & 839 & 98.74 \\
\hline 162 & 03152 & Göttingen, Landkreis & 837 & 98.80 \\
\hline 163 & 07231 & Bernkastel-Wittlich, Landkreis & 837 & 98.85 \\
\hline 164 & 03405 & Wilhelmshaven, Kreisfreie Stadt & 837 & 98.91 \\
\hline 165 & 03360 & Uelzen, Landkreis & 836 & 98.97 \\
\hline 166 & 05966 & Olpe, Kreis & 831 & 99.03 \\
\hline 167 & 12060 & Barnim, Landkreis & 816 & 99.09 \\
\hline
\end{tabular}




\begin{tabular}{rrlrr}
\hline$\#$ & AGS & location name & output (t/a) & cumulated share (\%) \\
\hline 168 & 03254 & Hildesheim, Landkreis & 792 & 99.14 \\
169 & 03252 & Hameln-Pyrmont, Landkreis & 601 & 99.18 \\
170 & 09187 & Rosenheim, Landkreis & 600 & 99.23 \\
171 & 03402 & Emden, Kreisfreie Stadt & 537 & 99.26 \\
172 & 09780 & Oberallgäu, Landkreis & 428 & 99.29 \\
173 & 09761 & Augsburg, Kreisfreie Stadt & 427 & 99.32 \\
174 & 07137 & Mayen-Koblenz, Landkreis & 426 & 99.35 \\
175 & 07132 & Altenkirchen (Westerwald), Landkreis & 425 & 99.38 \\
176 & 03351 & Celle, Landkreis & 424 & 99.41 \\
177 & 05970 & Siegen-Wittgenstein, Kreis & 424 & 99.44 \\
178 & 09577 & Weißenburg-Gunzenhausen, Landkreis & 423 & 99.47 \\
179 & 08117 & Göppingen, Landkreis & 420 & 99.50 \\
180 & 09461 & Bamberg, Kreisfreie Stadt & 420 & 99.53 \\
181 & 09179 & Fürstenfeldbruck, Landkreis & 420 & 99.56 \\
182 & 07111 & Koblenz, Kreisfreie Stadt & 420 & 99.59 \\
183 & 09771 & Aichach-Friedberg, Landkreis & 420 & 99.62 \\
184 & 09576 & Roth, Landkreis & 420 & 99.65 \\
185 & 03251 & Diepholz, Landkreis & 420 & 99.68 \\
186 & 08421 & Ulm, Stadtkreis & 420 & 99.71 \\
187 & 03102 & Salzgitter, Kreisfreie Stadt & 420 & 99.74 \\
188 & 09279 & Dingolfing-Landau, Landkreis & 419 & 99.77 \\
189 & 16064 & Unstrut-Hainich-Kreis, Landkreis & 419 & 99.80 \\
190 & 06633 & Kassel, Landkreis & 419 & 99.82 \\
191 & 07133 & Bad Kreuznach, Landkreis & 419 & 99.85 \\
192 & 08135 & Heidenheim, Landkreis & 419 & 99.88 \\
193 & 09663 & Würzburg, Kreisfreie Stadt & 418 & 99.91 \\
194 & 09184 & München, Landkreis & 417 & 99.94 \\
195 & 08315 & Breisgau-Hochschwarzwald, Landkreis & 416 & 99.97 \\
196 & 03241 & Region Hannover, Landkreis & 309 & 100.00 \\
197 & 05366 & Euskirchen, Kreis & 108 & \\
\hline & & & & \\
\hline
\end{tabular}

Table B.2: Establishments' locations and output for optimal layout of poultry slaughtering (sector WZ 10.12) with 128 establishments, descending sorting based on annual output. For further information see section 5.1.9 (page 142).

\begin{tabular}{rrlrr}
\hline$\#$ & AGS & location name & output (t/a) & cumulated share (\%) \\
\hline 1 & 03456 & Vechta, Landkreis & 113328 & 7.93 \\
2 & 14713 & Leipzig, Kreisfreie Stadt & 111429 & 15.73 \\
3 & 03454 & Grafschaft Bentheim, Landkreis & 92430 & 22.19 \\
4 & 12063 & Oberhavel, Landkreis & 62047 & 26.54 \\
5 & 03460 & Ostprignitz-Ruppin, Landkreis & 51668 & 30.15 \\
6 & 06411 & Darmstadt, Kreisfreie Stadt & 47056 & 33.44 \\
7 & 03154 & Helmstedt, Landkreis & 45373 & 36.62 \\
8 & 13071 & Cuxhaven, Landkreis & 34353 & 39.02 \\
9 & 01001 & Mecklenburgische Seenplatte, Landkreis & 32643 & 41.31
\end{tabular}




\begin{tabular}{|c|c|c|c|c|}
\hline$\#$ & AGS & location name & output (t/a) & cumulated share (\%) \\
\hline 10 & 15003 & Magdeburg, Kreisfreie Stadt & 31089 & 43.48 \\
\hline 11 & 12053 & Soest, Kreis & 28356 & 45.47 \\
\hline 12 & 12051 & Schwerin, Kreisfreie Stadt & 27973 & 47.42 \\
\hline 13 & 05754 & Paderborn, Kreis & 27915 & 49.38 \\
\hline 14 & 09362 & Teltow-Fläming, Landkreis & 25203 & 51.14 \\
\hline 15 & 13004 & Vorpommern-Rügen, Landkreis & 25201 & 52.90 \\
\hline 16 & 12065 & Regensburg, Landkreis & 24844 & 54.64 \\
\hline 17 & 03352 & Herford, Kreis & 22775 & 56.24 \\
\hline 18 & 05774 & Nienburg (Weser), Landkreis & 22266 & 57.79 \\
\hline 19 & 11000 & Dahme-Spreewald, Landkreis & 21811 & 59.32 \\
\hline 20 & 04012 & Bremen, Kreisfreie Stadt & 21339 & 60.81 \\
\hline 21 & 03458 & Kiel, Kreisfreie Stadt & 20614 & 62.26 \\
\hline 22 & 13073 & Kleve, Kreis & 20585 & 63.70 \\
\hline 23 & 03404 & Recklinghausen, Kreis & 16805 & 64.87 \\
\hline 24 & 09372 & Delmenhorst, Kreisfreie Stadt & 16217 & 66.01 \\
\hline 25 & 12061 & Meißen, Landkreis & 15534 & 67.09 \\
\hline 26 & 05770 & Burgenlandkreis, Landkreis & 14363 & 68.10 \\
\hline 27 & 03358 & Hamm, Kreisfreie Stadt & 14211 & 69.09 \\
\hline 28 & 01002 & Märkisch-Oderland, Landkreis & 13864 & 70.06 \\
\hline 29 & 05562 & Heidekreis, Landkreis & 13023 & 70.98 \\
\hline 30 & 15088 & Cloppenburg, Landkreis & 12184 & 71.83 \\
\hline 31 & 08316 & Kassel, Kreisfreie Stadt & 11961 & 72.67 \\
\hline 32 & 05154 & Neuwied, Landkreis & 11879 & 73.50 \\
\hline 33 & 06535 & Werra-Meißner-Kreis, Landkreis & 11767 & 74.32 \\
\hline 34 & 15084 & Schwäbisch Hall, Landkreis & 10924 & 75.08 \\
\hline 35 & 05915 & Saalekreis, Landkreis & 10500 & 75.82 \\
\hline 36 & 07138 & Heinsberg, Kreis & 10134 & 76.53 \\
\hline 37 & 03462 & Wittmund, Landkreis & 9669 & 77.20 \\
\hline 38 & 06636 & Segeberg, Kreis & 9244 & 77.85 \\
\hline 39 & 09263 & Harz, Landkreis & 8920 & 78.48 \\
\hline 40 & 14522 & Jena, Kreisfreie Stadt & 8634 & 79.08 \\
\hline 41 & 09172 & Rotenburg (Wümme), Landkreis & 8446 & 79.67 \\
\hline 42 & 16071 & Wartburgkreis, Landkreis & 8399 & 80.26 \\
\hline 43 & 05116 & Altötting, Landkreis & 8091 & 80.82 \\
\hline 44 & 08119 & Nordwestmecklenburg, Landkreis & 7990 & 81.38 \\
\hline 45 & 09171 & Mittelsachsen, Landkreis & 7989 & 81.94 \\
\hline 46 & 05370 & Borken, Kreis & 7571 & 82.47 \\
\hline 47 & 06631 & Hof, Kreisfreie Stadt & 7566 & 83.00 \\
\hline 48 & 09464 & Aschaffenburg, Kreisfreie Stadt & 7564 & 83.53 \\
\hline 49 & 16077 & Spree-Neiße, Landkreis & 7561 & 84.06 \\
\hline 50 & 02000 & Halle (Saale), Kreisfreie Stadt & 6730 & 84.53 \\
\hline 51 & 14521 & Gütersloh, Kreis & 6302 & 84.97 \\
\hline 52 & 12070 & Offenbach am Main, Kreisfreie Stadt & 6238 & 85.41 \\
\hline 53 & 14627 & Gotha, Landkreis & 6067 & 85.83 \\
\hline 54 & 16062 & Münster, Kreisfreie Stadt & 5996 & 86.25 \\
\hline
\end{tabular}




\begin{tabular}{|c|c|c|c|c|}
\hline$\#$ & AGS & location name & output (t/a) & cumulated share (\%) \\
\hline 55 & 05711 & Potsdam, Kreisfreie Stadt & 5877 & 86.66 \\
\hline 56 & 01003 & Cham, Landkreis & 5461 & 87.05 \\
\hline 57 & 15001 & Bremerhaven, Kreisfreie Stadt & 5460 & 87.43 \\
\hline 58 & 05958 & Herzogtum Lauenburg, Kreis & 5459 & 87.81 \\
\hline 59 & 14729 & Mühldorf a. Inn, Landkreis & 5370 & 88.19 \\
\hline 60 & 09183 & Schleswig-Flensburg, Kreis & 5041 & 88.54 \\
\hline 61 & 05112 & Lüchow-Dannenberg, Landkreis & 5039 & 88.89 \\
\hline 62 & 03103 & Gießen, Landkreis & 4626 & 89.21 \\
\hline 63 & 06531 & Kyffhäuserkreis, Landkreis & 4621 & 89.54 \\
\hline 64 & 08212 & Regensburg, Kreisfreie Stadt & 4620 & 89.86 \\
\hline 65 & 09661 & Schaumburg, Landkreis & 4619 & 90.18 \\
\hline 66 & 06413 & Mönchengladbach, Kreisfreie Stadt & 4208 & 90.48 \\
\hline 67 & 15089 & Oberspreewald-Lausitz, Landkreis & 4201 & 90.77 \\
\hline 68 & 16056 & Nordfriesland, Kreis & 4201 & 91.07 \\
\hline 69 & 05515 & Krefeld, Kreisfreie Stadt & 4200 & 91.36 \\
\hline 70 & 05315 & Hohenlohekreis, Landkreis & 3861 & 91.63 \\
\hline 71 & 08125 & Greiz, Landkreis & 3803 & 91.90 \\
\hline 72 & 01053 & Düsseldorf, Kreisfreie Stadt & 3787 & 92.16 \\
\hline 73 & 08436 & Oder-Spree, Landkreis & 3783 & 92.43 \\
\hline 74 & 01059 & Dessau-Roßlau, Kreisfreie Stadt & 3781 & 92.69 \\
\hline 75 & 16065 & Miesbach, Landkreis & 3779 & 92.96 \\
\hline 76 & 08335 & Karlsruhe, Stadtkreis & 3611 & 93.21 \\
\hline 77 & 05913 & Steinburg, Kreis & 3497 & 93.45 \\
\hline 78 & 14612 & Heilbronn, Stadtkreis & 3361 & 93.69 \\
\hline 79 & 01054 & Deggendorf, Landkreis & 3361 & 93.92 \\
\hline 80 & 08136 & Schwandorf, Landkreis & 3359 & 94.16 \\
\hline 81 & 05114 & Donau-Ries, Landkreis & 3359 & 94.39 \\
\hline 82 & 05374 & Prignitz, Landkreis & 3358 & 94.63 \\
\hline 83 & 03256 & Rottal-Inn, Landkreis & 3354 & 94.86 \\
\hline 84 & 12071 & Flensburg, Kreisfreie Stadt & 3012 & 95.07 \\
\hline 85 & 03351 & Stade, Landkreis & 2945 & 95.28 \\
\hline 86 & 01058 & Wittenberg, Landkreis & 2938 & 95.49 \\
\hline 87 & 03359 & Salzlandkreis, Landkreis & 2519 & 95.66 \\
\hline 88 & 08225 & Aurich, Landkreis & 2517 & 95.84 \\
\hline 89 & 15091 & Berlin, Kreisfreie Stadt & 2142 & 95.99 \\
\hline 90 & 07232 & Havelland, Landkreis & 2107 & 96.14 \\
\hline 91 & 08435 & Euskirchen, Kreis & 2105 & 96.28 \\
\hline 92 & 16068 & Sigmaringen, Landkreis & 2099 & 96.43 \\
\hline 93 & 01062 & Bielefeld, Kreisfreie Stadt & 2099 & 96.58 \\
\hline 94 & 05314 & Dortmund, Kreisfreie Stadt & 2099 & 96.72 \\
\hline 95 & 08121 & Mansfeld-Südharz, Landkreis & 2077 & 96.87 \\
\hline 96 & 12064 & Traunstein, Landkreis & 2038 & 97.01 \\
\hline 97 & 09271 & Stormarn, Kreis & 2005 & 97.15 \\
\hline 98 & 05570 & Bonn, Kreisfreie Stadt & 1914 & 97.29 \\
\hline 99 & 09773 & Weimarer Land, Landkreis & 1685 & 97.40 \\
\hline
\end{tabular}




\begin{tabular}{|c|c|c|c|c|}
\hline \# & AGS & location name & output (t/a) & cumulated share (\%) \\
\hline 100 & 03405 & Elbe-Elster, Landkreis & 1682 & 97.52 \\
\hline 101 & 09177 & Konstanz, Landkreis & 1681 & 97.64 \\
\hline 102 & 09262 & Hildesheim, Landkreis & 1681 & 97.76 \\
\hline 103 & 12073 & Straubing, Kreisfreie Stadt & 1679 & 97.87 \\
\hline 104 & 03353 & Eisenach, Kreisfreie Stadt & 1679 & 97.99 \\
\hline 105 & 09463 & Anhalt-Bitterfeld, Landkreis & 1678 & 98.11 \\
\hline 106 & 06632 & Neckar-Odenwald-Kreis, Landkreis & 1677 & 98.23 \\
\hline 107 & 10041 & Köln, Kreisfreie Stadt & 1677 & 98.34 \\
\hline 108 & 08336 & Fulda, Landkreis & 1675 & 98.46 \\
\hline 109 & 14625 & Celle, Landkreis & 1607 & 98.57 \\
\hline 110 & 03153 & Vogelsbergkreis, Landkreis & 1573 & 98.68 \\
\hline 111 & 03255 & Friesland, Landkreis & 1550 & 98.79 \\
\hline 112 & 03254 & Straubing-Bogen, Landkreis & 1393 & 98.89 \\
\hline 113 & 14628 & Passau, Kreisfreie Stadt & 1260 & 98.98 \\
\hline 114 & 05358 & Mannheim, Stadtkreis & 1260 & 99.07 \\
\hline 115 & 03102 & Ortenaukreis, Landkreis & 1260 & 99.15 \\
\hline 116 & 08426 & Ravensburg, Landkreis & 1260 & 99.24 \\
\hline 117 & 08111 & Uckermark, Landkreis & 1259 & 99.33 \\
\hline 118 & 09561 & Harburg, Landkreis & 1259 & 99.42 \\
\hline 119 & 14626 & Bodenseekreis, Landkreis & 1258 & 99.51 \\
\hline 120 & 10043 & Olpe, Kreis & 1258 & 99.59 \\
\hline 121 & 05334 & Leipzig, Landkreis & 1221 & 99.68 \\
\hline 122 & 09577 & Uelzen, Landkreis & 843 & 99.74 \\
\hline 123 & 09673 & Sächsische Schweiz-Osterzgebirge, Landkreis & 840 & 99.80 \\
\hline 124 & 08421 & Düren, Kreis & 838 & 99.86 \\
\hline 125 & 03152 & Biberach, Landkreis & 837 & 99.91 \\
\hline 126 & 07133 & Oberbergischer Kreis, Kreis & 801 & 99.97 \\
\hline 127 & 12060 & Stuttgart, Stadtkreis & 419 & 100.00 \\
\hline 128 & 03356 & Ansbach, Kreisfreie Stadt & 0 & 100.00 \\
\hline
\end{tabular}

Table B.3: Establishments' locations and output for optimal layout of poultry slaughtering (sector WZ 10.12) with 64 establishments, descending sorting based on annual output. For further information see section 5.1.9 (page 142).

\begin{tabular}{rclrr}
\hline \# & AGS & location name & output (t/a) & cumulated share (\%) \\
\hline 1 & 14713 & Vechta, Landkreis & 116799 & 8.17 \\
2 & 03456 & Leipzig, Kreisfreie Stadt & 113440 & 16.11 \\
3 & 03454 & Grafschaft Bentheim, Landkreis & 102099 & 23.26 \\
4 & 03460 & Oberhavel, Landkreis & 73623 & 28.41 \\
5 & 12068 & Ostprignitz-Ruppin, Landkreis & 72164 & 33.46 \\
6 & 05915 & Darmstadt, Kreisfreie Stadt & 55027 & 37.31 \\
7 & 06411 & Helmstedt, Landkreis & 47475 & 40.63 \\
8 & 12065 & Cuxhaven, Landkreis & 46319 & 43.87 \\
9 & 03154 & Mecklenburgische Seenplatte, Landkreis & 45373 & 47.04 \\
10 & 15003 & Magdeburg, Kreisfreie Stadt & 35290 & 49.51
\end{tabular}




\begin{tabular}{|c|c|c|c|c|}
\hline$\#$ & AGS & location name & output (t/a) & cumulated share (\%) \\
\hline 11 & 01001 & Soest, Kreis & 32643 & 51.80 \\
\hline 12 & 04012 & Schwerin, Kreisfreie Stadt & 31165 & 53.98 \\
\hline 13 & 05774 & Paderborn, Kreis & 28571 & 55.98 \\
\hline 14 & 13072 & Teltow-Fläming, Landkreis & 27369 & 57.89 \\
\hline 15 & 12064 & Vorpommern-Rügen, Landkreis & 25208 & 59.66 \\
\hline 16 & 09362 & Regensburg, Landkreis & 25203 & 61.42 \\
\hline 17 & 13004 & Herford, Kreis & 25201 & 63.18 \\
\hline 18 & 12072 & Nienburg (Weser), Landkreis & 24785 & 64.92 \\
\hline 19 & 05711 & Dahme-Spreewald, Landkreis & 22682 & 66.51 \\
\hline 20 & 09372 & Bremen, Kreisfreie Stadt & 20837 & 67.96 \\
\hline 21 & 13073 & Kiel, Kreisfreie Stadt & 20585 & 69.40 \\
\hline 22 & 08212 & Kleve, Kreis & 20369 & 70.83 \\
\hline 23 & 12053 & Recklinghausen, Kreis & 20304 & 72.25 \\
\hline 24 & 05154 & Delmenhorst, Kreisfreie Stadt & 18486 & 73.54 \\
\hline 25 & 05314 & Meißen, Landkreis & 18385 & 74.83 \\
\hline 26 & 05770 & Burgenlandkreis, Landkreis & 17221 & 76.04 \\
\hline 27 & 02000 & Hamm, Kreisfreie Stadt & 16814 & 77.21 \\
\hline 28 & 03358 & Märkisch-Oderland, Landkreis & 16529 & 78.37 \\
\hline 29 & 05370 & Heidekreis, Landkreis & 16403 & 79.52 \\
\hline 30 & 06531 & Cloppenburg, Landkreis & 16388 & 80.66 \\
\hline 31 & 09171 & Kassel, Kreisfreie Stadt & 15975 & 81.78 \\
\hline 32 & 14522 & Neuwied, Landkreis & 15963 & 82.90 \\
\hline 33 & 08136 & Werra-Meißner-Kreis, Landkreis & 14709 & 83.93 \\
\hline 34 & 01002 & Schwäbisch Hall, Landkreis & 13864 & 84.90 \\
\hline 35 & 06636 & Saalekreis, Landkreis & 13507 & 85.84 \\
\hline 36 & 06631 & Heinsberg, Kreis & 12607 & 86.72 \\
\hline 37 & 16065 & Wittmund, Landkreis & 12536 & 87.60 \\
\hline 38 & 03352 & Segeberg, Kreis & 11801 & 88.43 \\
\hline 39 & 07138 & Harz, Landkreis & 11353 & 89.22 \\
\hline 40 & 15084 & Jena, Kreisfreie Stadt & 10924 & 89.99 \\
\hline 41 & 08336 & Rotenburg (Wümme), Landkreis & 9223 & 90.63 \\
\hline 42 & 13071 & Wartburgkreis, Landkreis & 8762 & 91.24 \\
\hline 43 & 09172 & Altötting, Landkreis & 8446 & 91.84 \\
\hline 44 & 16071 & Nordwestmecklenburg, Landkreis & 8399 & 92.42 \\
\hline 45 & 09464 & Mittelsachsen, Landkreis & 8022 & 92.98 \\
\hline 46 & 14521 & Borken, Kreis & 7562 & 93.51 \\
\hline 47 & 16077 & Hof, Kreisfreie Stadt & 7561 & 94.04 \\
\hline 48 & 08436 & Aschaffenburg, Kreisfreie Stadt & 7156 & 94.54 \\
\hline 49 & 03103 & Spree-Neiße, Landkreis & 7008 & 95.03 \\
\hline 50 & 01059 & Halle (Saale), Kreisfreie Stadt & 6719 & 95.50 \\
\hline 51 & 12071 & Gütersloh, Kreis & 6717 & 95.97 \\
\hline 52 & 15088 & Offenbach am Main, Kreisfreie Stadt & 6539 & 96.43 \\
\hline 53 & 09183 & Gotha, Landkreis & 6302 & 96.87 \\
\hline 54 & 09661 & Münster, Kreisfreie Stadt & 6257 & 97.31 \\
\hline 55 & 15002 & Potsdam, Kreisfreie Stadt & 5645 & 97.71 \\
\hline
\end{tabular}




\begin{tabular}{rrlrr}
\hline \# & AGS & location name & output (t/a) & cumulated share (\%) \\
\hline 56 & 01003 & Cham, Landkreis & 5461 & 98.09 \\
57 & 15001 & Bremerhaven, Kreisfreie Stadt & 5460 & 98.47 \\
58 & 08335 & Herzogtum Lauenburg, Kreis & 5288 & 98.84 \\
59 & 06413 & Mühldorf a. Inn, Landkreis & 4208 & 99.13 \\
60 & 03360 & Schleswig-Flensburg, Kreis & 3784 & 99.40 \\
61 & 01054 & Lüchow-Dannenberg, Landkreis & 3361 & 99.63 \\
62 & 05334 & Gießen, Landkreis & 2481 & 99.81 \\
63 & 03461 & Kyffhäuserkreis, Landkreis & 1488 & 99.91 \\
64 & 14626 & Regensburg, Kreisfreie Stadt & 1258 & 100.00 \\
\hline
\end{tabular}

Table B.4: Establishments' locations and output for optimal layout of poultry slaughtering (sector WZ 10.12) with 32 establishments, descending sorting based on annual output. For further information see section 5.1.9 (page 142).

\begin{tabular}{|c|c|c|c|c|}
\hline$\#$ & AGS & location name & output (t/a) & cumulated share (\%) \\
\hline 1 & 15084 & Vechta, Landkreis & 164032 & 11.48 \\
\hline 2 & 06411 & Leipzig, Kreisfreie Stadt & 120981 & 19.94 \\
\hline 3 & 12068 & Grafschaft Bentheim, Landkreis & 118902 & 28.26 \\
\hline 4 & 03456 & Oberhavel, Landkreis & 117528 & 36.49 \\
\hline 5 & 03454 & Ostprignitz-Ruppin, Landkreis & 92430 & 42.96 \\
\hline 6 & 05974 & Darmstadt, Kreisfreie Stadt & 77305 & 48.36 \\
\hline 7 & 03460 & Helmstedt, Landkreis & 71854 & 53.39 \\
\hline 8 & 03154 & Cuxhaven, Landkreis & 57982 & 57.45 \\
\hline 9 & 01001 & Mecklenburgische Seenplatte, Landkreis & 44946 & 60.59 \\
\hline 10 & 03352 & Magdeburg, Kreisfreie Stadt & 44115 & 63.68 \\
\hline 11 & 12053 & Soest, Kreis & 42057 & 66.62 \\
\hline 12 & 15003 & Schwerin, Kreisfreie Stadt & 40338 & 69.45 \\
\hline 13 & 13072 & Paderborn, Kreis & 36131 & 71.98 \\
\hline 14 & 05154 & Teltow-Fläming, Landkreis & 35724 & 74.48 \\
\hline 15 & 05915 & Vorpommern-Rügen, Landkreis & 30668 & 76.62 \\
\hline 16 & 13004 & Regensburg, Landkreis & 30663 & 78.77 \\
\hline 17 & 09362 & Herford, Kreis & 30244 & 80.88 \\
\hline 18 & 08119 & Nienburg (Weser), Landkreis & 30076 & 82.99 \\
\hline 19 & 14521 & Dahme-Spreewald, Landkreis & 26600 & 84.85 \\
\hline 20 & 01002 & Bremen, Kreisfreie Stadt & 26480 & 86.70 \\
\hline 21 & 09263 & Kiel, Kreisfreie Stadt & 25877 & 88.51 \\
\hline 22 & 12071 & Kleve, Kreis & 24560 & 90.23 \\
\hline 23 & 05770 & Recklinghausen, Kreis & 23521 & 91.88 \\
\hline 24 & 08317 & Delmenhorst, Kreisfreie Stadt & 22337 & 93.44 \\
\hline 25 & 13073 & Meißen, Landkreis & 20585 & 94.88 \\
\hline 26 & 03358 & Burgenlandkreis, Landkreis & 19203 & 96.22 \\
\hline 27 & 09172 & Hamm, Kreisfreie Stadt & 13918 & 97.20 \\
\hline 28 & 09171 & Märkisch-Oderland, Landkreis & 12612 & 98.08 \\
\hline 29 & 03457 & Heidekreis, Landkreis & 11778 & 98.90 \\
\hline 30 & 16077 & Cloppenburg, Landkreis & 7561 & 99.43 \\
\hline
\end{tabular}




\begin{tabular}{rclrr}
\hline$\#$ & AGS & location name & output (t/a) & cumulated share (\%) \\
\hline 31 & 08336 & Kassel, Kreisfreie Stadt & 6839 & 99.91 \\
32 & 14626 & Neuwied, Landkreis & 1258 & 100.00 \\
\hline
\end{tabular}




\section{Input Data for Model Application in Automotive Industry}

Table C.1: Overview of input data used for modelling the automotive supply chain

\begin{tabular}{|c|c|c|}
\hline area & model input & data source \\
\hline $\begin{array}{l}\text { industry } \\
\text { landscape }\end{array}$ & $\begin{array}{l}\text { business establishment sizes } \\
\left(f_{s}(e m p), n E m p^{s}, n E s t^{s}\right) \\
\text { location of business establishments }\left(n E m p_{i}^{s}\right) \\
\text { establishment input and output volumes } \\
\left(\text { prodFactor }_{s}, \text { inpFac }_{c, s}\right)\end{array}$ & $\begin{array}{l}\text { statistical data on establishment sizes (Statis- } \\
\text { tisches Bundesamt 2013a) } \\
\text { statistical data on employment by zones } \\
\text { (Statistisches Bundesamt 2013b), car plants } \\
\text { (Automobil Produktion 2008) } \\
\text { production volumes for car plants (Automobil } \\
\text { Produktion 2008), input per produced vehicle } \\
\text { estimated based on Statistisches Bundesamt } \\
\text { (2014b) }\end{array}$ \\
\hline $\begin{array}{l}\text { commc } \\
\text { flows }\end{array}$ & $\begin{array}{l}\text { commodity flow sizes }\left(\alpha_{c, s}\right) \\
\text { number of suppliers per establishment and } \\
\text { commodity }\left(\operatorname{dispFac} c_{c, s}, \beta_{c, s}\right) \\
\text { macro flows }\left(M F_{c}\right)\end{array}$ & $\begin{array}{l}\text { estimated } \\
\text { estimated } \\
\text { statistical data on commodity NST-2007 sec- } \\
\text { tion } 12 \text { from German federal transport plan } \\
\text { (BMVI 2014) }\end{array}$ \\
\hline general & $\begin{array}{l}\text { spatial zone system }\left(z o n e_{i}\right) \\
\text { road network based distance matrix }\left(d_{i, j}\right)\end{array}$ & $\begin{array}{l}\text { public geo data (GeoBasis-DE/BKG 2016) } \\
\text { public data (eurostat 2016) }\end{array}$ \\
\hline
\end{tabular}

Table C.2: Locations and annual output of German carplants as projected for 2008 according to Automobil Produktion (2008)

\begin{tabular}{rlclrr}
\hline \# & plant & AGS & location name & output (vehicles/a) & share (\%) \\
\hline 1 & Auto 5000 GmbH & Z03103 & Wolfsburg, Kreisfreie Stadt & 360180 & 6.49 \\
2 & Bochum & Z05911 & Bochum, Kreisfreie Stadt & 184566 & 3.32 \\
3 & Bremen 1 & Z04011 & Bremen, Kreisfreie Stadt & 254464 & 4.58 \\
4 & Bremen 2 & Z04011 & Bremen, Kreisfreie Stadt & 11491 & 0.21 \\
5 & Köln & Z05315 & Köln, Kreisfreie Stadt & 401225 & 7.22 \\
6 & Dingolfing & Z09279 & Dingolfing-Landau, Landkreis & 242910 & 4.37 \\
7 & Dresden & Z14612 & Dresden, Kreisfreie Stadt & 3578 & 0.06 \\
8 & Düsseldorf & Z05111 & Düsseldorf, Kreisfreie Stadt & 103714 & 1.87 \\
9 & Eisenach & Z16056 & Eisenach, Kreisfreie Stadt & 169200 & 3.05 \\
10 & Emden & Z03402 & Emden, Kreisfreie Stadt & 275299 & 4.96 \\
11 & Saarlouis & Z10044 & Saarlouis, Landkreis & 376366 & 6.78 \\
12 & Sindelfingen 1 & Z08115 & Böblingen, Landkreis & 453532 & 8.17 \\
13 & Sindelfingen 2 & Z08115 & Böblingen, Landkreis & 290 & 0.01 \\
14 & Wolfsburg & Z03103 & Wolfsburg, Kreisfreie Stadt & 429933 & 7.74
\end{tabular}




\begin{tabular}{rlclrr}
\hline$\#$ & plant & AGS & location name & output (vehicles/a) & share (\%) \\
\hline 15 & Zuffenhausen & Z08111 & Stuttgart, Stadtkreis & 36480 & 0.66 \\
16 & Hannover & Z03241 & Region Hannover, Landkreis & 165069 & 2.97 \\
17 & Ingolstadt 1 & Z09161 & Ingolstadt, Kreisfreie Stadt & 310985 & 5.60 \\
18 & Ingolstadt 2 & Z09161 & Ingolstadt, Kreisfreie Stadt & 180000 & 3.24 \\
19 & Leipzig & Z14713 & Leipzig, Kreisfreie Stadt & 193710 & 3.49 \\
20 & Ludwigsfelde & Z12072 & Teltow-Fläming, Landkreis & 58310 & 1.05 \\
21 & Mosel & Z14524 & Zwickau, Landkreis & 228340 & 4.11 \\
22 & München & Z09162 & München, Kreisfreie Stadt & 191250 & 3.44 \\
23 & Neckarsulm 1 & Z08121 & Heilbronn, Stadtkreis & 208800 & 3.76 \\
24 & Neckarsulm 2 & Z08121 & Heilbronn, Stadtkreis & 5709 & 0.10 \\
25 & Osnabrück & Z03404 & Osnabrück, Kreisfreie Stadt & 13781 & 0.25 \\
26 & Rastatt & Z08216 & Rastatt, Landkreis & 264268 & 4.76 \\
27 & Regensburg & Z09362 & Regensburg, Kreisfreie Stadt & 293136 & 5.28 \\
28 & Rheine & Z05566 & Steinfurt, Kreis & 15184 & 0.27 \\
29 & Rüsselsheim & Z06433 & Groß-Gerau, Landkreis & 121725 & 2.19 \\
\hline
\end{tabular}

Table C.3: Spatial employment data used for locating generated establishments during the model application for the automotive industry $\left(n E m p_{i}^{s}\right)$. Source: Bundesagentur für Arbeit (2013). Data gaps caused by blackening for secrecy obligations have been filled according to available data on the aggregate level of manufacturing.

\begin{tabular}{rrrrrr}
\hline zone & \multicolumn{5}{c}{ employment in sectors by zones (employees) } \\
(AGS) & WZ 29 & WZ 29.1 & WZ 29.2 & WZ 29.3 & manufacturing \\
\hline 01001 & 1112 & 0 & 61 & 0 & 36808 \\
01002 & 3279 & 0 & 179 & 1463 & 108563 \\
01003 & 2604 & 2097 & 0 & 0 & 86220 \\
01004 & 995 & 0 & 54 & 0 & 32944 \\
01051 & 0 & 0 & 0 & 0 & 35610 \\
01053 & 1271 & 0 & 69 & 567 & 42091 \\
01054 & 1577 & 0 & 86 & 0 & 52213 \\
01055 & 1619 & 0 & 88 & 722 & 53596 \\
01056 & 2497 & 2011 & 46 & 1114 & 82682 \\
01057 & 723 & 0 & 39 & 0 & 23941 \\
01058 & 2059 & 0 & 112 & 0 & 68161 \\
01059 & 1425 & 1147 & 78 & 636 & 47182 \\
01060 & 2350 & 0 & 128 & 1048 & 77802 \\
01061 & 1047 & 0 & 57 & 467 & 34677 \\
01062 & 1883 & 1818 & 248 & 1007 & 74745 \\
02000 & 25811 & 0 & 87 & 11517 & 854629 \\
03101 & 3491 & 2811 & 190 & 557 & 115590 \\
03102 & 1358 & 1093 & 74 & 606 & 44963 \\
03103 & 3406 & 2742 & 0 & 1947 & 112764 \\
03151 & 1082 & 871 & 59 & 483 & 35838 \\
03152 & 2835 & 0 & 154 & 1265 & 93874 \\
03153 & 1279 & 0 & 70 & 0 & 42337
\end{tabular}




\begin{tabular}{|c|c|c|c|c|c|}
\hline \multirow{2}{*}{$\begin{array}{r}\text { zone } \\
\text { (AGS) }\end{array}$} & \multicolumn{5}{|c|}{ employment in sectors by zones (employees) } \\
\hline & WZ 29 & WZ 29.1 & WZ 29.2 & WZ 29.3 & manufacturing \\
\hline 03154 & 597 & 0 & 33 & 267 & 19781 \\
\hline 03155 & 654 & 0 & 68 & 557 & 41335 \\
\hline 03156 & 724 & 0 & 0 & 323 & 23968 \\
\hline 03157 & 865 & 0 & 47 & 386 & 28636 \\
\hline 03158 & 0 & 0 & 0 & 0 & 22011 \\
\hline 03241 & 13646 & 10987 & 168 & 2055 & 451825 \\
\hline 03251 & 1839 & 0 & 99 & 811 & 60211 \\
\hline 03252 & 1463 & 0 & 80 & 0 & 48451 \\
\hline 03254 & 2511 & 2022 & 137 & 1120 & 83143 \\
\hline 03255 & 609 & 0 & 33 & 0 & 20158 \\
\hline 03256 & 1027 & 0 & 15 & 458 & 33992 \\
\hline 03257 & 1166 & 0 & 63 & 520 & 38594 \\
\hline 03351 & 1574 & 0 & 86 & 702 & 52113 \\
\hline 03352 & 1261 & 0 & 69 & 563 & 41767 \\
\hline 03353 & 1552 & 0 & 86 & 693 & 51398 \\
\hline 03354 & 383 & 0 & 21 & 171 & 12693 \\
\hline 03355 & 1515 & 1220 & 83 & 676 & 50177 \\
\hline 03356 & 685 & 552 & 0 & 0 & 22696 \\
\hline 03357 & 466 & 1182 & 80 & 655 & 48602 \\
\hline 03358 & 301 & 0 & 70 & 576 & 42722 \\
\hline 03359 & 1669 & 0 & 91 & 745 & 55264 \\
\hline 03360 & 797 & 0 & 0 & 356 & 26402 \\
\hline 03361 & 1251 & 0 & 68 & 558 & 41430 \\
\hline 03401 & 49 & 0 & 49 & 0 & 18677 \\
\hline 03402 & 939 & 756 & 0 & 419 & 31082 \\
\hline 03403 & 2240 & 0 & 122 & 1000 & 74176 \\
\hline 03404 & 2596 & 2090 & 141 & 1159 & 85966 \\
\hline 03405 & 815 & 656 & 0 & 0 & 26988 \\
\hline 03451 & 89 & 0 & 60 & 494 & 36648 \\
\hline 03452 & 1530 & 1232 & 83 & 683 & 50647 \\
\hline 03453 & 1604 & 1291 & 87 & 0 & 53109 \\
\hline 03454 & 857 & 296 & 186 & 1527 & 113308 \\
\hline 03455 & 784 & 0 & 0 & 350 & 25956 \\
\hline 03456 & 358 & 1009 & 68 & 559 & 41508 \\
\hline 03457 & 1237 & 996 & 67 & 0 & 40971 \\
\hline 03458 & 911 & 733 & 50 & 406 & 30161 \\
\hline 03459 & 838 & 2593 & 175 & 551 & 106637 \\
\hline 03460 & 1768 & 1451 & 101 & 804 & 59687 \\
\hline 03461 & 803 & 0 & 0 & 358 & 26573 \\
\hline 03462 & 0 & 0 & 0 & 0 & 14021 \\
\hline 04011 & 7487 & 6028 & 75 & 1986 & 247891 \\
\hline 04012 & 21 & 0 & 21 & 0 & 48688 \\
\hline 05111 & 11208 & 9025 & 610 & 1049 & 371122 \\
\hline 05112 & 358 & 0 & 261 & 2136 & 158486 \\
\hline
\end{tabular}




\begin{tabular}{rrrrrr}
\hline zone & \multicolumn{5}{c}{ employment in sectors by zones (employees) } \\
(AGS) & WZ 29 & WZ 29.1 & WZ 29.2 & WZ 29.3 & manufacturing \\
\hline 05113 & 6769 & 0 & 369 & 3020 & 224130 \\
05114 & 2509 & 2020 & 137 & 1119 & 83060 \\
05116 & 2570 & 0 & 140 & 1147 & 85095 \\
05117 & 1709 & 0 & 93 & 763 & 56583 \\
05119 & 1833 & 0 & 100 & 0 & 60700 \\
05120 & 710 & 1011 & 0 & 560 & 41574 \\
05122 & 1413 & 0 & 77 & 635 & 47105 \\
05124 & 1405 & 2775 & 188 & 1369 & 114101 \\
05154 & 216 & 2007 & 192 & 1112 & 82520 \\
05158 & 1725 & 0 & 86 & 1639 & 169550 \\
05162 & 182 & 3197 & 216 & 174 & 131488 \\
05166 & 2424 & 0 & 132 & 1082 & 80275 \\
05170 & 216 & 2938 & 199 & 1628 & 120824 \\
05314 & 4785 & 0 & 261 & 2135 & 158436 \\
05315 & 18840 & 11798 & 798 & 1674 & 485167 \\
05316 & 1819 & 0 & 99 & 812 & 60225 \\
05334 & 1029 & 4589 & 310 & 2543 & 188714 \\
05358 & 2259 & 0 & 123 & 1008 & 74810 \\
05362 & 464 & 3063 & 33 & 1697 & 125960 \\
05366 & 529 & 0 & 81 & 667 & 49523 \\
05370 & 8 & 1408 & 95 & 0 & 57908 \\
05374 & 4120 & 0 & 20 & 4100 & 91957 \\
05378 & 4238 & 1653 & 112 & 916 & 67998 \\
05382 & 1821 & 3309 & 224 & 1629 & 136065 \\
05512 & 950 & 0 & 52 & 424 & 31469 \\
05513 & 2228 & 1794 & 121 & 994 & 73781 \\
05515 & 4413 & 0 & 240 & 1969 & 146112 \\
05554 & 1958 & 3005 & 203 & 1665 & 123582 \\
05558 & 1741 & 1402 & 95 & 0 & 57643 \\
05562 & 1125 & 3624 & 245 & 2009 & 149042 \\
05566 & 1612 & 3262 & 221 & 1808 & 134153 \\
05570 & 1330 & 0 & 135 & 1104 & 81890 \\
05711 & 673 & 3264 & 221 & 606 & 134236 \\
05754 & 1789 & 3547 & 240 & 1389 & 145854 \\
05758 & 2602 & 0 & 142 & 1161 & 86144 \\
05762 & 1212 & 0 & 66 & 541 & 40117 \\
05766 & 1619 & 0 & 169 & 1386 & 102874 \\
05770 & 2140 & 2760 & 32 & 1529 & 113481 \\
05774 & 1608 & 2581 & 175 & 1492 & 106144 \\
05911 & 3801 & 3061 & 207 & 1696 & 125864 \\
05913 & 1534 & 4980 & 337 & 2760 & 204782 \\
05914 & 1199 & 0 & 110 & 901 & 66855 \\
05915 & 1565 & 0 & 85 & 698 & 51822 \\
05916 & 1306 & 0 & 71 & 583 & 43244
\end{tabular}




\begin{tabular}{|c|c|c|c|c|c|}
\hline \multirow{2}{*}{$\begin{array}{r}\text { zone } \\
\text { (AGS) }\end{array}$} & \multicolumn{5}{|c|}{ employment in sectors by zones (employees) } \\
\hline & WZ 29 & WZ 29.1 & WZ 29.2 & WZ 29.3 & manufacturing \\
\hline 05954 & 1530 & 2356 & 159 & 1132 & 96868 \\
\hline 05958 & 1056 & 0 & 201 & 855 & 92074 \\
\hline 05962 & 4190 & 3635 & 246 & 4045 & 149465 \\
\hline 05966 & 1810 & 0 & 21 & 1789 & 51598 \\
\hline 05970 & 851 & 0 & 174 & 1425 & 105724 \\
\hline 05974 & 828 & 2443 & 165 & 788 & 100468 \\
\hline 05978 & 553 & 0 & 184 & 1507 & 111846 \\
\hline 06411 & 45 & 2218 & 150 & 1229 & 91210 \\
\hline 06412 & 15352 & 12361 & 836 & 6850 & 508321 \\
\hline 06413 & 1323 & 1066 & 0 & 591 & 43819 \\
\hline 06414 & 3720 & 0 & 203 & 1660 & 123165 \\
\hline 06431 & 1987 & 1600 & 108 & 887 & 65804 \\
\hline 06432 & 2003 & 0 & 109 & 894 & 66311 \\
\hline 06433 & 2689 & 2165 & 146 & 1200 & 89043 \\
\hline 06434 & 2429 & 1956 & 0 & 1084 & 80441 \\
\hline 06435 & 1472 & 2816 & 190 & 1205 & 115806 \\
\hline 06436 & 2677 & 0 & 146 & 1195 & 88652 \\
\hline 06437 & 735 & 0 & 0 & 328 & 24337 \\
\hline 06438 & 3218 & 0 & 175 & 1436 & 106562 \\
\hline 06439 & 1182 & 952 & 0 & 528 & 39152 \\
\hline 06440 & 2259 & 1819 & 123 & 1008 & 74788 \\
\hline 06531 & 2638 & 2124 & 144 & 1177 & 87345 \\
\hline 06532 & 1886 & 0 & 141 & 1156 & 85803 \\
\hline 06533 & 693 & 1130 & 76 & 677 & 46478 \\
\hline 06534 & 2515 & 0 & 137 & 1122 & 83289 \\
\hline 06535 & 850 & 0 & 46 & 379 & 28130 \\
\hline 06611 & 6080 & 0 & 168 & 1377 & 102194 \\
\hline 06631 & 2475 & 1993 & 135 & 1105 & 81966 \\
\hline 06632 & 1320 & 0 & 0 & 589 & 43716 \\
\hline 06633 & 1995 & 0 & 109 & 890 & 66047 \\
\hline 06634 & 81 & 0 & 81 & 0 & 47597 \\
\hline 06635 & 1682 & 0 & 92 & 0 & 55684 \\
\hline 06636 & 803 & 0 & 44 & 358 & 26599 \\
\hline 07111 & 1997 & 1608 & 0 & 891 & 66130 \\
\hline 07131 & 896 & 721 & 49 & 400 & 29666 \\
\hline 07132 & 1467 & 816 & 55 & 1432 & 33557 \\
\hline 07133 & 1438 & 1158 & 26 & 642 & 47610 \\
\hline 07134 & 748 & 0 & 0 & 334 & 24773 \\
\hline 07135 & 535 & 0 & 29 & 239 & 17702 \\
\hline 07137 & 270 & 1415 & 96 & 784 & 58186 \\
\hline 07138 & 1652 & 1330 & 90 & 737 & 54697 \\
\hline 07140 & 964 & 776 & 52 & 430 & 31919 \\
\hline 07141 & 871 & 0 & 47 & 389 & 28829 \\
\hline 07143 & 1832 & 1475 & 100 & 818 & 60665 \\
\hline
\end{tabular}




\begin{tabular}{rrrrrr}
\hline zone & \multicolumn{5}{c}{ employment in sectors by zones (employees) } \\
(AGS) & WZ 29 & WZ 29.1 & WZ 29.2 & WZ 29.3 & manufacturing \\
\hline 07211 & 53 & 0 & 84 & 688 & 51016 \\
07231 & 187 & 883 & 60 & 17 & 36327 \\
07232 & 791 & 0 & 0 & 353 & 26190 \\
07233 & 532 & 428 & 29 & 237 & 17601 \\
07235 & 808 & 0 & 44 & 361 & 26753 \\
07311 & 477 & 0 & 0 & 213 & 15788 \\
07312 & 1515 & 1220 & 83 & 676 & 50178 \\
07313 & 601 & 0 & 33 & 268 & 19902 \\
07314 & 2844 & 0 & 0 & 1269 & 94174 \\
07315 & 25 & 2511 & 170 & 1391 & 103252 \\
07316 & 478 & 0 & 0 & 213 & 15825 \\
07317 & 0 & 0 & 0 & 0 & 19304 \\
07318 & 757 & 0 & 0 & 338 & 25053 \\
07319 & 912 & 0 & 0 & 407 & 30211 \\
07320 & 432 & 0 & 24 & 0 & 14319 \\
07331 & 0 & 0 & 0 & 0 & 28013 \\
07332 & 854 & 688 & 47 & 381 & 28289 \\
07333 & 599 & 0 & 33 & 267 & 19832 \\
07334 & 1277 & 1028 & 0 & 171 & 42278 \\
07335 & 680 & 0 & 37 & 303 & 22506 \\
07336 & 361 & 0 & 0 & 161 & 11954 \\
07337 & 780 & 0 & 27 & 348 & 25816 \\
07338 & 747 & 0 & 41 & 333 & 24728 \\
07339 & 1456 & 0 & 79 & 649 & 48195 \\
07340 & 434 & 349 & 0 & 193 & 14358 \\
08111 & 34862 & 8750 & 592 & 14823 & 359817 \\
08115 & 4790 & 3857 & 49 & 1422 & 158600 \\
08116 & 12530 & 4550 & 308 & 3793 & 187097 \\
08117 & 1676 & 1939 & 0 & 1074 & 79719 \\
08118 & 13883 & 4276 & 289 & 12158 & 175848 \\
08119 & 3488 & 3145 & 213 & 3382 & 129344 \\
08121 & 1912 & 0 & 0 & 853 & 63321 \\
08125 & 19425 & 2833 & 192 & 4522 & 116511 \\
08126 & 705 & 1211 & 82 & 671 & 49782 \\
08127 & 1327 & 0 & 117 & 961 & 71319 \\
08128 & 1501 & 1209 & 82 & 670 & 49701 \\
08135 & 1428 & 1150 & 78 & 637 & 47293 \\
08136 & 7479 & 0 & 179 & 1471 & 109150 \\
08211 & 945 & 0 & 0 & 422 & 31306 \\
08212 & 486 & 3976 & 269 & 318 & 163521 \\
08215 & 1771 & 3266 & 221 & 876 & 134317 \\
08216 & 21864 & 1959 & 132 & 13754 & 80575 \\
08221 & 1239 & 0 & 135 & 1108 & 82246 \\
08222 & 5160 & 4154 & 281 & 2302 & 170843
\end{tabular}




\begin{tabular}{|c|c|c|c|c|c|}
\hline \multirow{2}{*}{$\begin{array}{r}\text { zone } \\
\text { (AGS) }\end{array}$} & \multicolumn{5}{|c|}{ employment in sectors by zones (employees) } \\
\hline & WZ 29 & WZ 29.1 & WZ 29.2 & WZ 29.3 & manufacturing \\
\hline 08225 & 1269 & 0 & 69 & 566 & 42030 \\
\hline 08226 & 3129 & 3613 & 244 & 3069 & 148597 \\
\hline 08231 & 1544 & 0 & 84 & 689 & 51124 \\
\hline 08235 & 1966 & 1021 & 69 & 1885 & 41987 \\
\hline 08236 & 1628 & 0 & 22 & 726 & 53906 \\
\hline 08237 & 1282 & 1032 & 70 & 572 & 42442 \\
\hline 08311 & 3258 & 0 & 177 & 0 & 107888 \\
\hline 08315 & 1925 & 0 & 117 & 962 & 71385 \\
\hline 08316 & 722 & 1102 & 75 & 611 & 45332 \\
\hline 08317 & 1848 & 3841 & 260 & 2129 & 157944 \\
\hline 08325 & 1514 & 0 & 82 & 676 & 50130 \\
\hline 08326 & 2370 & 0 & 129 & 1057 & 78457 \\
\hline 08327 & 364 & 0 & 5 & 359 & 56433 \\
\hline 08335 & 950 & 2162 & 71 & 1198 & 88918 \\
\hline 08336 & 2105 & 0 & 0 & 939 & 69688 \\
\hline 08337 & 1454 & 0 & 43 & 649 & 48132 \\
\hline 08415 & 3212 & 2402 & 162 & 3005 & 98786 \\
\hline 08416 & 2048 & 0 & 111 & 914 & 67802 \\
\hline 08417 & 1858 & 0 & 101 & 829 & 61505 \\
\hline 08421 & 3691 & 2063 & 139 & 957 & 84825 \\
\hline 08425 & 211 & 0 & 81 & 663 & 49224 \\
\hline 08426 & 233 & 0 & 117 & 960 & 71226 \\
\hline 08435 & 612 & 1964 & 133 & 1089 & 80778 \\
\hline 08436 & 2341 & 2458 & 166 & 1362 & 101087 \\
\hline 08437 & 198 & 1015 & 69 & 562 & 41732 \\
\hline 09161 & 2656 & 2139 & 0 & 1185 & 87945 \\
\hline 09162 & 41059 & 17848 & 1207 & 1260 & 733967 \\
\hline 09163 & 0 & 0 & 0 & 0 & 30619 \\
\hline 09171 & 1281 & 0 & 70 & 0 & 42411 \\
\hline 09172 & 951 & 766 & 52 & 0 & 31484 \\
\hline 09173 & 702 & 812 & 55 & 660 & 33412 \\
\hline 09174 & 1037 & 0 & 56 & 463 & 34321 \\
\hline 09175 & 998 & 803 & 54 & 445 & 33034 \\
\hline 09176 & 979 & 788 & 53 & 437 & 32404 \\
\hline 09177 & 0 & 0 & 0 & 0 & 36398 \\
\hline 09178 & 1126 & 1796 & 121 & 995 & 73862 \\
\hline 09179 & 1283 & 0 & 70 & 573 & 42493 \\
\hline 09180 & 755 & 0 & 0 & 337 & 24993 \\
\hline 09181 & 947 & 0 & 52 & 422 & 31342 \\
\hline 09182 & 905 & 0 & 0 & 404 & 29970 \\
\hline 09183 & 1024 & 0 & 56 & 457 & 33894 \\
\hline 09184 & 1166 & 4628 & 313 & 2565 & 190322 \\
\hline 09185 & 877 & 706 & 48 & 392 & 29052 \\
\hline 09186 & 1030 & 0 & 56 & 460 & 34098 \\
\hline
\end{tabular}




\begin{tabular}{|c|c|c|c|c|c|}
\hline \multirow{2}{*}{$\begin{array}{r}\text { zone } \\
\text { (AGS) }\end{array}$} & \multicolumn{5}{|c|}{ employment in sectors by zones (employees) } \\
\hline & WZ 29 & WZ 29.1 & WZ 29.2 & WZ 29.3 & manufacturing \\
\hline 09187 & 2144 & 1726 & 117 & 957 & 70994 \\
\hline 09188 & 1259 & 0 & 69 & 562 & 41702 \\
\hline 09189 & 1756 & 1414 & 96 & 784 & 58146 \\
\hline 09190 & 1459 & 0 & 0 & 1459 & 41710 \\
\hline 09261 & 1012 & 0 & 0 & 451 & 33501 \\
\hline 09262 & 1046 & 0 & 57 & 467 & 34645 \\
\hline 09263 & 548 & 0 & 43 & 350 & 25989 \\
\hline 09271 & 2354 & 1065 & 72 & 2292 & 43805 \\
\hline 09272 & 624 & 0 & 34 & 278 & 20653 \\
\hline 09273 & 1031 & 0 & 56 & 460 & 34152 \\
\hline 09274 & 3621 & 1001 & 68 & 3616 & 41171 \\
\hline 09275 & 2341 & 0 & 85 & 700 & 51973 \\
\hline 09276 & 0 & 0 & 0 & 0 & 23422 \\
\hline 09277 & 1062 & 0 & 58 & 0 & 35174 \\
\hline 09278 & 630 & 507 & 34 & 281 & 20854 \\
\hline 09279 & 1365 & 1099 & 74 & 609 & 45199 \\
\hline 09361 & 727 & 0 & 0 & 325 & 24082 \\
\hline 09362 & 3175 & 2557 & 0 & 1417 & 105142 \\
\hline 09363 & 778 & 0 & 42 & 0 & 25767 \\
\hline 09371 & 1706 & 0 & 0 & 1706 & 25399 \\
\hline 09372 & 1388 & 1117 & 76 & 619 & 45947 \\
\hline 09373 & 1266 & 0 & 0 & 565 & 41908 \\
\hline 09374 & 1005 & 0 & 0 & 1005 & 26524 \\
\hline 09375 & 660 & 0 & 64 & 523 & 38778 \\
\hline 09376 & 2855 & 1187 & 80 & 2736 & 48821 \\
\hline 09377 & 657 & 0 & 36 & 0 & 21738 \\
\hline 09461 & 1472 & 0 & 80 & 657 & 48755 \\
\hline 09462 & 1292 & 0 & 0 & 576 & 42778 \\
\hline 09463 & 974 & 0 & 0 & 435 & 32252 \\
\hline 09464 & 707 & 0 & 39 & 0 & 23418 \\
\hline 09471 & 991 & 798 & 54 & 442 & 32818 \\
\hline 09472 & 691 & 0 & 0 & 308 & 22891 \\
\hline 09473 & 792 & 0 & 0 & 354 & 26237 \\
\hline 09474 & 795 & 0 & 0 & 355 & 26320 \\
\hline 09475 & 1022 & 0 & 56 & 0 & 33847 \\
\hline 09476 & 512 & 0 & 41 & 335 & 24857 \\
\hline 09477 & 369 & 0 & 42 & 346 & 25663 \\
\hline 09478 & 817 & 0 & 0 & 364 & 27039 \\
\hline 09479 & 806 & 0 & 44 & 0 & 26672 \\
\hline 09561 & 750 & 0 & 0 & 335 & 24827 \\
\hline 09562 & 2635 & 2122 & 143 & 0 & 87262 \\
\hline 09563 & 1235 & 0 & 0 & 551 & 40904 \\
\hline 09564 & 7283 & 6692 & 453 & 2671 & 275210 \\
\hline 09565 & 434 & 0 & 24 & 194 & 14374 \\
\hline
\end{tabular}




\begin{tabular}{|c|c|c|c|c|c|}
\hline \multirow{2}{*}{$\begin{array}{r}\text { zone } \\
\text { (AGS) }\end{array}$} & \multicolumn{5}{|c|}{ employment in sectors by zones (employees) } \\
\hline & WZ 29 & WZ 29.1 & WZ 29.2 & WZ 29.3 & manufacturing \\
\hline 09571 & 1635 & 0 & 0 & 730 & 54144 \\
\hline 09572 & 0 & 0 & 0 & 0 & 42555 \\
\hline 09573 & 660 & 0 & 0 & 294 & 21841 \\
\hline 09574 & 1300 & 0 & 79 & 649 & 48180 \\
\hline 09575 & 865 & 0 & 47 & 386 & 28640 \\
\hline 09576 & 985 & 0 & 54 & 440 & 32628 \\
\hline 09577 & 1094 & 0 & 48 & 392 & 29071 \\
\hline 09661 & 1388 & 1118 & 76 & 619 & 45956 \\
\hline 09662 & 1574 & 0 & 86 & 702 & 52123 \\
\hline 09663 & 57 & 0 & 132 & 1081 & 80178 \\
\hline 09671 & 1539 & 1156 & 78 & 641 & 47557 \\
\hline 09672 & 938 & 0 & 51 & 418 & 31053 \\
\hline 09673 & 890 & 0 & 0 & 397 & 29471 \\
\hline 09674 & 735 & 0 & 0 & 328 & 24353 \\
\hline 09675 & 868 & 0 & 47 & 387 & 28742 \\
\hline 09676 & 1165 & 0 & 63 & 520 & 38591 \\
\hline 09677 & 823 & 1067 & 72 & 791 & 43896 \\
\hline 09678 & 667 & 0 & 36 & 297 & 22072 \\
\hline 09679 & 1046 & 842 & 57 & 467 & 34636 \\
\hline 09761 & 3953 & 0 & 215 & 1764 & 130900 \\
\hline 09762 & 0 & 0 & 0 & 0 & 15903 \\
\hline 09763 & 1057 & 0 & 58 & 472 & 34988 \\
\hline 09764 & 859 & 0 & 47 & 383 & 28435 \\
\hline 09771 & 942 & 0 & 51 & 420 & 31191 \\
\hline 09772 & 1906 & 1534 & 104 & 850 & 63102 \\
\hline 09773 & 863 & 0 & 47 & 0 & 28582 \\
\hline 09774 & 1052 & 1089 & 74 & 604 & 44803 \\
\hline 09775 & 1711 & 1377 & 93 & 763 & 56645 \\
\hline 09776 & 843 & 0 & 46 & 376 & 27922 \\
\hline 09777 & 1257 & 1012 & 0 & 561 & 41627 \\
\hline 09778 & 1244 & 1002 & 68 & 555 & 41203 \\
\hline 09779 & 2841 & 0 & 88 & 724 & 53727 \\
\hline 09780 & 1310 & 1054 & 0 & 584 & 43360 \\
\hline 10041 & 4382 & 3528 & 239 & 1955 & 145088 \\
\hline 10042 & 866 & 0 & 47 & 386 & 28666 \\
\hline 10043 & 1052 & 0 & 0 & 469 & 34818 \\
\hline 10044 & 8808 & 1655 & 112 & 1869 & 68045 \\
\hline 10045 & 1883 & 0 & 103 & 840 & 62352 \\
\hline 10046 & 724 & 0 & 0 & 323 & 23958 \\
\hline 11000 & 4632 & 28944 & 1957 & 4499 & 1190273 \\
\hline 12051 & 818 & 0 & 0 & 365 & 27076 \\
\hline 12052 & 1341 & 0 & 73 & 0 & 44392 \\
\hline 12053 & 0 & 0 & 0 & 0 & 28016 \\
\hline 12054 & 2353 & 0 & 0 & 1050 & 77916 \\
\hline
\end{tabular}




\begin{tabular}{|c|c|c|c|c|c|}
\hline \multirow{2}{*}{$\begin{array}{r}\text { zone } \\
\text { (AGS) }\end{array}$} & \multicolumn{5}{|c|}{ employment in sectors by zones (employees) } \\
\hline & WZ 29 & WZ 29.1 & WZ 29.2 & WZ 29.3 & manufacturing \\
\hline 12060 & 1347 & 0 & 0 & 601 & 44586 \\
\hline 12061 & 1642 & 1322 & 89 & 0 & 54376 \\
\hline 12062 & 935 & 753 & 0 & 417 & 30964 \\
\hline 12063 & 1207 & 0 & 66 & 539 & 39975 \\
\hline 12064 & 1357 & 0 & 74 & 0 & 44927 \\
\hline 12065 & 1559 & 0 & 85 & 696 & 51631 \\
\hline 12066 & 1125 & 906 & 0 & 502 & 37239 \\
\hline 12067 & 1517 & 0 & 83 & 677 & 50222 \\
\hline 12068 & 984 & 792 & 54 & 0 & 32579 \\
\hline 12069 & 1618 & 1303 & 88 & 722 & 53578 \\
\hline 12070 & 788 & 0 & 43 & 0 & 26095 \\
\hline 12071 & 1076 & 0 & 59 & 0 & 35618 \\
\hline 12072 & 2593 & 1327 & 90 & 735 & 54574 \\
\hline 12073 & 1113 & 896 & 0 & 497 & 36856 \\
\hline 13003 & 2444 & 1968 & 0 & 0 & 80934 \\
\hline 13004 & 46 & 0 & 78 & 636 & 47197 \\
\hline 13071 & 2701 & 0 & 147 & 1205 & 89435 \\
\hline 13072 & 1885 & 1518 & 114 & 841 & 62423 \\
\hline 13073 & 2155 & 0 & 117 & 0 & 71366 \\
\hline 13074 & 1299 & 0 & 71 & 0 & 43008 \\
\hline 13075 & 2301 & 0 & 0 & 1027 & 76188 \\
\hline 13076 & 825 & 0 & 293 & 532 & 61438 \\
\hline 14511 & 3263 & 2627 & 178 & 1456 & 108037 \\
\hline 14521 & 2446 & 2653 & 179 & 2149 & 109094 \\
\hline 14522 & 1372 & 2607 & 176 & 1047 & 107226 \\
\hline 14523 & 1364 & 1895 & 128 & 924 & 77911 \\
\hline 14524 & 14144 & 2916 & 197 & 6273 & 119931 \\
\hline 14612 & 1111 & 5679 & 95 & 3147 & 233540 \\
\hline 14625 & 3147 & 0 & 171 & 1404 & 104207 \\
\hline 14626 & 2382 & 1918 & 130 & 0 & 78881 \\
\hline 14627 & 530 & 2011 & 136 & 1115 & 82712 \\
\hline 14628 & 1066 & 1743 & 118 & 785 & 71683 \\
\hline 14713 & 4595 & 5421 & 367 & 3005 & 222949 \\
\hline 14729 & 559 & 1722 & 116 & 306 & 70811 \\
\hline 14730 & 2018 & 0 & 110 & 901 & 66833 \\
\hline 15001 & 1027 & 827 & 0 & 0 & 33997 \\
\hline 15002 & 2759 & 0 & 0 & 1231 & 91352 \\
\hline 15003 & 3100 & 0 & 169 & 1383 & 102648 \\
\hline 15081 & 817 & 0 & 44 & 364 & 27043 \\
\hline 15082 & 1690 & 0 & 92 & 754 & 55958 \\
\hline 15083 & 533 & 1373 & 93 & 761 & 56480 \\
\hline 15084 & 1611 & 0 & 88 & 719 & 53354 \\
\hline 15085 & 2083 & 0 & 113 & 929 & 68962 \\
\hline 15086 & 834 & 0 & 45 & 372 & 27629 \\
\hline
\end{tabular}




\begin{tabular}{|c|c|c|c|c|c|}
\hline \multirow{2}{*}{$\begin{array}{r}\text { zone } \\
\text { (AGS) }\end{array}$} & \multicolumn{5}{|c|}{ employment in sectors by zones (employees) } \\
\hline & WZ 29 & WZ 29.1 & WZ 29.2 & WZ 29.3 & manufacturing \\
\hline 15087 & 1208 & 0 & 66 & 539 & 40001 \\
\hline 15088 & 1982 & 1596 & 108 & 0 & 65625 \\
\hline 15089 & 1224 & 202 & 99 & 809 & 60017 \\
\hline 15090 & 126 & 0 & 57 & 464 & 34432 \\
\hline 15091 & 1204 & 0 & 66 & 0 & 39868 \\
\hline 16051 & 2994 & 0 & 163 & 1336 & 99144 \\
\hline 16052 & 1069 & 0 & 3 & 477 & 35395 \\
\hline 16053 & 1547 & 1245 & 0 & 0 & 51213 \\
\hline 16054 & 469 & 0 & 104 & 209 & 15532 \\
\hline 16055 & 697 & 0 & 38 & 0 & 23077 \\
\hline 16056 & 4447 & 551 & 37 & 305 & 22644 \\
\hline 16061 & 816 & 0 & 55 & 450 & 33369 \\
\hline 16062 & 846 & 681 & 46 & 378 & 28017 \\
\hline 16063 & 2222 & 0 & 66 & 541 & 40137 \\
\hline 16064 & 659 & 0 & 53 & 438 & 32475 \\
\hline 16065 & 0 & 0 & 0 & 0 & 19573 \\
\hline 16066 & 1262 & 0 & 0 & 563 & 41773 \\
\hline 16067 & 1614 & 1116 & 75 & 992 & 45910 \\
\hline 16068 & 639 & 515 & 35 & 285 & 21169 \\
\hline 16069 & 594 & 0 & 0 & 265 & 19654 \\
\hline 16070 & 726 & 0 & 63 & 513 & 38045 \\
\hline 16071 & 714 & 575 & 0 & 0 & 23649 \\
\hline 16072 & 584 & 0 & 34 & 275 & 20414 \\
\hline 16073 & 1075 & 0 & 0 & 480 & 35602 \\
\hline 16074 & 799 & 0 & 43 & 0 & 26450 \\
\hline 16075 & 743 & 728 & 49 & 404 & 29958 \\
\hline 16076 & 867 & 0 & 47 & 387 & 28708 \\
\hline 16077 & 1018 & 655 & 44 & 776 & 26950 \\
\hline
\end{tabular}


D Simulation Results for Vertical Disintegration in the Automotive Industry 


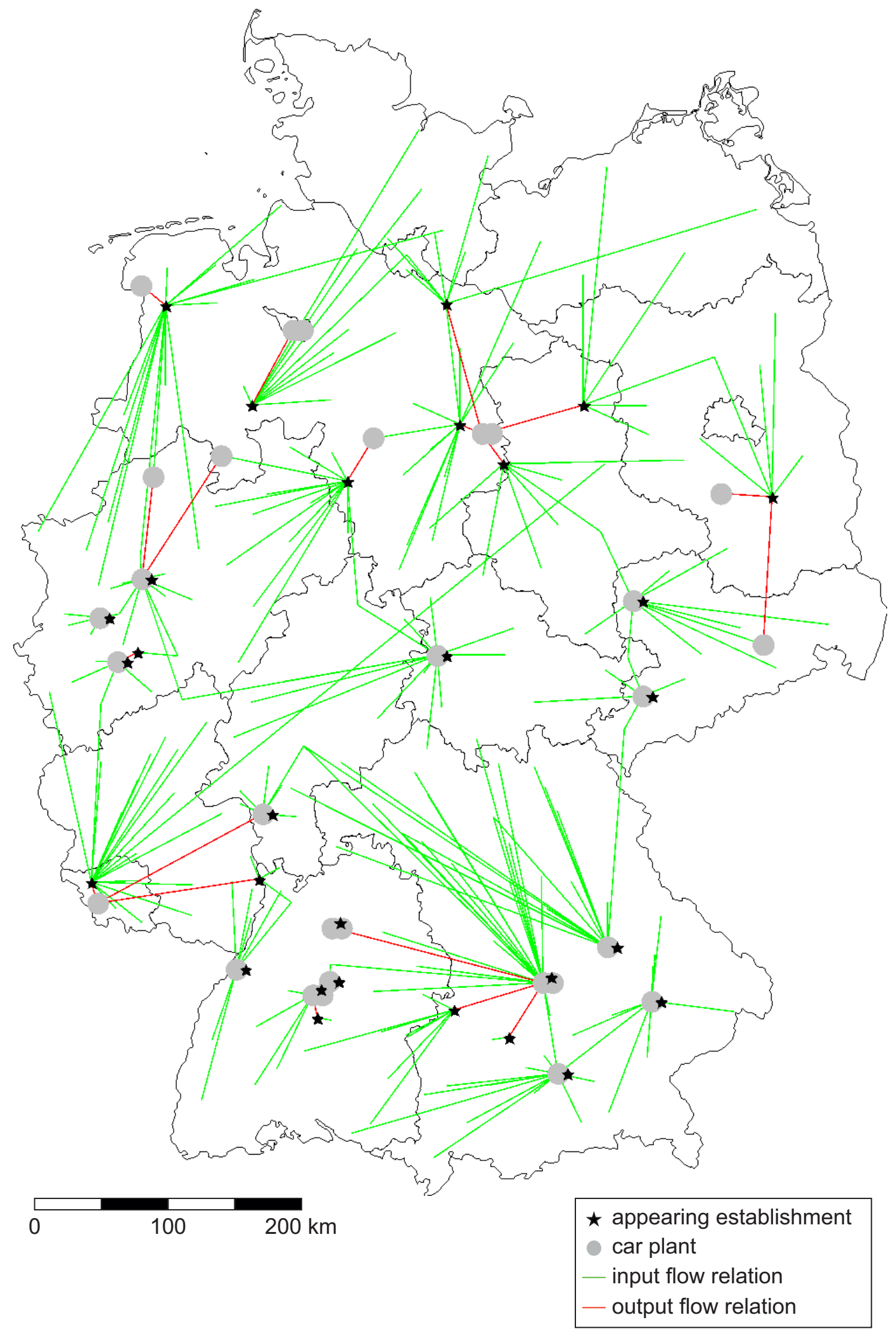

Figure D.1: Map showing establishments that appear during vertical disintegration in the automotive industry if optimal location choice, optimal assignment, and minimisation of freight transport performance are assumed (OptOptMin) 


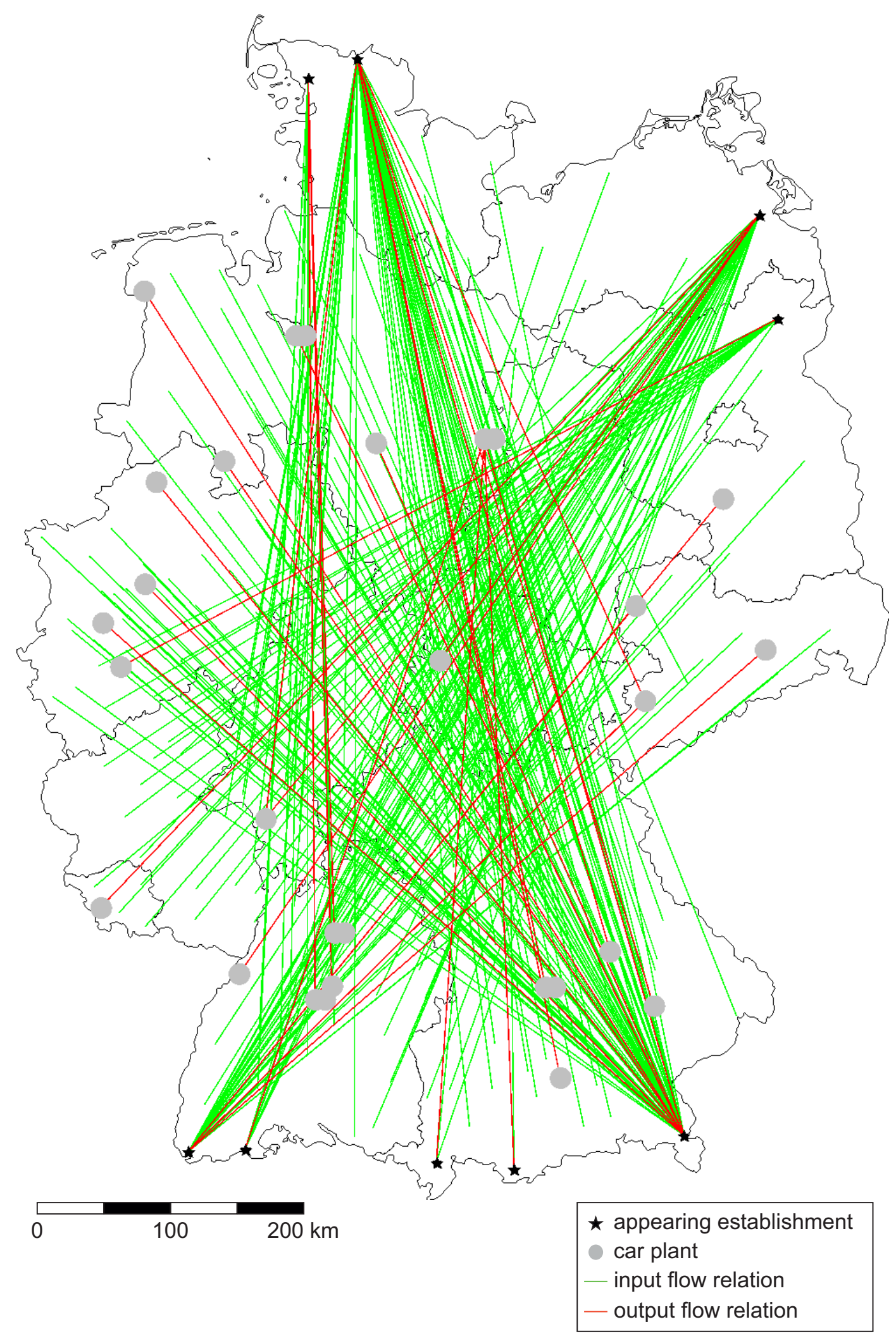

Figure D.2: Map showing establishments that appear during vertical disintegration in the automotive industry if optimal location choice, optimal assignment, and maximisation of freight transport performance are assumed (OptOptMax) 


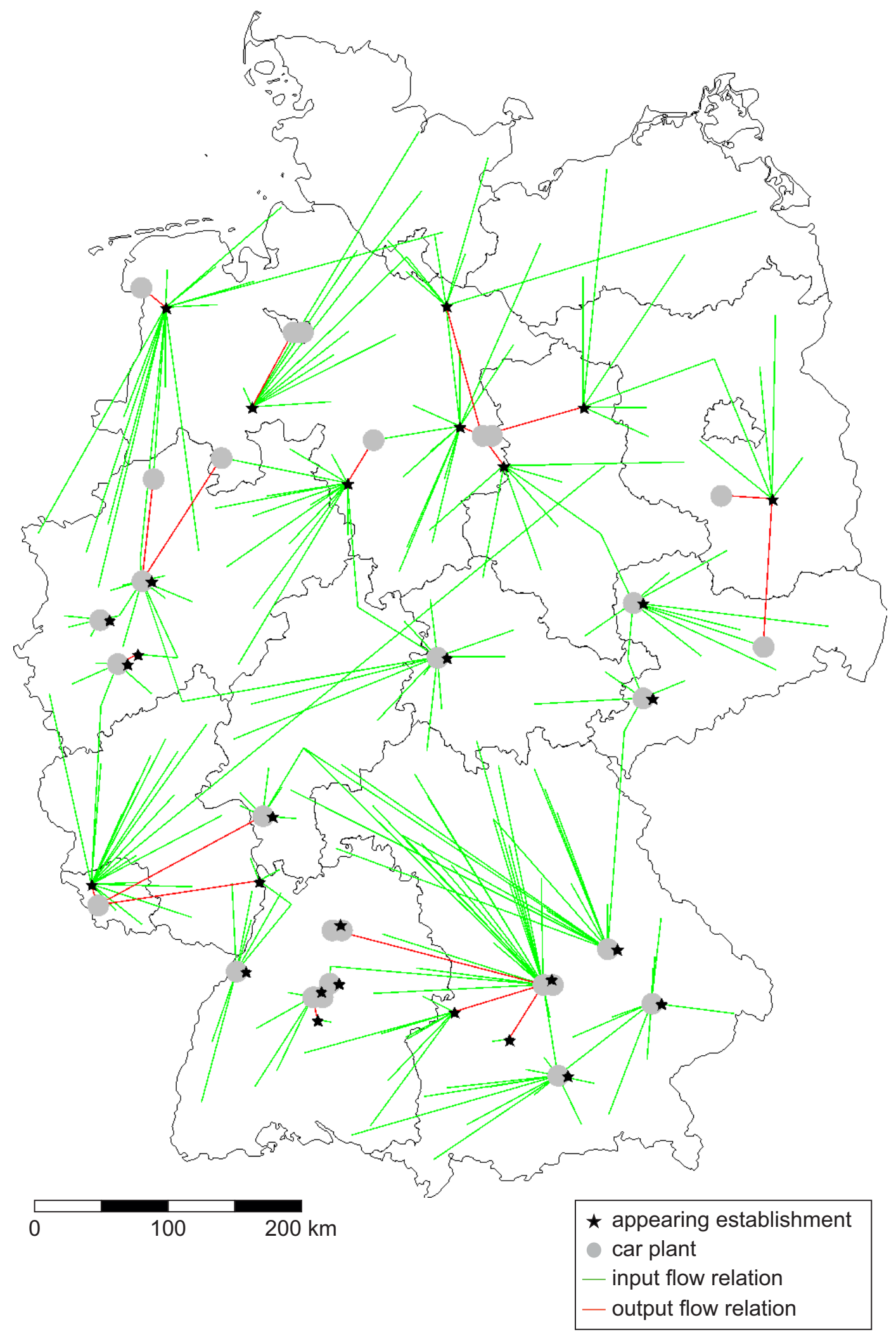

Figure D.3: Map showing establishments that appear during vertical disintegration in the automotive industry if stochastic location choice, optimal assignment, and minimisation of freight transport performance are assumed (StochOptMin) 


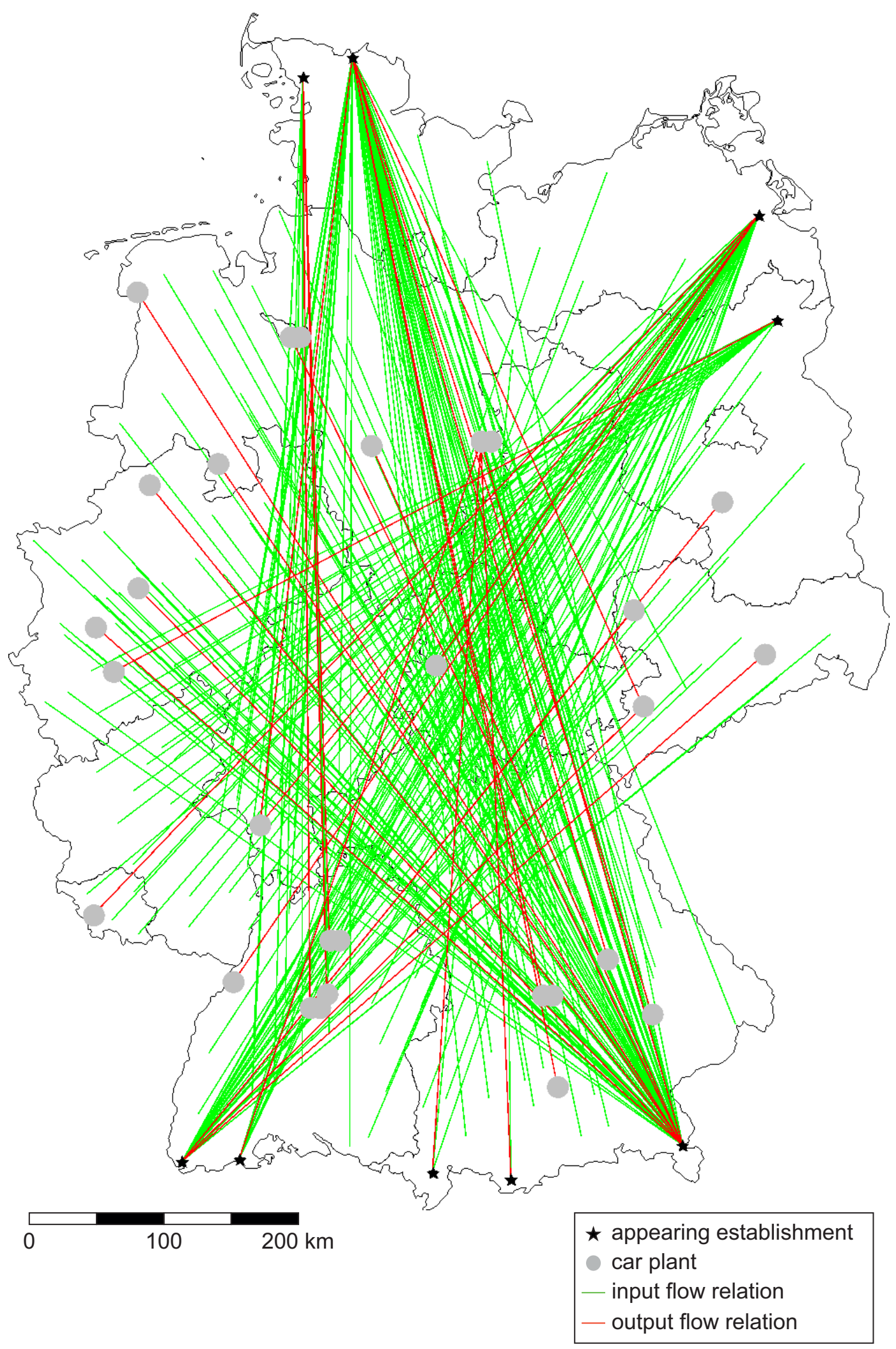

Figure D.4: Map showing establishments that appear during vertical disintegration in the automotive industry if stochastic location choice, optimal assignment, and maximisation of freight transport performance are assumed (StochOptMax) 


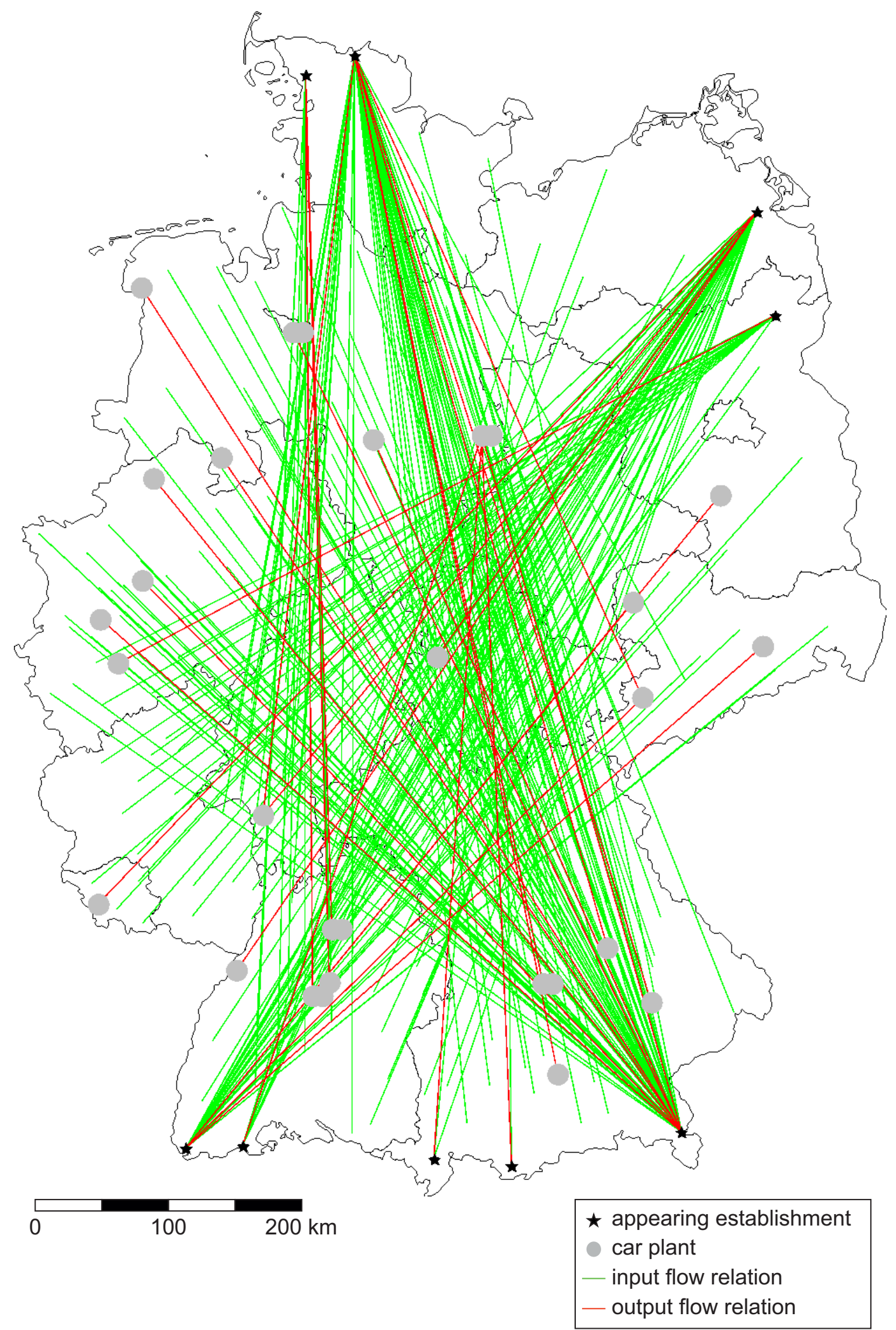

Figure D.5: Map showing establishments that appear during vertical disintegration in the automotive industry if stochastic location choice and macro flow assignment are assumed (StochMacro) 


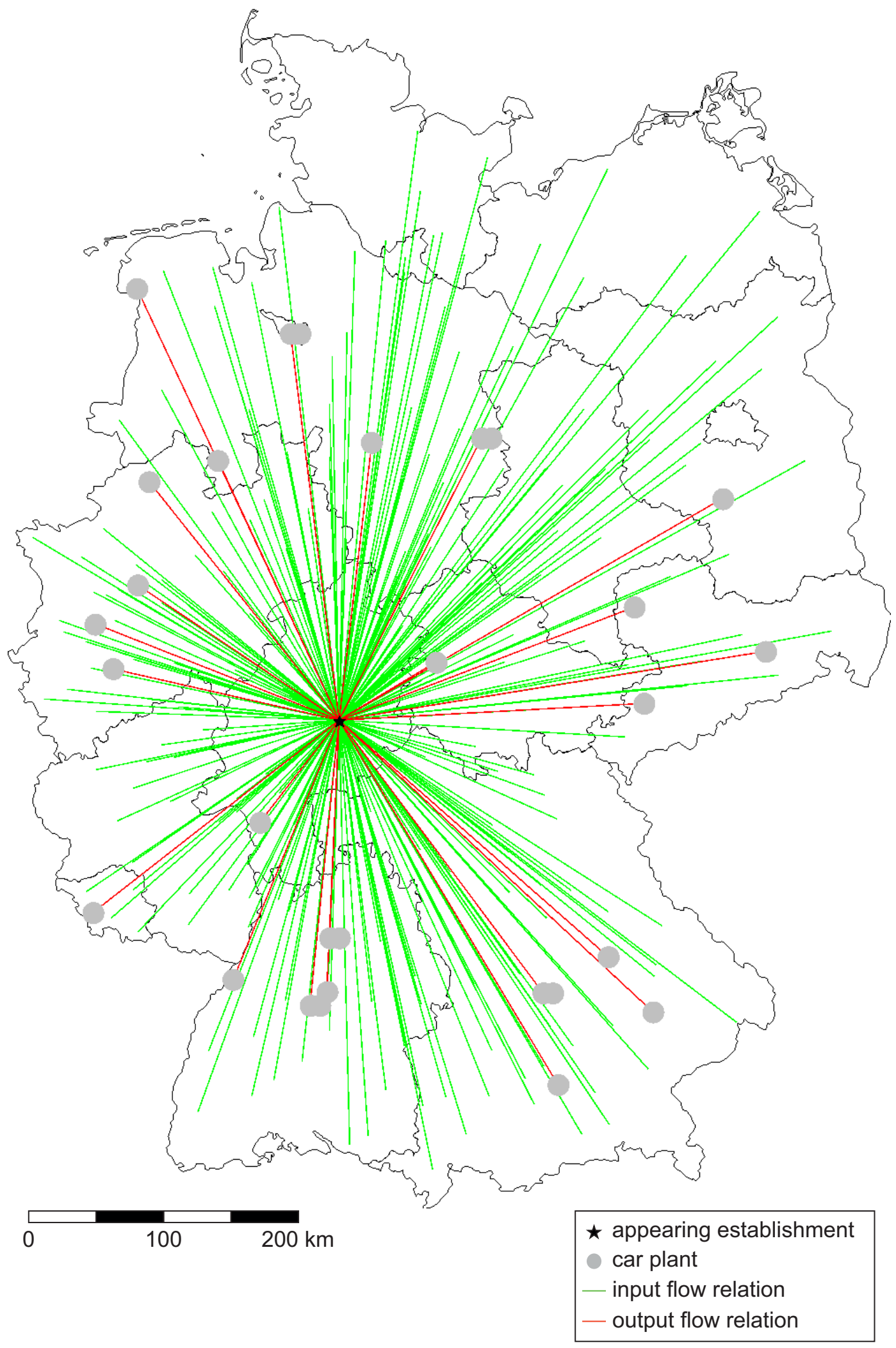

Figure D.6: Map showing establishment $(n=1)$ that appears during vertical disintegration in the automotive industry if optimal location choice, optimal assignment, and minimisation of freight transport performance are assumed (OptOptMin) 


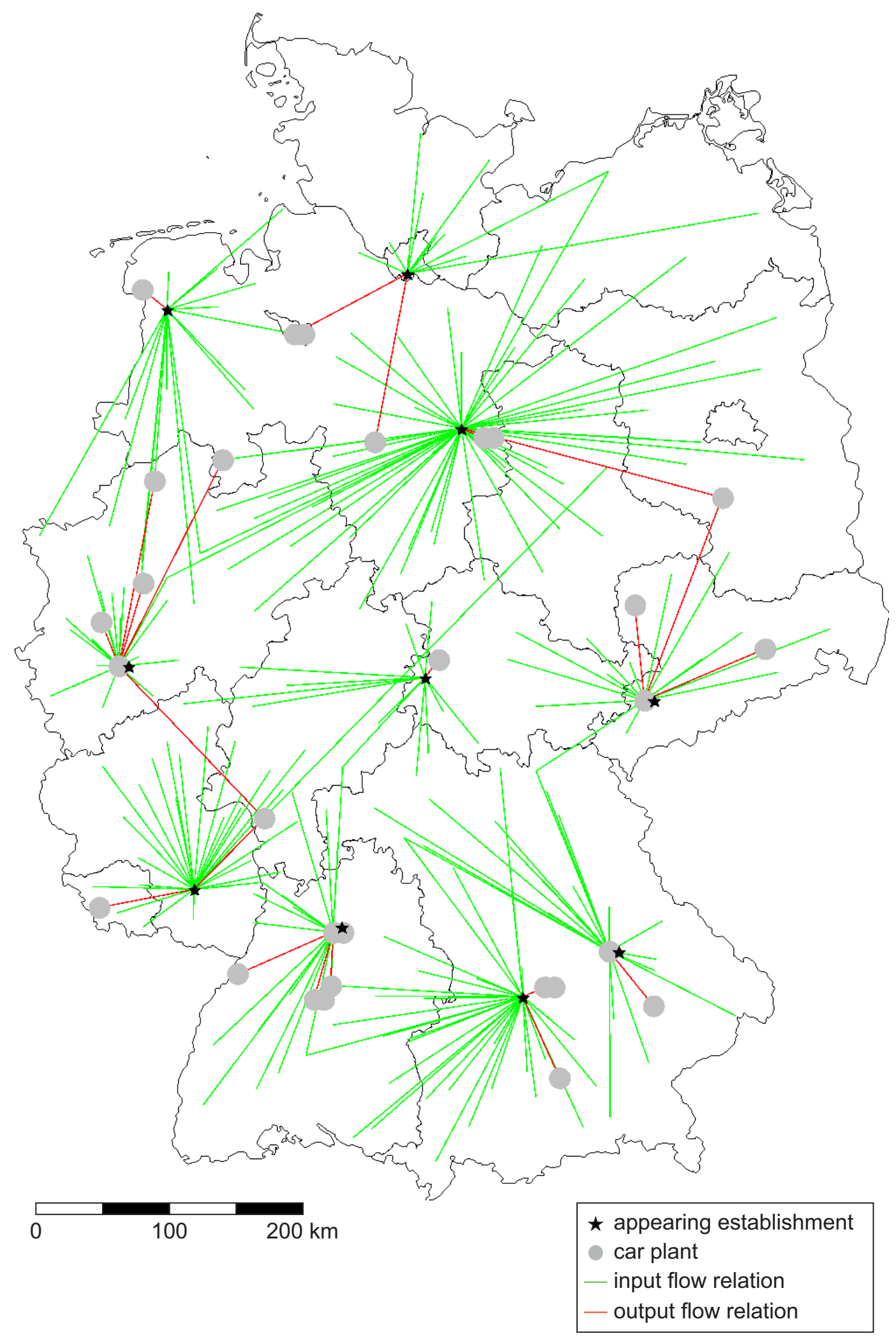

Figure D.7: Map showing establishments $(n=10)$ that appear during vertical disintegration in the automotive industry if optimal location choice, optimal assignment, and minimisation of freight transport performance are assumed (OptOptMin) 


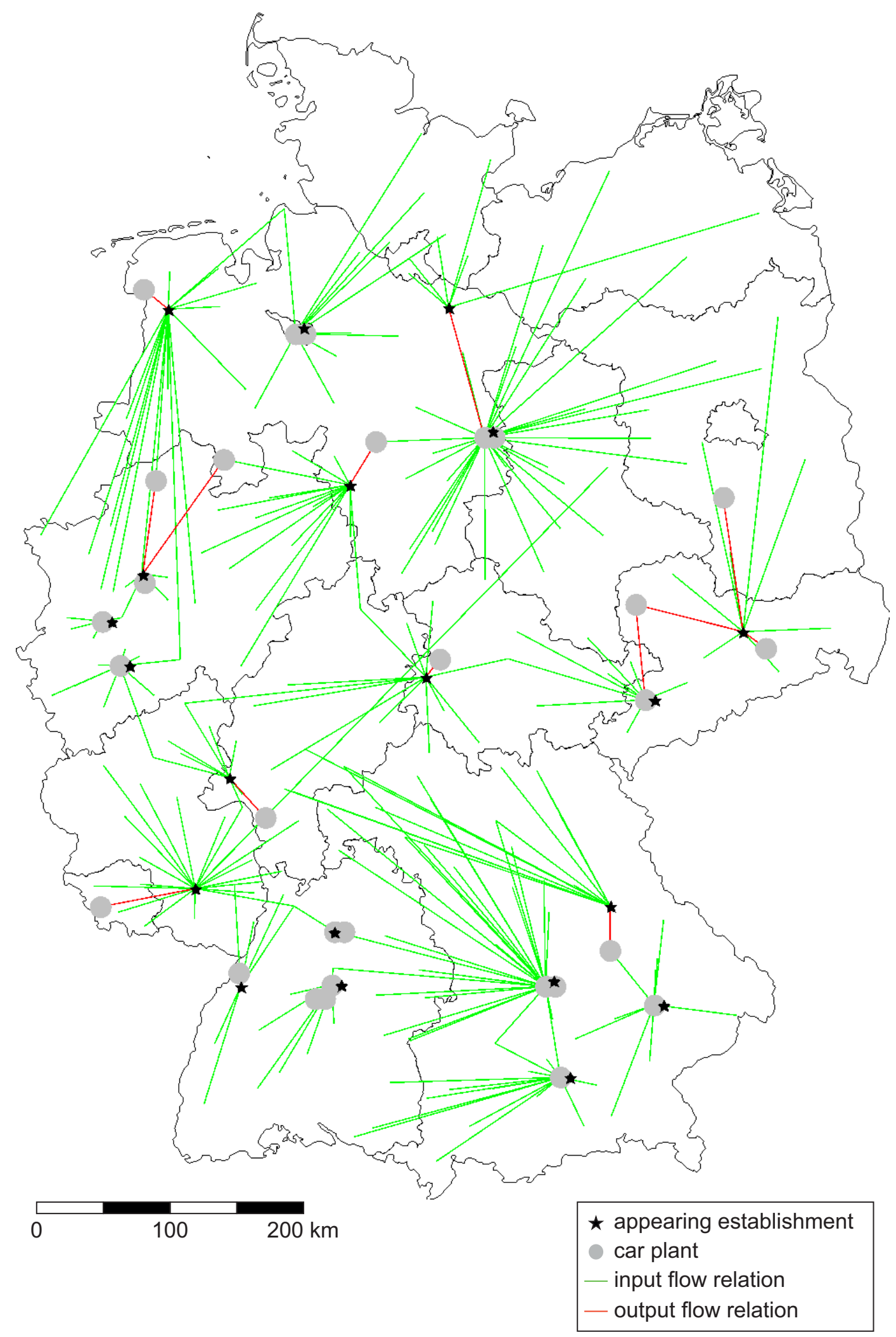

Figure D.8: Map showing establishments $(n=20)$ that appear during vertical disintegration in the automotive industry if optimal location choice, optimal assignment, and minimisation of freight transport performance are assumed (OptOptMin) 


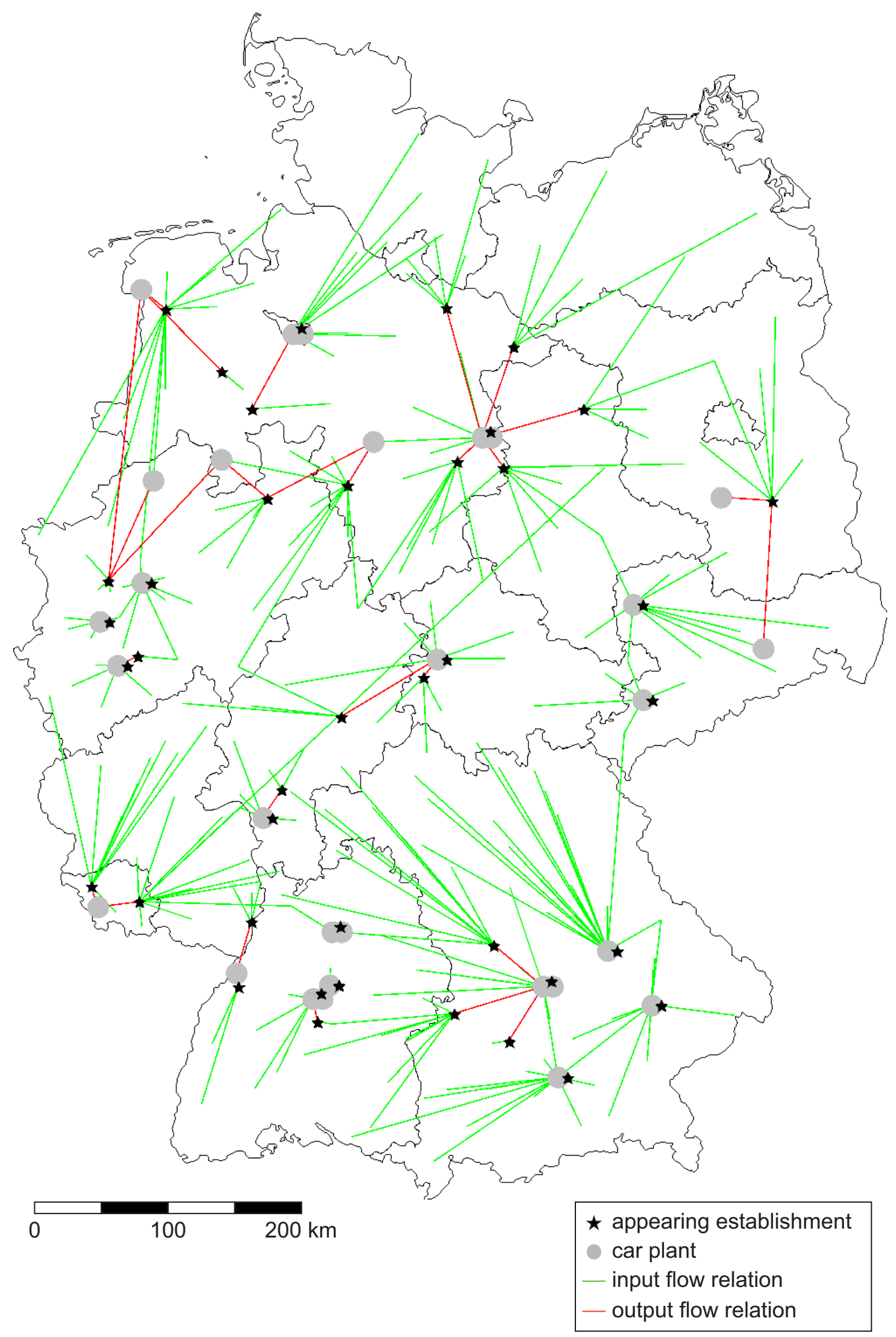

Figure D.9: Map showing establishments $(n=40)$ that appear during vertical disintegration in the automotive industry if optimal location choice, optimal assignment, and minimisation of freight transport performance are assumed (OptOptMin) 


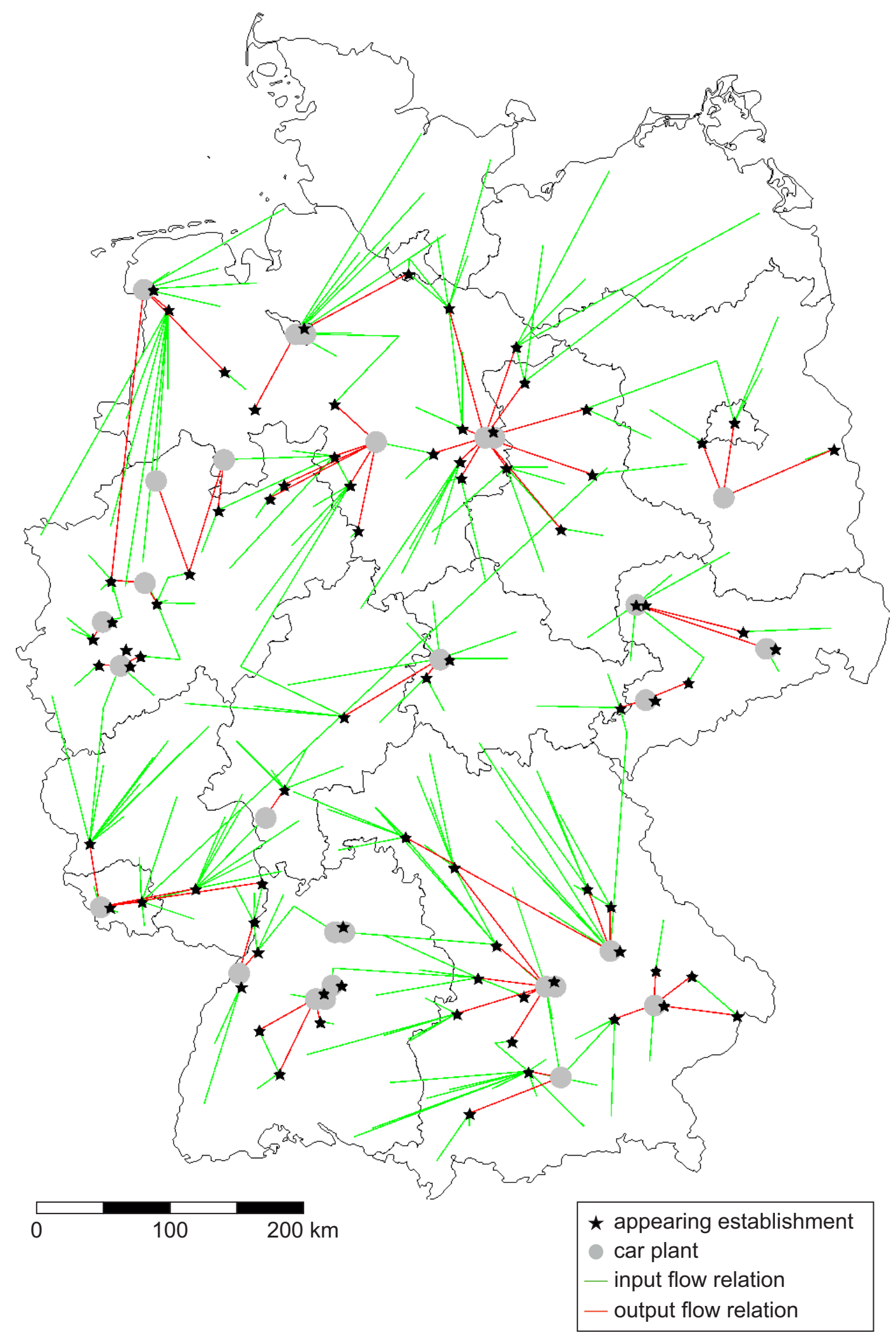

Figure D.10: Map showing establishments $(n=80)$ that appear during vertical disintegration in the automotive industry if optimal location choice, optimal assignment, and minimisation of freight transport performance are assumed (OptOptMin) 


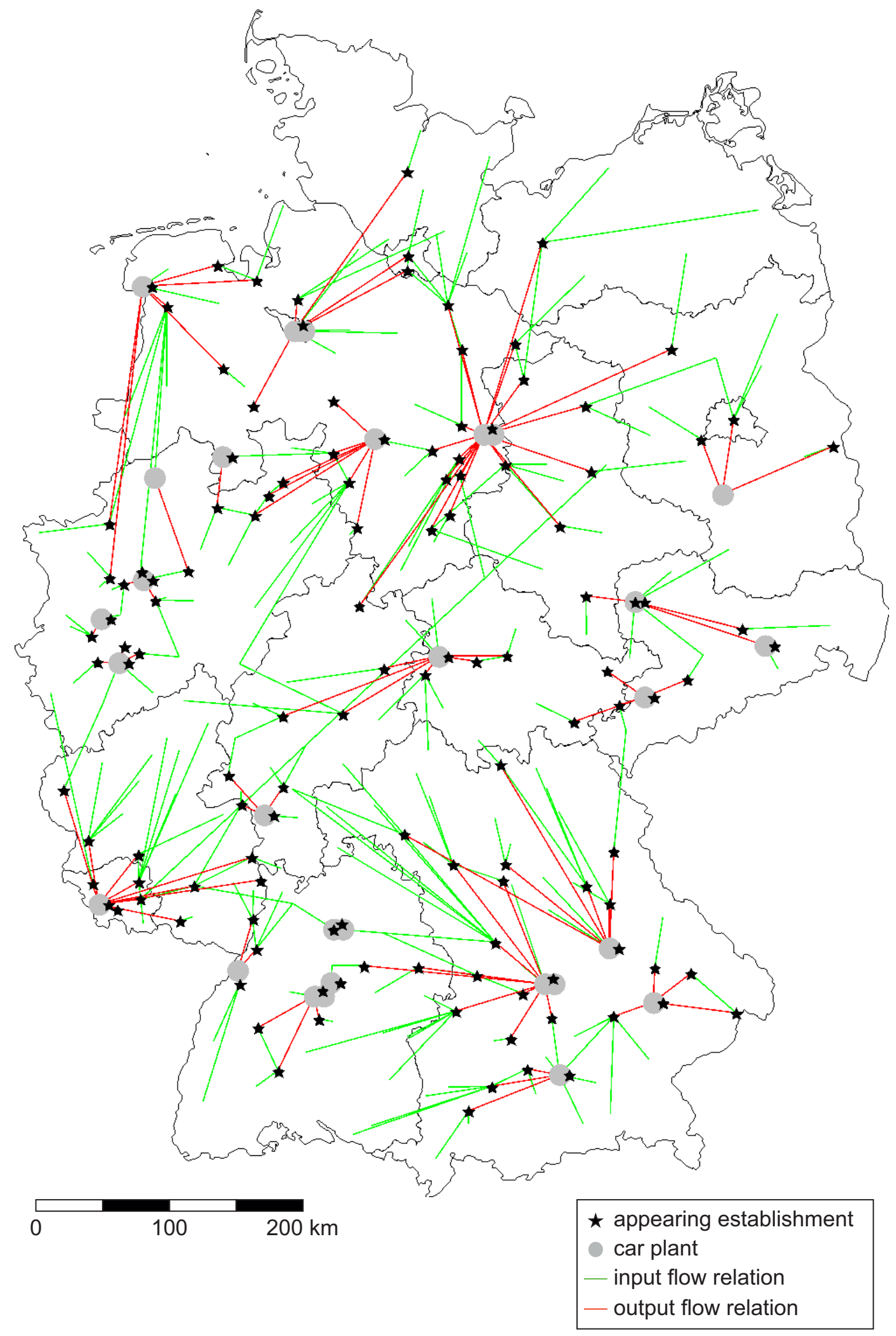

Figure D.11: Map showing establishments ( $n=160$ ) that appear during vertical disintegration in the automotive industry if optimal location choice, optimal assignment, and minimisation of freight transport performance are assumed (OptOptMin) 


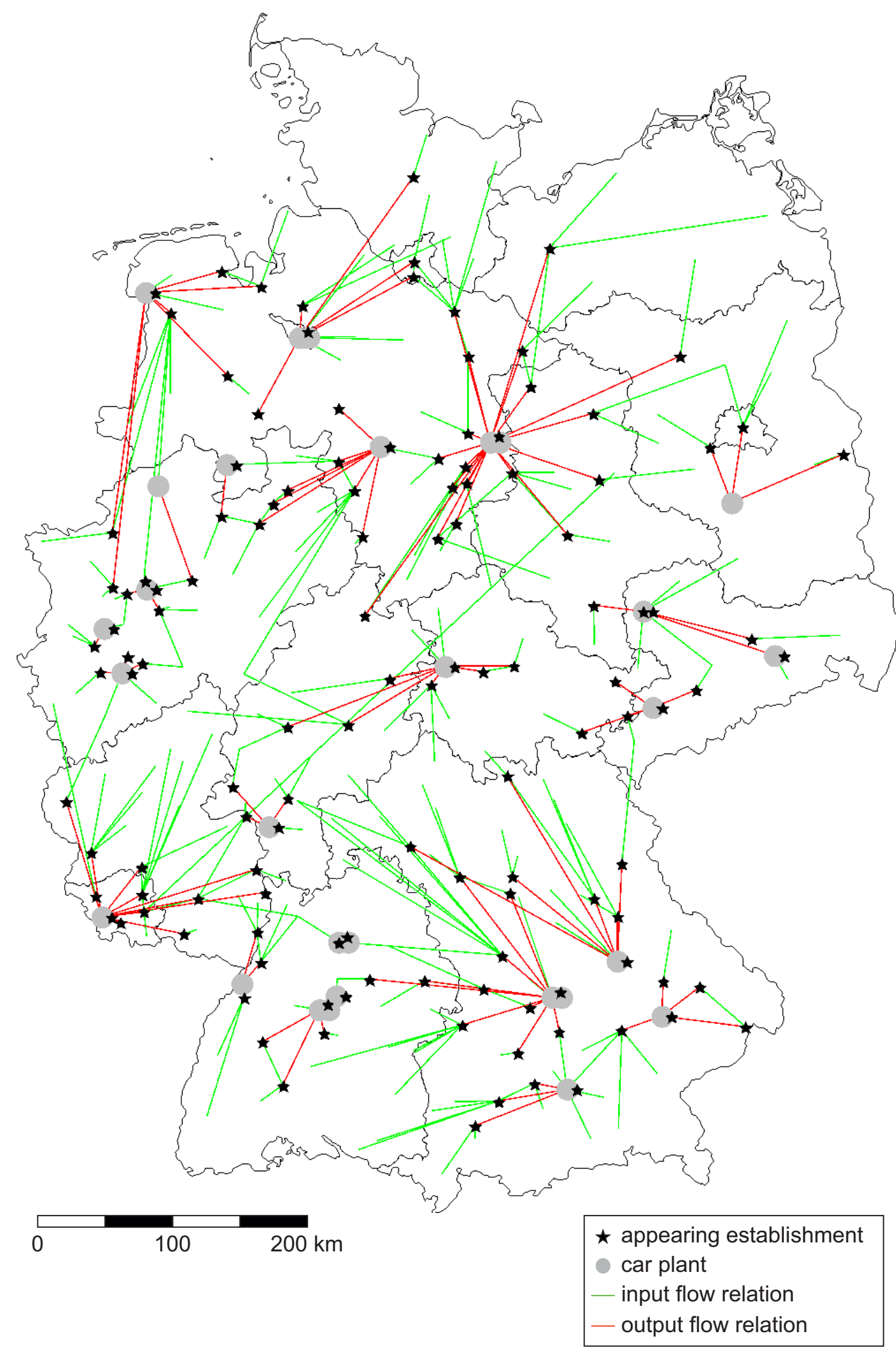

Figure D.12: Map showing establishments $(n=320)$ that appear during vertical disintegration in the automotive industry if optimal location choice, optimal assignment, and minimisation of freight transport performance are assumed (OptOptMin) 


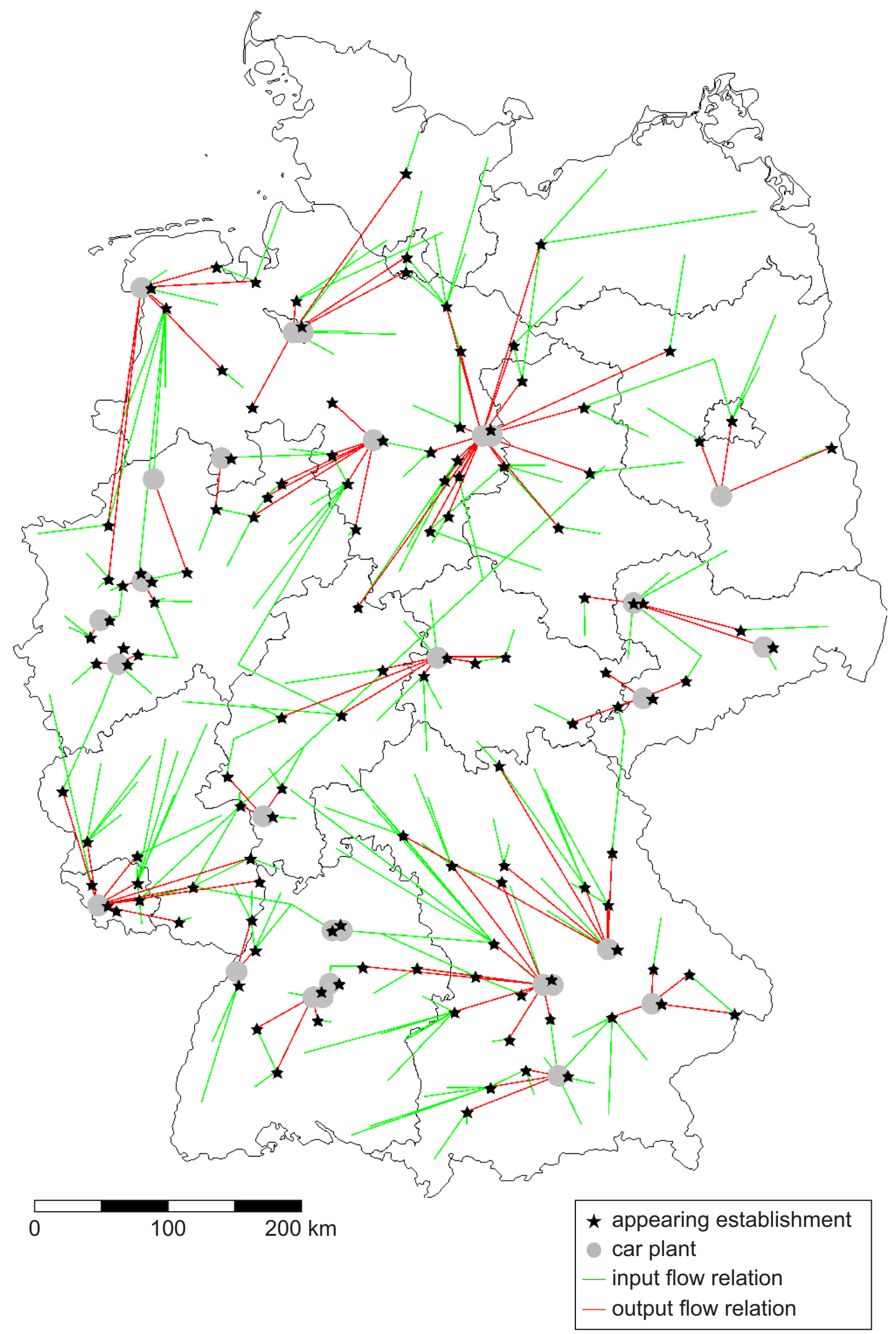

Figure D.13: Map showing establishments $(n=402)$ that appear during vertical disintegration in the automotive industry if optimal location choice, optimal assignment, and minimisation of freight transport performance are assumed (OptOptMin) 
